HTGR-86-024
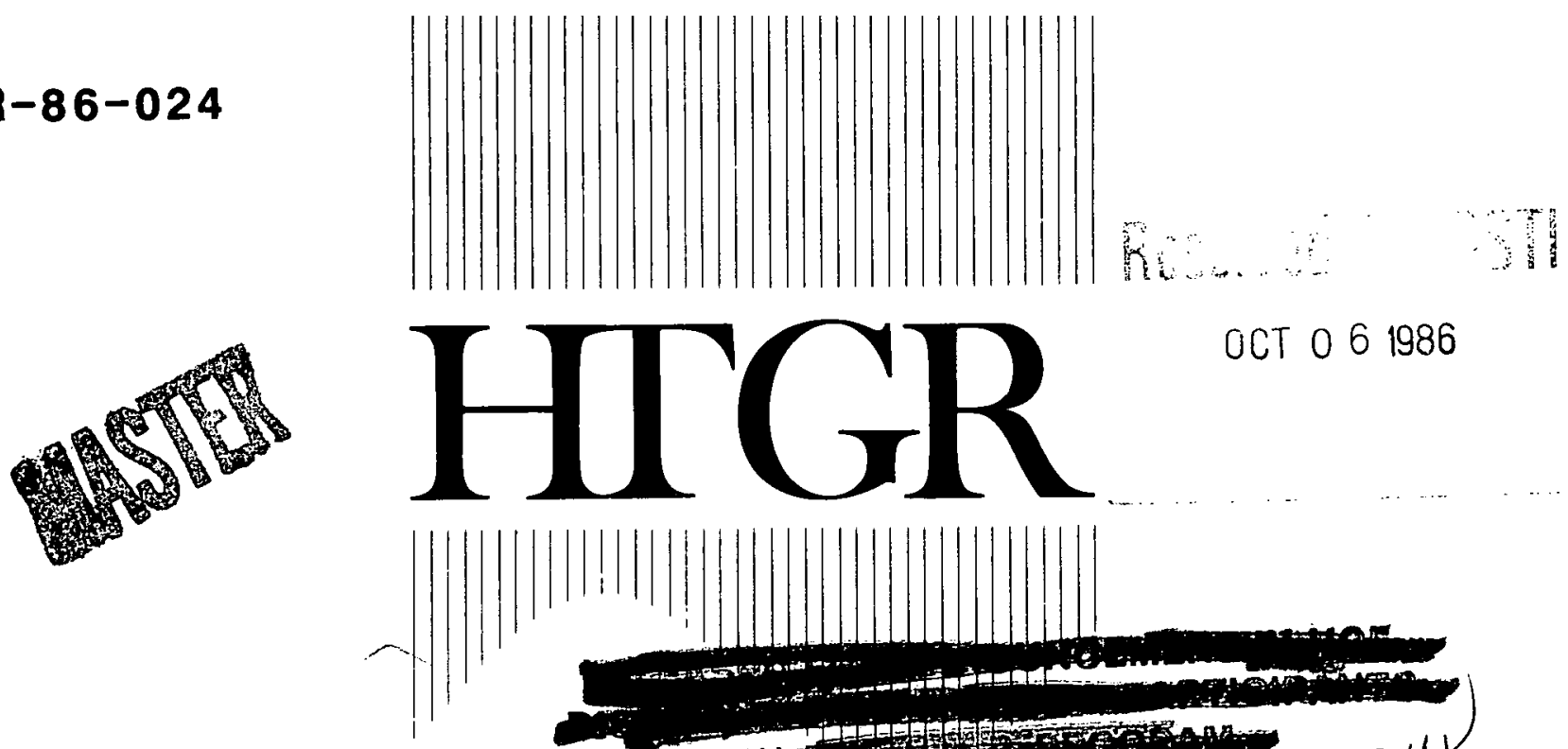

OCT O 61986

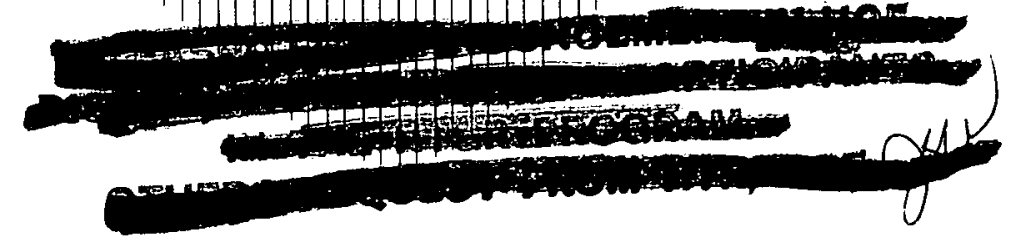

PRELIMINARY SAFETY INFORMATION DOCUMENT FOR THE STANDARD MHTGR

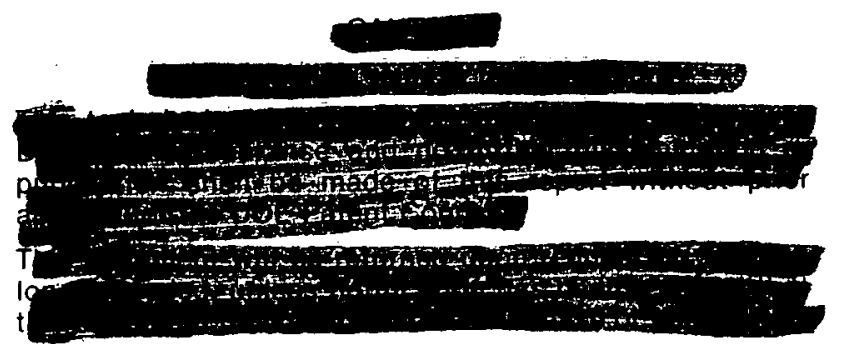

AUTHORS/CONTRACTORS

BECHTEL NATIONAL, INC.

COMBUSTION ENGINEERING, INC.

DEPARTMENT OF ENERGY

EG\&G IDAHO, INC.

GA TECHNOLOGIES, INC.

GAS-COOLED REACTOR ASSOCIATES

GENERAL ELECTRIC COMPANY

OAK RIDGE NATIONAL LABORATORY

STONE \& WEBSTER ENGINEERING CORP.

PUBLISHED BY STONE \& WEBSTER ENGINEERING CORP. UNDER SUBCONTRACT TO GAS-COOLED REACTOR ASSOCIATES FOR THE DEPARTMENT OF ENERGY CONTRACT DE-AC03-78SF02034

This derumeni to WUBLICLY TRLEASABLE
DISTRIBUTION OF THIS DOCUMENT IS UNLIMTEED 
HTGR-86-024
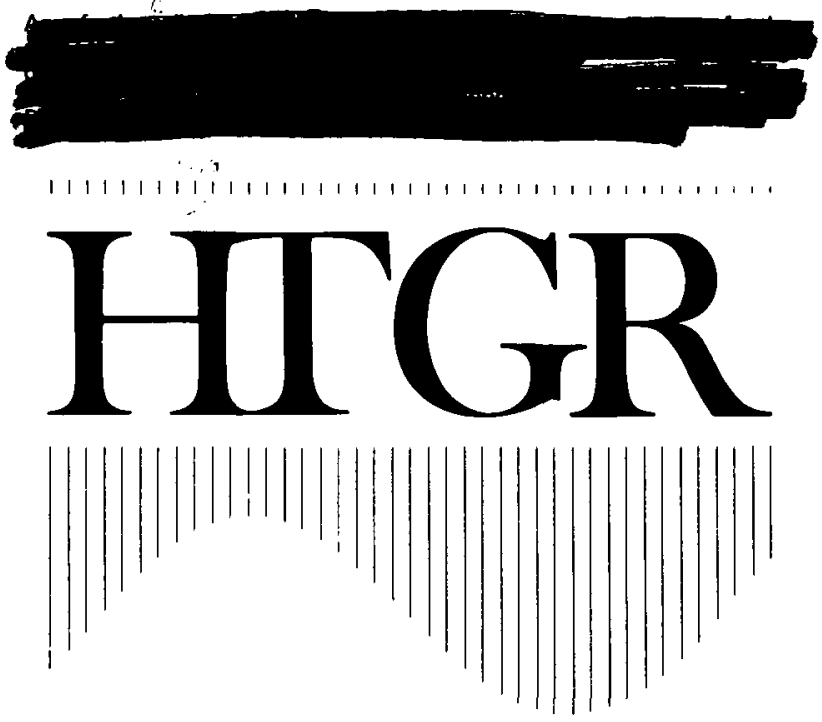

\section{PRELIMINARY SAFETY INFORMATION DOCUMENT FOR THE STANDARD MHTGR}

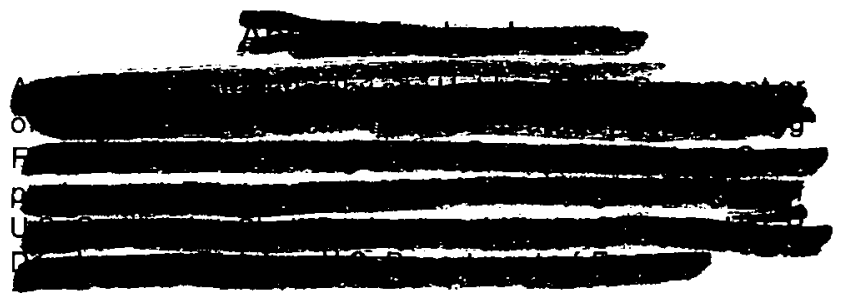

AUTHORS/CONTRACTORS

BECHTEL NATIONAL, INC.

COMBUSTION ENGINEERING, INC.

DEPARTMENT OF ENERGY

EG\&G IDAHO, INC.

GA TECHNOLOGIES, INC.

GAS-COOLED REACTOR ASSOCIATES

GENERAL ELECTRIC COMPANY

OAK RIDGE NATIONAL LABORATORY

STONE \& WEBSTER ENGINEERING CORP.

PUBLISHED BY STONE \& WEBSTER ENGINEERING CORP.

UNDER SUBCONTRACT TO GAS-COOLED REACTOR ASSOCIATES

FOR THE DEPARTMENT OF ENERGY CONTRACT DE-AC03-78SF02034 


\section{DISCLAIMER}

This report was prepared as an account of work sponsored by an agency of the United States Government. Neither the United States Government nor any agency Thereof, nor any of their employees, makes any warranty, express or implied, or assumes any legal liability or responsibility for the accuracy, completeness, or usefulness of any information, apparatus, product, or process disclosed, or represents that its use would not infringe privately owned rights. Reference herein to any specific commercial product, process, or service by trade name, trademark, manufacturer, or otherwise does not necessarily constitute or imply its endorsement, recommendation, or favoring by the United States Government or any agency thereof. The views and opinions of authors expressed herein do not necessarily state or reflect those of the United States Government or any agency thereof. 


\section{DISCLAIMER}

Portions of this document may be illegible in electronic image products. Images are produced from the best available original document. 


\section{This report was prepared as an account of work sponsored by the United} States Government. Neither the United States nor the United States Depart. ment of Energy, nor any of their employees, makes any warranty, express or implied, or assumes any legal liability or responsibility for the accuracy, completeness, or usefulness of any information, apparatus, product, or process disclosed, or represents that its use would not infringe privately owned rights. Reference herein to any specific commercial product, process, or service by trade name, mark, manufacturer, or otherwise, does not necessarily constitute or imply its endorsement, recommendation, or favoring by the United States Government or any agency thereof. The views and opinions of authors expressed herein do not necessarily state or reflect those of the United States Government or any agency thereof. 


\section{MODULAR HTGR PLANT DESIGN CONTROL OFFICE}

P.O. Box 85608

San Diego. CA $92138-5608$

(619) $455-4294$

\section{Received PST}

FEB 0.61989

PDCO-39-89

WBS 9300

February 3, 1989

TO:

Distribution

SUBJECT: PSID Amendment 10

By direction of A.C. Millunzi, U.S. DOE, enclosed is Amendment 10 to the MHTGR PSID (HTGR-86-024). This amendment is primarily in response to a commitment that pertinent MHTGR Program correspondence to NRC reviewers which was not reflected in the PSID would be incorporated in an amendment. Attachment 1 provides a cross-reference between the correspondence and PSID Amendment 10. This amendment also includes corrections for Chapter 11 including the deletion of Tables 11.2-1, 11.3-1 and 11.4-1 which were essentially duplicates of existing Tables $11.1-5,11.1-4$, and 11.1-6, respectively.

This amendment does not provide any substantive new or different material. It is simply a re-issue in appropriate format, or clarification of material previously sent to NRC reviewers.

Included with the amendment are page changes to the PSID and assembly instructions for the page changes.

This amendment and all previous amendments ( 1 through 9) are designated "Applied Technology." Your attention is directed to the "Applied Technology" notice on the PSID volume covers.

Sincerely,
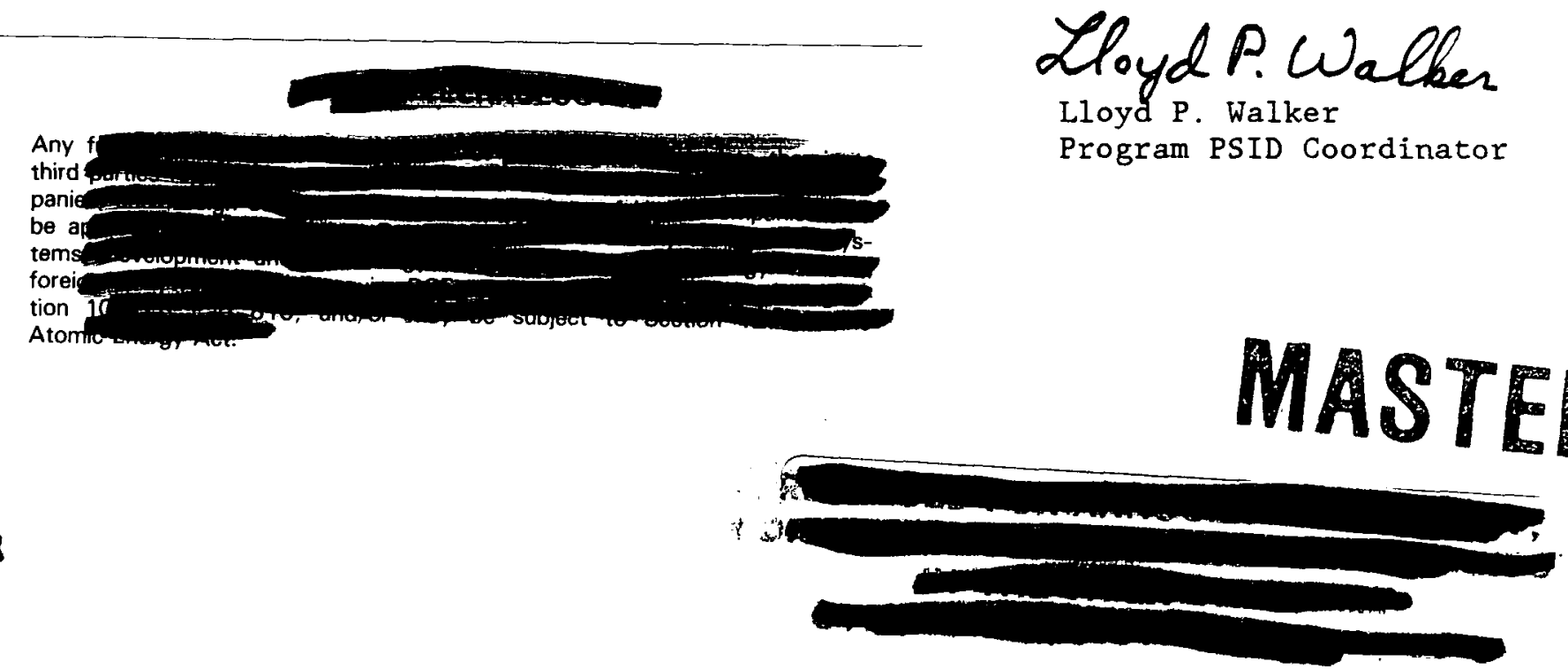
HTGR - $86-024$

\section{CONTENTS}

$\underline{\text { Section }}$

Volume

CHAPTER 1

INTRODUCTION AND GENERAL DESCRIPTION OF THE PLANT

1

1.1 PURPOSE, SCOPE, AND CONTENT OF PSID

1.2 SAFETY PHILOSOPHY AND METHODOLOGY

1.3 GENERAL PLANT DESCRIPTION

1.4 REQUIREMENTS FOR FURTHER TECHNICAL INFORMATION

1.5 MATERIAL INCORPORATED BY REFERENCE

1.6 STANDARD DESIGN INTERFACES

CHAPTER 2

STANDARD SITE CHARACTERISTICS

$2.1 \quad$ INTRODUCTION

2.2 GEOGRAPHY AND DEMOGRAPHY

1

2.3

NEARBY INDUSTRIAL, TRANSPORTATION, AND MILITARY FACILITIES

1

2.4 METEOROLOGY

1

2.5 HYDROLOGY

1

2.6 SEISMOLOGY

CHAPTER 3

LICENSING BASES AND THE CRITERIA AND METHODOLOGY FOR DESIGN OF STRUCTURES, SYSTEMS, AND COMPONENTS

3.1 CONFORMANCE WITH NRC CRITERIA

3.2 STANDARD MHTGR LICENSING BASES

1

3.3 WIND AND TORNADO LOADING

1

3.4 WATER LEVEL (FLOOD) DESIGN

3.5 PROTECTION AGAINST MISSILES AND EXTERNALLY GENERATED HAZARDS

1

3.6 PROTECTION AGAINST DYNAMIC EFFECTS ASSOCIATED WITH THE POSTULATED RUPTURE OF PIPING 
HTGR - $86-024$

CONTENTS

(Continued)

\section{Section}

Volume

3.8 DESIGN OF STRUCTURES

1

3.9 DESIGN OF MECHANICAL SYSTEMS AND COMPONENTS

CHAPTER 4

REACTOR

1

4.1 REACTOR SYSTEM 1

4.2 REACTOR CORE SUBSYSTEM

4.3 NEUTRON CONTROL SUBSYSTEM 1

4.4 REACTOR INTERNALS SUBSYSTEM 1

CHAPTER 5

VESSEL SYSTEM AND HEAT REMOVAL SYSTEMS 2

5.1 INTRODUCTION 2

5.2 VESSEL SYSTEM AND SUBSYSTEMS

5.3 HEAT TRANSPORT SYSTEM AND SUBSYSTEMS 2

5.4 SHUTDOWN COOLING SYSTEM AND SUBSYSTEMS 2

5.5 REACTOR CAVITY COOLING SYSTEM 2

CHAPTER 6

BUILDINGS AND STRUCTURES 2

6.1 NUCLEAR ISLAND 2

6.2 ENERGY CONVERSION AREA 2

CHAPTER 7

PLANT PROTECTION, INSTRUMENTATION, AND CONTROL 3

7.1 INTRODUCTION 3

7.2 PLANT PROTECTION AND INSTRUMENTATION SYSTEM 


\section{HTGR $-86-024$}

CONTENTS

(Continued)

Section

Volume

7.3 PLANT CONTROL, DATA, AND INSTRUMENTATION SYSTEM

7.4 MISCELIANEOUS CONTROL AND INSTRUMENTATION GROUP

CHAPTER 8

ELECTRICAL SYSTEMS

8.1 SUMMARY DESCRIPTION

8.2 ESSENTIAL UNINTERRUPTIBLE POWER SUPPLY SYSTEM

8.3 ESSENTIAL DC POWER SYSTEM 3

8.4 OFFSITE POWER AND MAIN GENERATOR TRANSMISSION SYSTEM

8.5 AC DISTRIBUTION SYSTEM 3

8.6 UNINTERRRUPTIBLE POWER SUPPLY SYSTEM

8.7 DC POWER SUPPLY 3

8.8 GROUNDING, LIGHTNING PROTECTION, HEAT TRACING, AND CATHODIC PROTECTION 3

8.9 COMMUNICATION SYSTEM 3

8.10 LIGHTING AND SERVICE POWER SYSTEM

CHAPTER 9

SERVICE SYSTEMS

9.1 NUCLEAR ISLAND 3

9.2 ENERGY CONVERSION AREA 3

CHAPTER 10

STEAM AND ENERGY CONVERSION SYSTEMS

10.1 FEEDWATER AND CONDENSATE SYSTEM 4

10.2 HEATER DRAINS AND CONDENSATE RETURNS 4

10.3 CONDENSATE POLISHING SYSTEM 4

10.4 STEAM VENTS AND DRAINS 4 
HTGR $-86-024$

CONTENTS

(Continued)

Section

Volume

10.5 TURBINE PLANT SAMPLING

4

10.6 TURBINE-GENERATOR AND AUXILIARIES

4

10.7 CHEMICAL FEED SYSTEM

4

10.8 MAIN AND BYPASS STEAM SYSTEM

10.9 DEMINERALIZED WATER MAKEUP

4

10.10 EXTRACTION AND AUXILIARY STEAM SYSTEM

4

10.11 CIRCULATING WATER

10.12 TURBINE BUILDING CLOSED COOLING WATER

10.13 CIRCULATING WATER MAKEUP AND BLOWDOWN

10.14 SERVICE WATER

10.15 STARTUP AND SHUTDOWN SUBSYSTEM

10.16 STEAM AND WATER DUMP

CHAPTER 11

OPERATIONAL RADIONUCLIDE CONTROL

11.1 RADIONUCLIDE DESIGN CRITERIA

4

11.2 LIQUID RADIOACTIVE WASTE SYSTEM

4

11.3 GASEOUS RADIOACTIVE WASTE SYSTEM

4

11.4 SOLID RADIOACTIVE WASTE SYSTEM

4

11.5 PLANT NORMAL OPERATIONS

11.6 PLANT ANTICIPATED OPERATIONAL OCCURRENCES

11.7 PLANT DOSE ASSESSMENT

CHAPTER 12

OCCUPATIONAL RADIATION PROTECTION

12.1 OCCUPATIONAL RADIATION EXPOSURE

4

12.2 OCCUPATIONAL RADIATION SOURCES

12.3 OCCUPATIONAL RADIATION PROTECTION DESIGN FEATURES

12.4 OCCUPATIONAL DOSE ASSESSMENT 
HTGR - 86- 024

$$
\begin{gathered}
\text { CONTENTS } \\
\text { (Continued) }
\end{gathered}
$$

$\underline{\text { Section }}$

Volume

CHAPTER 13

CONDUCT OF OPERATIONS

4

13.1 POSITION ON EMERGENCY PREPAREDNESS 4

13.2 DESCRIPTION OF OPERATIONAL MODES 4

13.3 PLANT SECURITY 4

CHAPTER 14

INITIAL TEST PROGRAM 4

CHAPTER 15

SAFETY ANALYSIS

15.1 GENERAL FEATURES OF THE ANALYSIS 4

15.2 LOSS OF HTS AND SCS COOLING (DESIGN BASIS EVENT NO. 1) 4

15.3 HTS TRANSIENT WITHOUT CONTROL ROD TRIP (DESIGN BASIS

EVENT NO. 2) 4

15.4 CONTROL ROD WITHDRAWAL WITHOUT HTS COOLING (DESIGN

BASIS EVENT NO. 3) 4

15.5 CONTROL ROD WITHDRAWAL WITHOUT HTS AND SCS COOLING

(DESIGN BASIS EVENT NO. 4) 4

15.6 EARTHQUAKE (DESIGN BASIS EVENT NO. 5) 4

15.7 MOISTURE INLEAKAGE (DESIGN BASIS EVENT NO. 6)

15.8 MOISTURE INLEAKAGE WITHOUT SCS COOLING (DESIGN BASIS

EVENT NO. 7) 4

15.9 MOISTURE INLEAKAGE WITH MOISTURE MONITOR FAILURE (DESIGN BASIS EVENT NO. 8) 4

15.10 MOISTURE INLEAKAGE WITH STEAM GENERATOR DUMP FAILURE (DESIGN BASIS EVENT NO. 9) 4

15.11 PRIMARY COOLANT LEAK (DESIGN BASIS EVENT NO. 10) 4 


$$
\begin{aligned}
& \text { HTGR - 86-024 } \\
& \text { CONTENTS } \\
& \text { (Continued) }
\end{aligned}
$$

Section

Volume

15.12 PRIMARY COOLANT LEAK WITHOUT HTS AND SCS COOLING (DESIGN BASIS EVENT NO. 11)

4

15.13 ASSESSMENT OF LIMITING DESIGN CONDITIONS FOR SAFETY

RELATED SYSTEMS, STRUCTURES, AND COMPONENTS

4

CHAPTER 16

TECHNICAL SPECIFICATIONS

4

16.1 OPERATIONAL APPROACH TO TECHNIGAL SPECIFICATIONS

CHAPTER 17

QUALITY ASSURANCE

4

17.1 QUALITY ASSURANCE FOR DESIGN

4

R

RESPONSES TO NRC COMMENTS

5 
HTGR - 86- 024

LIST OF ACRONYMS

AIS

ALARA

AMB

$\mathrm{AOO}$

ASC

ATWS

BOC

BOEC

BOIC

BMW

$B P F$

CAS

CCTV

CLR

CPU

CRAW

CRD

CRDM

CROW

CRP

CRS

$\mathrm{C} / \mathrm{Th}$

$\mathrm{C} / \mathrm{U}$

CWB

DBDA

DBE

DBT

DCF

DMS

DP

DSS

$\mathrm{EAB}$

ECA

EES
Analytic Instrumentation System

As Low As Is Reasonably Achievable

Active Magnetic Bearings

Anticipated Operational Occurrence

Auxiliary Service Cask

Anticipated Transient Without Scram

Beginning-Of-Cycle

Beginning of Equilibrium Cycle

Beginning of Initial Cycle

Bi-Metallic Weld

Blade Passing Frequency

Central Alarm Station

Closed Circuit Television

Core Lateral Restraint

Central Processing Unit

Control Room Assistant Work Station

Control Rod Drive

Control Rod Drive Mechanism

Control Room Operator Work Station

Control Radiation Processor

Core Refueling Subsystem

Carbon to Thorium Atom Ratio

Carbon to Uranium Atom Ratio

Chilled Water Building

Design Basis Depressurization Accident

Design Basis Event

Design Basis Tornado

Dose Conversion Factor

Data Management System

Design Pressure

Decontamination Service Subsystem

Exclusion Area Boundary

Energy Conversion Area

Economizer/Evaporator/Superheater 
HTGR - 86-024

\begin{tabular}{|c|c|}
\hline EFPD & Effective Full Power Days \\
\hline EOC & End-Of-Cycle \\
\hline EOEC & End-Of-Equilibrium-Cycle \\
\hline EOIC & End-Of-Initial-Cycle \\
\hline $\mathrm{EMCP}$ & Electric Motor Control Power \\
\hline EPBE & Emergency Planning Basis Event \\
\hline EPZ & Emergency Planning Zone \\
\hline FHEP & Fuel Handling Equipment Positioner \\
\hline FHM & Fuel Handling Machine \\
\hline FHSS & Fuel Handling and Storage System \\
\hline FIMA & Fissions Per Initial Heavy Metal Atom \\
\hline FRS & Floor Response Spectra \\
\hline FSH & Finishing Superheater \\
\hline FSIF & Fuel Sealing and Inspection Facility \\
\hline FTC & Fuel Transfer Cask \\
\hline FW & Feedwater \\
\hline GCSS & Graphite Core Support Structure \\
\hline $\mathrm{HP}$ & High Pressure \\
\hline HPS & Helium Purification System \\
\hline HSFS & Hot Service Facility Subsystem \\
\hline HSS & Helium Storage Structure \\
\hline HSTS & Helium Storage and Transfer System \\
\hline HTGR & High Temperature Gas-Cooled Reactor \\
\hline HTS & Heat Transport System \\
\hline HVAC & Heating, Ventilating, and Air Conditioning \\
\hline IC & Initial Cycle \\
\hline IFMU & In-Vessel Flux Mapping Units \\
\hline INCA & Inner Neutron Control Assemblies \\
\hline IPTP & Initial Proof Test Pressure \\
\hline IPyC & Inner Pyrocarbon \\
\hline ISI & In-Service Inspection \\
\hline LBB & Leak-Before-Break \\
\hline LBP & Lumped Burnable Poison \\
\hline LBE & Licensing Basis Event \\
\hline LCO & Limiting Conditions of Operation \\
\hline LEU & Low-Enriched Uranium \\
\hline
\end{tabular}


HTGR - 86- 024

\begin{tabular}{|c|c|}
\hline $\mathrm{LN}_{2}$ & Liquid Nitrogen \\
\hline LNS & Liquid Nitrogen System \\
\hline LP & Low Pressure \\
\hline LPZ & Low Population Zone \\
\hline LRP & Local Radiation Processor \\
\hline LTA & Low Temperature Adsorber \\
\hline LWR & Light Water Reactor \\
\hline $\mathrm{MBCP}$ & Magnetic Bearings Control and Power \\
\hline MC & Main Circulator \\
\hline MCC & Motor Control Center \\
\hline MCIG & Miscellaneous Control and Instrumentation Group \\
\hline MCR & Main Control Room \\
\hline MCS & Main Circulator Subsystem \\
\hline MCSS & Metallic Core Support Structure \\
\hline MHTGR & Modular High Temperature Gas-Cooled Reactor \\
\hline MLSV & Main Loop Shutoff Valve \\
\hline MOC & Middle-Of-Cycle \\
\hline MOEC & Middle-Of-Equilibrium-Cycle \\
\hline MOIC & Middle-Of-Initial-Cycle \\
\hline MVP & Maximum Vessel Pressure \\
\hline NCS & NSSS Control Subsystem \\
\hline NCSS & Neutron Control Subsystem \\
\hline NDTT & Nil-Ductility Transition Temperature \\
\hline NI & Nuclear Island \\
\hline NICWB & Nuclear Island Cooling Water Building \\
\hline NOP & Normal Operating Pressure \\
\hline NPSH & Net Positive Suction Head \\
\hline NSSS & Nuclear Steam Supply System \\
\hline OBE & Operating Basis Earthquake \\
\hline ONCA & Outer Neutron Control Assemblies \\
\hline OPyC & Outer Pyrocarbon \\
\hline PA & Peak Accelerograph \\
\hline PAG & Protective Action Guidelines \\
\hline PAX & Private Automatic Exchange \\
\hline PCDIS & Plant Control Data and Instrumentation System \\
\hline PCS & Plant Control System \\
\hline
\end{tabular}


HTGR - 86-024

$\mathrm{P}+\mathrm{D}$

PDC

PF

$\mathrm{P} / \mathrm{F}$

PFPS

$\mathrm{P}+\mathrm{I}+\mathrm{D}$

$P \& I$

PMF

PMP

PPIS

$\mathrm{PP} / \mathrm{PA}$

PRA

PRS

PSB

PSCS

PSG

PSID

PSR

PV

PyC

$\mathrm{RAB}$

$\mathrm{RB}$

$\mathrm{R} / \mathrm{B}$

RCCS

RCSS

RESF

RISS

RIV

RMS

RPCWS

RPV

RS

RSA

RSB

RSC

RSCE
Proportional Plus Derivative

Principal Design Criteria

Process Flow

Power-to-Flow Ratio

Plant Fire Protection System

Proportional Plus Integral Plus Derivative Expression

Piping and Instrumentation

Probable Maximum Flood

Probable Maximum Precipitation

Plant Protection and Instrumentation System

Page-Party/Public Address

Probabilistic Risk Assessment

Pressure Relief Subsystem

Personnel Service Building

Plant Supervisory Control Subsystem

Peak Strain Gauge

Preliminary Safety Information Document

Permanent Side Reflector

Pressure Vesse1

Pyrocarbon

Reactor Auxiliary Building

Reactor Building

Release Rate to Birth Rate Ratio

Reactor Cavity Cooling System

Reactor Core Subsystem

Reactor Equipment Service Facility

Reactor Internals Subsystem

Reactor Isolation Valve

Radiation Monitoring System

Reactor Plant Cooling Water System

Reactor Pressure Vesse1

Reactor System

Response Spectra Analyzer

Reactor Service Building

Reserve Shutdown Control

Reserve Shutdown Control Equipment 
HTGR - 86- 024

\begin{tabular}{|c|c|}
\hline RSCM & Reserve Shutdown Control Material \\
\hline RSE & Reserve Shutdown Equipment \\
\hline RSS & Reserve Shutdown System \\
\hline RTD & Resistance Temperature Detector \\
\hline RV & Reactor Vessel \\
\hline RVS & Reactor Vessel System \\
\hline RWB & Radioactive Waste Building \\
\hline SAS & Secondary Alarm Station \\
\hline $\operatorname{SCC}$ & Shutdown Cooling Circulator \\
\hline $\operatorname{sccs}$ & Shutdown Cooling Circulator Subsystem \\
\hline $\mathrm{SCHE}$ & Shutdown Cooling Heat Exchanger \\
\hline SCHES & Shutdown Cooling Heat Exchanger Subsystem \\
\hline $\operatorname{SCS}$ & Shutdown Cooling System \\
\hline SCWHE & Shutdown Cooling Water Heat Exchanger \\
\hline SCWS & Shutdown Cooling Water Subsystem \\
\hline SDA & Startup Detector Assemblies \\
\hline SFCS & Spent Fuel Cooling System \\
\hline SFHS & Site Fuel Handling System \\
\hline SG & Steam Generator \\
\hline SGS & Steam Generator Subsystem \\
\hline SGV & Steam Generator Vessel \\
\hline $\mathrm{SiC}$ & Silicon Carbide \\
\hline SIVR & Steam Induced Vaporization and Recirculation \\
\hline SLSV & Shutdown Loop Shutoff Valve \\
\hline SMS & Seismic Monitoring System \\
\hline SRDC & "Safety-Related" Design Condition \\
\hline SS & Seismic Switch \\
\hline SSC & Systems, Structures, and Components \\
\hline SSE & Safe Shutdown Earthquake \\
\hline SSI & Soil-Structure Interaction \\
\hline SWS & Service Water System \\
\hline TBD & To Be Determined \\
\hline THA & Time History Accelerometer \\
\hline UPS & Uninterruptible Power Supply \\
\hline UPTPS & Upper Plenum Thermal Protection Structure \\
\hline $\mathrm{U} / \mathrm{Th}$ & Uranium to Thorium Ratio \\
\hline
\end{tabular}




\section{HTGR - 86- 024}

VDS

VS

VSS

ZPA
Vessels and Ducts Subsystem

Vessel System

Vessel Support Subsystem

Zero Period Acceleration 
HTGR - $86-024$

\section{CHAPTER 1}

INTRODUCTION AND GENERAL DESCRIPTION OF THE PLANT CONTENTS

Section

1.1

1.1 .1

1.1.2

1.1 .3

1.1 .4

1.1 .5

1.2

1.2.1

1.2.2

1.2 .2 .1

1.2.2.2

1.3

1.3 .1

1.3 .2

1.3 .3

1.3 .4

1. 3.5

1.3 .6

1.4

1.5

1.6
Title

PURPOSE, SCOPE AND CONTENT OF PSID

Purpose

Scope

Format and Content

Consistency With NRC's Advanced Reactor Policy

Requested NRC Response

SAFETY PHILOSOPHY AND METHODOLOGY

Philosophy

Design Approach

Top-Level Criteria and Requirements

Integrated Approach

GENERAL PLANT DESCRIPTION

Site Characteristics

Plant Arrangement

Vessel and Heat Removal Systems

Reactor Core

Reactor Fuel

Safety Features

REQUIREMENTS FOR FURTHER TECHNICAL INFORMATION

MATERIAL INCORPORATED BY REFERENCE

STANDARD DESIGN INTERFACES
Page

$1.1-1$

$1.1-1$

$1.1-1$

$1.1-2$

$1.1-3$

$1.1-4$

1.2-1

$1.2-1$

1. 2-2

1. $2-3$

1. $2-4$

1. 3-1

1. 3-1

1. 3-2

1. $3-2$

1. $3 \cdot 3$

1. $3-4$

1. $3-5$

1. 4-1

1. $5-1$

1. $6-1$ 
HTGR - 86-024

\section{LIST OF TABLES}

Table

Title

1.3-1 Features of the Standard MHTGR

1.6-1 Nuclear Island, Energy Conversion Area, and Interfacing Systems

1.6-2 Buildings and Structures 
HTGR $-86-024$

LIST OF FIGURES

\section{Figure Title}

1.2-1 Standard MHTGR Design and Licensing Approach

1.2-2 Plant Goals

1.2-3 Functional Analysis Tree (Goal 3)

1.3-1 Plot Plan

1.3-2 Isometric View Through Reactor Building

1.3-3 $350 \mathrm{MW}(t)$ HTGR Module

1.3-4 Simplified Flow Diagram

1.3-5 Reactor Plant View

1.3-6 Fuel Element Components 
1-ii and 1-iii

$1-i v$

1.1-1 and 1.1-2

1.1-3

1. 1-4

1.1-5 through 1.1-7

1.2-1 and 1.2-2

1.2-3 and 1.2-4

1. $2-5$

1. $2-6$

Figure 1.2-1

Figure 1.2-2 and 1.2-3

1.3-1 through 1.3-6

Table 1.3-1

Figures 1.3-1 through 1.3-6

1. 4-1

$1.4-2$

1. 5-1.

1.6-1 and 1.6-2

Table 1.6-1

0

Table 1.6-2

0

1

1 
HTGR - $86-024$

CHAPTER 1

INTRODUCTION AND GENERAL DESCRIPTION OF THE PLANT

1.1 PURPOSE, SCOPE AND CONTENT OF PSID

\section{1 .1 Purpose}

With NRC concurrence (Ref. 1), the Licensing Plan for the Standard HTGR (Ref. 2) describes an application program consistent with 10CFR50, Appendix 0 to support a U. S. Nuclear Regulatory Commission (NRC) review and design certification of an advanced Standard Modular High Temperature Gas-Cooled Reactor (MHTGR) design. Consistent with the NRC's Advanced Reactor Policy (Ref. 3, also see Section 1.1.4), the Plan also outlines a series of preapplication activities which have as an objective the early issuance of an NRC Licensability Statement on the Standard MHTGR conceptual design.

This Preliminary Safety Information Document (PSID) has been prepared as one of the submittals to the NRC by the U.S. Department of Energy in support of preapplication activities on the Standard MHTGR. Other submittals to be provided include a Probabilistic Risk Assessment, a Regulatory Technology Development Plan, and an Emergency Planning Bases Report.

\section{$1.1 .2 \underline{\text { Scope }}$}

This PSID documents the licensing criteria and bases which have been established for the Standard MHTGR, the conceptual design that has been developed, and the analytical results which indicate that the criteria can be met.

The design description is focused on the Nuclear Island portion of the plant with the interfaces with the remainder of the plant (hereafter referred to as the Energy Conversion Area) and a standard site identified. The Nuclear Island is considered to be that portion of the plant that has within its boundaries the standard reactor modules and "safety-related" (as defined in Section 3.2) buildings, structures, systems and components dedicated to assuring reactor 
shutdown, decay heat removal, fission product retention, and prevention of fuel chemical attack. Additionally, the Nuclear Island includes structures, systems and components not "safety-related", but which directly support reactor operation.

Accidents beyond the design basis for the Standard MHTGR are not addressed in the PSID; such accidents are the subject of a Probabilistic Risk Assessment (PRA) submitted to the NRC separately. (Ref. 4) This PRA will also support the selection of the licensing bases identified within the PSID. In addition, information on the base technology program that supports the design is provided in a separate submittal entitled Regulatory Technology Development Plan. (Ref. 5) Finally, the analysis required to support the approach to emergency planning is not documented in the PSID; this will be the subject of a separate Emergency Planning Bases Report. (Ref. 6)

$\therefore$

\subsubsection{Format and Content}

The format of the PSID generally follows the outline previously documented and agreed to by the NRC. (Refs. 7 and 8) Except for the key modifications noted below, the format is generally consistent with that identified in Regulatory Guide 1.70.

The chapter topics in the PSID are the same as the Regulatory Guide with one exception, Chapter 6, which, in the PSID, is entitled "Buildings and Structures". This modification has been made because plant safety features, with the exception of buildings and structures, are discussed in Chapters 4 , 5 , and 7 and therefore no additional information, as in the Regulatory Guide format, is necessary for Chapter 6 . This change also enables the discussion of the buildings and structures usually in Chapter 3 to be combined into one chapter.

Details within the chapters describing structures, systems, and components have been modified so that information from the Standard MHTGR design documents (e.g. System Design Descriptions and Subsystem Design Descriptions) can be included in the PSID. This change provides additional assurance that 
HTGR - $86-024$

the licensing documention provided by the PSID is consistent with program design documents.

Owing to the conceptual stage of the Standard MHTGR design, it should be expected that the detail provided in the PSID is somewhat less than a PSAR-type document. Furthermore, the level of detail and completeness of the supporting analyses and assessments is representative of the stage of design. Consequently, the focus of safety assessments in this document is on events which have been identified as of greatest significance by PRA results to date and experience based on detailed assessments of prior HTGR concepts. The primary purpose of these assessments is to determine whether the Top-Level Regulatory Criteria (Ref. 9) are met for the limiting conditions investigated. It is to be expected that design evolution and more detailed and complete analyses may lead to detailed modifications in the plant and consequential improvement in the plant's response to Licensing Basis Events. Also, intentionally less detail has been provided in areas where standard industry practices are to be followed; otherwise, greater detail is provided. Structures, systems, and components required for radionuclide control are described in more detail than systems having little or no radionuclide control requirements.

Another modification to the guidance provided by Regulatory Guide 1.70 is the clear distinction given to structures, systems and components within the Nuclear Island as opposed to those in the Energy Conversion Area (see Section 1.6). The discussion of the latter systems, which have no radionuclide control functions, is limited to a functional description and an identification of interfaces with the Nuclear Island.

\subsubsection{Consistency with NRC's Advanced Reactor Policy}

The PSID is responsive to and consistent with the policy guidelines provided in the NRC's Advanced Reactor Policy. (Ref 3) Key areas of consistency are noted below. 
1. Early Interaction

The NRC Policy encourages "the earliest possible interaction of applicant, vendors and government agencies with the NRC." The PSID submitted herein provides the vehicle for an early preapplication interaction with potential applicants, vendors, and government agencies.

\section{Safety Criteria}

The NRC Policy states that "the Commission expects, as a minimum, at least the same degree of protection of the public and the environment that is required for current generation LWRs." Also, "the Commission also expects that advanced reactor designs will comply with the Commission's forthcoming safety goal policy statement." Section 3.? to this PSID describes the Top-Level Regulatory Criteria which have been applied to the design of the Standard MHTGR and demonstrates their consistency with criteria imposed on current generation LWRs as well as with the Commission's safety goal policy statement.

\section{Licensing Approach}

The NRC Policy notes that "Advanced reactor designers are encouraged as part of their design submittals to propose specific review criteria or novel regulatory approaches which NRC might apply to their designs." Sections 1.2, 3.1, and 3.2 of this PSID describe the nove1 regulatory approach which has been proposed to the NRC for application to the Standard MHTGR design.

4. Design Features

The NRC Policy states that "the Commission expects that advanced reactors will provide enhanced margins of safety and/or utilize simplified, inherent, passive, or other innovative means to accomplish their safety functions." Sections 1.2 and 1.3 summarize the approach which has been taken in the design of the standard MHTGR to produce a design which relies only on simplified, inherent or passive means to accomplish safety functions. 


\section{1 .5 Requested NRC Response}

The NRC is requested to conduct a review of the PSID and the companion submittals described in the Licensing Plan and document the conclusions of this review in a Preliminary Safety Evaluation Report. Following briefings and feedback from the Advisory Committee on Reactor Safeguards on the results of this review, the NRC is further requested to issue a summary statement, referred to herein as a Licensability statement, which states the key conclusions of this review and which reaches conclusions as to whether the Standard MHTGR reactor concept is Iicensable.

Conditioned on the conceptual stage of the Standard MHTGR design, the overall licensability statement should reach conclusions on the following questions:

1. Is the Standard MHTGR design reactor concept licensable?

Basis: PSID, PRA, Regulatory Technology Development Plan, and Emergency Planning Basis Report.

2. Are the interfaces between the Standard MHTGR Nuclear Island and the Energy Conversion Area and the Site appropriately identified and characterized?

Basis: PSID

3. Are the Top-Level Regulatory Criteria acceptable and can they remain valid through Final Design Approval?

Basis: Top-level Regulatory Criteria for the Standard MHTGR (HTGR-85-002, Rev. 2, October 1986)

4. Is the methodology for proceeding from the Top-Level Regulatory Criteria through risk assessments and other safety analysis to the deterministic licensing bases acceptable and can it remain valid through Final Design Approval?

Basis: Bridging Methods for Standard HTGR Licensing Bases (HTGR-86-039, Rev. 2, February 1986); Application of Bridging Methods 
for Standard HTGR Licensing Bases (HTGR-86-017, Rev. 1, February 1986); Licensing Basis Event Selection Criteria (HTGR-86-001, Rev. 1, February 1986); Licensing Basis Events for the Modular HTGR (HTGR-86-034, April 1986), PSID

5. Is the approach for emergency planning acceptable? Basis: PSID, PRA, and Emergency Planning Bases Report.

6. Is the proposed Regulatory Technology Development Plan adequate for the Standard MHTGR Final Design Approval? Basis: Regulatory Technology Development Plan

7. Is the proposed Application procedure acceptable? Basis: Licensing Plan for the Standard MHTGR (HTGR-85-001, Rev. 3; February 1986) 
HTGR - 86-024

REFERENCES

SECTION 1.1

1. U. S. Nuclear Regulatory Commission. Letter from William Dircks to James Vaughn, July 11, 1985.

2. U. S. Department of Energy. Licensing Plan for the Standard HTGR. HTGR-85-001, Rev. 3, February, 1986.

3. U. S. Nuclear Regulatory Commission. Policy for the Regulation of Advanced Nuclear Power Plants. 51FR24643, July 8, 1986.

4. U. S. Department of Energy. Probabilistic Risk Assessment for the Standard MHTGR Plant. DOE-HTGR-86-011, Rev. 3, January 1987.

5. U. S. Department of Energy. Regulatory Technology Development Plan for the Standard MHTGR. DOE-HTGR-86-064, Rev. 0, January 1987.

6. U. S. Department of Energy. Emergency Planning Bases for the Standard MHTGR. DOE-HTGR-87-001, Rev. 0, February 1987.

7. U. S. Nuclear Regulatory Commission. Letter from Themis Speis to Francis Gavigan, "Outline for Preliminary Safety Information Document (PSID) for the Standard HTGR", October 25, 1985.

8. U. S. Department of Energy. PSID Outline for the Standard HTGR. HTGR-85-063, July 1985.

9. U.S. Department of Energy. Top-Level Regulatory Criteria for the Standard HTGR. HTGR-85-002, Rev. 2, October 1986. 


\subsection{SAFETY PHILOSOPHY AND METHODOLOGY}

\subsubsection{Philosophy}

The overall philosophy guiding the design of the Standard MHTGR is similar to that which has guided and continues to guide all reactor designs. This philosophy may be stated, in its simplest terms, as follows:

Produce a safe, economical plant design which meets NRC and user requirements by providing defense-in-depth through pursuit of four Goals:

1. Maintain Plant Operation

Reliably maintain the functions necessary for normal plant operation, including the plant states of energy production, shutdown, refueling, and startup/shutdown operations.

2. Maintain Plant Protection

Assume that despite the care taken to maintain plant operation, failures will occur and provide additional design features or systems to prevent plant damage.

3. Maintain Control of Radionuclide Release Provide additional design features or systems to ensure containment of radionuclides in the event that normal operating conditions cannot be maintained and/or plant protection is not assured.

\section{Maintain Emergency Preparedness}

Maintain adequate emergency preparedness to protect the health and safety of the public in the event that control of radionuclide release is not accomplished.

With regard to the achievement of NRC criteria for the accomplishment of Goal 1 and 2 functions, measures are taken in the design of the Standard MHTGR, as they are in other reactor concepts, to minimize defects in the fuel and to purify the primary circuit of any radionuclides which do escape the fuel so that normal operational releases or any accidental releases of primary circuit 
activity are low and worker exposures are minimized. These techniques have been proven to be effective in other gas-cooled reactors as has been demonstrated by measuring releases and worker exposures from operating plants.

The unique aspect of the Standard MHTGR, however, is the approach which has been taken to achieve the functions of Goal 3. To accomplish this goal with high assurance, the design of the standard MHTGR has been guided by the additional philosophy that control of radionuclide releases be accomplished by retention of radionuclides within the fuel particles with minimal reliance on active design features or operator actions. The overall intent here is to provide a simple safety case that will provide high confidence that the Goal 3 safety criteria are met. There are two key elements to this philosophy which have had a profound impact on the design of the Standard MHTGR (especially in the selection of core size and geometry, power density, and vessel type); the basis for each element is described below.

First, the philosophy requires that control of radionuclides be accomplished with minimal reliance on active systems or operator actions. By minimizing $\therefore$ the need to rely on active systems or operator actions, the safety case centers on the behavior of the laws of physics and on the integrity of passive design features. Arguments need not center on an assessment of the reliability of pumps, valves and their associated services or on the probability of an operator taking various actions, given the associated uncertainties involved in such assessments.

Second, the philosophy requires control of releases by the retention of radionuclides within the coated fuel particle rather than reliance on secondary barriers (such as the primary coolant boundary or Reactor Building). The judgement made here is that the proof of containment is dramatically simplified if arguments can center on issues associated with fuel particle coating integrity alone.

The following sections describe the method which has been employed to ensure the consistent incorporation of this safety philosophy into the design. 
HTGR - 86-024

\subsubsection{Design Approach}

The approach to safety for the Standard MHTGR has been applied in a "top-down" fashion as illustrated in Figure 1.2-1. The process begins with the quantification of top-level criteria pertaining to how well each of the four Goals defined in the previous section is to be achieved. Next, an integrated systems engineering approach is systematically applied to develop the functions, requirements, and specific design selections necessary to achieve, in a balanced fashion, all of the Top-Level Regulatory Criteria and user requirements. The product of this Integrated Approach is the plant design described in this document.

A set of specific licensing bases for the Standard MHTGR has been derived as represented in Figure 1.2-1. The bridge is the method by which those regulatory bases for the design as implemented in the Integrated Approach design process are cast in a framework and format similar to the traditional licensing bases applied to current generation LWRs. The licensing bases include the licensing basis events which demonstrate the design's compliance with the Top-Level Regulatory Criteria, the 10CFR100 Design Criteria which specify how the Standard MHTGR will meet the 10CFR100 dose limits, and the classification of equipment that can be assured to respond to the events in the manner specified to meet the Top-Level Regulatory Criteria. The method employed to derive this licensing basis is described in Section 3.2 of this document.

\subsubsection{Top-Level Criteria and Requirements}

Top-level criteria and requirements are defined primarily from two sources: the regulator, whose concern is primarily public health and safety, and the user, whose concern is all encompassing (e.g. safety, performance, availability, and economics). Each of the four Goals has been quantified by a series of top-level criteria and requirements (Ref. 1, 2). The Top-Level Regulatory Criteria are a necessary and sufficient set of direct quantitative statements of acceptable health and safety consequences (doses) or risks to

the public that are independent of reactor type and site. Demonstration of 
the ability to meet the Top-Level Regulatory Criteria is an essential part of the licensability assessment. Section 3.1 of this document describes the bases for and identifies the Top-Level Regulatory Criteria. The following paragraphs provide examples of top-level user requirements for each goal. The examples are chosen to illustrate the close relationship between the top-level user requirements and the Top-Level Regulatory Criteria in meeting all four Goals (see Figure 1.2-2).

Goal 1 encompasses normal plant operations, including the planned operating states of energy production, shutdown, refueling, and startup/shutdown. Goal 1 user requirements include that the plant be designed for an average equivalent unavailability due to planned outages not to exceed 10 percent and minimizing worker doses to less than an average of 10 percent of 10CFR20 allowables. The design lifetime is to be 40 years from start of plant operation.

Goal 2 is protection of the plant investment to ensure that economic losses associated with unscheduled events are limited. Top-level user requirements for Goal 2 include limiting average annual equivalent unscheduled unavailability to less than 10 percent and limiting the frequency for events resulting in reactor loss to less than $10^{-5}$ per plant year.

Goal 3 is to ensure that releases of radioactive materials remain within acceptable limits for transients or accidents having the potential for release of radionuclides. In addition to the Top-Level Regulatory Criteria described in Section 3.1 which quantify this goal, it is a top-level user requirement that radionuclides be controlled to the extent that the emergency planning does not require provisions for the offsite sheltering or evacuation of the public.

Goal 4 assures emergency preparedness in the event an accident occurs in which radionuclide release is not controlled. As described above, the user has required that the design control radionuclide releases so reliably that measures should not be required for the offsite evacuation or sheltering of the public. 
HTGR - 86- 024

\subsubsection{Integrated Approach}

The Integrated Approach is the systematic systems engineering process utilized to develop the functions, requirements, and design selections to achieve all of the top-level regulatory criteria and the user requirements. The analysis tools include the use of functional analysis, reliability evaluations probabilistic risk assessments, trade studies, and engineering analyses. The product of the Integrated Approach is the Standard MHTGR plant design.

A key element of the Integrated Approach is functional analysis. Functional analysis is a process of systematically ordering, from the top down, the many functions which must be achieved to meet the overall goals. Figure 1.2-2 shows the starting point for the functional analysis, namely the four Goals identified to achieve safe, economic power. Figure 1.2-3 shows a typical expansion of a Goal, in this case Goal 3, Maintain Control of Radionuclide Release. As illustrated in this figure, each subsequent level of functions is developed by examining the next upper level function and answering the question, "How is the function to be achieved?" In such a manner, a "tree" of increasing levels of detail is defined until a specific design selection results.

After determining what functions must be accomplished for each goal, it is necessary to determine how well each function must be accomplished to meet the top-level criteria and requirements. For this purpose, reliability evaluations and probabilistic risk assessment techniques (Ref. 3) have been used to supplement standard engineering techniques and to provide an integrated allocation of the top-level criteria and requirements to specific plant systems. PRA techniques have also been used to identify the relative importance of events and plant structures, systems, and components in responding to such events, as described in Section 3.2. 
HTGR - 86- 024

\section{REFERENCES}

SECTION 1.2

1. U.S. Department of Energy. Top-Level Regulatory Criteria for the Standard HTGR. HTGR-85-002, Rev. 2, October 1986.

2. Gas-Cooled Reactor Associates. Utility/User Requirements for the Modular High Temperature Gas-Cooled Reactor Plant. GCRA 86-002, Rev. 2, September 1986.

3. U.S. Department of Energy. Probabilistic Risk Assessment for the Standard MHTGR Plant. DOE-HTGR-86-011, Rev. 3, January 1987. 


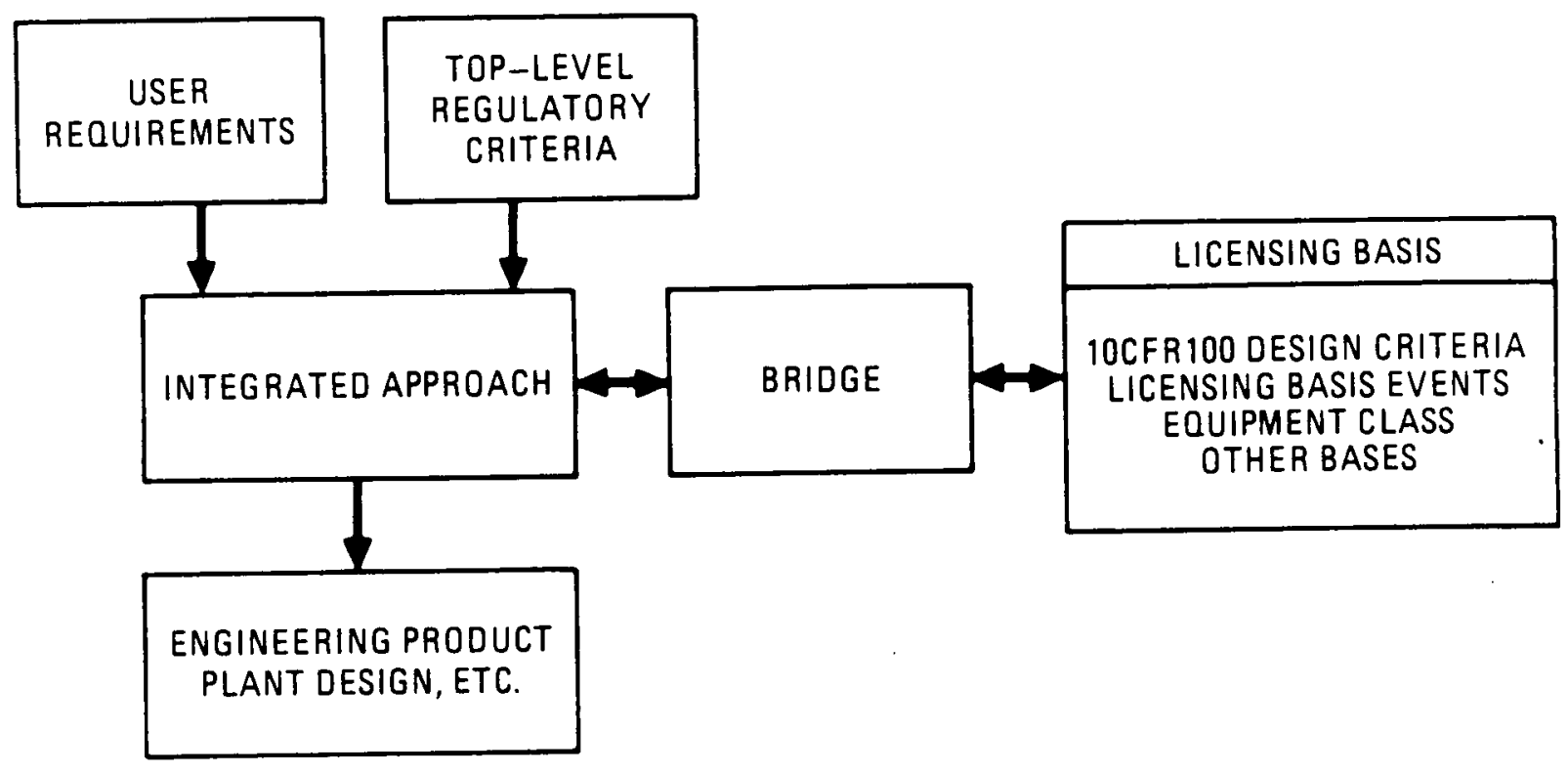

FIGURE 1.2.1

STANDARD MHTGR DESIGN AND LICENSING APPROACH

HIGH TEAPERATURE GASCOOLED REACTOA PRELIMIMARY SAFETY INFORMATION DOCUMENT HTGR-86-124 


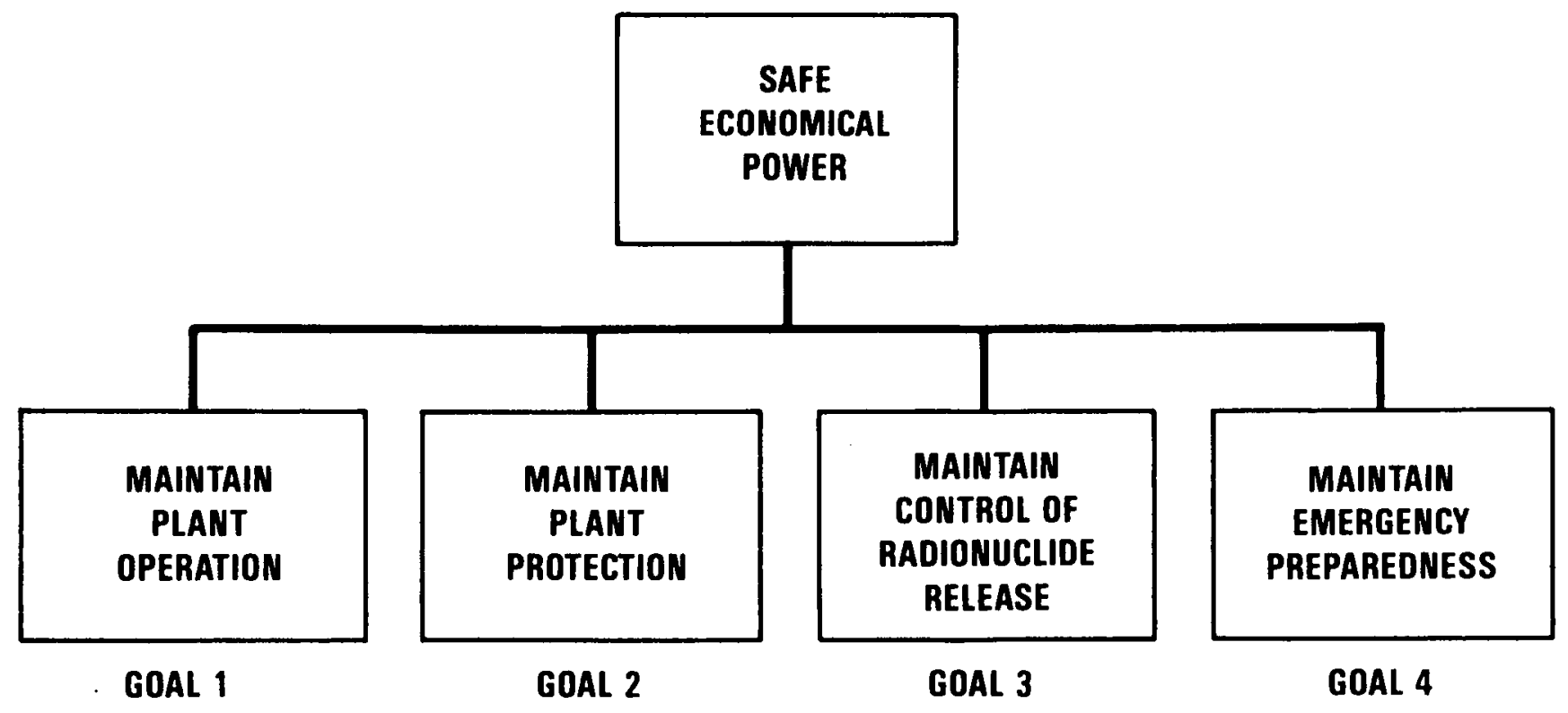

FIGURE 1.2.2

PLANT GOALS

HIGH TEMPERATURE GAS-COOLED REACTOR

PRELMMINARY SAFETY INFORMATION DOCUMENT HTER 86-024 


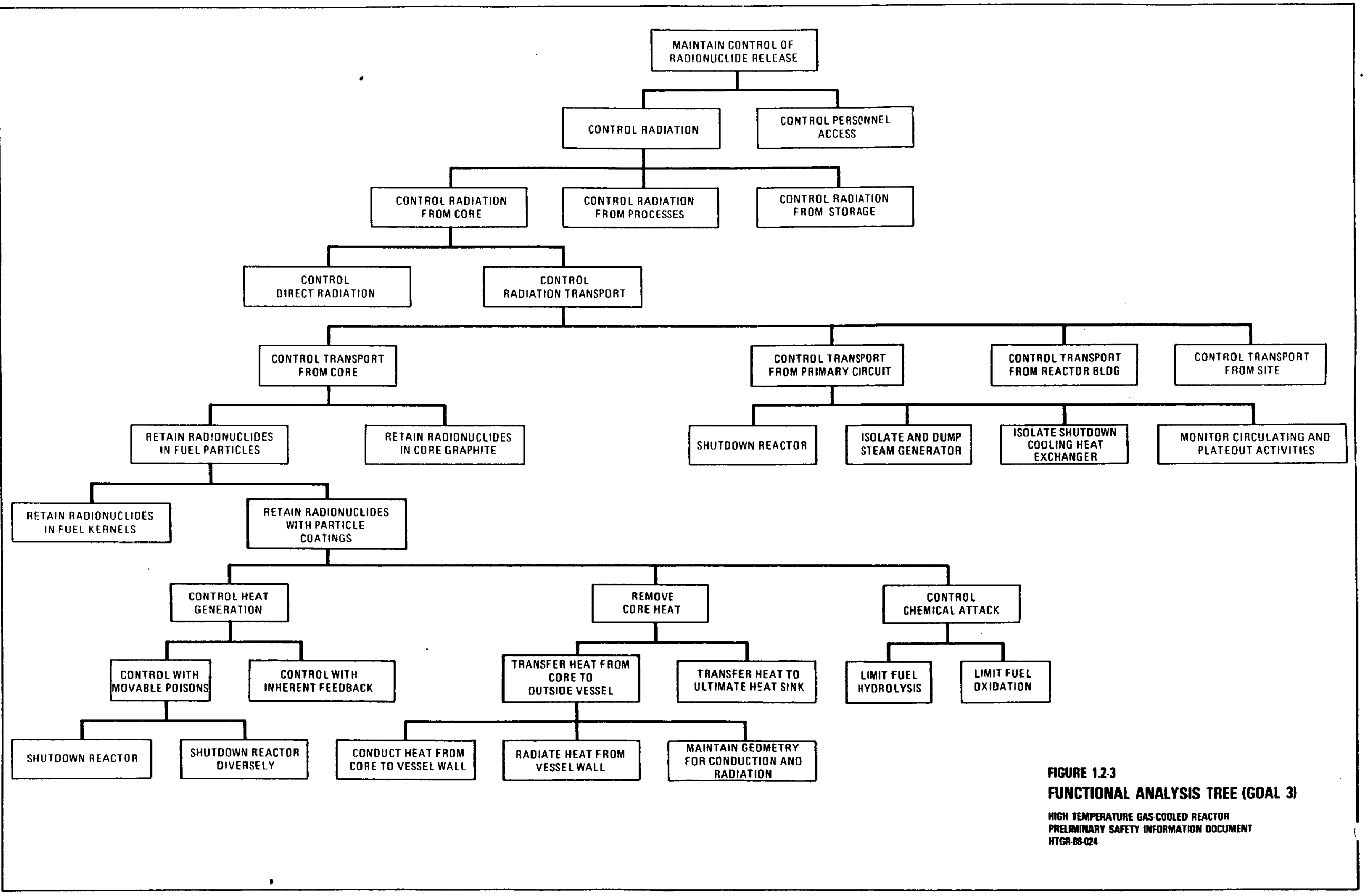



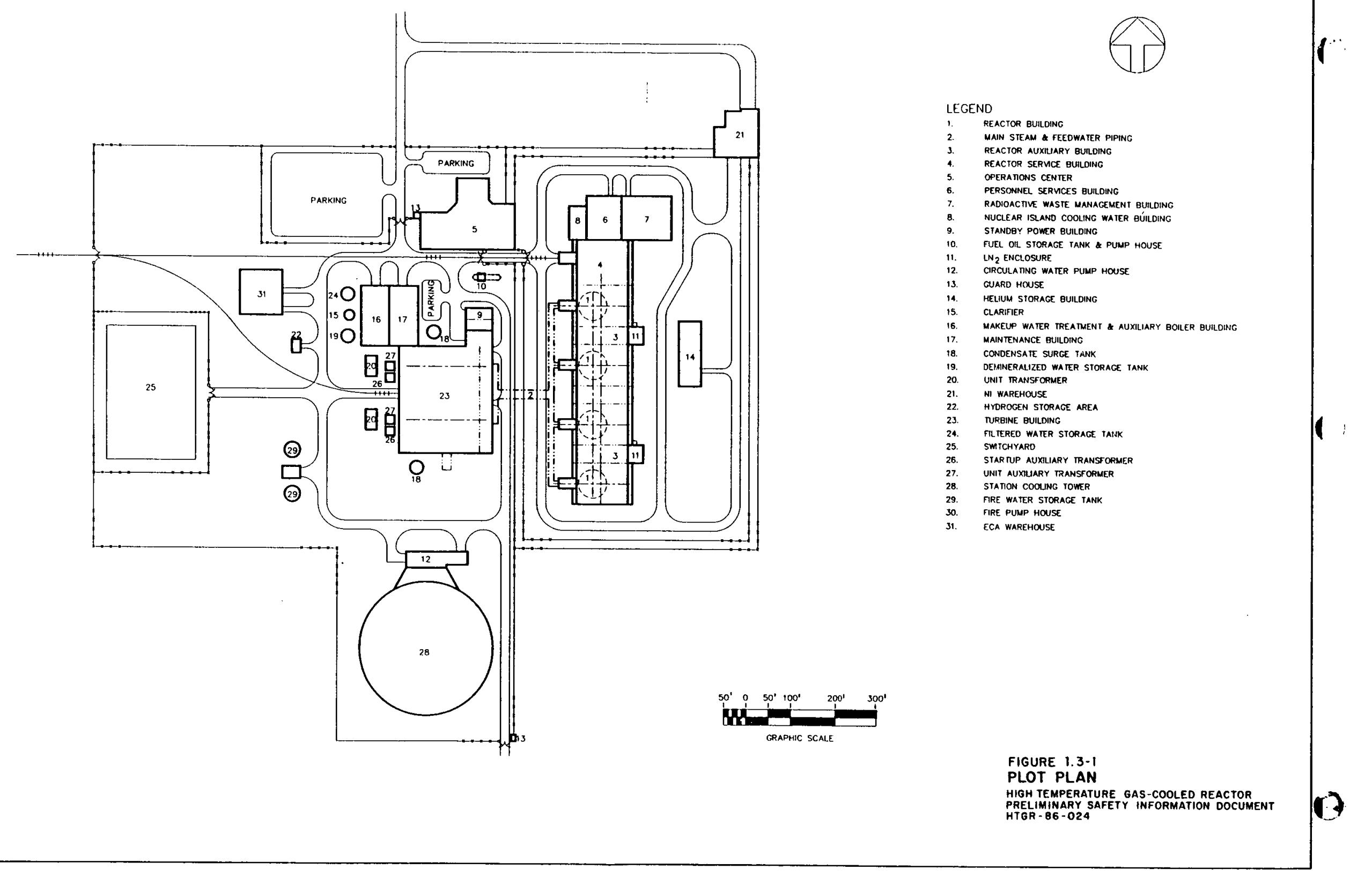


\subsection{GENERAI PLANT DESCRIPTION}

The Standard MHTGR design is based on the substantial body of existing technology and plant operating experience gained over the past 30 years. Especially relevant, of course, is that experience derived from the design and operation of other HTGR plants such as Peach Bottom $I$ and Fort St. Vrain. The Standard MHTGR shares a number of design features with its predecessors, especially the use of ceramic coated fuel particles and pressurized helium as a coolant. The specific design features selected for the Standard MHTGR design, however, have been influenced greatly by the philosophy of producing a design which is relatively simple and which places maximum reliance on passive or inherent safety features to achieve the levels of safety required by the NRC and by the current utility environment.

The following sections provide a general overview of the design and its safety characteristics, starting with a description of the overall plant and site and working inward to the fuel. Table 1.3-1 summarizes some of the key design features and parameters associated with the Standard MHTGR.

For additional information related to this section see the response to NRC Comment G-10.

\subsubsection{Site Characteristics}

A specific site has not been selected for the Standard MHTGR. However, the parameters chosen to evaluate the safety characteristics of the design cover a large number of potential sites in the United States. The plant is designed for a site adjacent to a source of cooling water such as a river or lake with an assumed elevation of $30.5 \mathrm{~m}$ (100 ft) above mean sea level. The plant area required, as shown by the plot plan in Figure $1.3-1$, is approximately 13.2 hectares ( 32.5 acres), excluding the switchyard. Based upon an assumed exclusion area boundary (EAB) of 425 meters, a minimum of 56.7 hectares ( 140 acres) is required for the site. 


\subsubsection{Plant Arrangement}

The plant arrangement as shown in Figures 1.3-1 and 1.3-2 consists of four reactor modules with common support facilities. The four modules are cross headered to feed two turbine generators operating in parallel to produce a combined net output of about 550 MWe. All four modules and the ECA systems are controlled from a single control room. The passive safety characteristics and slow response of the modular design provide a basis for not designating the control building as "safety related".

Systems containing radionuclides and "safety-related" systems are minimized and contained within a well defined Nuclear Island which is separated physically and functionally from the remainder of the facility. This allows the construction and operation of the other areas in accordance with conventional standards and practices.

Within the Nuclear Island, each reactor module is housed in adjacent, but separate, reinforced concrete structures located below grade enclosed by a common maintenance hall. This configuration provides significant design benefits by reducing the seismic amplification that can occur with above grade structures.

\subsubsection{Vessel and Heat Removal Systems}

Figure 1.3-3 shows a cutaway drawing of the nuclear steam supply module which is the fundamental building block of the Standard MHTGR. It consists primarily of a reactor vessel and steam generator connected by a concentric crossduct.

The reactor vessel is similar in size to a large BWR vessel. The single steam generator vessel houses a helically coiled steam-generator bundle as well as a single motor-driven circulator. The pressure-retaining components are constructed of steel and designed using existing technology. The reactor vessel is uninsulated to provide for decay heat removal under accident conditions. 
Figure 1.3-4 is a simplified flow diagram illustrating how reactor heat is transferred in normal operation. Within the Vessel System, helium coolant flows to the reactor vessel in the outer annular region of the crossduct, flows down through the core, returns through the center region of the 
crossduct, down through the steam-generator bundle, then back up the annular region around the steam-generator back to the inlet of the single helium circulator. On the secondary coolant side, feedwater enters the separate steam generator vessel at the bottom and flows through a helical coil tube bundle, exiting as superheated steam at the side of the vessel.

When the reactor is shut down for maintenance or refueling, decay heat can be removed from the core by the normal Heat Transport system (HTS) described above, or alternatively by an independent shutdown Cooling system (SCS). The SCS consists of a motor-driven circulator coupled with a water-cooled heat exchanger mounted beneath the reactor core within the reactor vessel. The SCS is provided for investment protection and flexibility of operation. The SCS and HTS are not "safety-related".

As a third means of providing decay heat removal, a "safety-related" Reactor Cavity Cooling System (RCCS) is provided within each reactor cavity. The RCCS cooling is provided by natural circulation of outside air within enclosed panels along the reactor cavity walls. The panels are designed such that outside air does not communicate with air within the cavity. The RCCS is capable of removing from the reactor vessel, decay heat conducted and radiated from the core. The RCCS is always functioning in its natural circulation mode to provide cooling of the reactor cavity concrete during normal operation and is therefore always available to remove decay heat under accident conditions without reliance on active components, power supplies, or operator action.

\subsubsection{Reactor Core}

The reactor core power, power density, and geometry have been specifically constrained to maintain fuel particle integrity by limiting the maximum fuel temperature during all licensing basis events, including a loss of coolant and loss of all active cooling from full power operation.

Figure 1.3-5 shows a cross section of the reactor core. The active core consists of fueled graphite blocks in an annular region surrounding an inner 
reflector consisting of unfueled graphite blocks. The core is surrounded by an outer side reflector region also consisting of unfueled graphite blocks. The inner reflector region has been provided to allow for a higher core power level while still ensuring that peak fuel temperatures are successfully limited under accident conditions.

Two independent and diverse means are provided to control reactor power. A control rod system inserts poison rods into channels provided in the reflector regions adjacent to the core. The control rod system is used for normal control and plant shutdown. A reserve shutdown system is also provided using boron carbide pellets which can be dropped into channels in the inner active core region. This system provides a diverse backup shutdown capability.

\subsubsection{Reactor Fuel}

The fuel system used in the Standard MHTGR has been developed through extensive operating experience with helium cooled reactors. Figure 1.3-6 shows the fuel components of the Standard MHTGR core, which are essentially identical to those of Fort St. Vrain. A primary objective of the fuel design is to provide a high integrity barrier, serving to localize radioactive fission products at the point of production. Fabrication processes for coated microspheres have been developed which give very high fission product retention capability for the fuel particles. Work is in progress (see Regulatory Technology Development Plan) to fabricate fuel which retains that capability in commercially produced fuel. This will lead to extremely low levels of radioactivity throughout the balance of the primary circuit.

The fuel kernels (approximately 350 microns in diameter) are coated with a porous graphite buffer to absorb gaseous fission products and provide a space for fission gas expansion. Two external coatings of pyrolytic carbon and one external coating of silicon carbide are added to retain the fission products within the fuel particle and buffer region. Fertile thorium oxide particles are fabricated in a similar configuration. 
HTGR - 86- 024

The microparticles are mixed with a binder material and formed into fuel rods approximately $1.3 \mathrm{~cm}(0.5 \mathrm{in.})$ in diameter and $5.0 \mathrm{~cm}$ (2 in.) in length. The fuel rods are stacked in holes drilled in the graphite fuel element blocks.

The fuel elements are hexagonal graphite blocks approximately $79 \mathrm{~cm}$ (31 inches) in length and $35 \mathrm{~cm}$ (14 inches) across the flats. A standard fuel element contains approximately 200 fuel holes and 100 coolant holes.

\subsubsection{Safety Features}

The safety features of the Standard MHTGR are dominated by the safety characteristics common to all HTGRs as well as features unique to the particular configuration of the Standard MHTGR module. The general safety characteristics of an HTGR design tend to be dominated by the inherent characteristics of the coolant, core materials, and fuel as described below.

1. Helium Coolant - The inert and single phase helium coolant has several advantages. No flashing or boiling of coolant is possible, pressure measurements are certain, no coolant level measurements are required and pump cavitation cannot occur. Further, there are no reactivity effects associated with the helium and no chemical reaction between coolant and fuel or cladding is possible.

2. Coated Fuel Particle - The multiple ceramic coatings surrounding the fuel kernels constitute tiny independent pressure vessels which contain fission products. These coatings are capable of maintaining their integrity to very high temperatures in the $1600^{\circ}$ to $1800^{\circ} \mathrm{C}$ $\left(2910-3270^{\circ} \mathrm{F}\right)$ temperature range.

3. Graphite Core - The strength of the graphite core and the stability of the ceramic fuel coating at high temperatures result in a wide margin between operating temperatures and temperatures that would result in core damage. Further, the high heat capacity and low power density of the core result in very slow and predictable temperature transients. 
Consistent with the safety philosophy described in Section 1.2 , the Standard MHTGR has been designed specifically to take advantage of these inherent HTGR characteristics so that minimal reliance may be placed on active or powered systems or operator actions to accomplish safety functions. Specifically, the geometry and size of the reactor core, its power density, and the uninsulated steel vessel have been selected to allow for decay heat removal from the core to the ultimate heat sink through the natural processes of radiation, conduction and convection. As a result, the Standard MHTGR can withstand a loss of helium coolant in combination with the loss of all forced circulation from full power without fuel temperatures exceeding a level at which significant incremental fuel particle failure would be observed.

The above described passive features are intrinsic. They require neither operator action nor active powered systems. Thus, by combining the inherent characteristics common to all HTGRs with special features unique to the MHTGR design, a level of safety is provided by the standard MHTGR that is consistent with the NRC's Advanced Reactor Policy. 
HTGR - 86- 024

TABLE 1.3-1

FEATURES OF THE STANDARD MHTGR

\begin{tabular}{|c|c|}
\hline Fue1 & $\mathrm{UCO}+\mathrm{ThO}_{2}$ Microparticles \\
\hline Coating & Ceramic (PyC/SiC/PyC) \\
\hline Moderator & Graphite \\
\hline Coolant & Helium \\
\hline Coolant Boundary & Steel Pressure Vessel \\
\hline Power per Module & $140 \mathrm{MWe} / 350 \mathrm{MWt}$ \\
\hline Power Density & $5.9 \mathrm{~W} / \mathrm{cc}$ \\
\hline Fuel Temperature (Max/Ave) & $1060 / 677 \mathrm{C}(1940 / 1250 \mathrm{~F})$ \\
\hline Coolant Temperature (In/Out) & $259 / 687 \mathrm{C}(497 / 1268 \mathrm{~F})$ \\
\hline Coolant Pressure & $6.4 \mathrm{MPa}$ (925 psig) \\
\hline Steam Temperature & $541 \mathrm{C}(1005 \mathrm{~F})$ \\
\hline Steam Pressure & 2500 psig \\
\hline
\end{tabular}




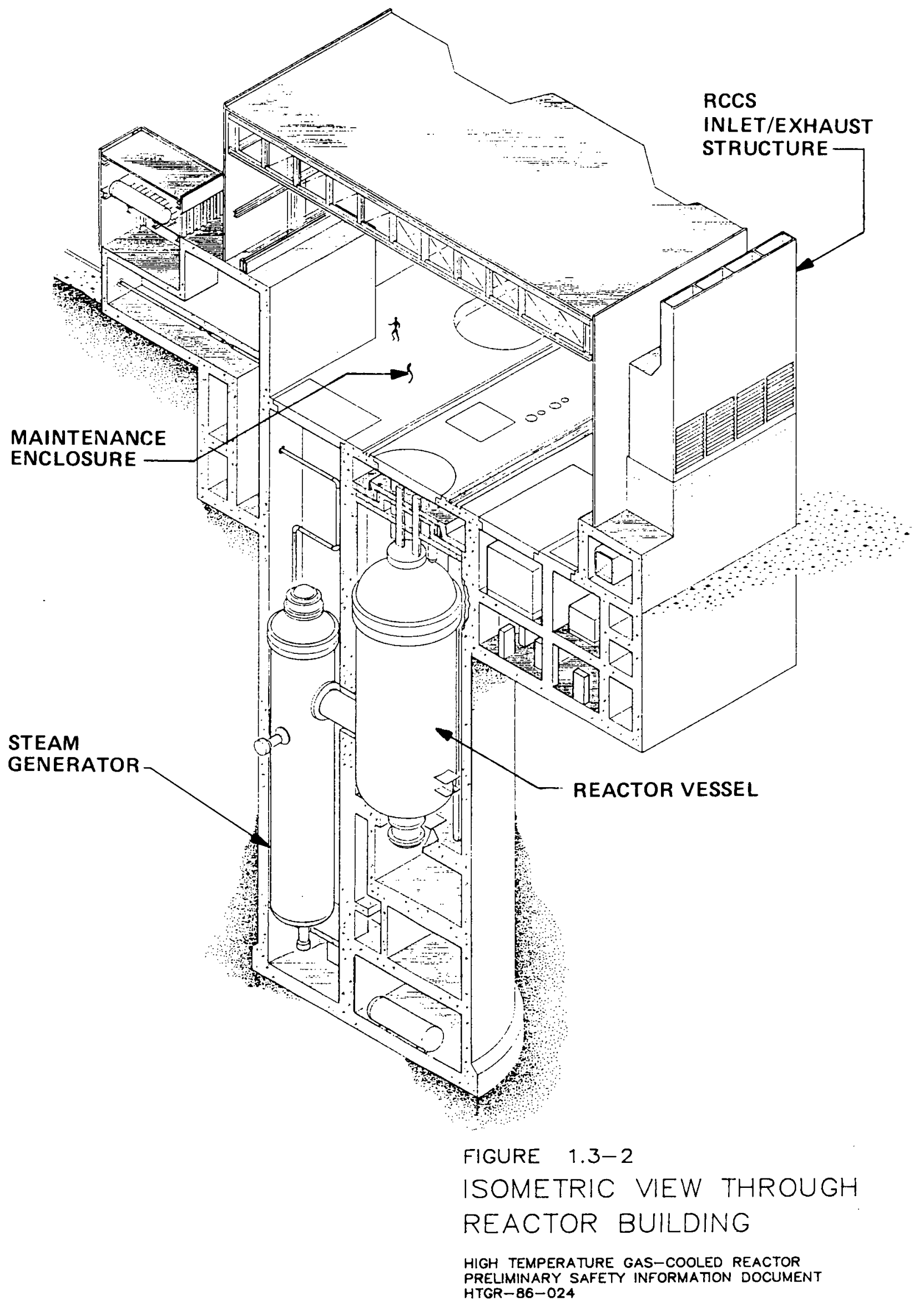




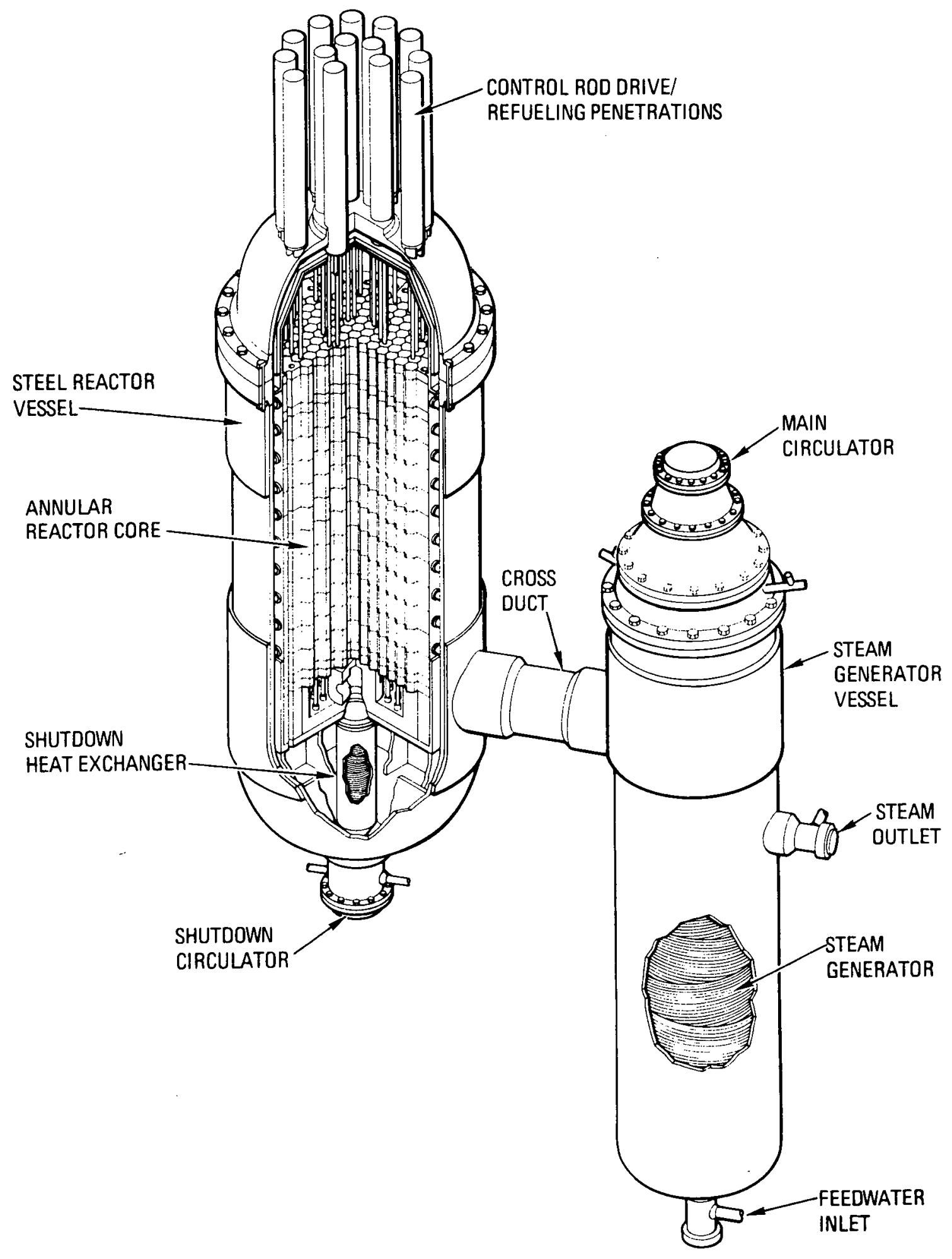

FIGURE 1.3-3

350 MW(t) HTGR MODULE

HIGH TEMPERATURE GAS-COOLED REACTOR PRELIMINAARY SAFETY INFORMATION DOCUMENT 
$\sigma$

$\sigma$

$\sigma$ 


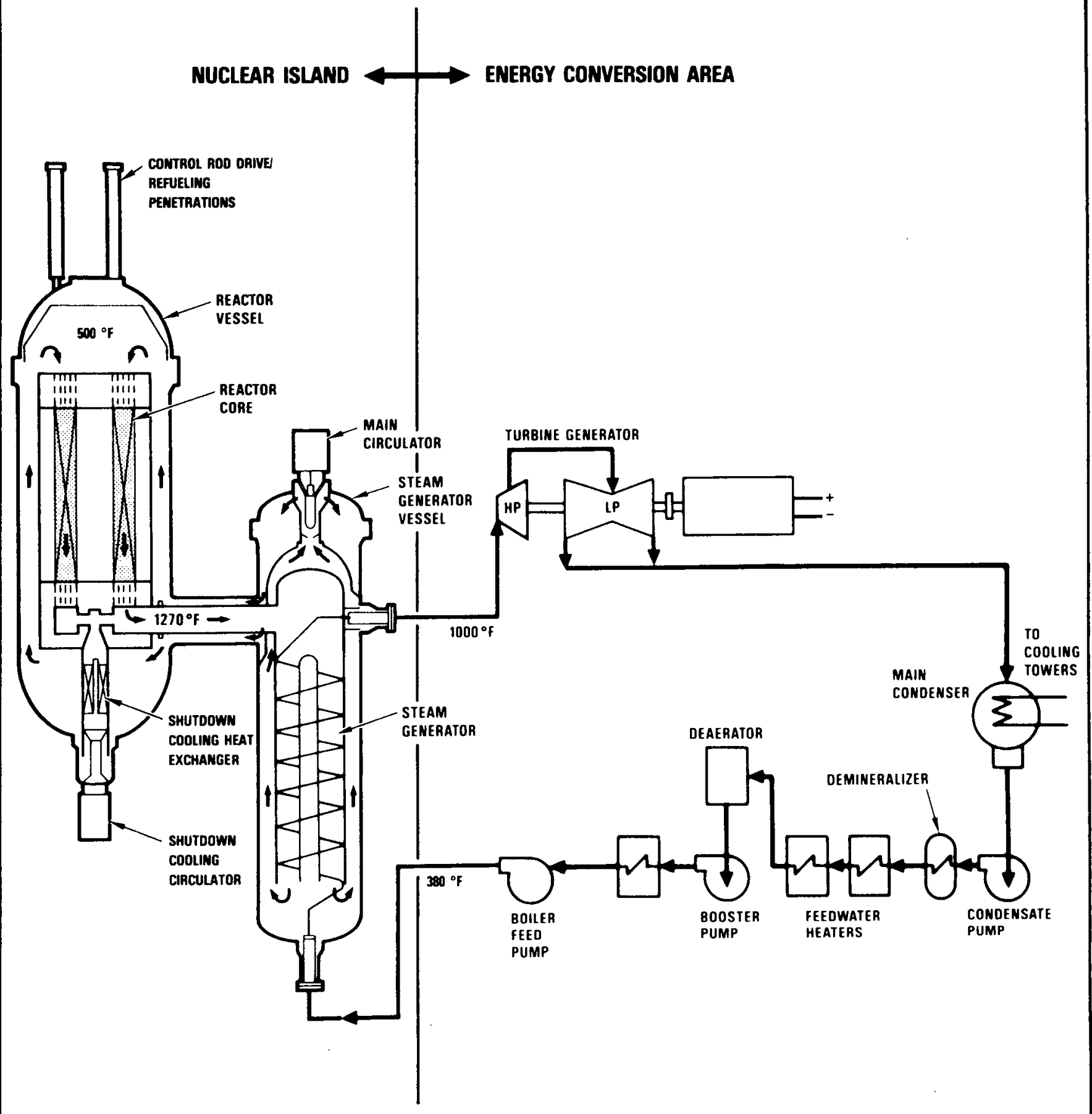

FIGURE 1.3-4

SIMPLIFIED FLOW DIAGRAM 


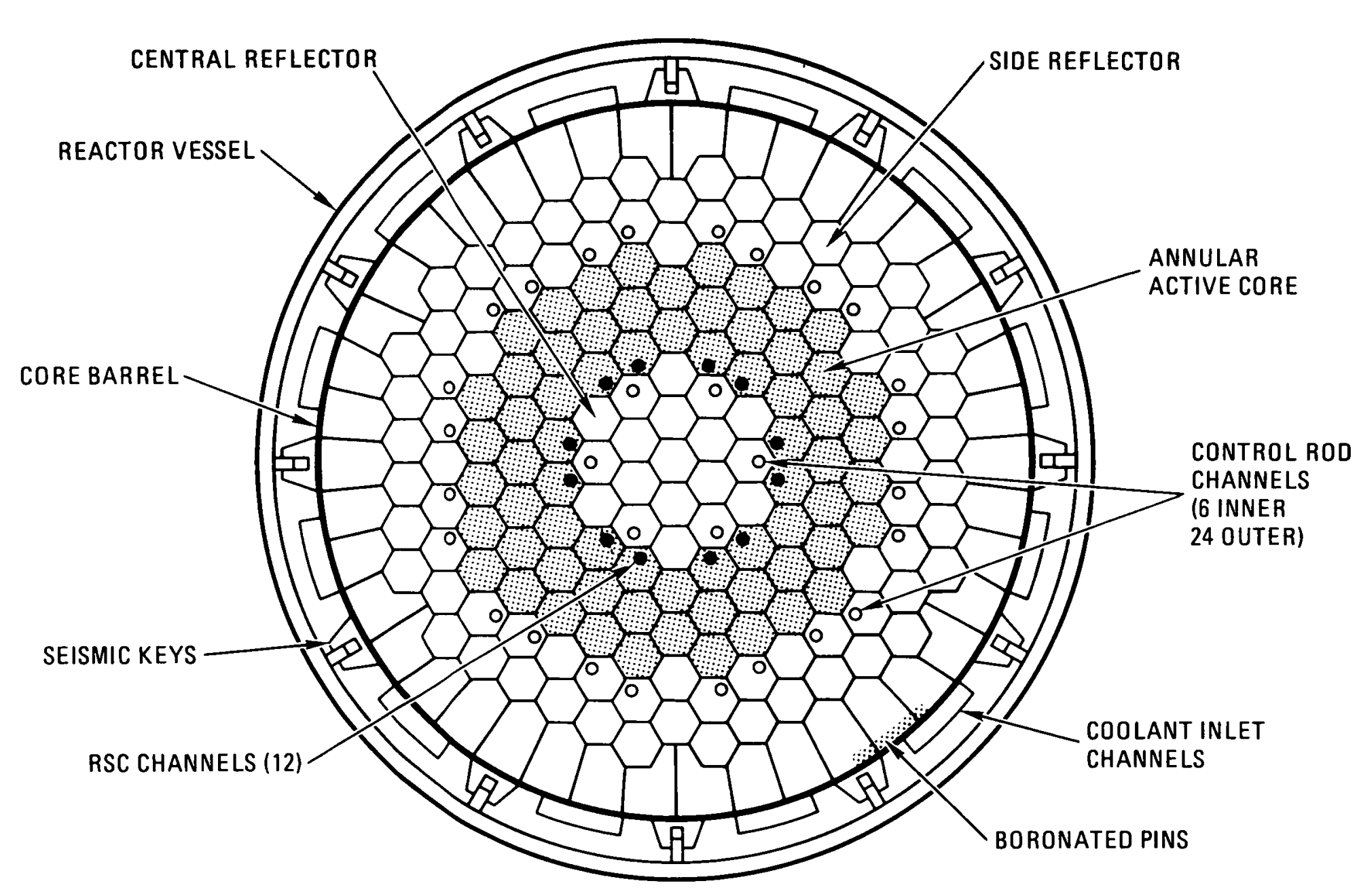

FIGURE 1.3-5

REACTOR PLAN VIEW

HIGH TEMPERATURE GAS-COOLED REACTOR PRELMMINARY SAFETY INFORMATION DOCUMENT HTGR-S624 
FUEL PARTICLES

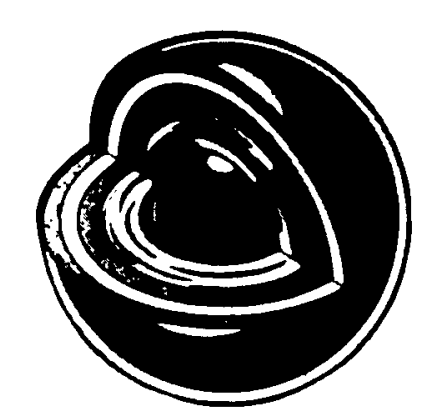

FISSILE (URANIUM 20\% ENRICHED)

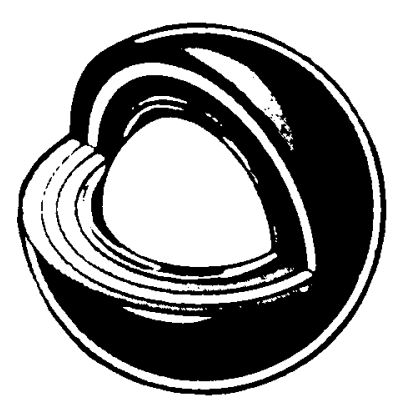

FERTILE (THORIUM)
PRISMATIC

FUEL ELEMENT

\section{FUEL COMPACT}
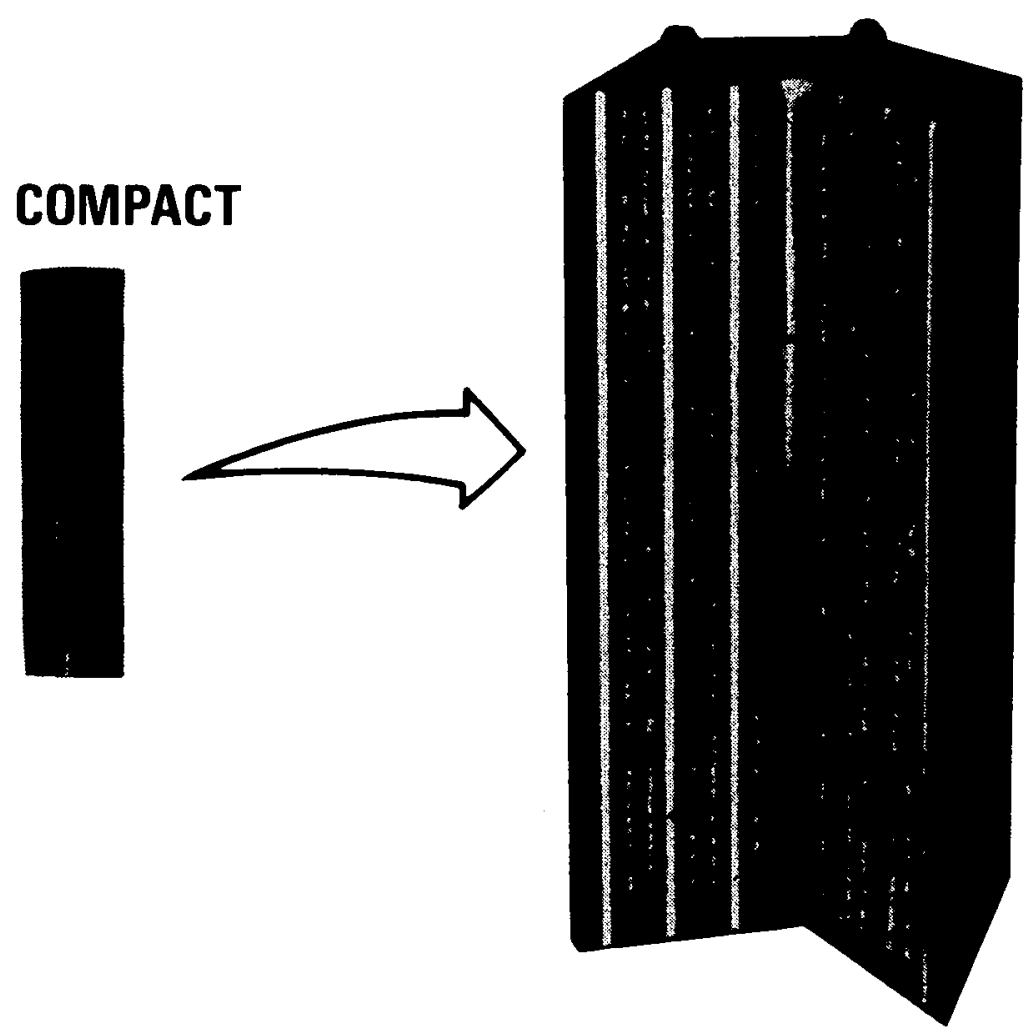

FIGURE 1.36

FUEL ELEMENT COMPONENTS

HIGH TEMPERATURE GAS-COOLED REACTOR

PRELIMINARY SAFETY INFORMATION DOCUMENT HTGR-16-024 


\subsection{REQUIREMENTS FOR FURTHER TECHNICAL INFORMATION}

Research and development programs, either planned or in progress, that provide further technical information directly related to plant safety are identified and reported in the Regulatory Technology Development Plan. (Ref. 1) 
HTGR - 86- 024

REFERENCES - SECTION 1.4

1. Department of Energy. Regulatory Technology Development Plan for the Standard MHTGR. DOE-HTGR-86-064, Rev. 0, January 1987. 


\subsection{MATERIAL INCORPORATED BY REFERENCE}

The following material is incorporated by reference in the PSID:

U.S. Department of Energy. Top-Level Regulatory Criteria for the Standard HTGR. HTGR-85-002, Rev. 2, October 1986.

U.S. Department of Energy. Bridging Methods for Standard HTGR Licensing Bases. HTGR-86-039, Rev. 2, February 1986.

U.S. Department of Energy. Application of Bridging Methods for the Standard HTGR Licensing Bases. HTGR-86-017, Rev. 1, February 1986.

U.S. Department of Energy. Probabilistic Risk Assessment for the Standard MHTGR Plant. DOE-HTGR-86-011, Rev. 3, January 1987.

U.S. Department of Energy. Regulatory Technology Development Plan for the Standard MHTGR. DOE-HTGR-86-064, Rev. O, January 1987.

U.S. Department of Energy. Licensing Plan for the Standard HTGR. HTGR-85-001, Rev. 3, February 1986.

U.S. Department of Energy. Licensing Basis Event Selection Criteria. HTGR-86-001, Rev. 1, February 1986.

U.S. Department of Energy. Licensing Basis Events for the Modular HTGR. HTGR-86-034, April 1986.

U.S. Department of Energy. Methodology for Development of Principal Design Criteria for the Standard HTGR. HTGR-85-166, Rev. 1, January 1987. 


\subsection{STANDARD DESIGN INTERFACES}

The Reference Plant design separates the plant into two areas, the Nuclear Island and the Energy Conversion Area.

The Nuclear Island is defined as that portion of the plant that has within its boundary the following:

1. The standard reactor modules and "safety-related" buildings, structures, systems, portions of systems, and components dedicated to assuring reactor shutdown, decay heat removal, fission product retention, and security, including new (unirradiated) fuel.

2. At the designer's discretion, buildings, structures, systems, portions of systems, and components that are not safety-related but support reactor operation or investment protection.

The Energy Conversion Area is that portion of the plant not included within the Nuclear Island.

A number of systems additionally provide services to both the Nuclear Island and the Energy Conversion Area. Table 1.6-1 shows the listing of systems and subsystems comprising the Nuclear Island, the Energy Conversion Area and systems which service both the Nuclear Island and the Energy Conversion Area. Table 1.6-2 similarly shows a listing of major buildings and structures and identifies their location in the Nuclear Island or the Energy Conversion Area.

The Standard MHTGR, which is the subject of this PSID, consists of all the systems, subsystems and buildings and structures identified in the first column of Tables $1.6-1$ and $1.6-2$, i.e., the Nuclear Island. In addition, those portions of the interfacing systems and subsystems (second column of Table 1.6-1) that are physically contained within the Nuclear Island boundary are also part of the Standard MHTGR. The interfacing systems identified with an asterisk in Table 1.6-1 are presented in detail to emphasize the particular importance to radionuclide control of their interfaces with the Nuclear Island. 
Each Nuclear Island system described in the following Chapters of the PSID contains a discussion of interfaces with other systems and subsystems, and interface requirements. Energy Conversion Area Systems, Section 9.2 and Chapter 10, specifically discuss interfaces with the Nuclear Island and safety consequences, if any, from that interface. 
TABLE $1.6-1$

NUCLEAR ISLAND, ENERGY CONVERSION AREA, AND INTERFACING SYSTEMS

Nuclear Island (Sub) Systems

(Sub) System Name

\section{Reactor}

Vessels and Ducts

Heat Transport

Shutdown Cooling

Reactor Cavity Cooling

Plant Protection \& Instrumentation

NSSS Analytical Instrumentation

Seismic Monitoring

Class IE Uninterruptible Power

Class 1E DC Power

Fuel Handling \& Storage

Reactor Services

Steam/Water Dump

Liquid Radioactive Waste

Gaseous Radioactive Waste

Solid Radioactive Waste

Nuclear Area Fire Protection

Heating, Ventilating and

Air Conditioning (NI)

\section{Interfacing (Sub) Systems}

PSID

Sect.

(Sub) System Name

Ch. 4

5.2

5.3

5.4

5.5

7.2

7.4 .1

7.4 .3

8.2

8.3

9.1.1

9.1 .2

10.16

11.2

11.3

11.4

\subsubsection{Plant Drains}

Feedwater and Condensate

9.1.3.2 Main and Bypass Steam

Service Water

Startup and Shutdown

Non Class $1 E$ Uninterruptible

Power

Non Class 1E DC Power

Instrument and Service Air

Demineralized Water Makeup
Energy Conversion Area (Sub) Systems

PSID

Sect. (Sub)Systems

PSID

Sect.

\subsubsection{ECA Control}

7.3.2 Offsite Power, Main Generator

7.3 .3

8.4

7.4 .2

7.4 .4

7.4 .5

7.3 .4

8.5

8.8

Waste Water Treatment

Auxiliary Boiler

Raw Water Treatment

Heating, Ventilating, Air

Conditioning (ECA)

Heater Drains, Condensate Return

Condensate Polishing

8.9

8.10

9.2 .1

9.2 .2

9.2 .3

9.2 .4

9.2 .9

9.2.10

Steam Vents \& Drains

Turbine Plant Sampling

Turbine Generator \& Auxiliary

Chemical Feed

Extraction and Auxiliary Steam

Circulating Water

Turbine Building Closed Cooling

Water

10.1

Circulating Water Makeup

Blowdown

10.14

10.15

8.6

8.7

9.2 .8

10.9
9.2 .51

9.2 .6

9.2 .71

9.2 .11

10.2

10.3

10.4

10.5

10.6

10,7

10.10

10.11

10.12

10.13

\footnotetext{
*Interfacing systems or subsystems which are currently described in detail for PSID review.
} 
HTGR - 86-024

TABLE $1.6-2$

BUILDINGS AND STRUCTURES

Nuclear Island

Reactor Building

Reactor Auxiliary Building

Reactor Service Building

(including Nuclear Island

Cooling Water Building \&

Chilled Water Building)

Personnel Services Building

Helium Storage Structure

Radioactive Waste Management

Building
Energy Conversion Area

Turbine Building

Fire Pumphouse

Energy Conversion Area Warehouse

Makeup Water Treatment \& Auxiliary

Boiler Building

Maintenance Building

Intake Pumphouse and Discharge

Structure

Operations Center (including Control

Room)

Cooling Tower Basin and Circulating

Water Pumphouse

Standby Power Building

Nuclear Island Warehouse 
HTGR - $86-024$

CHAPTER 2

STANDARD SITE CHARACTERISTICS

CONTENTS

Section

Title

Page

2.1

INTRODUCTION

$2.1-1$

2.2

GEOGRAPHY AND DEMOGRAPHY

$2.2-1$

2.2 .1

Site Location

2. $2-1$

2.2 .2

Site Description

2. $2-1$

2.2 .3

Population Distribution

$2.2-1$

2.3

NEARBY INDUSTRIAL, TRANSPORTATION AND MILITARY

FACILITIES

$2.3-1$

2.4

METEOROLOGY

$2.4-1$

2.4 .1

Regional Climatology

$2.4-1$

2.4 .2

Local Meteorology

$2.4-1$

2.4 .3

Short-Term (Accident) Diffusion Estimates

$2.4-2$

2.4 .4

Long Term (Routine) Diffusion Estimates

2.4-2

2.5

HYDROLOGY

$2.5-1$

2.6

SEISMOLOGY

$2.6-1$ 
HTGR - $86-024$

\section{LIST OF EFFECTIVE PAGES}

\section{Page Number}

\section{Amendment}

$2-i$

0

$2-i i$

1

2.1-1 0

2. $2-1$ 1

2. $3-1$ 1

2.4-1

1

2. 4-2

2. $5-1$

0

2. $6-1$

1.




\section{HTGR - 86- 024 \\ CHAPTER 2 \\ STANDARD SITE CHARACTERISTICS}

\subsection{INTRODUCTION}

The Standard MHTGR plant is not designed for a specific site; however, the parameters chosen to evaluate the safety characteristics of the design generally cover a large number of potential sites (about 85 percent) in the United states. In the following sections, the enveloping parameters used in the design of the Standard MHTGR are identified. 
HTGR - 86- 024

\subsection{GEOGRAPHY AND DEMOGRAPHY}

\section{2 .1 Site Location}

The Standard MHTGR plant is designed for an inland site within the United States adjacent to a source of cooling tower makeup water such as a river or a lake.

\section{2 .2 Site Description}

The Standard MHTGR plant is assumed to be located at an elevation of $30.5 \mathrm{~m}$ (100 feet) above mean sea level. The plant area required is approximately 13.2 hectares ( 32.5 acres - excluding the switchyard). Based on an assumed exclusion area boundary of 425 meters, a minimum of 56.7 hectares (140 acres) is required for the site.

The Standard MHTGR plant is broken up into two major areas: a Nuclear Island containing the four reactor modules and the Energy Conversion Area containing the two turbine generators. A11 "safety-related" structures, systems, and components are contained within the Nuclear Island portion of the plant.

The reactor vessels are housed in vertical concrete enclosures, fully embedded in the earth, so that the Reactor system is completely below grade (see Section 6.1.1).

\subsubsection{Population Distribution}

Population data are site specific and will be presented at the time of application for a specific site. However, for purposes of estimating population doses, a population density is assumed to average 500 persons per square mile over a radial distance out to $30 \mathrm{miles}$. A bounding low population zone of 425 meters (i.e. coincident with the exclusion area boundary) has been selected for purposes of safety analyses. 


\section{3 NEARBY INDUSTRIAL, TRANSPORTATION, AND MILITARY FACILITIES}

The hazard to the plant presented by such facilities are site specific and, in all but special cases, can be expected to be enveloped by those produced by the climatological conditions assumed for the design of the Standard MHTGR (see Section 2.4).

Evaluation of the capability of the plant to withstand the effects of potential accidents resulting from the operation of industrial or military installations near the specific site will be presented at the time of application for a specific site. 
HTGR - 86- 024

\subsection{METEOROLOGY}

\subsubsection{Regional Climatology}

The following meteorological conditions are assumed for the design of structures, systems, and components required to meet 10CFR100 and for the Standard MHTGR:

1. Precipitation (Snow) - A maximum snow load of $2391 \mathrm{~Pa}$ (50 psf) is as sumed.

2. Tornadoes, Hurricanes, and High Winds - the design basis tornado produces the most severe wind loads assumed in the plant design. The design basis tornado is assumed to have the following characteristics:

Designation (RG 1.76)

Maximum Wind Speed

Rotational speed

Translational Velocity

External Pressure Drop

High Winds
Region I

$579 \mathrm{~km} / \mathrm{hr}(360 \mathrm{mi} / \mathrm{hr})$

$467 \mathrm{~km} / \mathrm{hr}(290 \mathrm{mi} / \mathrm{hr})$

$113 \mathrm{~km} / \mathrm{hr}(70 \mathrm{mi} / \mathrm{hr})$

$20,684 \mathrm{~Pa}(3.0 \mathrm{psi})$

(a) $14 \mathrm{~K} \mathrm{~Pa} / \mathrm{sec}(2.0 \mathrm{psi} / \mathrm{sec})$

$177 \mathrm{~km} / \mathrm{hr}(110 \mathrm{mi} / \mathrm{hr})$ a $10 \mathrm{~m}$

3. Maximum Temperature - a dry bulb maximum temperature of $43 \mathrm{C}$ (110 F) and a wet bulb maximum temperature of $28 \mathrm{C}(82 \mathrm{~F})$ is assumed.

4. Minimum Temperature - a dry bulb minimum temperature of $-43 \mathrm{C}$ ( $-45 \mathrm{~F})$ is assumed.

\subsubsection{Local Meteorology}

A program of onsite data collection, supplemented by National Weather Service (NOAA) sumnaries from locations near a specific site, will be conducted. Information from the onsite program will be used to confirm that the limiting offsite dose analyses and annual average $X / Q$ values are adequate relative to exclusion area boundary radius and low population zone requirements. 


\subsubsection{Short-Term (Accident) Diffusion Estimates}

The meteorological factors used for the design of the Standard MHTGR in terms of accidental releases of activity are based on the guidelines found in Regulatory Guide 1.4.

The limiting exclusion area boundary short term atmospheric dispersion factors (in $\mathrm{sec} / \mathrm{m}^{3}$ ) are assumed to be:
$0-8 \mathrm{hr}$
$1.21 \times 10^{-3}$
$8-24 \mathrm{hr}$
$6.34 \times 10^{-4}$
1 - 4 days
$2.30 \times 10^{-4}$
4 - 30 days
$5.22 \times 10^{-5}$

Consistent with Regulatory Guide $1: 4$, the 0 to $8 \mathrm{hr}$ release dispersion factor includes a Building Wake Correction factor of 2.1 based upon a maximum building cross-sectional area of $748 \mathrm{~m}^{2}$.

\subsubsection{Long-Term (Routine) Diffusion Estimates}

The annual average atmospheric dispersion factor at the exclusion area boundary is assumed to be $2 \times 10^{-5} \mathrm{sec} / \mathrm{m}^{3}$. 


\subsection{HYDROLOGY}

Evaluation of the capability of the plant to withstand the effects of severe hydrometeorological phenomena will be presented at the time of application for a specific site. For purposes of the analysis presented herein, yard grade for "safety-related" structures is set at an elevation above the water level that can be reached by the probable maximum event. Normal groundwater elevation is assumed to be 8 feet below grade. 
HTGR - $86-024$

\subsection{SEISMOLOGY}

The following site conditions related to seismology and geology are the basis for the design of structures, systems and components required to meet 10CFR100:

1. The Safe Shutdown Earthquake (SSE) maximum horizontal and vertical ground acceleration is less than or equal to $0.3 \mathrm{~g}$

2. The Operating Basis Earthquake (OBE) maximum horizontal and vertical ground acceleration is less than or equal to $0.15 \mathrm{~g}$

3 The soil characteristics consider a range of shear wave velocities between 305 and 2440 meters per second (1000 to 8000 feet per second) with an allowable static bearing capacity of $479 \mathrm{kPa}$ (10 ksf) 
CHAPTER 3

LICENSING BASES AND THE CRITERIA AND METHODOLOGY FOR DESIGN OF STRUCTURES, SYSTEMS, AND COMPONENTS

CONTENTS

Section

$\underline{\text { Title }}$

Page

3.1

CONFORMANCE WITH NRC CRITERIA

$3.1-1$

3.1 .1

Top-Leve1 Regulatory Criteria

$3.1-1$

3.1 .1 .1

Bases for Selection of Top-Level Regulatory Criteria

$3.1-1$

3.1.1.2

Top-Level Regulatory Criteria for the Standard MHTGR

$3.1-2$

3.1 .2

Comparison with NRC Criteria

$3.1-3$

3.1 .2 .1

51 FR 28044: Policy Statement on Safety Goals for the Operation of Nuclear Power Plants

$3.1-4$

3.1 .2 .2

10CFR20: Standards for Protection Against Radiation

$3.1-5$

3.1 .2 .3

10CFR50 Appendix I: Numerical Guides for Design

Objectives. . . to Meet the Criteria "As Low As Is

Reasonably Achievable" for Radioactive Material . .

In Effluents

$3.1-5$

$3.1 .2 \cdot 4$

40CFR190: Environmental Radiation Protection Standards

for Nuclear Power Operations

$3.1-6$

3.1 .2 .5

10CFR100: Reactor Site Criteria

$3.1-6$

3.1 .2 .6

EPA-520/1-75-001: Manual of Protective Action Guides

and Protective Actions for Nuclear Incidents

$3.1-7$

3.2

STANDARD MHTGR LICENSING BASES

$3.2-1$

3.2 .1

Licensing Basis Events

$3.2-2$

3.2 .1 .1

Licensing Basis Event Selection Criteria

$3.2-2$

3.2 .1 .2

Selection of Licensing Basis Events

$3.2-2$

3.2 .2

10CFR100 Design Criteria

$3.2-4$

Classification of Structures, Systems, and Components

$3.2-6$

3.2 .3

Description of Classification System and Associated

3.2 .3 .1

Requirements

$3.2-6$

Method of Establishing Classifications

$3.2-8$

3.2 .3 .2

Classification of Standard MHTGR Structures, Systems,

3.2 .3 .3

and Major Components

3. $2-10$ 


\section{CONTENTS}

(Continued)

Section

Title

$\underline{\text { Page }}$

3.3 WIND AND TORNADO LOADING

$3.3-1$

3.3 .1

Wind Loading

$3.3-1$

3.3.1.1

Design Wind Velocity

$3.3-1$

3.3 .1 .2

Determination of Applied Forces

$3.3-2$

3. 3.2

Tornado Loading

$3.3-2$

3. 3.2 .1

Applicable Design Parameters

$3.3-2$

3.3 .2 .2

Determination of Forces on Structures

$3.3-3$

3.3 .2 .3

Effect of Failure of Structures or Components

Not Required to be Designed for Tornado Loads

$3 \cdot 3-3$

3.4

WATER LEVEL (FLOOD) DESIGN

$3.4-1$

3.5

PROTECTION AGAINST MISSILES AND EXTERNALLY-GENERATED

HAZARDS

$3.5-1$

3.5 .1

Hazard Selection and Description

$3.5-1$

3. 5.1 .1

Internally Generated Missiles

$3.5-1$

3.5 .1 .2

Turbine Missiles

$3.5-1$

3.5 .1 .3

Missiles Generated by Natural Phenomena

$3.5-1$

3.5 .1 .4

Hazards Generated by Events Near the Site

$3.5-2$

Aircraft Hazards

$3.5-2$

3.5 .1 .5

Structures, Systems, and Components to be Protected

3.5 .2

3.5 .3

from Externally Generated Hazards

$3.5-2$

Barrier Design Procedures

$3.5-3$

3.6

PROTECTION AGAINST DYNAMIC EFFECTS ASSOCIATED WITH THE POSTULATED RUPTURE OF PIPING

$3.6 \cdot 1$

3.7

SEISMIC DESIGN

$3.7-1$

3.7 .1

Seismic Input

$3.7-1$

3.7 .1 .1

Generic Site Characteristics

$3.7-1$

3.7 .1 .2

Generic Input Spectra

3. $7-1$

3.7 .1 .3

Validation of a Specific Site

3. $7-1$ 
3.7.3.1 Analysis/Qualification by Test of Mechanical

$$
\text { and Electrical Components }
$$

3.7.3.1.2 Steam Generator Isolation Valves and Primary Coolant 
HTGR - 86- 024

\section{CONTENTS}

(Continued)

Section

$\underline{\text { Title }}$

Page

3.8.2.2 Loading Combinations

$3.8-4$

3.8 .3

Design and Analysis Procedures

$3.8-6$

3.8 .3 .1

Analysis Procedures

$3.8-6$

3.8 .3 .2

Design Procedures

$3.8-7$

3.8 .4

Structural Acceptance Criteria

$3.8-7$

3.8 .5

Materials

$3.8-8$

3.8 .6

Testing and In-Service Inspection Requirements

$3.8-8$

3.9

DESIGN OF MECHANICAL SYSTEMS AND COMPONENTS

$3.9-1$

3.9 .1

Plant Duty Cycle

$3.9-1$

3.9 .2

Mechanical Component Design Bases

3.9-3

3.9 .2 .1

Loading Combinations, Design Transients, and Stress

Limits

$3.9-3$

Operability Assurance of "Safety-Related" Valves

$3.9-3$

3.9 .2 .2

Design and Installation Details for Mounting of Pressure Relief Devices

$3.9-6$

Component Supports and Core Support Structures

$3.9-6$

3.9 .2 .4

Valve Electric Motor Operator Qualification

3.9-6

3.9 .2 .5

Design and Installation Criteria for Pressure-Relieving Devices

3.9-7

In-Service Inspection, Testing, and Surveillance

$3.9-8$

3.9 .3

In-Service Inspection and Surveillance of systems,

Structures, and Components

3. $9-8$

Scope of In-Service Inspection and Safety Surveillance

$3.9-9$

3.9 .3 .1 .1

Accessibility

3. $9-9$

3.9 .3 .1 .3

Examination Techniques and Procedures

$3.9-10$

3.9 .3 .1 .4

Inspection Intervals

3. $9-10$

3.9 .3 .1 .5

Examination Records

3. $9-10$

3.9 .3 .1 .6

System Leakage and Pressure Tests

$3.9-10$

3.9 .3 .2

In-Service Testing of Valves

$3.9-10$

3.9 .4

Acoustic and Flow-Induced Vibrations

$3.9-11$ 
HTGR - 86-024

\section{CONTENTS}

(Continued)

\section{$\underline{\text { Section }}$}

3.9 .4 .1

3.9 .4 .2

3.9 .4 .2 .1

3.9 .4 .2 .2

3.9 .4 .2 .3

3.9 .4 .3

3.9 .4 .4
Title

Applicable Components and Structures

Systems Analysis

Flow-Induced Vibrations

Acoustic Vibration

Prediction of Damage Due to Fatigue

Component Testing

Preoperational and Startup Testing
Page

$3.9-11$

$3.9-12$

$3.9-12$

$3.9-13$

$3.9-15$

3. $9-16$

3. $9-16$ 


\section{HTGR - $86-024$}

\section{LIST OF TABLES}

Table

$\underline{\text { Title }}$

3.1-1 Top-Leve1 Regulatory Criteria

3.2-1 Anticipated Operational Occurrences

3.2-2 Design Basis Events

3.2-3 Emergency Planning Basis Events

3.2-4 Modular High-Temperature Gas-Cooled Reactor Equipment Classification

3.3-1 Tornado Wind Velocities and Pressures

3.5-1 Tornado Missiles

3.8-1 ACI-349 Load Combinations and Load Factors

3.8-2 Symbols Used in Load Combinations

3.8-3 Stability Factors of Safety

3.9-1 Plant Duty Cycle

3.9-2 Systems and Subsystems Subject to In-Service Inspection and Surveillance

3.9-3 Frequency and Extent of ISI Examinations

3.9-4 ISI Material Surveillance Program

3.9-5 ISI Testing Schedule for Safety and Relief Valves

3.9-6 Flow Velocity Design Values for the Primary Coolant 
HTGR - $86-024$

\section{LIST OF FIGURES}

Figure

Title

3.2-1 Licensing Basis Regions for Licensing Basis Event Selection

3.2-2 Major 10CFR100 Related Functions and Safety-Related Design Selections

3.7-1 Preliminary Reactor Building Soil-Structure

Interaction Model

3.7-2 CRUNCH-2D ModeI

3.7-3 MCOCO Mode1

3.7-4 NSSS Finite Element Model

3.9-1 Weekly Load Following Cycle

3.9-2 REVERB Model of the Standard MHTGR Primary Coolant System

3.9-3 Sound Pressure Design Levels for the Primary Coolant Loop 
HTGR - $86-024$

\section{LIST OF EFFECTIVE PAGES}

Page Number

Amendment

$3-i$ and $3-i 1$

1

3-iii through 3-vii

0

3-viii

6

$3-i x$

5

3. 1-1

1

3. $1-2$

0

$3.1-3$

3. $1-4$

0

$3.1-5$

2

3.1-6 and 3.1-7

3. $1-8$

1

Table 3.1-1 (1 of $4 / 4$ of 4)

$3.2-1$

3. $2-2$

3. 2-3 and 3.2-4

$3.2-5$

3.2-6 through $3.2-8$ 1

3. $2-9$ 2

3. $2-10$

$3.2-11$

Tables 3.2-1 and 3.2-2

Table 3.2-3

Table $3.2-4$ (1 of $33 / 27$ of 33 ) 0

Table 3.2-4 (28 of $33 / 30$ of 33 ) 2

Table $3.2-4$ ( 31 of $33 / 33$ of 33 )

Figure 3.2-1

Figure 3.2-2

3.3-1 and 3.3-2

0

$3.3-3$ and $3.3-4$

Table 3.3-1

$3.4-1$

3.4 .2 
HTGR - 86- 024

\section{LIST OF EFFECTIVE PAGES}

(Continued)

Page Number

Amendment

3.5-1 through 3.5-2a

1

3.5-3 and 3.5-4

0

Table 3.5-1

0

3.6-1 through 3.6-3

4

3.7-1 through 3.7-23

5

Figures 3.7-1 through 3.7-11

5

3.8-1 through 3.8-6a

1

$3.8-7$ and $3.8-8$

0

Table 3.8-1

Tables 3.8-2 through 3.8-3

1

3.9-1 through 3.9-8

$3.9-9$

$3.9-10$

2

3. $9-11$

1

3.9-12 through 3.9-16

3. $9-17$

Table 3.9-1 ( 1 of $3 / 3$ of 3 )

Table 3.9-2 (1 of 2)

Table 3.9-2 (2 of 2)

2

Tables 3.9-3 through 3.9-6

0

Figures 3.9-1 through 3.9-3 


\section{LIST OF EFFECTIVE PAGES}

(Continued)

Page Number

Amendment

3.5-1 through 3.5-2a

1

$3.5-3$ and $3.5-4$

Table 3.5-1

3.6-1 through 3.6-3

4

3.7-1 through 3.7-7

0

3. 7-8

4

3.7-9. and 3.7-10

1

3.7-11 through 3.7-17

3. $7-18$

3.7-19 through 3.7-21

Figures 3.7-1 through 3.7-4

3.8-1 through 3.8-6a

3.8-7 and 3.8-8

Table 3.8-1

Tables 3.8-2 through 3.8-3

3.9-1 through $3.9-8$

1

3.9-9

0

3. $9-10$

2

3. $9-11$

1

3.9-12 through 3.9-16

0

3. $9-17$

1

Table 3.9-1 (1 of $3 / 3$ of 3 )

Table 3.9-2 (1 of 2)

1

Table 3.9-2 (2 of 2)

2

Tables 3.9-3 through 3.9-6

0

Figures 3.9-1 through 3.9-3

0 
CHAPTER 3

LICENSING BASES AND THE CRITERIA AND METHODOLOGY FOR DESIGN OF STRUCTURES, SYSTEMS, AND COMPONENTS

\subsection{CONFORMANCE WITH NRC CRITERIA}

Section 1.2 introduced the concept of developing the Standard MHTGR design in a top-down fashion using the Integrated Approach to satisfy both the user's requirements and the Top-Level Regulatory Criteria. (Ref. 1, 2) In addition, it noted the existence of a bridging methodology for casting the quantitatively implemented regulatory bases contained in the latter criteria into a framework and format similar to that of traditional licensing bases. While the user's requirements and the Integrated Approach were discussed in. some detail in Section 1.2, this chapter discusses the Top-Level Regulatory Criteria and development of the licensing bases used to provide the necessary regulatory assurance that these criteria are met by the Standard MHTGR design. This section provides a discussion of the Top-Level Regulatory Criteria, while development of the Standard MHTGR licensing bases is discussed in Section 3.2 .

\subsubsection{Top-Leve1 Regulatory Criteria}

\subsubsection{Bases for Selection of Top-Level Regulatory Criteria}

The successful achievement of the overall objective of the Standard MHTGR to produce safe, economical nuclear power involves the consideration and blending of factors related to safety as well as plant economics and performance. The Integrated Approach explicitly recognizes this by having the Top-Level Regulatory Criteria as an input at its highest level to specify the bases for judging the adequacy of the design's capability to protect the public health and safety and the environment. To be of most benefit to the Integrated Approach's top-down, analytically-based process and to ensure a focus on the risk-critical aspects of nuclear power plant operation which are independent of plant design, the following bases were adopted for the selection of Top-Level Regulatory Criteria: 
1. Top-level regulatory criteria should be a necessary and sufficient set of direct statements of acceptable health and safety consequences or risks to individuals or the public.

2. Top-level regulatory criteria should be independent of reactor type and site.

3. Top-level regulatory criteria should be quantifiable.

The first basis ensures that the criteria are fundamental to the protection of the public and the environment. The second, consistent with the first, requires that the criteria be stated in terms which do not discriminate among reactor types and sites. Finally, the third basis ensures that compliance. with the selected criteria can be demonstrated through measurement or calculation.

\subsubsection{Top-Level Regulatory Criteria for the Standard MHTGR}

Through comparison with the selection bases identified in Section 3.1.1.1, the following regulatory sources have been found to contain numerically-expressed criteria or limits which may appropriately form top-level regulatory criteria:

1. 51 FR 28044 - Policy Statement on Safety Goals for the Operation of Nuclear Power P1ants

2. 10CFR20 - Standards for Protection Against Radiation

3. 10CFR50, Appendix I - Numerical Guides for Design Objectives . . . to Meet the Criteria "As Low As Reasonably Achievable" for Radioactive Material. . . in Effluents

4. 40CFR190 - Environmental Radiation Protection Standards for Nuclear Power Operations

5. 10CFR100 - Reactor Site Criteria 
6. EPA-520/1-75-001 - Manual of Protective Action Guides and Protective Actions for Nuclear Incidents.

It should be recognized that these sources, in addition to stating numerical criteria or limits, may contain additional guidance or direction on how the criteria or limits should be implemented or met. This guidance is not considered appropriate as top-level regulatory criteria as it does not meet the bases identified in Section 3.1.1.1. Rather, only the numerical consequence or risk values contained within the above regulatory sources are candidates for inclusion.

Table 3.1-1 lists, by Integrated Approach goal, the specific numerical criteria or limits from the above sources that have been selected as Top-Level Regulatory Criteria for the Standard MHTGR design.

\subsubsection{Comparison with NRC Criteria}

As stated in Section 3.1.1.2, the criteria listed in Table 3.1-1 have been evaluated and selected as Top-Level Regulatory Criteria following review of the various regulatory sources applicable to power reactors. The other portions of Title 10 of the Code of Federal Regulations (CFR), CFR implementation guidance, and other regulatory sources were found not to be appropriate as top-level criteria either because they are not numerically expressed or otherwise quantifiable, they are reactor type- or site-specific, they are not direct statements of acceptable risks or consequences to individual or public health and safety or to the environment, or, under an analytically-based, top-down engineering approach, they should more appropriately be assessed at a lower level for their applicability to the Standard MHTGR design. This includes the General Design Criteria (GDC) of 10CFR50, Appendix A. For the Standard MHTGR, 10CFR100 Design Criteria have been developed as qualitative statements of the design commitments made to ensure that the Standard MHTGR will meet the dose limits of 10CFR100 and, therefore, protect public health and safety under accident conditions. Section 3.2.2 discusses the development of these criteria. 
For those regulatory sources that were found to contain criteria or limits found appropriate for selection as Top-Level Regulatory Criteria, the comparison made for each against the selection bases listed in Section 3.1.1.1 is discussed below.

3.1.2.1 51 FR 28044: Policy Statement on Safety Goals for the Operation of Nuclear Power Plants

The NRC has adopted two qualitative safety goals intended to broadly define an acceptable level of radiological risk which might be imposed on the public as a result of nuclear power plant operation. (Ref. 3) To support the use of these qualitative safety goals in the regulatory decision making process, the NRC also has adopted two health effects as the quantitative objectives concerning mortality risks to be used in measuring achievement of the qualitative goals. These quantitative objectives meet all of the selection bases of Section 3.1.1.1 and are therefore listed in Table 3.1-1 as Top-Level Regulatory Criteria.

In addition to the safety goals and supporting health objectives, the NRC has proposed a general performance guideline to be used, subject to further staff examination, as a basis for developing specific staff guidelines for determining whether a level of safety ascribed to a plant is consistent with the safety goal policy. This proposed plant performance design objective specifies that "the overall mean frequency of a large release of radioactive materials to the environment from a reactor accident should be less than 1 in $1,000,000$ per year of reactor operation." While this objective does quantify the frequency, it fails to quantify the limiting consequence. Additionally, it does not consitute a direct statement of acceptable health and safety consequences or risks to individuals or the public. For these reasons, it has not been included as a top-level regulatory criterion. This is not to say that plant performance goals will not be identified for the Standard MHTGR as lower-level criteria. However, such goals as are identified will be based on achieving the overall objective of producing safe, economical nuclear power. 
HTGR - 86- 024

\subsubsection{10CFR20: Standards for Protection Against Radiation}

Those portions of 10CFR20 specifying permissible occupational dose levels and levels of radiation and activity concentrations in unrestricted areas are consistent with all of the selection bases and, therefore, are included as top-level regulatory criteria.

3.1.2.3 10CFR50 Appendix I: Numerical Guides for Design Objectives . . . to Meet the Criteria "As Low As Is Reasonably Achievable" for Radioactive Material . . . in Effluents

Section II of 10CFR50 Appendix I provides numerical guides to assist applicants for LWR licenses in demonstrating compliance with the 10CFR50.34a and $50.36 \mathrm{a}$ requirement that radioactive material in plant effluents be kept "as low as is reasonably achievable." The consistency of the dose levels identified in Appendix I with the objective that top-level regulatory criteria should not be design specific is somewhat problematical. In principle, the stated dose values have been derived based on LWR design features and, in fact, are specifically stated to be "appropriate only for light-water-cooled nuclear power reactors and not for other types of nuclear facilities." In practice, however, they have been applied without modification to the licensing of the Fort St. Vrain HTGR (FSV-HTGR) plant. (Ref. 4) Further, while the stated doses are only guidelines and not regulatory limits, it can be argued that they represent suitable power reactor allocation of the overall fuel cycle limits stated in 40CFR190, "Environmental Radiation Protection Standards for Nuclear Power Operations" (see Section 3.1.2.4). Therefore, on this basis, the Appendix I dose values are included as top-level regulatory criteria.

Section II of Appendix I also includes a numerical cost-benefit guideline to judge the necessity for additional improvements in radioactive waste treatment systems. This guideline has not been included as a top-level regulatory criterion as it is not a direct statement of acceptable health or safety consequence or risk to the public. Similarly, the other operative 
sections of Appendix I do not constitute top-level criteria as they deal with design implementation or the establishment of operating procedures.

\subsubsection{40CFR190: Environmental Radiation Protection Standards for Nuclear Power Operations}

This regulation specifies both numerical dose criteria intended to protect the health and safety of the public and numerical radionuclide release criteria intended to protect the environment from the consequences of all normal uranium fuel cycle operations. Both limits are consistent with all of the selection bases and, therefore, are included as top-level regulatory criteria.

For the Standard MHTGR, the numerical criteria of 40 CFR 190 and 10CFR50 Appendix I are complementary, and the plant will be assessed against both. 10CFR50 Appendix I provides limits on the dose due to effluents from an individual reactor module, including the allocations from shared facilities. In contrast, 40 CFR190 sets a limit on exposure from all sources, both effluent and direct, from the plant as a whole. On a site-specific basis, however, one may prove to be more limiting, depending on the existence of any other contributing uranium fuel cycle operation in the vicinity and the expected types and levels of effluents. Therefore, both 10CFR50 Appendix I and 40CFR190 are included as top-level regulatory criteria, and the maximum allowable dose to any member of the public shall be the lower of the limits established by their application.

\subsubsection{10CFR100: Reactor Site Criteria}

The numerical dose values given in 10CFR100 for determining the extent of the exclusion area and low population zone (LPZ) are consistent with all of the selection bases and have been applied, without modification, to the licensing of the FSV-HTGR plant. Therefore, these dose values have been included as top-level regulatory criteria. 
The other portions of 10CFR100 are either site- or reactor type-specific and, as such, are not appropriate for inclusion as top-level criteria. This is especially true of the procedural methodology given in Technical Information Document (TID) 14844, which has been incorporated in 10 CFR 100 by reference. Analysis assumptions and methodology used in implementing these or any other criteria should be oriented to the characteristics of the specific reactor type and design, consistent with the suggestion in the NRC's policy statement on advanced reactors that review criteria specific to their design be proposed by advanced reactor designers. (Ref. 5) The guidance given in TID 14844 is specific to LWRs and, as such, is not appropriate for assessment of the Standard MHTGR or inclusion as top-level regulatory criteria.

3.1.2.6 EPA-520/1-75-001: Manual of Protective Action Guides and Protective. Actions for Nuclear Incidents

For purposes of emergency planning, EPA-520/1-75-100 provides Protective Action Guides (PAGs) for exposure to airborne radioactive materials, contaminated foodstuff or water, and contaminated property or equipment. (Ref. 6)

The NRC has provided implementation requirements in 10CFR50 Section 50.47 and Appendix $E$ for emergency planning. Therein, it is noted that, generally, a plume exposure pathway Emergency Planning Zone (EPZ) of 10 miles in radius and an ingestion pathway EPZ of 80 kilometers ( 50 miles) in radius provide an adequate planning basis. The technical basis for the selection of these EPZ distances is given in NUREG-0396, wherein it is found for LWRs that, for all but the most improbable events, the PAGs would not be expected to be exceeded beyond these distances. (Ref. 7) However, 10CFR50 Appendix E further states that "the size of the EPZs also may be determined on a case-by-case basis for gas-cooled nuclear reactors and for reactors with an authorized power level less than 250 MW thermal." For the FSV-HTGR plant, smaller EPZ radii have been selected for planning purposes. (Ref. 8) Therefore, while the PAGs provide numerical guidelines for emergency planning purposes which are appropriate as top-level regulatory criteria, alternative implementing bases for determining appropriate EPZ distances can and have been developed for the Standard MHTGR (see Sections 1.2 and 13.1). 


\section{REFERENCES - SECTION 3.1}

1. Gas-Cooled Reactor Associates. Utility/User Requirements for the Modular High Temperature Gas-Cooled Reactor Plant. GCRA 86-002, Rev. 2. GCRA, San Diego, CA, September 1986.

2. Gas-Cooled Reactor Associates (GCRA). Top-Level Regulatory Criteria for the Standard MHTGR. HTGR-85-002, Rev. 2. GCRA, San Diego, CA, October 1986.

3. U.S. Nuclear Regulatory Commission. Safety Goals for the Operation of Nuclear Power Plants; Policy Statement. Federal Register, Vol. 5I, No. 149, August 4, 1986, pp. 28044-28049.

4. Public Service Company (PSC) of Colorado. Amendment to Facility Operating License, Docket 50-267, Fort St. Vrain. Amendment No. 37. PSC, Denver, CO, November 23, 1986.

5. U.S. Nuclear Regulatory Commission. Regulation of Advanced Nuclear Power Plants; Statement of Policy. Federal Register, Vol. 51, No. 130, July 8 , 1986, pp. 24643-24648.

6. U.S. Environmental Protection Agency (EPA). Manual of Protective Action Guides and Protective Actions for Nuclear Incidents. EPA-520/1-75-001. EPA, Springfield, VA, June 1980.

7. U.S. Nuclear Regulatory Commission (NRC) and U.S. Environmental Protection Agency (EPA). Planning Basis for the Development of state and Local Radiological Emergency Response Plans in Support of Light-Water Nuclear Power Plants. NUREg-0396: EPA 520/1-78-016. NRC/EPA, Springfield, VA, December 1978.

8. U.S. Nuclear Regulatory Commission. Emergency Planning. Federal Register, Vol. 45, No. 162, August 19, 1980, p. 55402. 
HTGR - 86- 024

TABLE $3.1-1$

TOP-LEVEL REGULATORY CRITERIA

\section{Goal 0. Safe Economical Power}

A) Policy Statement of Safety Goals (51 FR 28044)

Individual and Societal Mortality Risks:

1) The risk to an average individual in the vicinity of a nuclear power plant of prompt fatalities that might result from reactor accidents should not exceed one-tenth of one percent $(0.1 \%)$ of the sum of prompt fatality risks resulting from other accidents to which members of the U.S. population are generally exposed.

2) The risk to the population in the area near a nuclear power plant of cancer fatalities that might result from nuclear power plant operation should not exceed one-tenth of one percent (0.18) of the sum of cancer fatality risks resulting from all other causes.

\section{Goal 1, Maintain Plant Operation}

A) 10CFR20

1) Section 20.101 - Radiation dose standards for individuals in restricted areas:

Whole body dose $<3$ rem in calendar quarter

Whole body dose $<5$ (N-18) rem lifetime

2) Section 20.103 - Exposure of individuals to concentrations of radioactive materials in air in restricted areas:

Limits specified in Appendix B, Table I, Column 1 
HTGR - $86-024$

TABLE 3.1-1 (Cont.)

3) Section 20.105 - Permissible levels of radiation in unrestricted areas :

Whole body dose $<0.5$ rem in calendar year

Whole body dose $<0.002$ rem in any one hour

Whole body dose $<0.1$ rem in any seven consecutive days

4) Section 20.106 - Radioactivity in effluents to unrestricted areas:

Limits specified in Appendix B, Table II.

B) 10CFR50 Appendix I

Sec. II: Guides on design objectives for light-water-cooled nuclear power reactors

1) Paragraph A

Estimated annual dose from liquid effluents less than 0.003 rem whole body or 0.01 rem to any organ.

\section{2) Paragraph $B$}

Estimated annual dose from gaseous effluents less than 0.005 rem to the whole body or 0.015 rem to the skin or any organ.

\section{3) Paragraph $\mathrm{C}$}

Estimated annual dose from radioactive material in particulate form in effluents to the atmosphere less than 0.015 rem to any organ.

C) 40CFR190

1) Section 190.10(a) - Annual dose equivalent to a member of the general public from uranium fuel cycle operations (as defined in 190.02):

Whole body dose $<0.025 \mathrm{rem}$

Thyroid < 0.075 rem

Any other organ $<0.025$ rem 
HTGR $-86-024$

TABLE 3.1-1 (Cont.)

2) Section $190.10(\mathrm{~b})$ - Total quantity of radioactive materials entering the general environment from the entire uranium fuel cycle, per gigawatt-year of electrical energy produced by the fuel cycle:

Krypton-85<50,000 curies

Iodine-129<5 millicuries

Plutonium and other alpha-emitting and transuranic nuclides with half-lives greater than 1 year $<0.5$ millicuries

\section{Goal 2. Maintain Plant Protection}

Goal 2 criteria consist of occupational exposure limits, which will be as specified in A.1 and A.2 of Goal 1. Top-level regulatory criteria applicable to the general public are covered under Goal 3.

\section{Goal 3, Maintain Control of Radionuclide Release}

A) 10CFR50 Appendix I

Same criteria as Goal 1 above except applied on an expected value basis (i.e., the sum of the product of the frequency of the event and its consequence over all events would meet the criteria).

B) 10CFR100

Two-hour exclusion area boundary and 30-day low population zone accident doses less than 25 rem whole body and 300 rem thyroid.

\section{Goal 4. Maintain Emergency Preparedness}

A) Dose Protective Action Guides (PAGs) of EPA-520/1-75-001.

1) Protective Action Guides for Exposure to Airborne Radioactive Materials: 
HTGR - 86- 024

TABLE 3.1-1 (Cont.)

Intervention indicated for general population if whole body dose exceeds 1 to 5 rem or thyroid dose exceeds 5 to 25 rem.

2) Protective Action Guides for Exposure from Foodstuffs or Water:

(later)

3) Protective Action Guides for Exposure from Material Deposited on Property or Equeipment

(later) 


\subsection{STANDARD MHTGR LICENSING BASES}

As discussed in Section 1.2.2.2, the Standard MHTGR is engineered using the Integrated Approach to develop the functions, requirements, and design selections which satisfy both the user's requirement and the Top-Level Regulatory Criteria. The adequacy of the design developed under this Integrated Approach to protect both the health and safety of the public and the owner's investment is probabilistically assessed against these top-level criteria as expressed in frequency-vs-consequence terms. Consistent with the safety philosophy set forth in Section 1.2.1, this design places ultimate reliance on passive means or features inherent in the standard MHTGR for the protection of public health and safety.

For the purpose of deriving the licensing bases of the Standard MHTGR, however, the probabilistic regulatory bases for the design as implemented in the Integrated Approach have been cast in a framework and format similar to that of traditional licensing approaches through the application of the Bridging Methods for Standard HTGR Licensing Bases, the "bridge" of Figure 1.2-1. (Ref. 1) Under this methodology, the resultant licensing bases consist of three major elements:

1. Licensing basis events, which are used to demonstrate compliance with the Top-Level Regulatory Criteria for a spectrum of off-normal or accident conditions.

2. 10CFR100 Design Criteria, which are qualitative statements of the design commitments made to ensure that the dose criteria of 10CFR100 will be met and, therefore, that public health and safety will be protected under accident conditions.

3. "Safety-related" systems, structures, and components, which make up the set of equipment capable of performing all the functions required to limit releases under accident conditions to those allowed by $10 \mathrm{CFR} 100$.

Specific application of this methodology to the Standard MHTGR is described in detail in the Application of Bridging Methods for Standard HTGR Licensing Bases ("Application of Bridging Methods") and summarized here. (Ref. 2) 


\subsubsection{Licensing Basis Events}

Selection of licensing basis events (LBEs) is based on the probabilistic risk assessment (PRA) performed as part of the Integrated Approach and constitutes the process which establishes the bridge between the engineering approach and the licensing basis for the standard MHTGR. The use of the PRA for LBE selection provides a basis for judging, in a quantitative manner, the frequency of the entire event sequence and, therefore, the appropriate dose or risk criteria to be applied.

\subsubsection{Licensing Basis Event Selection Criteria}

The initial step in the selectio of LBEs is to establish a frequency-consequence risk plot defining three regions bounded in frequency by three agreed-upon mean frequencies and in consequence by allocated dose limits related to 10CFR50 Appendix I, 10CFR100, or the PAGs. Figure 3.2-1 provides this plot as established for the Standard MHTGR. Development of the numerical. definition of the bounding frequencies is discussed in detail in the Licensing Basis Event Selection Criteria document. (Ref. 3)

Families of events whose frequencies of occurrence plot near the upper boundary of a region may have significant uncertainties in the estimate of their frequencies, which is acknowledged in the LBE selection process. The consideration of these uncertainties is necessary to ensure that all events will be assessed against the appropriate criteria. The mean value of frequency, which involves an integral over the complete uncertainty spectrum, is the selected function for accounting for frequency uncertainties. A factor is then placed on the mean frequency to provide margin and to dispel concern over event families falling just below the frequency boundary of a region and, therefore, being assessed against less rigorous criteria than those which later analysis might actually prove more appropriate. A factor of 2 is used at this stage.

\subsubsection{Selection of Licensing Basis Events}

As previously noted, the adequacy of the design developed under the Integrated 
HTGR $-86-024$

Approach to protect both the health and safety of the public and the owner's investment is probabilistically assessed. To do so, a PRA is performed to demonstrate that a design appropriate to the level of development has, in fact, been established which meets the requirements of Goals 1,2 , and 3 . It is this PRA that is used in the selection of LBEs, with its results being compared against the selection criteria of the preceding section. Those families of events having the potential for radionuclide releases or consequences in excess of those allowed by the Top-Level Regulatory Criteria were it not for design selections that function to control the release of radionuclides are those selected as LBEs. Depending upon their predicted frequency, the selected events are encompassed by one of the following three categories:

1. Anticipated Operational Occurrences (AOOs): These are families of events expected to occur once or more in the plant lifetime. The families of events selected as AOOs at this stage in the Standard MHTGR design are listed in Table 3.2-1. These AOO event families are described and their realistically analyzed dose consequences are provided in Section 11.6 to demonstrate compliance with 10CFR50 Appendix I.

2. Design Basis Events (DBEs): These are families of events lower in frequency than AOOs that are not expected to occur in the lifetime of one plant but which might occur in a large population of MHTGRs (approximately 200). The families of events selected as DBEs at this stage in the Standard MHTGR design are listed in Table 3.2-2. These DBEs, along with their dose consequences, are described in Chapter 15. Uncertainties on the doses are assessed, and conservative (95z confidence level) doses are compared against the 10CFR100 dose criteria.

3. Emergency Planning Basis Events (EPBEs): These are families of events lower in frequency than DBEs that are not expected to occur in the lifetime of a large number of MHTGRs. The families of events selected as EPBEs at this stage in the Standard MHTGR design are 1 isted in Table 3.2-3. EPBE descriptions and their related analyses are given in 
the PRA Report. (Ref. 4) Consequences are analyzed realistically using PRA techniques for emergency planning purposes and environmental protection assessments. The approach to emergency preparedness for the Standard MHTGR is discussed in Section 13.1 .

The application of the process resulting in the selection of these LBEs for the Standard MHTGR is further described in the Licensing Basis Events for the Modular HTGR. (Ref. 5)

In addition to demonstrating compliance with the dose limits of the Top-Level Regulatory Criteria defining the region with which each individual LBE is associated, the LBEs may be considered collectively to show compliance with the Goal 0 criteria drawn from the NRC policy statement on safety goals (see Section 3.1.2.1). The process whereby such compliance may be demonstrated is discussed in the Application of Bridging Methods. (Ref. 2).

In developing the remaining elements of the Standard MHTGR licensing bases the Principal Design Criteria and the classification of equipment - attention is focused on demonstrating particular regulatory compliance with the dose limits of 10CFR100 under accident conditions. Therefore, further consideration of LBEs is concentrated on DBEs and, to a lesser extent, EPBEs.

\subsubsection{CFR100 Design Criteria}

By definition, DBEs are those families of events having the potential for exceeding the dose limits of 10CFR 100 were it not for the accomplishment of certain functions serving to control the release of radionuclides. Through examination of the defined DBE sequences, the subset of Goal 3 functions (see Fig. 1.2-3) shown on Figure 3.2-2 has been identified as the only set of radionuclide control functions necessary to meet the 10CFR100 limits for all event sequences. This identification process is described in detail in the Application of Bridging Methods. (Ref. 2).

For the purposes of defining the standard MHTGR 1icensing bases, the 10CFR100 Design Criteria are qualitative statements, specific to the Standard MHTGR, 
HTGR - 86-024

which describe the manner in which this set of radionuclide control functions will be performed. As such, they represent the design commitments being made to ensure that the dose criteria of 10CFR100 will be met under DBE conditions. The 10CFR100 Design Criteria are a necessary and sufficient set of criteria for ensuring that 10CFR100 dose limits are met for all LBEs.

The set of functions that must be performed and the Principal Design Criterion that relates to each are:

FUNCTION: Retain Radionuclides in Fuel: This function refers to the Standard MHTGR safety design approach to design, fabricate, and operate the fuel so that normal operation releases are limited to the extent that only the radionuclide inventory within the fuel itself presents a potential challenge to meeting the 10CFR100 doses. Thus, only the fuel conditions need be maintained for off-normal events to assure 10CFR100 compliance. The three sub-functions described in the following paragraphs are those required to maintain the fuel within the required conditions.

10CFR100 DESIGN CRITERION I: The reactor fuel shall be designed, fabricated, and operated such that radionuclides are retained within the fuel to the extent that releases to the primary coolant will not exceed acceptable values.

FUNCTION: Control Chemical Attack: This function refers to the necessity to prevent fuel degradation caused by the intrusion of compounds other than helium into the primary coolant. The principal chemical attacks to be avoided are those of air and water, which could react with the fuel or the graphite and, as a result, degrade the fuel. Excessive air ingress is prevented by limiting the loss of primary coolant boundary integrity. Excessive water ingress is prevented by terminating the source of water following loss of primary to secondary coolant boundary integrity.

10CFR100 DESIGN CRITERION II: The vessels and other components that limit or prevent the ingress of air or water shall be designed, fabricated and operated such that the amount of air or water reacting with the core will not exceed acceptable values. 
FUNCTION: Control Heat Generation: This function refers to the necessity to control the heat generation of the reactor so that fuel temperatures are not excessive. Since Criterion II limits exothermic chemical reactions, the sole requirement of this function is to assure reliable reactor shutdown.

10CFR100 DESIGN CRITERION III: The reactor shall be designed, fabricated, and operated such that the inherent nuclear feedback characteristics ensure that the reactor thermal power will not exceed acceptable values. Additionally, the reactivity control system(s) shall be designed, fabricated and operated such that during insertion of reactivity the reactor thermal power will not exceed acceptable values.

FUNCTION: Remove Core Heat: This function refers to the necessity to remove the reactor heat during off-normal conditions so that fuel temperatures are not excessive. Since the design selections needed to meet Criterion II and Criterion III limit chemical attack and fission heat generation, the principal requirement is to assure reliable decay heat removal.

10CFR100 DESIGN CRITERION IV: The intrinsic dimensions and power densities of the reactor core, internals, and vessel, and the passive cooling pathways from the core to the environment shall be designed, fabricated and operated such that the fuel temperatures will not exceed acceptable values.

\subsubsection{Classification of Structures, Systems, and Components}

\subsubsection{Description of Classification System and Associated Requirements}

The final element of the Standard MHTGR licensing bases is the classification of plant equipment. In concert with development of the 10CFR100 Design Criteria, this classification of equipment is done to focus attention on the minimum set of structures, systems, and components (SSCs) capable of performing all of the radionuclide control functions required to limit releases from DBEs to those allowed by 10CFR100, and, therefore, capable of fulfilling the design commitments made in the criteria. To draw this focus, these sscs are designated as "safety-related." 
HTGR - $86-024$

The engineering requirements applied to these or any other Standard MHTGR SSCs, in terms of industry codes and standards, regulatory guidance, or quality assurance (QA) programs, are only those necessary to obtain the requisite reliability, with sufficient confidence, to satisfy all of the top-level criteria. The engineering requirements which will actually be applied are determined solely on the basis of appropriate analyses and trade studies, including the relevant probabilistic risk assessment, irrespective of any "safety-related" designation.

To maintain consistency with this concept, the use of other terms traditionally associated in LWR practice with a "safety-related" designation (e.g., Seismic Category I, safety class, safety grade, etc.) has been avoided for the Standard MHTGR. Under current LWR practice, the application of these terms automatically imposes a prescriptive set of codes and standards, which is inconsistent with the Standard MHTGR development of requirements in a top-down fashion through use of the Integrated Approach.

An exception to this drawing of an absolute distinction between the licensing and engineering bases for the standard MHTGR is the utilization of "Safety-Related" Design Conditions (SRDCs). Consistent with the safety philosophy set forth in Section 1.2 .1 that reliance will be placed on inherent or passive means to protect public health and safety, SRDCs are the conditions imposed on "safety-related" SSCs if they were depended upon to respond following the initiation of any $D B E$ for which they assure compliance with the 10CFR100 criteria. These SRDCs correspond mechanistically to events that are lower in frequency than DBEs and have been referred to commonly as "beyond design basis events". This deterministic assumption of unavailability for those SSCs which are not designated as "safety-related" is made in response to the uncertainty involved with reliance on active components or systems, not because of any designation as "safety-related." That these primarily passive or inherent means are by themselves capable of ensuring compliance with the 10CFR100 criteria is demonstrated by the calculated dose consequences for these limiting conditions given in Section 15.13, which also provides a discussion of the SRDCs themselves. 
A similar situation exists with the treatment of hazards, especially external or natural hazards, in the Standard MHTGR design. Because the means for assessing such hazards and their consequences on a purely probabilistic basis are only in the early stages of development, these hazards are presently dealt with on a more traditional basis, as discussed in Sections 3.3 through 3.9. This is done to ensure, based upon design experience to date, that there is a high level of confidence that those items required to meet the dose limits of 10CFR100 will be capable of surviving the design basis hazard intensities as presently defined. However, as validated methodologies more consistent with the basic philosophy of the Integrated Approach become available or are developed, they will be applied to the design of the Standard MHTGR.

\subsubsection{Method of Establishing Classifications}

As with the other elements of the Standard MHTGR licensing bases, "safety-related" SSCs are selected through application of systematic procedures set forth in the Bridging Methods for Standard HTGR Licensing Bases. (Ref. 1) Specific application of this process to the Standard MHTGR is described in the Application of Bridging Methods. (Ref. 2) As with the 10CFR100 Design Criteria, this classification of plant equipment is done to demonstrate particular 
HTGR $-86-024$

regulatory compliance with the dose limits of $10 \mathrm{CFR} 100$ under accident conditions. Therefore, of the three categories of LBEs identified Anticipated Operational Occurrences, Design Basis Events, and Emergency Planning Basis Events - it is the last two that are of significance to the "safety-related" classification process.

Once the identification of DBEs and EPBEs is made, a two-step process is implemented to identify a set of plant features which are capable of performing the radionuclide control functions needed for compliance with the dose limits of 10CFR100 and, therefore, are to be designated as "safety-related".

Step 1 specifies that, for each DBE, classify as "safety-related" those design selections chosen for compliance with the 10 CFR100 region dose criteria. More specifically, for each DBE, various functions can be identified which must be performed if the consequences of the event are to remain within those allowed by the dose criteria. For the Standard MHTGR, these functions, as discussed previously in Section 3.2.2, are the retention of radionuclides in the fuel and, to maintain the fuel within its design conditions to assure such retention, the removal of core heat, control of the core heat generation rate, and prevention of chemical attack on the fuel. Step 1 requires that a set of SSCs which are capable of performing these functions for all DBEs for which they are required be classified as "safety-related."

Step 2 specifies that, for each EPBE with consequences greater than the 10CFR100 criteria, classify as "safety-related" those design selections chosen to assure that the event frequency, including uncertainties, will fall below the 10CFR100 region. As with step 1 , various functions can be identified which must be performed to provide this assurance. Step 2 requires that a set of SSCs capable of performing these functions be classified as "safety-related". No EPBE having consequences greater than the 10CFR 100 limits and, therefore, requiring performance of some function or functions to assure that its frequency will fall below the 10CFRloo region has yet to be identified for the Standard MHTGR. As a result, no SSC has yet been designated as "safety-related" through application of step 2. 
3.2.3.3 Classification of Standard MHTGR Structures, Systems, and Major Components

Table 3.2-4 lists the structures, systems, and major components of the plant and indicates the classification and, if "safety-related", the radionuclide control function of each. This correlation of equipment classified as "safety-related" to the radionuclide control function performed by each is also illustrated on Figure 3.2-2. The specific application of the classification process resulting in the indicated "safety-related" designations is discussed in Safety-Related Structures, Systems, and Components for the Standard MHTGR. (Ref. 6)

For additional information related to this section, see the response to NRC Comment G-14. 
HTGR $-86-024$

REFERENCES - SECTION 3.2

1. GA Technologies, Inc. (GA). Bridging Methods for Standard HTGR Licensing Bases. HTGR-86-039, Rev. 2. GA, San Diego, CA., February 1986.

2. GA Technologies Inc. (GA). Application of Bridging Methods for Standard HTGR Licensing Bases. HTGR-86-017, Rev. 1. GA, San Diego, CA., February 1986.

3. GA Technologies, Inc. (GA). Licensing Basis Event Selection Criteria. HTGR-86-001, Rev. 1. GA, San Diego, CA. , February 1986.

4. GA Technologies, Inc. (GA). Probabilistic Risk Assessment for the Standard MHTGR. DOE-HTGR-86-011, Rev. 3. GA, San Diego, CA., January 1987.

5. GA Technologies, Inc. (GA). Licensing Basis Events for the Standard MHTGR. DOE-HTGR-86-034, Rev. 1. GA, San Diego, CA., February 1987.

6. GA Technologies, Inc. (GA). Safety-Related Structures, Systems, and Components for the Standard MHTGR. DOE-HTGR-87-003, Rev. 0. GA, San Diego, CA, January 1987. 
HTGR - 86- 024

TABLE $3.2-1$

ANTICIPATED OPERATIONAL OCCURRENCES

$\underline{\text { A00 Number }}$

AOO- 1

$\mathrm{AOO}-2$

$\mathrm{AOO}-3$

$\mathrm{A} 0 \mathrm{O}-4$

AOO- 5
Anticipated Operational Occurrence

Main loop transient with forced core cooling

Loss of main and shutdown cooling loops

Control rod group withdrawal with control rod trip

Small steam generator leak

Small primary coolant leak 


\section{HTGR-86-024 \\ TABLE $3.2-2$ \\ DESIGN BASIS EVENTS}

DBE Number

Design Basis Event

$\mathrm{DBE}-1$

Loss of HTS and SCS cooling

DBE - 2

HTS transient without control rod trip

DBE - 3

Control rod withdrawal without HTS cooling

DBE -4

Control rod withdrawal without HTS and SCS cooling

DBE - 5

Earthquake

DBE -6

Moisture inleakage

$\mathrm{DBE}-7$

Moisture inleakage without SCS cooling

DBE -8

Moisture inleakage with moisture monitor failure

DBE -9

Moisture inleakage with steam generator dump failure

DBE -10

Primary coolant leak

DBE -11

Primary coolant leak without HTS and SCS cooling 
HTGR - 86- 024

TABLE $3.2-3$

EMERGENCY PLANNING BASIS EVENTS

EPBE Number

EPBE -1

EPBE - 2

$\mathrm{EPBE}-3$
Emergency Planning Basis Event

Moisture inleakage with delayed steam generator isolation and without forced cooling

Moisture inleakage with delayed steam generator isolation

Primary coolant leak in all four modules with neither forced cooling nor HPS pumpdown 
TABLE $3.2-4$

MODULAR HIGH TEMPERATURE GAS-COOLED REACTOR

EQUIPMENT CLASSIFICATION

\section{Principal Component}

REACTOR SYSTEM

Neutron Control

Neutron Control Assembly, Inner

Neutron Control Assembly, Outer

In-Vessel Flux Mapping Unit

Ex-Vesse1 Neutron Detection Equipment

Startup Detector Assembly

Reactor Trip Control Cabinet

Reserve Shutdown Control

Equipment Control Cabinet

Rod Drive Control Control Cabinet

Nuclear Instrument Cabinet

$$
\begin{aligned}
& x^{(1)} \\
& x^{(2)}
\end{aligned}
$$

"Safety- "Safety-

Related" Related"
10CFR100-Related

Radionuclide Control Functions
Control heat generation*

Control heat generation*

$\mathrm{X}$

$\mathrm{x}^{(2)}$

Control heat generation*

$\mathrm{X}$

Control heat generation*

Control heat generation*

\footnotetext{
(1) Reserve shutdown only

(2) Reactor trip only

*Denotes principal radionuclide control function needed to meet $10 \mathrm{CFR} 100$ criteria.
} 
TABLE $3.2-4$ (Cont)

\section{Principal Component}

REACTOR SYSTEM (continued)

\section{Reactor Internals}

Permanent Side Reflector

Structure (graphite)

Core Support Floor Structure (metal)

Core Support Structure (graphite)

Core Lateral Restraint Assembly (metal)

Hot Duct Assembly

Upper Plenum Thermal

Protection Structure

\section{$\underline{\text { Reactor Core }}$}

Fuel Elements (including fue1 kernels and particle coatings)

Hexagonal Reflector Elements
$\mathrm{X}$

$\mathrm{X}$
Not

"Safety- "SafetyRelated" Related"

10CFR100-Related Radionuclide Control Functions
Remove core heat*

Control heat generation*

Remove core heat* Control heat generation*

Remove core heat*

Control heat generation*

Remove core heat* Control heat generation*

$\mathrm{X}$

Control chemical attack*

Remove core heat*

Control heat generation* Control chemical attack*

Retain radionuclides in fuel*

Remove core heat*

Control heat generation* 
HTGR - 86- 024

TABLE 3.2-4 (Cont)

\section{Principal Component}

"Safety- "Safety-

Related" Related"

$\mathrm{X}$

Outer Control Rods

Inner Control Rods

Reserve Shutdown

Control Material

Plenum Elements

Neutron Source

VESSEL SYSTEM

$\frac{\text { Vessels and Duct }}{\lambda}$

Steel Vessel - Reactor

Steel Vessel - Steam Generator

Main Cross Duct

Thermal Insulation

Steam Generator Isolation valves
$\mathrm{X}$

$\mathrm{X}$

$\mathrm{X}$

X

$\mathrm{X}$

\section{CFR100-Related Radionuclide Control Functions}

Control heat generation*

$\mathrm{X}$

Control heat generation*

Control heat generation*
Remove core heat*

Control chemical attack*

Control chemical attack*

Control chemical attack*

Control chemical attack* 
TABLE $3.2-4$ (Cont)

\section{Principal Component}

VESSEL SYSTEM (Continued)

\section{Pressure Relief}

Pressure Relief Valve Assembly

Piping (Between Vessel and Valve)

Block Valve Assembly

Rupture Disk Assembly

Vesse1 Support

Reactor Vessel Supports

Steam Generator Vessel Supports

REACTOR SERVICES GROUP

Hot Service Facility

Hot $\mathrm{Cell}$

Handling Equipment
$\mathrm{X}$

$\mathrm{X}$

$\mathrm{X}$

$\mathrm{X}$

$\mathrm{X}$

$\mathrm{X}$
Not

"Safety- "SafetyRelated" Related"

10CFR100-Related

Radionuclide Control Functions

Control chemical attack*

Control chemical attack*

Control chemical attack*

Control chemical attack*

Control heat generation* Control chemical attack* Remove core heat*

Control chemical attack* 
TABLE $3.2-4$ (Cont)

\begin{tabular}{|c|c|c|}
\hline $\begin{array}{l}\text { "Safety- } \\
\text { Related" }\end{array}$ & $\begin{array}{l}\text { "Safety- } \\
\text { Related" }\end{array}$ & $\begin{array}{c}\text { 10CFR100-Related } \\
\text { Radionuclide Control }\end{array}$ \\
\hline
\end{tabular}

REACTOR SERVICES GROUP (Continued)

Decontamination Services

Tanks

$\mathrm{X}$

Pumps

$\mathrm{X}$

$\mathrm{X}$

$\mathrm{X}$

Air Heater

Reactor Service Equipment

and Storage Wells

Aux. Service Cask \& Transporter Assembly

Main Circulator Service Equipment

Shutdown Circulator Service

Equipment

Main Circulator Storage Wells

Shutdown Circulator Storage Wells

Neutron Control Assembly 
TABLE 3.2-4 (Cont)

\section{Principal Component}

"Safety- "Safety-

Related" Related"

10CFR100-Related

Radionuclide Control Functions

REACTOR SERVICES GROUP (Continued)

Core and Service Facility Tools

X

Neutron Detector Service Equipment

Hot Duct Service Equipment

Helium Purification

High Temperature Adsorber Module

$\mathrm{X}$

Oxidizer-Cooler Module

$\mathrm{X}$

Dryer Module

$\mathrm{X}$

Low Temperature Adsorber Module

$\mathrm{X}$

Regeneration Oxidizer Module

$\mathrm{X}$

Regeneration Module

$\mathrm{X}$

Purified Helium Compressor Module

High Temperature Filter Module

Piping and Valves 
TABLE $3.2-4$ (Cont)

\section{Principal Component}

"Safety- "Safety-

Related" Related"

REACTOR SERVICES GROUP (Continued)

Helium Storage and Transfer

Helium Storage Tanks

$\mathrm{X}$

Helium Transfer Compressors

X

Valves

X

High Pressure Helium Supply

$\mathrm{X}$

Tanks

Liquid Nitrogen

Liquid Nitrogen Tanks

$\mathrm{X}$

Nitrogen Recondensers

$\mathrm{X}$

Vacuum Jacketed Transfer Piping

Cryogenic Valves

Reactor Plant Cooling Water

Heat Exchangers

$\mathrm{X}$

Tanks

$\mathrm{X}$

Pumps and Valves 
TABLE 3.2-4 (Cont)

\section{Principal Component}

REACTOR SERVICES GROUP (Continued)

Liquid Radioactive Waste

Tanks

Pumps

Filters

Demineralizers

Piping and Valves

Gaseous Radioactive Waste

Gas Waste Tank

Liquid Drain Tank

Compressors

Exhaust Blower

Piping and Valves

Solid Radioactive Waste

Handling Equipment
Not

"Safety - "Safety -

Related" Related"

10CFR100-Related

Radionuclide Control Functions
$\mathrm{X}$

X

X

X

$\mathrm{X}$

X

X

X

X

X

X 
TABLE $3.2-4$ (Cont)

Not

"Safety - "Safety - 10CFR100-Related

Principal Component

Related" Related"

HEAT TRANSPORT SYSTEM

Main Circulator

Compressor/Motor Assembly

X

Shutoff Valve Assembly

X

X

$\mathrm{X}$

$\mathrm{X}$

Steam Generator

Tube Bundle Assemb1y

$\mathrm{X}$

PLANT PROTECTION AND INSTRUMENTATION SYSTEM

Investment Protection

Investment Protection Modules

Hygrometer Module Assemblies

$\mathrm{X}$

Compressor Module

$\mathrm{X}$

Accumulator Tanks

$\mathrm{X}$ 
TABLE $3.2-4$ (Cont)

Principal Component

PLANT PROTECTION AND

INSTRUMENTATION SYSTEM

Non-module Equipment

Instruments, Hardware and Software

Safety Protection

Safety Protection Cabinets

Safety Protection Remote

Instrumentation

Instruments, Hardware and Software

Special Nuclear Area

Instrumentation

PPIS Maintenance Consoles

PPIS Operator Interface Panels

Special Nuclear Area Instrumentation

Special Nuclear Area Monitors

Instruments, Hardware, and Software
$\mathrm{X}$
$\mathrm{X}$

$\mathrm{X}$
Not

"Safety- "Safety-

Related" Related"

10CFR100-Related

Radionuclide Control Functions

\author{
Control heat generation* \\ Control heat generation* \\ Control heat generation*
}




\section{Principal Component}

MISCELLANEOUS CONTROL AND

INSTRUMENTATION GROUP

\section{NSSS Analytical Instrumentation} System

Control Boards

Instrument Enclosures and Racks

Instrument Hardware

Valves

\section{Radiation Monitoring}

Control Boards

Instrument Enclosures and Racks

Instrument Hardware

Seismic Monitoring

Control Boards

Instrument Enclosures and Racks

Instrument Hardware
TABLE $3.2-4$ (Cont)

Not

"Safety- "Safety- 10CFR100-Related

Related" Related"
$\mathrm{X}$

$\mathrm{X}$

$\mathrm{X}$

$\mathrm{X}$

$\mathrm{X}$

$\mathrm{X}$

$\mathrm{X}$

$\mathrm{X}$

$\mathrm{X}$

$\mathrm{X}$ 
TABLE 3.2-4 (Cont)

\section{Principal Component}

MISCELLANEOUS CONTROL AND INSTRUMENTATION GROUP

\section{Meteorological Monitoring}

Meteorological Tower

Instruments and Racks

Data Handling and

Processing Equipment

\section{Fire Detection and Alarm}

Central Processing Unit

Initiating Equipment

Alerting Equipment

Multiplexers/Annunciators

Security Monitoring

Monitoring Consoles

Central Processing Units

Cameras
$\mathrm{X}$

$\mathrm{X}$

$\mathrm{X}$

$\mathrm{X}$

$\mathrm{X}$

$\mathrm{X}$

$\mathrm{X}$

$\mathrm{X}$

$\mathrm{X}$

$\mathrm{X}$
Not

"Safety - "SafetyRelated" Related"

10CFR100-Related Radionuclide Control Functions 
TABLE 3.2-4 (Cont)

\begin{tabular}{|c|c|c|}
\hline & $O c$ & 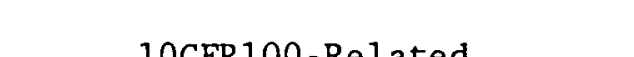 \\
\hline Related" & Related" & Radionuclide Control Functions \\
\hline
\end{tabular}

MISCELLANEOUS CONTROL AND INSTRUMENTATION GROUP

Multiplexers

Sensors

FUEL HANDLING, STORAGE, AND SHIPPING SYSTEM

\section{Core Refueling}

Fuel Handling Machine

Fuel Handling Equip. Positioner

Plug Actuator \& Turntable Assembly

Reactor Isolation Valve

Fuel Transfer Cask

Fuel Transfer Cask Adapter

Fuel Handling Support Structure

Fuel Handling Control Station
$\mathrm{X}$

$\mathrm{X}$

$\mathrm{X}$

$\mathrm{X}$

$\mathrm{X}$

$\mathrm{X}$

$\mathrm{X}$

$\mathrm{X}$

X 
TABLE 3.2-4 (Cont)

\section{Principal Component}

FUEL HANDLING, STORAGE, AND

SHIPPING SYSTEM

Site Fuel Handling

Hoist \& Grapple Assembly, FSIF

Floor Valve FSIF

Spent Fuel Sealing Equipment

New Fuel Handling Equipment

New Fuel Storage Racks

Reflector Packaging Equipment

Reflector Storage Racks

Shipping Port Closure Equipment

Shipping Cask Transporter

Shipping Cask Closure Service Equipment

Control Module, FSIF

Spent Fuel Storage Wells

Spent Fuel Storage Cooling

Tanks
$\mathrm{X}$

$\mathrm{X}$

X

X

X

X

X

X

X

X

X

$\mathrm{x}$

$\mathrm{X}$
Not

"Safety- "Safety-

Related" Related"

10CFR100-Related

Radionuclide Control Functions 


\section{Principal Component}

FUEL HANDLING, STORAGE, AND SHIPPING SYSTEM

Pumps and Valves

Heat Exchangers

Water Makeup System

PLANT CONTROL, DATA AND INSTRUMENTATION

\section{NSSS Control}

Control Boards and Consoles

Instrument Enclosures and Racks

Instrument Hardware

\section{ECA Control}

Control Boards and Consoles

Instrument Enclosures and Racks

Instrument Hardware
TABLE $3.2-4$ (Cont)

Not

"Safety- "Safety-

Related" Related"

10CFR100-Related

Radionuclide Control Functions
$\mathrm{X}$

$\mathrm{X}$

$\mathrm{X}$

X

X

X 
TABLE 3.2-4 (Cont)

\section{Principal Component}

PLANT CONTROL, DATA AND

INSTRUMENTATION

\section{Plant Supervisory Contro1}

Control Room Operator Workstation

Assistant Operator Workstation

Supervisory Control Computers

Plant Operations Support

Control Boards and Consoles

Instrument Enclosures and Racks

Instrument Hardware

Data Acquisition and Processing

General Purpose Computers

Data Communication Network

Data Communication Computers

Operations Support Workstations

Technical Support Workstations

$\begin{array}{llc} & \text { Not } & \\ \text { "Safety- } & \text { "Safety - } & \text { 10CFR100-Related } \\ \text { Related" } & \text { Related" } & \text { Radionuclide Control Functions }\end{array}$

X

X

X

X

X

X

X

X 
TABLE 3.2-4 (Cont)

\section{Principal Component}

PLANT CONTROL, DATA AND

INSTRUMENTATION (Continued)

Shift Supervisor Workstation

POWER CONVERSION GROUP

\section{Turbine Generator and Auxiliaries}

Turbine-Generator

Turbine Controls

Gland Seal System

Hydrogen Cooling System

Lube 0il System

Feedwater and Condensate

Main Condensate Pumps

Main Feedwater Pumps

Condensate Surge Tanks

Main Condenser

Deaerators
10CFR100-Related

"Safety- "Safety-

Related" Related" Radionuclide Control Functions
$\mathrm{X}$

$\mathrm{X}$

$\mathrm{X}$

$\mathrm{X}$

$\mathrm{X}$

$\mathrm{X}$

$\mathrm{X}$

$\mathrm{X}$

$\mathrm{X}$

$\mathrm{X}$

$\mathrm{X}$ 
TABLE 3.2-4 (Cont)

$\begin{array}{llc} & \text { Not } & \text { 10CFR100-Related } \\ \text { "Safety- } & \text { "Safety- } & \text { Radionuclide Control Functions } \\ \text { Related" } & \text { Related" } & \text { R }\end{array}$

POWER CONVERSION GROUP (Continued)

Feedwater Heaters

$\mathrm{X}$

Valves

$\mathrm{X}$

Demineralized Water Make-up

Pumps and Valves

$\mathrm{X}$

Main and Bypass Steam

Pressure Reducing Stations

$\mathrm{X}$

Desuperheating Equipment

$\mathrm{X}$

Valves

$\mathrm{X}$

Extraction and Auxiliary Steam

Valves

Pressure Reducing Stations

Heater Drains and Condensate

Returns

Valves

X

Condensate Drain Pumps 
HTGR - 86-024

\section{Principal Component}

POWER CONVERSION GROUP (Continued)

Condensate Polishing System

Demineralizer Modules

Regeneration System

Valves

\section{Steam Vents and Drains}

Valves

Relief Valves

\section{Turbine Plant Sampling}

Sample Coolers

Valves

Chemical Feed System

Injection Pumps and Valves

Chemical Storage Tanks
TABLE 3.2-4 (Cont)

Not

"Safety- "Safety-

Related" Related"

10CFR100-Related

Radionuclide Control Functions
$\mathrm{X}$

$\mathrm{X}$

$\mathrm{X}$

X

$\mathrm{X}$

X

X

$\mathrm{X}$

X 
TABLE 3.2-4 (Cont)

$\begin{array}{llc} & \text { Not } & \\ \text { "Safety- } & \text { "Safety- } & \text { 10CFR100-Related } \\ \text { Related" } & \text { Related" } & \text { Radionuclide Control Functions }\end{array}$

HEAT REJECTION GROUP (Continued)

Turbine Bldg. Closed

Cooling Water

Pumps and Valves

$\mathrm{X}$

Heat Exchangers

$\mathrm{X}$

Tanks

$\mathrm{X}$

Startup and Shutdown

Startup and Shutdown Feed Pump

$\mathrm{X}$

Startup and Shutdown Deaerator

$\mathrm{X}$

Startup and Shutdown Tank

$\mathrm{X}$

Valves

$\underline{\text { Steam and Water Dump }}$

Dump Valves

$\mathrm{X}$

Dump Tank . 


\section{Principal Component}

HEAT REJECTION GROUP (Continued)

Circulating Water

Cooling Tower

Pumps and Valves

Circulating Water Makeup

and Blowdown

Pumps and Valves

Filters and Strainers

Service Water

Tanks

Heat Exchangers

Pumps and Valves
TABLE $3.2-4$ (Cont)

Not

"Safety- "SafetyRelated" Related"

10CFR100-Related Radionuclide Control Functions
$\mathrm{X}$

$\mathrm{X}$

$\mathrm{X}$

$\mathrm{X}$

$\mathrm{X}$

$\mathrm{X}$ 
TABLE 3.2-4 (Cont)

\section{Principal Component}

REACTOR CAVITY COOLING SYSTEM

Reactor Cavity Cooling Panels

Panel Assemblies

Ducting

Plenum Structures

Intake/Exhaust Structures

SHUTDOWN COOLING SYSTEM

Shutdown Cooling Circulator

Compressor/Motor Assembly

Ducting and Shutoff Valve Assembly

Service Module

Motor Power Supply

Shutdown Cooling Heat Exchanger

Tube Bundle Assembly

$\begin{array}{ll} & \text { Not } \\ \text { "Safety- } & \text { "Safety- } \\ \text { Related" } & \text { Related" }\end{array}$

$\mathrm{X}$

X

X

$\mathrm{X}$
X

X

$\mathrm{X}$

$\mathrm{X}$

X
10CFR100-Related

Radionuclide Control Functions
Remove core heat*

Remove core heat*

Remove core heat*

Remove core heat* 
TABLE $3.2-4$ (Cont)

Principal Component

Not

"Safety-

Related" Related"

SHUTDOWN COOLING SYSTEM (Continued)

Shutdown Cooling Water

Shutdown Cooling Water Heat

Exchanger

Surge Tank

Pumps and Valves

Chemistry Control Module

BUILDINGS, STRUCTURES AND

BUILDING SERVICES GROUP

Reactor Bldg.

Reactor Service Bldg.

Reactor Auxiliary Bldg.

Operations Center

Standby Power Bldg.

Radioactive Waste Management Bldg.

$\mathrm{X}$

$\mathbf{X}$

$\mathrm{X}$

$\mathrm{x}$

$\mathrm{X}$

$\mathrm{X}$

$\mathrm{X}$

Personnel Service Bldg.
10CFR100-Related Radionuclide Control Functions 
TABLE 3.2-4 (Cont)

Principal Component

Not

"Safety- "SafetyRelated" Related"

BUILDINGS, STRUCTURES AND

BUILDING SERVICES GROUP (Continued)

Turbine Bldg.

Fire Pump House

Warehouse Bldg.

Maintenance B1dg.

Intake Pump House and Discharge Structure

Cooling Tower Basin and Circ.

Water Pump Intake

Auxiliary Boiler Make-up Water Treatment and Auxiliary Boiler Bldg.
$\mathrm{X}$

$\mathrm{X}$

$\mathrm{X}$

$\mathrm{X}$

$\mathrm{X}$

$\mathrm{X}$

$\mathrm{X}$
10CFR100-Related Radionuclide Control Functions 
Principal Component

MECHANICAL SERVICE GROUP

Plant Fire Protection

Tanks

Pumps and Valves

Hydrants

Hose Stations

Sprinklers

Diesel Fuel Oil Tank

$\mathrm{Co}_{2}$ Blanketing System

Halon 1301 Cylinders

Auxiliary Boiler System

Auxiliary Boiler (Electric)

Condensate Makeup Pumps

Feed Pumps and Valves

Deaerator
TABLE $3.2-4$ (Cont)

Not

"Safety - "Safety -

Related" Related"

10CFR100-Related

Radionuclide Control Functions
$\mathrm{X}$

$\mathrm{X}$

X

X

$\mathrm{X}$

$\mathrm{X}$

$\mathrm{X}$

$\mathrm{X}$

X

X

$\mathrm{X}$

X 
TABLE 3.2-4 (Cont)

\section{Principal Component}

MECHANICAL SERVICE GROUP (Continued)

\section{$\underline{\text { Raw Water Treatment }}$}

\section{Filters}

Chemical Treatment Equipment

Valves

Instrument and Service Air

Compressors

Receivers

Aftercoolers

Driers

Valves

Central Hot Water Heating

Water Heater

Pumps and Valves
Not

"Safety- "SafetyRelated" Related"
$\mathrm{X}$

X

X

X

$\mathrm{X}$

X

$\mathrm{X}$

X

X

$\mathrm{X}$
10CFR100-Related

Radionuclide Control Functions 
TABLE $3.2-4$ (Cont)

\section{Principal Component}

Not

"Safety- "Safety. Related" Related"
10CFR100-Related Radionuclide Control Functions

MECHANICAL SERVICE GROUP (Continued)

Heating, Ventilation, and

Air Conditioning

Air Conditioning Units

$\mathrm{X}$

Vaneaxial Fans

$\mathrm{X}$

Centrifugal Fans

$\mathrm{X}$

Propeller Fans

Pumps

Centrifugal Chillers

Electric Heaters

Ductwork and Dampers

Filters 
TABLE $3.2-4$ (Cont)

\section{Principal Component}

ELECTRICAL GROUP

\section{Off-Site and Main Generator \\ Transmission}

Switchyard Circuit Breakers

$240 \mathrm{kV}$ Transmission Lines

Unit Transformers

Unit Auxiliary Transformers

Startup Auxiliary Transformers

Isolated Phase Bus

AC Distribution System

4160-Volt Switchgear

480-Volt Unit Substation

480-Volt Motor Control Centers

Backup Generators
Not

"Safety- "Safety-

Related" Related"

10CFR100-Related

Radionuclide Control Functions
$X$

$x$

$\mathrm{X}$

$\mathrm{X}$

$\mathrm{X}$

$\mathrm{x}$

$\mathrm{X}$ 
TABLE $3.2-4$ (Cont)

\section{Principal Component}

ELECTRICAL GROUP (Continued)

Cabling, Conduit/Trays

Uninterruptible Power Supply System

\section{Rectifier/Inverters}

Distribution Panels

Regulating Transformers

Cabling, Conduit, and Raceways

Essential Uninterruptible Power

Supply System

Rectifiers/Inverters

Distribution Panels
Not

"Safety- "Safety-

Related" Related"

$\mathrm{X}$

$\mathrm{X}$

$\mathrm{X}$

$\mathrm{X}$

$\mathrm{X}$

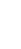

$\mathrm{X}$

$\mathrm{X}$
10CFR100-Related

Radionuclide Control Functions
Control heat generation* Control chemical attack*

Control heat generation* Control chemical attack* 
HTGR - 86- 024

TABLE $3.2-4$ (Cont)

\section{Principal Component}

ELECTRICAL GROUP (Continued)

Regulating Transformers

Cabling and Conduit/Trays

\section{Power System}

\section{Station Batteries}

Battery Chargers

Distribution Switchboards

Cabling and Conduit/Trays

Essential DC Power System

Station Batteries
Not

$\begin{array}{ll}\text { "Safety- } & \text { "Safety- } \\ \text { Related" } & \text { Related" }\end{array}$

\begin{tabular}{l} 
"Safety- "Safety \\
Related" \\
\hline
\end{tabular}

Related"

$x$

$\mathrm{X}$

$\mathrm{X}$

$\mathrm{X}$

$\mathrm{X}$

$\mathrm{X}$

$\mathrm{X}$
Control heat generation* Control chemical attack*

Control heat generation* Control chemical attack*

\section{Radionuclide Control Functions}


HTGR - 86- 024

TABLE 3.2-4 (Cont)

\begin{tabular}{ll} 
& Not \\
"Safety- & "Safety- \\
Related" & 10CFR100-Related \\
\hline
\end{tabular}

$\mathrm{X}$

$\mathrm{X}$

X

Cabling and Conduit/Trays

\section{Communications System}

Page Party Equipment

Sound Powered Telephone Equipment

Hand-Held Radio Communication Equipment

Private Automatic Exchange (PAX)

Maintenance Jack Equipment
Control heat generation* Control chemical attack*

Control heat generation* Control chemical attack* 
TABLE $3.2-4$ (Cont)

\section{Principal Component}

ELECTRICAL GROUP (Continued)

\section{Lighting and Service Power}

Systems

Emergency Area Lighting

Plant Lighting

Convenience Outlets $480-\mathrm{V}$; $220-\mathrm{V}, 110-\mathrm{V}$

\section{Plant Security}

Communication Equipment

Door Equipment

Computer Equipment

Backup Generator

UPS Equipment

Motor Control Centers

\section{Not \\ "Safety- "Safety- \\ Related" Related" \\ 10CFR100-Related \\ Radionuclide Control Functions}

X

$\mathrm{X}$

$\mathrm{X}$

$\mathrm{X}$

$\mathrm{X}$

$\mathrm{X}$

$\mathrm{X}$

X

X 
TABLE $3.2-4$ (Cont)

Not
"Safety- $\quad$ "Safety-

Related" Related"
10CFR100-Related

Radionuclide Control Functions

ELECTRICAL GROUP (Continued)

\section{Grounding, Lightning, Heat}

Tracing, and Cathodic Protection

Ground Wire

$\mathrm{X}$

Heat Tracing Components

$\mathrm{X}$

Cathodic Protection Components

$\mathrm{X}$

Lighting Protection Equipment 


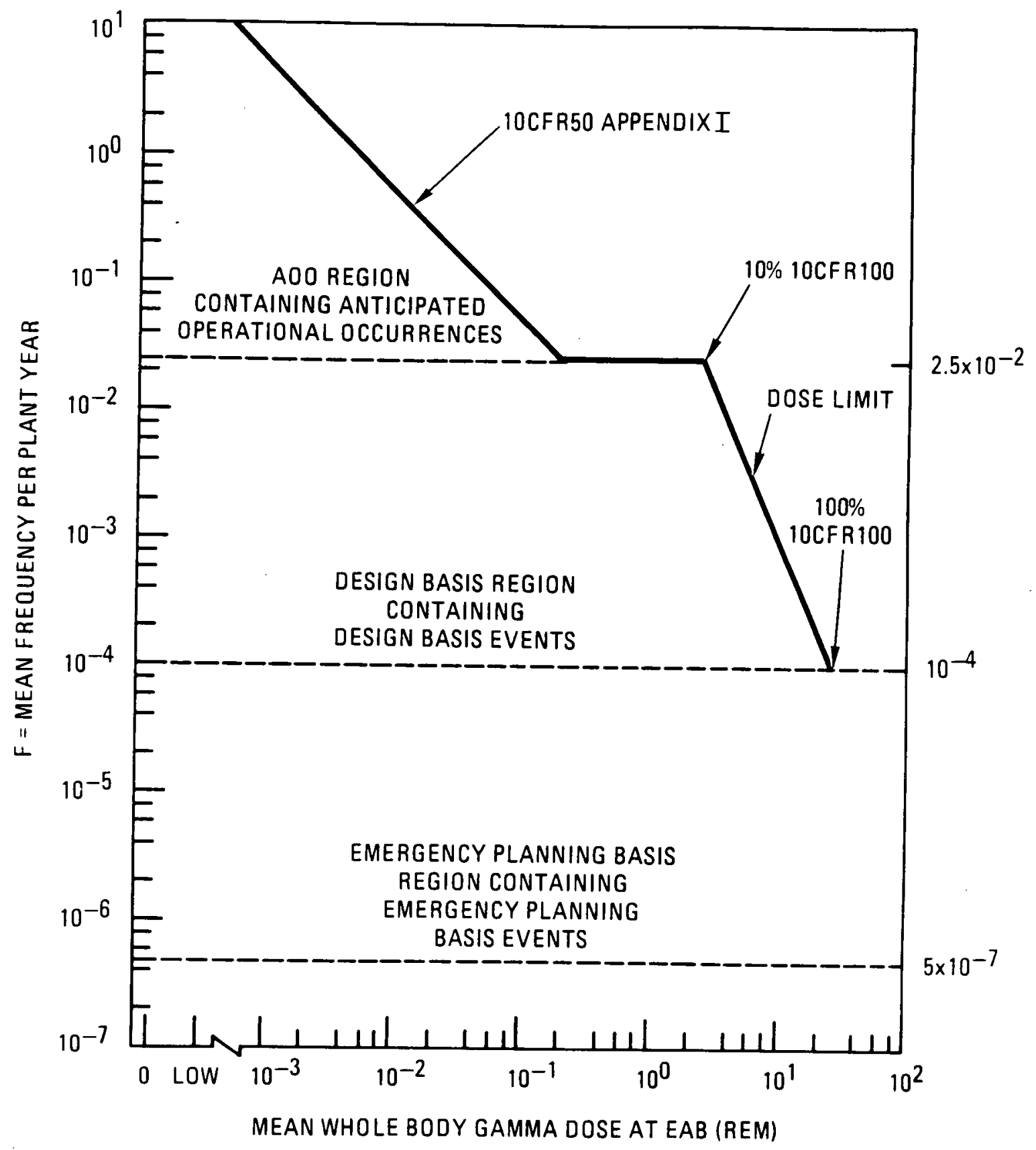

FIGURE 3.2-1

LICENSING BASIS REGIONS FOR LICENSING BASIS EVENT SELECTION

MEH TEUPERATURE GASCOOLEO REACTOA PREAMMMARY SAFETY INFORMATHON DOCJMEAT HTERESTL4 


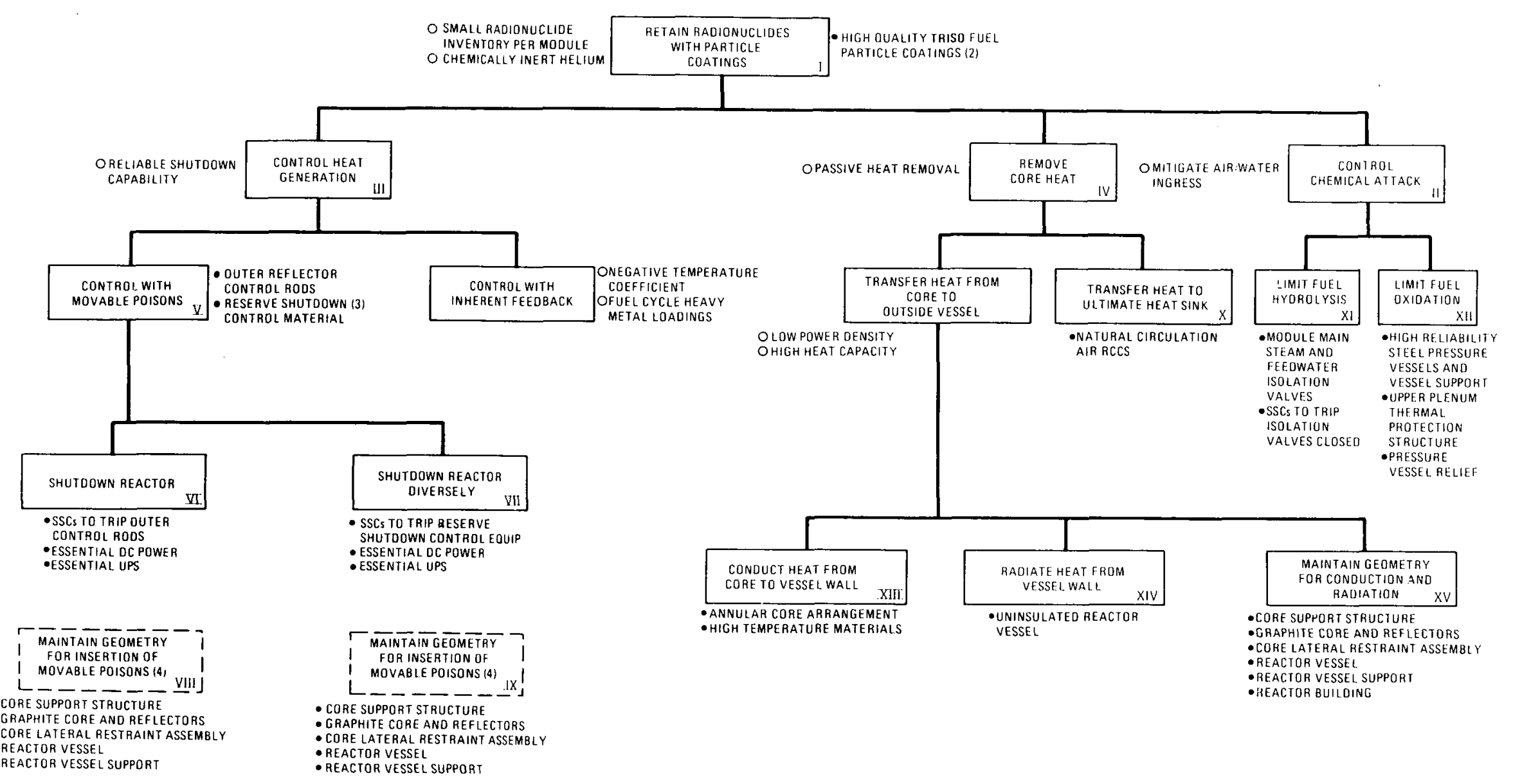

(1) ATI R!CUTES SELLECTED ARE PRECEDED BY O.

FIGURE 3.2-2

(2) REDUCE ALL OWABLE COATING DEFECTS DESIGNEO TO MEET MORE RESTRICTIVE PAG LIMITS

MAJOR 10CFR100 RELATED FUNCTIONS

(3) GOAL 3 SPECIFIC DESIG SELECTION TO MEET IOCFRIOO DOSE IMITS

AND SAFETY RELATED DESIGN

SELECTIONS (1)

HIGH TEMPERATURE GAS-COOLED REACTOR

PRELIMINARY SAFETY INFORMATION DOCUMENT

HTGR-86-024 


\subsection{WIND AND TORNADO LOADINGS}

Certain Standard MHTGR structures must serve to ensure, with a high level of confidence, that systems or components they house can fulfill their 10CFR100-related radionuclide control functions under design basis conditions. These structures are identified in Chapter 6. This section gives the criteria for which these designated Standard MHTGR plant structures are designed. In the case of wind loads, an envelope of conditions is defined in Section 2.6. As sites are chosen, local wind conditions will be analyzed to assure that they fall within the design envelope.

For tornadoes, that specified in Regulatory Guide 1.76 for Region I has been selected as the Design Basis Tornado (DBT), being the maximum tornado currently required for light water reactors (LWRs). (Ref. 1) When the results of the probabilistic risk analysis (PRA) are known, a different DBT may be proposed where the analyses support it. (Ref. 2) The appropriate licensing document will be revised accordingly if and when such a proposal is made.

Tornado criteria furnishing data, formulae, and procedures consistent with those currently employed for LWR design are used for determining the maximum wind loading on Standard MHTGR structures and parts of structures. (Ref. 3)

\subsubsection{Wind Loading}

\subsubsection{Design Wind Velocity}

The specified design wind velocity in Section 2.6 for all structures exposed to wind effects is $177 \mathrm{~km} / \mathrm{hr}(110 \mathrm{mi} / \mathrm{hr})$ at $10 \mathrm{~m}$ (33 ft) above ground.

The design for wind loading is consistent with current LWR practice, using the following parameters (Ref. 4):

1. Exposure is Category C.

2. The building classification is ANSI A58.1 Category III. 
3. Importance factor is 1.11 .

\subsubsection{Determination of Applied Forces}

The procedures used to convert the wind velocity into applied forces for structures are consistent with current LWR practice. (Ref. 3, 4) The wind velocity on which the applied forces depend is given in Section 3.3.1.1. The design pressures or design loads are obtained by multiplying the effective velocity-pressures by appropriate pressure coefficients. (Ref. 3)

For structures which are to be designed for tornado loading, the applied forces due to wind are calculated to determine if they are less severe than the applied forces due to tornado loading. The applied tornado force magnitude and distribution are determined as discussed in section 3.3.2. Appropriate stress levels and load factors discussed in section 3.8 of this PSID are considered in the determination of the governing loads.

\subsubsection{Tornado Loading}

\subsubsection{Applicable Design Parameters}

Structures which must serve to ensure, with a high level of confidence, that systems or components that they house can fulfill their 10CFR100-related radionuclide control functions under design basis conditions and which may be exposed to tornado effects are designed to withstand tornado loading (not coincident with any unrelated accident condition or earthquake) consistent with current LWR practice. (Sections 3.3 and 3.4, Ref. 3) Tornado design wind velocities and pressures are given in Table 3.3-1. Tornado wind pressure loads, differential atmospheric pressure changes, associated time intervals, and missile effects are combined in accordance with current LWR practice. (Ref. 2) Design tornado missiles are included in Section 3.5.

\subsubsection{Determination of Forces on Structures}

Loading combinations, the methods employed to convert tornado loading into forces, and the distribution across the structures are consistent with 
HTGR - 86- 024

current LWR practice. (Ref. 3) These combined effects constitute the total tornado load, which is then combined with other applicable loads as specified in Section 3.8 of this PSID.

3.3.2.3 Effect of Failure of Structures or Components Not Required to be Designed for Tornado Loads

Failure of structures not required to be tornado-protected will not adversely affect the ability of tornado-protected structures to perform their functions, especially that of serving to ensure that systems or components they house can fulfill their 10CFR100-related functions. 


\section{REFERENCES - SECTION 3.3}

1. U.S. Nuclear Regulatory Commission. Design Basis Tornado for Nuclear Power Plants. Regulatory Guide 1.76, Washington, DC, April 1974.

2. GA Technologies, Inc. (GA). Probabilistic Risk Assessment for the Standard MHTGR Plant. DOE-HTGR-86-011, Rev. 3. GA, San Diego, CA, January 1987 .

3. Bechtel Power Corporation (BPC). Bechtel Topical Report: Tornado and Extreme Wind Design Criteria for Nuclear Power Plants. BC-TOP-3A, Revision 3. BPC, San Francisco, CA, August 1974.

4. American National Standards Institute. American National Standard: Minimum Design Loads for Buildings and Other Structures. ANSI A58.1-1982. New York, NY, 1982. 
HTGR - 86- 024

TABLE 3.3-1

TORNADO WIND VELOCITIES AND PRESSURES

$\underline{\text { Item }}$

Maximum wind speed

Rotational speed

Maximum translational speed

Radius of maximum rotational speed

Pressure drop

Rate of pressure drop
Value

$579 \mathrm{~km} / \mathrm{h}(360 \mathrm{mi} / \mathrm{h})$

$467 \mathrm{~km} / \mathrm{h}(290 \mathrm{mi} / \mathrm{h})$

$113 \mathrm{~km} / \mathrm{h}(70 \mathrm{mi} / \mathrm{h})$

$45.7 \mathrm{~m}(150 \mathrm{ft})$

$20.7 \mathrm{kPa}$ (3.0 psi)

$13.8 \mathrm{kPa} / \mathrm{s}(2.0 \mathrm{psi} / \mathrm{s})$ 


\subsection{WATER LEVEL (FLOOD) DESIGN}

Facilities which must serve to ensure, with a high level of confidence, that systems or components they house fulfill their 10CFR100-related radionuclide control functions under design basis conditions are designed for a normal groundwater level of $2.4 \mathrm{~m}(8 \mathrm{ft})$ below the ground surface and a maximum groundwater level at the ground surface.

The assumption is made for the Standard MHTGR that no surface flooding occurs, so no flood protection measures are included in the design. For each specific Standard MHTGR plant site, analyses will be made using the methods in Regulatory Guide 1.59 to establish the probable maximum flood (PMF), the probable maximum precipitation (PMP), seiche, or other hydrological considerations, as applicable, to demonstrate that this assumption remains valid. (Ref. 1) Different water level (flood) criteria may be proposed based on the results of site-specific probabilistic risk assessments.

Structures with equipment spaces below grade are protected from the inleakage of groundwater by a continuous waterproof membrane and by waterstops in construction joints of exterior walls and slabs where groundwater conditions so require. Any inleakage which may occur will be collected in instrumented sumps inside the affected space. If the inflow to the sump exceeds the removal capability, the potentially affected systems and components will be placed in a safe condition and appropriate remedial measures taken. Past experience with occupied spaces constructed below the water table, including underwater tunnels and spaces housing safety-related components in LWR plants, indicates that any ground-water inleakage which may occur becomes apparent during construction and can be corrected before the plant goes into operation. Chemical grouting from the inside of the structure is one technique used to stop water inflow into a below-grade structure.

Analyses will be made to mechanistically identify credible leaks from fluid-containing tanks and vessels within structures housing systems or components which must be able to fulfill, with a high level of confidence, their 10CFR100-related radionuclide control functions under design basis conditions. Sumps or other passive measures will be used as required to limit fluid levels to those which will allow safe plant shutdown to be achieved and maintained. 


\section{REFERENCES - SECTION 3.4}

1. U.S. Nuclear Regulatory Commission. Design Basis Floods for Nuclear Power Plants. Regulatory Guide 1.59, Revision 2. Washington, DC, August 1977, including Errata July 30, 1980. 


\subsection{PROTECTION AGAINST MISSILES AND EXTERNALLY-GENERATED HAZARDS}

\subsubsection{Hazard Selection and Description}

The location below grade of the major portion of the Standard MHTGR systems and components which must fulfill, with a high level of confidence, their 10CFR100-related radionuclide control functions under design basis conditions provides inherent protection against many externally-generated missiles and other hazards. Specific categories are discussed further below.

\subsubsection{Internally Generated Missiles}

Analysis will be made of systems that have pressures high enough to cause missiles from valve stem failure, tank rupture, etc. and of rotating equipment that could generate missiles which are proximate to systems and components which must fulfill, with a high level of confidence, their 10CFR100-related radionuclide control functions under design basis conditions. These analyses will be done on a mechanistic, probabilistic basis, with the results to be presented in later licensing documents.

\subsubsection{Turbine Missiles}

The probability of a turbine missile strike on any given area of the Nuclear Island is a function of the energy and direction of an ejected missile and the orientation of the turbine with respect to that area. The turbine-generator is arranged so that the planes of rotation of the turbine disks do not intersect any structures, systems, or components required to function to meet 10CFR100 limits, thus minimizing the probability of adverse effects from a turbine missile. The orientation of the turbine is shown on the plot plan, Figure 1.3-1.

\subsubsection{Missiles Generated by Natural Phenomena}

The tornado missiles used for design of the Standard MHTGR plant are those designated as Spectrum II missiles in Section 3.5.1.4 of the Standard Review Plan (SRP) for Region I tornadoes. (Ref. 1) Table 3.5-1 summarizes these 
missiles and missile velocities. As stated in Section 3.3, different missiles and/or velocities may be proposed in the future based on the results of the probabilistic risk assessment.

\subsubsection{Hazards Generated by Events Near the Site}

The hazards presented by events occurring near the site are site specific. Dynamic hazards, such as explosions and explosion-generated missiles, are expected to be enveloped in all but special cases by the tornado-generated hazards discussed in the preceding section. Their safety significance is further reduced by the below-grade placement of nearly all items essential to safety. For other hazards, such as combustible and toxic gases, the inherent passive safety characteristics of the Standard MHTGR, which make unnecessary the reliance upon operator action to meet 10CFR100, eliminate such hazards, in most cases, as safety concerns. As sites are selected for the Standard MHTGR plants, the possibilities for such events and their consequences will be assessed on a probabilistic basis.

\subsubsection{Aircraft Hazards}

The hazards posed by aircraft operations near the site are site specific and are expected to be enveloped by missile and tornado design provisions. As sites are selected, this subject will be addressed on a site-by-site basis.

\subsubsection{Structures, Systems, and Components To Be Protected from Externally Generated Hazards}

A tabulation of the structures, shields, and barriers for hazard protection will be developed later as the design develops.

Al1 systems and components which must fulfill, with a high level of confidence, their 10CFR100-related radionuclide control functions under design basis conditions are located inside buildings or structures which are designed to withstand the impact from tornado-generated missiles. The major portions of the Reactor Buildings, Reactor Auxiliary Buildings, and Reactor 
Service Building are below grade and electrical/control interconnections are run underground in tunnels between these structures. These tunnels are located at such a depth that the backfill and tunnel enclosure provide adequate protection from tornado missiles.

All doorways, hatches, or other closures at penetrations through protective barriers are analyzed to ensure that the functionality of items which must 
fulfill, with a high level of confidence, their 10CFR100-related radionuclide control functions under design basis conditions is not affected by missile impact.

\subsubsection{Barrier Design Procedures}

To prevent damage to protected components, missile-resistant barriers and structures are designed to withstand and absorb missile impact loads without being fully perforated. In addition, the overall structural response is evaluated to ensure structural integrity under missile impact loads. For concrete missile barriers, the possibility of generation of secondary missiles due to spalling or scabbing is also taken into consideration so that protective measures can be provided. Minimum thicknesses of concrete tornado barriers are consistent with the provisions of SRP Section 3.5.3, Table 1. (Ref. 1) The other barrier design procedures are also consistent with current LWR practice. (Ref. 2) 


\section{HTGR - 86- 024 \\ REFERENCES - SECTION 3.5}

1. U.S. Nuclear Regulatory Commission (NRC). Standard Review Plan for the Review of Safety Analysis Reports for Nuclear Power Plants, LWR Edition. NUREG-0800, Rev. 4. NRC, Springfield, VA, July 1981.

2. Bechtel Power Corporation (BPC). Bechtel Topical Report: Design of Structures for Missile Impact. BC-TOP-9-A, Rev. 2. BPC, San Francisco, CA, 1974. 


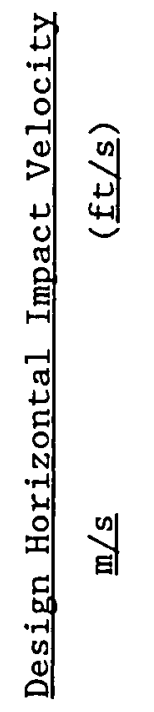

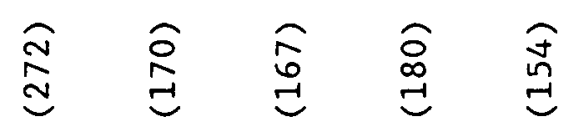

芽

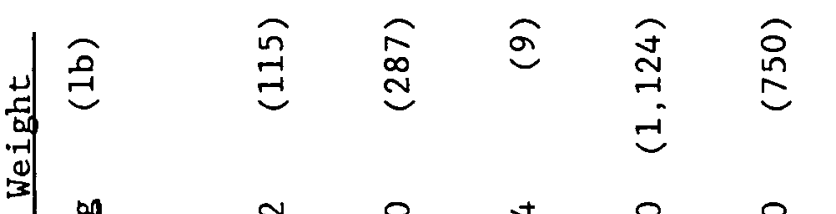

胥

ฉ

n

9

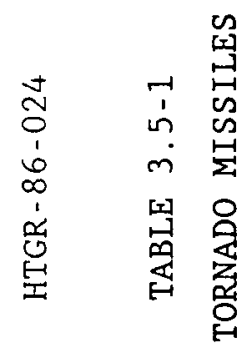

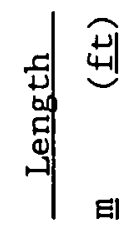

ฐ

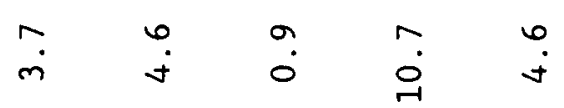

ลั

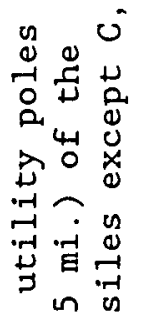

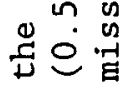

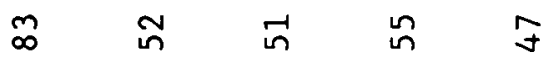

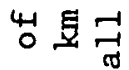

常

है

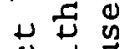

证

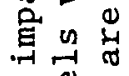

o $D$

古 $\stackrel{0}{-1}$

$\stackrel{0}{0} \stackrel{0}{0}$

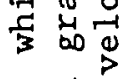

응

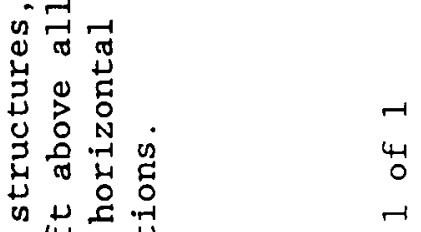

0 \&

岳诲步

440

州

눙

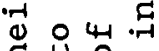

E 10

空总怘总

ब

㟧塄年

ब.

㟧品品

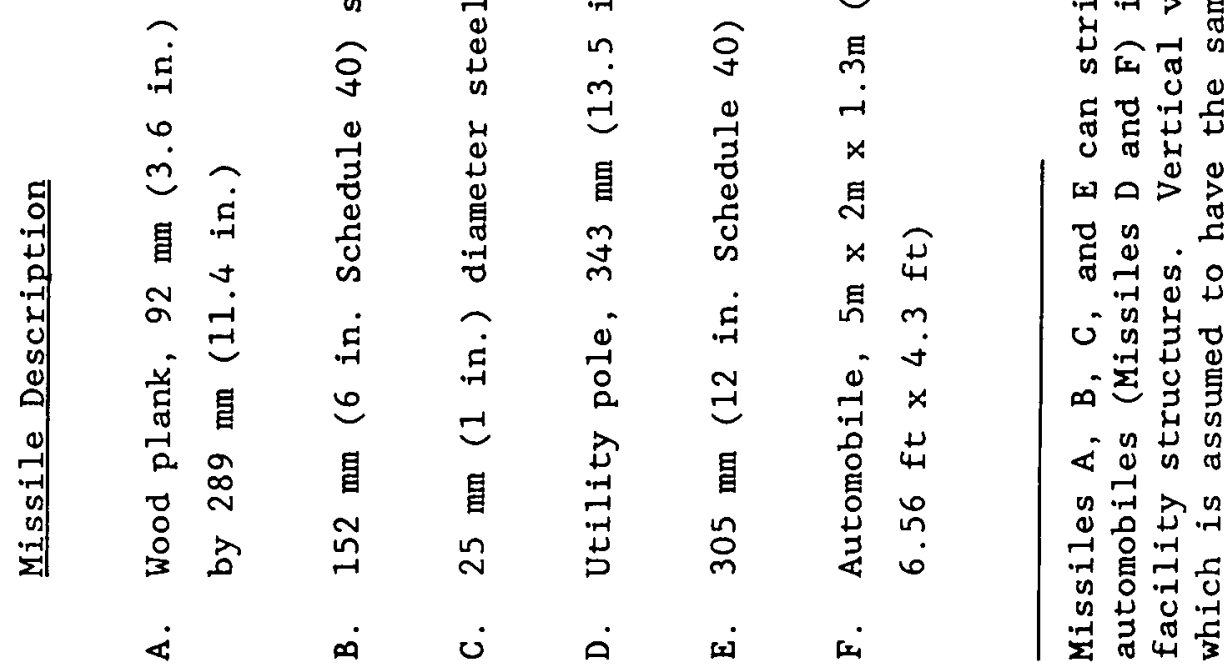




\subsection{PROTECTION AGAINST DYNAMIC EFFECTS ASSOCIATED WITH THE POSTULATED RUPTURE OF PIPING}

For all piping in areas proximate to systems and components which must fulfill, with a high level of confidence, their 10CFR100-related radionuclide control functions under design basis conditions, mechanistic studies are made to determine the extent of protection, if any, to be provided against the effects of pipe breaks.

In performing analyses on piping systems, consideration is given to:

1. The Leak-Before-Break (LBB) concept and the associated leak detection requirements

2. Stress levels and load combinations.

3. Materials, i.e., corrosion and susceptibility to intergranular stress corrosion cracking.

4: In-service inspection provisions

5. Unusual conditions, such as water hammer, other repetitive loads and thermal fatigue.

The crossduct portion of the primary pressure boundary conveys the primary helium from the steam generator vessel to the reactor vessel. In order to insure high quality and reliability, the crossduct will be designed, fabricated, tested, and installed in accordance with ASME Section III rules for a Class 1 pressure vessel. In-service inspection in accordance with ASME Section XI will be employed to detect any flaws which might propagate to cause failure. Consequently, the crossduct will be no more susceptible to failure than the reactor vessel or steam generator vessel. Furthermore, it will be shown by means of deterministic fracture mechanics analyses (which have been employed in the Leak-Before-Break (Ref. 2) approach for 1ight-water reactor piping systems) that a postulated double-ended guillotine break (DEGB) of the crossduct will not occur. It will be demonstrated by 
deterministic analyses that the detection of small flaws, by either in-service inspection or leakage monitoring systems, will be assured long before the flaws can grow to critical or unstable sizes, thereby precluding large break areas such as the DEGB or its equivalent. Probabilistic fracture mechanics techniques will also be used to demonstrate very low failure probabilities, if necessary.

Where mechanistic analyses show that the break of a pipe has a high enough probability to be considered as a design basis, all effects of the pipe break are considered in the design, including:

\section{Pipe whip and reaction forces}

\section{Jet impingement forces}

3. Subcompartment pressurization and temperature rise

\section{Flooding}

5. Associated transient loads in the unbroken portions of the system.

The simultaneous occurrence of pipe break and either safe shutdown earthquake (SSE) or operating basis earthquake (OBE) as in Section 2.6, is considered too improbable to be incorporated in the plant design basis. This is reflected in the loading combinations for structures in Section 3.8. It is expected that the probabilistic risk assessment (PRA) will confirm the above, and additional revisions to load factors and load combinations may be made if they are supported by the results of probabilistic analyses. (Ref. 1) The current design is based on the following:

1. No break is postulated in the crossduct in the primary system between the reactor vessel and the steam generator. Fracture mechanics techniques as part of the Leak-Before-Break approach (Ref. 2), as is currently being done for some light water reactor (LWR) primary system piping, will be used to demonstrate a failure probability sufficiently low to be of no concern. 
2. Venting area currently included in the design of the Reactor Building is that for the blowdown from a double-ended guillotine break of a main steam line.

3. No special provisions beyond standard power plant industrial practice are currently included for protection against pipe break effects in the rest of the plant. Analyses of high and moderate energy lines in the proximity of systems or components which must fulfill, with a high level of confidence, their 10CFR100-related radionuclide control functions under design basis conditions will be performed to assure adequate protection is provided. 


\section{REFERENCES - SECTION 3.6}

1. GA Technologies, Inc. (GA). Probabilistic Risk Assessment for the Standard MHTGR Plant. DOE-HTGR-86-011, Rev. 3. GA, San Diego, CA, January 1987 .

2. Johnston, W. V. Combustion Engineering, Inc., CESSAR Docket Elimination of Large Primary Loop Pipe Ruptures. U.S. Nuclear Regulatory Commission, Docket No. STN-50-470F, September 1984. 
HTGR $-86-024$

\subsection{SEISMIC DESIGN}

It is the intention to follow current light water reactor (LWR) seismic analysis and design practice wherever applicable. This section covers primarily those seismic design features which are unique to the standard MHTGR plant.

\section{7 .1 Seismic Input}

The seismic requirement for the MHTGR plant is to develop a standard plant design which could be sited on 85 percent of the prospective U.S. sites. To satisfy this requirement, over 100 prospective U.S. sites were surveyed and the appropriate seismic parameters were developed and incorporated into the seismic analysis to form the basis for the conceptual design.

\subsubsection{Generic Site Characteristics}

The Standard MHTGR is seismically analyzed for the range of site characteristics with shear-wave velocities varying from 305 to $2438 \mathrm{~m} / \mathrm{s}$ (1000 to $8000 \mathrm{ft} / \mathrm{sec}$ ), assuming no variation of soil properties with depth. However, analyses are also performed to assess the effect of significant variations in soll properties with depth, including layering, as these may control some aspects of plant design. The foundation material is assumed to have an allowable static bearing capacity of $479 \mathrm{kPa}$ ( $10 \mathrm{ksf}$ ) and the normal groundwater level is approximately $2.4 \mathrm{~m}$ ( $8 \mathrm{ft}$ ) below grade.

\subsubsection{Generic Input Motion}

Structures, systems, and components which must serve to ensure with a high degree of confidence, that systems or components they house can fulfill their 10CFR100-related radionuclide control functions under design basis conditions for the Standard MHTGR plant are currently designed to accommodate seismic loadings produced by two earthquakes - the Operating Basis Earthquake (OBE) with a maximum, free-field zero-period acceleration (ZPA) of $0.15 \mathrm{~g}$ and the Safe Shutdown Earthquake (SSE) having a maximum, free-field ZPA of $0.30 \mathrm{~g}$. These accelerations are equal in the horizontal and vertical directions and 
remain constant over the entire range of site shear-wave velocities stated above. The input motion is applied at the ground surface, not the foundation level, for these structures, the major portions of which are located mostly below grade. Appendix A to 10 CFR 100 specifies that the design ground motion be applied at the foundation level of Category I structures. With a deeply-embedded structure, such as the Standard MHTGR plant, however, this requirement is clearly not applicable. Measurements during actual earthquakes have shown that the free-field ground excitation at a given site is greatest at the surface and decreases with depth. In addition, the Regulatory Guide 1.60 design response spectra, used as the basis for seismic input, is based on strong earthquake records obtained at the surface level at various sites. (Ref. 1) The application of the input motion based on surface records to the foundation level of a structure more than 46m (150 feet) below the surface would yield unrealistic results, particularly in the upper region of the model. For these reasons, the input motion is applied to the three-dimensional finite-element model at the grade level. Input of seismic motion at the grade level rather than the foundation level was the strong consensus of the attendees at the Workshop on Soil-structure Interaction on June 16-18, 1986 in Bethesda, MD, sponsored by the NRC. (Ref. 2)

\subsubsection{Validation of a Specific Site}

When a specific site is identified and the required seismologic and geologic data are developed, a site-specific seismic analysis will be performed culminating in preparation of floor response spectra (FRS). These will be compared with the Standard MHTGR FRS to assure that the site-specific FRS are bounded by the Standard FRS.

\subsubsection{Damping Values}

The damping values used are those provided in Regulatory Guide 1.61, Damping Values for Seismic Design of Nuclear Power Plants, except as described below. (Ref. 3) 
The damping values used for the steam generator tube bundle are 5 percent and 10 percent for $O B E$ and SSE, respectively, which differ substantially from the values given in Regulatory Guide 1.61. (Ref. 3) These damping values are based on data obtained from dynamic tests performed on a helical coil tube bundle similar in design to the standard MHTGR tube bundle. This test noted a minimum bundle damping value of approximately 11 percent of critical damping. Thus the values chosen for the analysis represent conservative estimates of the true damping value.

Damping values for the reactor core are 10 percent and 20 percent for the $O B E$ and SSE respectively. These values are based on data obtained from scale model tests on a similar core configuration of graphite fuel and reflector elements. Typical values of 20 percent were obtained when the core is oscillating as a lumped mass in response to sinusoidal excitation. Such damping values are mainly attributed to friction and aerodynamic energy losses. Significantly higher damping was observed when less lumped mass behavior is exhibited causing additional energy losses from impacts between elements. The damping values chosen, therefore, are conservative estimates since the core exhibits less lumping when excited by motions more closely simulating actual earthquakes.

\subsubsection{Time History Development}

Time history analyses are performed using synthetic earthquake records, generated on a basis consistent with the methodology of Regulatory Guide 1.60 , as input at plant grade. (Ref. 1) Each horizontal and vertical synthetic earthquake acceleration time history is 24 seconds long and is digitized at 0.005 seconds intervals. These synthetic time histories are scaled to appropriate g-levels, which changes the amplitudes of the response while leaving the time steps unchanged. Response spectra developed from these time histories meet the requirements for input response spectra given in Section 3.7.II.1.b of the standard Review Plan. (Ref. 4) As shown in Figure 3.7-1 and 3.7-2, the input spectra that correspond to the input time historic used, conservatively envelope the Regulatory Guide 1.60 spectra (Ref. 1) 
HTGR $-86-024$

\subsubsection{Plant Seismic Analysis}

The general analytical methods used in the plant seismic analysis are, except where noted in the following discussion, consistent with current LWR practice. (Ref. 5) The initial analysis described below were performed for the $O B E$ as this is more limiting than the SSE. In these analyses, seismic waves are assumed to propagate vertically. The effects of inclined seismic waves (dependent on fault locations) and building interactions (dependent on the number of modules) are considered site-specific. These effects will be accommodated when site-specific analysis are performed. Also, these analyses include the consideration of codirectional responses from simultaneous time history inputs in three directions.

\subsubsection{Analysis of Deeply Embedded Structures}

The Reactor Building is a multi-cell reinforced concrete structure set below grade, as described in Section 6.1.1. Below elevation $-10.67 \mathrm{~m}(-35 \mathrm{ft})$, the building is configured as a vertically-oriented cylinder (the silo) and contains the major NSSS components. A plan of the silo is shown in Figure 3.7-3. At elevation $-10.67 \mathrm{~m}(-35 \mathrm{ft})$, the shape of the building changes to a rectangular prism subdivided into several compartments to house nuclear auxiliaries dedicated to each reactor. As described further in Section 6.1, the four identical Reactor Buildings, along with the two identical Reactor Auxiliary Buildings and the Reactor Service Building, also all below-grade structures, are set in a row. Since the Reactor Building is embedded, seismic analysis techniques for above-grade structures are inappropriate and soil-structure interaction (SSI) effects take on greater importance.

The plant seismic analysis approach is divided into two phases:
- A parametric site screening study
- An analysis of three representative sites

The objective of the parametric site screening study was to develop three representatives sites whose soil conditions would envelope 85 percent of the prospective U.S. sites. 
Based on the specific Nuclear Steam Supply System (NSSS) design currently available, the parametric site screening study was performed with the CLASSI computer code to ascertain the site conditions which will produce the largest seismic responses in selected NSSS components. On the basis of this study, the following three representative sites shown in Figure 3.7-4 and described below were selected for further study with the SASSI computer code:

1. A uniform rock site with $v_{s}=2438 \mathrm{~m} / \mathrm{s}(8000 \mathrm{ft} / \mathrm{s})$, as it controls the design in the rigid range of the spectrum (frequency $>33 \mathrm{~Hz}$ )

2. A linearly varying soil profile from $v_{s}-335 \mathrm{~m} / \mathrm{s}(1,100 \mathrm{ft} / \mathrm{s})$ at grade to $v_{s}-762 \mathrm{~m} / \mathrm{s}(2500 \mathrm{ft} / \mathrm{s})$ at a depth of $47.5 \mathrm{~m}(156 \mathrm{ft})$ and then constant below, since this case represents the maximum linear rate variation of soil properties over the silo length based upon avallable site data. Furthermore, this soil profile controls the spectrum responses at certain NSSS components in the range of 4 to $11 \mathrm{~Hz}$.

3. A soft soil with $v_{s}=335 \mathrm{~m} / \mathrm{s}(1,100 \mathrm{ft} / \mathrm{s})$ down to $22.9 \mathrm{~m}$ (75 ft) below grade overlaying rock with $v_{s}-2438 \mathrm{~m} / \mathrm{s}(8,000 \mathrm{ft} / \mathrm{s})$, as it may produce the limiting conditions for silo design and for its potential for causing rocking effects.

The above representative sites are, to a large degree, specific to the current design of the Reactor Vessel and Steam Generator Support Subsystem. It is likely that, by changing the stiffness of these components and their supports, the conclusions may change somewhat. However, the three representative sites should provide a sound basis for developing the enveloping floor response spectra required for the design of NSSS components.

In the second phase of the seismic analysis, the MHTGR Reactor Building and NSSS were analyzed for the three representative sites. These analyses were performed using the SASSI computer program. (Ref. 6) The objective of the SASSI analyses were to develop envelopes for the three representative sites. These envelopes included: 

- NSSS spectra
- NSSS time histories
o Bullding forces and moments

A plant designed in accordance with these representative site envelopes would therefore satisfy the seismic input motions at 858 of the U.S. sites. The SASSI computer program considers the rigidity of the silo which in soft-soil sites creates strong kinematic interaction effects leading to effective seismic motions to the structure quite different from those in the free field. Since the SASSI program considers silo flexibility, it is particularly well suited to this second phase of the analysis because the silo structure has a large depth-to-diameter ratio and is fully embedded and since, for the softer soil sites, the effect of the dynamic soil pressures on the silo outer walls must be established for design purposes.

The analysis method used in the SASSI computer program is the flexible volume method. This method is formulated in the frequency domain using the complex frequency response method and the finite element technique. The following list represents a brief description of the features available in the SASSI computer program:

1. The three-dimensional Iinear-elastic finite-element formulation permits the analysis of general three-dimensional structures of arbitrary geometry.

2. The foundation can be a uniform half-space or can model horizontally layered media, i.e., soil/rock properties can be varied from layer to layer.

3. The flexibility of the silo basemat and walls can be considered in the analysis.

4. The formulation accounts automatically for material damping and radiation damping (dissipation of earthquake energy through wave scattering effects). 
HTGR - $86-024$

5. Nonlinear soil behavior is modeled by the equivalent linear method, in which an approximate nonlinear solution is obtained by iterating a linear solution until the soil shear modulus and damping values used in the analysis are compatible with the effective shear strain amplitudes computed at all points in the soil mass system.

Several studies using the SASSI program have been performed to provide verification for the procedure used, with the results discussed in Section 3.7.5. A preliminary model for SSI analysis of the Reactor Building silo is shown in Figure 3.7-5. The rectangular portion of the reactor building from elevation $0.0 \mathrm{~m}$ to $-10.7 \mathrm{~m}(-35.1 \mathrm{ft})$ was modeled as a cylinder by incorporating the appropriate mass and stiffness properties. This approach conservatively neglects the additional soil/building interface area contributed by this portion of the reactor building. The mass and stiffness properties of the internal walls were modeled by a vertical beam connected to the silo at the appropriate points. The NSSS model is included in the SASSI model. A summary of this NSSS model is shown in Figure $3.7-5$ and the complete SASSI NSSS model is shown in Figure 3.7-6.

\subsubsection{Development of Floor Response Spectra}

The SASSI analysis results in floor response spectra at selected nodes identified in the mathematical model. The floor response spectra are converted into design response spectra by a smoothing and broadening process to eliminate valleys and various spectral fluctuations and by an enveloping process to obtain a single spectrum from those for the upper and lower bounds of soil moduli. This procedure is consistent with the methodology of Regulatory Gulde 1.122. (Ref. 7)

Variations of structural properties, damping, soll properties, and soil-structure interaction could shift the peak values of the floor response spectra on either side of the indicated frequency. To account for these variations, the peaks of the spectra obtained from the analysis are widened by plus or minus 10 percent. 
Separate response curves are obtained at each node for each soil case calculated. A single spectrum is developed at each node for several damping values which envelop the range of soil cases considered. This is done to simplify the analysis and qualification of systems and components which must fulfill, with a high degree of confidence, their 10CFR100-related radionuclide control functions under design basis conditions. Where this procedure is found to be too conservative, however, the response spectra for individual soils may be used.

In addition, the SASSI analysis produced time histories at selected nodes in the NSSS.

\subsubsection{Interaction of Structures}

Those structures or other items which need not serve to ensure the continued functionality of systems or components to meet the limits of 10CFR100 but are connected to, supported by or adjacent to structures which do serve to ensure such continued functionality are analyzed for SSE loadings to assure that they do not fail in such a way as to prevent the latter facilities from performing their required functions.

\subsubsection{Torsional Effects}

In the three-dimensional finite-element analysis of below-grade structures which must serve to ensure, with a high degree of confidence, that systems or components they house can fulfill 10CFR100-related radionuclide control functions under design basis conditions torsional effects are inherently accounted for in the analysis so no artificial torsional loads will be imposed.

In the analysis of structures founded at grade, however, torsional effects are considered as they are in LWR design practice. 


\subsubsection{System Seismic Analysis}

3.7.3.1 Analysis/Qualification by Test of Mechanical and Electrical Components

3.7.3.1.1 General

The system or component is analyzed using the seismic input (floor response spectra or time histories) derived at the particular points of support on the structure. Only the significant modes of the mathematical model which contribute to the total combined modal response of the system are included in the analysis. The number of significant modes is determined such that inclusion of additional modes will not result in more than a 10 percent increase in total response. Where the response spectrum method is used, the individual modal responses are combined by the square root of the sum of the squares (SRSS), except for closely spaced modes (frequencies less than about 10 percent apart), where the modal responses are combined by the absolute sum. This analysis is performed independently in each of the two horizontal directions and in the vertical direction. The total response from either time history or response spectra analysis is obtained by taking the SRSS of the representative maximum values of each of the three directions. The total response is compared with allowable values. This is consistent with Regulatory Guide 1.92. (Ref. 8)

3.7.3.1.2 Steam Generator Isolation Valves and Primary Coolant Pressure Relief Valves

The steam generator isolation valves and primary coolant pressure relief valves must perform their mechanical motion during and after a seismic event. A qualification program consistent with Regulatory Guide 1.148 and comprising qualification tests and/or analyses of these valves assures operability during and after a seismic event.

The operability of the valves is assured through an extensive program of design verification, qualification testing, and thorough survelllance of the manufacturing, assembly, and shop testing of each active component. Each 
aspect of the design related to pressure boundary integrity and operability is either tested or verified by calculations. Test methods and test requirements are consistent with the provisions of IEEE Standard 344-1975. (Ref. 9) The design analyses of the component take into consideration all environmental conditions, including loadings developed from seismic, operational effects, and pipe loads. If necessary, the conclusions of these analyses will be confirmed by test.

Procurement specifications for the valves stipulate that vendor shall submit either detailed calculations and/or test data to demonstrate operability when subjected to seismic excitation. The decision to accept actual or prototype test data or analysis for operability assurance is made during the normal design and procurement process. The decision to test is based on (1) whether the component is amenable to analysis, (2) whether proven analytical methods are available, and (3) whether applicable prototype test data are available. If analysis or prototype test data are not sufficient, testing will be conducted to qualify the component or to verify the analytical technique. The valves shall be designed to have a first natural frequency which is greater than $33 \mathrm{~Hz}$. This is shown by suitable test or analysis.

An analysis of the extended valve structure is also performed for static equivalent seismic SSE loads applied at the center of gravity of the extended structure.

Where appropriate, valve stem deflection calculations are performed to determine deflections due to short term seismic loadings. Deflections so determined are compared to allowable clearances. It must be noted that seismic events are of short duration; thus, contact (if it occurs) does not necessarily mean that operability is adversely affected.

\subsection{Plant Protection and Instrumentation System}

The Safety Protection Subsystem of the Plant Protection and Instrumentation System (PPIS) is that portion of the PPIS which performs 10CFR100-related functions. It includes the reactor trip instrumentation hardware and associated system sensors which are used to detect abnormalities in the plant 
process variables. The reactor trip instrumentation activates either the outer bank of control rod assemblies or the reserve shutdown control equipment (RSCE) in response to sensor trip parameters. In addition, the main loop shutdown trip closes the steam generator isolation valves and opens the main circulator breakers. The sensors include the ex-core neutron flux detectors located outside the reactor vessel, primary coolant pressure transducers at the core inlet and outlet, resistance temperature detector (RTD) at the circulator outlet, and circulator speed probe. A detailed description of this equipment is given in Section 7.2.1.

The reactor trip and main loop shutdown instrumentation hardware and sensors are designed to withstand the forces imposed by the OBE and SSE so as to remain functional during and after either earthquake. System failures which could result in loss of function are identified as follows:

1. Loss of capability to de-energize the breakers to trip the control rods and main circulator, and to close the steam generator isolation valves

2. Loss of capability to energize the fusible links to dump the reserve shutdown control (RSC) material

3. Sensor mechanical failure

Seismic qualification testing of this equipment to assure no loss of function is performed on a basis consistent with provisions of IEEE Standard 344-1975. (Ref. 9)

3.7.3.2 Piping Analysis, Air Panel and Duct Analysis, Electrical Raceway Analysis

For these items, the procedures and criteria used for seismic analysis are comparable to those committed to in recent LWR Final Safety Analysis Reports (FSARs). 


\subsubsection{Buried Pipe and Tunnels}

For these items, the procedures and criteria used for seismic analysis are comparable to those committed to in recent LWR FSARs.

\subsubsection{Analysis of Reactor System}

The Reactor System, including the core and its support components, and portions of the the neutron control systems must perform, with a high degree of confidence, 10CFR100-related radionuclide control functions under design basis conditions. Since the seismically induced forces on these components from an OBE or an SSE could potentially affect the safe operation and safe shutdown of the reactor, the criteria and methods described below are aimed at providing assurance that these components can be adequately designed to assure their continued functionality during and after these events.

\subsection{Reactor Core and Core Supports}

The scope of the reactor core analysis includes the fuel elements, plenum elements, inner and outer reflector elements, permanent side reflector, core support posts, core metallic support structure and core barrel lateral restraint structure.

The approach to verifying the design adequacy of the core and the core support structures is based on a combination of analysis and testing. It includes the development of analytical methods and a validation of those methods through correlation with model test data. Analysis and testing of core components are also performed to establish their structural strength capacity. Application of this data will, in combination with design conditions other than seismic, demonstrate the compliance with all design and licensing requirements.

Since the Standard MHTGR core design has evolved from past prismatic designs (the fuel elements are identical to the Fort St. Vrain fuel elements except that four dowels are employed instead of three and the graphite grade is $\mathrm{H}-451$ instead of $\mathrm{H}-327$ ), the design data generated in the past can be 
employed to a considerable extent. This includes computer codes and data developed from the core seismic program initlated for the $3000 \mathrm{MW}(t)$ Summit plant and concluded during the $2240 \mathrm{MW}(t)$ steam cycle/cogeneration project.

The design of HTGR cores is unique in the sense that conventional analytical methods and code standards are not readily applicable. The core represents analytically a structure with dominant nonlinear features caused by clearances between fuel elements which tend to become larger with element residence time due to irradiation shrinkage of graphite. Other non-linearities are the structural discontinuity of stacking the elements on top of each other and the clearances in the dowel/socket links which provide vertical alignment of the elements in a column. These non-linearities also exist in the permanent reflector structure. Subjected to seismic disturbances, the core elements, therefore, are free to displace laterally by the amount of the accumulated clearances. This can cause the elements to impact each other. Since the core is not restrained vertically, the elements can also levitate if subjected to high vertical acceleration levels.

The structural integrity of the core and the support structures is required to be maintained for the OBE and SSE events. At and below the OBE level, normal reactor operation should be able to be maintained during the earthquake or resumed after shutdown and inspection. Up to the SSE level, however, the ability to insert control rods into the replaceable reflector columns or reserve shutdown material into the innermost fuel columns during or after the earthquake must be maintained. The structural failure modes which could cause these requirements not to be satisfied have been identified as follows:

1. Fuel element and replaceable reflector element fracture and separation into pieces

2. Failure of fuel element or replaceable reflector element dowels causing vertical misalignment

3. Failure of core support posts causing collapse of core 
HTGR $-86-024$

4. Vertical separation (levitation) of fuel elements or replaceable reflector elements from the dowels causing vertical misalignment

5. Failure of the metallic core support structure causing core collapse

6. Failure of core barrel seismic keys causing excessive core deflections

To adequately demonstrate that the failures listed above are very unlikely, stress criteria consistent with ASME III, Div. 1, subsection NG for steel structures and ASME III, Div. 2 for the permanent side reflector and core support graphite govern their design. (Ref. 10) For the fuel and replaceable reflector element graphite, stress criteria currently under development will govern.

The development of these stress criteria for graphite is based on probabilistic considerations and includes a damage model which equates damage (failure) with the inability of the graphite component to accommodate safe shutdown by insertion of control rods or RSC material. Based on the risk contributions from graphite damage to the overall plant risk envelope, reliability allocations for the structural components are obtained. These allocations are then expressed in terms of non-probabilistic structural requirements such as stress-to-strength limits.

The seismic analysis of the core is performed with the two-dimensional special purpose computer codes $\mathrm{CRUNCH}-2 \mathrm{D}$ and $\mathrm{MCOCO}$, which account for the non-Iinearities in the structural design. Both CRUNCH-2D and MCOCO are based on the use of lumped masses and inertia concepts. A core element, therefore, is treated as a rigid body while the element flexibilities are input as discrete springs and dampers at the corners of the element. CRUNCH-2D models a horizontal layer of the core and the core barrel structures (Figure 3.7-7). The model is one element deep and can represent a section of the core at any elevation. MCOCO models a strip of columns in a vertical plane along a core diameter and includes column support posts and core barrel structures (Figure 3.7-8). The strip has a width equal to the width of a permanent reflector block. Both models extend out to the reactor vessel, 
which is considered rigid. Time history motion is input to the models at the rigid boundary. The models calculate core element relative horizontal and vertical displacements, impact forces, dowel forces, and core support forces. The combined use of the two-dimensional horizontal and vertical models and accounting for biaxiality effects provides the core response in three dimensions.

Seismic stresses in the hexagonal fuel elements and reflector elements are obtained from the two-dimensional finite-element code TWOD using the maximum equivalent static element loads from CRUNCH-2D and MCOCO as input. The peak stress-to-strength ratio for the element is calculated and added to the peak stress-to-strength ratios for thermal and irradiation induced loads to obtain the maximum combined stress to strength ratio. This provides a conservative estimate of margin to failure.

To provide adequate verification of the Standard MHTGR core design, the current data base will be supplemented with several tests. The core element impact load predictions from CRUNCH-2D and MCOCO will be validated with data from seismic tests on a small array of full-scale fuel elements and replaceable reflector elements. The elements will be tested to failure by applying an artificial earthquake at increasing intensities. The structural integrity of the elements will be observed as cracking or other structural damage takes place. Dynamic strength tests on single fuel elements will also be performed to determine crack progression to failure and the failure load. For this purpose, virgin fuel elements and irradiated fuel elements with residual stresses from extended exposure to temperature and fluences representing Standard MHTGR core conditions will be tested by simulating actual earthquake loadings on the elements. The results aim to validate the dynamic strength predictions made with the TWOD static finite-element code and the assumption that the seismic and thermal/irradiation induced stresses can be linearly combined.

\subsection{Neutron Control Subsystem}

The seismic qualification of the Neutron Control Subsystem includes the control rod assemblies and the reserve shutdown control equipment (RSCE) assemblies and their associated electrical controls. 
The design of this equipment, which is described in detail in sections 4.3.4.2 and 4.3.4.3, has several seismic features. The control rod and reserve shutdown control assemblies, located in penetrations in the top head of the reactor vessel, are seismically supported by a skirt structure off the reactor vessel head. Guide tubes between the penetrations and the core provide guidance for the rods during insertion and withdrawal from the core. Similar guide tubes funnel the shutdown material into separate core channels. The control equipment for initiating reactor trip or RSE activation is mounted in the Reactor Building of the associated reactor module. Following receipt of a trip signal, the control rods fall by gravity into the core, where the downward motion is slowed by dynamic braking through the torque motor. The reserve shutdown pellets are dumped into the core by breaking the fusible links holding the RSE hopper gate shut.

It is required that the structural integrity and the safe shutdown functions of the neutron control assemblies are maintained for the OBE and SSE events. At the $O B E$ level, the neutron control assemblies must be able to perform their safety function. Additionally, the ability to perform their power generation function during and after the earthquake should also be maintained. Their operation must be unaffected by any credible misalignment of the core control channels due to core deflections as a result of the seismic disturbance. A maximum misalignment of $7.6 \mathrm{~cm}$ (3 in) is allowed. At the SSE level, the neutron control assemblies must retain their safety function during and after the earthquake. The failure modes which could cause the seismic requirements not to be satisfied are identified as follows:

1. Control rod assembly -.

a. Drive mechanism mechanical or electrical failure

b. Rod binding in the core channel causing delay in rod insertion time

c. Rod structural failures due to impact 
d. Guide tube displacement or failure causing vertical misalignment with the core control channel

e. Fallure of penetration support structure

2. Reserve shutdown control equipment assembly --

a. Hopper gate mechanism mechanical or electrical failure

b. Guide tube displacement or failure causing vertical misalignment with the core control channel

c. Failure of penetration support structure

Analyses to determine the structural adequacy of the penetration support structure and the control rod components are performed. In addition, qualification tests on control rod and reserve shutdown assembly prototypes in a test rig, which simulates the penetration support structure and the reactor core, are undertaken to demonstrate the required performance in a seismic environment.

The electrical panels associated with the safe shutdown function of the Neutron Control Subsystem control equipment will be seismically qualified by test. (Ref. 9)

\subsubsection{Analysis of Vessels and Supports}

The Vessel System, including the support subsystem, is analyzed using the NSSS finite-element model and response spectra input generated by the plant seismic analysis discussed in section 3.7.2. This three-dimensional finite-element model is based on the Vessel System arrangement and is shown in Figure 3.7-6. The analysis is performed using the ANSYS computer code and the analysis procedures discussed in Section 3.7.3.1.1. (Ref. 11)

In the finite-element model, each component is represented by a series of beam-like structural elements with occasional use of lumped-mass or spring 
elements. Each beam element is defined by the coordinates of its endpoints, its cross-sectional area, moment of inertia and elastic material properties. The values are specified constants based on the nominal dimensions and material properties of the components. The material properties are dependent on the component temperature and are assumed constant over the life of the plant; material degradation during the life of the plant is accounted for in the detailed stress analysis of the component using the seismic responses generated by this analysis.

In this Vessel System model, the uniform masses of the elements are concentrated at a series of mass points or nodes. The nodes are selected at changes of sections, locations of component support, or at intermediate locations to limit the length of the elements so that the model will adequately represent the actual system. The total number of mass points is taken to be equal to at least twice the number of modes with frequencies less than $33 \mathrm{~Hz}$.

The local shell flexibilities at the vessel support points are accounted for by modeling dummy beam elements at the shell-to-support interface. These dummy beams have stiffness properties which reflect the shell flexibility at the interface. This flexibility at the interface is determined by either a finite-element analysis of the interface region or by the procedure described in Reference 12.

Further detailed finite-element modeling and analysis are performed to determine vessel stresses at critical locations such as the vessel/support interfaces and vessel/crossduct intersections. The seismic response loads from the NSSS model are used as input to these models.

\subsubsection{Analysis of Steam Generator Components}

A three-dimensional finite-element model of the steam generator is generated using the ANSYS computer program. Taking advantage of symmetry, a one-half ( $180^{\circ}$ section) of the geometry is modeled. Shell elements are used to model the shrouds and the radial tube support plates. The helical tubes are treated as circular rings due to the small helix angle and modeled by beam 
elements. A lumped tube system with equivalent cross-sectional properties is used in the mode1. This equivalent model is considered appropriate for preconceptual design. The radial and vertical displacements of the elements representing the tubes are coupled with the respective displacements of the radial support plates at the locations of intersection. The contact interaction between the radial support plates and the shrouds is modeled by the uniaxial gap elements. The seismic input to the steam generator is derived from the analysis of the NSSS model (Figure 3.7-4).

\section{7 .4 Seismic Instrumentation}

The seismic instrumentation program (see Section 7.4.3) is consistent with the Regulatory Guide 1.12, Rev. 1, except for the items listed below: (Ref. 13)

1. Response spectrum recorders are not supplied as discrete instruments. A permanently installed response spectrum analyzer provides more complete information than that provided by response spectrum recorders. Data from the strong motion accelerometers are fed into the response spectrum analyzer to produce earthquake spectra immediately following an earthquake. The response spectrum analyzer is located in the Reactor Service Building with readout both there and in the Control Room. This system achieves the intent of Regulatory Guide 1.12, Revision 1. (Ref. 13)

2. Instruments are located at the top and bottom levels of the Reactor Building similar to those required by Regulatory Guide 1.12 at the base and operating floor of the containment building of an LWR. (Ref. 13) The first two Reactor Buildings on a site will be instrumented to allow for one set of instruments being out of service. Instruments are also located at the base level and grade level of the Reactor Service Building and in the free field.

The remainder of the seismic sensing instrumentation is located on a basis consistent with the intent of the regulatory position of Regulatory Guide 1.12 which acknowledges the basic differences in characteristics between the MHTGR and LWRs. 


\subsubsection{Results of Seismic Analyses}

Initial seismic analyses have been performed for the Reactor Building, the Vessel system including supports, and the reactor core and internal structure using the methodology described in Sections 3.7.1 through 3.7.3. Results indicate that these key elements in the Standard MHTGR design will have acceptable stresses or otherwise perform their required functions when subjected to the SSE. Based on these results, it is anticipated that the Standard MHTGR can be demonstrated to perform the four radionuclide control functions given in Section 3.2 during seismic events up to and including the SSE.

\subsubsection{Reactor Building}

Figures 3.7-9, 3.7-10 and 3.7-11 compare spectra at three selected nodes at the NSSS/building interface with the free field input spectra. The spectra in these three figures are in the horizontal direction perpendicular to the cros: duct (tangent to the vessels). Although the NSSS/building interface spectra consider codirectional responses from all three input directions, the less significant input spectra in the horizontal direction parallel to the cross duct and in the vertical direction are not plotted for clarity. All spectra on these figures are at the two percent damping level. These plots show that the embedded reactor building approach used for the MHTGR results in very low levels of seismic amplification at the NSSS supports as compared to buildings founded at or near grade.

An assessment of the structural adequacy of the Reactor Building was performed. The structural code used was ACI 349 modified in accordance with Section 3.8 of the PSID to be consistent with Regulatory Guide 1.142. (Ref. 14) The loads considered were:

- Static earth plus groundwater pressure

- Dead Weight

- Seismic loads from the SASSI analysis. The envelope loads from the three representative sites were used. 
HTGR $-86-024$

These loads with the appropriate ACI 349 load factors were applied to a separate finite element model of the Reactor Building and the following maximum membrane shear stress and moments resulted:

- Membrane shear $117 \mathrm{MT} / \mathrm{m} 2(24 \mathrm{k} / \mathrm{ft} 2)$

- Meridian moment $279 \mathrm{MT}-\mathrm{m} / \mathrm{m}(616 \mathrm{k}-\mathrm{ft} / \mathrm{ft})$

- Circumferential moment $148 \mathrm{MT}-\mathrm{m} / \mathrm{m}(326 \mathrm{k}-\mathrm{ft} / \mathrm{ft})$

These stresses and moments resulted in the following reinforcing densities:

- Maximum $208 \mathrm{~kg} / \mathrm{m} 3(351 \mathrm{Ib} / \mathrm{yd} 3)$

- Typical $95 \mathrm{~kg} / \mathrm{m} 3(1601 \mathrm{~b} / \mathrm{yd} 3)$

These reinforcing densities are within the code maximum/minimum limits and are very reasonable for this structure.

This preliminary analysis demonstrates that the MHTGR embedded reactor building as designed is structurally adequate when sited on 85 percent of the prospective U.S. sites during the SRDC 5 event of interest. 
HTGR - $86-024$

REFERENCES - SECTION 3.7

1. U.S. Nuclear Regulatory Commission. Design Response Spectra for Seismic Design of Nuclear Power Plants. Regulatory Guide 1.60, Revision 1. Washington, DC, December 1973.

2. U.S. Nuclear Regulatory Commission. Proceedings of the Workshop on Soil-Structure Interaction. Bethesda, Maryland, June 16-18, 1986. NUREG/CP-0054 BNL-NUREG-52011, Washington, DC, 1986.

3. U.S. Nuclear Regulatory Commission. Damping Values for Seismic Design of Nuclear Power Plants. Regulatory Guide 1.61, Washington, $D C$, October 1973.

4. U.S. Nuclear Regulatory Commission. Standard Review Plan for the Review of Safety Analysis Reports for Nuclear Power Plants, IWR Edition. NUREG-0800, Rev. 4. Springfield, VA, July 1981.

5. Bechtel Power Corporation (BPC). Bechtel Topical Report: Seismic Analysis of Structures and Equipment for Nuclear Power Plants. BC-TOP-4, Rev. 3, BPC, San Francisco, CA 1974.

6. Lysmer, J.; Tabatabaie, M.; Tajirian, F.; Vahdani, S.; and Ostadan, F. SASSI - - A System for Analysis of Soil-Structure Interaction. Report No. UCB/GT/81-02. Geotechnical Engineering, Dept. of Civil Engineering, University of California, Berkeley, Apri1 1981.

7. U.S. Nuclear Regulatory Commission. Development of Floor Design Response Spectra for Seismic Design of Floor-Supported Equipment or Components. Regulatory Guide 1.122, Revision 1, Washington, DC, February 1978.

8. U.S. Nuclear Regulatory Commission. Combining Model Responses and Spatial Components in Seismic Response Analysis. Regulatory Guide 1.92, Revision 1, Washington, DC, February 1976. 
HTGR - 86- 024

9. Institute of Electrical and Electronics Engineers (IEEE). IEEE Recommended Practices for Seismic Qualification of Class 1E Equipment for Nuclear Power Generating Stations. IEEE Standard 344-1975. IEEE, New York, NY, 1975.

10. American Society of Mechanical Engineers (ASME). Nuclear Power Plant Components. ASME Boiler and Pressure Vessel Code, Section III. ASME, New York, NY, 1985.

11. Swanson Analysis Systems, Inc. ANSYS Engineering Analysis System. Revision 4.1, Swanson Analysis Systems, Inc., Houston, PA, March 1, 1983.

12. Bijlaard, P. P. Stresses from Radial Loads in Cylfndrical Pressure Vessels. Welding Journal 33 (12), Research Supplement 615-S to 623-S (1954).

13. U.S. Nuclear Regulatory Commission. Instrumentation for Earthquakes. Regulatory Guide 1.12, Revision 1, Washington, DC, Apri1 1974.

14. U.S. Nuclear Regulatory Commission. Safety-Related Concrete Structures for Nuclear Power Plants (Other than Reactor Vessels and Containnents). Regulatory Guide 1.142, Revision 1, Washington, DC, November 1981. 


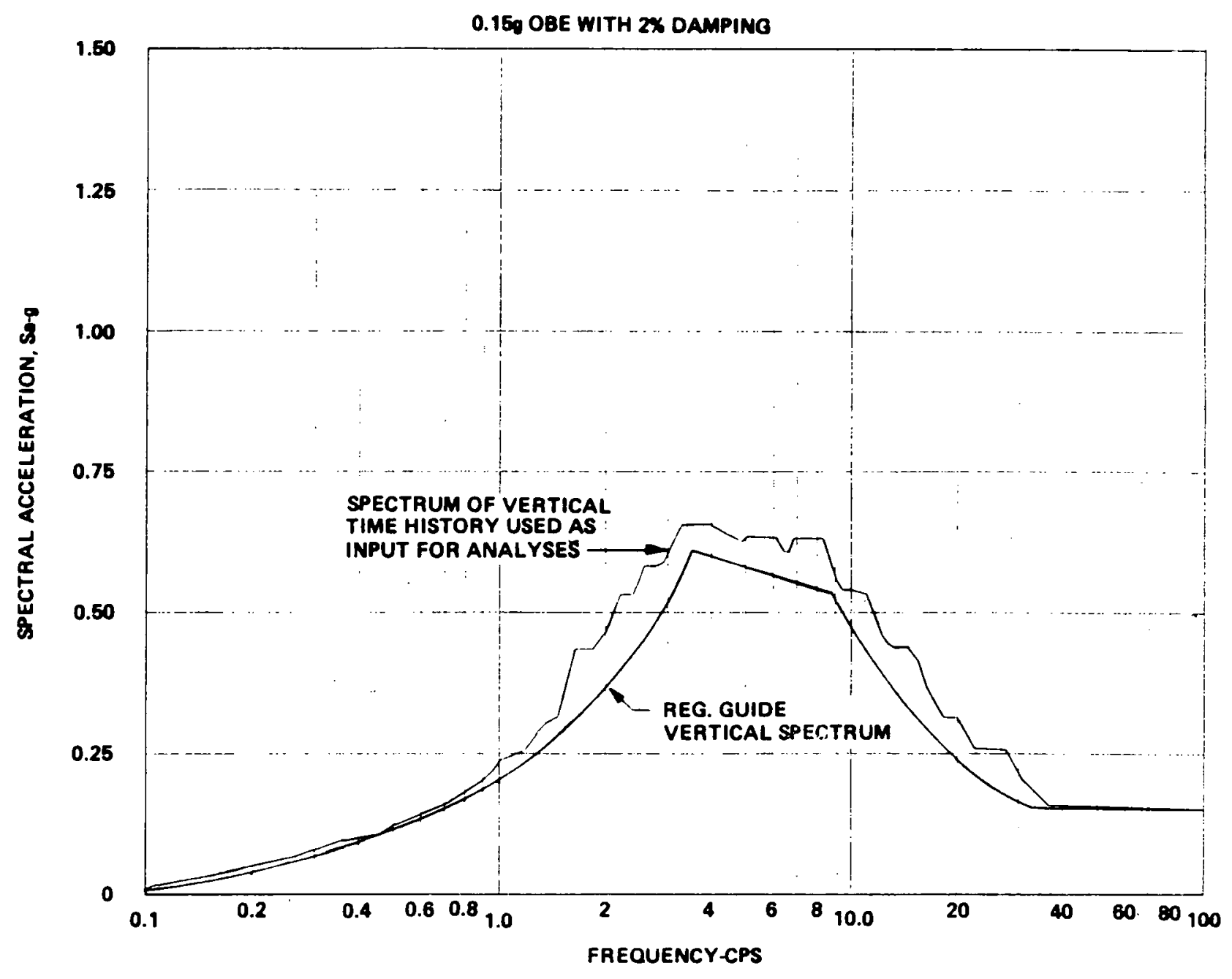

FIGURE $3.7-1$

COMPARISON OF VERTICAL

INPUT SPECTRUM WITH

REG. GUIDE 1.60 SPECTRUM

HICH TEMPERATURE GAS-COOED REACTOR

PREUUMINARY SAFETY INFORMATION DOCUMENT

HTGR-86-024 


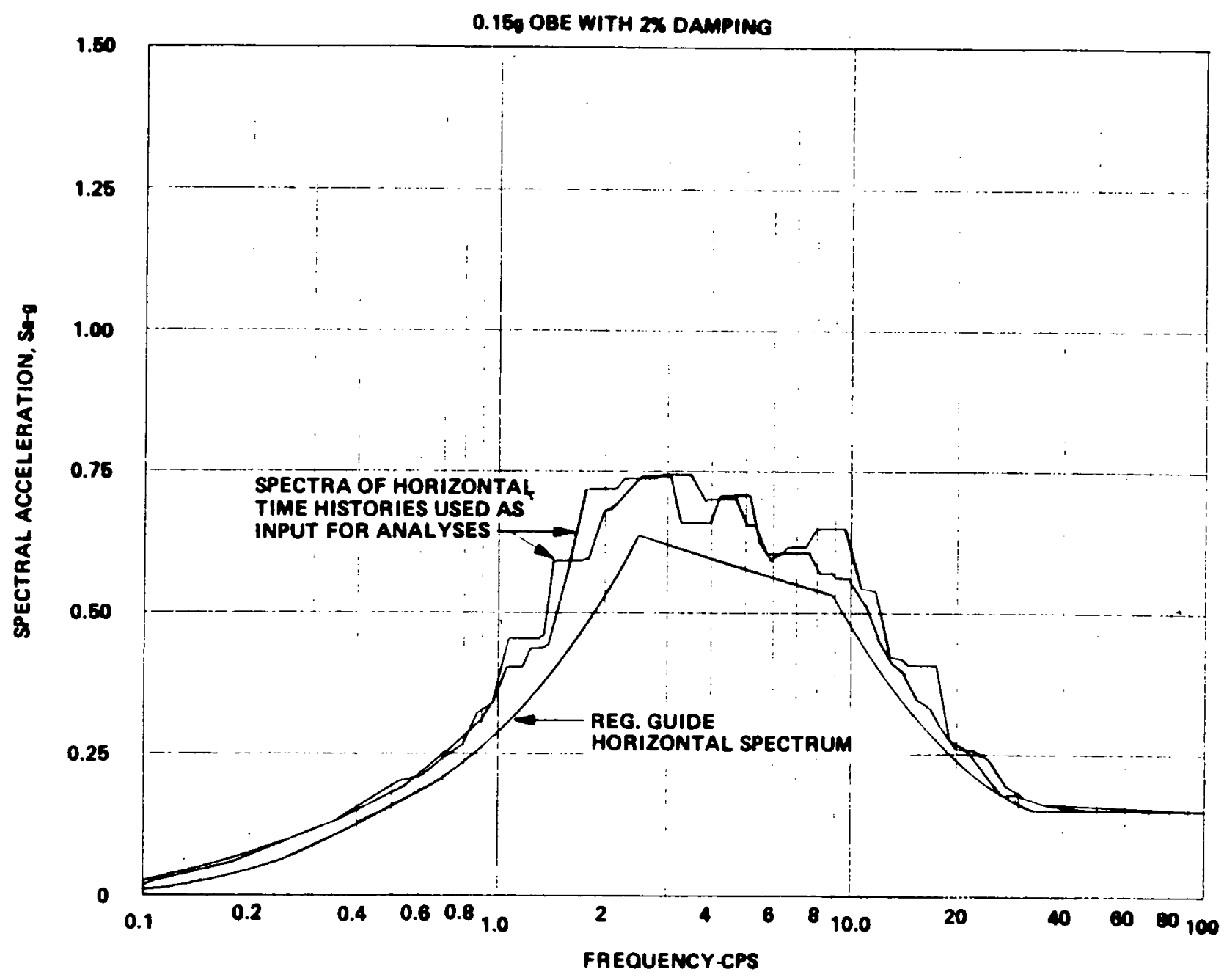

FIGURE 3.7-2

COMPARISON OF HORIZONTAL INPUT SPECTRA WITH

REG. GUIDE 1.60 SPECTRUM

HIGH TEMPERATURE GAS-COQLD REACTOR PREUMINARY SAFETY INFORMATION DOCUMENT HTER-88-024 


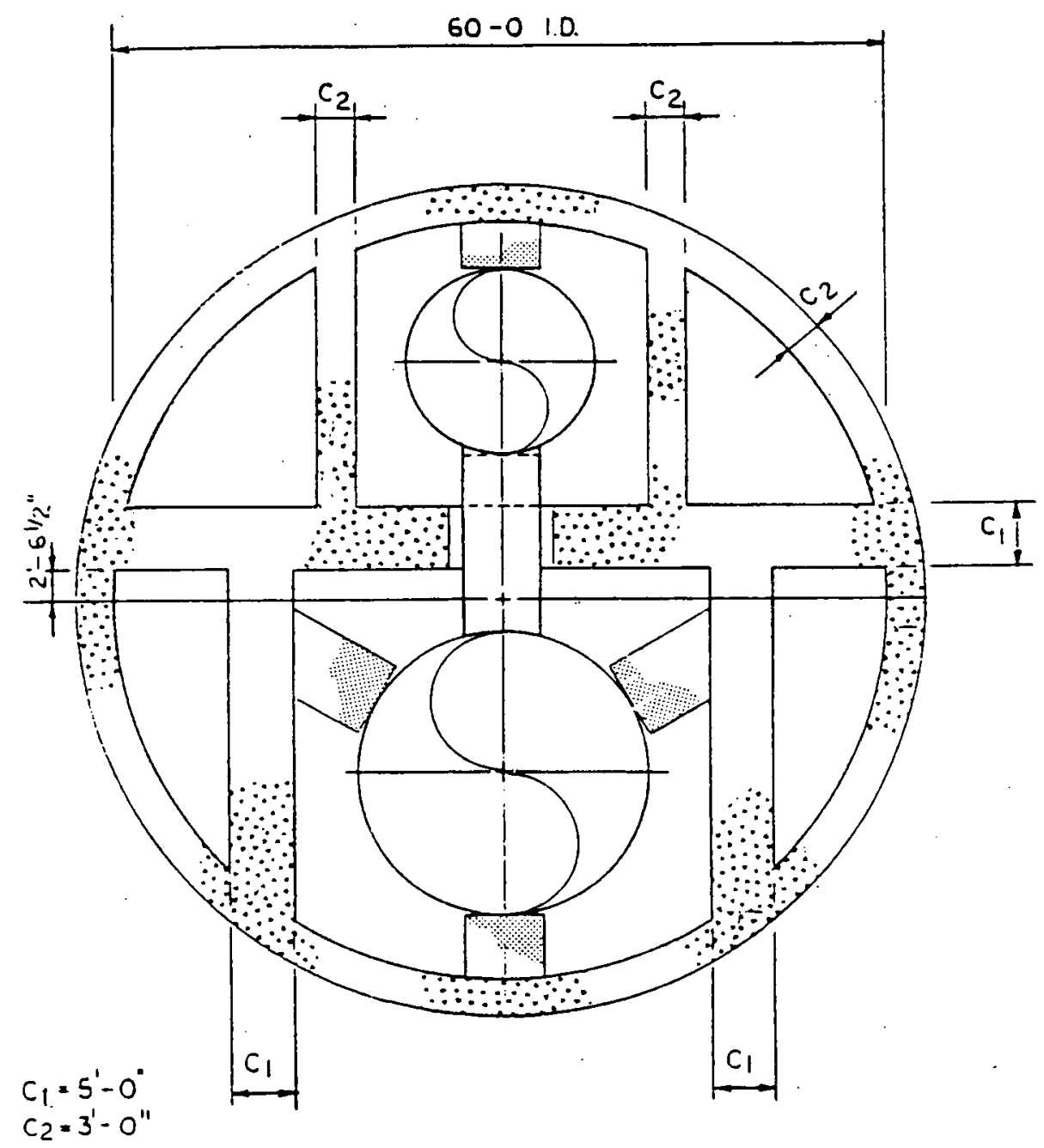

FIGURE 3.7-3

REACTOR BUILDING SILO CONFIGURATION UTILIZED IN SASSI ANALYSIS

HEY TEMPERATURE GAS-COOLED REACTOR PREUMINARY SAFETY INFORMATON DOCUMENT HTRR-80-024 


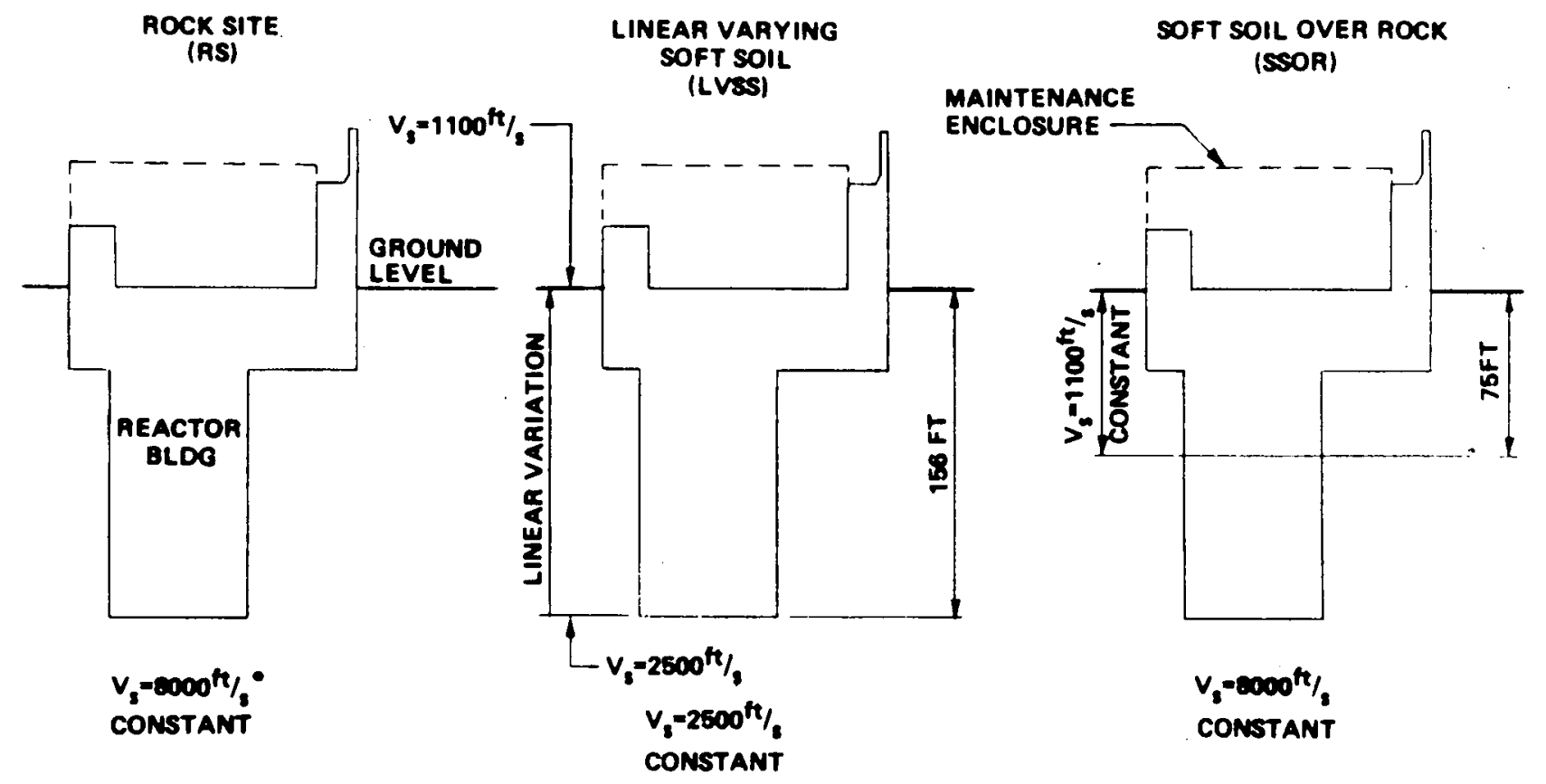

- SOIL ASSUMED INFINITELY RIGID 


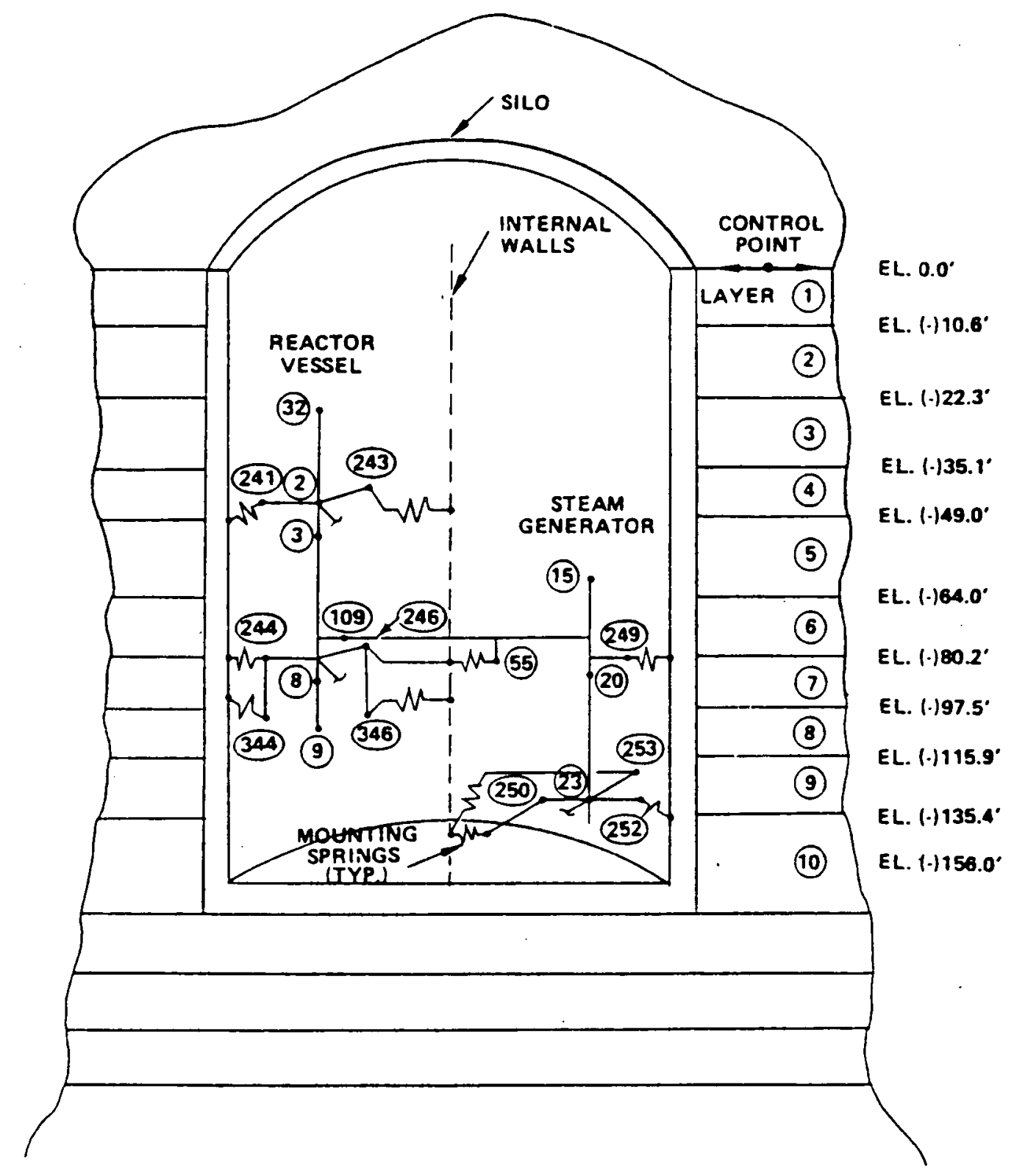

HALFSPACE

FIGURE 3.7-5

PRELIMINARY REACTOR BUILDING SOIL-STRUCTURE INTERACTION MODEL 


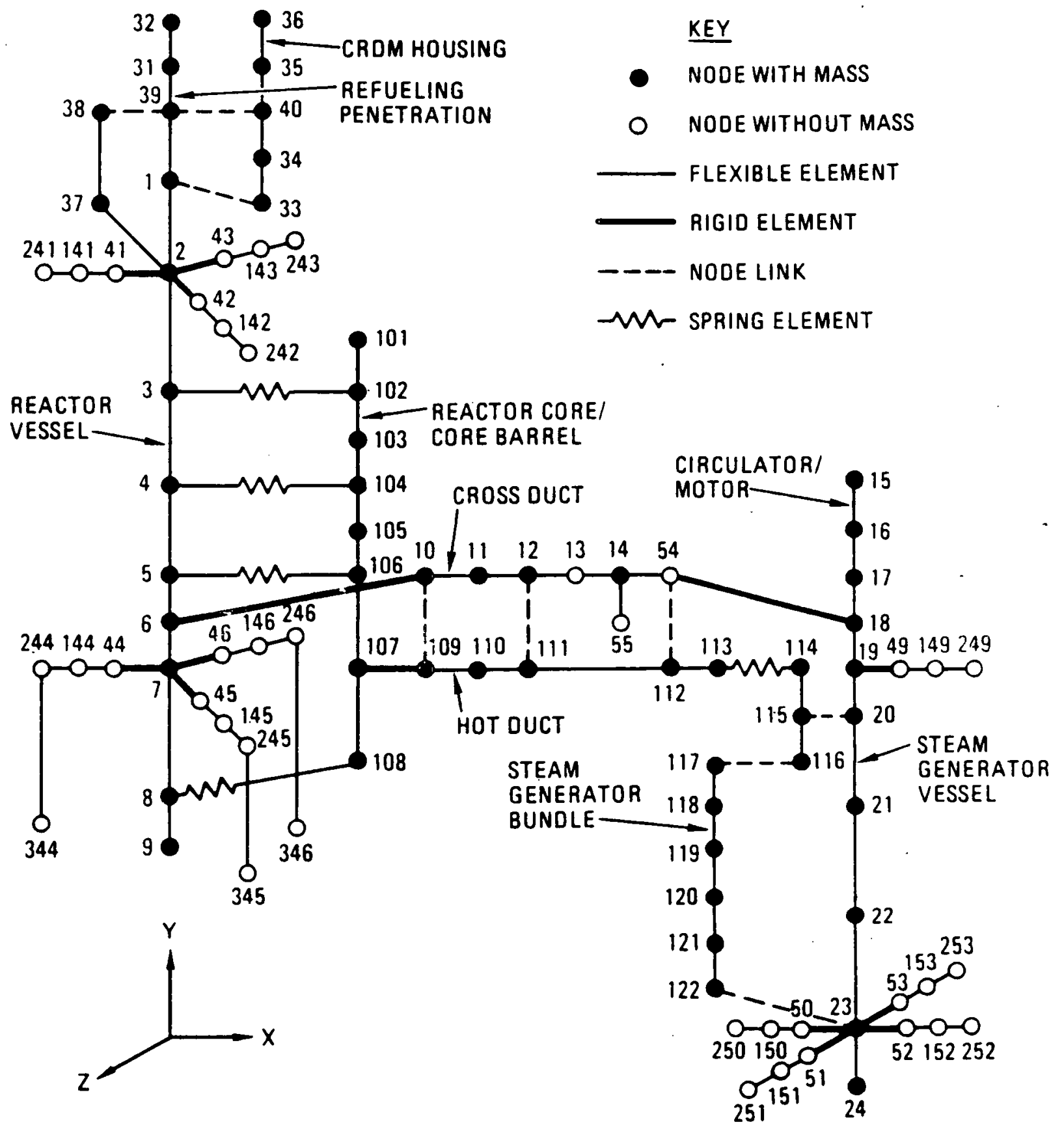

FIGURE $3.7-6$

NSSS FINITE ELEMENT MODEL 


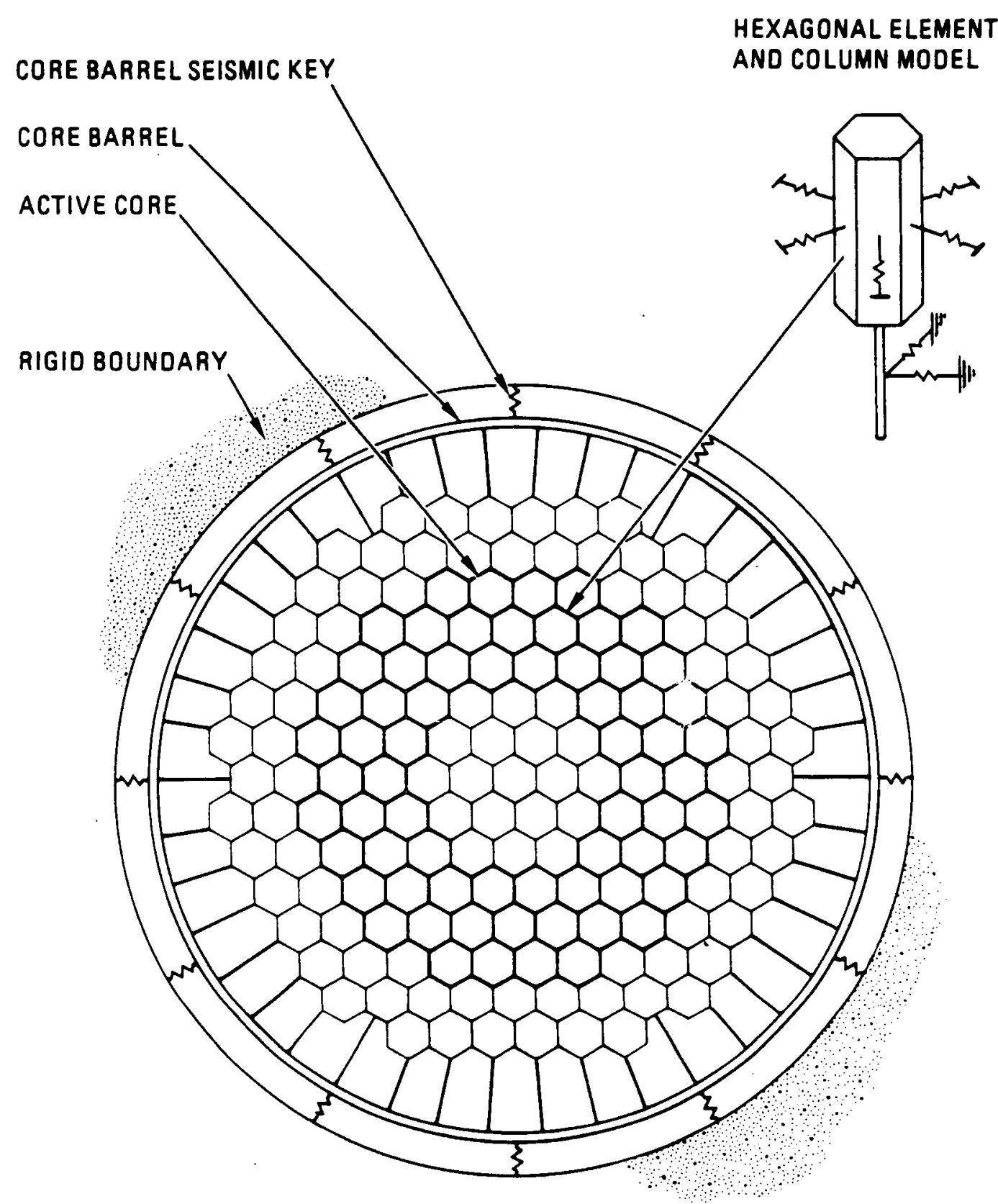

FIGURE 3.7-7

CRUNCH-2D MODEL 

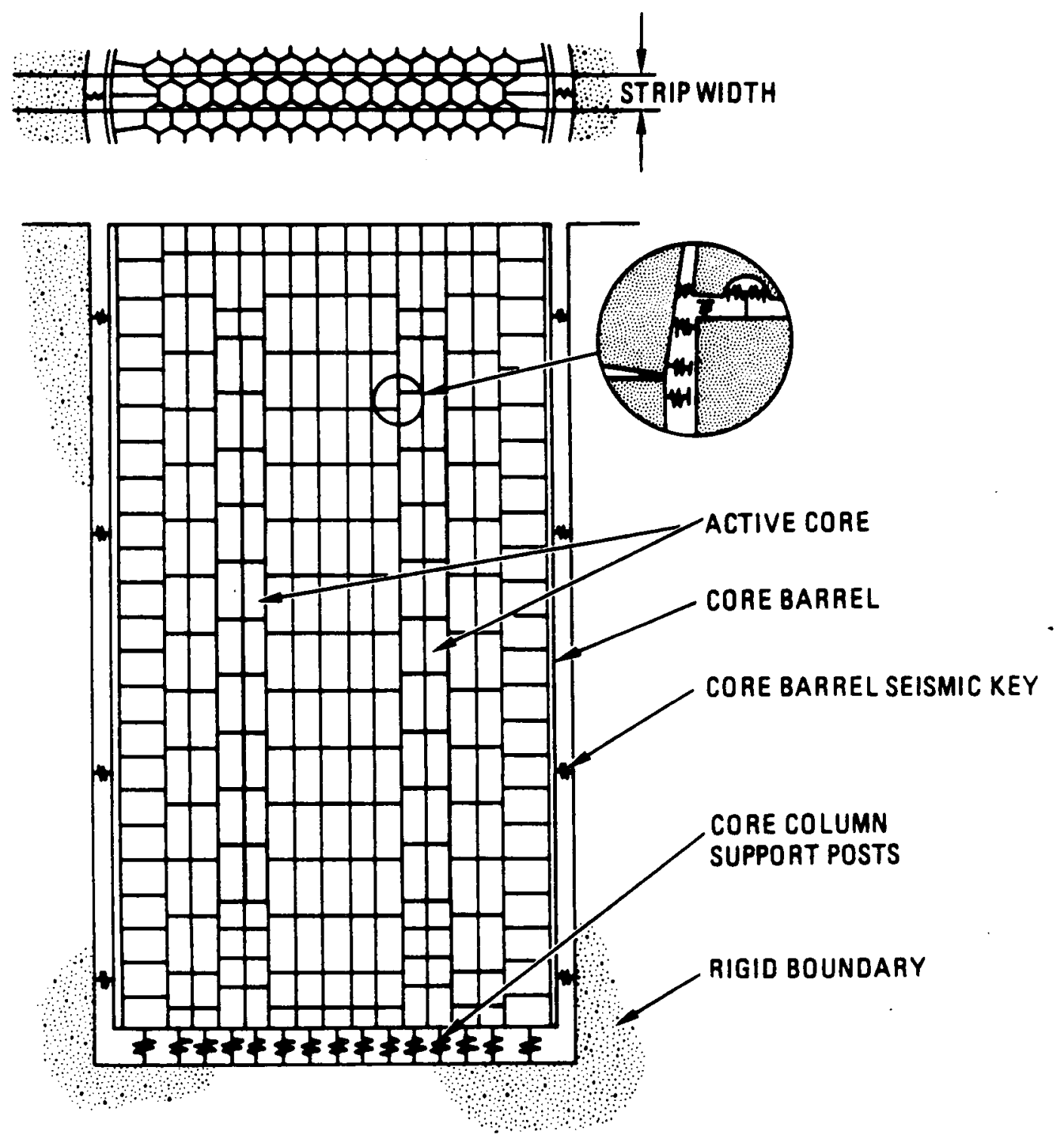

FIGURE 3.7-8

MCOCO MODEL 


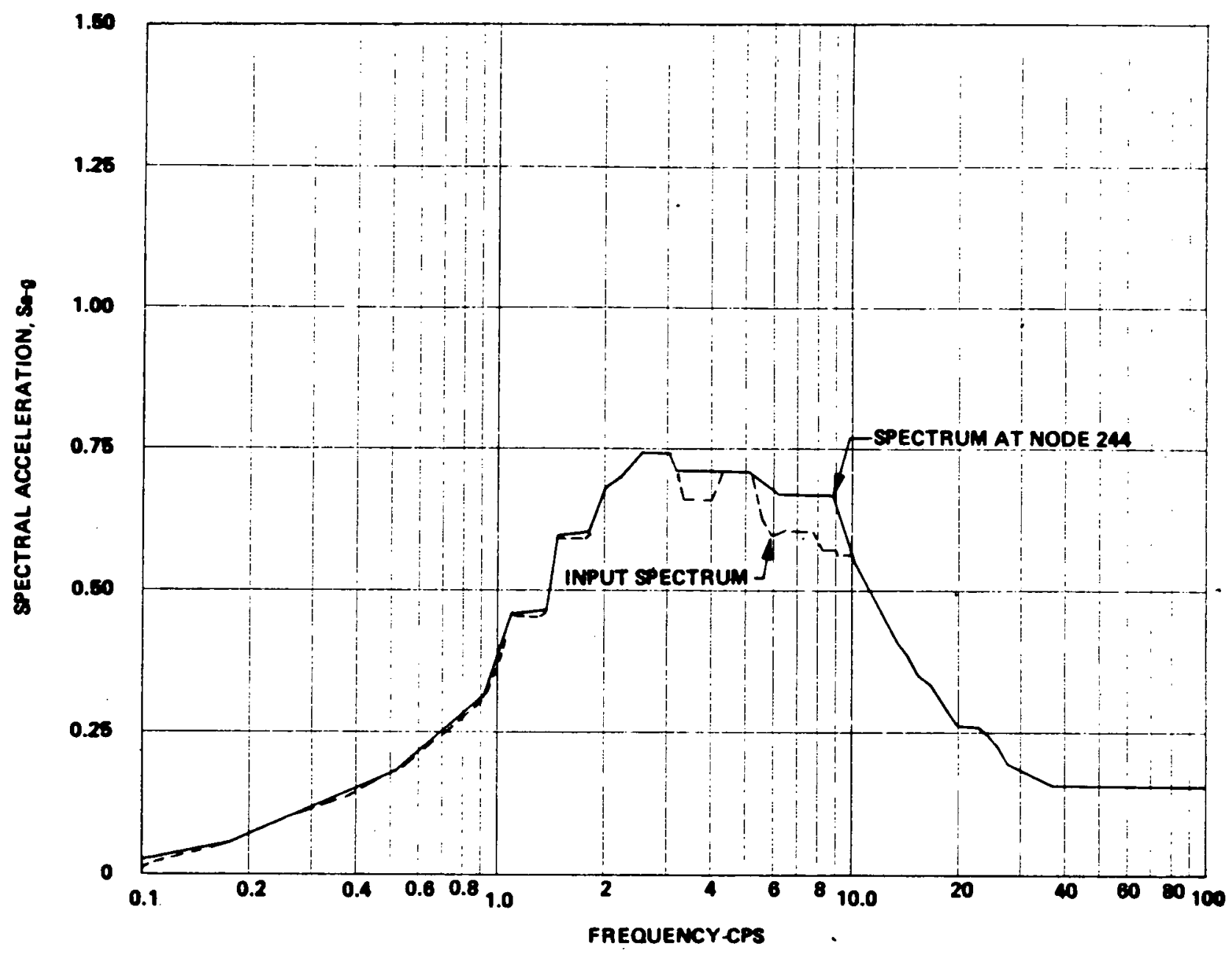

FIGURE 3.7-9

COMPARISON OF SPECTRUM AT LOWER REACTOR VESSEL SUPPORT (NODE 244) WITH INPUT SPECTRUM

HWG TEMPERATURE QAS-COOND REACTOR PREUMNNATY SAFETY INFCFOMATION DOCUMENT HTCR- 6024 


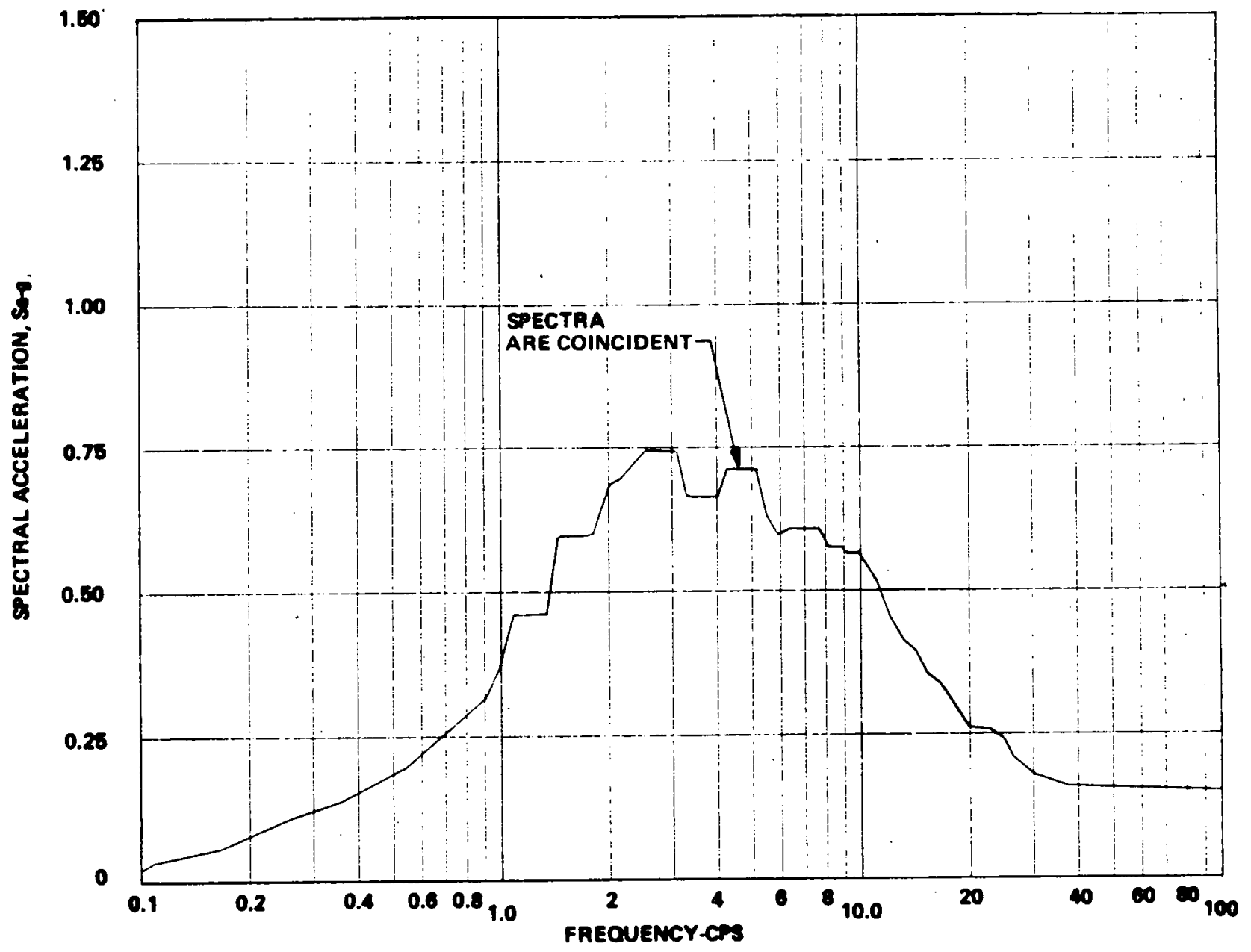

FIGURE $3.7-10$

COMPARISON OF SPECTRUM

AT LOWER STEAM GENERATOR

SUPPORT (NODE 252)

WITH INPUT SPECTRUM 


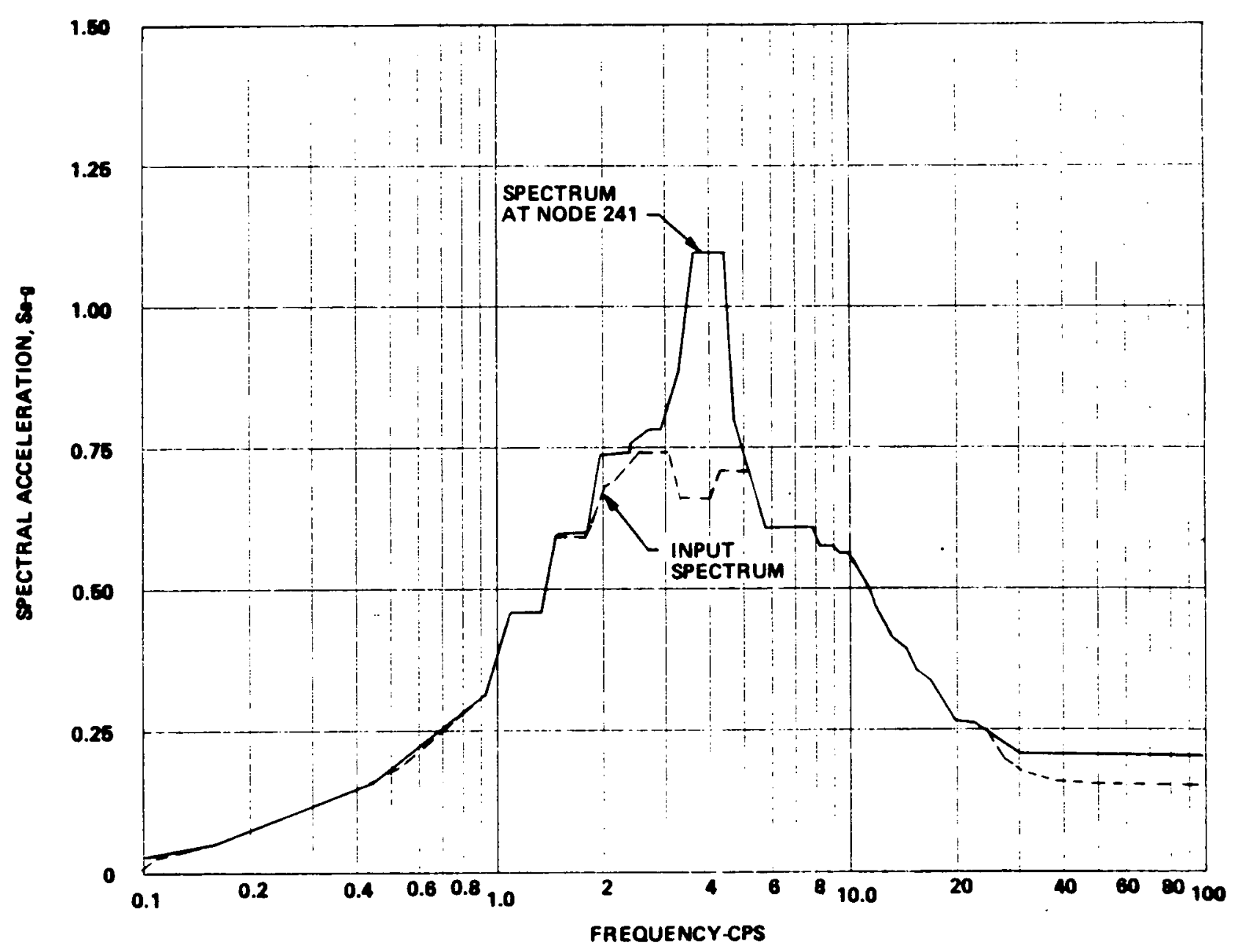

FIGURE 3.7-11

COMPARISON OF SPECTRUM

AT UPPER REACTOR VESSEL

SUPPORT (NODE 241)

WITH INPUT SPECTRUM

HIGH TEAPERATURE GAS-COOLD REACTOR

PREUMINARY SAFETY INFORMATION DOCUMENT

HTCR-86-024 


\subsection{DESIGN OF STRUCTURES}

The description of buildings and structures, including their function and classification, is given in Chapter 6 . This section describes the criteria to be applied to the design of structures which must serve to ensure, with a high level of confidence, that systems or components they house can fulfill their 10CFR100-related radionuclide control functions under design basis conditions in general. Chapter 6 gives its applicability to each facility described.

\subsubsection{Applicable Codes, Standards, and Specifications}

\subsubsection{Design Codes}

Buildings and structures which must serve to ensure that systems or components they house can fulfill 10CFR100-related radionuclide control functions under design basis conditions are currently designed and constructed in accordance with the applicable sections of the following codes :

1. ACI-349, American Concrete Institute, Code Requirements for Nuclear "Safety-Related" Concrete Structures

2. AISC-S326, American Institute of Steel Construction, Specification for the Design. Fabrication and Erection of Structural Steel for Buildings.

3. ASME-III, American Society of Mechanical Engineers, Boiler and Pressure Vessel Code, Section III, Division 1 Nuclear Power Plant Components

These codes are utilized because they presently provide the most reasonable, practical, and currently established methodology for the practical design of structures which serve to ensure, with a high degree of confidence, the continued functionality of systems or components they house under the conditions described in Sections 3.3 through 3.7. While the Integrated 
Approach is founded upon a mechanistic, probabilistic basis, as noted in Section 3.2.3.1 the means for assessing external hazards and their consequences on a purely probabilistic basis are only in the early stages of development. This includes a process for assessing the fragility of structures designed to various codes in response to seismic events of varying intensity. Should validated analytical methodologies consistent with the basic philosophy of the Integrated Approach be developed and found capable of providing results in which adequate confidence can be placed, these codes may be modified or other codes applied. In such an event, an appropriate amendment will be made to any licensing documents submitted to the NRC.

\subsubsection{Applicable NRC Regulatory Guides}

On the same basis as has been applied in the selection of design codes, the methodologies set forth in the following Regulatory Guides, as supplemented by current state-of-the-art design approaches, are applied to the design of the Standard MHTGR:

1. 1.60, Design Response Spectra for Seismic Design of Nuclear Power Plants

2. 1.61, Damping Values for Seismic Design of Nuclear Power Plants (Modified as specified in ASME Code Case N-411 and in Section $3.7 .1 .4)$

3. 1.92, Combined Modal Responses and Spatial Components in Seismic Response Analysis

4. 1.122, Development of Floor Design Response Spectra for Seismic Design of Floor-Supported Equipment or Components

5. 1.142, Safety-Related Concrete Structures for Nuclear Power Plants (Other than Reactor Vessels and Containments) (Regulatory Positions 6,10 , and 11 only) 


\subsubsection{Loads and Loading Combinations}

As a result of probabilistic analysis, different loads and load combinations may be specified.

\subsubsection{Loads}

The primary loads considered in the design of reinforced-concrete structures which must serve to ensure, with a high level of confidence, that systems or components they house can fulfill their 10CFR100-related radionuclide control functions under design basis conditions are as follows:

1. The dead load (D) includes the weight of the following:

a. The major reinforced concrete and structural steel structures. The unit weight of concrete of $2403 \mathrm{~kg} / \mathrm{m}^{3}\left(1501 \mathrm{~b} / \mathrm{ft}^{3}\right)$ is used.

b. All major equipment

c. An allowance of $2.39 \mathrm{kPa}\left(50 \mathrm{lb} / \mathrm{ft}^{2}\right)$ on floors, where applicable, to account for the load of small piping, electrical trays, small equipment, etc.

2. The live load (L) has the following characteristics:

a. For local structural design, the following live loads are applied:

$\begin{array}{lcc}\text { Ground floor } & 12.0 \mathrm{kPa} & (250 \mathrm{psf}) \\ \text { Concrete floors at } & 9.58 \mathrm{kPa} & (200 \mathrm{psf}) \\ \quad \text { elevations other than grade } & & \\ \text { Platforms and Grating } & 4.79 \mathrm{kPa} & (100 \mathrm{psf}) \\ \text { Stairs and walkways } & 4.79 \mathrm{kPa} & (100 \mathrm{psf}) \\ \text { Roofs (snow load) } & 2.39 \mathrm{kPa} & (50 \mathrm{psf})\end{array}$


b. For global structural design involving the entire structure (such as seismic), the live load considered will be those loads expected to be present during plant operation or during maintenance activities, depending on the function of a specific area. For example, the simultaneous presence of cranes and other mobile maintenance equipment as well as laydown loads will be considered only if consistent with predicted possible maintenance operations. Given the overall light occupancy of power plants, occupancy load need not be considered when investigating the behavior of a structure or a large portion thereof.

Seismic loads ( $E_{O}$ and $E_{S S}$ ) are from the operating basis earthquake (OBE). and the safe shutdown earthquake (SSE), respectively. These seismic loads are inertial forces corresponding to maximum accelerations at floor elevations given for a range of site conditions. Seismic loads are determined based on analysis as described in Section 3.7.

Thermal loads $\left(T_{0}\right.$ and $\left.T_{a}\right)$ and pressure loads $\left(P_{a}\right)$ will be determined later. $T_{0}$ is the operating thermal load on the structure, and $\mathrm{T}_{a}$ and $P_{a}$ are loads due to credible accident events.

Wind loads are given in Section 3.3.1.

Tornado loads $\left(w_{t}\right)$, including wind pressures, differential atmospheric pressures, and missile spectrum, are given in Sections 3.3 .2 and 3.5 .

\subsubsection{Loading Combinations}

Table 3.8-1 shows the load combinations specified in ACI 349 as modified by Regulatory Guide 1.142, Revision 1, Regulatory Position 6 (see Section 3.8.1). These load combinations are based on the strength design philosophy. As stated in Section 3.6, some of these load factors and load combinations are believed to be too conservative (load combinations 7 and 8 , 
for example) and are modified as shown in Table 3.8-1. Table 3.8-2 gives the definition of the symbols used in Tables 3.8-1.

Elastic working stress design methods as specified in Part 1 of the AISC Specification for the Design, Fabrication, and Erection of Structural Steel for Buildings (see Section 3.8.1.1.) are used for design of all steel structures which must serve to ensure, with a high degree of confidence, the continued functionality of certain systems and components under both service load and factored load conditions. (See Table 3.8-2 for the definition of symbols used in the following load combinations.)

For service loads, including earthquake (OBE) and wind loads (if applicable), the following AISC load combinations are satisfied:

$$
\begin{aligned}
& \text { 1. } S=D+L \\
& \text { 2. } S=D+L+E_{O} \\
& \text { 3. } S=D+L+W .
\end{aligned}
$$

If thermal stresses due to $T_{0}$ and $R_{0}$ are present, the following combinations are also satisfied:

$$
\begin{aligned}
& \text { 1(a). } 1.5 \mathrm{~S}=\mathrm{D}+\mathrm{L}+\mathrm{T}_{\mathrm{O}}+\mathrm{R}_{\mathrm{O}} \\
& \text { 2(a). } 1.5 \mathrm{~S}=\mathrm{D}+\mathrm{L}+\mathrm{T}_{\mathrm{O}}+\mathrm{R}_{\mathrm{O}}+\mathrm{E}_{\mathrm{O}} \\
& \text { 3(a). } 1.5 \mathrm{~S}=\mathrm{D}+\mathrm{L}+\mathrm{T}_{\mathrm{O}}+\mathrm{R}_{\mathrm{O}}+\mathrm{W} .
\end{aligned}
$$

Both cases of L having its full value or being completely absent are checked.

For factored loads, including earthquake (OBE or SSE), tornado and pipe break effects, etc., the following load combinations are satisfied:

$$
\text { 4. } 1.6 S=D+L+T_{o}+R_{O}+E_{S S}
$$




$$
\begin{aligned}
& \text { 5. } 1.6 \mathrm{~S}=\mathrm{D}+\mathrm{L}+\mathrm{T}_{0}+\mathrm{R}_{0}+\mathrm{W}_{\mathrm{T}} \\
& \text { 6. } 1.6 \mathrm{~S}=\mathrm{D}+\mathrm{L}+\mathrm{T}_{\mathrm{a}}+\mathrm{R}_{\mathrm{a}}+\mathrm{P}_{\mathrm{a}} \\
& \text { 7. } 1.6 \mathrm{~S}=\mathrm{D}+\mathrm{L}+\mathrm{T}_{\mathrm{a}}+\mathrm{R}_{\mathrm{a}}+\mathrm{P}_{\mathrm{a}}+1.0\left(\mathrm{Y}_{\mathrm{r}}+\mathrm{Y}_{\mathrm{j}}+\mathrm{Y}_{\mathrm{m}}\right) \\
& \text { 8. } 1.7 \mathrm{~S}=\mathrm{D}+\mathrm{L}+\mathrm{T}_{\mathrm{a}}+\mathrm{R}_{\mathrm{a}}+\mathrm{P}_{\mathrm{a}}+1.0\left(\mathrm{Y}_{\mathrm{r}}+\mathrm{Y}_{\mathrm{j}}+\mathrm{Y}_{\mathrm{m}}\right)
\end{aligned}
$$

In combinations 4 to 8 inclusive, thermal loads may be neglected when it can be shown that they are secondary and self-limiting.

In combinations 6,7 , and 8 , the maximum values of $P_{a}, T_{a}, R_{a}, Y_{r}$, $Y_{j}$, and $Y_{m}$, including an appropriate dynamic load factor, are used unless a time-history analysis is performed to justify otherwise.

Combinations 5, 7, and 8 are first satisfied without the tornado missile load in 5 and without $Y_{r}, Y_{j}$, and $Y_{m}$ in 7 and 8 . When considering these loads, however, local section strengths may be exceeded under the effect of these concentrated loads, provided there is no loss of function of any "safety-related" system. If non-linear concrete behavior is considered in the design of concrete missile barriers, ACI $349-76$ and its 1979 Supplement, as modified by Regulatory Positions 10 and 11 of Regulatory Guide 1.142, Revision 1 , will be utilized in the design of such barriers.

For stability investigation, the structures which serve to ensure, with a high level of confidence, that systems or components they house can fulfill their 10CFR100-related radionuclide control functions under design basis conditions and their foundations are checked to meet a set of minimum factors of safety against the load combinations given in Table 3.8-3. 


\subsubsection{Design and Analysis Procedures}

\subsubsection{Analysis Procedures}

Structural analysis of the below-grade portion of the Reactor Building is performed using a general purpose, three-dimensionsl analysis program. Boundary conditions of the three-dimensional model at the soil/structure interface are represented by linear spring elements at each node of the model in three orthogonal directions. The spring constants are obtained using the half-space theory.

Classical theory, equations, and numerical methods are used as necessary in the analysis of other structures which serve to ensure, with a high level of confidence, that systems or components they house can fulfill their 10CFR100-related radionuclide control functions under design basis conditions.

Loads and loading combinations as delineated in section 3.8 .2 are considered. Wind loads, tornado loads, and accident loads are converted to equivalent static loads and are applied to the structure as uniform or concentrated loads. 
HTGR - 86- 024

Linear structural analysis of the models are performed under the action of loads described in section 3.8.2.1. Reinforced-concrete sections are designed to satisfy the requirements described in section 3.8.2.2 using all the loads except for the temperature loading. A two-step analysis procedure is employed to determine the thermal stresses. A linear analysis of the structure designed for mechanical loads is performed under the thermal loading. The concrete sections where the tensile stresses exceed the rupture strength of concrete are identified as cracked sections. The stiffness of the cracked sections are reduced, taking into consideration the extent of cracking. The structure is reanalyzed under the thermal loads using the modified stiffness properties. The sections are evaluated for their ability to resist the effect of mechanical plus thermal loads. The reinforcement and concrete thicknesses are adjusted based on this evaluation.

\subsubsection{Design Procedures}

Design procedures are in accordance with the applicable portions of the codes, standards, and specifications listed in Section 3.8.1.

Reinforced-concrete structural elements are designed by the strength method in accordance with the ACI 349 code.

Structural steel frames or components of the buildings are designed by the elastic analysis method in accordance with the provisions of AISC-S326.

Classical methods used in the design are those in standard textbooks, handbooks, and publications as used in engineering practice.

\subsubsection{Structural Acceptance Criteria}

The structural design complies with all the applicable requirements of the codes, standards, and specifications in Section 3.8.1. 


\subsubsection{Materials}

Normal-weight concrete with a 28 -day cylinder strength of $27.6 \mathrm{MPa}$ (4000 psi) is used. The constituents of the concrete and the methods of mixing, testing, transporting, pouring, and curing are all in accordance with the ACI 349 Code requirements.

All reinforcing steel conforms to ASTM A-615, Grade 60.

Structural steel conforms to ASTM-A36.

Supports for those components found to be required to be designed to ASME Section III to meet the top-level criteria conform to ASME Section III, Div. 1, Subsection NF.

\subsubsection{Testing and Inservice Inspection Requirements}

There are no requirements for post-construction testing or inspection of any Standard MHTGR structure. 
HTGR - 86- 024

TABLE 3.8-1

LOAD COMBINATIONS AND LOAD FACTORS ${ }^{(1)}$

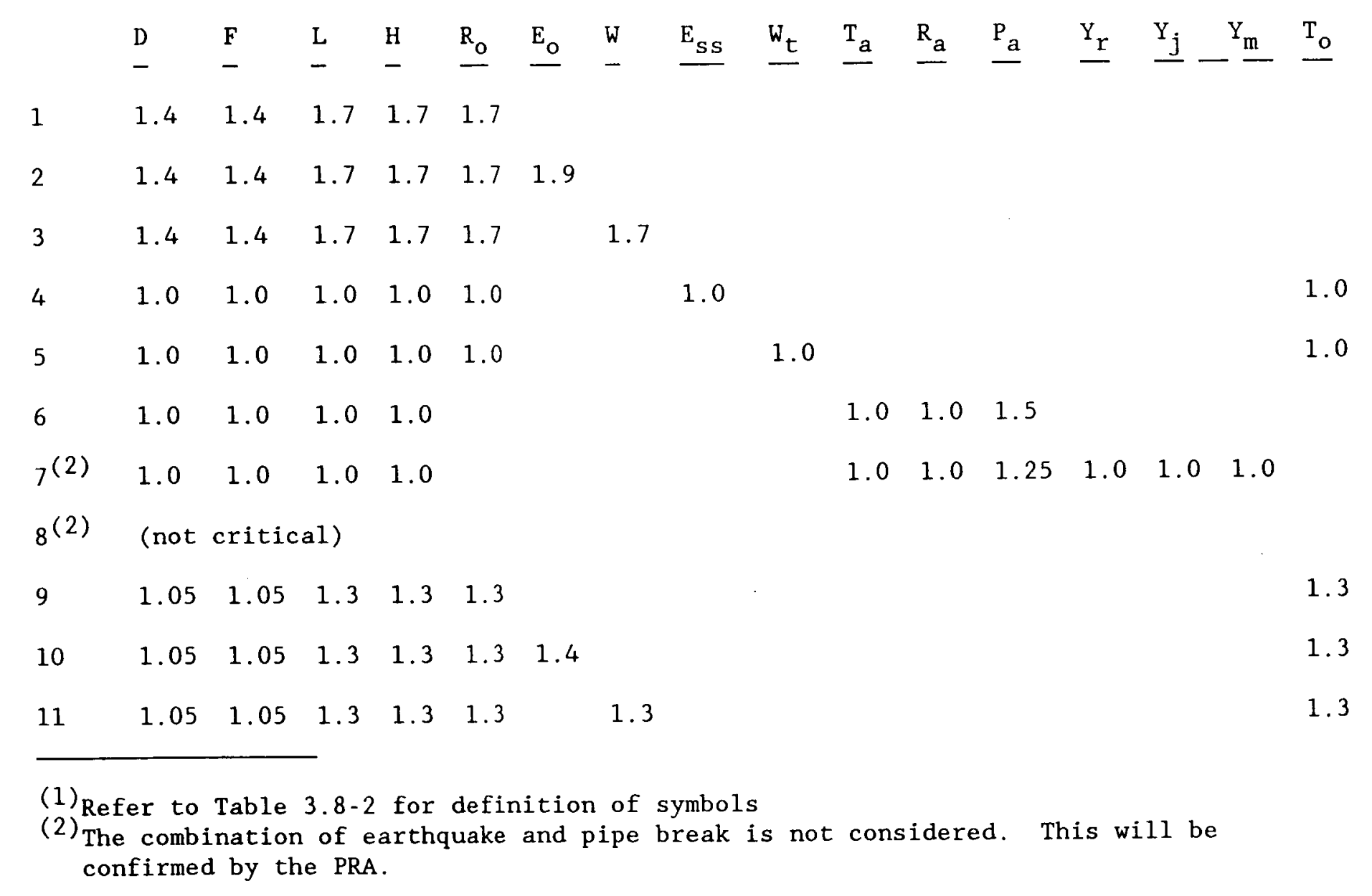


HTGR $-86-024$

TABLE $3.8-2$

SYMBOLS USED IN LOAD COMBINATIONS

Symbo1

Description

D Dead loads

$\mathrm{E}_{\mathrm{O}} \quad$ Operating basis earthquake loads

$E_{\text {SS }} \quad$ Safe shutdown earthquake loads

F Lateral and vertical pressure of liquids

$F_{1} \quad$ Buoyant force due to maximum groundwater leve1

$\mathrm{F}_{2} \quad$ Buoyant force due to maximum flood level

$\mathrm{H} \quad$ Lateral earth pressure

L Live loads

$\mathrm{P}_{\mathrm{a}} \quad$ Differential accident pressure loads

$\mathrm{R}_{\mathrm{a}} \quad$ Accident pipe reaction loads

$\mathrm{R}_{\mathrm{O}} \quad$ Operating pipe reaction loads

$S$ Section strength for structural steel determined on the basis of the elastic design methods and allowable stresses defined in Part $\mathrm{L}_{1}$ of the AISC specifications

$\mathrm{T}_{\mathrm{a}} \quad$ Accident temperature loads

$\mathrm{T}_{\mathrm{o}} \quad$ Operating thermal loads

$\mathrm{U}$ Section strength for reinforced concrete based on the strength design method

W Severe wind loads

$\mathrm{W}_{t} \quad$ Tornado loads

$\mathrm{Y}_{\mathrm{r}} \quad$ Equivalent static load on the structure generated by the reaction on the broken pipe during [a credible accident event]

$\mathrm{Y}_{\mathrm{j}} \quad$ Jet impingement equivalent static load on the structure generated by the broken pipe during [a credible accident event]

$\mathrm{Y}_{\mathrm{m}} \quad$ Missile impact equivalent static load on the structure generated by or during [a credible accident event], such as pipe whipping 


\section{HTGR - 86- 024}

TABLE $3.8-3$

STABILITY FACTORS OF SAFETY

\section{Minimum Factor of Safety}

\section{Load Combinations ${ }^{(1)}$ overturning Sliding Floatation}
(a) $D+H+E_{O}$
1.5
1.5
(b) $\mathrm{D}+\mathrm{H}+\mathrm{W}$
1.5
1.5
(c) $\mathrm{D}+\mathrm{H}+\mathrm{E}_{\mathrm{SS}}$
1.1
1.1
(d) $\mathrm{D}+\mathrm{H}+\mathrm{W}_{\mathrm{T}}$
1.1
1.1
(e) $\mathrm{D}+\mathrm{F}_{1}$
(f) $D+F_{2}$
$-$
-
1.5
1.1

${ }^{(1)}$ See Table 3.8-2 for definition of symbols. 


\subsection{DESIGN OF MECHANICAL SYSTEMS AND COMPONENTS}

This section describes the design of mechanical systems and components for the Standard MHTGR. Mechanical systems and components required to fulfill 10CFR100-related radionuclide control functions under design basis conditions to meet the Top-Level Regulatory Criteria are designed to the applicable sections of ASME III (Ref. 1) as described below. Should validated methods consistent with the basic philosophy of the Integrated Approach be developed and found to be capable of providing results in which adequate confidence can be placed, the ASME Code may be modified or alternative methods applied and submitted for NRC concurrence.

This code is utilized because it provides the most reasonable, practical, and currently established methodology for the design of mechanical systems and components which must fulfill, with a high degree of confidence, 10CFR100-related radionuclide control functions under design basis conditions. The loads and load combinations to be applied are discussed in Section 3.2.3.1. Exceptions to these loads and load combinations may be proposed based upon the results of relevant probabilistic analyses or assessments.

\subsubsection{Plant Duty Cycle}

The plant duty cycle establishes the plant design events, their frequency of occurrence, and the ASME Boiler and Pressure Vessel Code Service Level for operation of a Standard MHTGR. The plant duty cycle is developed based on a plant operating life of 40 calendar years from the start of operation at 808 capacity factor. Both base load and load following operation are accommodated as well as occurrences which result from unplanned component failures or protective trips. The weekly load following cycle shown in Figure $3.9-1$ is used when the plant is operated in a load following mode.

The events which make up the plant duty cycle for the Standard MHTGR are listed in Table 3.9-1.

Included in Table 3.9-1 are normal operating events and events which result from protective trips or from failure of plant components or systems. The 
individual events may have several initiating causes. The total number of design occurrences for each event is the sum of occurrences due to all initiating causes. The number of occurrences is based on a conservatively high estimate such that the character and frequency of unlisted events of significant probability are accommodated by those events listed. The plant is designed, from a component limiting or stress point of view, according to Table 3.9-1 to minimize unnecessary conservatism, while ensuring the 40-yr plant operating life. The ASME Boiler and Pressure Vessel Code Service Level has been identified for each of the events listed in Table 3.9-1 in order to provide the basis for the structural evaluation.

The SRDCs provide limiting design conditions for "safety-related" systems, structures, and.components (SSCs) and, as such, are included in the plant duty cycle. These conditions are used to ensure that the "safety-related" SSCs can be depended upon to respond to the design basis events (DBEs) to meet the dose limits of 10CFR100. Although the "safety related" design conditions (SRDCs) have been developed strictly as a licensing tool, they are included in the plant duty cycle to ensure that the "safety-related" SSCs can withstand the operating environment.

The number of occurrences for each event has been specified on a per reactor module basis. When performing an analysis of Energy Conversion Area equipment such as the turbine, the design number of occurrences is multiplied by the number of reactor modules associated with that component for event sequences in which the initiating event is at the module level. Thus, if two reactor modules supply steam to a single turbine, then that turbine is exposed to twice as many reactor trip transients as the number shown in Table 3.9-1. For event sequences in which the initiating event is external to the plant (e.g., earthquake, loss of offsite power), the design number of occurrences is the same for reactor modules and Energy Conversion Area equipment.

Having been designed for the plant duty cycle events described above, the Standard MHTGR is assessed for safety and licensing purposes. Analyses of AOOs appear in Section 11.6 and DBEs in Chapter 15. The expected performance 
of the plant is determined for each $A O O$ and $D B E$, and the resultant radiological release and dose, if any, are calculated. While the AOOs and DBEs are not necessarily included in the plant duty cycle, evalutions have been performed for the major systems and components for each of the licensing basis events with respect to structural integrity and performance as it applies to the dose assessment.

\subsubsection{Mechanical Component Design Bases}

\subsubsection{Loading Combinations, Design Transients, and Stress Limits}

Systems and components which are ASME Boiler and Pressure Vessel Code Section III, shall be designed to meet the requirements of Subsections NB, NC, or ND as applicable. The design pressure, temperature, and other loading conditions and allowable stresses are given in the design specification and Subsections NB, NC, or ND as applicable. Component supports will be designed in accordance with ASME Section III, Subsection NF. The design transients considered are covered in Section 3.9.1. Core support structures will be designed in accordance with ASME Section III, Subsection NG.

\subsubsection{Operability Assurance of "Safety-Related" Valves}

Active components are those that must perform a mechanical motion during the course of accomplishing its primary radionuclide control function.

Inactive components are those for which mechanical movement does not occur in order for the component to accomplish its intended primary radionuclide control function.

Operability of the small number of active valves in the Standard MHTGR is assured by satisfying the requirements of the following program.

Valve Operability Program. "Safety-related" active valves must perform their mechanical motion during the course of an accident. Assurance will be provided that these valves will operate during the accident, including a seismic event, when appropriate. Qualification tests accompanied by analyses will be conducted for all active valves. 
Valves without significant extended structures will be proven seismically adequate by analysis. For valves with operators having significant extended structures, and if these structures are essential to maintaining pressure integrity, analysis will be performed based upon static forces resulting from equivalent earthquake accelerations acting at the centers of gravity of the extended masses. For active valves, this requirement for analysis will be extended to the mechanical (nonpressure boundary) components of the valve to ensure operability.

In addition, the "safety-related" valves will be subjected to a series of stringent tests prior to service and during plant life. Prior to installation, the following tests will be performed:

1. She11 hydrostatic test to ASME III requirements

2. Backseat and main seat leakage tests

3. Functional tests to verify that the valve will open and close within the specified time limits when subjected to the design differential pressure

4. Operability qualification of motor operators for the environmental conditions over the installed life (i.e., aging, radiation, accident environmental simulation, etc) according to IEEE Standard 382.

Cold hydro qualification tests, hot functional qualification tests, periodic in-service inspections, and periodic in-service operation will be performed in situ to verify and assure the functional ability of the valve. These tests will guarantee reliability of the valve for the design life of the plant. The valves will be designed using either stress analyses or the pressure containing minimum wall thickness requirements. On all active valves, an analysis of the extended (e.g., actuator) structure will also be performed for static equivalent SSE loads supplied at the center of gravity of the extended structure. The maximum stress limits allowed in these analyses will assure structural integrity. 
In addition to these tests and analyses, representative valves of each design type will be tested for verification of operability during a simulated seismic event. The valves will be mounted in a manner which conservatively represents a typical valve installation. The valve will include the operator and all appurtenances normally attached to the valve in service.

The above testing program applies only to valves with extended structures (i.e., the motor operator). The testing will be conducted on a representative number of valves. Valves from each of the primary "safety-related" design types (e.g., motor operated gate valve) will be tested. Valve sizes which cover the range of sizes in service will be qualified by the tests, and the results will be used to qualify all valves within the intermediate range of sizes. Stress and deformation analysis will be used to support the interpolation.

Valves which are "safety-related" and which do not have an overhanging structure, such as safety relief valves, will be qualified separately.

Safety and relief valves will be subjected to the following tests and analyses:

1. Stress analysis including the SSE loads,

2. In-shop hydrostatic test,

3. In-shop seat leakage test, and

4. Periodic in situ valve exercising and inspection to assure the functional ability of the valve.

In addition, a static load equivalent to the SSE will be applied to the top of bonnet and the internal pressure will be increased until the valve mechanism is actuated. Successful actuation within design limits will assure its overpressurization safety capabilities during a seismic event. 
Using the method described, all the "safety-related" valves in the system will be qualified for operability during a seismic event, except those that need not function during the earthquake. These methods conservatively simulate the seismic event and will ensure that the active valves perform their "safety-related" function when necessary.

Alternative valve operability testing, such as dynamic vibration testing, will be used if it is shown to assure the functional ability of the valve system adequately. These alternate methods, if used, will be completely described in the FSAR.

\subsubsection{Design and Installation Details for Mounting of Pressure Relief Devices}

The design criteria for all "safety-related" safety and relief valves are in accordance with the rules in Subarticles NB-3677 and NC-3677 of ASME Section III and the rules of Code Case 1569 applicable to the classification of the piping component under investigation. The maximum stresses are calculated based upon the full discharge loads, including the effects of the system dynamic response, and the system design internal pressure. Stresses are determined for all significant points in the piping system including the safety valve inlet pipe nozzle and the nozzle to shell juncture.

\subsubsection{Component Supports and Core Support Structures}

Component supports and core support structures which are affected by seismic events and which are within the jurisdiction of ASME Section III, Subsection NF and NG, respectively, utilize applicable loading conditions in design specifications.

\subsubsection{Valve Electric Motor Operator Qualification}

Active valve electric motor operators and limit switches and pilot solenoid valves, will be seismically qualified by meeting the requirements of IEEE Standard 344. If the testing option is chosen, sine-beat testing must be 
justified. This justification may be provided by satisfying one or more of the following requirements to demonstrate that multi-frequency response is negligible or the sine-beat input is of sufficient magnitude to conservatively account for this effect:

1. The equipment response is basically due to one mode

2. The sine-beat response spectra envelopes the floor response spectra in the region of significant response, or

3. The floor response spectra consists of one dominant mode and has a peak at this frequency.

Seismic qualification by analysis alone, or by a combination of analysis and testing, may be used when justified. The analysis program can be justified by:

1. Demonstrating that equipment being qualified is amenable to analysis, and

2. Demonstrating that the analysis be correlated with test data or be performed using standard analysis techniques. If the analytical option is employed for the qualification of valve electric motor operators, (or limit switches or pilot solenoid valves) the methods of analyses will be described in the FSAR.

\subsubsection{Design and Installation Criteria for Pressure-Relieving Devices}

The design of relief valve systems includes the criteria of local stresses at the header-to-relief valve inlet piping junction and the stresses in the relief valve inlet piping and header.

Forces and moments on the piping resulting from thrust developed by full opening of the relief valve(s) are determined in the stress analysis. Dynamic amplification load factors are considered in the determination of the 
loads imposed on attached piping or headers. The loads considered in the design of relief valves are as follows: internal pressure, deadweight, seismic loads, and thermal and reaction forces of blowing valves, including entrainment.

\subsubsection{In-Service Inspection. Testing, and Surveillance}

3.9.3.1 In-Service Inspection and Surveillance of Systems, Structures, and Components

In-service inspection (ISI) and surveillance will be carried out for structures, systems, and components (SSCs) of the Standard MHTGR to meet the applicable provisions of the ASME Boiler and Pressure Vessel Code, Section $X I$, Rules for In-Service Inspection of Nuclear Power Plant Components, Divisions 1 and 2 . The determination of the applicable portions of Section $X I$ is based on the following criteria: the SSC is required to achieve requisite reliability with confidence to meet licensing requirements and the principal radionuclide control function of the SSC is maintained by the ISI program. Based on these criteria, the existing Section XI, Divisions 1 and 2 were reviewed to determine the specific examinations which will be carried out. For the primary coolant pressure boundary, which consists of the steel vessels, crossduct, and associated penetrations, bolting, etc, the provisions of Division 1 provide a basis for determining ISI requirements. A primary function of the primary coolant boundary is to prevent large failures which would cause air ingress resulting in unacceptable chemical reactions with the core. Therefore, the provisions of Section XI, Division 1 that are applied to LWR vessels are substantially applicable to the Standard MHTGR. For inspection of other components, the provisions of Division 2, Rules for Inspection and Testing of Components of Gas-Cooled Plants, provides a basis for determining ISI requirements. For these components, the functions are considered for each, and only those provisions of Section XI, Division 2 which provide continuing assurance that the principal radionuclide control function is maintained are established as requirements. Material surveillance is also included in the Section XI requirements. 
For electrical and electronic components requiring high reliability in meeting licensing requirements, the applicable provisions of the Institute of Electrical and Electronic Engineers (IEEE) standards (e.g., IEEE-308, IEEE-338, and IEEE-603) for surveillance are met: Also the provisions of the IEEE standards which provide continuing assurance that the SSCs primary neutron control function is maintained are established as requirements.

\subsection{Scope of In-Service Inspection and Safety Surveillance}

The systems and subsystems which will be inspected and have surveillance in accordance with the applicable requirements of ASME Section XI and IEEE standards, are identified in Table 3.9-2. The maintenance and inspection requirements are discussed in Refs. 4 and 5.

\subsection{Accessibility}

The design and arrangement of SSCs is such that all required ISI and SS can be carried out.

The access to SSCs subject to ISI and surveillance is either direct contact (hands-on) or remote. Contact will be used where possible and when radiation levels are less than $100 \mathrm{mr}$ and there are no physical barriers to contact. Remote access will be utilized when radiation levels are in excess of $100 \mathrm{mR}$, physical barriers are present, or for efficiency or effectiveness.

Provision has been made to ensure adequate access and workspace for personnel and equipment. Where hands-on access is permitted, clearance is provided for the head and shoulders of a man within arm's length of the area to be inspected or surveyed. Access routes to locations requiring ISI or surveillance are provided. These routes permit storage of ladders and temporary platforms as required. Insulation and penetration plugs are designed for easy removal and installation. Temporary working platforms will be provided where necessary to facilitate access to areas for inspection and surveillance. 
HTGR - 86- 024

\subsection{Examination Techniques and Procedures}

In-service inspection examination techniques include visual, surface, and volumetric.

\subsection{Inspection Intervals}

Inspection intervals (10 years) for ASME Section XI components are shown in Table 3.9-3. Material surveillance inspection intervals for ASME Section XI are shown in Table 3.9-4. Material surveillance will be done on material samples removed from the reactor. Inspection intervals for IEEE surveillance will be established in accordance with the applicable IEEE standards.

\subsection{Examination Records}

Examination records will be kept in accordance with ASME XI and IEEE.

\subsection{System Leakage and Pressure Tests}

System leakage and pressure tests will be performed and test records kept in accordance with the requirements of ASME Section XI.

\subsubsection{In-Service Testing of Valves}

An in-service test program will be developed that includes preservice (baseline) testing and a periodic inservice test program to insure that all "safety-related" valves will be in a state of operational readiness to perform their principal radionuclide control function throughout the life of the plant. The test program will be based on the ASME Boiler and Pressure Vessel Code, Section XI, Division 2, Subsection IGV (primarily IGV-1000).

The ISI testing schedule for safety and relief valves is given in Table 3.9-5. 


\subsubsection{Acoustic and Flow-Induced Vibrations}

This section provides information pertaining to the design of reactor and steam generator vessel internal components and structures which are subjected to vibrations from acoustic and flow-induced phenomena. These vibrations can cause fatigue failures and could potentially affect the safe operation and shutdown of the reactor.

The approach to demonstrate the design adequacy of the internals is based on a combination of analysis and testing. In the early design stages, a survey of the reactor system based on calculated flow fields and acoustic pressure levels will be made for the purpose of identifying and correcting potential problems. This will be supplemented with analysis and testing as required in the final design stage to verify the design of "safety-related" components and structures. In addition, verification of structural integrity, including quantification of safety margins associated with normal operation and operating transients, will be performed by implementing USNRC Regulatory Guide 1.20, "Comprehensive Vibration Assessment Program for Reactor Internals During Preoperational and Initial Startup Testing." Since Regulatory Guide 1.20 is written for water reactors, the intent of the regulatory position will be met as it applies to the Standard MHTGR.

\subsubsection{Applicable Components and Structures}

The reactor and steam generator internals important to acoustic and flow-induced design considerations comprise those systems, components, and structures whose structural integrity in service is essential to maintaining the safety function of the Neutron Control System and the Reserve Shutdown Control Equipment.

"Safety-related" components and structures which might fail and thereby directly impede safe reactor operation and shutdown include:

1. Control rod and reserve shutdown control guide tubes

2. Core plenum elements 
HTGR $-86-024$

\section{Reflector control elements \\ 4. Core elements for reserve shutdown control \\ 5. Core support plate structures \\ 6. Core barrel and lateral key support structures}

Failure of some "nonsafety-related" components and structures, which are located downstream of the circulator and upstream of the core, can potentially affect safe reactor operation indirectly. The debris created from failures of such structures could possibly migrate to the core inlet where damage of or interference with the control rods or reserve shutdown control equipment could result. These components include:

1. Main circulator assembly

2. Shutdown circulator assembly

3. Hot duct str'cture

\subsubsection{Systems Analysis}

\subsection{Flow-Induced Vibrations}

The flow of the coolant around components and structures can cause structural vibrations due to the unsteady characteristics of the gas motion. The turbulence and the vortex shedding from an object protruding into the flow are the main sources of flow-induced vibrations that are considered. Flow-induced vibration analysis is done in two steps: 1) determination of the flow conditions and 2) calculation of the vibration response of the components and structures.

Since flow in many parts of the reactor is complex and difficult to determine accurately, the upper bound estimates of the fluid flow velocities are used 
for the calculation of forces on components and structures. The velocities for main loop operation are based on reactor operation at the maximum design condition (Table 5.1-1). This condition has higher turbulence levels than any postulated steady state or transient conditions. The maximum flow velocities for depressurized shutdown cooling operation (e.g., during refueling) are based on the maximum flow rate for the Shutdown Cooling System (SCS) circulator (Table 5.1-5). Flow velocity design values for both main loop operation and SCS operation are given in Table 3.9-6.

\subsection{Acoustic Vibrations}

Acoustic analysis is done in three steps: 1) determination of source strength, 2) calculation of sound pressure levels throughout the primary coolant system, and 3) calculation of random vibration response of components and structures.

Acoustically induced vibrations may originate from several noise sources in the primary coolant system including the main circulator, the SCS circulator, and jets of gases exiting from narrow passages. Among these, the circulator sources are shown to be dominant in the Standard MHTGR system.

The main and SCS circulators are axial compressors. The radiated overall sound power levels (OPWL) from these machines are estimated from the Peistrup-Wesler correlation modified for application to a helium coolant (Ref. 2):

$$
\begin{aligned}
\text { OPWL }= & 93.3+17.7 \log _{10}(\mathrm{HP})-2.7 \log _{10} \mathrm{~N} \\
& +7.7 \log _{10} \frac{\left(\rho \mathrm{sTP}_{\mathrm{Sir}}\right)}{\left(\rho c^{3}\right) \mathrm{He}}
\end{aligned}
$$

Where:

$\mathrm{HP}=$ rated horsepower 
HTGR $-86-024$

$$
\begin{aligned}
& N=\text { number of rotor blades } \\
& \rho=\text { density } \\
& c=\text { speed of sound }
\end{aligned}
$$

Employing the aerothermodynamic parameters at the design points for the main and SCS circulators (Tables 5.1-1 and 5.1-5, respectively), the overall sound power levels are estimated as:

$$
\begin{aligned}
& \text { OPWL (main circulator) }=139 \mathrm{~dB}(81.4 \mathrm{~W}) \\
& \text { OPWL (SCS circulator) }=130 \mathrm{~dB}(10.7 \mathrm{~W}) \\
& \left(\mathrm{W}_{\text {ref }}=10^{-12} \mathrm{~W}\right)
\end{aligned}
$$

The calculated overall sound power levels include a factor of 2 to allow for analytical modeling uncertainties. The sound power is distributed as broadband noise over a large frequency range and as pure tone at the circulator blade passing frequency (BPF) and harmonics. The main circulator and SCS circulator BPF are $4237 \mathrm{~Hz}$ and $5833 \mathrm{~Hz}$, respectively, based on rotational speeds at 100 percent operation.

The sound pressure levels in the primary coolant system are calculated by the computer code REVERB. The code, which is based on room acoustic theory and performs acoustical analysis of a system of volumes (cavities) connected by windows, is strictly speaking only applicable at frequencies where the wave length of sound is much shorter than the typical dimension of a cavity. For the Standard MHTGR primary loop configuration, this applies above approximately $800 \mathrm{~Hz}$. At these frequencies, the sound pressure response can be considered independent of the details of any one cavity mode since the resonances are close. Below $800 \mathrm{~Hz}$, the cavity resonances are separated, and the response is dependent on the characteristics of each mode. However, for simplicity, it is assumed that the magnitude of the sound pressure response level within each volume is constant for all frequencies and equal to the sound pressure calculated at BPF. These sound pressure levels are regarded as conservative since most of the circulator energy is transmitted at the BPF. 
HTGR - $86-024$

The REVERB model for main loop operation is shown in Figure 3.9-2. The parametric input include cavity volumes, window areas, density, and damping factors. The circulator is modeled as two acoustic power sources, one at the circulator inlet and one at the outlet assuming 90 percent of the power is released downstream and 10 percent upstream.

The sound pressure levels at BPF are plotted in Figure 3.9-3 for both main circulator and SCS circulator operation. These levels are used as the basis for the component design analysis.

Small structures and structures with large mass and stiffness are generally not excited by acoustic pressure waves because the associated wave length is

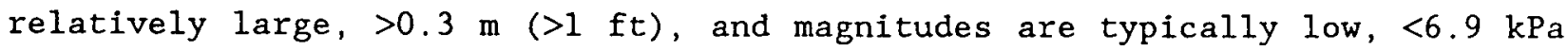
$(<1 \mathrm{psi})$. Plate and shell structures, on the other hand, can be strongly excited provided the surface area to thickness ratio is large.

Response calculations of plate and shell structures to acoustic loads are based on standard random vibration methods assuming that the acoustic pressure acts at the natural frequencies of the structure. This conservatively gives the maximum response obtainable by any given pressure oscillation. Since these structures are likely of complex shapes, numerical techniques are used to evaluate their boundary conditions. The response calculated represents the RMS stresses at the significant natural frequencies of the structure.

\subsection{Prediction of Damage Due to Fatigue}

A fatigue analysis due to acoustic and flow-induced stress cycling is performed to demonstrate the design adequacy of the identified components and structures. In this context, the effect of thermal cycling, earthquakes, and other design basis transients are included.

The structural fatigue due to vibration at a single frequency is calculated from the RMS stress amplitude. For comparison with fatigue endurance limits which are based on peak stresses, the RMS stress is multiplied by a factor of 3.5 [peak stresses do not exceed 3.5 times the RMS stress (Ref. 3)]. 
HTGR - 86- 024

The fatigue damage is calculated based on ASME III, Division I, NG criteria for cumulative damage (Miner's linear damage rule). For this procedure, design fatigue curves up to $10^{6}$ cycles are used except for austenitic steels and chrome-nickel alloys for which curves up to $10^{11}$ cycles are used.

\subsubsection{Component Testing}

To provide adequate verification of the critical structures in the upper core plenum, the analysis will be supplemented with testing. Flow tests on a selected group of full-scale control rod and reserve shutdown control guide tubes, plenum elements, and related components will be performed. The identification of the frequency and magnitude of significant vibrations will be made and the components inspected for damage.

\subsubsection{Preoperational and Startup Testing}

A vibration assessment program during preoperational and startup testing will be conducted, consistent with Regulatory Guide 1.20. The assessment program will consist of systems flow-induced and acoustic analyses, vibration measurements, inspection, and correlation between analysis and test. The analyses, which will be conducted prior to the testing, will be used as a basis for instrumentation and inspection programs. 
HTGR $-86-024$

\section{REFERENCES - SECTION 3.9}

1. American Society of Mechanical Engineers (ASME) Boiler and Pressure Vessel (B\&PV) Code, Section III, Nuclear Power Plant Components.

2. Burton, T.E., Vibration of HTGR Plates and She11s, GA Report GA-A13942, August 1977 (p. 9-9).

3. Richards, E. J., Noise and Acoustic Fatigue in Aeronautics, Wiley and Sons, London, 1968 (p. 439).

4. GA Technologies, Inc. (GA). MHTGR Nuclear Island Steam Supply System Maintainability Assessment. HTGR-86-053. GA, San Diego, CA, June 1986.

5. GA Technologies, Inc. (GA). Nuclear Island ISI Surveillance Assessment, Modular High-Temperature Gas-Cooled Reactor. HTGR-86-026. GA, San Diego, CA, May 1986, Draft. 
HTGR - $86-024$

TABLE $3.9-1$

PLANT DUTY CYCLE

\section{Event}

1. Startup from Refueling Conditions

2. Startup with Full Helium Inventory

3. Shutdown to Refueling Conditions

4. Shutdown with Full Helium Inventory

5. Rapid Load Increase ( 58 per min) $(258-100 \%)$

6. Normal Load Increase (0.5\% per min) $(258-1008)$

7. Rapid Load Decrease (5\& per min) $(1008-25 \%)$

8. Normal Load Decrease ( 0.58 per min) $(100 z-258)$

9. Step Load Increase (+158)

10. Step Load Decrease (-158)

11. Depressurized Decay Heat Removal, HTS to SCS Transition

12. Depressurized Decay Heat Removal, SCS to HTS Transition

13. Pressurized Decay Heat Removal, HTS to SCS Transition

14. Pressurized Decay Heat Removal, SCS to HTS Transition

15. Circulator Trip

16a. Reactor Trip from $100 \%$

16b. Reactor Trip from 258

17. Turbine Trip or Load Rejection

18. Sudden Reduction of FW Flow
Design No. of Occurrences (per Reactor) Module)

143

312

101

105

1000

A

20800

A

1000

A

17500

A

1000

A

1000

A

80

A

122

A

61

A

86

A

30

B

$180^{(1)}$

B 
TABLE $3.9-1$ (Cont.)

Event

19. Steam Generator Tube Leak (Sma11)

20. Control Rod Insertion

21. Main Loop Overcooling

22. Operating Basis Earthquake (OBE)

23. Slow Primary System Depressurization.

24a. Rod Withdrawal (normal rod speed) (Power to Flow Ratio Trip)

24b. Rod Withdrawal (slow) (Steam Generator Helium Inlet Temperature Trip)

25. Failure of Circulator Speed Control

26. Circulator Trip with He Shutoff Valve Failure

27. Steam Generator Tube Rupture

28. SCS Heat Exchanger Tube Leak

29. Total Loss of FW Flow

30a. Total Loss of SCS Cooling Water (HTS operating)

30b. Total Loss of SCS Cooling Water (SCS operating)

31. Pressurized Conduction Cooldown (SRDC - 1)

32. Pressurzed Conduction Cooldown Without Contro1 Rod Trip (SRDC-2)

33. Pressurized Conduction With Control Rod Withdrawal (SRDC-3, -4)

34. Pressurized Conduction Cooldown With Earthquake (SRDC-5)

35. Depressurized Conduction Cooldown with Moderate Moisture Ingress (SRDC-6, -7)
Design No. of

Occurrences

(per Reactor) Module)

Service Level

9

B

5

B

10

B

1

B

8

B

1

C

1

C

1

C

1

C

1

C

4 C

4

C

1

C

1

${ }_{C}(2)$

1

$D^{(2)}$

1

$D^{(2)}$

1

$D^{(2)}$

1 
HTGR $-86-024$

TABLE 3.9-1 (Cont.)

$\underline{\text { Event }}$

36. Depressurized Conduction Cooldown With Smal1 Moisture Ingress (SRDC-8, -9)

37. Depressurized Conduction Cooldown With Moderate Primary Coolant Leak (SRDC-10)

38. Depressurized Conduction Cooldown With Small Primary Coolant Leak (SRDC-11)

39. Main Steam Pipe Rupture
Design No. of Occurrences (per Reactor) Module)

Service Leve1

1

$D^{(2)}$

1

1 $D^{(2)}$

1

$\mathrm{D}$

(1) For components where reactor trip from 1008 load is worse the breakdown should be 131 trips from 1008 and 49 trips from 258. For components where reactor trip from 258 load is worse, the breakdown should be 63 trips from 1008 and 117 trips from 258.

(2) In general, Service Level $D$ is assigned to SRDCs for specified safety functions of safety-related SSCs. However, Level D limits are intended primarily for guidance. The plant level requirement is that 10CFRl00 dose requirements not be exceeded. Event No. 31 (SRDC No. 1) is an exception to this. Due to its higher frequency of occurrence, more stringent Service Leve1 $\mathrm{C}$ is assigned for investment protection. With the exception of event number 31, the SRDCs apply to "safety-related" systems, structures, and components only. 
TABLE 3.9-2

SYSTEMS AND SUBSYSTEMS SUBJECT TO IN-SERVICE INSPECTION AND SURVEILIANCE

Systems/Subsystems/Components

1. Reactor System

Neutron Control

- Outer Control Rods and Drive Subsystems

- Reserve Shutdown System

Reactor Internals

o Permanent Reflector

- Core Lateral Restraint

- Core Support Floor Structure

- Upper Plenum Thermal Protection Structure

2. Vessel System

Reactor Vessel

Steam Generator Vessel

Crossduct

Pressure Relief System

Steam Generator Isolation Valves

3. Reactor Cavity Cooling System

RCCS Passive Components

- Ducting

o Heat Transfer Panels 
HTGR - 86- 024

TABLE 3.9-2 (Cont.)

Systems/Subsystems/Components

4. Plant Protection and Instrument Systems

Safety Protection

- Reactor Trip Circuits

Release of Outer Control Rods

- RSCE Trip Circuits

Release of Reserve Shutdown Control Material

- Main Loop Shutdown Trip Circuits

Closure of Steam Generator Isolation Valves

Trip of the Main Circulator

5. Electrical Group

Class 1E Systems

a Uninterruptible AC Power Supply

Batteries

Inverters

Control Equipment

- Uninterruptible AC Distribution

System

Neutron Detection

Safety Pratection Instruments

- DC Power System

Reserve Shutdown Actuation 
HTGR - 86-024

TABLE 3.9-3

FREQUENCY AND EXTENT OF ISI EXAMINATIONS

\begin{tabular}{|c|c|c|c|}
\hline Inspection & $\begin{array}{l}\text { Inspection Period, } \\
\text { Calendar Years of }\end{array}$ & $\begin{array}{l}\text { Minimum } \\
\text { Examinations }\end{array}$ & $\begin{array}{l}\text { Maximum } \\
\text { Examinations }\end{array}$ \\
\hline Interval & Plant Service & Completed, 8 & Credited, 8 \\
\hline \multirow[t]{3}{*}{$1 s t$} & 3 & 16 & 34 \\
\hline & 7 & 50 & 67 \\
\hline & 10 & 100 & 100 \\
\hline \multirow[t]{3}{*}{ 2nd } & 13 & 16 & 34 \\
\hline & 17 & 50 & 67 \\
\hline & 20 & 100 & 100 \\
\hline \multirow[t]{3}{*}{$3 r d$} & 23 & 16 & 34 \\
\hline & 27 & 50 & 67 \\
\hline & 30 & 100 & 100 \\
\hline \multirow[t]{3}{*}{4 th } & 33 & 16 & 34 \\
\hline & 37 & 50 & 100 \\
\hline & 40 & 100 & $\cdots$ \\
\hline
\end{tabular}

Ref: Examination Program B (Table IGB-2412-1 of the ASME B\&PV Code, Section XI, Division 2)

Example: At the second inspection interval, during the 13 th year of service, all of the required inspections were conducted during the first 10 years and at least 168 of the required inspections were conducted again during year 13. If more than $16 \%$ of the required inspections were conducted during year 13, only 348 may be considered complete for purposes of inspection in year 13. During year 17 additional inspections must be conducted to raise the total to $50 \%$. If more than 508 of the required inspections are conducted, not more than 678 may be credited. 
HTGR - $86-024$

TABLE $3.9-4$

ISI MATERIAL SURVEILLANCE PROGRAM

Surveillance Specimen

Removal Interval

Interval Definition

1 st

At 1 st or 2 nd planned outage ${ }^{(1)}$

or between 1st and 2nd planned

outage

2nd

After 2 nd but no later than 4 th

planned outage

$3 r d$

At 8 th or 9 th planned outage or between 8 th and 9 th planned

outage

4 th

At 22 nd or $23 \mathrm{rd}$ planned outage

or between $22 \mathrm{nd}$ and $23 \mathrm{rd}$ planned outage

${ }^{(1)}$ An extended planned outage at intervals $\leq 18$ months. 


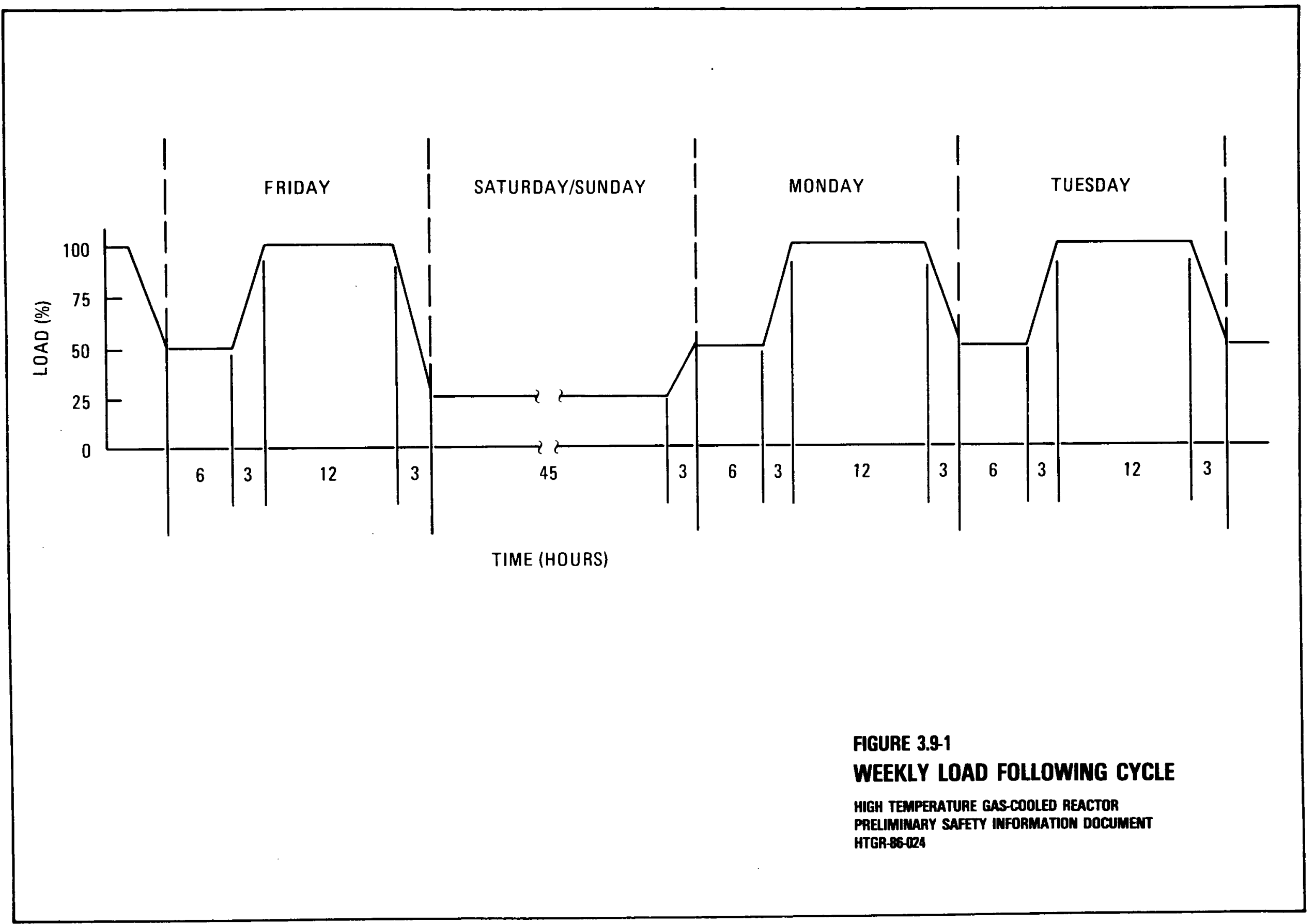




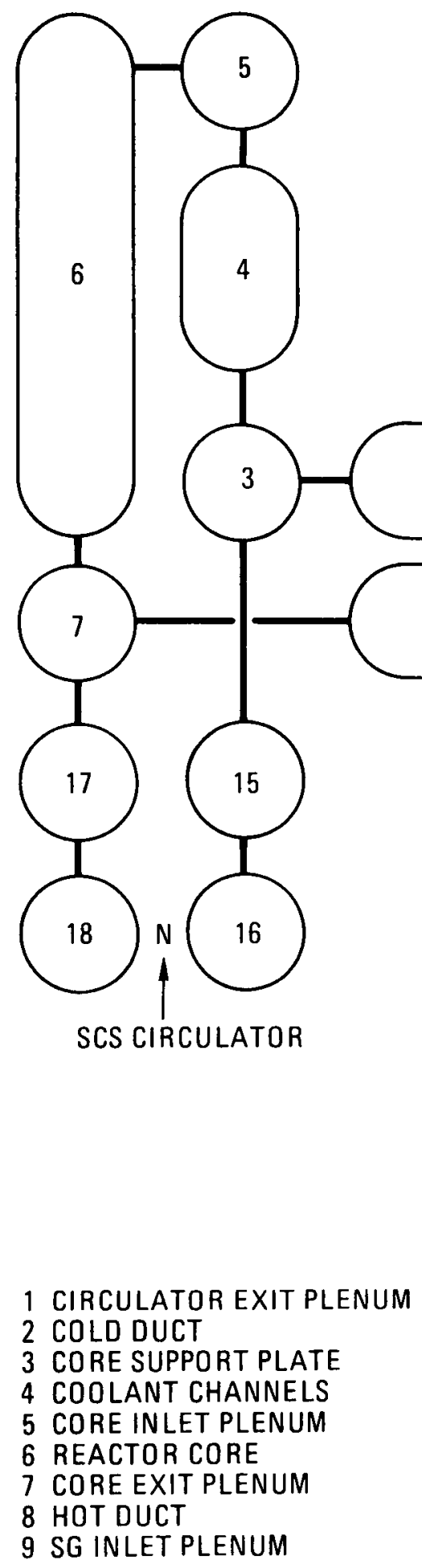

MAIN CIRCULATOR

1 CIRCULATOR EXIT PLENUM

2 COLD DUCT

3 CORE SUPPORT PLATE

4 COOLANT CHANNELS

5 CORE INLET PLENUM

6 REACTOR CORE

7 CORE EXIT PLENUM

9 SG INLET PLENUM
10 SG BUNDLE

11 SG OUTLET PLENUM

12 SG ANNULUS

13 CIRCULATOR INLET PLENUM

14 CIRCULATOR INLET

15 RV BOTTOM HEAD

16 SCS CIRCULATOR EXIT PLENUM

17 SCS HX BUNDLE

18 SCS CIRCULATOR INLET

FIGURE 3.9-2

REVERB MODEL OF THE MHTGR PRIMARY COOLANT SYSTEM 
SOUND PRESSURE LEVEL (dB)

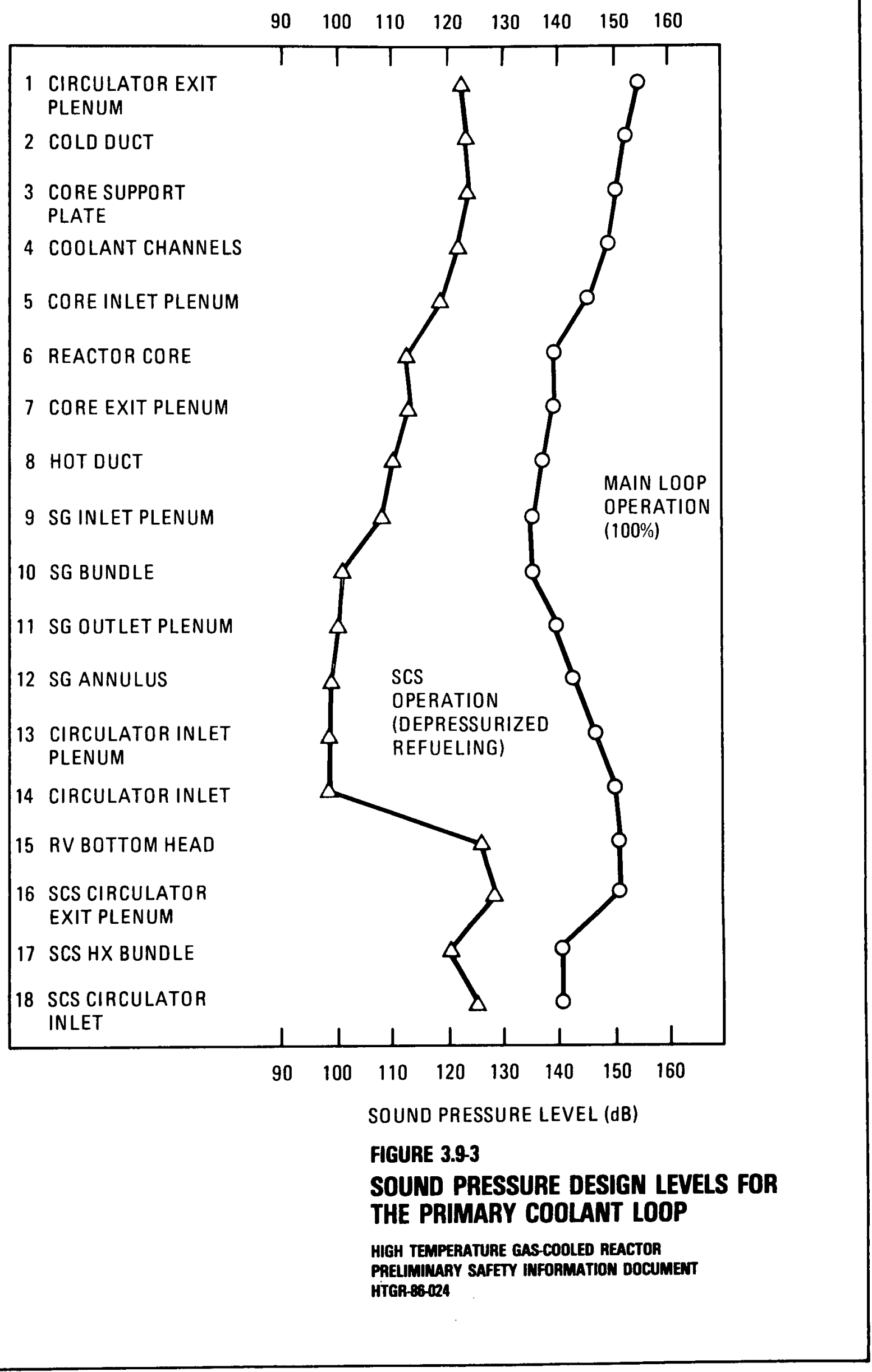


CHAPTER 4

REACTOR

CONTENTS

Section

4.1

4.1.1

4.1.2

4.1.2.1

4.1.2.2

4.1.2.3

4.1 .2 .4

4.1 .3

4.1 .4

4.1.4.1

4.1.4.2

4.1 .4 .3

4.1.4.4

4.1 .4 .5

4.1 .5

4. 1.6

4.2

4.2.1

4.2. 2

4.2.2.1

4.2.2.2

4.2.2.3

4.2 .2 .4

4.2 .3

4.2 .4

4.2.4.1

4.2.4.1.1

4.2.4.1.2

4.2 .4 .1 .3
Title

Page

REACTOR SYSTEM

4. $1-1$

Summary Description

4. $1-1$

Functions and 10CFR100 Design Criteria

4. $1-3$

Power Generation Functions

Radionuclide Control Functions

$4.1-3$

4. $1-4$

Classification

$4.1-5$

10CFR100 Design Criteria for Radionuclide Control

$4.1-5$

Radionuclide Control Design Requirement

4. $1-6$

Design Description

$4.1-7$

4.1-7

$4.1-10$

$4.1-10$

4. $1-12$

4. $1-12$

4. $1-12$

4. $1-12$

Interfaces

REACTOR CORE SUBSYSTEM

4. $2-1$

4. $2-1$

4. 2 - 1

4. $2-2$

4. $2 \cdot 2$

$4.2 \cdot 3$

4. $2-3$

4. $2 \cdot 3$

4. $2-6$

4. $2-6$

4. $2-6$

4. $2-8$

4. $2-9$ 


\section{CONTENTS}

(Continued)

Section

4.2 .4 .1 .4

4.2.4.1.5

4.2.4.1.6

4.2.4.2

4.2.4.3

4.2.4.4

4.2 .4 .5

4.2 .5

4.2.5.1

4.2.5.1.1

4.2.5.1.2

4.2.5.2

4.2.5.2.1

4.2.5.2.1.1

4.2.5.2.1.2

4.2 .5 .2 .1 .3

4.2 .5 .2 .1 .4

4.2 .5 .2 .1 .5

4.2 .5 .2 .1 .6

4.2.5.2.2

4.2.5.2.2.1

4.2.5.2.2.1.1

4.2.5.2.2.1.2

4.2.5.2.2.1.3

4.2 .5 .2 .2 .2

4.2.5.2.2.2.1

4.2.5.2.2.2.2

4.2 .5 .2 .2 .2 .3

4.2.5.2.2.2.4

4.2.5.2.2.2.5

4.2 .5 .2 .3
Title

Control Rods

Reserve Shutdown Material

Startup Neutron Sources

Subsystem Arrangement

Subsystem Operating Modes

Instrumentation and Control

Subsystem Limitations

Design Evaluation

Failure Modes and Effects

Coolant Channel Blockage

Control Channel Blockage

Steady-State Performance

Nuclear Performance

Reactivity Control

Fuel Cycle

Power Distribution

Control Rod Positions for Rise-to-Power

Stability of Power Distribution to Xenon Oscillations

Residual Heat Loads

Fuel Performance

Methodology and Assumptions

Fission Product Release Barriers

Computer Codes

Application of the Methodology

Results and Discussion

Fuel and Graphite Temperature Distributions

Fluence and Burnup Distributions

Fuel Particle Failure

Fission Gas Release

Metallic Fission Product Release

Thermal/Hydraulic Performance
Page

4. $2 \cdot 10$

4. $2-11$

$4.2-11$

4. $2-11$

4. $2-11$

$4.2-11$

4. $2-12$

4. $2-12$

4. $2-12$

4. $2-12$

4. $2-13$

4. $2-13$

4. $2-14$

4. 2.14

4. 2- 21

4. 2.22

4. $2-24$

4. $2-25$

4. $2-26$

4. $2-26$

4. $2-27$

4. $2-27$

4. $2-30$

4. $2-32$

4. $2-37$

4. $2-38$

4. $2 \cdot 38$

4. $2-39$

4. $2 \cdot 40$

4. $2-40$

4. $2-42$ 
HTGR $-86-024$

CONTENTS

(Continued)

Section

4.2 .5 .2 .4

Structural/Mechanical Performance

$4.2 \cdot 5 \cdot 2.4 .1$

4.2 .5 .2 .4 .2

$4.2 \cdot 5 \cdot 2 \cdot 4 \cdot 3$

$4.2 .5 \cdot 2 \cdot 4 \cdot 4$

4.2 .5 .3

4.2 .5 .4

4.2 .5 .5

4.2 .6

4.3

4. 3.1

4.3 .2

4.3.2.1

4.3 .2 .2

4.3 .2 .3

4.3 .2 .4

4.3 .3

4.3 .4

4.3 .4 .1

4.3.4.1.1

4.3.4.1.1.1

4.3.4.1.1.2

4.3 .4 .1 .2

4.3.4.1.2.1

4.3.4.1.2.2

4.3.4.1.2.3

4.3.4.1.3

4.3 .4 .1 .4

4.3.4.1.5

4.3 .4 .2

Title

Stress Field Description

Stress Analysis Results

Oxidation Effects on Strength

Design Basis Event Performance

Interfaces
Page

$4.2 \cdot 44$

Graphite Core Component Allowable Stress Limits

Anticipated Operational Occurrence Performance

"Safety-Related" Design Condition Performance

$4.2-44$

4. $2 \cdot 45$

$4.2 \cdot 47$

4. $2-48$

4. $2-49$

$4.2-52$

4. $2-56$

$4.2-59$

4. 3-1

4. $3-1$

4. $3-2$

4. $3-2$

4. $3 \cdot 3$

4. $3-3$

4. $3-3$

4. 3-4

$4.3-4$

4. 3-4

$4.3-5$

4. 3-5

4. $3-7$

4. 3 - 8

$4.3-8$

4. $3-9$

4. $3-9$

4. 3-11

4. $3-12$

4. 3-13

4. $3-13$ 
HTGR - 86- 024

CONTENTS

(Continued)

Section

$4.3 \cdot 4.3$

4. 3.4 .4

4.3.4.4.1

4.3.4.4.2

4.3.4.4.3

4. 3.4 .4 .4

4.3.4.4.5

4. 3.4. 4.6

4. 3.4 .5

4. 3.5

4.3.5.1

4.3.5.1.1

4.3.5.1.2

4.3.5.1.3

4.3.5.1.4

4.3.5.1.5

4.3.5.2

4.3.5.2.1

4.3.5.2.2

4.3.5.2.3

4.3.5.2. 4

4.3.5.2.5

4.3.5.3

4.3.5.4

4.3.5.5

4.3 .6

4.4

4.4 .1

4.4.2

4.4.2.1
Title

Page

Subsystem Operating Modes

4. $3-14$

Instrumentation and Control

Neutron Control Assembly Structural Equipment

$4.3-14$

$4.3-14$

Control Rod Drive Equipment

Reserve Shutdown Control Equipment

$4 \cdot 3-14$

$4.3-16$

Ex-Core Neutron Detection Equipment

$4.3 \cdot 16$

$4.3-16$

4.3 .17

$4.3-17$

$4.3-18$

$4.3-18$

$4.3-18$

4. 3-19

4. $3-19$

4. $3-20$

4. $3-20$

4. $3-20$

4. $3-20$

4. 3-21

4. 3-22

4. $3-22$

4. 3-22

4. 3-23

4. $3 \cdot 23$

4. 3-24

4. 3-24

Interfaces

4.4-1

4. 4-1

4. 4-1

4. 4-1 
HTGR - 86-024

CONTENTS

(Continued)

Section

4.4.2.2

4.4 .2 .3

4.4 .2 .4

4.4 .3

4.4 .4

4.4.4.1

4.4.4.1.1

4.4.4.1.1.1

4.4.4.1.1.2

4.4.4.1.2

$4.4 \cdot 4 \cdot 1.2 .1$

4.4 .4 .1 .2 .2

$4.4 .4 \cdot 1.2 .3$

4.4.4.1.2.4

4.4.4.1.3

4.4.4.2

$4.4 \cdot 4.3$

4.4 .4 .4

4.4.4.5

4.4 .5

4.4 .5 .1

4.4.5.1.1

4.4.5.1.1.1

4.4.5.1.1.2

4.4.5.1.1.3

4.4.5.1.1.4

4.4.5.1.2

4.4.5.1.2.1

4.4.5.1.2.2
Title

Page

Radionuclide Control Functions

$4.4-1$

Classification

4. 4-2

10CFR100 Design Criteria for Radionuclide Control

4. 4-2

Radionuclide Control Design Requirements

4. $4-2$

Design Description

$4.4-3$

Subsystem Configuration

$4.4-3$

Graphite Structures

$4.4-4$

Permanent Side Reflector

$4.4-4$

$4.4-5$

$4.4-8$

$4.4-8$

4. 4-9

4. 4-10

4. $4-10$

4. 4-11

4. 4-12

4. 4-12

4. $4-13$

4. 4-13

4. 4-13

$4.4 \cdot 13$

4. $4-13$

4. $4-13$

$4.4 \cdot 14$

4. 4-16

4. 4-16

4. 4-17

4. $4-17$

Core Lateral Restraint Failure Modes and Effects

Metallic Core Support Structure Failure Modes

and Effects

$4.4-18$ 
HTGR - 86- 024

CONTENTS

(Continued)

Section

Title

$\underline{\text { Page }}$

4.4.5.1.2.3 Upper Plenum Thermal Protection Structures Failure

Modes and Effects

$4.4-18$

$4.4 .5 \cdot 1 \cdot 2 \cdot 4$

Hot Duct Failure Modes and Effects

$4.4-19$

4.4 .5 .2

Steady-State Performance

$4.4-20$

4.4.5.2.1

Thermal Hydraulic Performance

$4.4-20$

4.4 .5 .2 .2

Structural/Mechanical Performance

$4.4-21$

4.4 .5 .2 .2 .1

Graphite Structure

$4.4-21$

4.4 .5 .2 .2 .2

Metallic Structure

$4.4-22$

4.4 .5 .2 .2 .2 .1

Core Lateral Restraint

$4.4-22$

4.4 .5 .2 .2 .2 .2

Metallic Core Support Structure

$4.4-23$

4.4 .5 .2 .2 .2 .3

Upper Plenum Thermal Protection Structure

$4.4-23$

4.4 .5 .2 .2 .2 .4

Hot Duct

$4.4-23$

$4 \cdot 4 \cdot 5 \cdot 2 \cdot 3$

Shielding Performance

$4.4-24$

$4 \cdot 4 \cdot 5 \cdot 2 \cdot 3.1$

Permanent Side Reflector

$4.4-24$

4.4 .5 .2 .3 .2

Graphite Core Support Structure

$4.4-25$

4.4 .5 .3

Anticipated Operational Occurrence Performance

4. 4-25

$4 \cdot 4 \cdot 5 \cdot 3.1$

Structural/Mechanical Performance

$4 \cdot 4-25$

$4.4 \cdot 5 \cdot 3.1 .1$

Graphite Structures

4. $4-26$

4.4 .5 .3 .1 .2

Metallic Structures

$4.4 \cdot 27$

4.4 .5 .3 .1 .2 .1

Core Lateral Restraint

4. $4-27$

4.4 .5 .3 .1 .2 .2

Metallic Core Support Structure

$4.4 \cdot 28$

$4.4 \cdot 5 \cdot 3 \cdot 1 \cdot 2 \cdot 3$

Upper Plenum Thermal Protection Structure

$4.4 \cdot 28$

$4.4 \cdot 5 \cdot 3.1 .2 .4$

Hot Duct

4. $4 \cdot 29$

4.4 .5 .4

Design Basis Event Performance

4. $4 \cdot 29$

$4.4 \cdot 5 \cdot 4.1$

Structural/Mechanical Performance

4. $4-29$

4.4.5.4.1.1

Graphite Structures

4. 4-29

4.4.5.4.1.2

Metallic Structures

4. 4- 32

4.4.5.4.1.2.1 Core Lateral Restraint

$4.4 \cdot 32$

4.4.5.4.1.2.2 Metallic Core Support Structure

4. $4-33$

4.4.5.4.1.2.3 Upper Plenum Thermal Protection Structure

4. $4-33$

4.4.5.4.1.2.4 Hot Duct

4. $4-33$ 
HTGR - 86-024

CONTENTS

(Continued)

Section

4.4 .2 .2

4.4 .2 .3

4.4 .2 .4

4.4 .3

4.4 .4

4.4.4.1

4.4.4.1.1

4.4.4.1.1.1

4.4 .4 .1 .1 .2

4.4.4.1.2

4.4.4.1.2.1

4.4.4.1.2.2

4.4 .4 .1 .2 .3

4.4 .4 .1 .2 .4

4.4.4.1.3

4.4.4.2

4.4.4.3

4.4 .4 .4

4.4 .4 .5

4.4 .5

4.4 .5 .1

4.4 .5 .1 .1

4.4.5.1.1.1

4.4.5.1.1.2

4.4 .5 .1 .1 .3

4.4.5.1.1.4

4.4.5.1.2

4.4.5.1.2.1

4.4.5.1.2.2
Title

Page

Radionuclide Control Functions

4. 4-1

Classification

4. $4-2$

Principal Design Criteria for Radionuclide Control

$4.4-2$

Radionuclide Control Design Requirements

4. 4-2

Design Description

$4.4-3$

Subsystem Configuration

$4.4-3$

$4.4-4$

$4.4-4$

$4.4 \cdot 5$

$4.4-8$

$4.4-8$

4.4-9

4. $4-10$

4. $4-10$

4. $4-11$

4. $4-12$

$4.4-12$

$4.4-13$

$4.4-13$

$4.4-13$

$4.4-13$

4. $4-13$

4. $4-13$

$4.4-14$

4. $4-16$

$4.4 \cdot 16$

4. $4-17$

Metallic Structures

4. $4-17$

Core Lateral Restraint Failure Modes and Effects

Metallic Core Support Structure Failure Modes

and Effects 
HTGR - 86- 024

CONTENTS

(Continued)

Section

Title

$\underline{\text { Page }}$

4.4.5.1.2.3 Upper Plenum Thermal Protection Structures Failure Modes and Effects

$4.4-18$

4.4.5.1.2.4 Hot Duct Failure Modes and Effects

$4.4-19$

4.4 .5 .2

Steady-State Performance

4. $4-20$

4.4 .5 .2 .1

Thermal Hydraulic Performance

$4.4-20$

4.4 .5 .2 .2

Structural/Mechanical Performance

$4.4-21$

4.4 .5 .2 .2 .1

Graphite Structure

4. $4-21$

4.4 .5 .2 .2 .2

Metallic Structure

4. $4-22$

4.4 .5 .2 .2 .2 .1

Core Lateral Restraint

4. $4-22$

4.4.5.2.2.2.2 Metallic Core Support Structure

$4.4-23$

4.4 .5 .2 .2 .2 .3

Upper Plenum Thermal Protection Structure

$4.4-23$

4.4 .5 .2 .2 .2 .4

Hot Duct

4. $4-23$

4.4 .5 .2 .3

Shielding Performance

$4.4-24$

$4 \cdot 4 \cdot 5 \cdot 2 \cdot 3.1$

Permanent Side Reflector

$4.4-24$

4.4 .5 .2 .3 .2

Graphite Core Support Structure

$4.4-25$

$4 \cdot 4 \cdot 5.3$

Anticipated Operational Occurrence Performance

$4.4-25$

4.4.5.3.1

Structural/Mechanical Performance

$4.4-25$

$4 \cdot 4 \cdot 5 \cdot 3 \cdot 1.1$

Graphite Structures

4. $4-26$

$4 \cdot 4 \cdot 5 \cdot 3 \cdot 1.2$

Metallic Structures

$4.4-27$

4.4.5.3.1.2.1 Core Lateral Restraint

$4.4-27$

4.4.5.3.1.2.2 Metallic Core Support Structure

$4.4-28$

$4.4 .5 \cdot 3 \cdot 1.2 .3$

Upper Plenum Thermal Protection Structure

$4.4-28$

$4.4 .5 \cdot 3 \cdot 1.2 .4$

Hot Duct

$4.4-29$

4.4 .5 .4

Design Basis Event Performance

4. $4-29$

$4 \cdot 4 \cdot 5 \cdot 4.1$

Structural/Mechanical Performance

4. $4-29$

4.4.5.4.1.1 Graphite Structures

$4.4 \cdot 29$

4.4.5.4.1.2 Metallic Structures

$4.4-32$

4.4.5.4.1.2.1 Core Lateral Restraint

$4.4-32$

4.4.5.4.1.2.2 Metallic Core Support Structure

$4.4-33$

4.4.5.4.1.2.3 Upper Plenum Thermal Protection Structure

$4.4-33$

4.4.5.4.1.2.4 Hot Duct

$4.4-33$

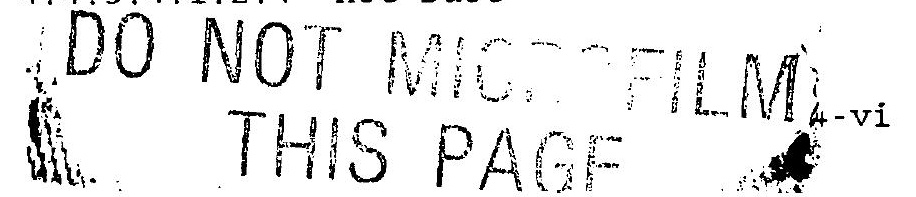


HTGR - 86- 024

\section{CONTENTS}

(Continued)

Section

Title

$\underline{\text { Page }}$

4.4.5.5 "Safety-Related" Design Condition Performance

$4.4-34$

4.4 .5 .5 .1

Structural/Mechanical Performance

$4.4-34$

4.4 .5 .5 .1 .1

Graphite Structures

4.4 .5 .5 .1 .2

Metallic Structures

$4.4-34$

4.4.5.5.1.2.1 Core Lateral Restraint

$4.4-35$

4.4.5.5.1.2.2 Metallic Core Support Structure

$4.4-35$

4.4.5.5.1.2.3 Upper Plenum Thermal Protection Structure

$4.4-36$

$4.4-36$

4.4.5.5.1.2.4 Hot Duct

$4.4-37$

4.4 .6

Interfaces

$4.4-37$ 
HTGR - $86-024$

\section{LIST OF TABLES}

$\underline{\text { Table }}$

\section{$\underline{\text { Title }}$}

4.1-1 Nominal Reactor Design Parameters

4.1-2 Identification of RS Interfaces Imposed on Other Systems

4.2-1 TRISO Particle Design

4.2-2 Basis for Specification of TRISO - Coated Fuel Properties

4.2-3 Fuel Compact Characteristics

4.2-4 Fuel Quality and Performance Limits

4.2-5 Reactivity Control Requirements

4.2-6 Control Rod and Reserve Shutdown Reactivity Worths

4.2-7 Control Rod and Reserve Shutdown Reactivity Worths

4.2-8 Random Reactivity Uncertainty Components

4.2-9 Total Reactivity Uncertainties Affecting Cold Shutdown Margin

4.2-10 Estimated Cold Shutdown Margins

4.2-11 Reserve Shutdown Requirements and Reactivity Worth

4.2-12 Active Core and Corresponding Reflector Temperatures Used in One-Dimensional Radial Diffusion Calculation of the Temperature Coefficient Evaluations

4.2-13 Fuel Loadings 
HTGR-86-024

\section{LIST OF TABLES}

(Continued)

$\underline{T a b l e}$

Title

4.2-13a Relative Power Production Rates, Percent

4.2-14 Estimated Control Rod Positions for Rise-to-Power

4.2-15 Estimated Afterheat Rates with LEU/Th fuel

4.2-16 TRISO Fuel Particle Nominal Dimensions and Standard Deviations

4.2-17 Temperature and Core-Averaged Fuel Particle Failure Summaries

4.2-18 Peak Core Averaged Gaseous Releases Comparison of Predicted-Releases and Criteria

4.2-19 Comparison of Predicted Cs-137 Release with Criteria

4.2-20 Comparison of Predicted Sr-900 Plateout Inventory with Criteria

4.2-21 Comparison of Predicted Ag-110m Plateout Inventory with Criteria

4.2-22 Replaceable Graphite Core Component Stress-to-Strength Ratio Limits

4.3-1 Safety Classification for Neutron Control Subsystem Equipment

4.3-2 Setpoints for Neutron Control Equipment

4.4-1 Reactor Internals Metallic Components and Materlals 
HTGR-86-024

LIST OF FIGURES

Figure

Title

4.1-1 Reactor System-Elevation View

4.1-2 Reactor Plan View

4.2-1 Standard Fuel Element

4.2-2 Reserve Shutdown Fuel Element

4.2-3 Fuel Element Components

4.2-4 Side Reflector Block

4.2-5 Schematic of Control Rod Section

4.2-6 Temperature Coefficient - Initial Core BOC (with Xenon and 2.5\% $\Delta \mathrm{k}$ Inserted Control Rods)

4.2-7 Temperature Coefficient - Equilibrium Core EOC (with Xenon - No Rods Inserted)

4.2-8 Temperature Coefficient (Total Reactor with Reflector Heatup)

4.2-9 Relative Radial Power Distribution (Beginning of Initial Cycle with Xenon)

4.2-10 Relative Radial Power Distribution (End of Equilibrium Cycle with Xenon Rods Withdrawn)

4.2-11 Relative Axial Power Distribution for Equilibrium Cycle

4.2-12 Axial Xenon Transient - Equilibrlum Cycle (Fuel Zoned Axially Temperature Coefficient $3.5 \times 10^{-5} /{ }^{\circ} \mathrm{C}$ )

4.2-13 Radial Xenon Transient

4.2-14 MHTGR Peak Fuel Temperature Volume Distribution for Fuel Segment 2

4.2-15 MHTGR Time-Average Fuel Temperature Volume Distribution for Fuel Segment 2

4.2-16 MHTGR Peak Graphite Temperature Volume Distribution for Fuel Segment 2

4.2-17 MHTGR Time-Average Graphite Temperature Volume Distribution for Fuel Segment 2

4.2-18 Fast Fluence Volume Distribution for Fuel Segment 2

4.2-19 Fissile Burnup Volume Distribution for Fuel Segment 2

4.2-20 Fertile Burnup Volume Distribution for Fuel Segment 2

4.2-21 Fissile Particle Failure 
HTGR - 86-024

\section{LIST OF FIGURES}

(Continued)

Figure

Title

4.2-22 Fertile Particle Predicted Failure

4.2-23 Core-Average Release/Birth for $\mathrm{Kr}-85 \mathrm{~m}$

4.2-24 Core-Average Release/Birth for Xe-138

4.3-1 Outer Neutron Control Assembly

4.3-2 Inner Neutron Control Assembly

4.3-3 Control Assemblies Installed in Vessel

4.3-4 Ex-Vessel Detectors and Location

4.3-5 Plan View of Reactor Core

$4 \cdot 3-6$

$4.3-7$

$4 \cdot 3-8$

4.3-9

Vertical Section of Reactor Core

Control Rod Drive Mechanism

4. $3-10$

Reserve Shutdown Control Equipment In An Inner Neutron Control Assembly

$4.3-11$

Reserve Shutdown Control Equipment Hopper

Reserve Shutdown Control Equipment Fuse Link

$4.3-12$

4. 4-1

4. 4-2

4. 4-3

4. 4-4

4. 4-5

4. 4-6

$4.4 \cdot 7$

Nuclear Instrumentation Ranges

4. $4-8$

$4.4-9$

Nuclear Instrumentation

Reactor Core and Internals Arrangement - Elevation View

Reactor Core and Internals Arrangement - Plan View

Graphite Core Support Structure - Plan View

4. $4-10$

PSR Block Structure to the Hot Duct Entrance

$4.4-11$

Support Post and Seat Geometry

Bottom Reflector

4. $4-12$

Bottom Reflector and Graphite Core Support

Flow Distribution and Post Blocks

Flow Distribution Block

$4.4-13$

Post Block

$4.4-14$

4. $4-15$

Core Lateral Restraint Structure - Elevation View

Core Lateral Restraint Structure - Plan View

Metallic Core Support Structure

Upper Plenum Thermal Protection Structure - Isometric View

Hot Duct - Elevation View 
HTGR - $86-024$

LIST OF EFFECTIVE PAGES

Page Number

Amendment

4-i

3

4-ii

0

4-iii through 4-v

3

4-vi through 4-xi

0

4-xii through 4-xiv

6

4.1-1 and 4.1-2

0

4.1-3

3

4.1-4

0

4.1-5 through 4.1-8a

3

4.1-9 through 4.1-11

0

4. $1-12$

6

Table 4.1-1

3

Table 4.1-2 (1 of $3 / 3$ of 3 )

0

Figures 4.1-1 and 4.1-2

0

4. $2-1$

3

4. 2-2

4. $2-3$

4. $2-4$

4. $2-5$

4.2-6 and 4.2-7

4. $2-8$

4.2-9 through 4.2-11

4.2-12 through 4.2-14a

4.2-15 through 4.2-17

3

4. $2-18$

4.2-19 through 4.2-25

0

4. $2-26$

3

4. 2-27

6

4.2-28 through 4.2-30a

3

4.2-31 through 4.2-34

0

4. $2-35$

3

4.2-36 and 4.2-37

0 


\section{LIST OF EFFECTIVE PAGES \\ (Cont.)}

Page Number

Amendment

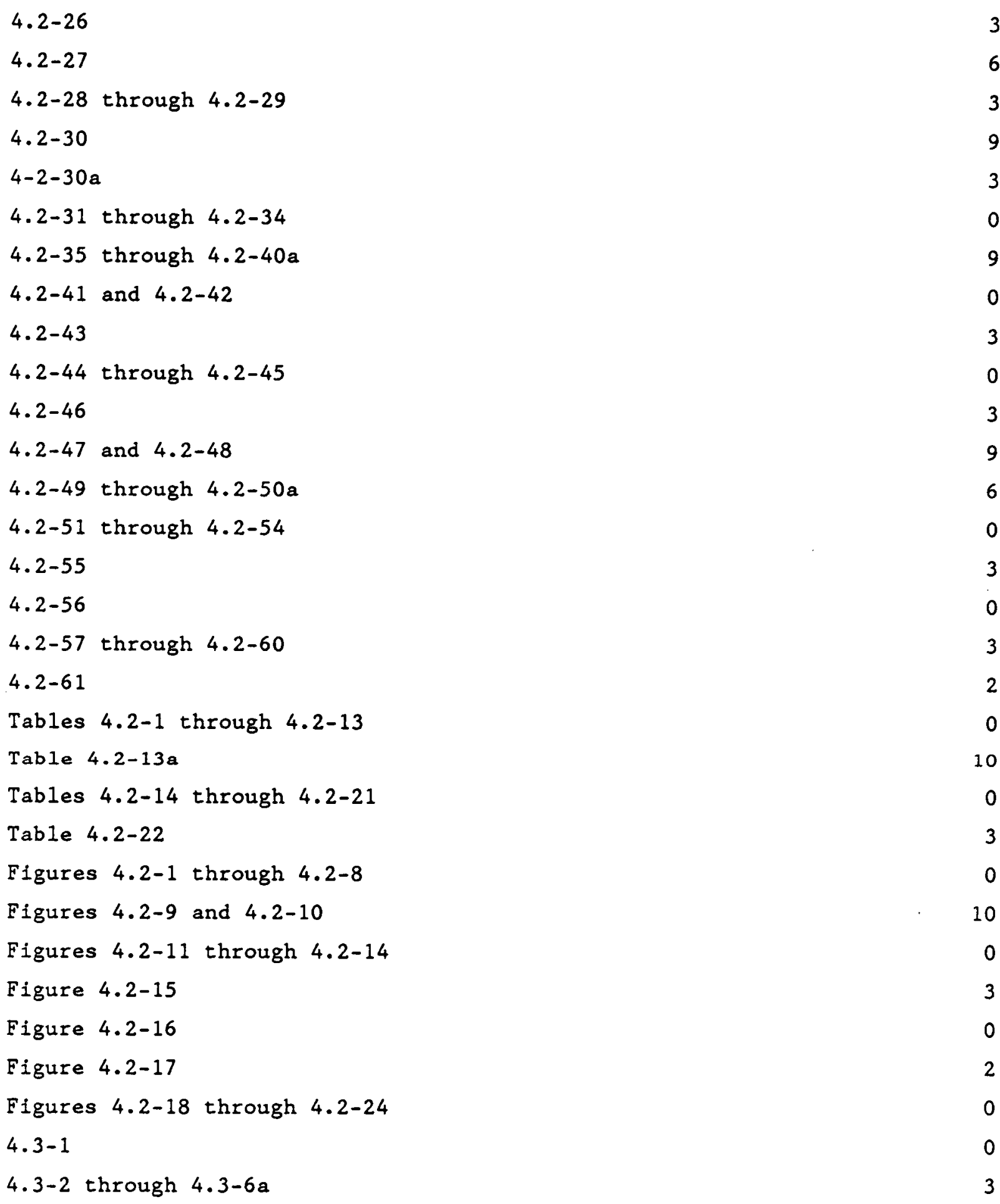




\section{LIST OF EFFECTIVE PAGES}

(Cont.)

\section{Page Number}

Amendment

4.3-7 through 4.3-10

4.3-11 through 4.3-12a

4.3-13 through 4.3-16

4.3-17 and 4.3-18

4.3-19 through 4.3-24

Table 4.3-1 ( 1 of $2 / 2$ of 2 )

Table 4.3-2

Figures 4.3-1 through 4.3-12

4.4-1 through 4.4-3

4.4-4 through 4.4-12

.... 4.4.-13 through 4.4-14a

4.4-15 through 4.4-18

4.4-19 and 4.4-20

2... 4. 4-21

4. 4-22

4. 4-23

4.4-24

4.4-25 through 4.4-35

4. 4-36

4. 4-38

Table 4.4-1

Figures 4.4-1 through 4.4-3

Figure 4.4-4

Figures 4.4-5 through 4.4-15 
HTGR - 86- 024

CHAPTER 4

REACTOR

\subsection{REACTOR SYSTEM}

The Reactor System (RS) is identical for each of the four modules of the 4 x 350 MWt Standard MHTGR plant. It consists of three subsystems, i.e., Reactor Core Subsystem (RCSS), Neutron Control Subsystem (NCSS), and Reactor Internals Subsystem (RISS). These subsystems are described in detail in Sections $4.2,4.3$, and 4.4 , respectively.

\subsubsection{Summary Description}

The Reactor System, and particularly the Reactor Core Subsystem, design has evolved to the current level of design detail, as described below, through a series of design choices which individually, and in combination, emphasize passive or inherent safety, and which assure that both user and top-level regulatory requirements will be met by the design.

A few of the more important design choices which are discussed below have included the power density, annular core configuration and dimensions, core height, top entry, and gravity-assisted control for both the primary and backup (diverse) control system(s). In addition, a high as-manufactured fuel quality has been specified to assure that the primary containment of radionuclides within the fuel particle coatings is realized to the required degree, i.e., to assure that the PAG dose limits are met at the EAB and that the occupational exposure are less than 10 percent of 10CFR20. A fuel loading and fuel cycle selection has been made to achieve a high burnup for minimizing fuel cycle costs while assuring a strong negative temperature coefficient of reactivity over all normal operation and accident temperature ranges.

The radial annular active core dimensions, in combination with the choice of the outer reflector dimensions allow the maximum power rating while providing a cooling pathway to the vessel wall to assure acceptable fuel temperatures during passive decay heat removal. The annular configuration allows a 350 
HTGR - 86- 024

MWt module power rating whereas a maximum rating of only 250 MWt could be achieved with a cylindrical core.

The active core height has been chosen to allow a maximum power rating while assuring axial power shape stability to xenon oscillations over a normal burnup cycle.

The number and location of the top entry control rods and the diverse reserve shutdown control have been specified to assure that the reactor thermal power is controlled both for normal and off-normal conditions. The radial thickness of the active core annulus was specified on the basis of assuring that the control rod worths of the reflector-located rods would meet all shutdown and operating control worth requirements. The choice of reflector control, coupled with the choice of a control system withdrawal sequence and safety classification was made to assure that the control rod integrity is maintained during passive decay heat removal.

The Standard MHTGR does not have a PWR-type containment building. The required degree of fission product control is achieved by the use of high-quality fuel and by taking credit for the intrinsic retentivity of the ceramic core and the natural removal mechanisms for radionuclides that occur in the primary coolant circuit.

The primary components of each RS (core, reflectors, and associated supports, restraints, and controls) are contained in the reactor vessel. The nuclear heat is generated in the reactor core. Removal of the heat energy is provided by the Heat Transport System (HTS) with the main circulator providing the driving force to supply helium coolant into an upper core inlet plenum and to draw heated coolant from a bottom core outlet plenum. The primary coolant is distributed to numerous coolant channels running vertically through the core. The outlet plenum directs the flow to the central portion of the coaxial cross duct which channels the helium flow to the steam generator vessel (see Chapter 5). 
Control of the fission energy generation rate during reactor power operation and assurance of adequate shutdown margin is provided by movable control rods. The mechanisms which drive the control rods are located in penetrations in the reactor vessel top head.

Monitoring of core power level during power operation is provided by ex-vessel neutron flux detectors. Flux monitoring at lower powers and at shutdown conditions is provided by source range detectors which are located in the side reflector. The reactor core and reflectors rest vertically on a support structure below the core and are restrained by a core lateral restraint structure located between the outer side reflector and the reactor vessel.

\subsubsection{Eunctions and 10CFR100 Design Criteria}

The functions and the 10CFR100 Design Criteria for the RS are given in the following sections.

\subsubsection{Power Generation Functions}

The power generation functions, which must be performed by the RS, are to:

\section{Produce reactor energy}

2. Maintain energy transfer

3. Maintain reactor shutdown

Reactor energy is produced, for power production and startup/shutdown conditions, by generating heat from the fission energy produced in a controlled manner. The energy is then transferred to the helium primary coolant flow within the core.

Reactor shutdown is maintained by the insertion of sufficient poison material to meet the shutdown margin, and by transferring the decay heat to the primary coolant. 


\subsubsection{Radionuclide Control Functions}

The radionuclide control functions that must be performed to meet all dose criteria for all three goals, but especially 10 CFR 100 of Goal 3 , are described in the following paragraphs (see Figure 1.2-3).

In order to control radionuclide release from the core, the RS must function to control radionuclide transport from the core which, in turn, requires the retention of radionuclides in the coated fuel particles while limiting fuel temperatures to ensure that the required graphite attenuation of radionuclides outside of the coated fuel particle is accomplished.

Additional Goal 3 functions that are required to retain the radionuclides within the coated fuel particles and to limit fuel temperatures are to control heat generation, to remove core heat, and to control chemical attack.

The RCSS and NCSS must provide the capability to control heat generation with moveable poisons and to control heat generation with inherent feedback. The moveable poison control function is accomplished both with a primary and a diverse secondary moveable poison control, while control with inherent feedback requires a negative temperature coefficient of reactivity. The NCSS and the RISS within the RS, also perform the function of heat generation control by maintaining the geometry for insertion of moveable poisons into the core. The NCSS monitors the neutron flux.

The function of achieving reactor shutdown is accomplished by moveable poison control employing both primary and diverse control capability. The function of removing core heat is accomplished by conducting and radiating heat to the vessel wall and by maintaining the geometry for such heat transfer. The core power density and geometry facilitate the function for removing core heat to the vessel wall.

The function to control chemical attack requires that the effects of air and moisture ingress be mitigated to limit fuel hydrolysis and oxidation and retain the radionuclides within the coated particles. The RISS performs the 
function of limiting fuel oxidation by including an upper plenum thermal protection structure which limits the upper vessel temperature and maintains primary coolant boundary protection to limit the potential for ingress of air into the core.

\subsubsection{Classification}

The RS is "safety related".

\subsubsection{10CFR100 Design Criteria for Radionuclide Control}

The following 10CFR100 Design Criteria apply:

10CFR100 Design Criterion I: The reactor fuel shall be designed, fabricated, and operated such that radionuclides are retained within the fuel to the extent that releases to the primary coolant will not exceed acceptable values.

10CFR100 Design Criterion II: The vessels and other components that limit or prevent the ingress of air or water shall be designed, fabricated, and operated such that the amount of air or water reacting with the core will not exceed acceptable values.

10CFR100 Design Criterion III: The reactor shall be designed, fabricated, and operated such that the inherent nuclear feedback characteristics ensure that the reactor thermal power will not exceed acceptable values. Additionally, the reactivity control system(s) shall be designed, fabricated, and operated such that during insertion of reactivity the reactor thermal power will not exceed acceptable values.

10CFR100 Design Criterion IV: The intrinsic dimensions and power densities of the reactor core, internals, and vessel, and the passive cooling pathways from the core to the environment shall be designed, fabricated, and operated such that the fuel temperatures will not exceed acceptable values. 


\subsubsection{Radionuclide Control Design Requirements}

The radionuclide control design requirements are:

1. The RS shall limit releases of the following key radionuclides from the plant during short-term ( 0 to $2-\mathrm{hr})$ and long-term ( 0 to 30 -day) accidents to:

Nuclide

PAG (User) Limits (Ci)* Short-Term Long-Term

$\mathrm{Kr}-88$

$\mathrm{Xe}-133$

I - 131

Sr -90

Ag- $110 m$

Cs -137

$\leq 170 \quad \leq \mathrm{TBD}$

$\leq \mathrm{TBD}$

$\leq 2.6$

$\leq 0.1$

$\leq \mathrm{TBD}$

$\leq \mathrm{TBD}$

$\leq 29$

$\leq 1.2$

$\leq \mathrm{TBD}$

$\leq \mathrm{TBD}$ $\leq 2300$

\begin{tabular}{cl} 
10CFR100 (Reg) Limits (C \\
\hline Short-Term & Long-Term \\
\cline { 2 - 2 }$\leq 3400$ & $\leq \mathrm{TBD}$ \\
$\leq \mathrm{TBD}$ & $\leq 46,000$ \\
$\leq 78$ & $\leq 870$ \\
$\leq 3$ & $\leq 36$ \\
$\leq \mathrm{TBD}$ & $\leq \mathrm{TBD}$ \\
$\leq \mathrm{TBD}$ & $\leq \mathrm{TBD}$
\end{tabular}

The above Curie release limits from the plant were derived from and meet the PAG and 10CFR100 dose limits, respectively, using the meteorology and breathing rates from NRC Regulatory Guide 1.4 and the effectivities from Regulatory Guide 1.109.

2. The RS shall limit radionuclide release from the core so that exposure to personnel shall be $<10$ percent of limits specified in 10CFR20 (Applies to normal operation and A0Os only).

3. The RS shall include features to control radiation exposure to plant personnel from all core-derived radiation sources (including direct shine radiation).

4. The RS shall control radiation sufficiently to facilitate total, collective occupational exposure to $<100$ man-rem/GW(e)-yr (Applies to normal operation and AOOs only).

*See response to NRC Comment 4-7 for dissucssion of TBDs. 
HTGR - $86-024$

5. The RS along with the RVS and the Building and structures system shall assure that the Reactor Building access shall be $\geq 40 \mathrm{hr} / \mathrm{wk}$.

6. The $R S$ shall retain radionuclides sufficiently so that the radiation due to fission product plateout shall be less than:

$10 \mathrm{mR} / \mathrm{h}$ for planned maintenance.

$100 \mathrm{mR} / \mathrm{h}$ for unplanned maintenance.

7. The RS shall be designed to meet the Top-Level Regulatory Criteria for the Standard MHTGR given in Section 3.2.

For additional information related to this section, see the response to NRC Comment 4-7.

\subsubsection{Design Description}

\subsubsection{System Configuration}

The RS is located inside a steel pressure vessel which is connected to the steam generator vessel by a crossduct. The arrangement of all components within the RS is shown in Figure 4.1-1.

The active core consists of hexagonal graphite fuel elements containing blind holes for fuel rods and full length channels for helium coolant flow. Selected fuel elements contain channels for insertion of reserve shutdown material. The reserve shutdown material channel is blind in the bottom-most fuel row in these selected elements. The hexagonal fuel elements are stacked to form columns (10 fuel elements per column), which rest on support structures. The columns of the active core form an annulus, with columns of hexagonal replaceable graphite reflector elements in the central region and surrounding the active core. A plan view of the RS is shown in Figure 4.1-2. The annular core configuration (Figure 4.1-2) was selected, in combination with the power density, to achieve a maximum power rating and still permit passive core heat removal while maintaining fuel temperature at 
$-\leq 1600^{\circ} \mathrm{C}\left(2912^{\circ} \mathrm{F}\right)$ during depressurized core heat removal by the Reactor Cavity Cooling System (RCCS). Selected reflector elements in both the central and side reflector contain channels for top entry control rods and for nuclear instrumentation. Nominal reactor design parameters are given in Table 4.1-1, and in Section 5.1.

Around the outside of the hexagonal replaceable side reflector is a permanent side reflector which provides a transition from the core periphery to a cylindrical outer boundary. Interfacing of the graphite reflector with the reactor vessel is provided by a core lateral restraint structure which is composed of a core barrel and seismic keys.

The weight of the core and other vertical loads is transferred to the bottom head of the reactor vessel by graphite and metallic core support structures.

A metal plenum element is located on top of each core column, and forms a small flow plenum through which the primary coolant enters the top reflector and flows into the active core. The cold helium enters the reactor vessel through the outer annulus of the coaxial cross duct and then flows upward through the core inlet passages outside the core barrel to the top of the core. The coolant is heated as it flows down through the active core. It then exits into the core outlet plenum where mixing occurs and the hot helium is then channeled through the inner portion of the coaxial crossduct to the steam generator vessel.

Approximately 89 percent of the circulator helium flow passes through the upper plenum and traverses the active core through the coolant channels in the fuel elements. The remaining 11 percent bypasses the core in the coolant channels in the gaps between columns in the core and reflector and the control rod channels. The primary coolant, which passes through fuel columns, is collected into six enlarged channels in the lower portion of each of the bottom reflector blocks. The flow then splits and mixes with the coolant flow from the neighboring fuel columns in the core support block layer prior to exiting to the lower plenum. From the lower plenum the flow is channeled to the steam generator through the hot duct in the coaxial cross duct. 
The core reactivity is controlled by a combination of fixed lumped burnable poison (LBP) and movable poison. The LBP consists of boronated graphite rods located in the active core. The movable poison consists of two diverse, independent control devices of different design principles, each with the 
HTGR - $86-024$

capability to shut down the reactor. Each system relies on gravity for insertion when tripped.

The normal operating control rods are fabricated from natural boron in annular graphite compacts with metal cladding for structural support. The rods are located in channels in the outer ring of the central reflector elements and in the inner ring of the hexagonal side reflector (Figure 4.1-2). These control rods enter the core through top reactor vessel penetrations, in which the control rod drives are housed. The 24 control rods located in the inner ring of the hexagonal side reflector are "safety-related" and are used for normal control and for trip from high power conditions. They are located so as not to be damaged during depressurized or pressurized passive-heat removal events.

The six control rods located in the central reflector are not "safety-related" and are inserted only from hot-shutdown or low-power conditions to achieve a cold shutdown. Boronated graphite pellets housed in hoppers above the core provide a reserve shutdown capability. Upon actuation, these pellets drop into channels in selected columns of the active core to provide reactor shutdown in the event that the control rods are inoperable, or if necessary, to provide additional shutdown margin over what may be provided by the control rods located in the hexagonal side reflector.

Signals to the Plant Protection and Instrumentation System (PPIS) and the NSSS Control Subsystem (NCS) are supplied by neutron detectors. During power operation, the neutron flux levels are monitored by detectors located in wells between the reactor vessel and the concrete cavity wall. These detectors are distributed symmetrically around the reactor vessel at about the core midplane. During low power operation, starting up, shutting down, and while shut down, the neutron flux levels are monitored by source-range detectors, located in selected side reflector elements near the bottom of the active core. 


\subsubsection{System Arrangement}

The RS consists of three subsystems. The arrangement of the subsystems is discussed in Sections 4.2.4.2, 4.3.4.2, and 4.4.4.2.

\subsubsection{System Operating Modes}

During the startup/shutdown mode, the $\mathrm{RS}$ is in a transition mode between shutdown and energy production, with a fission power generation up to 28 percent of rated power (25 percent feedwater flow). The core thermal energy is transferred to the coolant through the same flow path as during energy production. Neutron flux monitoring at startup requires that the source range detector signals have overlapping signals with the power range ex-vessel detectors at low power levels (see Figure 4.3-11). In-vessel flux mapping units are available for periodic flux monitoring. Reactor startup from a cold shutdown condition is initiated by withdrawal of the inner reflector control rods. The inner rods are withdrawn in groups of three. For most times in the life of the plant, it is expected that the reactor will reach a cold critical state during the withdrawal of the second group of inner rods, i.e., the first group of rods will typically be fully withdrawn before a cold critical point is reached. As the power and temperature are increased, the second inner group of rods is withdrawn and the power rise is continued by the successive removal of the outer rod groups (three rods per group) in a predetermined sequence. In general, fully automatic control, which involves automatic control with a selected outer rod group, may require the availability of a group both ahead of and behind the "controlling" group. The inner rods, even though fully withdrawn, will be available for a trip following a cold startup up to the time that one group of outer rods has been withdrawn, at which point the inner rods would be inhibited from tripping.

For a planned reactor shutdown the outar rods are sequentially inserted and a warm shutdown condition is reached. (Near the end of an operating cycle a cold shutdown can be achieved with the outer rods only, prior to the full decay of xenon.) If a full cold shutdown is required, the inner rods are 
HTGR - 86-024

Inserted after a delay time such that they would not be damaged in the event of a subsequent pressurized conduction cooldown involving loss of forced core cooling.

In the energy production mode, the RS delivers thermal energy from fissions in the core, at power levels between 98 and $350 \mathrm{MWt}$ (25 percent to 100 percent feedwater flow) to the circulating helium coolant. During energy production, control is with the outer control rods only (the control rods in the central reflector are in the fully withdrawn position). These outer control rods are operated automatically on the demand signal from the NCS in symmetric groups of three control rods per group. The neutron flux level (power) is continuously monitored by the ex-vessel detectors which supply signals to both the NCS and PPIS.

In the refueling mode, the reactor vessel is depressurized. All control rods in the inner and outer reflectors are fully inserted except for two inner and two outer rods which may be removed for refueling a 60 degree sector of the core. The neutron flux level is continuously monitored by the source range detectors.

In the shutdown mode, the reactor vessel is fully pressurized or, at different times, in various stages of depressurization. Afterheat from fission product decay is generated at rates of up to about 7 percent of the core power level prior to shutdown, depending on the time interval since shutdown. The core decay heat is removed by the HTS. When the HTS is not available, the heat is removed by the Shutdown Cooling system (SCS). The outer control rods are normally fully inserted during shutdown, and meet the required shutdown margin, with due allowances for uncertainties, even if the maximum reactivity worth rod remains fully withdrawn. For cold shutdown, the control rods in the inner reflector are also inserted and for this case, the maximum reactivity worth control rod is in the inner reflector. The neutron flux level is continuously monitored by the source range detectors. 


\subsubsection{Instrumentation and Control}

The instrumentation and control required for operation of the RS is provided by the Neutron Control Subsystem (NCSS) and is discussed in Section 4.3.4.4.

\subsubsection{System Limitations}

The operating limits for the RS are discussed in Sections 4.2.4.5, 4.3.4.5, and 4.4 .4 .5 .

\subsubsection{Design Evaluation}

The evaluation of the reactor design is discussed in Sections 4.2.5, 4.3.5, and 4.4.5. For additional information related to this section, see the response to NRC Comment G-15.F.

\subsubsection{Interfaces}

Interface requirements imposed on other systems or subsystems within other systems by the Neutron Control Subsystem are identified in Table 4.1.2, which also includes a description of the interface and a quantitative expression for the interface. 
Table 4.1-1

NOMINAL REACTOR DESIGN PARAMETERS

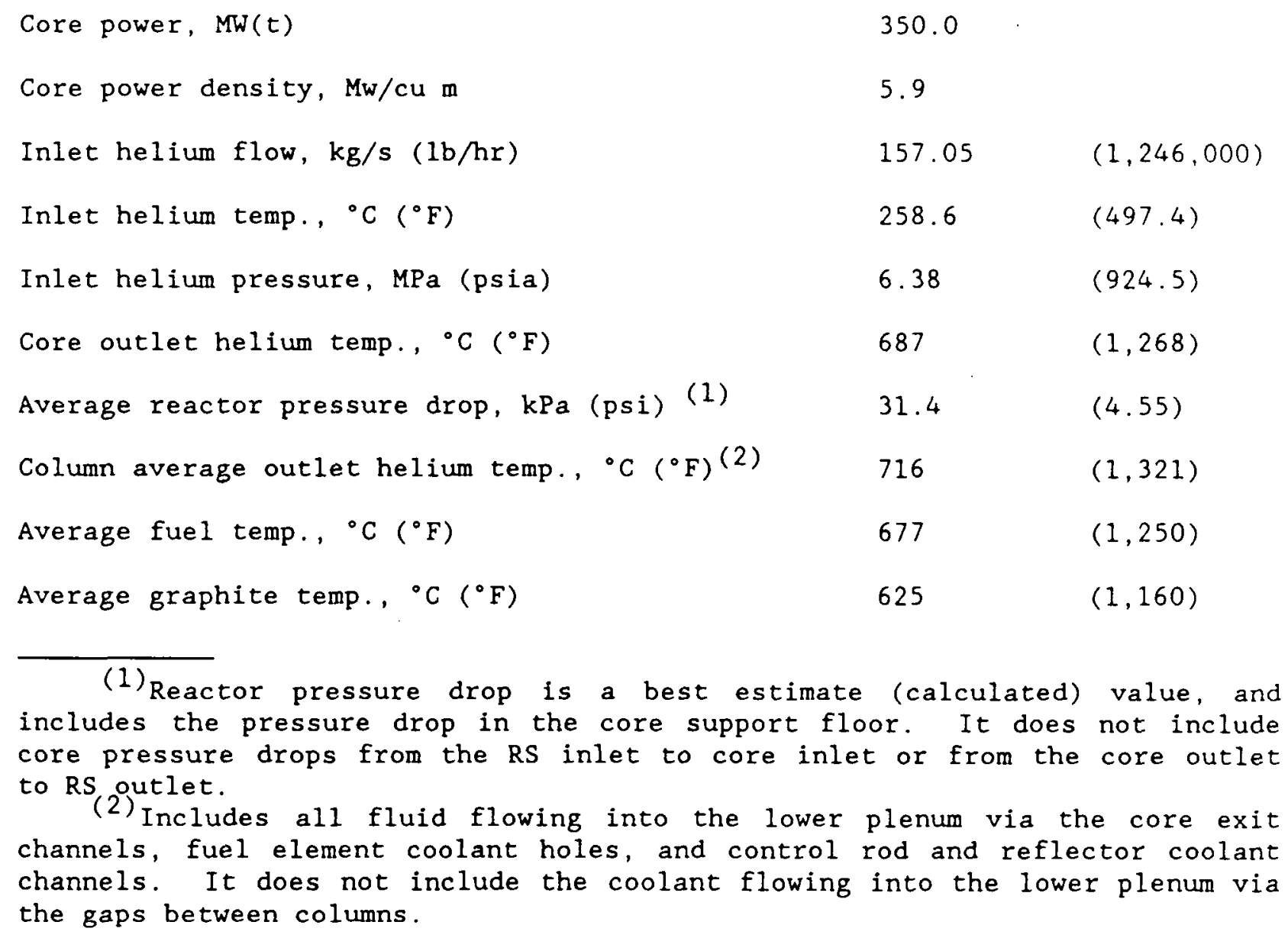

(1) Reactor pressure drop is a best estimate (calculated) value, and includes the pressure drop in the core support floor. It does not include core pressure drops from the RS inlet to core inlet or from the core outlet to RS outlet.

(2) Includes all fluid flowing into the lower plenum via the core exit channels, fuel element coolant holes, and control rod and reflector coolant channels. It does not include the coolant flowing into the lower plenum via the gaps between columns. 
HTGR $-86-024$

TABLE $4.1-2$

IDENTIFICATION OF RS INTERFACES IMPOSED ON OTHER SYSTEMS

Interfacing System

Vesse1 System
Nature of Interface

Provide support for core support structure assembly loads.

Provide support for core lateral restraint assembly loads.

Provide support for hot duct assembly.

Provide support and alignment neutron control assemblies.

\section{Interface Requirement}

Quantity: Deadweight, pressure drop, and vertical OBE seismic loads (for $0.15 \mathrm{~g}$ rated event).

Physical Interface: Reactor vessel bottom head.

Quantity: Core barrel seismic key mechanical loads owing to horizontal OBE seismic loads (for $0.15 \mathrm{~g}$ rated event).

Physical Interface: Reactor vessel sidewall.

Quantity: Hot duct mechanical loads owing to pressure drop, thermal expansion and horizontal and vertical OBE seismic loads (for $0.15 \mathrm{~g}$ rated event).

Physical Interface: Crossduct.

Quantity: Each neutron control assembly penetration shall support and align the neutron control assemblies to assure the capability for control rod insertion during an SSE event. 
Interfacing System

Provide instrumentation and controls to process the signals from two ex-core vessel neutron detectors in each well.

Plant Control, Data, Reactor power control. and Instrumentation

System

Electric Group

(Class 1E

Uninterruptible

Power Supply)

Electric Group

(Class 1E DC

Power System) control equipment.
Nature of Interface

\section{Interface Requirement}

Quantity: Monitor plant power level, and average linear power.

Physical Interface: Electrical connections at the neutron detector wells.

Quantity: The NSSS Control Subsystem shall provide setpoint signals to the neutron flux controller for use in automatically controlling the rods.

Physical Interface: Electrical connections in the nuclear instrumentation cabinet.

Power for neutron control

Quantity: The Electrical System shall supply four separate power sources per reactor module.

Physical Interface: Electric feeders.

Power for reserve shutdown
Quantity: The Electrical System shall supply two separate power sources per reactor module.

Physical Interfaces: Electric feeders. 


\section{Interfacing Systems}

Heat Transport

Shutdown Cooling

Plant Protection and Instrumentation System

\section{Nature of Interface}

Reactor core coolant.

Reactor core coolant.

Provide reactor trip system execute features.

Provide "safety-related" reactor trip systems execute features.

Provide "safety related" reserve shutdown equipment features.

\section{Interface Requirement}

Quantity: Provide helium coolant.

Physical Interface: Top of reactor core.

Quantity: Provide helium coolant when all HTS loops are inoperational and the reactor is shut down.

Physical Interface: Top of reactor core.

Quantity: Provide a power interruption system which will cause the inner control rods to fall into the core when a reactor trip is needed.

Physical Interface: Electrical connections in the reactor trip power control cabinet.

Quantity: Provide a power interruption system which will cause the outer control rods to fall into the core upon appropriate command signals.

Physical Interface: Electrical connections in the reactor trip power control cabinet.

Quantity: Provide a power control system to cause the reserve shutdown equipment to be activated upon appropriate command signals.

3 of 3 


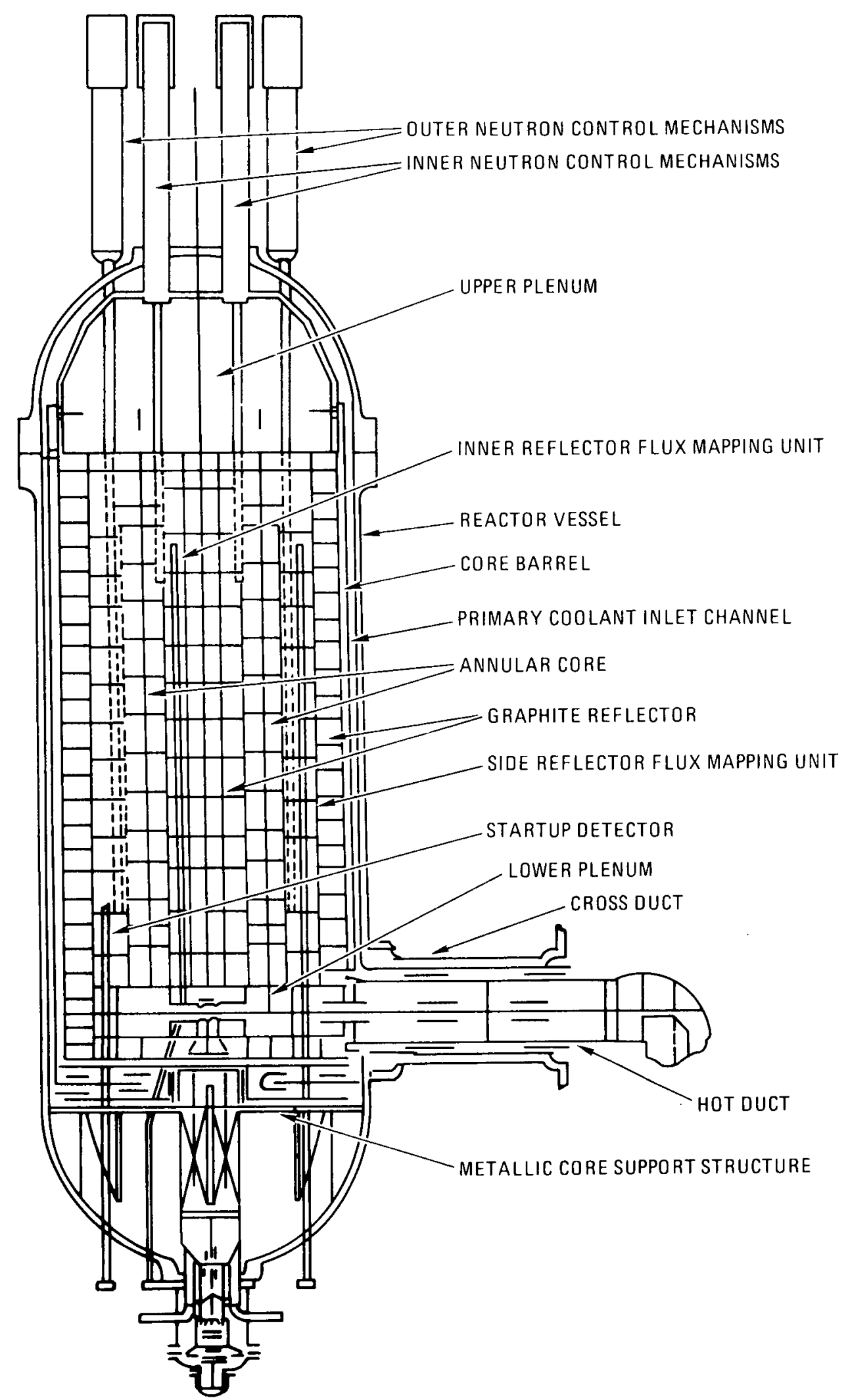

FIGURE 4.1-1

REACTOR SYSTEM - ELEVATION VIEW 


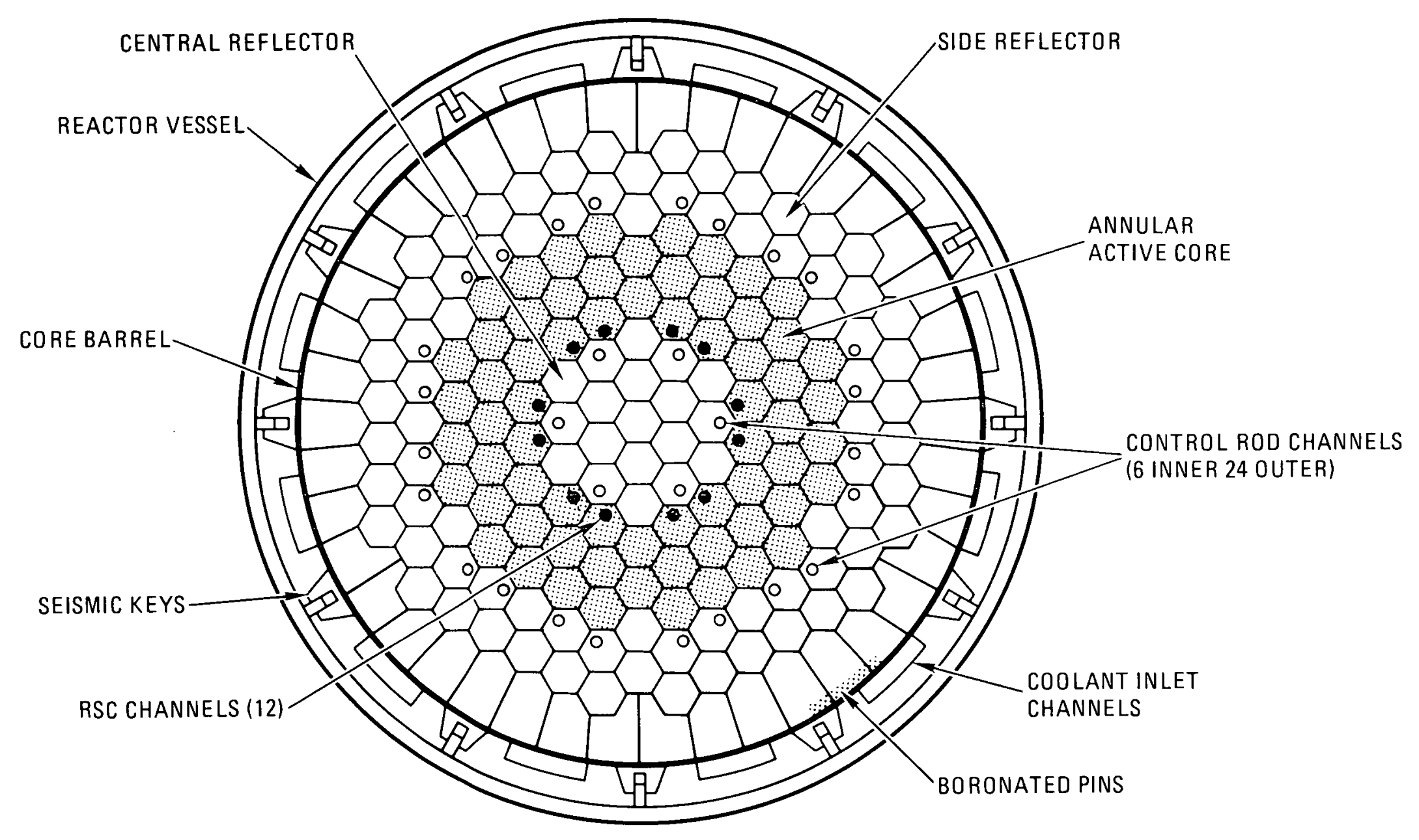

FIGURE 4.1-2

REACTOR PLAN VIEW

HIGH TEMPERATURE GAS-COOLED REACTOR PRELIMINARY SAFETY INFORMATION DOCUMENT HTGR-86-024 


\subsection{REACTOR CORE SUBSYSTEM}

\subsubsection{Summary Description}

The Reactor Core Subsystem (RCSS) consists of fuel elements, hexagonal graphite reflector elements, plenum elements, startup sources, and reactivity control material, all located inside a reactor pressure vessel. The RCSS, together with graphite components of the Reactor Internals Subsystem, constitutes a graphite assembly which is supported on a graphite support structure and restrained by a core lateral restraint structure. (See Figures 4.1-1 and 4.1-2).

The hexagonal fuel elements are stacked in columns that form an active core annulus with columns of hexagonal graphite reflector elements in the central region and surrounding the active core, as shown in Figure 4.1-2. The core produces a power of $350 \mathrm{MWt}$ at a power density of $5.9 \mathrm{MW} / \mathrm{cu} \mathrm{m}$.

To channel the coolant flow, metal plenum elements containing radiationshielding material are placed on top of the upper graphite reflector, one per column. Hexagonal graphite reflector elements are beneath the active core. These lower reflector elements initially continue the coolant hole pattern from the active core. Flow in these channels exits into the core support blocks.

The RCSS, in order to control heat generation, contains both fixed and movable poison for normal operation. The fixed poison is in the form of lumped burnable poison (LBP) rods and the movable poison is in the form of metal clad control rods. In the event that the control rods become inoperable, a backup reserve shutdown control is provided in the form of boronated pellets that may be released into the core.

\subsubsection{Functions and 10CFR100 Design Criteria}

The functions and 10CFR100 Design Criteria for the RCSS are given in the following sections. 


\subsubsection{Power Generation Functions}

The primary power generation functions, which must be performed by the RCSS, are to

1. Generate nuclear reactor heat

2. Control the neutron generation rate

3. Transfer fission and decay heat to the primary coolant flow in the core and

4. Provide sufficient neutron absorbing material to ensure that the core shutdown margin is met

Nuclear reactor heat is generated by fissioning fuel and by sustaining the chain reaction. The neutron generation rate is controlled by absorption in poisons and by inherent feedback. The shutdown margin is ensured by the use of both fixed and movable poisons. Heat transfer to the primary coolant flow is ensured by control of the core bypass flow and by maintaining the core coolant passage geometry.

\subsubsection{Radionuclide Control Functions}

The radionuclide control functions that must be performed by the RCSS to ensure meeting the dose criteria of Goal 3 were discussed in detail in Section 4.1.2.2 in relationship to the Goal 3 tree given in Figure 1.2-3. In summary, the more important radionuclide control functions are:

1. Retain radionuclides in the fuel with fuel particle coatings.

2. Control heat generation with movable control rods and with inherent feedback.

3. Remove core heat by transferring heat to helium coolant and by providing heat transfer to the RCCS by conduction and radiation. 
HTGR - $86-024$

4. Control chemical attack by selection of corrosion-resistant materials.

\subsubsection{Classification}

A11 components of the RCSS, except the neutron startup sources, are "safety related".

\subsubsection{10CFR100 Design Criteria for Radionuclide Control}

The following 10CFR100 Design Criteria apply:

10CFR100 Design Criterion I: The reactor fuel shall be designed, fabricated, and operated such that radionuclides are retained within the fuel to the extent that releases to the primary coolant will not exceed acceptable values.

10CFR100 Design Criterion III: The reactor shall be designed, fabricated, and operated such that the inherent nuclear feedback characteristics ensure that the reactor thermal power will not exceed acceptable values. Additionally, the reactivity control systems(s) shall be designed, fabricated, and operated such that during insertion of reactivity the reactor thermal power will not exceed acceptable values.

10CFR100 Design Criterion IV: The intrinsic dimensions and power densities of the reactor core, internals, and vessel, and the passive cooling pathways from the core to the environment shall be designed, fabricated, and operated such that the fuel temperatures will not exceed acceptable values.

\subsubsection{Radionuclide Control Design Requirements}

The radionuclide control design requirements are given below:

1. The RCSS shall be designed to limit primary circuit activity during normal operation to the following levels at the 50 and 95 percent 
confidence levels:

\begin{tabular}{|c|c|c|c|c|}
\hline \multirow[b]{3}{*}{ Nuclide } & \multicolumn{2}{|c|}{ Circulating (Ci) } & \multicolumn{2}{|c|}{ Plateout (Ci) } \\
\hline & $(P \geq 50$ & $(P \geq 95$ & $(P \geq 50$ & $(P \geq 95$ \\
\hline & Percent) & Percent) & Percent) & Percent) \\
\hline $\mathrm{H}-3$ & 0.2 & 0.7 & - & - \\
\hline $\mathrm{Kr}-88$ & 5.5 & 22 & - & - \\
\hline $\mathrm{Xe}-133$ & 2.5 & 10 & - & - \\
\hline$I-131$ & 0.02 & 0.08 & 20 & 80 \\
\hline Sr -90 & - & - & 0.32 & 3.2 \\
\hline$A g-110 m$ & - & - & 7.3 & 73 \\
\hline $\mathrm{Cs}-137$ & - & - & 70 & 700 \\
\hline Cs -134 & - & - & 13 & 132 \\
\hline
\end{tabular}

The above limits were derived from the plant release limits defined in Section 4.1 .3 with the following assumptions:

a. Compliance with the 0-2 hr PAG dose limits during a rapid depressurization imposes the most constraining requirements on the fuel design.

b. The fractional liftoff of plateout activity will be less than 5 percent for all credible depressurization transients, and

c. A building wake factor of 1.5 is appropriate for the Standard MHTGR Reactor Building design.

2. The RCSS shall be designed to limit radionuclide release from the core during core conduction cooldown transients to: 
HTGR - 86-024

$$
\begin{array}{cc}
\text { PAG (User) Limits ( } i) & \text { 10CFR100 (Reg) Limits (Ci) } \\
(P \geq 50 & (P \geq 95
\end{array}
$$

Nuclide

$\mathrm{Kr}-88$

$\mathrm{Xe}-133$

I - 131

Sr -90

$\mathrm{Ag}-110 \mathrm{~m}$

Cs -137
Percent)*

$\leq \mathrm{TBD}$

$\leq 2300$

$\leq 870$

$\leq 36$

$\leq \mathrm{TBD}$

$\leq \mathrm{TBD}$

\section{Percent)*}

$\leq \mathrm{TBD}$

$\leq 46,000$

$\leq 26,000$

$\leq 1080$

$\leq \mathrm{TBD}$

$\leq \mathrm{TBD}$

The above core release limits were derived from the 0.30 day release limits given in section 4.1 .3 with the assumption that the core releases of condensibles would be attenuated by a factor of 30 by primary circuit removal mechanisms prior to environmental release.

3. The RCSS shall be designed to limit incremental radionuclides release from the core during short-term design basis events, such as steam ingress, with direct release to the environment:

$\begin{array}{lllll} & \begin{array}{l}\text { PAG (User) } \\ (P \geq 50\end{array} & \begin{array}{l}\text { Limits (Ci) } \\ (P \geq 95\end{array} & \begin{array}{l}\text { 10CFR100 } \\ (P \geq 50\end{array} & \begin{array}{c}\text { Reg) Limits (Ci) } \\ (P \geq 95\end{array} \\ \text { Nuclide } & \begin{array}{l}\text { Percent)* } \\ \text { Percent) }\end{array} & \begin{array}{l}\text { Percent)* } \\ \text { Percent) }\end{array} \\ \mathrm{Kr}-88 & \leq \mathrm{TBD} & \leq 148 & \leq \mathrm{TBD} & \leq 3378 \\ \mathrm{I}-131 & \leq \mathrm{TBD} & \leq 260 & \leq \mathrm{TBD} & \leq 7800\end{array}$

The above I-131 release limits were derived from the $0-2 \mathrm{hr}$ limits given in Section 4.1 .3 with the assumption that the core release would be attenuated by a factor of 100 by plateout and washout in the primary and secondary coolant circuits prior to environmental release. This assumption will be validated by the Regulatory Technology Development Plan.

For additional information related to this section, see the response to NRC Comment 4-8.

*See response to NRC Comment 4-7 for discussion of TBDs. 


\subsubsection{Design Description}

\subsubsection{Subsystem Configuration}

The annular reactor core consists of fuel elements, graphite reflector elements, plenum elements, reactivity control material, and neutron startup sources. Each of these components is described below.

\subsection{Fuel Elements}

There are two types of fuel elements, i.e., standard elements and elements that contain a channel for reserve shutdown control material.

All fuel elements are $H-451$ graphite in the form of right hexagonal prisms $793 \mathrm{~mm}$ ( $31.2 \mathrm{in.}$ ) high and $360 \mathrm{~mm}$ ( $14.2 \mathrm{in.}$ ) across the flats. Fuel and coolant holes are parallel through the length of the prism in a regular triangular pattern of two fuel holes per coolant hole. The standard fuel element, shown in Fig. 4.2-1, contains a continuous pattern of fuel and coolant holes except for a central handling hole surrounded by smaller coolant holes and the corner holes in which the fuel is replaced with lumped burnable poison (LBP). Twelve reserve shutdown fuel elements differ in that they contain a $95.25 \mathrm{~mm}$ (3.75 in.) diameter channel for reserve shutdown material, as shown in Figure 4.2-2. This channel replaces 20 fuel and 12 coolant holes.

At each element-to-element interface in a column, there is a dowel/socket connection which provides alignment for refueling, alignment of coolant channels, and which transfers seismic loads on fuel elements.

A $35.0 \mathrm{~mm}$ (1.38 in.) diameter handling hole, located at the center of the element, extends down about one-third of the height, with a ledge where the grapple of the fuel handling machine engages.

The LBP consists of boron carbide $\left(B_{4} C\right)$ granules dispersed in graphite rods. The $\mathrm{B}_{4} \mathrm{C}$ granules are pyrocarbon $(P y C)$ coated to limit oxidation and 
loss from the system. The amount of burnable poison is determined by reactivity control requirements, which may vary with each reload cycle. The diameters of the rods and their concentration are specified according to requirements for self-shielding of the absorber material to control its burnout rate relative to the fissile fuel burnout rate. The goals are near complete burnout of the material when the element is replaced, as well as to minimize the hot excess reactivity swing over the cycle.

The fuel compacts, contained in the fuel holes, have a $12.45 \mathrm{~mm}(0.49 \mathrm{in}$.) diameter with a length of $49.3 \mathrm{~mm}$ ( $1.94 \mathrm{in.})$. Each fuel compact is a mixture of fissile, fertile, and graphite shim particles bonded by a carbonaceous matrix. These fuel compacts are stacked in each of the fuel element fuel holes. Each stack contains 15 fuel compacts except for the six stacks under each of the four dowels which contain 14 fuel compacts.

The reference fuel cycle employs low-enriched uranium and thorium (LEU/Th). The fissile fuel is a two-phase mixture of 19.9 percent enriched $\mathrm{UO}_{2}$ and $\mathrm{UC}_{2}$, usually referred to as UCO, having an oxygen-to-uranium ratio of 1.7 in fresh fuel. The fertile fuel is $\mathrm{ThO}_{2}$. Both fertile and fissile fuels are in the form of dense microspheres coated in a fluidized bed with a TRISO coating whose primary purpose is to retain fission products. The coated fissile and fertile particles are blended and bonded together with a carbonaceous binder into fuel compacts. Figure 4.2-3 illustrates the TRISO coating concept and how the fuel is packaged in the fuel element. Details of the TRISO particle design are given in Table 4.2-1. The purpose of each TRISO particle component and reason for specification of the properties is given in Table 4.2-2.

The TRISO particles are bonded into a fuel compact (see Table 4.2-3) for the following reasons:

1. Prevent mechanical interaction between the fuel particles and moderator graphite by maintaining the fuel as a free standing nonstructural component of the fuel element. 
2. Maximize the thermal conductivity in the fuel.

3. Provide a secondary barrier to metallic fission product release through adsorption mechanisms.

The as-manufactured fuel quality and in-service performance limits are given in Table 4.2-4. Analysis with the design methods described in Section 4.2.5.2.2.1.2 has demonstrated that fuel of this quality will assure that the radionuclide requirements established in section 4.2 .3 are satisfied. Fuel quality is being developed and qualified as part of the Regulatory Technology Development Plan. (Ref.1)

For additional information related to this section, see the response to NRC Comment 4-3.

\subsection{Reflector Elements}

The hexagonal H-451 graphite reflector elements have similar size, shape, and handling hole to the fuel elements (except that some are half-height or three-quarter height). Differences exist in the hexagonal reflectors, depending on their locations in the core, i.e., top, bottom, side, and central reflectors which are described below.

The reflector above the active core is composed of two layers, a layer of full-height elements over a layer of half-height elements. The top reflector elements channel coolant flow to the active core and provide for the insertion by gravity, of reserve shutdown material into the active core. They have the same array of coolant holes as the fuel element and the same holes for the insertion of reactivity control devices.

The bottom reflector under the active core is also composed of two layers, a layer of three-quarter height elements over a layer of half-height elements. The bottom reflector elements provide for the passage of coolant from the active core into the core support. In the standard columns, this is accomplished by collecting the coolant channel flows into six intermediate coolant holes $68 \mathrm{~mm}(2.68$ in.) in diameter. The channel for the reserve shutdown material is blind and stops in the lower reflector. 
HTGR $-86-024$

The side reflector consists of two rows of hexagonal reflector columns, as shown in Figure 4.1-2. The side reflector hexagonal elements are solid elements, with the exception of the fuel handling hole, and the control rod channel in 24 of the reflector columns adjacent to the active core as shown in Figure 4.2-4. The control rod channel diameter is $102 \mathrm{~mm}$ ( 4 in.) and stops at an elevation just below the active core. The control rod channel is centered $119.4 \mathrm{~mm}$ ( $4.7 \mathrm{in.})$ from the center of the reflector element, in the corner nearest the active core.

The central reflectors consist of two types of hexagonal graphite elements, the standard element and the control element which contains a control rod channel of the same size as in the side reflector control columns. In addition, the elements adjacent to the active core have coolant holes.

The hexagonal reflector elements in the four areas are further distinguished by two residence-time designations: 1) replaceable - elements adjacent to the active core which are scheduled for periodic replacement, and 2) permanent - elements farther away from the core which are scheduled to reside in place for the lifetime of the plant.

There is a dowel/socket connection at the element-to-element interface for all elements in a column. This connection provides alignment for refueling, alignment of control rod channels, and transfers seismic loads on reflector elements.

\subsection{Plenum Elements}

The metal plenum elements rest on top of the upper reflector, one per core column. Their functions are to provide relatively tight gaps between elements for limiting the core bypass flow, to provide keyed connections between elements for limiting lateral motion of columns during refueling, and to provide boronated graphite for neutron shielding.

There are five variations in hole patterns for plenum elements, depending on location. All plenum elements have pickup holes for handling during 
refueling and bottom sockets for mating with the dowels on the top of the reflector elements. All hexagonal plenum elements also have dowels on top for the purpose of fuel element-to-element alignment during refueling. The plenum elements are made of Alloy $800 \mathrm{H}$.

The standard fuel column plenum elements have vertical channels to direct coolant to the channels in the top reflector. The volume between these vertical channels is filled with boronated graphite pellets to enhance shielding. The reserve shutdown fuel column plenum elements differ in that they contain a hole for reserve shutdown material.

The plenum elements located on top of the regular hexagonal reflector and reflector control columns also contain boronated graphite shielding and local coolant channels in selected locations. The plenum elements located on top of the permanent side reflector columns contain boronated graphite shielding, but do not have coolant holes.

\subsection{Control Rods}

The control rod is designed to be a semi-articulated type rod, similar to the Fort St. Vrain design, but greater in length. The control rod absorber material consists of 40 weight percent natural boron in $\mathrm{B}_{4} \mathrm{C}$ granules uniformly dispersed in a graphite matrix. The annular absorber compacts have an inner diameter of $52.8 \mathrm{~mm}(2.08 \mathrm{in.})$ and an outer diameter of $82.6 \mathrm{~mm}$ (3.25 in.). These compacts are enclosed in metal canisters (see Figure 4.2-5) for structural support and to restrict oxidation of the boron carbide. The canister material is Alloy $800 \mathrm{H}$ with a thickness of $1.27 \mathrm{~mm}$ $(0.050$ in. ).

Small tabs on the outside of the canisters center the control assembly string in the control rod channel. Coolant flows down the outside and down the center hole to remove heat generated in the canisters. The string of canisters is designed with mechanical flexibility to articulate any postulated offset between elements during a seismic event. Thus, full insertion is ensured for any operating condition. The control rod drive 
mechanisms are described in Section 4.3.

\subsection{Reserve Shutdown Material}

The reserve shutdown material consists of 40 weight percent natural boron in $\mathrm{B}_{4} \mathrm{C}$ granules dispersed in a graphite matrix and formed into pellets. The $\mathrm{B}_{4} \mathrm{C}$ granules are coated with $\mathrm{PyC}$ to limit oxidation and loss from the system during high-temperature, high-moisture events. When released into the reserve shutdown channel in the fuel element, the pellets have a packing fraction of $\geq 0.55$. The release mechanism is described in section 4.3.

\subsection{Startup Neutron Sources}

Small neutron sources in the fuel handing hole in selected fuel elements provide adequate neutron flux levels to ensure a controlled startup.

\subsubsection{Subsystem Arrangement}

The RCSS arrangement is illustrated in Figures 4.1-1 and 4.1-2, where the active core is shown surrounded by the reflectors. The control rod and reserve shutdown locations are also shown in Figure 4.1-2.

\subsubsection{Subsystem Operating Modes}

The operating modes of the Reactor Core Subsystem, in conjunction with the Neutron Control and Reactor Internals Subsystems, are discussed in Section 4.1.4.3.

\subsubsection{Instrumentation and Control}

All instrumentation and control required for the operation of the Reactor Core Subsystem is provided by the Neutron Control Subsystem (NCSS) and discussed in Section 4.3.4.'. 


\subsubsection{Subsystem Limitations}

The RCSS has several design limits. These include limits on fast neutron fluence to the graphite components, peak graphite stress limits, fuel particle packing fraction limits, metallic component temperature limits, including control rods, and core shutdown margin limits. These limits are:

$\begin{array}{lll} & \text { Operating } & \text { Accident } \\ \text { Fast neutron fluence } & 2.5 \times 10^{21} \mathrm{n} / \mathrm{cm}^{2} & 2.5 \times 10^{21} \mathrm{n} / \mathrm{cm}^{2} \\ \text { Core shutdown margin } & \geq 18 & \geq 18 \\ \text { Fuel particle packing } & & \\ \text { fraction } & \leq 608 & \leq 608 \\ \text { Peak graphite stress } & 358 \text { of mean } & 808 \text { of mean } \\ & \text { strength } & \text { strength } \\ \text { Plenum element temp. } & 700^{\circ} \mathrm{F} & 1900^{\circ} \mathrm{F} \\ \text { Control rod clad temp. } & 1200^{\circ} \mathrm{F} & 2200^{\circ} \mathrm{F}\end{array}$

\subsubsection{Design Evaluation}

The evaluation of the reactor core design is discussed in the following sections.

\subsubsection{Failure Modes and Effects}

\subsection{Coolant Channel Blockage}

The coolant flow paths through the reactor core are maintained by the integrity of the core graphite elements and their dowel/socket connections. The elements and their dowel/socket connections are designed conservatively such that cracking or other damage that would result in blockage of any flow path is highly unlikely. (The potential for damage is also discussed in conjunction with the structural design criteria in Section 4.2.5.2.4.4.) 
It is unlikely, but remotely possible that flow to the coolant channels may be disrupted by materials, such as thermal insulation, entering the core upper plenum and blocking the coolant hole entrance. In the unlikely event that such blockage should occur, the consequence depends on the number of channels blocked, the extent of the obstruction, and the location of the blockage. The most likely blockage would be a partial blockage of one or a few coolant channels. Flow in the affected channels would be reduced, but even in the event of a complete local blockage, would not be zero over the full column height. Some cross-flow to and from the affected coolant channels would occur upstream and downstream of the blockage.

The heat generated near the affected coolant channels would be removed in part by the reduced flow in the coolant channels and in part by conduction to adjacent, unaffected coolant channels in the affected column and adjacent fuel columns.

The increase in fuel temperature for severe blockage incidents can result in some local failure of fuel particle coatings, releasing activity to the coolant. However, due to the high-temperature structural integrity of graphite, the fuel remains in the graphite matrix, and safe conduction of heat to nearby unblocked channels is maintained. A very extensive blockage would result in more significant fuel failure and would be detected ultimately by an increase in the gaseous fission product activity in the primary circuit. If, as a result, circulating activity levels approach operating limits, the reactor would be shutdown and the damaged fuel replaced.

\subsection{Control Channel Blockage}

Like the coolant channels, the neutron absorber channels are maintained by the structural integrity of the graphite elements and other components within the RS. (These channels are the control rod channels in the reflector columns adjacent to the active core and the reserve shutdown channels in the innermost ring of fuel columns.) Although some limited cracking of the graphite elements is possible (see discussion in Section 4.2.5.2.4.4), 
HTGR - 86- 024

extensive structural damage which could lead to blockage of the channels is extremely unlikely. For blockage to occur, it would be necessary to either shear off the dowels or sever the graphite elements into several pieces, neither of which is a credible event.

Even if such extensive damage should occur, several control channels would have to be blocked before the ability to shut down the reactor would be affected. Shutdown is normally accomplished with the outer control rods. If one or more of these should fail to be inserted because of channel blockage, the reserve shutdown control could be used.

\subsubsection{Steady-State Performance}

The steady-state performance of the reactor core is discussed in the following subsections on nuclear, thermal/hydraulics, structural, and fuel performance.

\subsection{Nuclear Performance}

\subsection{Reactivity Control}

The core reactivity is controlled by a combination of LBP, movable poison, and a negative temperature coefficient. The LBP consists of boronated graphite rods located in the corners of fuel elements.

The control rods are used for reactivity control during operation, as well as ensuring that a minimum shutdown margin of $0.01 \Delta \rho$ is met ( $\Delta \rho$ is defined as $\left.k_{2}-k_{1}\right)$. The control rods are designed to be operated

$$
k_{1} k_{2}
$$
either individually or in groups (three control although control on groups of rods would normally be carried out under automatic control. The rods can be operated either manually or automatically (in the load range of 25 percent to 100 percent feedwater flow): The control rod group withdrawal speed is 1.2 ips. This speed permits load changes at $\leq 5$ percent per minute, ensures acceptable core performance in the event of a control rod withdrawal accident, and ensures adequate response to a PPIS trip. 
HTGR - 86- 024

For additional information related to this section, see responses NRC Comments G-7.B, G-7.C, 4-15 and 4-16.

Nominal Reactivity Control Requirements: The components that make up the nominal expected reactivity control requirements for typical beginning-ofcycle (BOC), middle-of-cycle (MOC), and end-of-cycle (EOC) conditions are listed in Table 4.2-5. The maximum core operating excess reactivities are the currently estimated values to be expected at the three indicated times in cycle and these estimates reflect two systematic biases. First, the mass flow rates are based on a fissile uranium loading required to give an EOC unrodded reactor $k_{\text {eff }}$ of 1.01 in all cycles and second, the uranium mass flow calculations neglect impurities in the graphite which are expected to be worth about 0.5 percent $\Delta \rho$ at EOC. These two systematic biases then yield, on net, a best estimate of an EOC operating excess reactivity of 0.5 percent $\Delta p$ which is to cover any unforeseen uncertainties related to achieving the reference burnup. Additional details of the random uncertainties related to the control requirements, as well as the control worths, are discussed below. 
HTGR $-86-024$

Nominal Reactivity Control Worths: The calculation of control rod and reserve shutdown control (RSC) worths under both hot and cold conditions have been performed for both the initial cycle BOC conditions and the equilibrium cycle EOC condition. In addition, the worth of all 30 control rods has been calculated for other times in cycle for both the initial core and an equilibrium reload cycle to determine how the total control rod bank worth is expected to change over the cycle. Other specific rod pattern control worths for hot conditions for the selected withdrawal of groups of three rods each in the outer bank of control rods were analyzed to define the maximum group worth for use in the transients analyzed in Chapter 15. These calculations were only performed for the EOC equilibrium core loading since that cycle condition yields the minimum temperature coefficient of reactivity and the maximum rod group reactivity worth for a rod group withdrawal transient. No reduction in control rod poison worth due to burnup has been assumed in this or other EOC rod worth calculations discussed below, although this effect would be minimal.

A summary of the calculated control reactivity worths for both hot and cold conditions is given in Table 4.2-6 for the end-of-equilibrium cycle conditions. The eight groups of three rods each which make up the outer bank of rods were analyzed under hot conditions for several withdrawal sequences. The minimum group reactivity worth was for the first group withdrawn and was worth 0.9 percent $\Delta \rho$. The maximum group worth was found to be 2.1 percent and 20 percent uncertainty was assumed for the Chapter 15 rod withdrawal transients in which a value of 2.5 percent $\Delta \rho$ was assumed. The total worth of the trip of the outer rod bank is 12.7 percent $\Delta \rho$ hot, but this worth was reduced to 9 percent $\Delta \rho$ for all Chapter 15 transients involving a trip.

These results show that hot control reactivity worths are typically 15 to 20 percent higher than the cold worths. The nominal cold reactivity worth of all 30 control rods is 20.2 percent $\Delta \rho$. which is significantly larger 
HTGR $-86-024$

than the currently estimated nominal requirement of 7.7 percent $\Delta \rho$ for the EOC conditions. If a maximum worth rod in the inner bank is assumed stuck out at shutdown, the nominal cold shutdown margin for EOC conditions would be about 10 percent $\Delta \rho$.

Similar nominal values of the calculated control worths for the initial core and at other times in cycle have been combined with selected values for the EQ-EOC conditions and are given in Table 4.2-7.

Calculations of the 30-rod bank worths for other time points during the depletion show that the rod and RSC worths are a function of time in the cycle rather than which cycle it is (initial or equilibrium) even though the cycles differ greatly in length and fuel loading. (The initial cycle is all fresh fuel with a cycle length of 555 effective full-power days (EFPD) and a carbon-to-thorium atom ratio of 600 , while the equilibrium reload has half new fuel and the remainder depleted fuel, loaded for 482 EFPD and a $\mathrm{C} / \mathrm{Th}=$ 1000.)

Random Reactivity Uncertainties Affecting Shutdown Margins: Uncertainties in calculations, input data, measurements, fuel loadings, basic constants, etc., must be taken into account in any estimate of core reactivity and shutdown margin calculations to ensure that the minimum criteria are met. Two types of uncertainties are considered, i.e., random uncertainties and systematic errors. The reactivity effects of random uncertainties, such as fuel loading tolerances, can be combined in a root mean square (RMS) fashion; while the reactivity effects of systematic errors, such as core impurities, must be summed.

The uncertainties are assumed to be independent parameters, i.e., random in nature. Because of their randomness, the net effect was calculated by taking a square root of the sum of squares of the relevant items. The calculated and/or estimated reactivity uncertainties are given in Table 4.2-8. The total uncertainties affecting the cold shutdown margin during the cycle are given in Table 4.2-9. The estimated cold shutdown margin, including all uncertainties, is given in Table 4.2-10. 
HTGR - 86- 024

The reactivity uncertainties due to systematic biases were not included in Table 4.2-8. A systematic bias is defined as a known effect, which affects reactivity, but which was not, for various practical reasons, included in analytical calculations. As noted earlier, the systematic biases due to added fissile loading and neglect of graphite impurities have already been taken into account in the expected nominal reactivity requirements.

From the results given in Table 4.2-10 it is seen that the inclusion of the nine random uncertainties results in combined uncertainties of typically \pm 1.7 to \pm 2.0 percent $\Delta \rho$ for EOC conditions. In the worst case of the maximum worth stuck rod, the shutdown margins, including uncertainties, range from 2.56 percent $\Delta \rho$ to 8.65 percent $\Delta \rho$ depending on time in cycle.

Reserve Shutdown Requirements and Reactivity Worths: The primary reactivity requirement for the reserve shutdown control (RSC) is to maintain shutdown $(k \leq 0.99)$ indefinitely at or below the refueling temperature $192^{\circ} \mathrm{C}\left(377^{\circ} \mathrm{F}\right)$. Any partially inserted control rods or other fully withdrawn control rods are assumed not to be inserted in determining the RSC capability to meet this requirement, i.e., the maximum core operating excess reactivity is assumed to be held down by control rods and this excess reactivity is not a component of the requirement for the RSC. The reserve shutdown control equipment (RSCE) is also required to trip following the trip of the outer bank of control rods, and after some delay, for transients initiated by moisture ingress during power operation.

Table 4.2-11 gives the reactivity control requirement and the estimated RSC reactivity worth for the beginning, middle, and end of cycle. The uncertainty assignment treatment is similar to that assumed for the control rod shutdown margin uncertainty except that the uncertainty reflects \pm 10 percent uncertainties in the RSC requirement and predicted worths. The nominal predicted RSC worth for the three times in cycle has been based on the predicted RSC reactivity worth without any inserted outer control rods that would normally be inserted to hold down the hot excess reactivity. This results in an underestimate of the RSC worth, particularly for the MOC condition. For example, in Table 4.2-7, the beginning of initial cycle 
(BOIC) cold reactivity worth of $12 \mathrm{RSC}$ alone is 10.1 percent $\Delta \rho$ and the worth of 24 outer rods alone is worth 8.1 percent $\Delta \rho$ while the worth of 12 RSC and 24 outer rods is worth 28.4 percent $\Delta \rho$. Therefore, the worth of 12 RSC in the presence of 24 outer rods is 28.4 percent $\Delta \rho-8.1$ percent $\Delta \rho=20.3$ percent $\Delta \rho$, which is double the worth of the RSC alone. The expected MOC operating conditions would require approximately one to two groups of outer rods inserted which would increase the RSC worth by about 10 percent or more over the currently calculated value. This effect has been conservatively neglected in these calculated RSC worths. The comparisons are also conservative in that the $\operatorname{cold} 27^{\circ} \mathrm{C}\left(80^{\circ} \mathrm{F}\right)$ RSC worths have been assumed to apply to the refueling temperature condition.

These results indicate that the RSC worth exceeds the requirements for shutdown at refueling temperature for all times in cycle. The RSC would also meet cold shutdown requirements for both the MOC and EOC condition but would not quite allow shutdown to cold conditions for the BOC condition.

Temperature Coefficient of Reactivity: A 10CFR100 Design Criterion for the RCSS is that the core shall have inherent feedback characteristics to control heat generation. As discussed below, this criterion is met for all temperature ranges including accident temperatures.

The overall isothermal temperature coefficient has contributions from the 1) prompt fuel doppler, 2) moderator, and 3) the inner and outer reflectors. The active-core doppler and active-core isothermal temperature coefficients are strongly negative, particularly over the operating temperature range for the beginning-of-cycle initial core (BOC-IC) condition [up to $700^{\circ} \mathrm{C}\left(1292^{\circ} \mathrm{F}\right)$ ] and at the heatup temperature range [greater than $700^{\circ} \mathrm{C}\left(1292^{\circ} \mathrm{F}\right)$ ] for the end of cycle equilibrium core (EOC-EQ) condition. Calculations for the beginning of equilibrium cycle condition also show strong negative coefficients. The active core isothermal temperature coefficient is about $-7.0 \times 10^{-5} /{ }^{\circ} \mathrm{C}$ at the BOC-IC condition and about $-3.7 \times 10^{-5} /{ }^{\circ} \mathrm{C}$ for the EOC-EQ condition at full power operating temperature of $700^{\circ} \mathrm{C}\left(1292^{\circ} \mathrm{F}\right)$.

The effective reactivity coefficient for the reflector heatup is positive for the $B O C$ and the EOC condition and is equivalent to about $+2 \times 10^{-5} /{ }^{\circ} \mathrm{C}$ for 
HTGR - 86- 024

BOC conditions and about $+3 \times 10^{-5} /{ }^{\circ} \mathrm{C}$ for EOC conditions over the normal operating temperature range. In the calculation of the total reactor isothermal temperature coefficient of reactivity, the fuel and moderator temperatures up to about $1700^{\circ} \mathrm{C}\left(3092^{\circ} \mathrm{F}\right)$ have been varied isothermally. The inner and outer reflector temperatures on which the reflector contributions to the temperature coefficient calculations are based, are assumed to be in equilibrium with the respective fuel temperatures as discussed later. Table 4.2-12 lists the assumed temperature conditions used to determine the temperature coefficients of reactivity that have been plotted as a function of the active core temperature in Figures 4.2-6 to 4.2-8. A nine neutron group radial diffusion calculational model with cross sections based on the temperatures indicated in Table 4.2-12, was utilized to determine the temperature coefficients of reactivity.

The total reactivity change (temperature defect) due to temperature changes over the normal operating range must include the heatup of both the inner and outer reflectors to their full power temperatures and this effect is included in the evaluation and in the reactivity control requirements to cover the hot-to-cold reactivity swing given in Table 4.2-5. For all anticipated operational occurrences (AOOs), design basis events (DBES), or "safety-related" design conditions (SRDCs) initiated by moisture ingress or rod bank withdrawal, the resulting core temperature rise is modest up to the time of the trip and the reflector temperature rise greatly lags behind the active core temperature rise. The positive feedback due to reflector heatup can be ignored in the near-term transient analysis, as discussed in Chapter 15, for all cases for which a trip is assumed to occur. For long-term transient analysis such as conduction cooldown, the equilibrated reflector temperatures to be expected at the indicated fuel temperature have been assumed (see Table 4.2-12).

For long-term transient events such as conduction cooldown, the inner reflector temperature rise lags behind the core temperature rise by typically 3 to $4 \mathrm{hr}$ and only catches up to the active core temperature rise after 50 or more hours at which time the total reactor isothermal temperature coefficient is extremely negative (approximately $-10 \times 10^{-5} /{ }^{\circ} \mathrm{C}$ ) i.e. Curve $C$ of Figures 
4.2-6 and 4.2-7, as discussed below, apply only to long-term heatup temperatures and only at high temperatures.

Figure 4.2-6 shows the calculated temperature coefficient of reactivity for the BOC-IC condition. Curve $A$ is the fuel prompt doppler coefficient due to heatup of the fuel compact matrix as a function of the assumed fuel temperature. Curve $B$ is the active core isothermal temperature coefficient and is the sum of the doppler coefficient and the moderator temperature coefficient of reactivity which is also strongly negative, due in large measure to the presence of LBP in the BOC condition. The moderator coefficient, not shown in Figure 4.2-6, would be the difference between Curve $\mathrm{B}$ and Curve $\mathrm{A}$ and would be $-4.0 \times 10^{-5} /{ }^{\circ} \mathrm{C}$ at $800^{\circ} \mathrm{C}\left(1472^{\circ} \mathrm{F}\right)$, for example. Curve $\mathrm{C}$ is the total reactor isothermal coefficient and includes the positive contribution of the reflector heatup to the estimated inner and outer reflector temperatures that would result when the fuel reaches the indicated temperature.

Transients from full power conditions involving a reactor trip result in higher fuel element temperatures for the EOC-EQ condition. Figure 4.2-7 shows the calculated temperature coefficients of reactivity for that condition where the three indicated curves have the same meaning as discussed above for the BOC-IC condition. Curves $A$ and $B$, and the moderator coefficient represented by the difference between these two curves, were used in the analyses in Chapter 15 . In this case the moderator coefficient would be $-1.1 \times 10^{-5} /{ }^{\circ} \mathrm{C}$ at $800^{\circ} \mathrm{C}\left(1472^{\circ} \mathrm{F}\right)$ for example. The moderator coefficient is slightly positive in the range of $400^{\circ} \mathrm{C}\left(752^{\circ} \mathrm{F}\right)$ to about $700^{\circ} \mathrm{C}\left(1292^{\circ} \mathrm{F}\right)$ and produces a small positive reactivity prior to the trip in some of the DBEs and SRDCs. The small positive reactivity due to the moderator heatup is overshadowed by the much larger negative reactivity contribution due to the doppler coefficient. The moderator coefficient and the active-core isothermal coefficient become very negative at high fuel temperatures due in large part to the relatively high neutron capture rate in plutonium-240 at EOC conditions. The hardening of the thermal neutron spectrum with increasing moderator temperature leads to an increasing parasitic neutron capture rate in the large plutonium-240 capture resonance at $1.05 \mathrm{eV}$. 
HTGR-86-024

High-power conditions result in steady-state conditions of fuel and moderator temperatures in the $700^{\circ} \mathrm{C}\left(1292^{\circ} \mathrm{F}\right)$ to $800^{\circ} \mathrm{C}\left(1472^{\circ} \mathrm{F}\right)$ range. To verify that the EOC-EQ condition yields the least negative temperature coefficient, an additional time point corresponding to the BOC-EQ condition was also analyzed. The total reactor isothermal temperature coefficient for the BOC-EQ condition, as well as the equivalent curves for the other two time points discussed above, are plotted in Figure 4.2-8. As may be noted, the BOC-EQ condition yields a result that is similar to the BOC-IC condition and the EOC-EQ condition clearly has the least negative temperature coefficient at, or somewhat above, the nominal full power temperature range.

\subsection{Fuel Cycle}

The core Incorporates a graded LEU/Th fuel cycle with an initial cycle length of 1.9 years. Equilibrium burnup cycles are 3.3 years (equivalent full power years) and one-half of the active core being replaced each 1.65 years. There are three transition reload cycles prior to reaching the equilibrium cycle, which on average require replacing one-half of the core every 1.5 years. The transition cycle lengths have been specified to minimize radial power peaking factors due to fuel age differences so that such factors do not exceed those encountered in the equilibrium cycles. This fuel cycle is based on a 66-column annular core which operates at $350 \mathrm{MWt}$, corresponding to a power density of $5.9 \mathrm{MW} / \mathrm{cu} \mathrm{m}$.

The core is refueled by column and the two reload segments consist of one-half of the fuel element columns distributed uniformly throughout the core. Each refueling column extends the full height of the active core, i.e., ten fuel elements.

The initial core loading is characterized by an average carbon-to-thorium atom ratio (C/Th) of 600 and a carbon-to-uranium $(C / U)$ atom ratio of 834 . This provides initial metal loadings of $2346 \mathrm{~kg}(5161 \mathrm{lb})$ Th plus $1726 \mathrm{~kg}$ (3797 lb) $U$ (enriched to 19.9 percent in U-235). The cycle length and resultant core loadings assure a strong negative temperature coefficient to control heat generation with inherent feedback. 
HTGR-86-024

The specification of the equilibrium-cycle fuel loadings and of the loadings in the transition to equilibrium from the first core involves an optimization process. ClTh values by reload are determined which minimize the equilibrium uranium requirements consistent with satisfying limits on power peaking caused by fresh fuel in proximity to partially burned fuel. Minimizing the uranium makeup loading contributes toward minimizing fuel-cycle costs.

After the initial cycle and three transition reloads, reloading is done at $1.65 \mathrm{yr}$ intervals. For the equilibrium conditions $(\mathrm{C} / \mathrm{Th}=1000, \mathrm{C} / \mathrm{U}=700)$, the average fuel loadings are $706 \mathrm{~kg}(1553 \mathrm{lb})$ Th plus $1032 \mathrm{~kg}(2270 \mathrm{lb})$ U (19.9 percent U-235). These are the equilibrium combinations that sustain a 3.3-yr burnup lifetime at 80 percent equivalent availability. Table 4.2-12 gives the fuel loading for the first seven cycles.

The core delayed neutron fraction $(\beta)$ varies from 0.0065 at beginning of cycle in the initial core to 0.005 at the end of an equilibrium cycle. This average delayed neutron fraction was obtained by weighting the $\beta$ 's of each of the three major core fission isotopes, U-235, Pu-239, and U-233, by their relative contribution to the neutron production rate. For example, the relative production rate contribution from U-235 varies from $100 \%$ at the beginning of the initial cycle to $57 \%$ at the end of an equilibrium cycle. The relative production rates of these three nuclides are given in Table 4.2-13a.

\subsection{Power Distributions}

Power distributions are controlled to limit fuel temperature, to limit fuel element stresses, and to meet the core exit gas temperature hot streak requirements. The principal means of power distribution control is the creation of zones of differing average fuel concentrations.

The power talloring by zone is achleved by redistributing the fissile and fertile fuel separately, basically providing heavier concentrations of fissile material (uranium) in the higher power zones, but keeping the total core or reload fuel loadings unchanged. The requirement for reasonably stable power 
distributions with burnup means that the within-zone conversion ratios must be about the same. To achieve this, the relative distribution of the uranium does not necessarily match the power distribution exactly, and the thorium and uranium zoning factors are not identical. The burnable poison constituents also are zoned to maintain the specified power split among the three radial zones of the active core.

The current zoning scheme consists of three radial and three axial zones. The three axial zones consist of five, three, and two fuel elements in the top, middle, and bottom zones, respectively. The three radial zones 
HTGR - 86-024

correspond to the three annular rings of fuel elements, i.e., 18, 24, and 24 fuel columns as seen in Figure 4.1-2. Both fissile and fertile particles are zoned for each of the nine fuel zones. The fuel zoning decreases the average power in the inner two fuel zones, and increases the average power in the outer fuel zone such that radial relative power factors of $0.87,1.00,1.10$ are achieved and maintained over the cycle.

The advantages to shifting the power outward in the core are:

1. Stress in the outer blocks is decreased, because the outer reflector is cooler than the inner one.

2. The reactivity worth of the outer control rods is increased, and the worth of the inner control rods is decreased. This ensures earlier withdrawal of the inner rods.

3. A reduction in peak fuel temperature in cooldown transients.

Figure 4.2-9 gives the hexagonal averaged relative power distribution at the beginning of the initial cycle, after equilibrium xenon-135 is reached. The values given correspond to seven hexagonal regions per fuel column and in turn are an area-weighted average of seven point powers in each of the seven hexagonal regions that comprise a fuel column. Each column was subdivided into these seven subregions to yield greater power profile detail and to allow within-column burndown of localized power tilts. The average relative power by fuel zone is $0.87 / 1.01 / 1.08$, i.e., close to the desired shape as noted above.

This power distribution assumes that the control rods are withdrawn in groups of three, separated by $120 \mathrm{deg}$, i.e., one rod in each sector. This minimum size of rod group reduces the impact of the control rods on the axial power profile. Control rod withdrawal during the depletion is performed by: first, removal of the two inner rod groups, followed by the four outer groups next to the older fuel segment, and then the four outer groups next to the newest fuel segment. The order within these sets of four groups maintains the widest separation between inserted rods. 
The effect on power distribution of the outer control rods is seen in Figure 4.2-9. All control rods are fully withdrawn except for group 1, which is partially withdrawn. Although each of the eight outermost columns in the 120 degree sector has the same fuel loading, the relative power varies significantly because of the presence of these control rods.

Figure 4.2-10 gives the hexagonal averaged relative power distribution for the end of cycle 6 with all control rods withdrawn. The average relative power by radial fuel zone is $0.71 / 1.05 / 1.16$. This illustrates another effect of the control rods on the power distribution. The control rod withdrawal sequence removes outer rod group 1 last, which means that it is inserted for almost the entire cycle. This suppression of the fuel burnup in the adjoining column creates a power peak when outer rod group 1 is withdrawn at the end of the cycle. This more limiting radial power profile is only typical of the last few days of an equilibrium cycle. This limiting power profile, for which a 1.75 radial power factor results, was used for obtaining the maximum fuel temperature in the Chapter 15 transients including those DBEs and SRDCs related to a three rod group withdrawal transient. A switching of control group sequence one or two times in the 1.65-year burnup cycle would reduce the 1.75 radial power factor to a lower value, but this has been retained conservatively for the accident analysis.

Figure 4.2-11 shows the axial power distribution for an equilibrium cycle. This distribution indicates 65 percent of the power in the top zone, 25 percent in the middle zone, and 10 percent in the bottom zone. This distribution is expected to minimize peak fuel temperatures. The selection of the active core height of ten fuel elements was made to yield a maximum power rating while maintaining an axial power shape that remains stable with burnup and stable to axial xenon transients.

\subsection{Control Rod Positions for Rise-to-Power}

From the control requirements, given in Table 4.2-5, estimates of the inner and outer control rod group positions for typical conditions and time in cycle are made. These estimates are given in Table 4.2-14 for typical BOC, 
HTGR - 86-024

MOC, and EOC conditions. Nominal calculated values of the components of the control requirements at each cycle condition were used and these preliminary estimates of critical rod positions do not include either requirements uncertainties or rod group reactivity worth uncertainties.

The data shown includes the estimated hot-unrodded $k_{\text {eff }}$, cold shutdown $k_{\text {eff }}$ cold critical rod patterns, hot 25 percent power rod patterns and hot 100 percent power rod patterns expected for each cycle condition. Critical rod "positions" are expressed as the expected percentage of the rod group reactivity worth that is withdrawn at the indicated condition. A range of critical rod "positions" at the indicated power level is shown and corresponds to position changes expected as xenon buildup takes place at the indicated power level.

As shown, the maximum hot excess reactivity is expected to occur at mid-cycle (MOC) conditions and is the result of the differing burnout rate of LBP compared to fissile fuel burnout. This hot excess reactivity results in the highest value of the cold shutdown $k_{e f f}$ and thus to the least inner rod group withdrawal prior to reaching the cold critical or 25 percent power level.

The conceptual design iteration, upon which these results are based, has not yet included a detailed and optimized LBP design required to yield an MOC hot excess reactivity of $\leq 2.5$ percent $\Delta k$. Additional detailed LBP design will be required to achieve the goal of $\leq 2.5$ percent $\Delta k$. The estimates given for MOC conditions assume that this goal will be achieved after more detailed LBP design studies have been completed.

\subsection{Stability of Power Distribution to Xenon Oscillations}

Preliminary analyses were made on the stability of the radial and axial power shapes to xenon-induced transients. The degree of damping, with time, of the resulting power oscillation was used to indicate the relative power stability of the core. The perturbations incorporated into these test calculations were much more severe than could be encountered in actual operation at power 
due to repositioning of control rods or other effects. (The perturbation involved removing all the xenon from the bottom half of the core and doubling the xenon in the top half of the core.)

Figure 4.2-12 represents the current evaluation of axial xenon oscillation stability to the hypothetical xenon redistribution. The relative power in axial element 4 (in top half) and element 10 (at bottom of core) were used to illustrate the power stability to the hypothetical xenon redistribution. The power factors in these two element locations prior to the transient were 1.42 for element 4 and 0.67 for element 10. As noted from the results given in Figure 4.2-12, the power perturbation is damped and the relative power in these two locations returns to values that are close to their original values after about 75 hours.

The radial power stability of the core was calculated for an end of equilibrium cycle condition without control rods or burnable poison present.

The two columns studied were the column with the highest power prior to the beginning of the transient and the geometrically opposite column through the center of the core. The relative power for these two columns as a function of time after the transient is shown in Figure 4.2-13. The radial power perturbation that resulted from the xenon perturbations was strongly damped in this case. There was no evidence of power peaks rotating around the core.

These data show that the reactor is stable to xenon-induced transients.

\subsection{Residual Heat Loads}

The preliminary afterheat rates, expressed as percent of normal operating power, are given in Table 4.2-15. Fits to these data points have been used to define the residual heat loads for use in the transient analyses reported in Chapter 15 .

For additional information related to this section, see the responses to NRC Comment 4-18. 
HTGR - 86- 024

\subsection{Fuel Performance}

A fuel performance analysis was conducted to predict the core temperature distributions, fuel particle failure, and gaseous and metallic fission product release under normal operating conditions at full power. The calculated fission product releases were then compared with the radionuclide design criteria, summarized in section 4.2 .3 and presented in detail in Section 11.1 to determine the adequacy of the fuel and core designs with regard to the radionuclide control requirements.

For additional information related to this section see the responses to NRC Comments 4-1, 4-4, 4-5, 4-9; G-15.E, 11-7 and 11-8.

\subsection{Methodology and Assumptions}

\subsection{1 Fission Produc: Release Barriers}

Typically, the two dominant sources of fission product release from the core are as-manufactured, heavy metal contamination (i.e., heavy metal outside the coated particles) and particles whose coatings fail in service. In addition, the volatile metals (Cs, $\mathrm{Ag}, \mathrm{Sr}$ ) can, at sufficiently high temperatures and long times, diffuse through the SiC coating and be released from intact TRISO particles.

There are multiple barriers to the release of fission products from an HTGR core: the fuel kernel, the particle coatings, the fuel rod matrix, and the fuel element graphite. The effectiveness of the individual barriers to fission product release may depend upon a number of factors including the chemistry and half-iffes of the various fission products, temperature, and irradiation effects. These barriers are described briefly below.

The first barrier to fission product release is the fuel kernel itself. The kernel of a failed fuel particle retains $>95$ percent of the radiologically important, short-lived fission gases such as $\mathrm{Kr}-88$ and $\mathrm{I}-131$; however, the effectiveness of a UCO kernel for retaining gases can be reduced if the exposed kernel is hydrolyzed by reaction with trace amounts of water vapor 
which may be present in the helium coolant; the $\mathrm{ThO}_{2}$ kernel does not hydrolyze, and its release characteristics are unaffected by the presence of water. (These kernal compositions were selected to minimize the susceptibility to chemical attack; $U C O$ and $\mathrm{ThO}_{2}$ are more stable in the presence of oxidants than the all-carbide kernels used in previous HTGR designs.) The retentivity of oxiditic fuel kernels for long-lived, volatile fission metals such as $\mathrm{Cs}, \mathrm{Ag}$, and $\mathrm{Sr}$ is strongly dependent upon the temperature and the burnup.

The primary barrier to fission product release from the core is the silicon carbide and/or pyrocarbon coatings of each fuel particle. Both the SiC and outer pyrocarbon (OPyC) coatings provide a barrier to the release of fission gases. The SiC coating acts as the primary barrier to the release of metallic fission products because of the low diffusion coefficient of fission metals in SiC; the OPYC coating is also partially retentive of Cs at lower temperatures but provides 1ittle holdup of $\mathrm{Ag}$ and $\mathrm{Sr}$.

The fuel rod matrix is rather porous and provides little holdup of the fission gases which are released from the fuel particles. However, the matrix is a composite material which has a high content of amorphous carbon, and this constituent of the matrix is highly sorptive of metallic fission products, especially Sr. While the matrix is highly sorptive of metals, it provides little diffusional resistance to the release of fission metals because of its high interconnected porosity.

The fuel element graphite, which is denser and has a more ordered structure than the fuel rod matrix, is somewhat less sorptive of the fission metals than the matrix, but it is much more effective as a diffusion barrier than the latter. The effectiveness of the graphite as a release barrier decreases as the temperature increases. Under typical steam-cycle core conditions, the fuel element graphite attenuates the release of $\mathrm{Cs}$ and $\mathrm{Ag}$ from the core by more than an order of magnitude, and the $\mathrm{Sr}$ is essentially quantitatively retained.

The above discussion applies to the transport of fission products that are produced in the kernels of intact particles. Obviously, fission products 
HTGR - 86-024

resulting from fissions in heavy metal contamination outside of the particles are not attenuated by the kernels or coatings, nor are the fission products produced in the kernels of failed particles appreciably attenuated by the failed coatings. In these cases, the fission products must be controlled by limiting the respective sources and by the fuel element graphite in the case of the fission metals.

For additional information related to this section, see the response to NRC Comment 4-2.

\section{Fuel Particle Fallure}

The existing HTGR fuel data base, which includes that obtained from the Peach Bottom I Nuclear Plant and the Fort St. Vrain Nuclear Generating Station, and the DOE HTGR fuel development program has allowed a fundamental understanding of the failure mechanisms and performance characteristics of the HTGR fuel system. A discussion of the extensive fuel fabrication and fuel irradiation experience for HTGR fuels is provided in the Regulatory Technology Plan (Ref. 1). The existing data base has supported the development of performance models for predicting the behavior of fuel materials under all conditions expected in a prismatic core HTGR.

Under normal operating conditions, the performance of coated fuel particles is calculated by models defining several potential failure mechanisms. The HTGR fuel performance models calculate fission product release to the reactor coolant during normal operation from the following six sources:

1. Coating damage during fuel manufacture, resulting in heavy metal contamination on coating surfaces and in the fuel body matrix.

2. Pressure vessel failure in particles with defective or missing coating layers.

3. Pressure vessel failure in standard particles, i.e., particles without manufacturing defects. 
4. Failure of the SiC coating caused by fission product/SiC interaction.

5. Failure of the SiC coating by thermal decomposition.

6. Failure of the SiC coating due to kernel migration in the presence of a thermal gradient.

These failure mechanisms and the physical models to describe them are discussed in Ref. 2 and are embodied in the SURVEY/PERFOR code described in Section 4.2.5.2.2.1.2.

\section{Fission Gas Release}

The models and material property data for predicting fission gas release from heavy metal contamination and failed particles are described in Refs. 2 and 3. These models give the release-rate-to-birthrate ratio ( $R / B$ ) from contamination and failed particles as a function of chemical element, isotope half-life, temperature, and burnup. In addition, the effect of fuel hydrolysis, or reaction of exposed fuel kernels with water, on gas release is included. These gas release models are embodied in the SURVEY/PERFOR code (Section 4.2.5.2.2.1.2).

\section{Fission Metal Release}

The models and material property data for predicting fission metal release from fuel particles and fuel elements are described in Ref. 4. The transport of fission metals through the kernel, coatings, fuel rod matrix, and fuel element graphite is modeled as a transient diffusion process in the TRAFIC code (Section 4.2.5.2.2.1.2). The sorption isotherms which are used in the calculation of the rate of evaporation of volatile metals from graphite surfaces account for an increase in graphite sorptivity with increasing neutron fluence. 
HTGR - $86-024$

4.2.5.2.2.1.2 Computer Codes

Fuel Performance/Fission Product Iransport Codes

The computer codes used to predict fuel performance and fission product transport are listed below, and the supporting codes which provide input to these fuel performance and fission product transport codes are described below under the heading, support Codes. 
HTGR - 86- 024

SURVEY/PERFOR (Ref. 5): An analytical/finite-difference, core-survey code which calculates the steady-state, full-core, fuel particle failure, and the core-average fission gas release rates. An automatic interface with SURVEY/THERM (see below) provides burnup, fluence, and temperature distributions; likewise, the temperature and fuel failure distributions calculated by SURVEY/PERFOR are passed on to the metallic release code TRAFIC.

SURVEY/HYDROBURN (Ref. 5): An optional subroutine in SURVEY which calculates the oxidation of fuel element graphite and the hydrolysis of failed fuel particles by coolant impurities, particularly water vapor. Transport of water vapor through the graphite web of the fuel element is modelled as a combination of diffusion and convection due to cross-block pressure gradients. The effects of catalysts and burnoff on the graphite oxidation kinetics are modelled.

TRAFIC (Ref. 6): A core-survey code for calculating the full-core release of metallic fission products. TRAFIC is a finite-difference solution to the transient diffusion equation for the multihole fuel element geometry with a convective boundary condition at the coolant surface. The temperature and failure distributions required as input are supplied by an automatic interface with the SURVEY/PERFOR code.

COPAR (Ref. 7): A stand-alone code, as well as a subroutine in the TRAFIC code, which calculates the transient fission product release from failed and intact coated particles with burnup-dependent kernel diffusivities. COPAR is an infinite-series solution to the transient diffusion equation for a multi-region spherical geometry and arbitary temperature and failure histories.

\section{$\underline{\text { Support Codes }}$}

SURVEY/THERM (Ref. 5): An analytical/finite-difference, core-survey code which calculates the steady-state, full-core fuel and graphite temperature distributions, fuel particle burnup distributions, and fluence distributions. 
Automatic interfaces with the physics codes provide the necessary 3D power and flux distributions required as input to SURVEY/THERM. Flow correlations required as input are calculated with the POKE code (Ref. 8). The particle burnups, fluences, and the fuel and temperature distributions calculated by SURVEY/THERM are passed on to the fuel performance code SURVEY/PERFOR and to the metallic release code TRAFIC.

RADC (Ref. 9): A zero-dimensional, steady-state inventory code for calculating the overall plant mass balance for an abitrary number of radionuclides, including the total core inventory, the circulating inventory, the plateout inventory, and the He Purification system inventory. The current version of RADC contains a 250-nuclide library with the nuclear properties (decay constants, fission yields, etc.) from the 1978 compilation by Meek and Ryder. RADC has been used extensively to calculate the source terms that appear in Section 11.1 of previous HTGR PSARs and of the Standard MHTGR PSID.

RANDI (Ref. 10): An advanced plant mass balance code with capabilities beyond those of the RADC code described above; these include explicit treatment of transient effects, a more detailed determination of core inventories including the inventories within fissile and fertile fuel particles, and a compartment model of the primary coolant circuit.

\subsection{3 Application of the Methodology}

The methodology described above can be used to evaluate the degree of fission product control that would be affected by a particular fuel and core design. The evaluation is a sequential and iterative process. The first step is to define the maximum allowable core release rates for the key nuclides (e.g., Kr88, Cs137, Sr90, I131) based upon externally imposed design requirements, such as offsite dose limits, occupational exposure limits, and minimum Reactor Building access times; these radionuclide design criteria are summarized in Section 4.2.3 for the key radionuclides and are developed in detail in Section 11.1 . 
A two-tier set of radionuclide design criteria, referred to as "Maximum Expected" and "Design" criteria, have been defined for the MHTGR. In principle, the "Design" criteria are derived from externally imposed requirements, such as site-boundary dose limits. The "Maximum Expected" criteria are then derived by dividing the "Design" criteria by an uncertainty factor, or design margin, to account for uncertainties in the design methods. This uncertainty factor is a factor of 4 for the release of fission gases from the core and a factor of 10 for the release of fission metals. The fuel and core are to be designed such that there is at least a $50 \%$ probability that the fission product release will be less than the "Maximum Expected" criteria and at least a 958 probability that the release will be less than the "Design Criteria".

The "Maximum Expected" fission product release criteria are used for Environmental Impact Reports, for planning component removal and maintenance procedures, and for other applications where "best-estimate" results are appropriate. The "Design" criteria represent upper limits for all design basis conditions. They are used for conservative safety analyses, sizing of the Helium Purification and Radwaste Systems, the design of plant hardware including service and shipping casks, and the specification of the associated shielding requirements.

The terminology "Maximum Expected" reflects the expectation that the actual primary circuit activity will always be less than that criteria throughout the life of the plant for the following reasons. First and foremost, the fuel and core are designed so the best estimate of the core releases are less than these "Maximum Expected" criteria. Secondly, the long-lived fission products, such as 30-year Cs-137, build up slowly in the primary circuit throughout the 40-year plant lifetime. Finally, the core release rates 
HTGR - 86- 024

fluctuate slightly during an operating cycle; they are lowest immediately following fuel reloading and highest at end of cycle (assuming constant power operation).

The uncertainty factors used in converting "Design" to "Maximum Expected" values quoted above are based primarily upon engineering judgment. There has been an ongoing effort for the past 15 years to quantify the predictive accuracies of the design methods and codes used to predict HTGR source terms by comparison of code predictions with observed fission product behavior in Peach Bottom Unit 1, Fort St. Vrain, and numerous fuel irradiation capsules and test loops. Although there is considerable scatter, the fission gas release predictions are typically within a factor of 4 of the measurements and the metal release predictions within a factor of 10 . Moreover, a technology development program (Ref. 1) is planned to support the design of the Standard MHTGR which is expected to refine and validate the methodology used to predict fuel performance and fission product transport.

Using the fuel quality specifications given in Table 4.2-4 and calculating the fission product release under various design basis conditions, releases are estimated to meet the above criteria for both confidence levels.

The mechanical design of the fuel and core for the standard MHTGR is described in section 4.2.4.1.1. The results of the nuclear analysis of the core (Section 4.2.5.2.1) provided the core power and flux distributions for the fuel performance analysis.

Nominal thermal and flow parameters were used in the fuel performance analysis except that the thermal power was increased to 102 percent of nominal full power per NRC Regulatory Guide 1.49 to account for uncertainties in core power measurements. The major thermal parameters used in the analysis are listed in Table 4.1-1. Nominal values of material properties were used in the analysis. The design correlations for the material properties of the H-451 graphite and the fuel rods account for thermal expansion, and the effects of fluence and temperature on thermal conductivity and irradiation-induced shrinkage. These thermal and flow parameters and 
HTGR - $86-024$

models were used to calculate fuel and graphite temperatures as a function of time during the first six cycles of power operation, which is sufficiently long to adequately approximate an equilibrium core.

The reference fuel design, quality, performance models, and methods discussed in Section 4.2.5.2.2.3 were used to calculate the fuel particle failure and the gaseous and metallic fission product releases as a function of time. The key attributes for fuel quality are summarized in Table 4.2-4 and the design is in Table 4.2-16. The following fuel particle failure mechanisms were considered in the analysis:

1. Manufacturing defect failure

2. Pressure vessel failure

3. Fission product/Sic corrosion

4. Kerne1 migration.

While particle failure from the latter two mechanisms are strongly dependent on fuel temperature history, particle failure from the first two are primarily functions of burnup and fluence; consequently, particle failures from the first two mechanisms are distributed throughout the entire core. The particle fallures from all four mechanisms were calculated at the 50 percent confidence level.

The gaseous fission product releases were calculated for the two reference isotopes $\mathrm{Kr}-85 \mathrm{~m}$ and $\mathrm{Xe}-138$. Nominal values for the material properties were used in the calculation. The releases for other isotopes can be obtained by assuming that the release-rate-to-birth rate ratio $(R / B)$ varies as the square root of isotope half-life. Moreover, it is conservatively assumed that bromine and selenium isotopes have the same release characteristics as krypton, and that iodine and tellurium isotopes have the same release characteristics as xenon.

Equilibrium core releases of cesium, strontium, and silver were calculated by using the results for the fuel and graphite temperature and fuel particle $4.2-35$ Amendment 3 
failure histories. In general, metallic fission product release evaluations consider three potential sources of release: heavy metal contamination in the fuel rod matrix, failed particles, and diffusive release from intact particles. The following simplifying assumptions, based upon previous rigorous analyses of steam-cycle HTCR cores, were used in modeling fission metal release from the fuel particles:

\section{For Cesium and Strontium}

1. No release from intact particles

2. Instantaneous release from failed particles

In addition to the direct release of $\mathrm{Sr}-90$ and $\mathrm{Cs}-137$ from failed particles, two additional sources of the $s r-90$ and $C s-137$ releases were considered:

1. Heavy-metal manufacturing contamination of fuel element coolant hole surfaces.

2. Precursor release and decay ( $\mathrm{Kr}-90$ and $\mathrm{Xe}-137$, respectively)

\section{For Silver}

1. Diffusive release from intact particles

2. Instantaneous release from failed particles.

No credit was taken for silver retention by the fuel rod matrix and fuel element graphite because of an inadequate data base for silver transport in fuel rod matrix and $H-451$ graphite. In reality, there will be some holdup of silver by these materials, especially in the colder parts of the core, so the reported silver releases may be conservative by about an order of magnitude.

The 40-year plateout inventories were calculated using the predicted 3.3-year equilibrium releases. Correction factors for the effects of mixed species on 
the sorption characteristics of the fuel materials were based on the fraction of fissions occurring in heavy nuclides and isotopic yields.

The nominal fuel fallure and fission product release rates are estimated using the segment average values of the as-manufactured fuel attributes given in Tables 4.2-4 and 4.2-16, nominal core operating conditions (with the exception of thermal power which is taken as 102 percent of full power), nominal fuel failure models, and nominal estimates of the fission product transport properties.

The fuel failure and fission product release rates at the upper 95 percent bound are determined by a full-core propagation-of-errors analysis comparable to that described in Reference 11. The uncertainties in the as-manufactured fuel attributes (e.g., defect fractions as defined in Table 4.2-4), the core operating conditions, the fuel failure models, and the fission product transport properties are combined by conventional statistical techniques to determine the total variances in the fuel failure and fission product release rates from which the upper 95 percent bound values can be calculated.

Once fission product release rates have been determined at the nominal and 95 percent upper bound values, they are compared with the "Maximum Expected" and "Design" core release criteria, respectively (Section 11.1). If any of the criteria are exceeded, changes are made in the fuel and/or the core design, particularly the as-manufactured fuel attributes, and the fuel performance analysis is repeated until all the criteria are satisfied.

\subsection{Results and Discussion}

The results of the fuel performance analysis under normal operating conditions at full power are presented and discussed in this section. Included in the results are fuel and graphite temperature predictions, fluence and burnup fractions, and fuel particle failure and fission product release predictions. A comparison is made between the predicted fission product releases and the fission product release criteria defined in Section 11.1. 
As described in the previous section, the requirement is to calculate both the nominal and the upper 95 percent bound fission product release rates for the core during normal operation and to compare the results to the "Maximum Expected" and "Design" release criteria, respectively (Section 11.1). The practice during the early design phases is to calculate just the nominal core release rates and to compare them to the "Maximum Expected" criteria. During later design phases, both nominal and upper 95 percent bound release rates will be determined.

\subsection{1 Fuel and Graphite Temperature Distributions}

Fuel centerline temperature volume distributions for refueling segment 2 are shown in Figure 4.2-14 and on a time-averaged basis in Figure 4.2-15; the temperatures for segment 1 were slightly lower. A summary of predicted fuel temperatures is given in Table 4.2-17. A peak fuel temperature of $1329^{\circ} \mathrm{C}$ $\left(2425^{\circ} \mathrm{F}\right.$ ) is predicted to occur in fuel segment 2 during fuel load 3 (see Figure 4.2-14). The local peak temperatures are predicted to occur at a few points of the active core near the outer reflector boundary in the proximity of control rods. Thus, only a very small fraction of fuel volume is predicted to experience such high temperatures, as can be seen in Figure 4.2-14. Also, such temperatures are predicted to occur at the end of year when control rods are withdrawn and to be maintained for only very short periods of time. Consequently, the maximum time-average temperature is predicted to be considerably lower, $1101^{\circ} \mathrm{C}\left(2014^{\circ} \mathrm{F}\right)$. This fuel temperature is considerably lower than the core design guideline for a time-average, maximum fuel temperature of $\leq 1250^{\circ} \mathrm{C}\left(2282^{\circ} \mathrm{F}\right)$.

Distribution of graphite temperatures are illustrated in Figure 4.2-16 and 4.2-17. The peak predicted graphite temperature is $1284^{\circ} \mathrm{C}\left(2344^{\circ} \mathrm{F}\right)$, and it is also limited to the points near the outer reflector boundary in the proximity of control rods.

\subsection{2 Fluence and Burnup Distributions}

Figure 4.2-18 shows the fuel volume distribution of fast neutron fluence by year from beginning of cycle (BOC) for refueling segment 2; again, the values 
for segment 1 were slightly lower. The peak fast fluence, predicted to occur in segment 2 at the end of year 6 , is $4.5 \times 10^{25} \mathrm{n} / \mathrm{sq} \mathrm{m}$, which is lower than the design guideline of $5.0 \times 10^{25} \mathrm{n} / \mathrm{sq} \mathrm{m}$. Figure 4.2 .19 shows the fuel volume distributions of fissile burnup by year for the two refueling segments; similar distributions of fertile burnup are shown in Figure 4.2-20. The maximum fissile and fertile burnup values are 0.25 and 0.035 FIMA, which are lower than the design guidelines of 0.26 and 0.07 FIMA, respectively.

\subsection{3 Fuel Particle Failure}

The reference fuel performance models account for the effect of partially failed fuel particles on the fission gas and fission metal releases; the particles with falled SiC but intact OPyC coatings retain fission gases but not metals. The peak predicted core-averaged fuel particle failures from all mechanisms are given in Table 4.2-17, which shows the failure fractions used to predict both the fission gas and fission metal releases. Time histories of particle failures are shown in Figures 4.2-21 and 4.2-22 for the fissile and fertile particles, respectively.

At each reload, the fuel failure fraction in the core decreases due to the replacement of the oldest one half of the fuel in the core with fresh fuel. The results indicated that the predicted fuel particle failure due to temperature effects was very small even at the high temperature points (at the outer boundary of the active core in the proximity of the control rods) since such high fuel temperatures are maintained for only short periods of time. The predicted pressure vessel failure was negligible. Thus, the overall particle failure was predicted to be caused by manufacturing defects, primarily by particles with missing buffer layers.

The peak fissile particle failure for fission gas release was predicted to be 0.00085 percent; the peak fissile failure for fission metal release was predicted to be 0.0063 percent. The difference between these two predicted failure rates reflects the fact that particles with failed Sic coatings but 
intact OPyC coatings retain fission gases but release fission metals. In other words, the first value is the percentage of totally failed particles with exposed kernels which release both gases and metals, and the second value is the sum of the totally failed particles (exposed kernels) and the "partially" failed particles (failed SiC but intact OPyC), both of which release metals. Comparable values for the fertile particles were 0.00011 percent and 0.00543 percent, respectively. The failures for the fertile particle were lower as a result of the lower burnup.

\subsection{4 Fission Gas Release}

The $R / B s$ or fractional release for the two reference isotopes $\mathrm{Kr}-85 \mathrm{~m}$ and $\mathrm{Xe-138}$ are shown in Figures 4.2-23 and 4.2-24 as a function of time; the values shown are 50 percent confident values. The peak core-averaged $R / B s$ are shown in Table 4.2-18 where the values for $\mathrm{ThO}_{2}$ and hydrolyzed UCO particles are given along with the percentage contribution due to failed fuel particles and heavy-metal contamination.

The dominant source of fission gas release was predicted to be as-manufactured, heavy metal contamination in the fuel rod matrix which accounted for up to 91 percent of the gaseous release. The peak predicted $\mathrm{R} / \mathrm{B}$ for $\mathrm{Kr}-85 \mathrm{~m}$ was $5.0 \times 10^{-8}$ which satisfies the "Maximum Expected" criterion of $9.3 \times 10^{-7}$ (Section 11.1) with a factor of 1.9 margin. The peak predicted $R / B$ for Xe-138 of $5.8 \times 10^{-8}$ also satisfies the "Maximum Expected" criterion of $6.8 \times 10^{-8}$. With the reference design assumptions that the $R / B$ varies as the square root of isotope half life and that $B r$ and Se isotopes behave like $\mathrm{Kr}$ isotopes and $\mathrm{I}$ and $\mathrm{Te}$ isotopes like Xe isotopes, the above results for $\mathrm{Kr}-85 \mathrm{~m}$ and $\mathrm{Xe}-138$ indicate that the core release criteria for all the fission gases, including the radiologically important lodine isotopes, are satisfied.

\subsection{5 Metallic Fission Product Release}

The Cs-137, Sr-90, and Ag-110m predicted releases are shown in Tables 4.2-19, 4.2-20, and 4.2-21, respectively. The maximum cesium release was predicted to occur at the bottom of axial layer 8 where relatively high fuel and 
HTGR - 86-024

graphite temperatures were predicted to occur; as a result of high graphite temperatures, graphite attenuation of cesium at this location is substantially reduced. Table 4.2-19 shows a large axial variation in the cesium release which could be made more uniform and, probably, lower by further optimization of the axial fuel zoning. The predicted 40-year Cs-137 plateout inventory of $37.3 \mathrm{Ci}$ is below the "Maximum Expected" criterion of $70.0 \mathrm{Ci}$.

The direct Sr-90 release is negligibly small, as shown in Table 4.2-20. The dominant contribution to the strontium release is from the release and subsequent decay of its $\mathrm{Kr}-90$ precursor, which accounts for 88 percent of total release; the remaining contribution is from heavy-metal manufacturing contamination of the fuel element coolant hole surfaces (a minimum fractional release of $5 \times 10^{-9}$ is assumed for all fission products to account for possible heavy metal contamination on the fuel element coolant hole surfaces). The predicted 40-year Sr-90 plateout inventory of $0.20 \mathrm{Ci}$ is below the "Maximum Expected" criterion of $0.34 \mathrm{Ci}$.

As shown in Table 4.2-21, the predicted 40-year plateout inventory of $\mathrm{Ag}-110 \mathrm{~m}$ is $38 \mathrm{Ci}$, which exceeded the "Maximum Expected" criterion of $8 \mathrm{Ci}$. However, it must be emphasized that the predicted inventory for silver is conservative since the only effective barrier to silver release considered in the analysis was the SiC coating, and no credit was taken for silver retention by the fuel rod matrix and fuel element graphite. The reason that no credit was taken for the matrix and graphite as a barrier to $\mathrm{Ag}$ release is because of the presently large uncertainties in the transport properties of $\mathrm{Ag}$ in irradiated matrix material and $\mathrm{H}-451$ graphite. Data from the German HTR program and from the previous Dragon Project. for somewhat different grades of matrix material and graphite imply that the fuel rod matrix and fuel element graphite in the Standard MHTGR core will attentuate the Ag release to the primary circuit by at least an order of magnitude under standard MHTGR core operating conditions. Technology development programs (Ref. 1) are planned to quantify the transport of $\mathrm{Ag}$ in graphite which should demonstrate significant $\mathrm{Ag}$ attenuation by the fuel element graphite, especially in the colder regions of the core. 
HTGR - 86- 024

Alternatively, it may be possible to relax the current Ag release criteria for the Standard MHTGR core. $\mathrm{Ag}-110 \mathrm{~m}$ is not a significant contributor to offsite doses during normal operation or accidents. Its importance is as a contributor to occupational doses during plant maintenance and in-service inspection (ISI), and even in this context it is a relatively minor contributor to the radiation fields around the NSSS compared to that from the Cs-134 and Cs-137 plateout and the from direct shine from the core.

\subsection{Thermal/Hydraulic Performance}

The fuel element hole pattern of two fuel holes per coolant hole and the pitch between the holes was selected to meet the core pressure drop limit in addition to limits on fuel temperature. In addition, the coolant channel roughness and the minimum pressure drop through the plenum elements are limited to ensure that the active core pressure drop limit of 5 psi is met. The calculated equilibrium cycle peak active core pressure drop at the nominal 100 percent feedwater flow operating conditions is 4.33 psi.

The active core bypass flows are roughly divided into four categories depending on their path. These are in-core gaps, ex-core gaps, reflector coolant channels and control rod channels. Approximately 1.0 percent to 1.5 percent of the total cavity flow is in the gaps between the fuel elements, and is called the in-core gap flow. The ex-core gaps include gaps around all reflector columns and the gap between the permanent side reflector columns and the core barrel. The ex-core gap flow, which totals less than 6.5 percent, consists of a maximum of 0.5 percent in the gaps around all central reflector columns, a maximum of 3 percent in the gaps around all side reflector columns, and a maximum of 3 percent in the gap between the permanent side reflector columns and the core barrel. Both the in-core and ex-core gap flows exit, for the most part, via the gaps in the core support floor blocks and into the lower core plenum.

About 3 percent of the total cavity flow is allocated to the reflector coolant and 30 control rod channels to cool the control rods. Flow is supplied to the control rod channels via small holes in the guide tubes 
HTGR $-86-024$

inside the plenum elements. This flow traverses the reflector control column and is directed into the flow channels around the post block as discussed above. Before being collected, however, the diameters of these control rod channels are reduced from $102 \mathrm{~mm}$ ( $4.0 \mathrm{in.})$ to $25 \mathrm{~mm}$ ( $1.0 \mathrm{in.}$ ).

The small holes in the guide tubes in the plenum elements and the reduced diameter channels in the lower reflector supply the principal flow resistances in the channels, even when the control rods are inserted. This design ensures that there are no large flows in these channels when the rods are withdrawn, and keeps the flow velocities in these channels low enough to prevent flow-induced vibrations of the control rods.

The 3 percent flow in the control rod columns is divided roughly into 0.75 percent in the coolant channels in the inner reflector control rod columns and 2.25 percent in the control rod channels.

The core bypass flows are estimated based on the time-averaged nominal gaps between the core as well as reflector columns. At the beginning-of-life cold conditions all gaps within the RCSS are nominally $1 \mathrm{~mm}(0.04 \mathrm{in.}$ ), except in the plenum element layer where they are reduced to $0.75 \mathrm{~mm}(0.03 \mathrm{in}$.). The core gaps normally increase at BOL hot conditions due to higher thermal expansivity for the metal core support structure than for core graphite. The gaps increase further with accumulation of fast neutron fluence.

Flow exchange between the coolant channels in the core columns and the gaps between columns (cross-flow) occurs when gaps between stacked columns develop as a result of thermal or irradiation-induced distortions, or column bowing from pressure or mechanical loads. Cross-flow may be controlled in part by adjusting the flow resistances in the plenum element and in the core support floor to create a pressure profile in the gaps as near as possible to that in the coolant channels. Similarly, the pressure profile in the control channels is made as near as possible to that in the coolant channels by selecting the relative resistances supplied by the guide tube holes and the small exit channels.

For additional information related to this section, see the responses to NRC Comments 4-28 and 4-29. 


\subsection{Structural/Mechanical Performance}

\subsection{Stress Field Description}

During normal steady-state operation, the graphite elements of the core are subjected to stresses induced by the strain gradients resulting from the varying temperature and fluence fields. In addition to stresses created by thermal and irradiation effects, the fuel elements are subject to mechanical loads of gravity, fluid forces and seismic events. Of these mechanical loads only the seismic loads are significant, and even those are small in relation to those due to thermal and irradiation effects.

The variation in strain is typically much greater in the in-plane (horizontal) direction than in the vertical direction, due to the larger in-plane temperature gradients. The strains build up stresses which are relaxed by irradiation-induced creep. If creep did not occur these strains would induce stresses that would cause extensive damage to the graphite structure. Thus, creep is an essential factor in maintaining the structural integrity of the core elements. The effects of creep are included in the structural analysis, using experimentally determined values of the creep coefficients. Since the variation in strain occurs primarily in the horizontal plane, the core elements are analyzed as generalized plane strain structures.

In a typical fuel element, the stresses vary across the web between fuel and coolant holes from tension on one side to compression on the other side. At the start of life, the area near the fuel hole is in compression because it is hotter than the average of the surrounding graphite, whereas the region around a coolant hole is in tension. During the first phase of the operating life, the fast fluence causes the hotter portions of the graphite to shrink more slowly than the cooler portions, such that the irradiation strain increases to the initial thermal strain. After the first phase is complete, the hotter portions shrink more quickly than the colder portions for the rest of the design life. Eventually, this shrinkage cancels the initial thermal strains and the stress fleld reverses with tension occurring near the fuel hole and compression near the coolant hole. 
When the reactor is shut down, the thermal strain field is eliminated from the total strain while the irradiation-induced strain remains. The stress caused by this residual strain is referred to as shutdown stress. If the reactor is shut down during the initial irradiation phase when the irradiation and thermal strains are additive, the shutdown stresses are lower than the operating stresses. After the initial phase is complete, the operating irradiation strains act in the opposite direction of the thermal strain, resulting in a higher shutdown stress. Thus, the beginning-of-life stresses are largest during operation, while later in life, the shutdown stresses tend to be largest.

In the side reflector elements where there are no coolant holes, stresses are induced by thermal and irradiation strain gradients across the elements. Furthermore, the exponentially decaying flux field causes the graphite nearest the active core to shrink faster than the graphite away from the active core. Thus, in addition to stresses, bowing of the elements is expected and sufficient clearance between elements has been provided to avoid potential interactions. In the control reflector elements, additional variations in strain are produced as a result of temperature differences between the control rod holes and the surrounding graphite. The control reflector elements also have some coolant holes which cause local temperature gradients.

\subsection{Stress Analysis Results}

The first step in the stress analysis of the core is to run the SURVEY code. This code models each fuel and reflector element with a coarse finite-element grid and takes into account all the important environmental and structural factors that contribute to the generation of thermal-and irradiation-induced stresses in the graphite structure. The grid is fine enough to differentiate and rank the core elements with regard to peak deformation and stress-tostrength ratio, but too coarse to give the detailed stress field. The most critically stressed and deformed elements, as identified by SURVEY, are 
selected for a follow-on analysis of the critical fuel elements to determine the detailed stress levels.

Due to the symmetry of the thermal load, it was only necessary to include one-half of the standard fuel element in the analyses. The maximum tensile stress/strength ratios during normal operation for the in-plane and axial principal stress directions are 0.35 and 0.30 , respectively. (Stress-tostrength ratios rather than simply stresses are given since the strength of the graphite is not a single value but varies both spatially and as a function of temperature and fluence.) Even though the compressive stresses are of the same order as the tensile stresses, the compressive stress/strength ratios are typically a factor of 4.5 smaller than the tensile ratios because of the much greater compressive strength of the material. As a result, only the tensile ratios are of concern and henceforth will be the only ones discussed. The highest values for the tensile stress/strength ratios are found in layer 5 , i.e., the fifth element from the top. Both the peak in-plane stress/strength ratio and the peak axial stress/strength ratio are found at mid-life. These stress/strength levels are within the allowable limit of 0.35 for standard fuel elements (a summary of the allowable limits is given in Table 4.2-22).

The stress-to-strength ratios for SRDC events are included in the response to NRC Comment 4-30.

The maximum tensile stress/strength ratios for the reserve shutdown fuel elements, for the in-plane and axial principal stress directions, are 0.35 and 0.30 , respectively. These highest values for the stress/strength ratios were found in layer 5. Both the peak in-plane and the peak axial stress/strength ratio are found at the mid-portion of the element's life. These stress levels are within the allowable limits for control fuel elements (see Table 4.2-22).

The highest value for the stress/strength ratios in reflector control elements was found in layer 5. Both the peak in-plane stress/strength ratio of 0.20 and the peak axial stress/strength ratio of 0.20 are found at mid-life. These stress/strength levels are within the allowable limits for control reflector elements (see Table 4.2-22).

The results discussed in the foregoing paragraphs are all for thermal/ 
HTGR $-86-024$

irradiation loads alone. The mechanical steady-state loads (pressure and deadweight) are, however, small and also largely compressive, and the resulting stresses have no significant effect on the structural performance of the core.

For additional information related to this section, see the response to NRC Comment 4-31.

\subsection{Oxidation Effects On Strength}

The calculations discussed above do not include the effects of graphite corrosion caused by impurities such as water, carbon dioxide, and other oxidants in the coolant. This corrosion, or "burnoff", of the graphite will result in some loss of strength and changes to the elastic modulus and other mechanical and thermal properties. The maximum burnoff occurs in the hottest element.

The effect of burnoff on graphite strength has been determined for $\mathrm{H}-327$ graphite which shows strength losses of 5 percent to 20 percent at 1 percent burnoff. In that study, the graphite samples were oxidized at $900^{\circ} \mathrm{C}$ $\left(1652^{\circ} \mathrm{F}\right)$, and the burnoff was relatively uniform throughout the samples, which maximizes the effect of burnoff on strength. In another study done at GA Technologies, Inc. (GA) the graphite was oxidized at $1000^{\circ} \mathrm{C}\left(1832^{\circ} \mathrm{F}\right)$, and lower strength losses with burnoff were found. Due to the high helium pressure in the reactor, the diffusion of water vapor through the graphite is greatly reduced, and calculations indicate that above $900^{\circ} \mathrm{C}\left(1652^{\circ} \mathrm{F}\right)$ the oxidation will not be uniform, but will be restricted mainly to surface attacks. Thus, at temperatures above $900^{\circ} \mathrm{C}\left(1652^{\circ} \mathrm{F}\right)$, the corrosion results in roughening of the coolant surfaces or perhaps slight enlargement of the coolant channels, and the concomitant strength loss is much less than the values given above. The near isotropic graphites such as $\mathrm{H}-45 \mathrm{I}$ have been shown to oxidize in the same manner as H-327 graphite; thus these results apply to either type of graphite.

It is estimated that loss of strength and decrease in elastic modulus due to 1 percent burnoff above $800^{\circ} \mathrm{C}\left(1472^{\circ} \mathrm{F}\right)$ will be about 5.2 percent and 10.5 
percent, respectively, for $\mathrm{H}-451$ graphite. With increasing temperature, the loss of strength and decrease in elastic modulus are lower [about 3.6 percent and 5.2 percent, respectively, at $\left.1000^{\circ} \mathrm{C}\left(1832^{\circ} \mathrm{F}\right)\right]$ for 1 percent burnoff. The estimation of 1 percent burnoff is for the hottest element $1900^{\circ} \mathrm{C}$ $\left(1652^{\circ} \mathrm{F}\right)$ to $\left.965^{\circ} \mathrm{C}\left(1769^{\circ} \mathrm{F}\right)\right]$ in a large HTGR core for a 4-year life with circulating impurities of $<1$ ppm for $\mathrm{H}_{2} \mathrm{O}, 9 \mathrm{ppm}$ for $\mathrm{CO}$, and $<0.5 \mathrm{ppm}$ for $\mathrm{CO}_{2}$. In this modular reactor, the burnoff is less due to the 3-year fuel cycle. Assuming a maximum of 1 percent burnoff and using the above values of 5.2 percent loss of strength and 10.5 percent reduction in elastic modulus, in combination with estimated values of other material properties, the effects of corrosion were conservatively estimated to result in about a 10 percent increase in the calculated stress/strength ratios.

\subsection{Graphite Core Component Allowable Stress Limits}

The replaceable graphite core components are designed to satisfy a set of limits on the ratio between the maximum principal stress in the structure and the mean value of the strength of the material at the same location. The allowable peak stress-to-strength ratios for the various graphite elements are shown in Table 4.2-22. Differences in the allowable ratios reflect differences in the function, structural redundancy, and loading of each type of element.

The allowable peak stress-to-strength ratios are developed on a probabilistic basis. In a probabilistic analysis, the safety and investment risk associated with the occurrence of structural damage is assessed and related to the overall plant risk envelope. Structural damage here refers to the inability of the elements to perform their functions, which are to 1) allow normal refueling, 2) maintain coolant-hole integrity, 3) retain fission products, and 4) maintain control channel integrity. The safety and investment risk goals for the core are then expressed in terms of the nonprobabilistic stress-to-strength limits given in Table 4.2-22.

The stress-to-strength limits in Table 4.2-22 are not intended to preclude limited cracking which does not reduce the capacity of the elements to perform their required functions and does not affect safety. Analyses and tests of Fort St. Vrain elements have demonstrated that 1) the effect of 
HTGR - 86- 024

cracks would be to relleve the stresses in elements and prevent more extensive cracking, 2) the seismic strength of the elements is not significantly reduced by the presence of the cracks, and 3 ) the calculated peak stress-to-strength ratio of the cracked elements was two to three times the limits in Table 4.2-22.

In addition to the limits in Table 4.2-22, limits are required to ensure adequate safety against fatigue failure. These limits have been tentatively proposed to be the limits in the draft of Subsection CE of the ASME Code which is used for permanent graphite core support structures. The data used to construct the design fatigue diagram accounts for the effects of operating temperatures and fast neutron fluence on the fatigue strength of graphite. Due to the high fatigue stength of graphite (manifested in a relatively flat $S-N$ curve, where $S$ is the stress amplitude and $N$ is the number of cycles to failure) fatigue failure is not expected to be a critical fallure mode.

For additional information related to this section, see the response to NRC Comment G-15.C.

\subsubsection{Anticipated Operational Occurrence Performance}

The structural effects of the five postulated anticipated operational occurrences (AOOS) on the reactor core are discussed in this section. The AOOs have no effect on fuel integrity as discussed in Section 11.6. The events, referred to as AOO-1 through A0O-5, are described in Chapter 11.

Event $A O O-1$ is a main loop transient with forced core cooling. The event has four variants, designated $\mathrm{AOO-1(A)}$ through A00-1(D) in Chapter 11 . Forced core cooling is maintained in all four variants. The response of the core is similar for variants $A, B$, and $C$, all three of which involve shutting down the reactor by inserting the outer control rods. The RCSS response is discussed in the following paragraph. For variant $D$, the reactor continues to operate and in this case, the transient is so mild that the effects on the core are negligible. 
HTGR $-86-024$

When the control rods are inserted in variants $A, B$ and $C$, the core temperatures drop in the following minutes from normal operating temperatures to near uniform temperatures, nearly equal to the core inlet temperature. During this transient period, the stress fields in the core components go from operating stresses to shutdown stresses.

In the fuel elements, the graphite temperatures change rapidly with the changing coolant temperatures. As a consequence, the stresses in the fuel elements during the transient will not be significantly greater than the normal operating or shutdown stresses (whichever is greater).

In the case of the reflector elements, however, especially the solid side reflector elements, the temperature of the graphite will drop at a slower rate than that of the coolant resulting in somewhat more severe gradients than during normal operation. The consequent increase in stresses is expected to be below 10-15 percent and well within the allowable limits, thus ensuring that no unacceptable structural damage will occur.

Event $\mathrm{AOO}-2$ is a loss of main and shutdown cooling loops. In this event the core undergoes a heatup, with decay heat in the core being removed by conduction and natural convection.

During this event, the temperatures in the core blocks initially change from the normal operating temperatures to near-uniform temperatures, and then gradually increase during the pressurized heatup. During the initial change to near uniform temperatures, the block stresses go from operating stresses to a stress field nearly the same as at shutdown. During the subsequent heatup, the temperature gradients imposed on the blocks are near uniform, which result in some block distortions and possibly small increases in peak stresses. However, since the graphite strength will increase (the strength of graphite increases with temperature up to about $\left.2500^{\circ} \mathrm{C}\left(4500^{\circ} \mathrm{F}\right)\right)$, the stress-to-strengh ratios in the fuel elements will be lower than during normal operation or shutdown (whichever is higher).

In the reflector elements above and outside the active core there will be some moderately severe temperature gradients, but due to the higher graphite 
HTGR - 86-024

-

strength, the stress-to-strength ratios are not expected to be significantly higher than during normal operation. The thermal expansion of the graphite 
HTGR-86-024

components will be less than that of the core barrel so the core will remain loose.

The temperature of the outer control rods will reach a maximum value of $870^{\circ} \mathrm{C}\left(1590^{\circ} \mathrm{F}\right)$ after about $100 \mathrm{hr}$ and will then gradually decrease (the inner control rods are not inserted during this condition). The time spent above the normal operating temperature of approximately $540^{\circ} \mathrm{C}\left(1000^{\circ} \mathrm{F}\right)$ will be in the range of 400 to 500 hours. At these temperatures, the structural effects on the metallic components of the control rods are minimal. The stresses will be less than 1000 psi which is well below the rupture strength of Incoloy $800 \mathrm{H}$ (for example, at $875^{\circ} \mathrm{C}\left(1600^{\circ} \mathrm{F}\right.$ ) the stress to rupture at $100 \mathrm{hr}$ is about 4000 psi). The amount of creep will be insignificant.

The temperature of the metal plenum elements on top of the core will reach a maximum level of about $760^{\circ} \mathrm{C}\left(1400^{\circ} \mathrm{F}\right)$ in the middle of the layer and be somewhat lower toward the outside. At these temperatures, no structural damage is expected in the plenum elements which are made of the same material (Incoloy $800 \mathrm{H}$ ) as the control rods. The temperatures are, however, considerably higher than those of the surrounding core barrel and to preclude any problem from high compressive forces developing due to the differential thermal expansion, the gaps between the plenum elements will be sufficiently large so that they do not close during the AOO-2 event. To the extent that this requirement is in conflict with the requirement for tight gaps during normal operation for flow control purposes (see Section 4.2.4.1.3) separate seals will be used.

Event $A O O-3$ is an accidental withdrawal of a group of control rods followed by reactor shutdown. The overall effects on the core are minimal; the average fuel temperature increases only about $50^{\circ} \mathrm{C}\left(90^{\circ} \mathrm{F}\right)$ and the graphite temperature even less. The local effects are somewhat more significant. The control reflector elements in the three columns from which the rods are withdrawn will develop somewhat more severe thermal gradients than during normal operation, but the stresses are expected to be within the allowable limits ensuring no unacceptable structural damage. In the fuel elements surrounding the withdrawn rods, the thermal gradients between the fuel and 
HTGR - 86-024

the coolant holes are expected to increase less than 10 percent and since these thermal gradients typically cause about 30 percent of the total operating stress, the increases in stresses will be very small (3 percent or less).

Event AOO-4 is a small steam generator leak which is estimated to release about $18 \mathrm{~kg}$ (40 lb) water into the primary coolant. The core temperatures remain at normal levels for the first few minutes of the event after which the temperatures start decreasing gradually to reach $200^{\circ} \mathrm{C}\left(400^{\circ} \mathrm{F}\right)$ after about 2 hours. At these temperatures, the rate of graphite oxidation is so low that only a fraction of the water is expected to react with the graphite. Even if all the water should be consumed in chemical reactions with the graphite, the total graphite weight loss would be only about $14 \mathrm{~kg}$ (30 1b). If limited to a single graphite element, this would amount to a 10 percent weight loss and a corresponding loss of strength of about 50 percent. Distributed over the several hundred elements of the core, however, the graphite corrosion and its effects would be negligible.

Event AOO-5 is a small primary coolant leak through a postulated $650 \mathrm{sq} \mathrm{mm}$ (1 sq in.) hole in the pressure boundary. The reactor vessel will be fully depressurized in less than 1 hour at which time the pressure in the remaining helium will be atmospheric. The depressurization will not have any significant effects on the core, as the temperatures are the same as or lower than during normal operation and the pressure forces are far from large enough to cause any disarray. Vent holes are provided in the control rod cans and in the plenum elements to prevent these components from becoming pressure vessels during this or other depressurizations. At the termination of the accident, a small amount of air may leak into the reactor vessel. If that happens, the resulting graphite corrosion will be minimal.

\subsubsection{Design Basis Event Performance}

The effects of the 11 postulated design basis events (DBEs) on the reactor core are discussed in the following. The effects of these events on fuel integrity are discussed in Chapter 15 which shows that the fuel integrity is 
HTGR $-86-024$

not compromised and the dose limits of 10CFR100 are not exceeded for any of the DBEs. The events, referred to as DBE-1 through DBE-11, are described in Chapter 15.

of these design basis events listed below, DBE-1, with loss of forced circulation represents a challenge to the function of heat removal. DBE-2, -3 and -4 represent challenges to the function of controlling heat generation. DBE- 6 and -7 , by addressing moisture ingress, not only challenge the function of heat generation control, but also chemical attack. DBE- 8 and -9, with smaller water ingress and DBE-10, which leaves the primary coolant system open to the environment, also challenge the function of controlling chemical attack. Finally DBE-11, a smaller depressurization event, challenges the function of heat removal but under depressurized conditions. The successful accomplishment of these three functions, as verified in the results obtained for these several DBEs, do not result in any unacceptable degradation of the fuel. The highly retentive fuel plays a dominant role in successfully meeting the challenges to these safety functions.

$\underline{\mathrm{DBE}-1}$ is a loss of HTS and SCS cooling involving a conduction cooldown similar to AOO-2. As discussed in section 4.2.5.3, the event will not have any adverse effects on the core components.

$\underline{\text { DBE-2 }}$ is a Heat Transport System (HTS) transient without control rod trip, requiring reactor shutdown with the reserve shutdown control equipment (RSCE), and core cooling with the shutdown Cooling system (SCS). During the first 5 minutes of the event the core temperatures rise by a maximum of about $80^{\circ} \mathrm{C}\left(150^{\circ} \mathrm{F}\right)$ above the normal operating levels. After this initial phase, the core gradually cools down.

At the start of this event, the temperature gradients are intitially reduced with the loss of flow and power. The temperatures in the blocks become more uniform, gradually increasing. Once the SCS begins operating, the core temperatures are then gradually reduced to shutdown temperatures.

Throughout this transient, the temperature gradients will be, for the most part, between those that exist during normal operation and at shutdown. 
HTGR $-86-024$

Consequently, the stresses during this period will not be significantly higher than the operating or shutdown stresses (whichever is greater).

$\underline{D B E-3}$ is an accidental withdrawal of a group of control rods followed by reactor shutdown. The event is similar to A0O-3, except that cooldown is with the SCS rather than the HTS. As discussed in Section 4.2.5.3 for AOO-3, the effects on the core are minimal.

DBE-4 is initiated by a spurious control rod group withdrawal, as in DBE-3. However, in this case both the HTS and SCS fail to provide forced helium circulation. Core heat removal is accomplished by conductive and radiative heat transport to the RCCS. The initial phase of this event is identical to AOO-3 and DBE-3, but the subsequent temperature history is that of a pressurized conduction cooldown. The effects on the core are therefore the same as for DBE-3 during the initial phase and the same as for SRDC-1 during the later phase. (The SRDCs are evaluated in Section 4.2.5.5.)

$\underline{\text { DBE-5 }}$ is an earthquake which trips the HTS. The duration of the earthquake is too short for any transient thermal effects to develop in the core. Consequently, during the first phase of the event, seismic loads are superimposed on the normal operating thermal-irradiation loads. The core must withstand the combination of these loads and retain its essential safety functions which are to maintain a coolable geometry and allow control rod insertion. These functions may be impaired if 1 ) the dowels which align the graphite elements within the core columns shear off, or 2) the elements break into two or more pieces.

The integrity of the fuel and reflector elements during an SSE is ensured by keeping the maximum combined seismic and thermal-irradiation stresses below the strength of the material to prevent cracking. A safety concern would not exist, even if the stresses should exceed the strength of the material in local areas, since only local cracking would result. Massive cracking, which could separate the element into pieces, would require the stresses to exceed the strength in the bulk of the volume of graphite. 
Current estimates give SSE design spectrum values for the core of about $1.0 \mathrm{~g}$ horizontally and $0.5 \mathrm{~g}$ vertically. Based on these loads, preliminary analyses show that the seismic stresses, in combination with the thermal and irradiation induced stresses, will not exceed the acceptable limits. The predicted stress-to-strength ratios and the corresponding acceptable limits are summarized in Table $R$ 4-30-1. The maximum shear forces predicted in the dowels during the SSE are below the experimentally determined shear capacity, thus ensuring the integrity of the dowels. (The seismic loads are the only significant dowel loads.)

Subsequent to the earthquake, the core will be cooled by the SCS. This phase of the DBE-5 event is similar to the corresponding phase of DBE-3 (following control rod insertion and SCS startup).

$\underline{\mathrm{DBE}-6}$ is a water ingress event that results from a moderate feedwater/steam leak in one or more steam generator tubes $[5.67 \mathrm{~kg} / \mathrm{sec}(12.5 \mathrm{lbm} / \mathrm{sec})]$. The reactor is shut down and subsequently cooled by the SCS. About $270 \mathrm{~kg}$ (700 lb) water are postulated to leak into the reactor vessel. Only a fraction of the water will react with the graphite in the core and the reactor internal structures and the amount of burnoff is very small, less than 0.1 percent weight loss in the region of maximum burnoff which is the bottom reflector. A weight loss of 0.1 percent will result in a loss of strength of about 0.5 percent which is negligible compared to the safety margins in the core.

DBE-7 is the same as DBE-6, except that the SCS fails to start and the core is cooled by conduction and radiation to the RCCS. The temperature history is similar to the conduction cooldown event in DBE-1. The amount of water entering the reactor vessel is the same as in DBE-6, but a larger fraction of the water reacts with the graphite as a result of the slower cooldown. However, the weight loss due to graphite oxidation is also, in this case, less than 0.1 percent even in the most exposed locations, resulting in negligible reductions in the structural strength.

$\underline{\mathrm{DBE}-8}$ is a moisture ingress with moisture monitor failure. More moisture leaks into the core than for $D B E-6$ or -7 , but less reacts than for $D B E-7$ because of the SCS cooldown. 
$\underline{\mathrm{DBE}-9}$ is a moisture inleakage with steam generator dump failure. This DBE includes the family of events that result from a small steam generator leak $[0.045 \mathrm{~kg} / \mathrm{sec}(0.1 \mathrm{lbm} / \mathrm{sec})]$ followed by a failure of the steam generator dump valves to reclose. DBE-9 is less severe than DBE- 6 because the leak is smaller and less moisture reaches the core.

In DBE-10 the reactor vessel is depressurized through an $8,200 \mathrm{sq} \mathrm{mm}$ (12.7 sq in.) primary coolant leakage area. Core cooling is with the SCS. The effects on the core of this event are minimal. The temperatures decrease gradually from the normal operating levels and the thermal gradients are the same or less severe. The maximum pressure forces due to the relatively rapid depressurization are only slightly higher than during normal operation. Any net upward pressure force will not develop. At the termination of the event there will be some air ingress, but the resulting graphite corrosion will be minimal.

In DBE-11 the reactor vessel is depressurized through a $32 \mathrm{sq} \mathrm{mm}$ ( $0.05 \mathrm{sq}$ in.) hole. Since the leakage area is so small, the depressurization will take about 19 hours. During the first phase of the event, the core will be cooled with the HTS. After 15 hours, the HTS is postulated to fail and subsequent core cooling will be through conduction and radiation to the RCCS. The maximum core temperature will reach about $870^{\circ} \mathrm{C}\left(1600^{\circ} \mathrm{F}\right)$. This will not have any adverse consequences on the structural integrity of the core, since the small increases in the severity of the thermal gradients will be more than compensated for by graphite strength. The temperature of the control rods will reach $1075^{\circ} \mathrm{C}\left(1970^{\circ} \mathrm{F}\right)$. Some creep and distortion of the Incoloy $800 \mathrm{H}$ cladding may occur, but this will not have any safety consequences since the rods already are inserted (reactor shutdown by inserting the outer control rods occurs about 35 minutes after the event is initiated).

\subsubsection{5 "Safety-Related" Design Condition Performance}

A set of 11 "safety-related" design conditions (SRDCs), which challenge the safety functions as in the similar set of DBE events described above, are 
defined and discussed in Chapter 15. In the SRDCs, defined to meet the challenges to the functions of controlling heat generation, heat removal, and/or chemical attack, only "safety-related" SSCs may be assumed for accomplishing the safety functions.

The effects of these conditions on fuel integrity and release rates are discussed in Chapter 15. The effects of the 11 defined SRDCs on the reactor core components are discussed in the following paragraphs.

For additional information related to this section, see the response to NRC Comment 4-17.

$\underline{\text { SRDC-1 }}$ is a conduction cooldown condition similar to AOO-1 and DBE-1. As discussed in Section 4.2.5.3, the condition will not have any adverse effects on the core components.

SRDC-2 is similar to SRDC-1, except that the reactor is shut down with the reserve shutdown rather than with the control rods. The initial phase of this condition is similar to the initial phase of DBE-2 and the later phases to SRDC-1. As stated in the discussions of those two cases, no damage or any safety consequences will occur.

$\underline{\text { SRDC-3 }}$ and SRDC-4 are both the same as DBE-4 and as discussed the effects on the core are minimal.

SRDC-5 is similar to DBE-5, except that following the earthquake the core is cooled by conduction and radiation to the RCCS rather than by the SCS. Accordingly, the response of the core is the same as for DBE-5 during the initial phase and the same as for the conduction cooldown case (DBE-1 and A00-3) during the later phases. As stated in the discussion of DBE-5, it is anticipated that the core can safely withstand the SSE.

$\underline{\text { SRDC }-6}$ and $\underline{\text { SRDC-7 }}$ are two essentially identical conditions involving water ingress through a moderate size leak in a steam generator tube. Core cooling is by conduction and as such the two conditions are the same as DBE-7. In DBE-7, however, the leakage is stopped after about 30 seconds such that only a small volume of water will enter the reactor vessel. As discussed in the 
evaluation of DBE-7, the graphite oxidation in that case is minimal. In SRDC- 6 and SRDC-7, on the other hand, the leak is detected in about 5 minutes and the duration of the leakage is no more than one-half hour. Since these are conduction cooldown cases, temperature of the core will continue to increase until a peak of about $1540^{\circ} \mathrm{C}\left(2800^{\circ} \mathrm{F}\right)$ is reached after approximately 100 hours. At these temperatures, the rate of graphite oxidation will be relatively high and some burnoff will occur. The weight loss as predicted is on the average no more than 2.1 percent with the hot channel about 3.1 percent. The corresponding strength loss is 10 and 14.5 percent respectively. However, since there are no large loads on the core beyond its own weight, the remaining strength would be more than sufficient to preclude core disarray or other damage which would interfere with any safety functions. The estimated stress-to-strength ratios for SRDC-6 are summarized in Table $R$ 4-30-1. As it can be seen, the ratios are well below the acceptable limits.

SRDC-8 involves water ingress through a small hole, but the sequence is otherwise the same as SRDC-6 and SRDC-7. Since, for SRDC-8, the water ingress will occur at a much slower rate, the effects of graphite oxidation are much less than for SRDC-6 and -7 when the ingress is stopped after no more than one-half hour.

$\underline{\text { SRDC-9 }}$ is another variant of the water ingress condition. The effects on the core are the same as for SRDC-8.

SRDC-10 differs from DBE-10 in that the core is cooled by conduction and radiation to the RCCS. For this reason, the core temperatures rise until a peak of $1620^{\circ} \mathrm{C}\left(2950^{\circ} \mathrm{F}\right)$ is reached after $80 \mathrm{hr}$. The peak temperature occurs in the fuel elements next to the central reflector at an elevation somewhat above core midheight. A portion of the central reflector is also hotter than $1600^{\circ} \mathrm{C}\left(2900^{\circ} \mathrm{F}\right)$. These high temperatures will have no adverse effects on the graphite structures; the thermal gradients will be the same or less severe than during normal operation and the strength of the graphite will be higher. The estimated stress-to-strength ratios are summarized in Table R 4-30-1. As can be seen, the ratios are well below the acceptable limits. As in DBE-10, some air is postulated to ingress after the reactor vessel is fully depressurized, but the resulting graphite corrosion is minimal. This 
condition produces control rod temperatures of $1130^{\circ} \mathrm{C}\left(2072^{\circ} \mathrm{F}\right)$ which are the highest of any of the postulated conditions. At these temperatures it is probable that metallic component damage will result. Little strength is left in those components, and the cable and spine have to support the assembly weight in tension. However, the damage will be limited to the metallic components and will not adversely affect the safe shutdown of the core. The neutron absorber compacts will remain trapped in the graphite control channel and maintain the reactor in a shutdown condition.

SRDC-11 involves depressurization at a slower rate than in SRDC-10, but the temperature rises and the effects on the core are essentially identical.

\subsubsection{Interfaces}

Interface requirements imposed on other systems by the Reactor Core Subsystem are identified in Table 4.1-2, which also includes a description of the interface and a quantitative expression for the interface. 
1. U.S. Department of Energy: Regulatory Technology Development Program Plan for the Standard MHTGR. DOE-HTGR-86-064. January 1987.

2. Stansfield, O. M., D. T. Goodin, D. L. Hanson, and R. F. Turner. Advances in HTGR Fuel Performance Models. U.S. DOE Report GA-A17913, GA Technologies, San Diego, CA, February 1985.

3. Haire, M. J., and D. W. McEachern. Gaseous Radioactivity Levels in the Primary Coolant of an HTGR. GA Report GA-Al2946, General Atomic, October 1, 1974 .

4. Alberstein, D., P. D. Smith, and M. J. Haire. Metallic Fission Product Release from the HTGR Core. GA Report GA-A13258, May 15, 1975.

5. Hudritsch, W. W., V. Jovanovic and D. L. Georghiou. SURVEY: A Computer Code for the Thermal and Fuel Performance Analysis of High-Temperature Gas-Cooled Reactors, GA-C17554, GA Technologies Inc., March 1984.

6. Smith, P. D. TRAFIC, A Computer Program for Calculating The Release of Metallic Fission Products from an HTGR Core, USDOE Report, GA.A14721, General Atomic, February 1978.

7. Smith, P. D. and R. G. Steinke. COPAR, A Program to Compute Release of Metallic Fission Products from Coated Particles. USDOE Report GA-A14721, General Atomic, November 1977.

8. Pfeiffer, W., Malek, G. J., and Lund, K. POKE - A Gas Cooled Reactor Flow and Thermal Analysis Code, GGA Report GA-10226, July 16, 1970.

9. Vanslager, F. E. RADC: A Computer Program for Calculating Fission Product Radioactivities, USAEC Report GAMD-6519, Gulf General Atomic, July $23,1965$. 
HTGR - $86-024$

\section{REFERENCES (CONT)}

10. Hudritsch, W. W. RANDI, A Zero-Dimensional Computer Program for Calculating HTGR Activities, GA Report GA-A14091, General Atomic, March, 1977.

11. General Atomic HTGR Accident Initiation and Progression Analysis Status Report Volume V. AIPA Fission Product Source Terms. USERDA Report GA-A13617, General Atomic, February 1976. 
HTGR - $86-024$

TABLE $4.2-22$

REPLACEABLE GRAPHITE CORE COMPONENT

STRESS -TO-STRENGTH RATIO LIMITS

$\begin{array}{llll}\text { Element Type } & \text { Operation } & \text { Basis Earthquake } & \text { DBE and SRDC } \\ \text { Standard Fuel Element } & 0.35 & 0.50 & 0.80 \\ \text { Reserve Shutdown Fuel } & 0.35 & 0.50 & 0.68 \\ \text { Element } & & & 0.57 \\ \text { Standard Reflector } & \text { TBD } & \text { TBD } & \\ \text { Element } & & & 0.57 \\ \text { Control Reflector } & 0.20 & 0.28 & \\ \text { Element } & & & \end{array}$


HTGR - 86- 024

TABLE $4.2-2$

BASIS FOR SPECIFICATION OF TRISO-COATED FUEL PROPERTIES

Particle Component

Kerne1

Buffer

IPyC

SiC

OPyC
Specified Property

Diameter

Density

Thickness and density

Thickness and density

Thickness and density

Thickness

Density

\section{Purpose of Specification}

Assure adequate heavy metal.

Control power produced per particle.

Control pressure vessel failure.

Assure adequate heavy metal.

Minimize fission gas release.

Control gas pressure.

Assure impermeability to chlorine during $\mathrm{SiC}$ deposition.

Control pressure vessel failure.

Minimize impact of SiC - fission product reactions.

Contain metallic and gaseous fission products.

Minimize core Si content.

Provide structural support to SiC layer throughout irradiation.

Provide backup to SiC for fission product containment

Provide bonding surface for fuel rod matrix.

Assure maximum irradiation stability with minimum permeability. 
HTGR - 86- 024

TABLE $4.2-3$

FUEL COMPACT CHARACTERISTICS

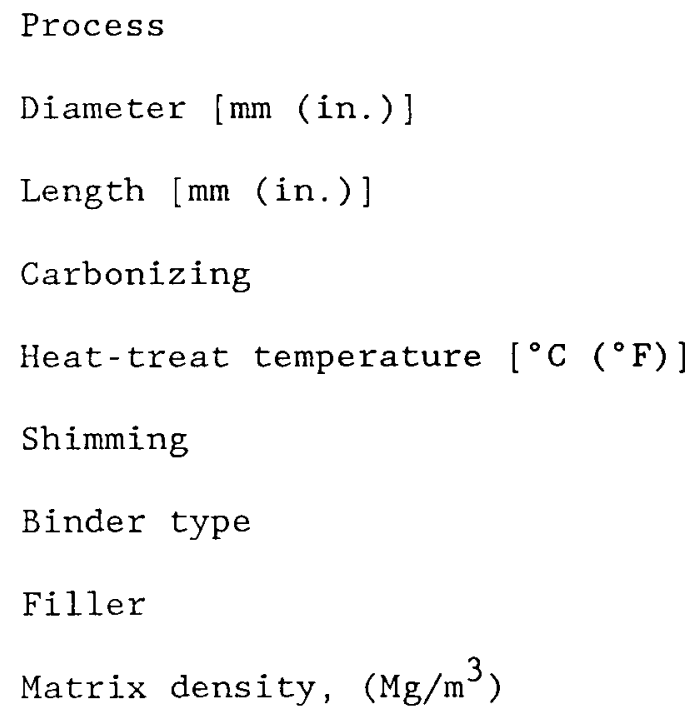


HTGR - 86- 024

TABLE $4.2-4$

FUEL QUALITY AND PERFORMANCE LIMITS

$\underline{\text { Parameter }}$

Segment

Average

Value

Upper 958 Bound

Value

As-Manufactured Fuel Quality:

- Heavy-Metal Contamination Fraction

$\leq 1.0 \times 10^{-5} \leq 2.0 \times 10^{-5}$

- Missing Buffer Fraction

$\leq 5.0 \times 10^{-5} \leq 2.0 \times 10^{-4}$

- Missing or Permeable Inner Pyrocarbon

$\leq 4.0 \times 10^{-5} \leq 1.0 \times 10^{-4}$

- SiC Coating Defect Fraction

$\leq 5.0 \times 10^{-5} \leq 1.0 \times 10^{-4}$

o Missing or Defective OPyC

$\leq 1.0 \times 10^{-4} \leq 1.0 \times 10^{-3}$

Fue1 Performance:
- In-service Failure Fraction (Normal)
$\leq 5.0 \times 10^{-5} \leq 2.0 \times 10^{-4}$
- Incremental Failure During Accident
$\leq 1.5 \times 10^{-4} \leq 6.0 \times 10^{-4}$ 
HTGR - 86- 024

TABLE $4.2-5$

REACTIVITY CONTROL REQUIREMENTS

Maximum core operating excess

Temperature effect (hot-to-cold)

Xenon decay

NP, PA, other short term decay

Shutdown

Total normal requirements (cold a $27^{\circ} \mathrm{C}$ )

(without random uncertainties included)

$\frac{\text { Percent }}{\underline{\mathrm{BOC}} \quad \underline{\mathrm{MOC}} \quad \underline{\mathrm{EOC}}}$

(1)

\begin{tabular}{lll}
1.0 & 2.5 & 0.5 \\
4.8 & 3.0 & 1.2 \\
3.7 & 3.7 & 3.7 \\
-- & 1.0 & 1.3 \\
1.0 & 1.0 & 1.0 \\
\hline 10.5 & 11.2 & 7.7
\end{tabular}

(1) $\Delta \rho=\frac{k_{2}-k_{1}}{k_{1} k_{2}}$ 
HTGR $-86-024$

TABLE 4.2 .6

CONTROL ROD AND RESERVE SHUTDOWN REACTIVITY WORTHS

Hot. End-of-Equilibrium-Cycle Conditions

$\underline{q} \Delta \rho$

Maximum-worth group of 3 outer rods, 0 other outer group inserted

Maximum-worth group of 3 outer rods, 1 other outer group inserted

2.1

Minimum-worth group of 3 outer rods, 7 outer groups inserted

0.9

24 outer rods

12.7

24 outer plus 6 inner

24.1

6 inner rods in presence of outer rods

11.4

12 RSC

13.2

12 RSC plus 24 outer rods

40.1

Cold. Decayed, End-of-Equilibrium-Cycle Conditions

24 outer rods

11.0

24 outer plus 6 inner

20.2

24 outer plus 5 inner rods (maximum-worth rod withdrawn)

18.0

24 outer plus 6 inner rods plus 12 RSC

35.7

24 outer rods plus 12 RSC

34.0

12 RSC

11.3 
HTGR - $86-024$

TABLE $4.2-7$

CONTROL ROD AND RSC REACTIVITY WORTHS

\begin{tabular}{|c|c|c|c|c|c|c|c|c|c|c|}
\hline (Number & insert & & & & Rea & tivits & Worth & $8 \Delta \rho$ & & \\
\hline $\begin{array}{l}\text { Inner } \\
\text { Rods }\end{array}$ & $\begin{array}{l}\text { Outer } \\
\text { Rods }\end{array}$ & RSC & $\begin{array}{l}\text { BOIC } \\
\text { Cold }\end{array}$ & $\begin{array}{l}\text { BOIC } \\
\text { Hot, } \\
1008\end{array}$ & $\begin{array}{l}\text { MOIC } \\
<-\ldots\end{array}$ & $\begin{array}{r}\text { EOIC } \\
-\quad \text { Hot }\end{array}$ & $\begin{array}{l}\text { BOEC. } \\
1008\end{array}$ & $\begin{array}{l}\text { MOEC } \\
-.->>\end{array}$ & $\begin{array}{l}\text { EOEC } \\
\text { Hot, } \\
1008\end{array}$ & $\begin{array}{l}\text { EOEC } \\
\text { Cold, } \\
\text { Decayed }\end{array}$ \\
\hline 6 & 0 & 0 & 4.5 & 5.4 & & & & & 5.8 & 4.7 \\
\hline 6 & 24 & 0 & 16.8 & 20.5 & 21.0 & 24.2 & 20.7 & 21.1 & 24.1 & 20.2 \\
\hline 0 & 24 & 0 & 8.1 & 9.9 & & & & & 12.7 & 11.0 \\
\hline 0 & 24 & 12 & 28.4 & 34.0 & & & & & 40.1 & 34.0 \\
\hline 6 & 24 & 12 & 30.4 & 36.3 & & & & & 42.1 & 35.7 \\
\hline 6 & 0 & 12 & 10.9 & 12.6 & & & & & 14.0 & 12.0 \\
\hline 0 & 0 & 12 & 10.1 & 11.7 & & & & & 13.2 & 11.3 \\
\hline
\end{tabular}


HTGR - 86-024

TABLE 4.2-8

RANDOM REACTIVITY UNCERTAINTY COMPONENTS

1. $\mathrm{U} \pm 18$

2. $T h \pm 18$

3. $\mathrm{LBP} \pm 3 \%$

4. Core graphite \pm 18

5. Combined (RMS)

6. Calculation model

7. Depletion effect

8. Combined (RMS)

9. Temperature defect \pm 108

10. Xenon \pm 108

11. Rod bank $\pm 10 \%$

12. Bank worth, max worth stuck rod out \pm 10 \%

Combined (RMS)

13. No stuck rod

14. With stuck rod

\begin{tabular}{|c|c|c|c|c|}
\hline $\mathrm{IC}-\mathrm{BOC}$ & IC-EOC & $\underline{E Q-B O C}$ & EQ-MOC & $E Q-E O C$ \\
\hline \pm 0.0021 & \pm 0.0018 & \pm 0.0012 & \pm 0.0009 & \pm 0.0007 \\
\hline \pm 0.0013 & \pm 0.008 & \pm 0.0005 & \pm 0.0004 & \pm 0.0003 \\
\hline \pm 0.0021 & \pm 0.0001 & \pm 0.0017 & \pm 0.004 & \pm 0.0001 \\
\hline \pm 0.0026 & \pm 0.0020 & \pm 0.0013 & \pm 0.0010 & \pm 0.0007 \\
\hline \pm 0.0041 & \pm 0.0084 & \pm 0.0025 & \pm 0.0042 & \pm 0.0010 \\
\hline \pm 0.005 & \pm 0.003 & \pm 0.003 & \pm 0.002 & \pm 0.001 \\
\hline 0.0 & \pm 0.003 & \pm 0.002 & \pm 0.0015 & \pm 0.001 \\
\hline \pm 0.005 & \pm 0.0042 & \pm 0.0036 & \pm 0.0025 & \pm 0.0014 \\
\hline
\end{tabular}

$\pm 0.0048 \pm 0.0012 \pm 0.0040 \quad \pm 0.0030 \pm 0.0012$

$\pm 0.0037 \pm 0.0037 \quad \pm 0.0037 \quad \pm 0.0037 \quad \pm 0.0037$

$\pm 0.0170 \pm 0.0200 \pm 0.0170 \quad \pm 0.0180 \quad \pm 0.0200$

$\pm 0.0150 \pm 0.0180 \pm 0.0150 \pm 0.0160 \pm 0.0180$

$\pm 0.0192 \pm 0.0224 \pm 0.0184 \quad \pm 0.0193 \pm 0.0204$

$\pm 0.0174 \pm 0.0207 \quad \pm 0.0165 \quad \pm 0.0174 \quad \pm 0.0184$ 
HTGR - $86-024$

TABLE $4.2-9$

TOTAL REACTIVITY UNCERTAINTIES AFFECTING COLD SHUTDOWN MARGIN

Reactivity Uncertainty $(\Delta \rho)$
$\underline{\text { IC-BOC }} \underline{\text { IC-EOC }} \underline{\text { EQ-BOC }} \underline{\text { EQ-MOC }} \underline{\text { EQ-EOC }}$

Shutdown Margin-A11 Rods

Combined RMS of items

5,8 , and 13 of Table 4.2-8

$\pm 0.0191 \pm 0.0225 \pm 0.0184 \pm 0.0192 \pm 0.0205$

Shutdown Margin-Max Rod Stuck Out ${ }^{(1)}$

Combined RMS of items

5,8 , and 14 of Table 4.2-8

$$
\pm 0.0174 \pm 0.0207 \pm 0.0166 \pm 0.0174 \pm 0.0185
$$

(1) Assumes maximum reactivity worth stuck rod reduces calculated rod bank worth by $2 \% \Delta \rho$ for all cycle conditions. 
HTGR - 86- 024

TABLE 4.2-10

ESTIMATED COLD SHUTDOWN MARGINS

\begin{tabular}{lll}
\multicolumn{5}{c}{ Shutdown Margin $(8 \Delta \rho)$} \\
\hline$\underline{I C-B O C}$ IC-EOC EQ-BOC $\quad$ EQ-MOC & EQ-EOC
\end{tabular}

\section{A11 Rods Inserted}

Nominal bank worth

16.8

19.8

17.0

17.3

20.2

Nominal requirement

10.5

8.0

10.5

11.2

7.7

Total uncertainty

$\pm 1.91$

$\pm 2.25$

$\pm 1.84$

$\pm 1.92$

$\pm 2.05$

Minimum shutdown margin (1)

4.39

9.55

4.66

4.18

10.45

Max Rod Stuck Out

Nominal worth (29 rods)

14.8

17.8

15.0

15.3

18.2

Nominal requirement

10.5

8.0

10.5

11.2

7.7

Total uncertainty

$\pm 1.74$

$\pm 2.07$

$\pm 1.66$

$\pm 1.74$

$\pm 1.85$

Minimum shutdown margin (1)

2.56

7.73

2.84

2.36

8.65

$\overline{\text { (1)Minimum }} \& \rho$ below a cold $\mathrm{k}$ eff of 0.99 , since the nominal requirement includes a $1.08 \Delta \rho$ shutdown margin as part of the total nominal requirement. 
HTGR - $86-024$

TABLE 4.2-11

RESERVE SHUTDOWN REQUIREMENTS AND REACTIVITY WORTH

\begin{tabular}{|c|c|c|c|}
\hline & Rea & E Wort & $\Delta \rho)$ \\
\hline & $\underline{\mathrm{BOC}}$ & $\underline{\mathrm{MOC}}$ & $\underline{\mathrm{EOC}}$ \\
\hline Temperature defect (to $192^{\circ} \mathrm{C}$ ) & 3.1 & 1.6 & 0.7 \\
\hline Xenon decay & 3.7 & 3.7 & 3.7 \\
\hline $\mathrm{Np}, \mathrm{Pa}$ and other decay & - - & 1.0 & 1.3 \\
\hline Shutdown & 1.0 & 1.0 & 1.0 \\
\hline Nominal requirement & 7.8 & 7.3 & 6.7 \\
\hline Uncertainty & \pm 1.10 & \pm 1.08 & \pm 1.08 \\
\hline Requirement with uncertainty & 8.9 & 8.4 & 7.8 \\
\hline Calculated RSC worth (cold) & 10.1 & 10.6 & 11.3 \\
\hline
\end{tabular}


HTGR $-86-024$

TABLE $4.2-12$

ACTIVE CORE AND CORRESPONDING REFLECTOR TEMPERATURES USED IN ONE-DIMENSIONAL RADIAL DIFFUSION CALCULATION OF THE TEMPERATURE COEFFICIENT EVALUATIONS

Normal Operating Range

$\begin{array}{ccc}\text { Total Reactor Isothermal Temperature } & {\left[\begin{array}{ll}\mathrm{C} & \left({ }^{\circ} \mathrm{F}\right)\end{array}\right]} \\ \begin{array}{c}\text { Inner } \\ \text { Reflector }\end{array} & \begin{array}{c}\text { Active } \\ \text { Core }\end{array} & \begin{array}{c}\text { Outer } \\ \text { Reflector }\end{array}\end{array}$

Normal Operating Range $\quad\left\{\begin{array}{rrrrrr}27 & (81) & 27 & (81) & 27 & (81) \\ 252 & (486) & 327 & (621) & 127 & (261) \\ 477 & (891) & 627 & (1160) & 327 & (621)\end{array}\right.$

Accident heatup Range $\quad\left\{\begin{array}{rrrrrr}827^{(1)}(1520) & 927 & (1700) & 452^{(1)}(845) \\ 1227 & (2240) & 1227 & (2240) & 627 & (1160) \\ 1527 & (2780) & 1527 & (2780) & 827 & (1520) \\ 1827 & (3320) & 1827 & (3320) & 1027 & (1880)\end{array}\right.$

(1) For active core temperature coefficient calculations, the inner and outer reflector temperatures were assumed constant at $827^{\circ} \mathrm{C}$ $\left(1520^{\circ} \mathrm{F}\right)$ and $452^{\circ} \mathrm{C}\left(845^{\circ} \mathrm{F}\right)$, respectively. 


\section{HTGR - 86- 024}

TABLE 4.2-13

FUEL LOADINGS

\begin{tabular}{|c|c|c|c|c|c|c|c|}
\hline \multirow[b]{2}{*}{ Cycle } & \multirow[b]{2}{*}{$\underline{E F P D}$} & \multirow[b]{2}{*}{$\underline{\mathrm{C} / \mathrm{Th}}$} & \multirow[b]{2}{*}{$\underline{\mathrm{C} / \mathrm{U}}$} & \multirow[b]{2}{*}{$\underline{\mathrm{C} / \mathrm{HM}}$} & \multicolumn{3}{|c|}{ Fuel Loading $[\mathrm{kg}(1 \mathrm{~b})]$} \\
\hline & & & & & Uran & um & Thorium \\
\hline 1 & 555 & 600 & 834 & 349 & 1726.4 & (3798) & $2346.3(5162)$ \\
\hline 2 & 380 & 1000 & 784 & 440 & 922.8 & $(2030)$ & 707.1 (1556) \\
\hline 3 & 490 & 1000 & 722 & 419 & 1001.1 & $(2202)$ & 706.1 (1553) \\
\hline 4 & 450 & 1000 & 730 & 422 & 990.7 & $(2180)$ & 706.2 (1553) \\
\hline 5 & 482 & 1000 & 701 & 412 & 1030.6 & $(2267)$ & 705.7 (1553) \\
\hline 6 & 482 & 1000 & 689 & 408 & 1048.2 & $(2306)$ & $705.4(1552)$ \\
\hline 7 & 482 & 1000 & 700 & 412 & 1032.2 & $(2271)$ & $705.7(1553)$ \\
\hline
\end{tabular}


HTGR-86-024

TABLE $4 \cdot 2-13 a$

RELATIVE POWER PRODUCTION RATES, PERCENT

\begin{tabular}{|c|c|c|c|c|}
\hline Isotope & BOC-IC & EOC-IC & BOC-Equilib & EOC-Equilib \\
\hline U-233 & -- & 18 & 4 & 13 \\
\hline$U-235$ & 100 & 61 & 86 & 57 \\
\hline$P u-239$ & -- & 17 & 8 & 23 \\
\hline Other* & -- & 4 & 2 & 7 \\
\hline
\end{tabular}

${ }^{*}$ Primarily $\mathrm{Pu}-241$ and U-238 fissions.

$\beta_{\text {eff }}(\mathrm{U}-235)=0.0065$

$\beta_{\text {eff }}(\mathrm{U}-233)=0.00266$

$\beta_{\text {eff }}(\mathrm{Pu}-239)=0.00212$

1 of 1 
HTGR $-86-024$

TABLE $4.2-14$

ESTIMATED CONTROL ROD POSITIONS FOR RISE-TO-POWER

\begin{tabular}{|c|c|c|c|c|}
\hline Condition & $\underline{B O C-I C}$ & $\underline{B O C-E Q}$ & $\underline{\mathrm{MOC}-\mathrm{EQ}}$ & $\underline{E O C-E Q}$ \\
\hline$k_{\text {eff }}$, hot unrodded & 1.010 & 1.010 & 1.025 & 1.005 \\
\hline $\begin{array}{l}\mathrm{k}_{\text {eff }}, \text { cold rodded; } \\
\text { xenon decayed }\end{array}$ & 0.93 & 0.93 & 0.94 & 0.88 \\
\hline Hot-to-cold $\Delta k_{\text {eff }}$ & 0.05 & 0.04 & 0.025 & 0.012 \\
\hline Xenon decay cold, $\Delta k_{\text {eff }}$ & 0.037 & 0.037 & 0.037 & 0.037 \\
\hline \multicolumn{5}{|c|}{ Critical rod group (GP) (\& withdrawal) (1) } \\
\hline - Cold critical & GP2 (668) & GP2 (668) & GP2 (408) & GP5 (TBD) \\
\hline - $25 \%$ power, no xenon & GP3 (TBD) & GP2 $(908)$ & GP2 (508) & GP5 (TBD) \\
\hline - $25 \%$ power, with xenon & GP4 (TBD) & GP4 (TBD) & GP2 (808) & GP6 (TBD) \\
\hline - 1008 power, 1008 xenon & GP10 (608) & GP10 (608) & GP9 (TBD) & GP10 (100 \\
\hline
\end{tabular}

(1) Percent withdrawal represents the percentage of the critical rod bank total reactivity worth that is withdrawn at the indicated condition.

Withdrawal sequence is:

Group 1, group 2 (inner), then group 3 through group 10 (outer). (A rod group consists of 3 control rods, separated by $120 \mathrm{deg}$ ) 
HTGR - 86- 024

TABLE $4.2-15$

ESTIMATED AFTERHEAT RATES WITH LEU/Th FUEL

\begin{tabular}{ll} 
Time & $\mathrm{P} / \mathrm{P}_{\mathrm{o}}(8)$ \\
\cline { 2 - 2 } $10 \mathrm{sec}$ & 6.5 \\
$100 \mathrm{sec}$ & 3.8 \\
$1 \mathrm{hr}$ & 1.5 \\
$5 \mathrm{hr}$ & 0.85 \\
$10 \mathrm{hr}$ & 0.77 \\
$20 \mathrm{hr}$ & 0.66 \\
$30 \mathrm{hr}$ & 0.56 \\
$240 \mathrm{hr}$ & 0.37 \\
$2,400 \mathrm{hr}$ & 0.097 \\
$3.2 \mathrm{yr}$ & 0.004
\end{tabular}

1 of 1 
HTGR $-86-024$

TABLE $4.2-16$

TRISO FUEL PARTICLE NOMINAL DIMENSIONS AND STANDARD DEVIATIONS

\begin{tabular}{|c|c|c|c|}
\hline \multicolumn{2}{|c|}{$\mathrm{ThO}_{2}$} & \multicolumn{2}{|r|}{ UCO } \\
\hline Nominal & Standard & Nominal & Standard \\
\hline $\begin{array}{l}\text { Dimension } \\
\frac{(\mu \mathrm{m})}{}\end{array}$ & $\begin{array}{c}\text { Deviation } \\
(8 \text { of nominal) }\end{array}$ & $\begin{array}{c}\text { Dimension } \\
\frac{(\mu \mathrm{m})}{}\end{array}$ & $\begin{array}{c}\text { Deviation } \\
(\& \text { of nomina } 1)\end{array}$ \\
\hline
\end{tabular}

$\begin{array}{lcccr}\text { Kernel diameter } & 500 & 4.9 & 350 & 5.0 \\ \text { Buffer thickness } & 65 & 18.0 & 100 & 18.0 \\ \text { IPyC thickness } & 50 & 16.3 & 50 & 16.3 \\ \text { SiC thickness } & 35 & 15.2 & 35 & 15.2 \\ \text { OPyC thickness } & 40 & 14.0 & 40 & 4.0 \\ \text { Particle diameter } & 880 & & 800 & \end{array}$

1 of 1 
HTGR $-86-024$

TABLE $4.2-17$

TEMPERATURE AND CORE-AVERAGED FUEL PARTICLE FAILURE SUMMARIES

Peak fuel temperature, ${ }^{\circ} \mathrm{C}\left({ }^{\circ} \mathrm{F}\right)$

1329 (2425)

Maximum time-average fuel temperature, ${ }^{\circ} \mathrm{C}\left({ }^{\circ} \mathrm{F}\right)$

1101 (2014)

Peak graphite temperature, ${ }^{\circ} \mathrm{C}\left({ }^{\circ} \mathrm{F}\right)$

1284 (2344)

Maximum time-average graphite temperature, ${ }^{\circ} \mathrm{C}\left({ }^{\circ} \mathrm{F}\right)$

1071 (1960)

Peak fissile particle percent failure

Total failure for fission gas release

0.00085

Total failure for fission metal release

0.0063

\section{Peak fertile particle percent failure}

Total failure for fission gas release

0.00011

Total failure for fission metal release

0.0054 


\author{
HTGR $-86-024$ \\ TABLE $4.2-18$ \\ PEAK CORE-AVERAGED GASEOUS RELEASES \\ COMPARISON OF PREDICTED RELEASES AND CRITERIA
}

$\underline{\mathrm{Kr}-85 \mathrm{~m}}$

Total Predicted R/B, Hydrolyzed Fue1, 50\% Confidence

$5.0 \times 10^{-7}$

Percent $R / B$ due to manufacturing contamination

91.1

Percent $R / B$ due to failed fissile particles

8.7

Percent $R / B$ due to failed fertile particles

0.2

Total R/B, "Maximum Expected" criterion (Section 11.1)

$9.3 \times 10^{-7}$

\title{
$\underline{\mathrm{Xe}-138}$
}

Total Predicted R/B, Hydrolyzed Fuel, 508 Confidence

Percent $R / B$ due to manufacturing contamination

$5.8 \times 10^{-8}$

Percent $R / B$ due to failed fissile particles

82.1

Percent $R / B$ due to failed fertile particles

17.8

0.1

Total R/B, "Maximum Expected" criterion (Section 11.1)

$\leq 6.8 \times 10^{-8}$ 

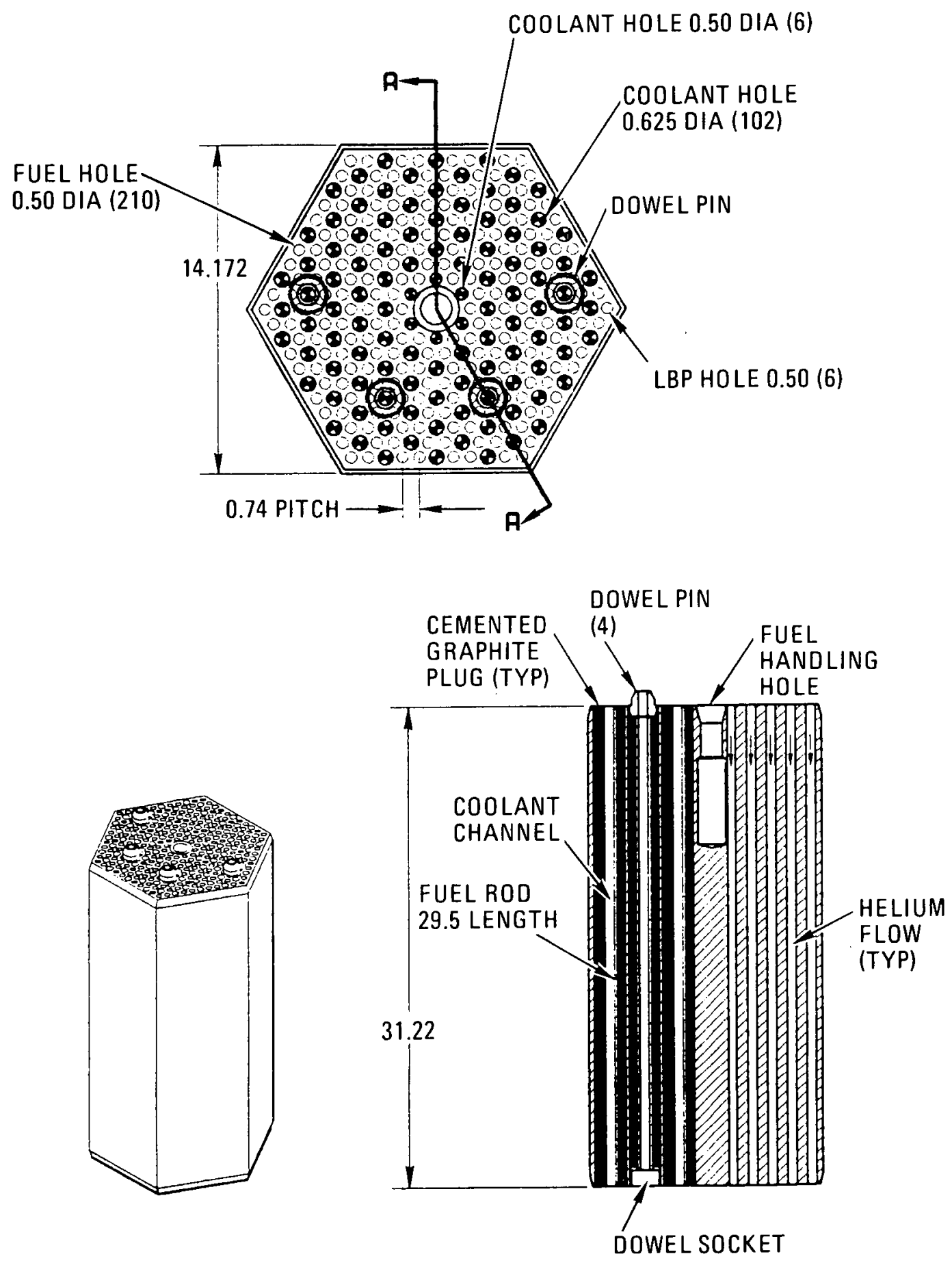

SECTION A-A

DIMENSION IN INCHES

FIGURE 4.2-1

STANDARD FUEL ELEMENT

HIGH TEMPERATURE GAS-COOLED REACTOR

PRELIMINARY SAFETY INFORMATION DOCUMENT

HTGR-86-024 


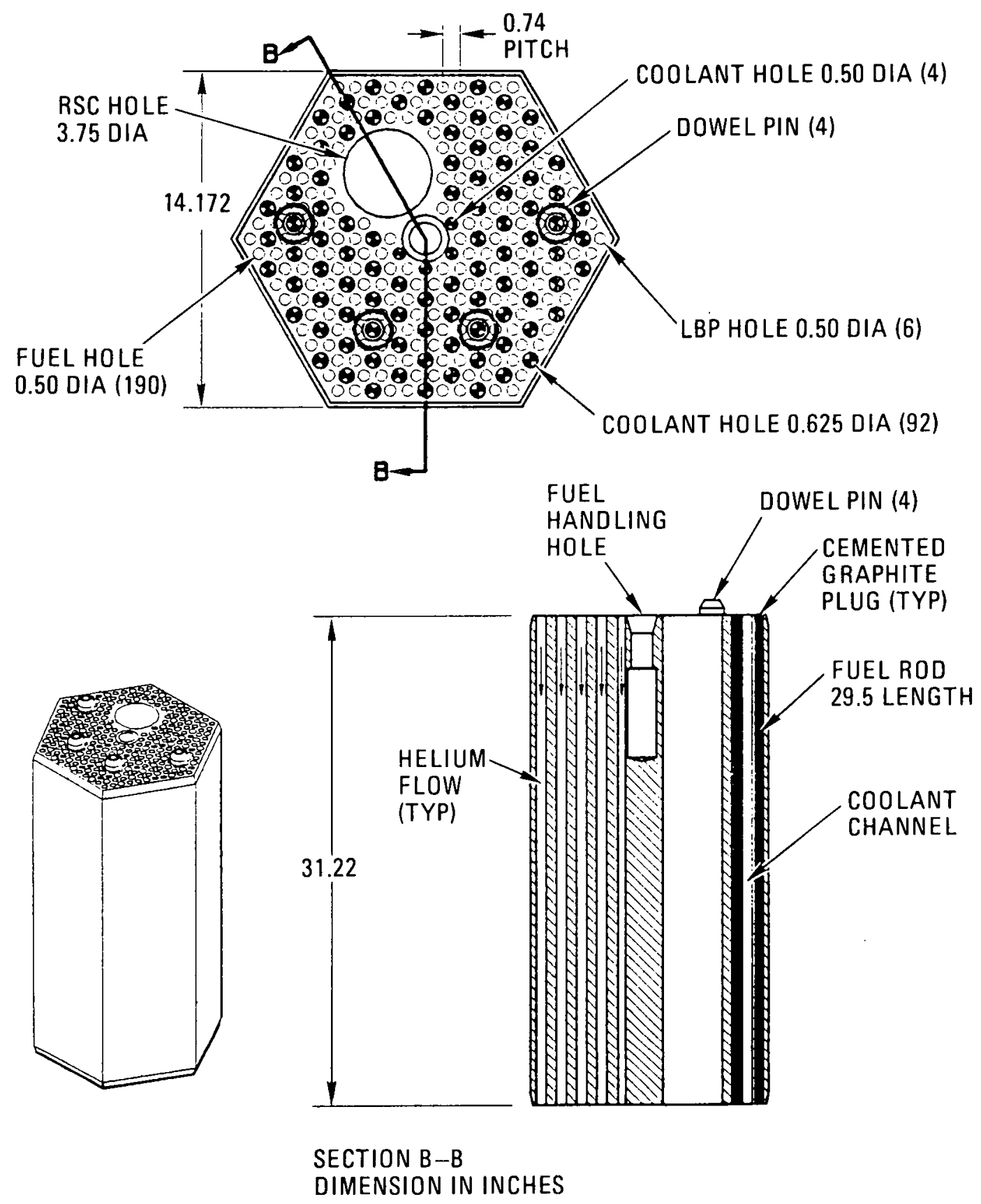

FIGURE $4.2-2$

RESERVE SHUTDOWN FUEL ELEMENT 


\section{FUEL PARTICLES}

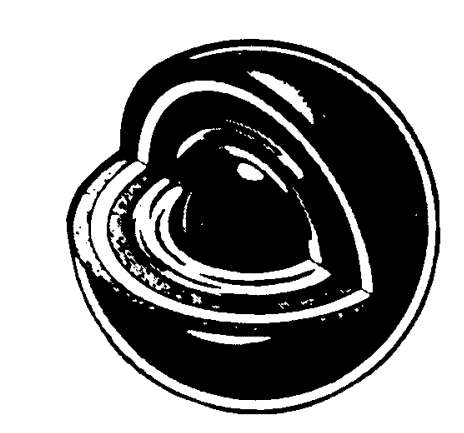

FISSILE (URANIUM 20\% ENRICHED)

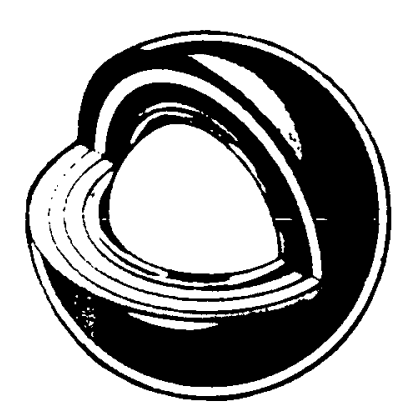

FERTILE (THORIUM)
PRISMATIC

FUEL ELEMENT

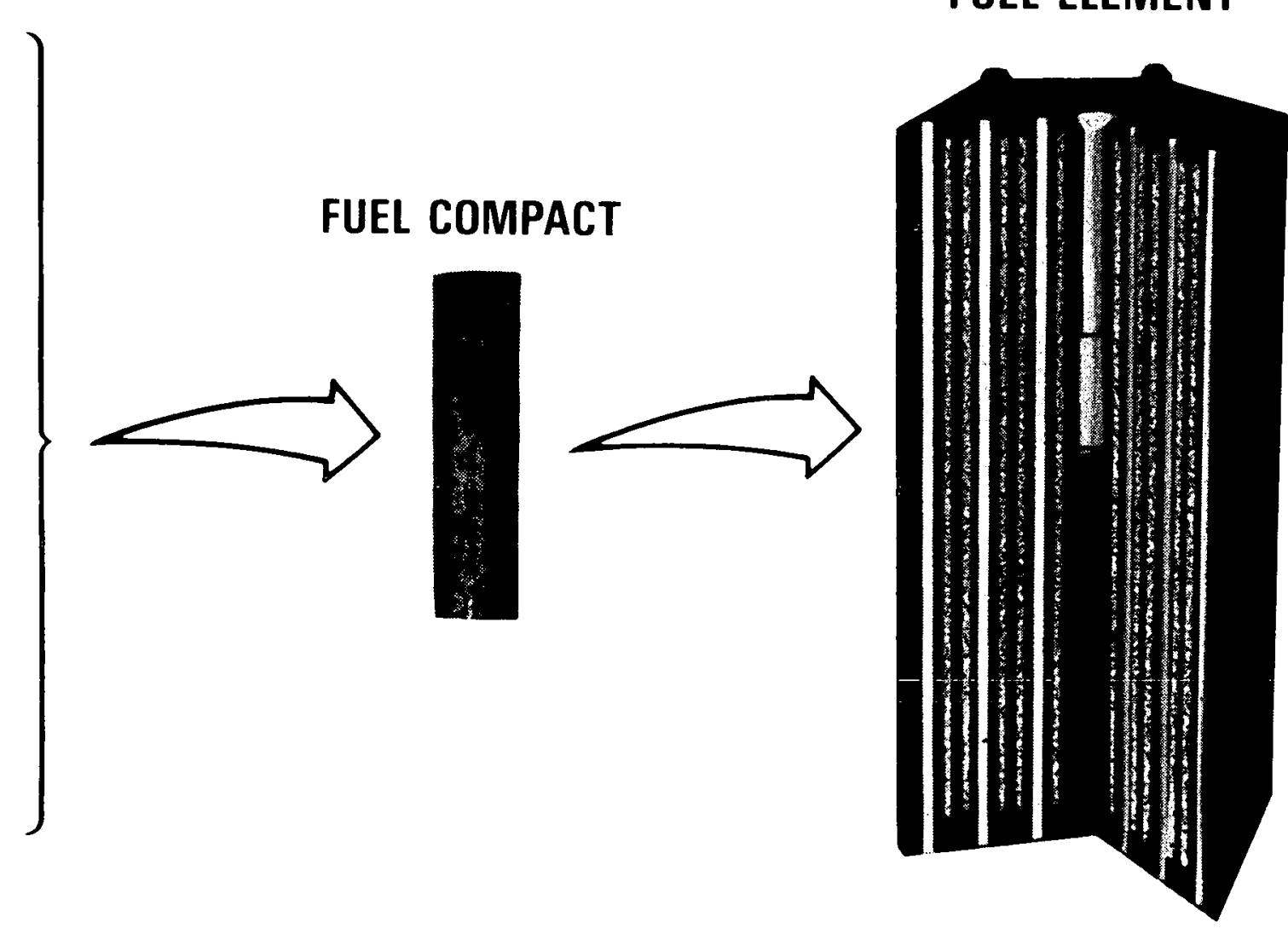

FIGURE 4.2-3

FUEL ELEMENT COMPONENTS

HIGH TEMPERATURE GAS-COOLED REACTOR

PRELIMINARY SAFETY INFORMATION DOCUMENT

HTGR-86-024 


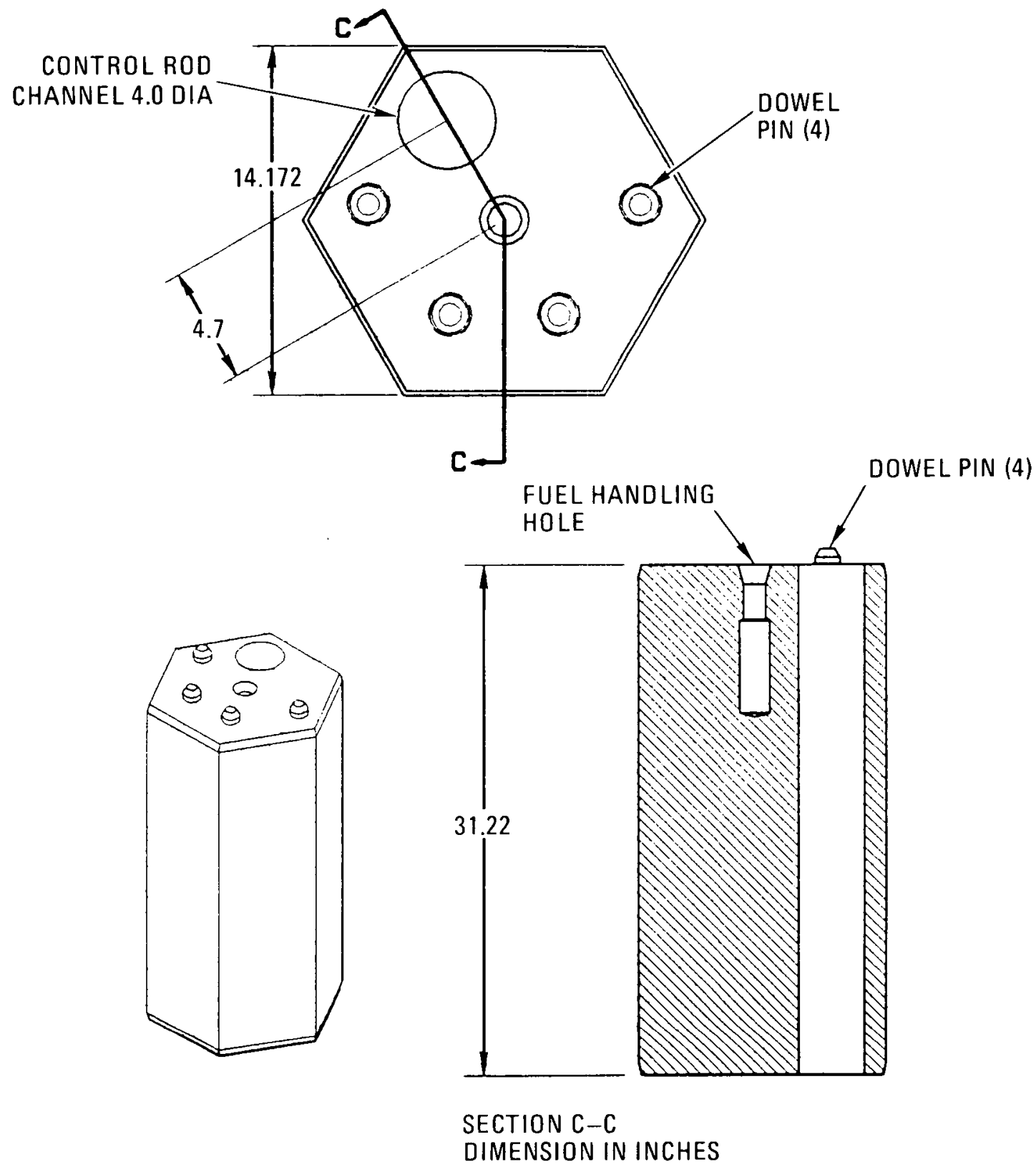

FIGURE 4.2-4

SIDE REFLECTOR BLOCK 


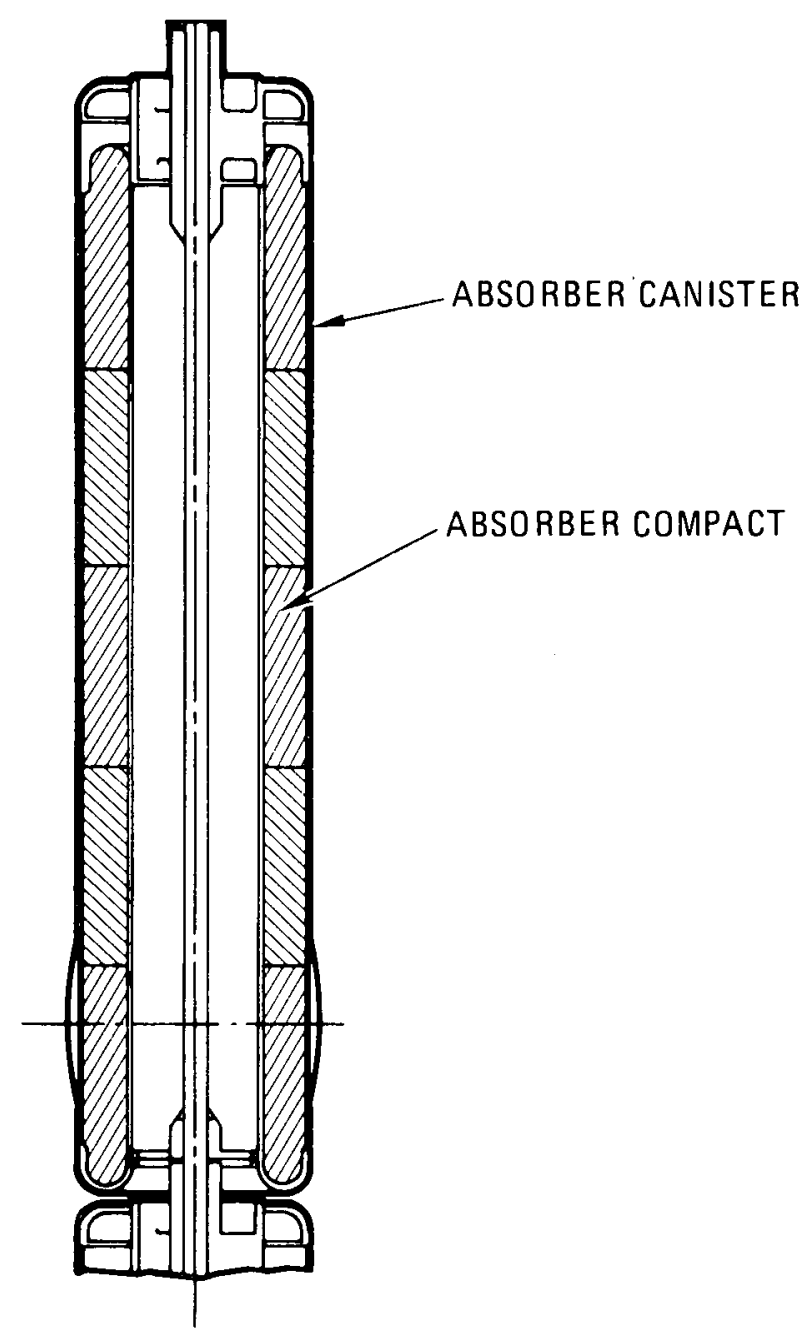

FIGURE 4.2-5

SCHEMATIC OF CONTROL ROD SECTION

HIGH TEMPERATURE GAS-COOLED REACTOR

PRELIMINARY SAFETY INFORMATION DOCUMENT

HTGR-86-024 


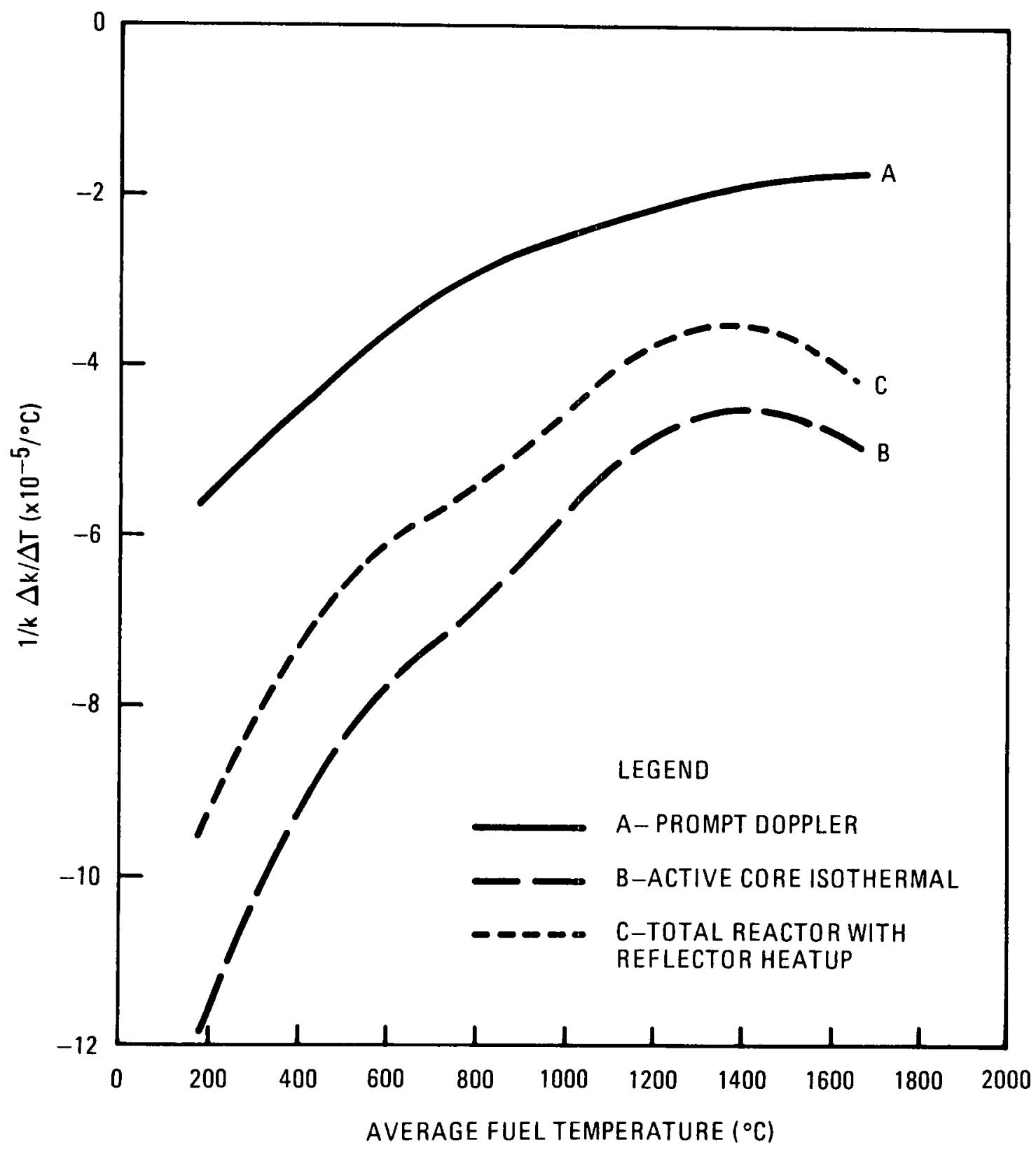

FIGURE 4.2-6

TEMPERATURE COEFFICIENT - INITIAL CORE-BOC (WITH XENON AND $2.5 \% \Delta K$ INSERTED CONTROL RODS) 


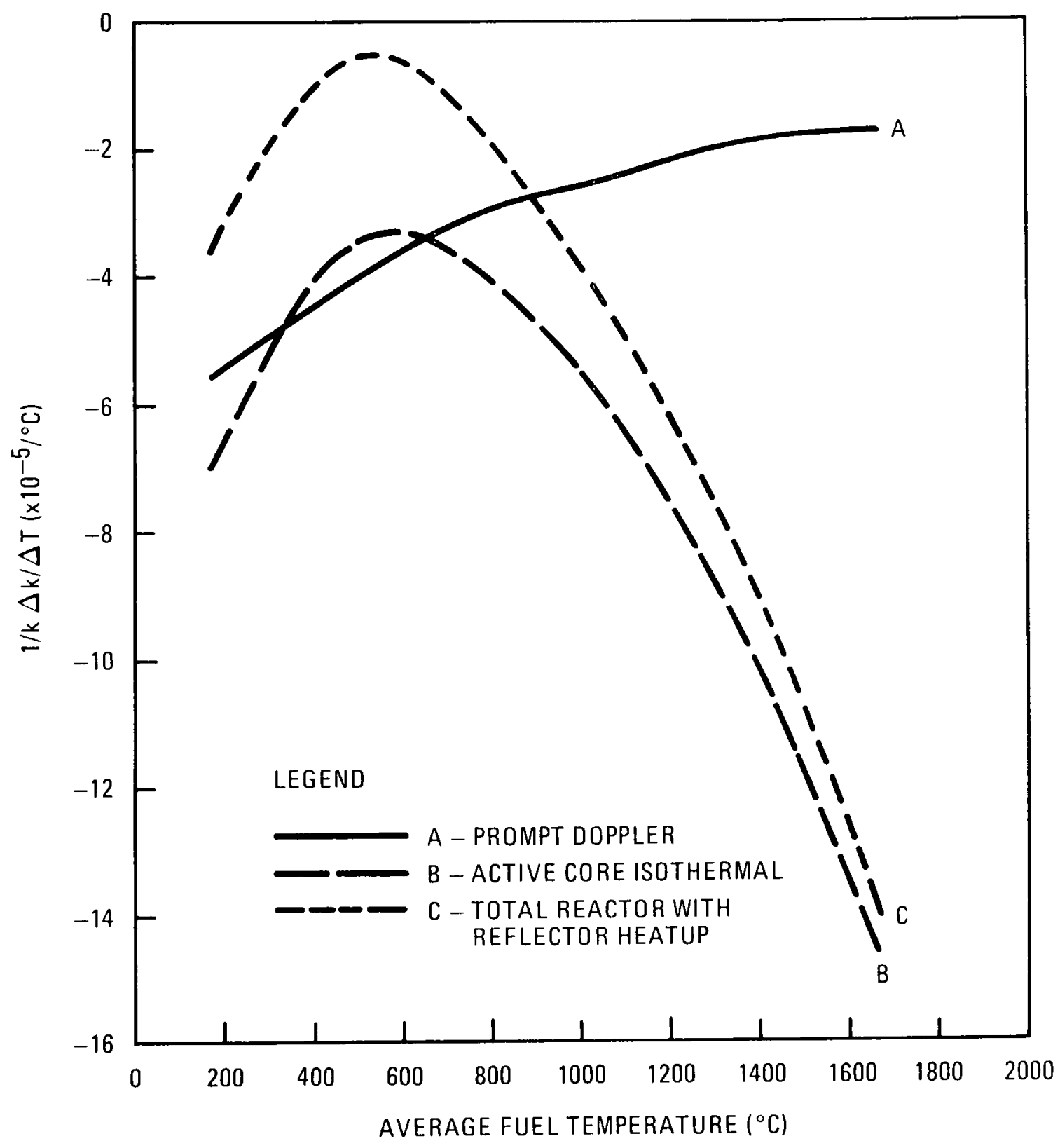

FIGURE 4.2-7

TEMPERATURE COEFFICIENT EQUILIBRIUM CORE EOC (WITH XENON - NO RODS INSERTED) 


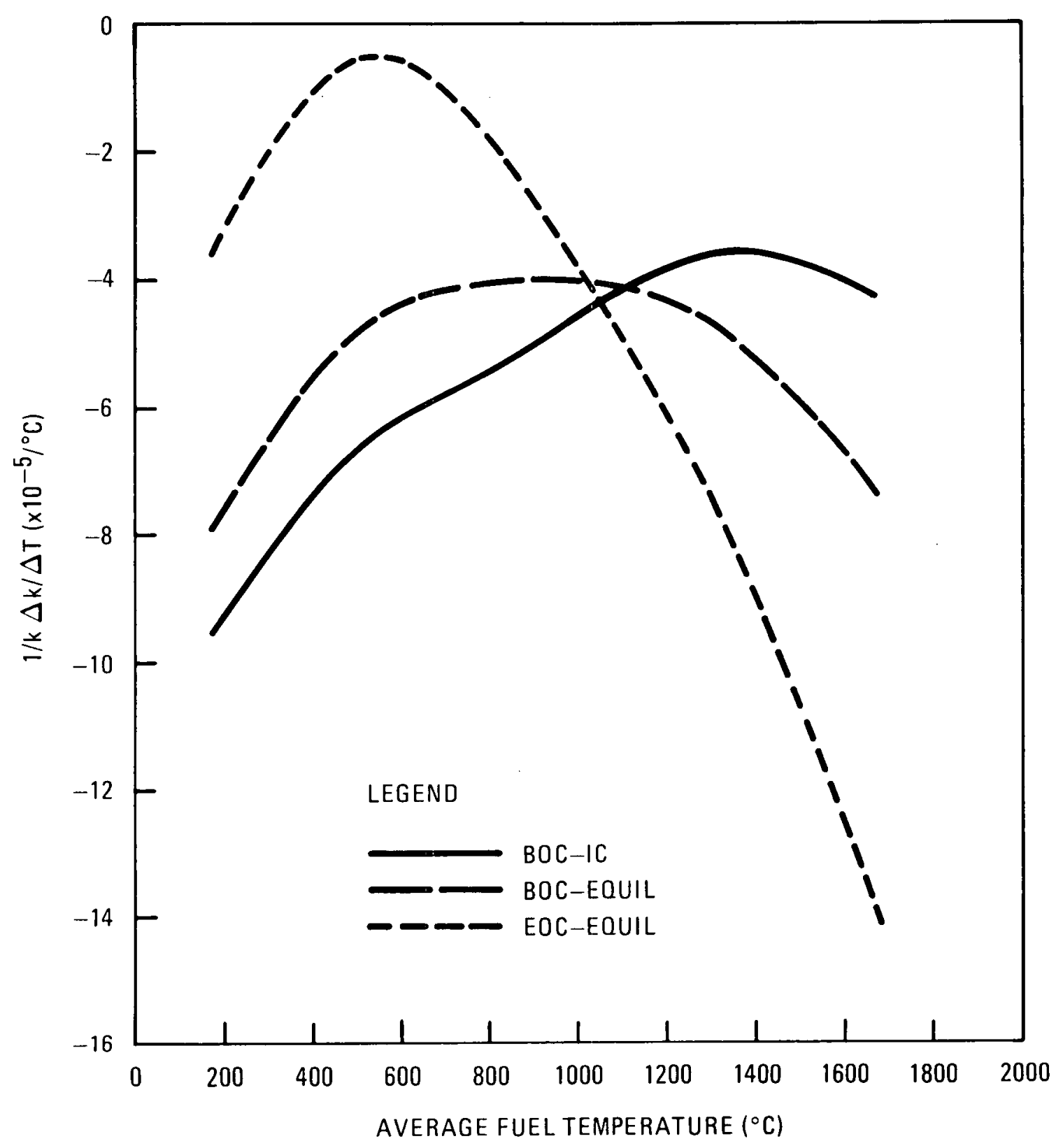

FIGURE 4.2-8

TEMPERATURE COEFFICIENT (TOTAL REACTOR WITH REFLECTOR HEATUP) 


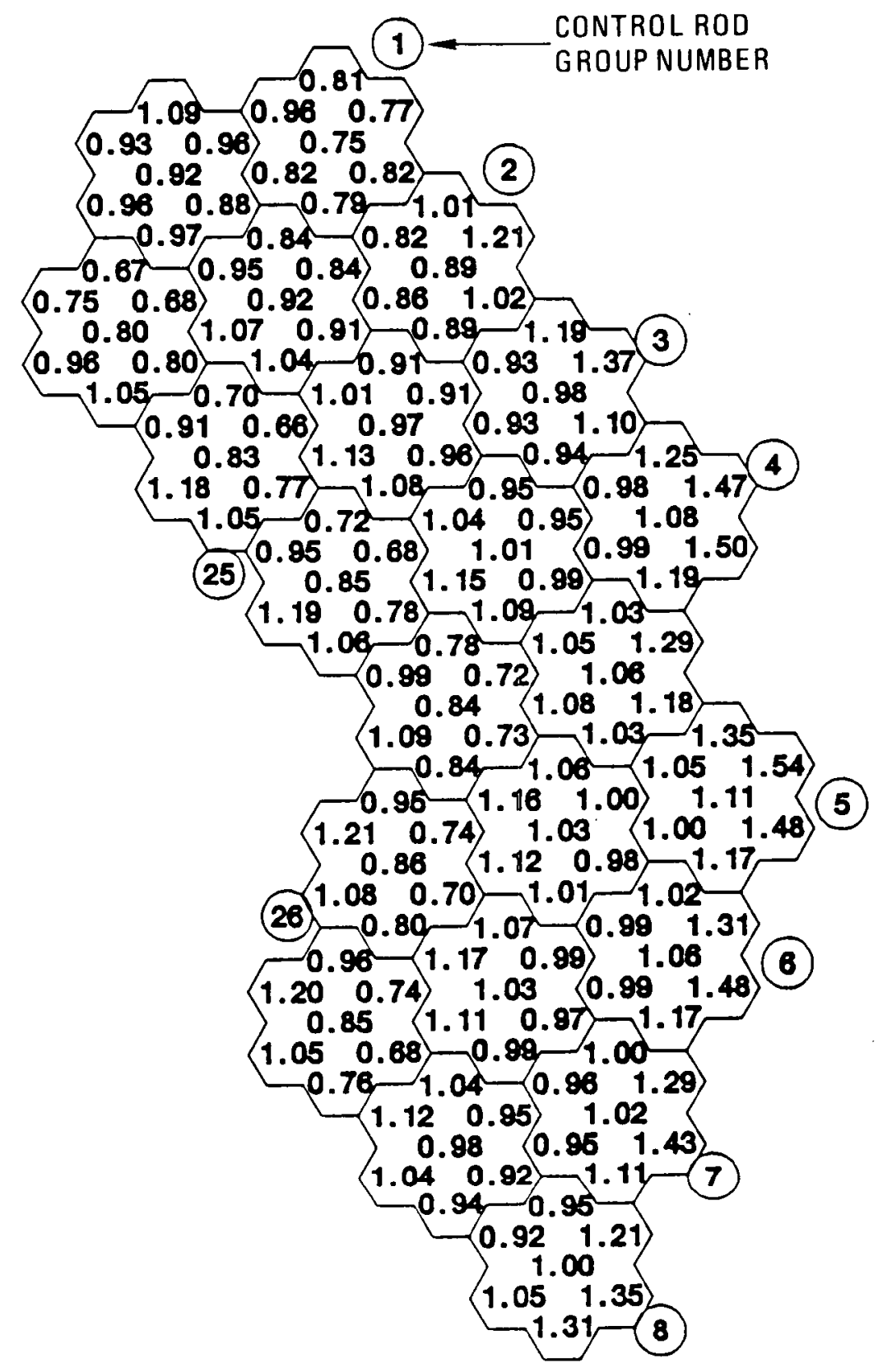

FIGURE $4.2 \cdot 9$

RELATIVE RADIAL POWER DISTRIBUTION (BEGINNING OF INITIAL CYCLE WITH XENON) 


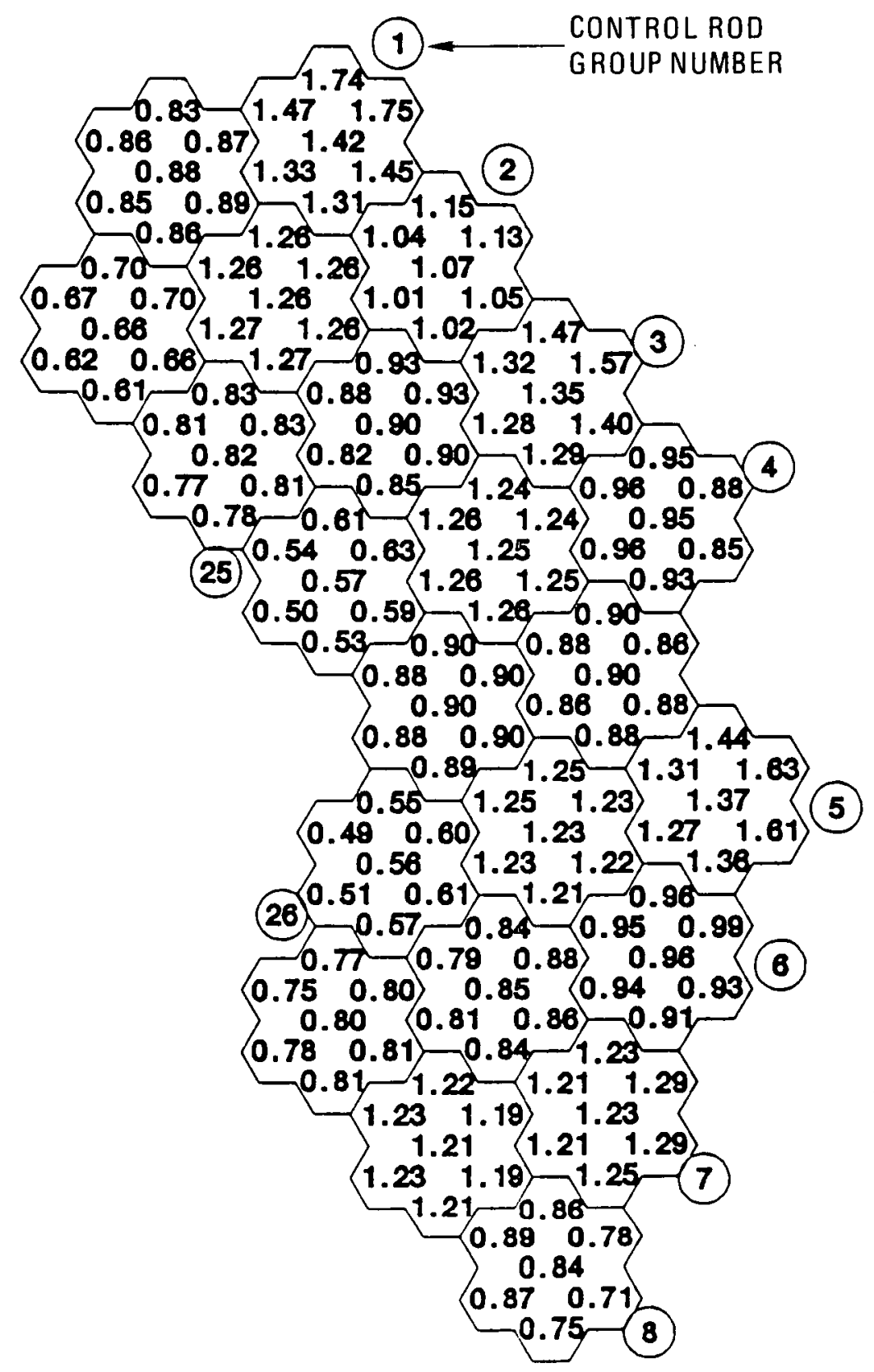

FIGURE 4.2-10

RELATIVE RADIAL POWER DISTRIBUTION (END OF EQUILIBRIUM CYCLE WITH XENON RODS WITHDRAWN)

HIGH TEMPERATURE GAS-COOLED REACTOR PRELIMINARY SAFETY INFORMATION DOCUMENT HTGR-86-024 


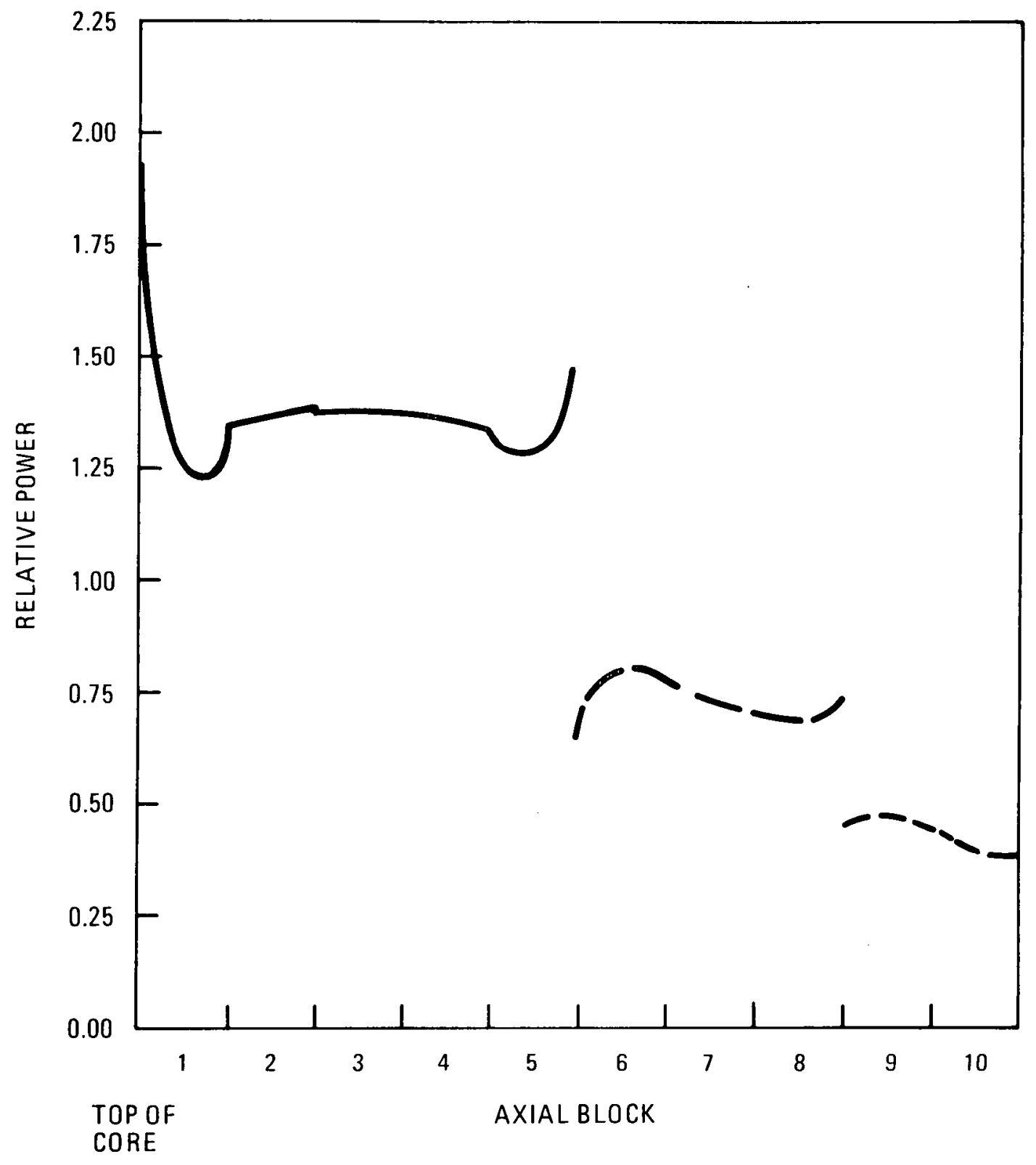

FIGURE 4.2-11

RELATIVE AXIAL POWER DISTRIBUTION FOR EQUILIBRIUM CYCLE 


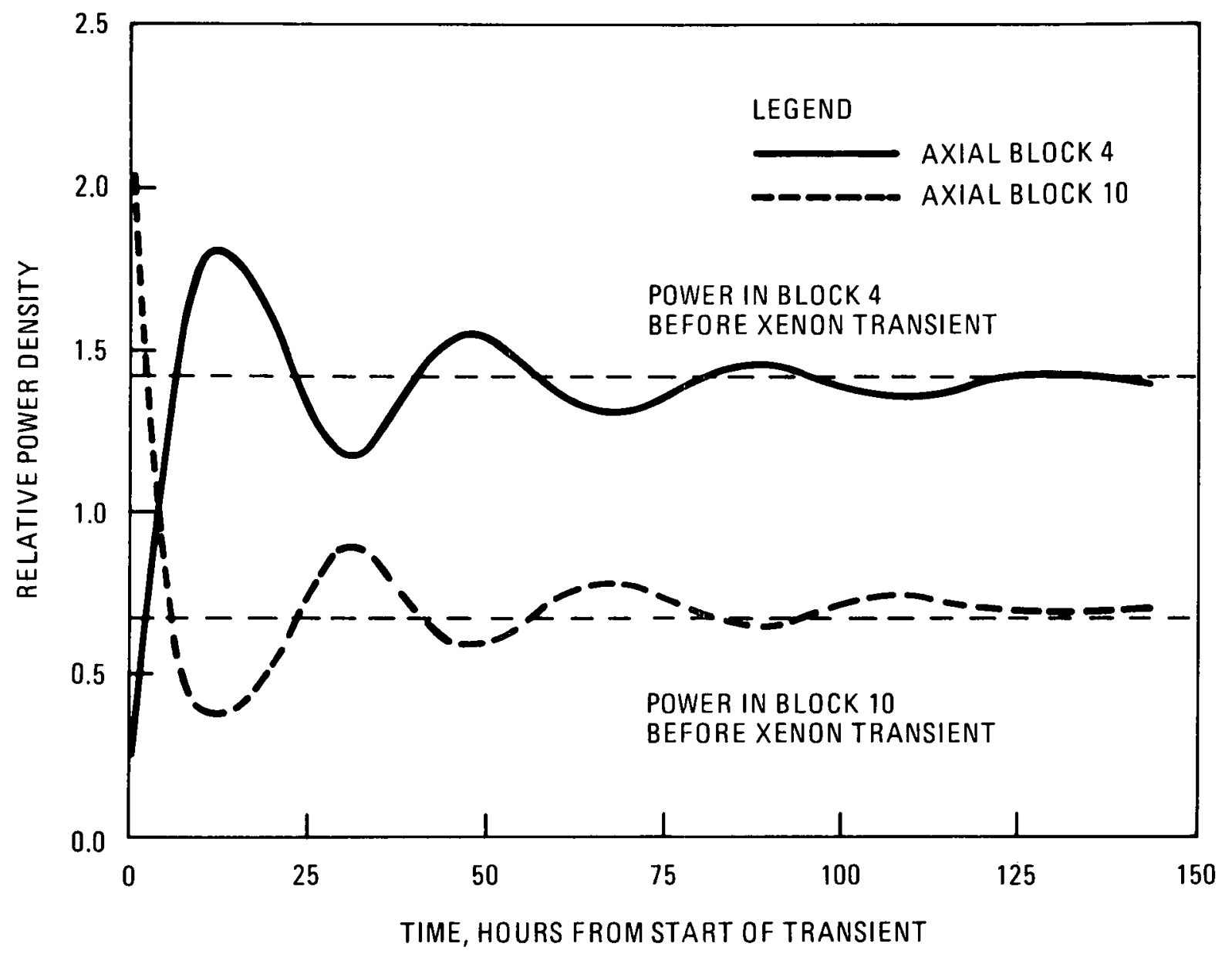

FIGURE 4.2-12

AXIAL XENON TRANSIENT EQUILIBRIUM CYCLE (FUEL ZONED AXIALLY - TEMPERATURE COEFFICIENT $\left.3.5 \times 10^{-5} /{ }^{\circ} \mathrm{C}\right)$ 


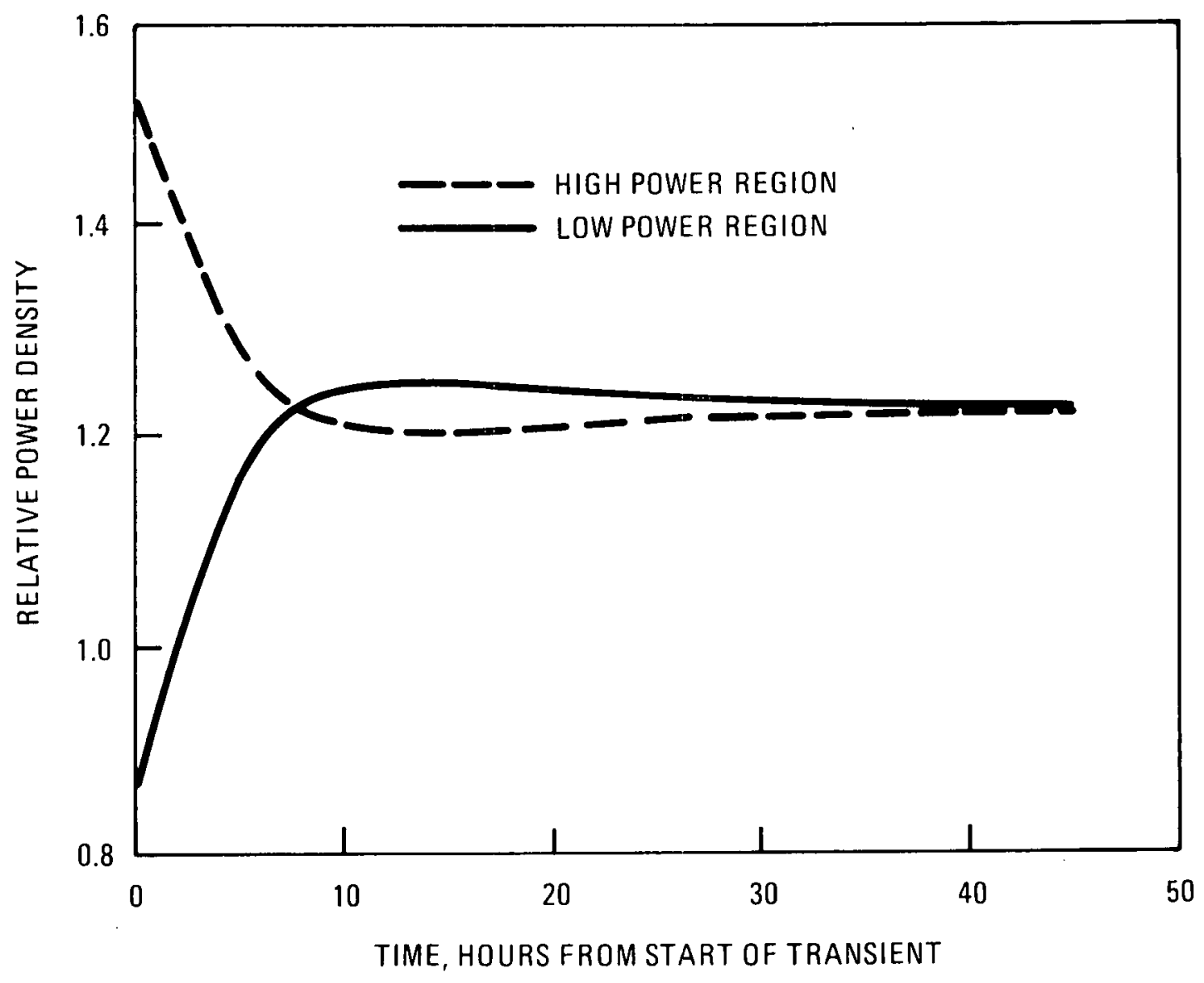

FIGURE 4.2-13

\section{RADIAL XENON TRANSIENT}




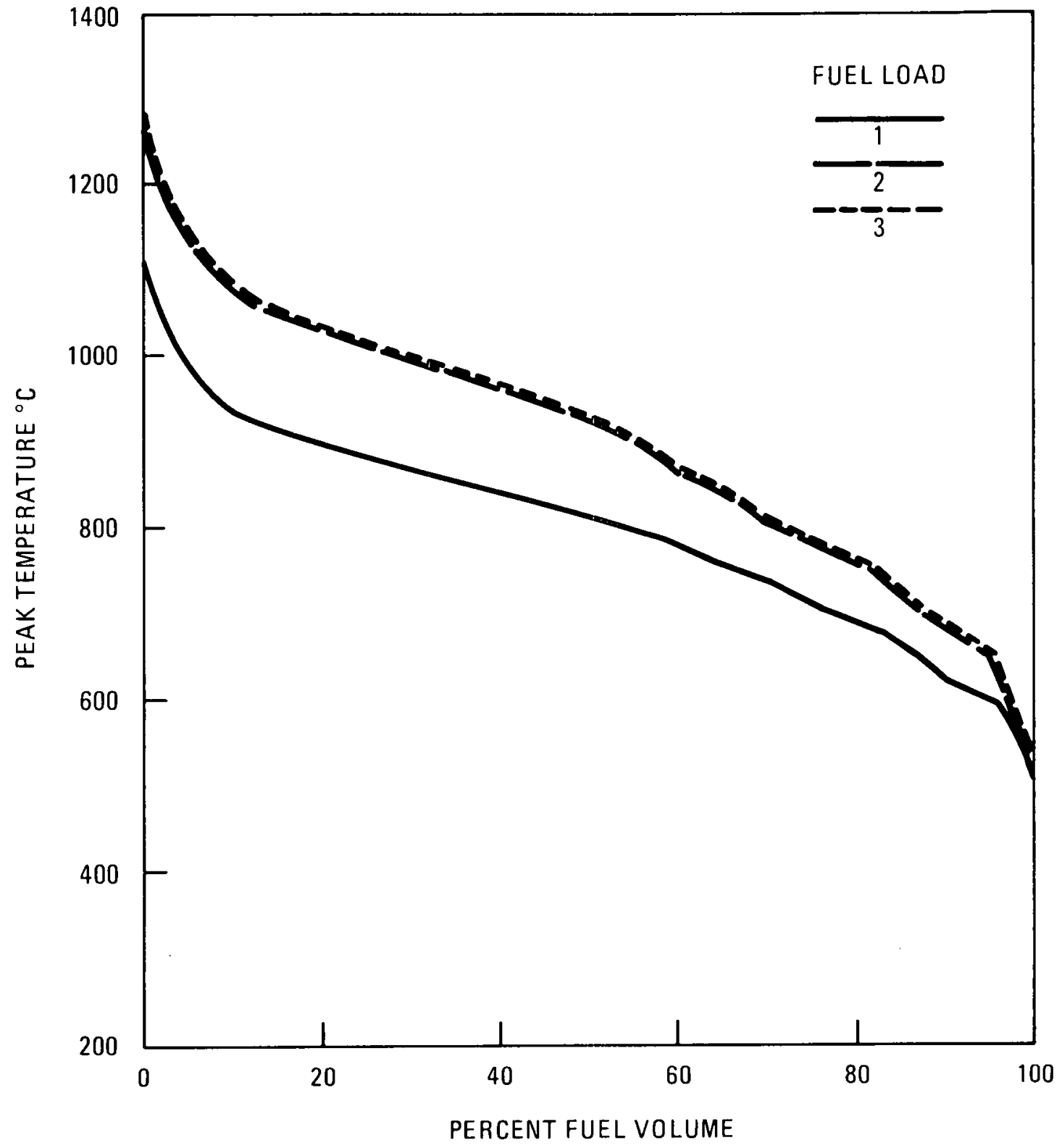

FIGURE 4.2-14

MHTGR PEAK FUEL TEMPERATURE VOLUME DISTRIBUTION FOR FUEL SEGMENT 2 


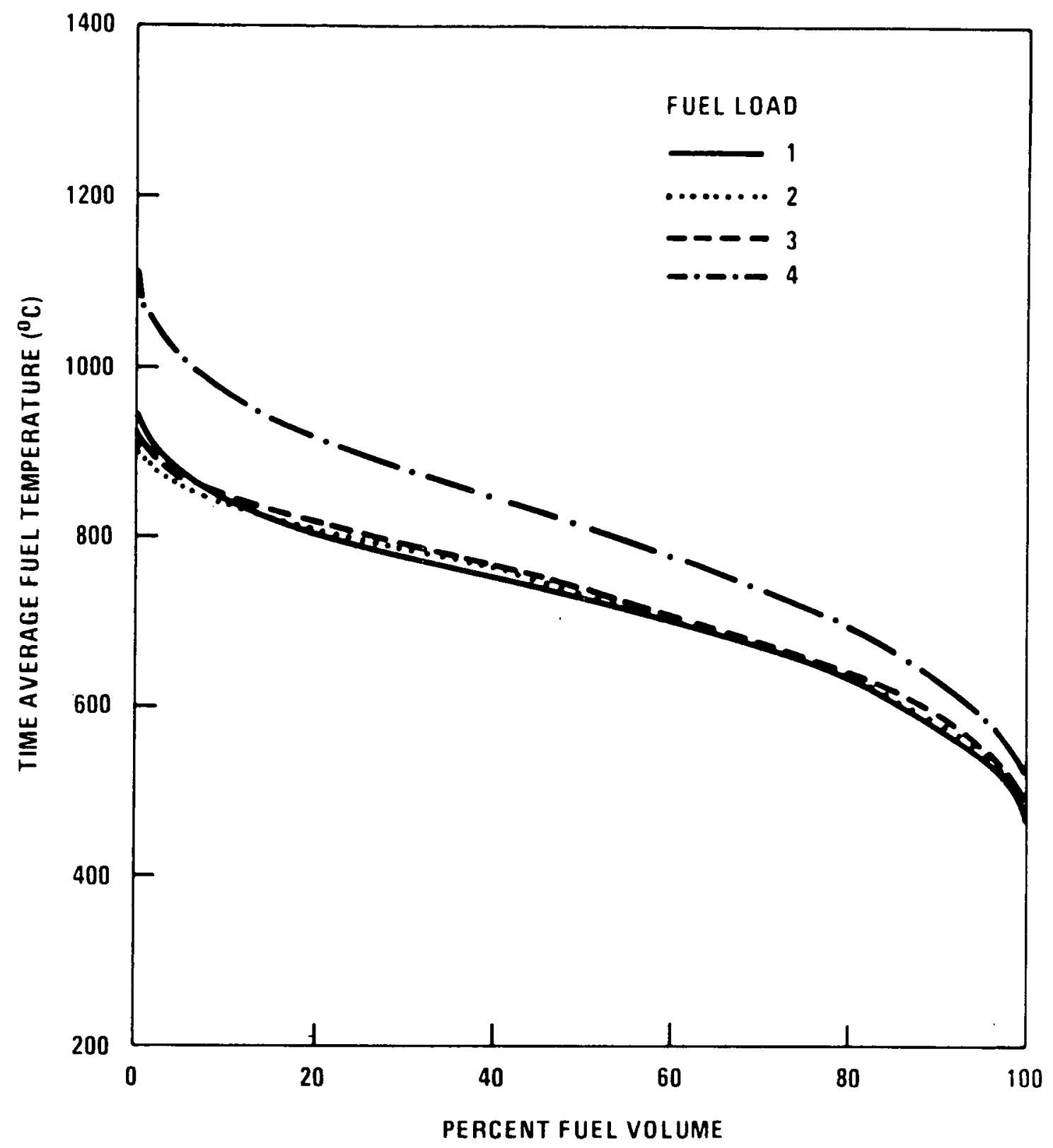

FIGURE 4.2-15

MHTGR TIME-AVERAGE FUEL TEMPERATURE VOLUME DISTRIBUTION FOR FUEL SEGMENT 1

HIGH TEMPERATURE GAS-COOLED REACTOR

PAELIMINAAY SAFETY INFORMATION DOCUMENT

HTGR 86-024 


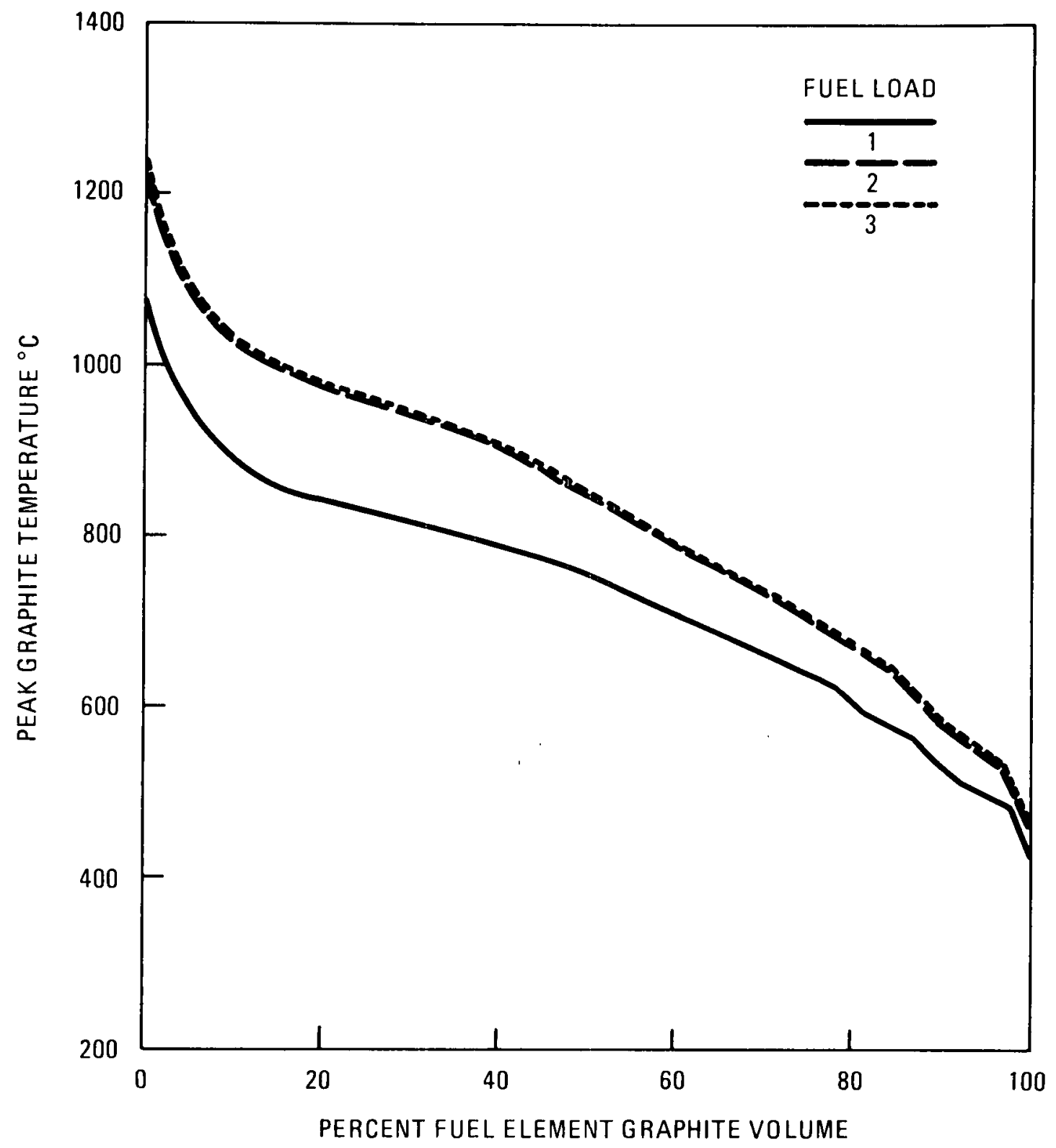

FIGURE 4.2-16

MHTGR PEAK GRAPHITE TEMPERATURE VOLUME DISTRIBUTION FOR FUEL SEGMENT 2 


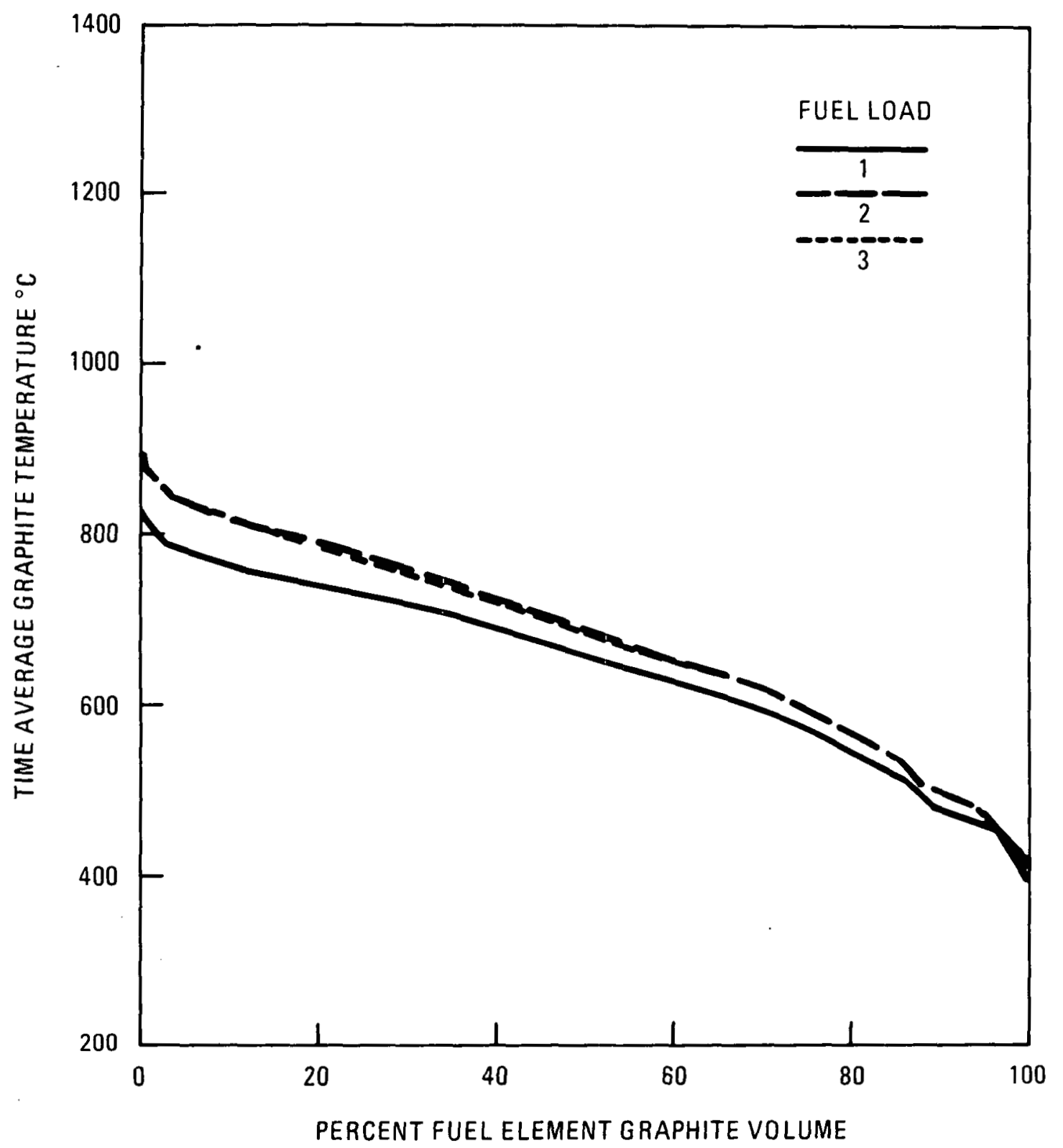

FIGURE 4.2-17

MHTGR TIME - AVERAGE GRAPHITE TEMPERATURE VOLUME DISTRIBUTION FOR FUEL SEGMENT 2

HIGH TEMPERATURE GAS-COOLED REACTOR PAELIMIMARY SAFETY INFORMATION DOCUMENT HTGR-86-024 


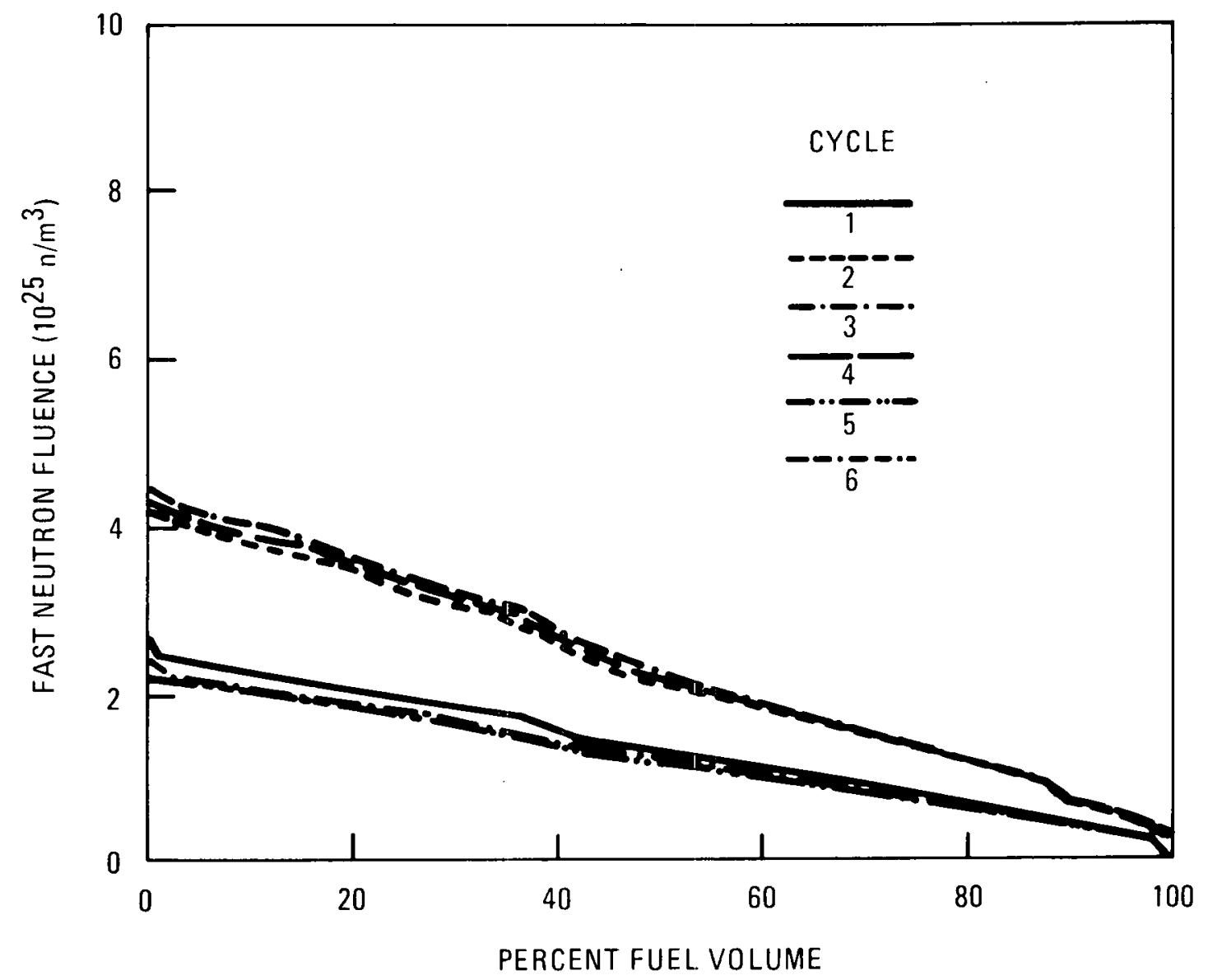

FIGURE 4.2-18

FAST FLUENCE VOLUME DISTRIBUTION FOR FUEL SEGMENT 2 


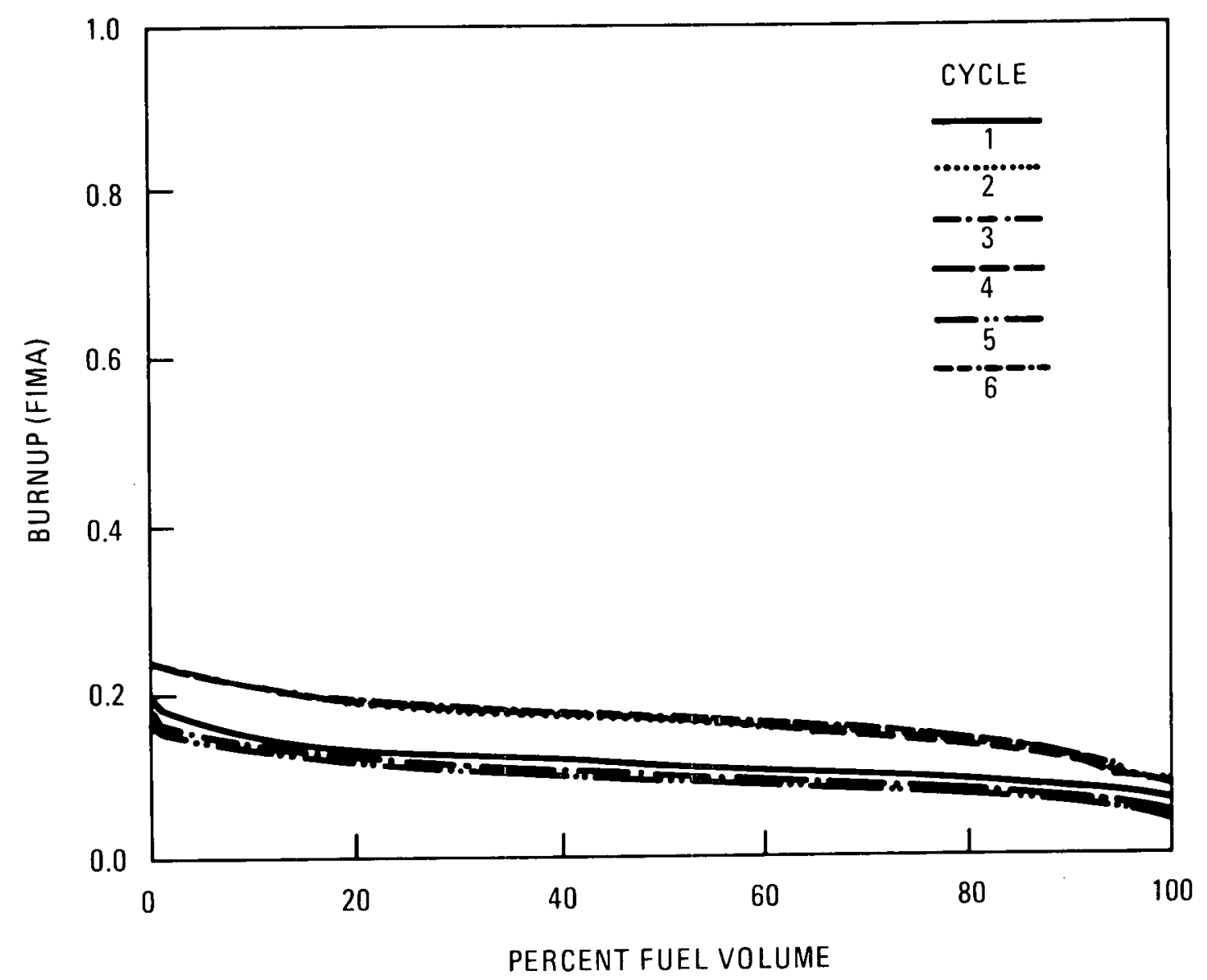

FIGURE 4.2-19

FISSILE BURNUP VOLUME DISTRIBUTION FOR FUEL SEGMENT 2 


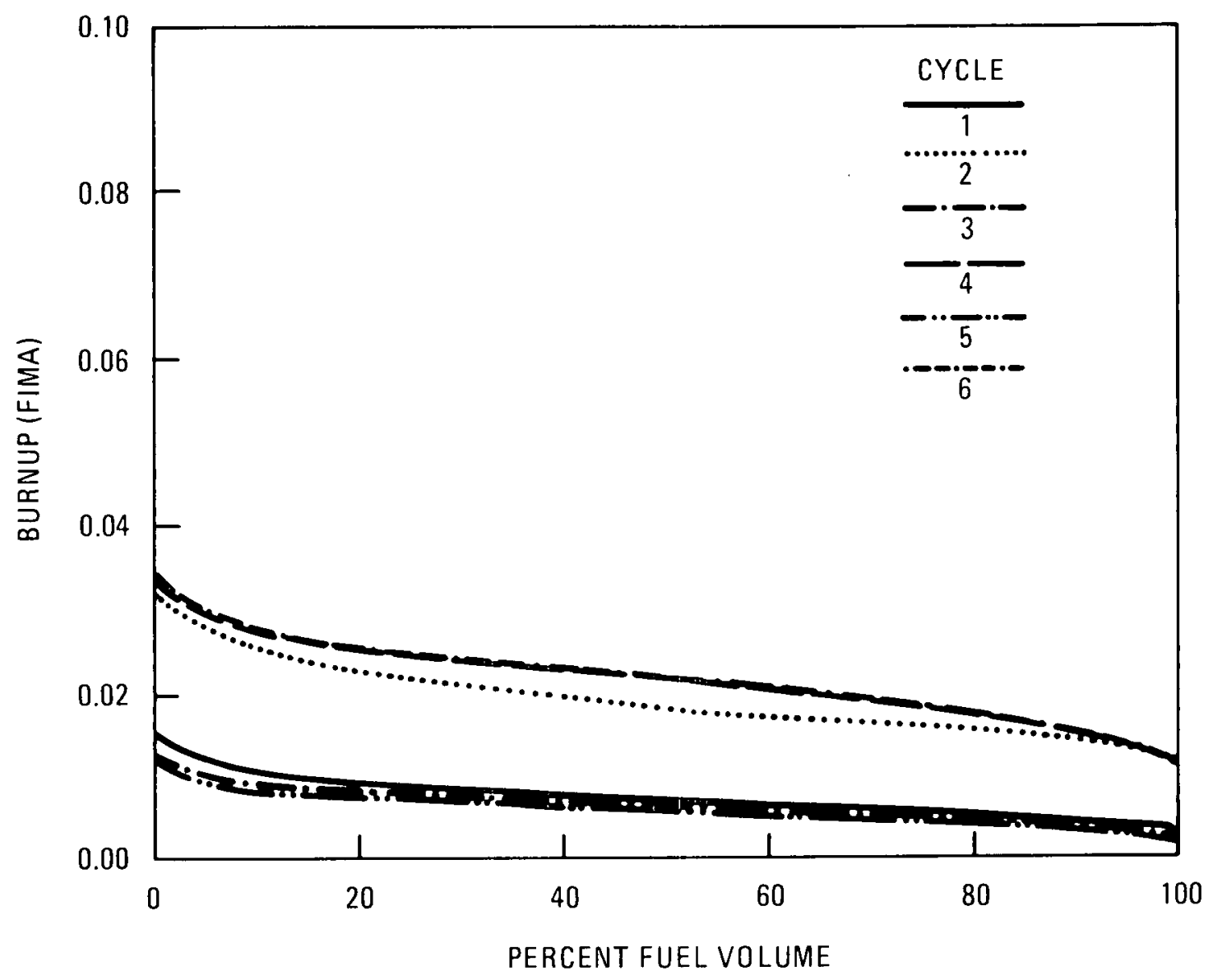

FIGURE 4.2-20

FERTILE BURNUP VOLUME DISTRIBUTION FOR FUEL SEGMENT 2

HIGH TEMPERATURE GAS-COOLED REACTOR PRELIMINARY SAFETY INFORMATION DOCUMENT HTGR-86-024 


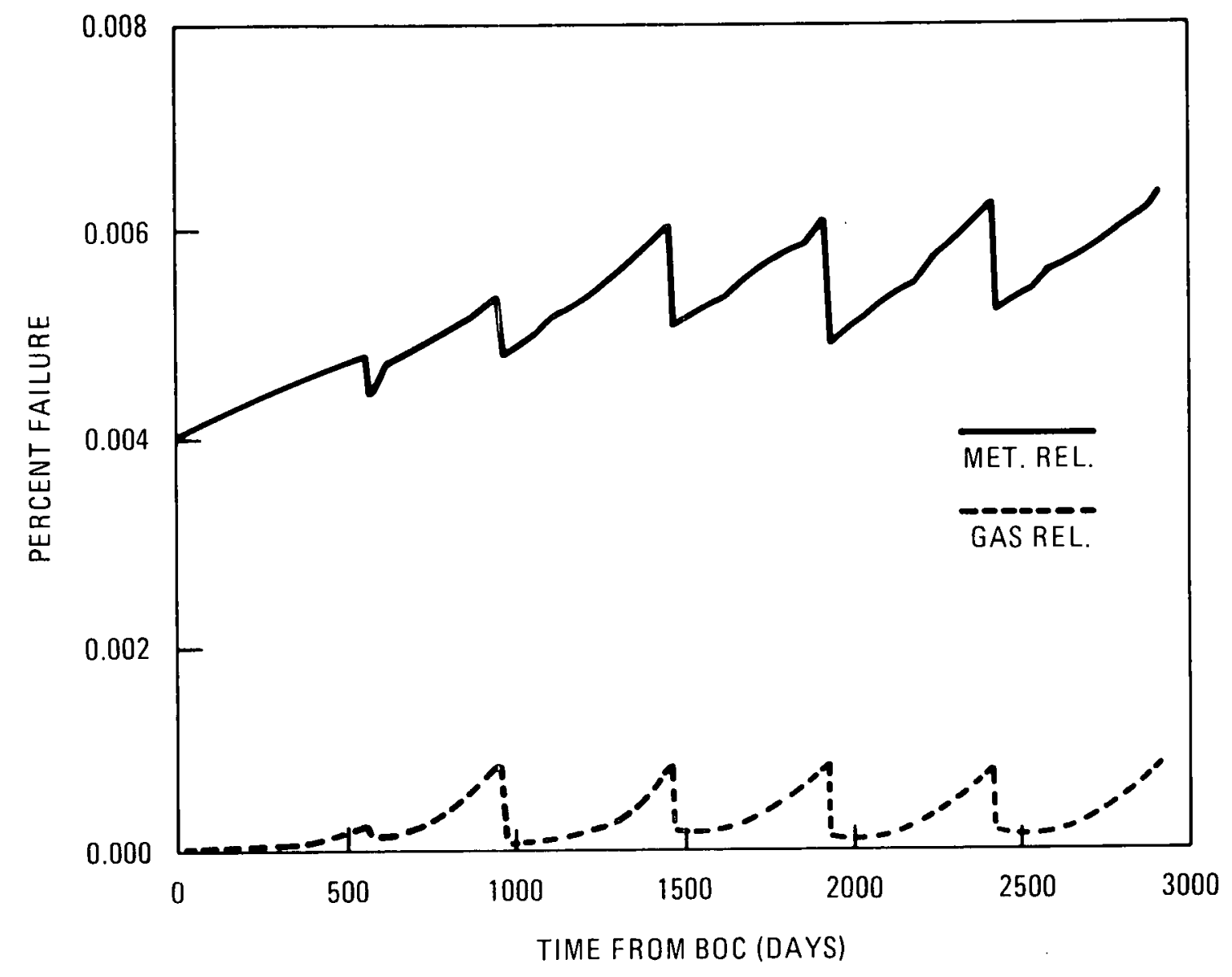

FIGURE 4.2.21

\section{FISSILE PARTICLE FAILURE}




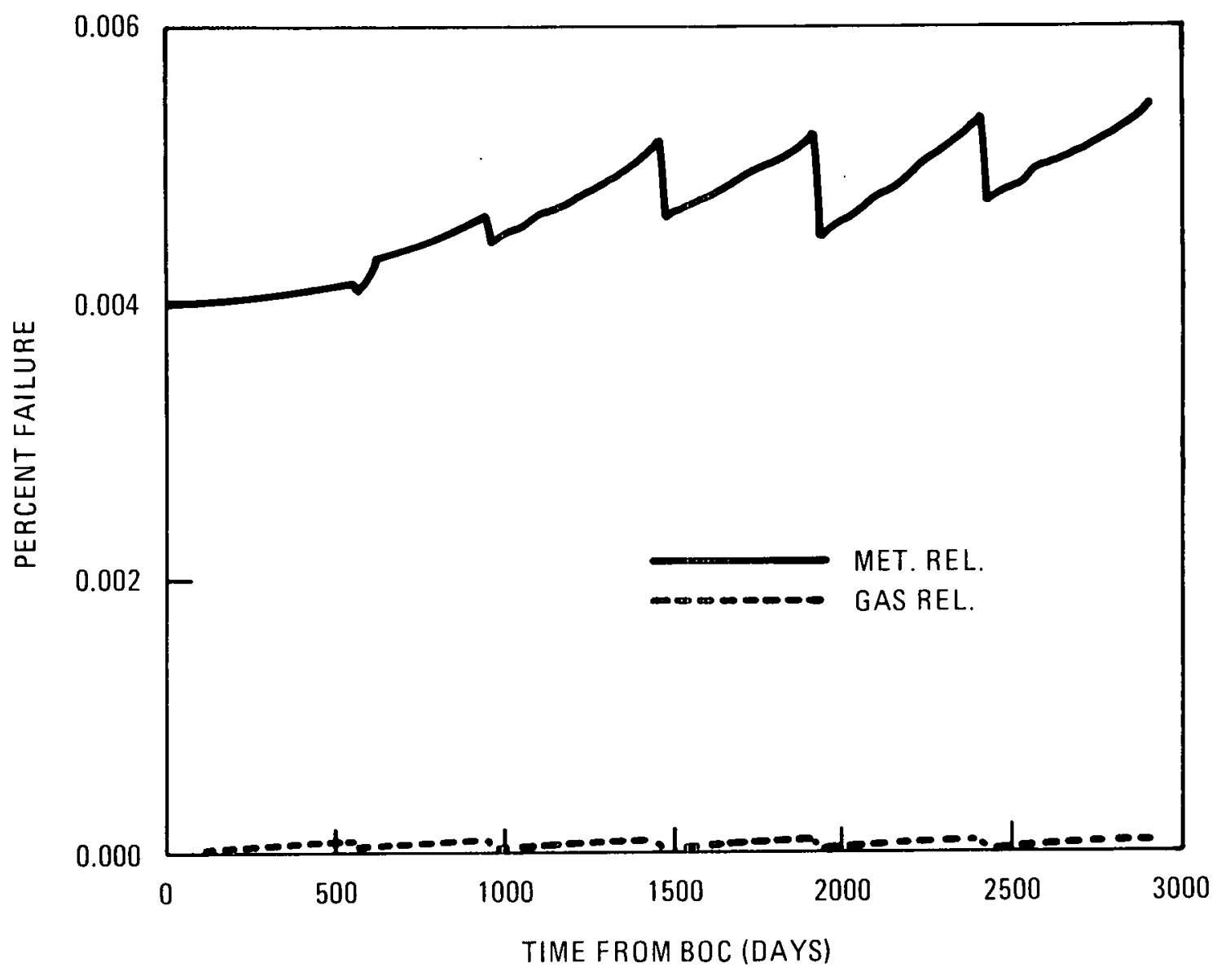

FIGURE 4.2.22 FERTILE PARTICLE PREDICTED FAILURE 


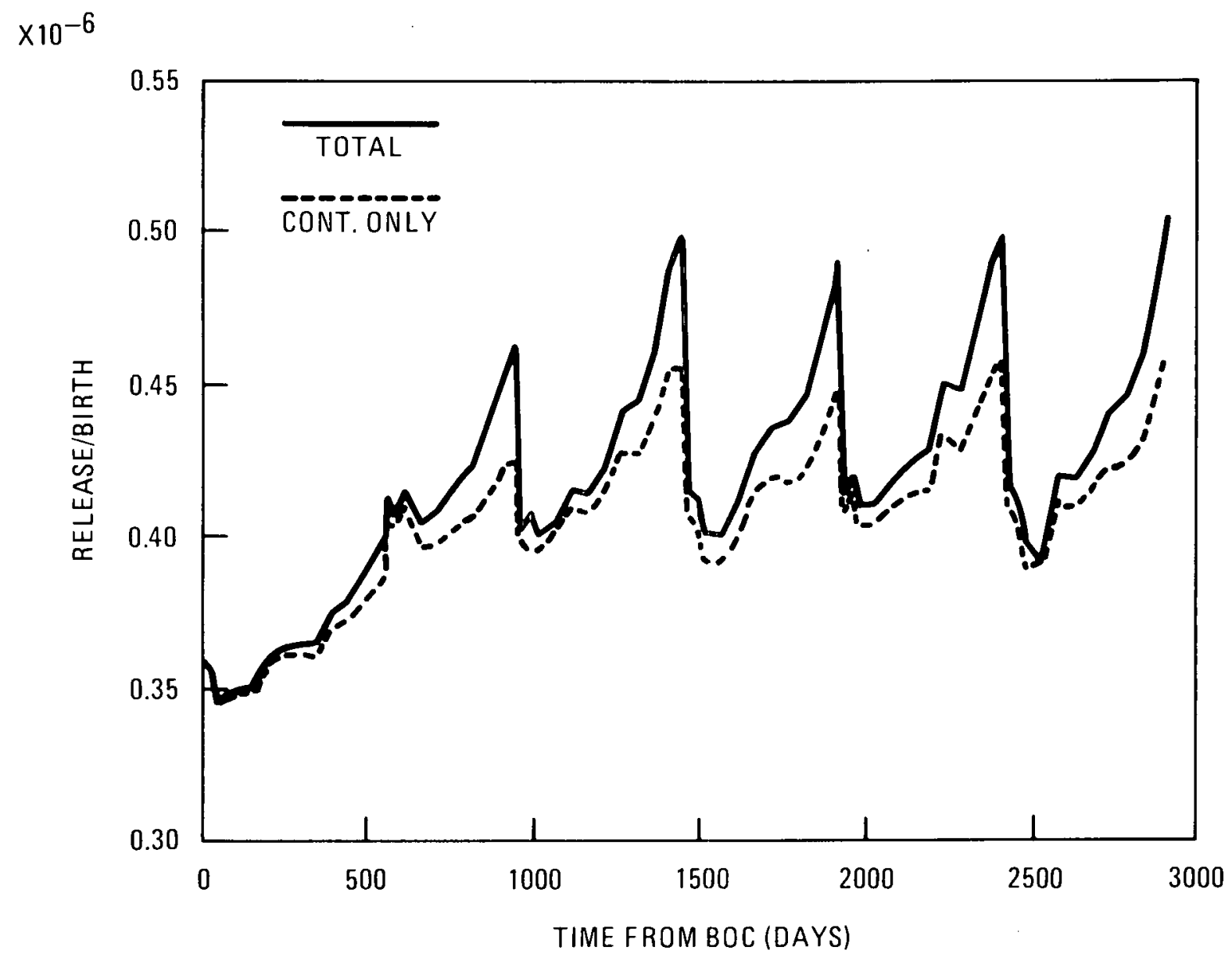

FIGURE $4.2-23$

CORE - AVERAGE RELEASE/BIRTH FOR KR-85m 


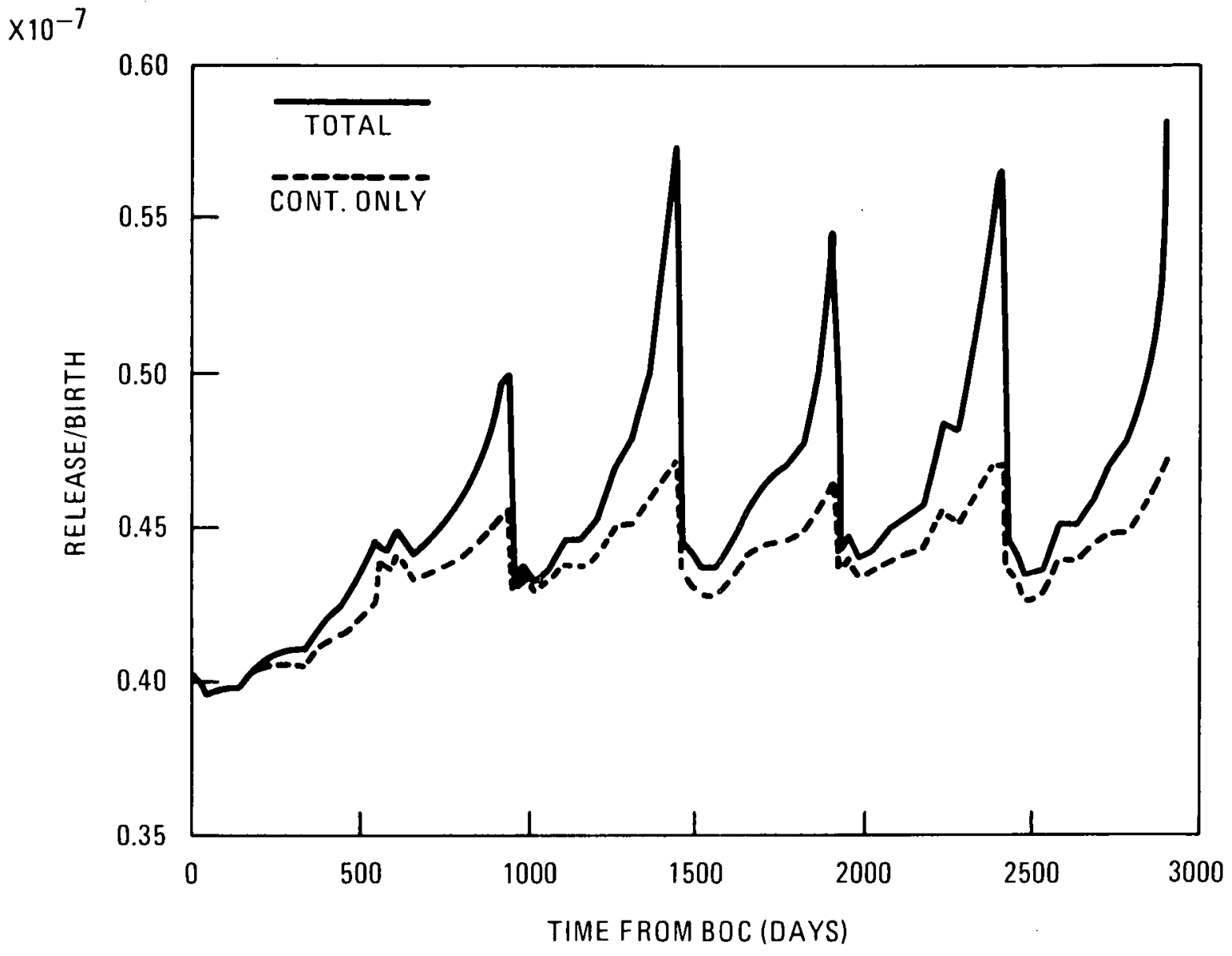

FIGURE 4.2-24

CORE - AVERAGE RELEASE/BIRTH FOR

\section{XE-138}

HIGH TEMPERATURE GAS-COOLED REACTOR

PRELIMINAAY SAFETY INFORMATION DOCUMENT

HTGR-86-024 


\subsection{NEUTRON CONTROL SUBSYSTEM}

\subsubsection{Summary Description}

The Neutron Control Subsystem (NCSS) consists of the drive mechanisms for positioning the control rods, the rod controls, the reserve shutdown control equipment (RSCE) with its controls, and the instruments for measuring neutron flux levels within the reactor vessel (i.e., in-vessel flux mapping units and startup detectors) and around the perimeter of the reactor outside the vessel (i.e., ex-vessel flux detectors). The control rods and the reserve shutdown material are part of the Reactor Core Subsystem (Section 4.2). Most of this equipment is configured into assemblies which are normally installed in penetrations in the top or bottom of the reactor vessel. These assemblies are periodically removed either to provide access to the core for refueling or for maintenance of the equipment.

Five types of assemblies are provided for each reactor module:

1. Twelve outer neutron control assemblies (ONCA).

2. Six inner neutron control assemblies (INCA).

3. Six ex-vessel neutron detector assemblies.

4. Three startup detector assemblies (SDA).

5. Five in-vessel flux mapping units (IFMU).

Each ONCA is equipped with two independent control rod and drive assemblies. These assemblies are interchangeable in any of the assigned penetrations. Figure 4.3-1 shows an overall view of an ONCA.

Each INCA is equipped with one control rod and drive assembly and two independent sets of RSCE. These assemblies are also interchangeable in any of the assigned penetrations. Figure 4.3-2 shows an overall view of an 
HTGR - $86-024$

INCA. Figure 4.3.3 shows the ONCAs and INCAs installed in the reactor vessel.

The ex-vessel neutron detection equipment consists of fission chamber neutron detectors mounted in six equally spaced vertical wells located just outside the reactor vessel as illustrated in Figure 4.3-4. The signals from these detectors are supplied to the nuclear instrumentation cabinet and Safety Protection Subsystem equipment located primarily in the reactor building. These data are used by the automatic control systems to operate the control rod drives or the reserve shutdown equipment, thereby changing the neutron flux levels within the reactor core.

The startup detector assemblies (SDA) are fission chambers with the appropriate cabling and support structure. The SDAs are inserted into vertical channels in the reflector elements near the bottom of the core through three equally spaced penetrations in the bottom head of the reactor vessel. The SDA locations are shown in the plan view and vertical section of reactor core, Figures 4.3-5 and 4.3-6. The SDAs are interchangeable in any of the assigned locations.

Each in-vessel flux mapping unit (IFMU) consists of a small vertical rod with multiple integral gamma detectors along its axis. The IFMUs are installed in vertical channels in the inner and outer reflector elements through penetrations in the bottom head of the reactor vessel. The integral gamma detectors are monitored periodically to obtain data on the core axial power offset. The IFMU locations are shown in the plan view and vertical section of the reactor core, Figures 4.3-5 and 4.3-6. Identical assemblies are installed at all locations, but the IFMUs are not normally interchanged between locations since the activation which they experience while installed in the reactor will normally require their destruction upon removal.

\subsubsection{Functions and 10CFR100 Design Criteria}

\subsubsection{Power Generation Functions}

The primary power generation function performed by the NCSS is to control the 
HTGR $-86-024$

neutron generation rate in the core. During power production and startup/shutdown the neutron generation rate is controlled by monitoring the neutron flux and by moving the poison material into or out of the core. During shutdown, the NCSS continues to monitor the neutron flux level.

\subsubsection{Radionuclide Control Functions}

The radionuclide control function performed by the Neutron Control Subsystem is to control heat generation assuring that control with movable poisons is accomplished to shut down the reactor. These functions are accomplished by:

1. Insertion of neutron absorbing materials to shut down the reactor

2. Maintaining geometry for insertion of the neutron-absorbing materials to shut down the reactor

3. Monitoring neutron flux and providing signals to the Plant Protection and Instrumentation System (PPIS).

The Neutron Control Subsystem also has the functions of controlling direct exposure to operating personnel and of controlling transport of radionuclides during handling operations.

\subsubsection{Classification}

The Neutron Control Subsystem is safety related. The classification of specific components is given in Table 4.3-1.

For additional information related to this section, see the response to NRC Comment $4-38$.

\subsubsection{10CFR100 Design Criteria for Radionuclide Control}

The following 10CFR100 Design Criterion applies: 
10CFR100 Design Criterion. III: The reactor shall be designed, fabricated, and operated such that the inherent nuclear feedback characteristics ensure that the reactor thermal power will not exceed acceptable values.

Additionally, the reactivity control system(s) shall be designed, fabricated, and operated such that during insertion of reactivity the reactor thermal power will not exceed acceptable values.

\subsubsection{Radionuclide Control Design Requirements}

Neutron control assemblies shall be provided to operate control rods in 24 columns in the inner ring of the hexagonal side reflector and in six columns in the outer ring of the inner (central) reflector. The neutron control assemblies shall also provide the ability to insert the reserve shutdown material into 12 columns of the active core.

The control assemblies shall incorporate features which ensure that the control rods and reserve shutdown material enter their designated channels for all reactor configurations resulting from anticipated operational occurrences (AOOs) and design basis events (DBEs).

The outer control rod drives (CRDs) shall be designed to permit the Safety Protection Subsystem to interrupt the power supply to the drives when reactor trip levels are reached, causing the control rods to drop by gravity into the core. The inner control rod drives shall operate in a similar manner but are tripped from the Investment Protection Subsystem. This trip command shall override all other commands. The reserve shutdown material shall be stored in hoppers above the core and released to fall into the core upon receipt of a signal from the Safety Protection Subsystem.

Two of the three ex-vessel detectors contained in the six wells equally spaced around the core shall generate signals for use by the Safety Protection Subsystem.

\subsubsection{Design Description}


4.3.4.1 Subsystem Configuration

The Neutron Control Subsystem uses five types of assemblies to monitor neutron flux, and to move control rods and insert reserve shutdown material in response to signals generated by the NSSS Control Subsystem (NCS) and the PPIS.

For additional information related to this section, see the response to NRC Comment 4-24.

\subsection{Outer Neutron Control Assembly}

\subsection{Outer Neutron Control Assembly Structural Equipment}

The ONCA structural equipment consists of an upper structural frame, gamma shielding, neutron shielding, thermal barrier, upper and lower guide tubes, and various seals. This equipment, which is illustrated in Figure 4.3-1, performs the mechanical functions for the (NCSS). The following paragraphs provide additional information about the various items.

Upper Structure and Seal: The upper structure consists of vertical carbon steel structural angles welded to a top lifting ring and a lower horizontal plate. The upper structure provides support for the mechanisms in the upper part of the refueling penetration where the environment is relatively mild, i.e., low radiation and moderate temperature.

A circular elastomer seal attached to the horizontal plate is normally in contact with the inner diameter of the surrounding penetration to restrict flow into or out of the upper region of the ONCA. Lifting the ONCA for removal retracts the elastomer seal to a smaller diameter to prevent damage during vertical movements of the ONCA.

Gamma Shield: The gamma shield is a round carbon steel plug that fits tightly into the penetration. It protects the mechanisms and the maintenance crew against gamma radiation from the core and the activated control rods. It provides small vertical passages for the control rod support cables. Each 
passage contains a hardened annular insert to minimize wear during control rod movements. The inner diameter of each insert is carefully sized to permit free motion of the control rod support cable while restricting the flow between the upper region of the ONCA and the control rod guide tubes.

The gamma shield provides structural attachments for the fixed guide tubes, the neutron shielding, and the thermal barrier.

Neutron Shield and Thermal Barrier: The neutron shield consists of a cylindrical stainless steel container filled with boronated graphite material which is positioned beneath the gamma shield. The container is approximately $356 \mathrm{~mm}$ ( $14 \mathrm{in.}$ ) in length and is intended to restrict activation of components in the upper portion of the ONCA.

Nine inches of thermal barrier is positioned between the gamma shielding and the neutron shielding and another $279 \mathrm{~mm}(11 \mathrm{in.})$ of thermal barrier is positioned near the lower end of the fixed guide tubes. The thermal barrier within the ONCA combines with additional thermal barrier and cooling coils provided by the Reactor Plant Cooling Water Subsystem outside the penetration to maintain the temperature of the upper portion of the ONCA within acceptable limits.

Guide Tubes: The guide tubes for the control rods extend from the gamma shield downward through the top head of the reactor vessel and the upper plenum to interface with the plenum elements on top of the core.

The primary purpose of the guide tubes is to provide guidance for the control rods during reactor operation and to assure a clear passage for these components as they are inserted and withdrawn from the core. The guide tube structure is subdivided into the upper and lower guide tubes.

The upper guide tubes are fixed and extend from the gamma shield, where they are attached, to the elevation of the top head of the reactor vessel where they are joined to the lower guide tubes. Circular stainless steel castings attached to the fixed guide tubes near their lower ends mate with a support ledge in the surrounding penetration and transfer the weight of the ONCAs to the reactor vessel. 


\section{HTGR - 86-024}

The lower guide tubes extend from the elevation of the top head downward through the upper core plenum to the interface point with the plenum blocks. The lower guide tubes have articulating joints which allow limited angular movements in all directions to compensate for core movements and misalignments. 
HTGR - 86- 024

A seal member surrounds the upper end of each of the lower guide tubes. This member is supported by a bellows attached to the upper end of the lower guide tube and is intended to restrict flow between the upper core plenum and the relatively stagnant helium layer in the region between the upper plenum structure and the top head of the reactor vessel while permitting misalignment of these two large structures.

\subsection{Control Rod Drive Equipment}

The control rod drive (CRD) mechanisms are located in the upper part of the ONCA as shown in Figure 4.3-1. A single mechanism is illustrated in Figure 4.3-7. It consists of a dc torque motor, harmonic drive unit which provides an 80:1 speed reduction, and the cable storage drum. The control rod is lowered and raised with a flexible aircraft quality steel cable which is taken up on the cable storage drum. Small cable guide rollers locate the cable in the proper position above the gamma shield penetration.

The motor speed reducer and storage drum are mounted on a metal frame. The frame is attached to the upper support structure by means of a pivoting support shaft. The rotation of the mechanism is resisted by redundant load cells which are used to monitor cable load (i.e., the weight of the control rod plus friction). These devices are used to detect a stuck control rod or a broken control rod cable.

The drive motor is a brushless dc torque motor, rated for continuous duty. Motor winding insulation is a high grade material which is capable of a service life of 40 years in the reactor helium atmosphere. The stator windings are vacuum impregnated.

Two load resistors are provided to slow down the control rod in case of power failure or reactor trip. In this case, the motor acts as a generator and the resistors absorb the energy. The resistors are lug-type tubular units of ceramic construction with enamel coating on the surface and are mounted on the inside of the mechanism frame for their protection. This feature is provided for investment protection of the rod and CRD but is not required for the safety function. 
Control rod position indication is accomplished with redundant precision potentiometers. The multiturn movement of the cable drum shaft is reduced with small harmonic drive speed reducers to less than one revolution on the potentiometer shaft.

All bearings in the CRD are precision ball bearings which are lubricated with a special grease that has been developed for this type of low radiation and moderate temperature application. This lubricant, which is also used in the harmonic drive components, has been subjected to long duration tests in helium. Therefore, the possibility of bearing or speed reducer seizure from deterioration of the lubricant is minimized. Relubrication of these components at regular maintenance intervals is planned.

A manual cable-locking device is provided for use during removal of the ONCA from its penetration. When the control rods are completely withdrawn from the core, the cable-locking device is manually actuated to ensure that the control rods will not accidentally drop while the ONCA is moved with the auxiliary service cask.

\subsection{Inner Neutron Control Assembly}

\subsection{Inner Neutron Control Assemblies Structural Equipment}

The INCA structural equipment consists of an upper structural frame, gamma shielding, neutron shielding, thermal barrier, upper and lower guide tubes, and various seals.

The INCA structural equipment is very similar to the ONCA structural equipment described earlier with minor differences to accommodate the different equipment within the INCA package. The following paragraphs provide additional information about the various items.

Upper Structure and Seal: The upper structure and seal components for the INCA package are only slightly different from the ONCA components. The steel structure has been modified to support a single CRD and the horizontal plate at the bottom of the upper structure has been modified to clear two 
HTGR - 86- 024

independent release mechanisms for the reserve shutdown material. The mechanisms are bolted to the upper surface of the gamma shield.

Gamma Shield: The gamma shield for the INCA package also differs only slightly from the ONCA gamma shield. It provides only one control rod cable passage and has additional passages for filling the reserve shutdown hoppers and movement of the actuator rods for the gates at the bottom of shutdown material hoppers.

Neutron Shield, Thermal Barrier, and Guide Tubes: The only differences in these components for the INCA in comparison to the ONCA are caused by:

1. The alternate construction at the point where the INCA enters the top head of the reactor vessel as a single large cylindrical member rather than two much smaller cylinders. A horizontal plate attached to the fixed guide tubes rests on a ledge in the surrounding penetration and transfers the weight of the INCA package to the reactor vessel.

2. A large diameter bellows permits limited misalignment of a seal member which engages the upper plenum structure and restricts the flow of hot helium to the relatively stagnant helium layer between the upper plenum structure and the pressure vessel.

\subsection{Control Rod Drive Equipment}

There is no difference in the construction of the control rod drive equipment for the INCA and the comparable equipment in the ONCA. There is, however, only one drive mechanism in the INCA package while two mechanisms are provided in each ONCA package.

\subsection{Reserve Shutdown Control Equipment}

Two sets of reserve shutdown control equipment (RSCE) are mounted in each INCA package. Each set consists of a reserve shutdown hopper which contains the shutdown material, the fuse link mechanism which opens the hopper gate 
by means of the actuation rod, and the reserve shutdown material gate. The reserve shutdown guide tube, provided with the INCA structural equipment, guides the reserve shutdown material into a special channel in the core. Figure 4.3-8 shows the arrangement of the RSCE within the INCA package. Figure 4.3-9 shows the construction of the storage hopper. Figure 4.3-10 shows the fuse link construction.

Reserve Shutdown Hopper: Each reserve shutdown hopper is a stainless steel cylinder, extending from a point just below the upper thermal barrier to the circular plate near the top of the lower guide tubes. The hopper is filled with neutron absorber material. A gate at the lower end of the hopper retains the material. After opening the gate, the material is channeled through a funnel into the RSE guide tube, which is capable of following lateral core movements by means of an articulating joint just like the lower guide tubes of the control rod system. The guide tube directs the neutron absorber material into the channel provided within the control column.

A storage hopper fill tube is provided to refill the hopper at the Reactor Equipment Service Facility after the neutron absorber material has been released into the core.

Removal of the reserve shutdown material from the core is accomplished with the reserve shutdown vacuum tool described in Section 9.1.2.1.4.1.4.

Fuse Link Actuators: The redundant fuse link actuators are shown in Figure 4.3-10. Two fuse links support the actuation rod for the hopper gate. Severing either fuse link by the application of an electrical current will allow the actuation rod to drop a short distance, which will open the hopper gate.

The structural portion of the fuse link actuator is a braided multistrand aluminum wire rope. Each aluminum wire is surrounded by a thin palladium jacket. Whenever the temperature of the wire is raised above a critical temperature, an exothermic chemical reaction between the palladium and the aluminum takes place, melting the wire and severing the fuse link. This allows the actuation rod to drop and the hopper gate to open, releasing the 
reserve shutdown material into the core.

To minimize the current required to sever the fuse link, a small starter wire of only six strands is provided and wrapped tightly around the mechanical load carrying strands of the fuse link. Upon actuation, a small amount of current is sufficient to start the exothermic reaction in the starter wire, which then carries over to the main link. Continuity in the starter wire is checked on-line by trickle current. Samples of manufacturer's batches of fusible links are tested prior to installation. Statistical sampling techniques will be used. Also, the fusible links will be test actuated when the control rod assembly is removed for periodic inspection and maintenance.

\subsection{Ex-Vessel Neutron Detection Equipment}

The ex-vessel neutron detection equipment consists of neutron detectors mounted in six equally spaced vertical wells located just outside the reactor vessel, near the core midplane, as illustrated in Figure 4.3-4. This spatial distribution of detectors provides adequate neutron monitoring coverage and redundancy in measurement.

Each well extends vertically upward from the accessible area beneath the reactor vessel to the opposite of the upper portion of the reactor core. The wells are located in the inlet air stream of the Reactor Cavity Cooling System (RCCS) to assure that the neutron detectors are not exposed to undesirable temperature transients. The atmosphere in the wells is air at ambient pressure.

Each well contains three neutron detectors. Two neutron detectors provide neutron flux signals to the PPIS for use in the reactor trip circuitry. The third neutron detector provides a neutron flux signal for use by the NCS and Rod Control Systems for reactivity control during plant operation. The detectors used are fission chambers. The ranges covered are shown in Figure 4. 3-11.

Signals from the ex-vessel neutron detectors in conjunction with the in-reactor startup neutron detectors are utilized to derive neutron flux 4. 3-11 
levels from startup source level to above 100 percent power. The associated electronics circuitry provides three basic types of nuclear channels as shown in Figure 4.3-12.

Three extended wide range nuclear channels combine signals from the three in-vessel detectors with signals from three ex-vessel detectors to measure reactor power on a logarithmic scale and rate of power change from startup source level to full power. These signals are used for rod drive control as the reactor is started up and brought to power.

One linear channel for power range (approximately 1.5 percent to 150 percent) flux control is provided for the reactor flux control portion of the NCS. This channel utilizes signals from the six mid-level detectors in each of the ex-vessel wells. (Three of these detectors are also employed in the extended wide-range channels.) The power range neutron flux controller utilizes the average of the six detector signals for rod drive control. (The controller includes comparators to monitor individual input signals and automatically disconnect a faulty input from the average calculation.) The power range neutron flux controller positions control rods to adjust reactor power based on a setpoint signal received from the NCS.

The remaining 12 ex-vessel neutron detectors (top and bottom) provide linear power signals to reactor trip portions of the Safety Protection Subsystem. (The signals are combined into four groups of three for use in the two-outof-four trip system.) The detectors and circuitry used for protection are separated from the detectors and circuitry utilized for control.

\subsection{Startup Detector Assemb1ies}

The need for startup neutron detectors in-vessel is dictated by the low neutron flux at the ex-vessel detector location at startup and to ensure a controlled startup. Therefore, in-vessel startup detectors are used for flux monitoring while the reactor is brought to a critical configuration and during reactor shutdown periods. Three startup neutron detectors are installed to ensure adequate neutron flux measurements during these low power intervals.

$$
4.3-12
$$


HTGR $-86-024$

The startup detector assemblies are fission chambers with appropriate cabling and support structures. The SDAs are inserted into vertical channels in the reflector elements near the bottom of the core through three equally spaced penetrations in the bottom head of the reactor vessel. The SDA locations are 
illustrated in Figure 4.3-5.

The neutron detectors employed are regenerative U-234/U-235 fission counters. The use of regenerative detectors results in a useful life of approximately 7-1/2 years at operating conditions without the need for retraction to a lower neutron flux environment to reduce detector burnup.

\subsection{In-Vessel Flux Mapping Units}

The in-vessel flux mapping units (IFMU) are required to measure the axial power offset over a plant power range of 5 percent to 100 percent. Each IFMU consists of a small cylindrical assembly with a string of six gamma thermometers along its axis. The IFMUs are installed in vertical channels in the inner and outer reflector through penetrations in the bottom head of the reactor vessel as illustrated in Figure 4.3-6. The integral gamma detectors are monitored periodically to obtain data on the core axial power offset.

For power measurements, gamma thermometers depend upon heating of the instrument sensing area by fission and fission product gamma rays. A central heater cable along the assembly is provided for in situ calibration.

\subsubsection{Subsystem Arrangement}

The mechanical arrangement of the Neutron Control Subsystem is illustrated in Figure 4.3-3, 4.3-4, 4.3-5, and 4.3-6. Figure 4.3-3 shows typical ONCA and INCA equipment installed in their respective penetrations in the top head of the reactor vessel. The neutron control assemblies are supported on ledges in their respective penetrations while the lower portions of the neutron control assemblies extend down into the control channels of the core sector below the penetration.

Figure 4.3-5 shows a plan view of the reactor core and the related neutron control equipment. There are a total of six fuel sectors shown on Figure 4.3-5. Each sector is equipped with two ONCAs and one INCA.

Figure 4.3-5 also shows the location of the five IFMUs which are installed in 
the reflector columns adjacent to the fuel columns and the three startup detector assemblies.

Figure 4.3-4 shows the location of the six ex-vessel detector wells. These vertical wells are equally spaced just outside the reactor vessel.

Electrical cabling joins the subsystem components to four local control cabinets within the reactor building and the appropriate power supply systems.

\subsubsection{Subsystem Operating Modes}

The operating modes of the Neutron Control Subsystem, in conjunction with the Reactor Core and Reactor Internals Subsystems, are discussed in Section 4.1.4.3.

\subsubsection{Instrumentation and Control}

\section{: 4.3.4.4.1 Neutron Control Assembly Structural Equipment}

The neutron control assemblies (i.e., ONCAs and INCAs) are equipped with thermocouples to monitor the ambient coolant temperature immediately above the thermal barrier in the lower portion of the assemblies and the ambient temperature in the general area of the drive mechanisms.

\subsection{Control Rod Drive Equipment}

Control rod withdrawal occurs when rotation of a selected drive motor is commanded by the rod control instrumentation. Control rod insertion can occur either by actuation of the drive motor or as a gravity powered movement following receipt of a reactor trip signal.

The position of the control rod is monitored by two redundant position sensors which are coupled to the cable storage drum through an instrument gear train. 
HTGR - 86- 024

The total tension in the control rod support cable is monitored by redundant load cells to assure that the control rod is intact and is moving freely in its guide tube and core channel.

Video display capability of abnormal cable tension, rod motion, rod position and various Control System malfunctions is available in the main control room. These displays provide alarm and system status indication to the operator.

Separation of power and signal cabling to the CRD mechanism is provided. One load cell and one position indicator are grouped together with their wires separated from the other system which supplies the other load cell and the other position indicator. The dc drive motor wires are grouped in a third cable to separate power from control.

The control rods are operated in groups of three. Various controls are used to withdraw or insert all control rods in a group simultaneously and to disengage any control rod from movement with the group. Interlocks in the Rod Drive Control System prevent withdrawal of more than one rod group at a time.

A rod worth calibration test capability is provided. The test is generally performed on each rod as it is first withdrawn during each cycle and requires a rod withdrawal speed approximately three times normal. A separate servo controller is used for this calibration test. Interlocks prevent the testing of more than one rod at a time.

A rod withdrawal interlock function is implemented for equipment protection and for enhancement of plant availability. Other control circuit interlocks prohibit control rod motion beyond the inner and outer limits of rod motion. Powered control rod motion is also prohibited if preset limits on allowable cable tension are exceeded.

The gravity powered insertion of the control rods is accomplished by disconnecting power to the holding brakes of the CRD motors. This disconnect is part of the PPIS and operates upon various reactor trip signals. Opening 
the circuit removes the rod holding power and the rods drop into the core. Any rods being withdrawn or inserted by the Rod Drive Control system at the time of reactor trip are also released.

\subsection{Reserve Shutdown Control Equipment}

The instrumentation and controls for the reserve shutdown control equipment are designed to actuate the release of the reserve shutdown material automatically. Major features include provisions for redundant actuation circuits, for continuous monitoring of the actuation circuits, and a limit switch on each release rod to confirm movement of the storage hopper gate.

The reserve shutdown control equipment is powered by two 125 VDC, Class 1E battery supplies.

The RSCE is actuated automatically by signals from the Safety Protection Subsystem. A time delay assures that power is applied for at least three seconds to ensure transferring enough energy to the fuse links to sustain the exothermic reaction. A limit switch in the actuator mechanism verifies that the actuation rod has dropped to open the gate.

For monitoring purposes a continuity circuit is provided as a means of verifying system integrity.

\subsection{Ex-Core Neutron Detection Equipment}

This instrumentation and control equipment consists of the neutron detectors that provide inputs to the PPIS, NCS, and the rod control assemblies. It is described in Section 4.3.4.1.3.

\subsection{Startup Detector Assemblies}

This instrumentation and control equipment consists of three startup detector assemblies, described in section 4.3.4.1.4. 


\subsection{In-Vessel Flux Mapping Units}

This instrumentation and control equipment consists of five IFMUs described in Section 4.3.4.1.5.

\subsubsection{Subsystem Limitations}

The rod control assembly is limited to operation when the reactor trip circuit is energized. Three rods at a time, constituting a group, can be operated simultaneously. Interlocks prevent the withdrawal of more than one group at a time. Also, only one rod at a time can be moved during rod worth testing when a higher rod drive speed is utilized. The speed at which the rods move is limited by the servo controller power which controls power to the CRD motor. Detection of slack cable stops rod motion as does detection of excessive cable tension. Interlocks prevent rod movement beyond inner and outer limits.

The reserve shutdown control equipment operates automatically as a bank. Once actuated, it necessitates plant depressurization, removal of the inner neutron control assemblies for reloading of adsorber material and removal of the reserve shutdown material from the core before the reactor can return to power.

The nuclear instrumentation must be operable prior to reactor startup. The automatic rod control during startup will not operate if more than one of the three ex-vessel wide-range channels is out of service. The Safety Protection Subsystem requires at least three of its four nuclear input channels operating. The power range neutron flux control will not operate automatically with more than two of the six input channels out of service.

Setpoints are given in Table 4.3-2.

\subsubsection{Design Evaluation}

For additional information related to this section, see the responses to NRC Comments 4-22, 4-23, 4-25 and 4-26. 


\subsubsection{Failure Modes and Effects}

The failure modes and effects discussion of the Neutron Control Subsystem is divided into separate discussions of the control rod drives, reserve shutdown control equipment, IFMUs, SDAs, and ex-vessel detectors.

\subsection{Control Rod Drives}

There are two effects which result from any of a multitude of failures in the CRDs. One effect is that the rods do not move when they should. The second is that the rods move when they should not.

Undesirable rod motion can result from control system failure and can be either inward or outward. Inward motion is a plant availability problem, but is not a safety concern. The extreme case of undesirable inward motion is an inadvertent reactor trip. This event might be caused by a loss of power or erroneous trip signals. This event places the plant in a safe condition.

Outward motion can be a more significant threat to equipment and people. The consequence of control system failures which cause rod withdrawal are limited by several system features. The first is the limit on rod withdrawal speed due to the maximum amount of power that can be delivered to the CRD motor. Second is the control circuitry which limits the number of control rods that may be withdrawn at any one time. Third is the alarm system which will inform the operator of the improper rod motion so that he may take corrective action. Finally, a reactor trip signal will cause rods to be inserted.

Failures which can prevent rod motion by a CRD mechanism are of concern because they might preclude a reactor trip of the associated rod. To detect such failures, redundant load cells and position sensors are installed. The load cells detect rod binding or breaking, and the position sensors measure rod position. The position sensors can be used to test all aspects of rod motion such as rod speed and rod mobility. When either the load cells or position sensors indicate a malfunction, this information is conveyed to the 
HTGR - 86- 024

reactor operator.

\subsection{Reserve Shutdown Control Equipment}

Failures in the RSCE can result in the RSCE hopper failing to dump when signalled to do so, or the RSCE hopper dumping inadvertently.

The situation in which the hopper fails to dump can be caused by actuation system failure (the actuation failures include electrical failures of the fusible links) or by material bridging in the hopper. The RSCE design minimizes the probability of failure due to actuation system malfunction by providing redundant and separate initiation circuits. Also, the continuity of the initiating circuits is continuously monitored during reactor operation. Material bridging in the hopper is undetectable during plant operation. Therefore, at each refueling, a minimum of one RSCE hopper is tested (out of the reactor) to see whether it can dump properly. If unsatisfactory conditions are encountered during the "out of reactor" test, additional assemblies will be removed for testing and/or modifications as appropriate .

The procedure for recovery of material which has been inserted into the core requires verification that the recovery equipment has been fully inserted and a weight check of the recovered material at the reactor equipment service facility. These two checks provide assurance that essentially all of the reserve shutdown material has been recovered.

\subsection{In-Vessel F1ux Monitoring Units}

Failures to this equipment can occur in the gamma thermometers or the signal conditioners, resulting in erroneous flux level readings. Because there are five strings of IFMUs, a failure in one or several detectors reduces the amount of data available to map the axial power offsets. These failures have no immediate effect on the plant operation. 


\subsection{Startup Detector Assemblies}

Failures in the SDA equipment lead to erroneous signals. However, sufficient redundancy in neutron detectors exists so that loss of a detector does not result in unsafe operation or require immediate plant shutdown.

Failure of a startup detector while at power is of little consequence because the power is above the startup detector range. Failure during startup, a small portion of the plant operation, can be handled by the redundancy provided. Failure during shutdown (or shutting down) would generally be corrected prior to the next startup.

\subsection{Ex-Vessel Detectors}

Failures in the ex-vessel neutron detectors can result in erroneous signals. However, sufficient redundancy in neutron detectors exists so that loss of a detector does not result in unsafe operation or necessitate immediate plant shutdown. The startup control and power range flux control both utilize several signals based on the input from several neutron detectors. Comparators between redundant channels automatically disconnect suspect inputs from the average signal and alert the operator.

Loss of an input to the Safety Protection Subsystem does not cause a spurious action at the system level because of the redundancy built into the protection system. Malfunctioning channels are alarmed.

\subsubsection{Steady-State Performance}

Specific characteristics of the NCSS normal operation are divided into discussions of five equipment groups: control rod drives, reserve shutdown control equipment, ex-vessel neutron detection equipment, startup detector assemblies, and in-vessel flux mapping units.

\subsection{Control Rod Drives}

Each outer neutron control assembly contains two independent control rod 
HTGR - $86-024$

drives while each inner neutron control assembly contains a single control rod drive. All of these CRDs are identical in their performance characteristics but are controlled somewhat differently depending upon their location. These differences will be identified whenever there is a significant effect on the subsystem performance.

The control rod positioning is generally done on a symmetrical group of three rods moving at a time.

The rods may also be operated one at a time in a rod worth calibration test mode. This latter mode is primarily used the first time rods are withdrawn following a refueling.

For a short time just after refueling, 25 percent of full power is achieved before the inner group of rods is fully withdrawn. During this brief period and at power levels below 25 percent, some of the inner control rods may be partially inserted to control core reactivity. Also, these inner rods may occasionally be used to control reactor power at other levels. However, in most circumstances the automatic operation will be limited to the outer control rod drives.

All CRDs not being driven to change reactor power level are held in position by holding power applied to one set of the motor windings. In the absence of either holding power or signals from a CRD motor controller, control rods that are either fully or partially withdrawn drop into the core by gravity. The rod velocity during this type of insertion is limited by resistors wired in parallel with the motor windings. The resistors limit damage during control rod deceleration but are not required for the rods to shut down the reactor effectively.

The normal holding power for the CRDs is controlled by the reactor trip portion of the Safety and Investment Protection Subsystems.

\subsection{Reserve Shutdown Control Equipment}

The RSCE is in standby at all times except when it is used to shut down the 
core following a reactor trip signal to which the control rods and/or control rod drives fail to respond adequately. That is: 1) an anticipated transient without scram (ATWS) or 2) following an outer rod trip to prevent recriticality following an unterminated large water ingress.

During refueling intervals, two of the six INCAs may be removed to provide access to the core. During these intervals, the remaining four INCAs which contain a total of eight independent reserve shutdown hoppers are on standby.

The continuity of the fuse link release is continuously monitored and loss of continuity of power is alarmed.

\subsection{Ex-Vesse1 Neutron Detectors}

The ex-vessel neutron detectors provide signals to the Safety Protection Subsystem, the NSSS Control Subsystem, and the rod drive control equipment from the startup range to as high as 200 percent power. Two detectors in each of six wells feed the Safety Protection Subsystem and one from each well feeds the NSSS Control Subsystem and rod drive control equipment. The NCS and rod drive control equipment use the signals to control reactor power through the flux controllers while the Safety Protection Subsystem signals are used to provide protection for abnormal plant conditions.

\subsection{Startup Detector Assemblies}

The startup detector assemblies (SDAs) are used at low power levels only. When the plant is above approximately $10^{-5}$ percent power, the ex-vessel detectors are utilized. During shutdown, the SDAs provide signals to allow monitoring of the core neutron activity. During startup, the SDAs monitor neutron flux changes as the control rods are withdrawn.

\subsection{In-Vessel Flux Mapping Equipment}

During plant operation, the in-vessel flux mapping units (IFMUs) are monitored at predetermined intervals to record the flux level at fixed axial positions, so that a core axial power offset can be determined. 
HTGR - 86- 024

\subsubsection{Anticipated Operational Occurrence Performance}

The plant anticipated operational occurrences (AOOs) are described in detail in Section 11.6. For the AOOs in which the outer control rods are tripped, the trip occurs quite early in the event, before there can be a significant temperature transient or environmental change affecting the equipment. For AOO-5 the trip may occur long after the event is initiated and there is no significantly detrimental transient imposed on the CRDs prior to the time when they are signalled to release the rods.

The RSCE, IFMUs, and SDAs are not called upon to respond to any AOOs.

The ex-vessel neutron detectors are involved in A00s. The ex-vessel detectors are unaffected by the transient imposed on the vessel internals by the rod withdrawal event (AOO-3) because they are located outside the vesse1. Their function is carried out when they detect a high power level and send the signal to the Safety Protection Subsystem which combines it with a flow signal resulting in a reactor trip command.

\subsubsection{Design Basis Event Performance}

The DBEs are discussed in detail in Chapter 15. All the DBEs include actions to shut down the reactor. The outer control rods are the means for shutting down in all but DBE No. 2 .

The PPIS receives signals from the ex-vessel detectors of the NCSS or other protection system sensors and interprets these signals to determine appropriate protective actions. In all DBEs except DBE-2, the control rod drives are tripped and their function is completed in the very early stages of the event. For DBE No. 2, which includes shutdown by the reserve shutdown control equipment, the shutdown action (release of the reserve shutdown material) is delayed for a brief interval (i.e., minutes). However, if the shutdown action should take place after considerable delay (i.e., several hours), the RSCE is designed to withstand the most severe environment to which it might be exposed prior to completing the required action. 


\subsubsection{5 "Safety-Related" Design Condition Performance}

The "safety-related" design conditions (SRDCs) are discussed in detail in Chapter 15. As in the DBEs, the NCSS performs its detection and shutdown functions early on, before conditions progress to a point where the capability of the NCSS equipment to perform its "safety-related" functions is threatened and none of the SRDCs cause a significant rise in the temperature of the control rod drives prior to their being tripped. The same is true of the reserve shutdown control equipment. Also, these two sets of equipment are not affected by pressure changes or other changes in environment that occur prior to their being called upon to perform.

\subsubsection{Interfaces}

Interface requirements imposed on other systems or subsystems within the Reactor System by the NCSS are identified in Table 4.1-2, which also includes a description of the interface and a quantitative expression for the interface. 
HTGR - 86- 024

TABLE $4.3-1$

SAFETY CLASSIFICATION FOR THE NEUTRON CONTROL SUBSYSTEM EQUIPMENT

Principal Component

1) Control Assembly Structural Equipment

Instrumentation \& Controls

2) Control Rod Drive Equipment

Mechanical Components

(cables, drive mechanisms, and associated parts)

Instrumentation \& Controls

a) Power to CRD Motor

b) CRD Motor, Potentiometer and Velocity Controls

3) Reserve Shutdown Control Equipment

Mechanical Components

(hoppers and gates, guide

tubes, fusible links,

and associated parts)

Instrumentation \& Controls
a) Actuation circuitry
b) Indicators of condition

4) Neutron Flux Monitoring Equipment

Ex-Vessel Detectors (supplying signals to the Safety Protection Subsystem)

Ex-Vessel Detectors (for use in the NSSS Control Subsystem)

\section{Classification}

"Safety related"

Not "safety related"

"Safety related"

Not "safety related"

Not "safety related"

"Safety related"

"Safety related"

Not "safety related"

"Safety related"

Not "safety related" 
HTGR - 86- 024

TABLE 4.3-1 (Cont)

Principal Component

In-Vessel Neutron Detection

Equipment

a) In-Vessel Flux Monitoring Equipment

Mechanical Components

Instrumentation and Controls

b) Startup Detector Equipment

Mechanical Components

Instrumentation and

Controls
Classification

Not "safety related"

Not "safety related

Not "safety related"

Not "safety related" 
TABLE 4. 3-2

SETPOINTS FOR NEUTRON CONTROL EQUIPMENT

$\begin{array}{ll}\text { Parameter } & \begin{array}{l}\text { System } \\ \text { Setpoint }\end{array} \\ \text { Rod "in" limit } & 0 \mathrm{in} . \\ \text { Rod "out" limit } & 366 \mathrm{in} . \\ \text { Rod cable tension - high } & 105 \text { percent nominal rod weight } \\ \text { Rod cable tension - low } & 95 \text { percent nominal rod weight } \\ \text { Rod controller speed } & 1.3 \text { ips } \\ \text { Rod worth test controller speed } & 3.5 \text { ips } \\ \text { Excessive rod speed } & >1.05 \text { normal } \\ \text { RSCE continuity detector } & \text { Loss } \\ \text { Startup level neutron flux } & \geq 2 \mathrm{cps} \\ \text { Rate of neutron flux change - high } & \geq 2 \text { dpm } . \\ \begin{array}{l}\text { Excessive wide range channel flux } \\ \text { deviation }\end{array} & \geq 15 \text { percent } \\ \text { Excessive power range flux deviation } & \geq 15 \text { percent }\end{array}$


CONTROL ROD

DRIVE MECH. (2 REQ)

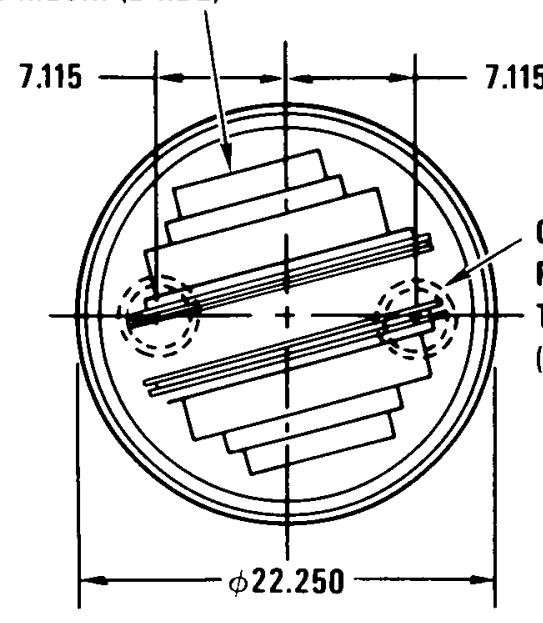

VIEW A.A

ENLARGED
7.115

CONTROL

ROD GUIDE

TUBE

(2 REQ)

THERMAL

BARRIER SEAL, TYP

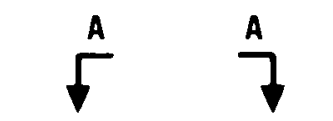

UPPER STRUCTURE SUPPORT \& SEAL

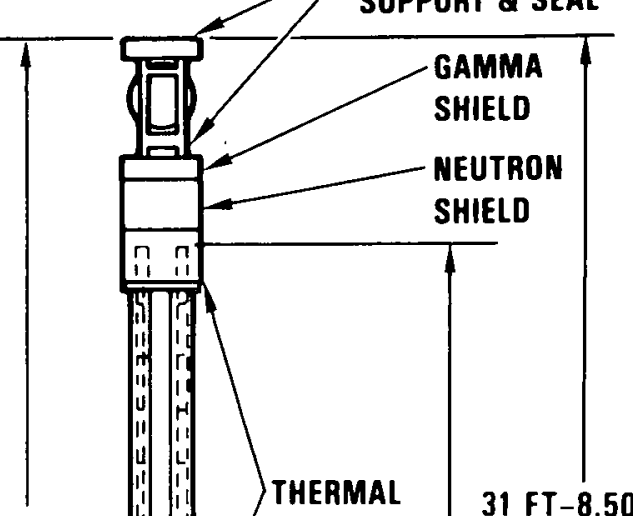

15 FT-9.25 IN. BARRIER

$31 \mathrm{FT}-8.50$ IN

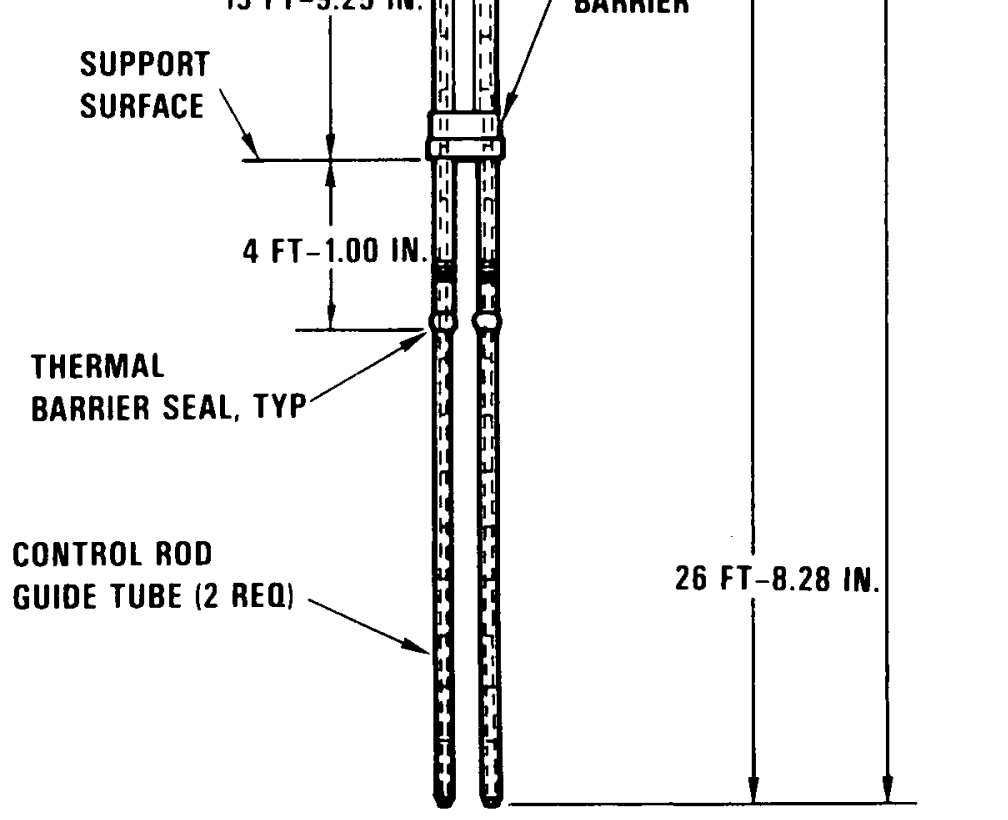

FIGURE $4.3-1$

OUTER NEUTRON CONTROL ASSEMBLY

HIGH TEMPERATURE GAS.COOLED REACTOR PRELIMINARY SAFETY INFORMATION DOCUMENT HTGR-86-024 


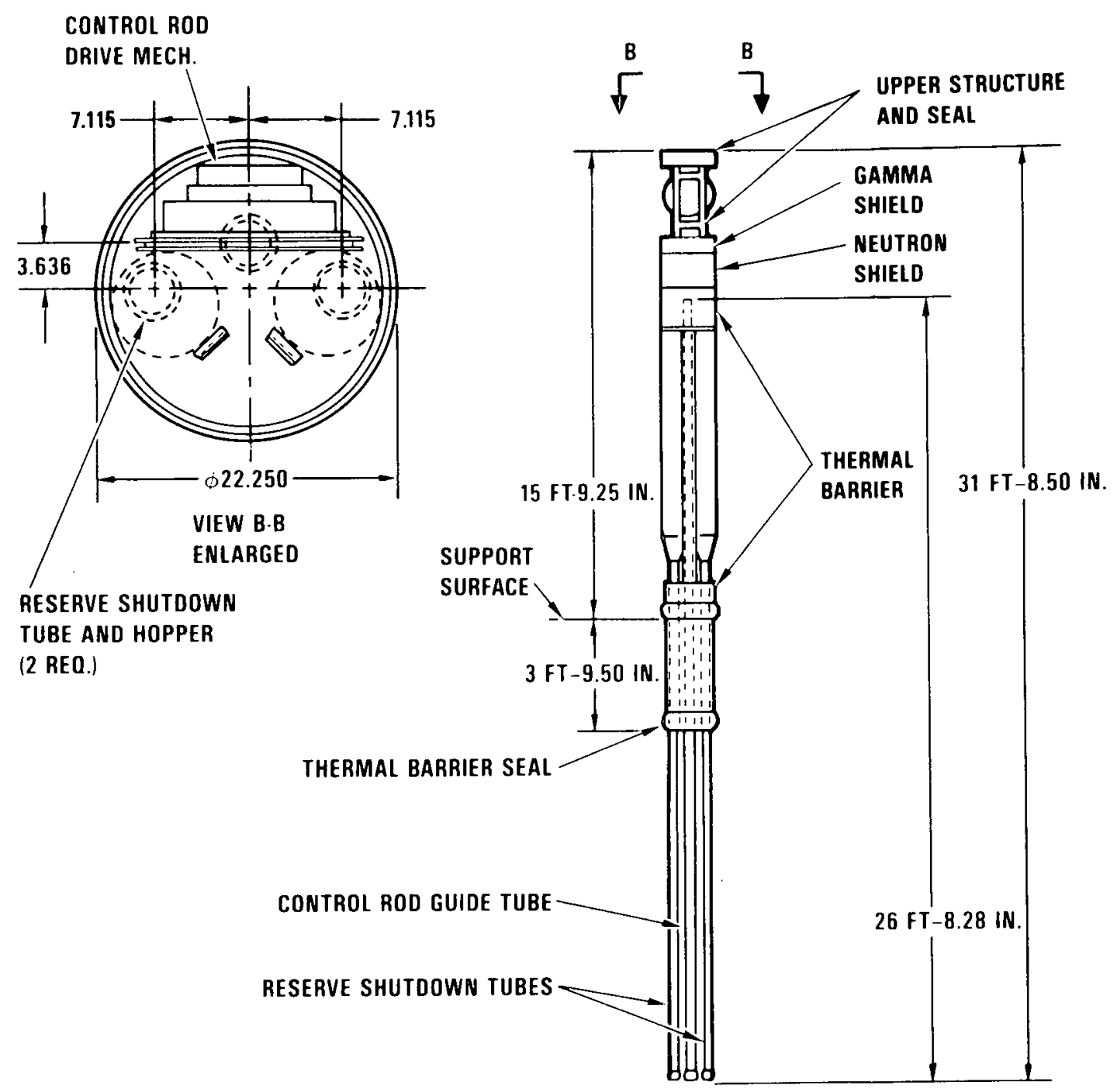

FIGURE 4.3-2

INNER NEUTRON CONTROL ASSEMBLY 


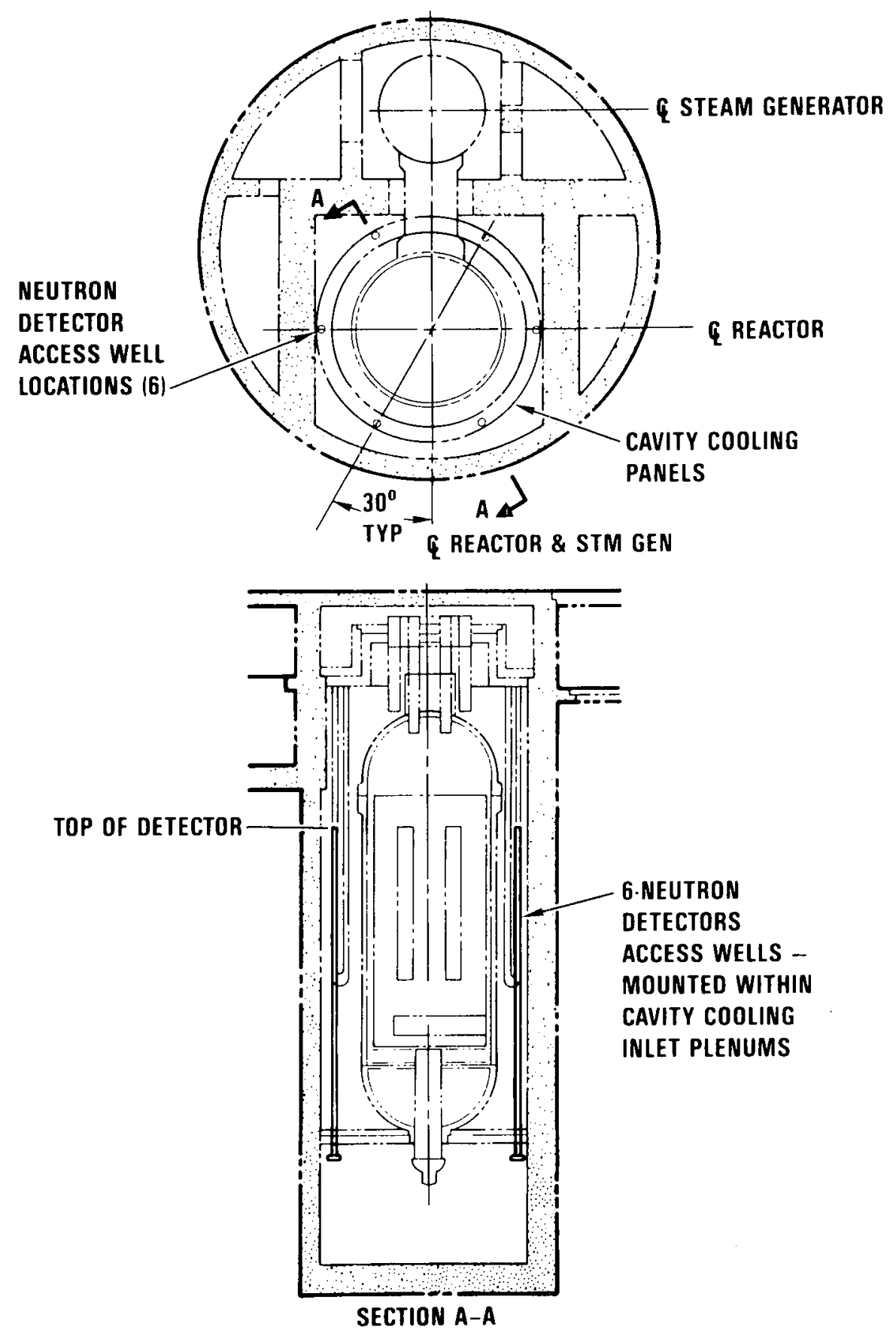

FIGURE 4.3-4

EX-VESSEL DETECTORS AND LOCATION 


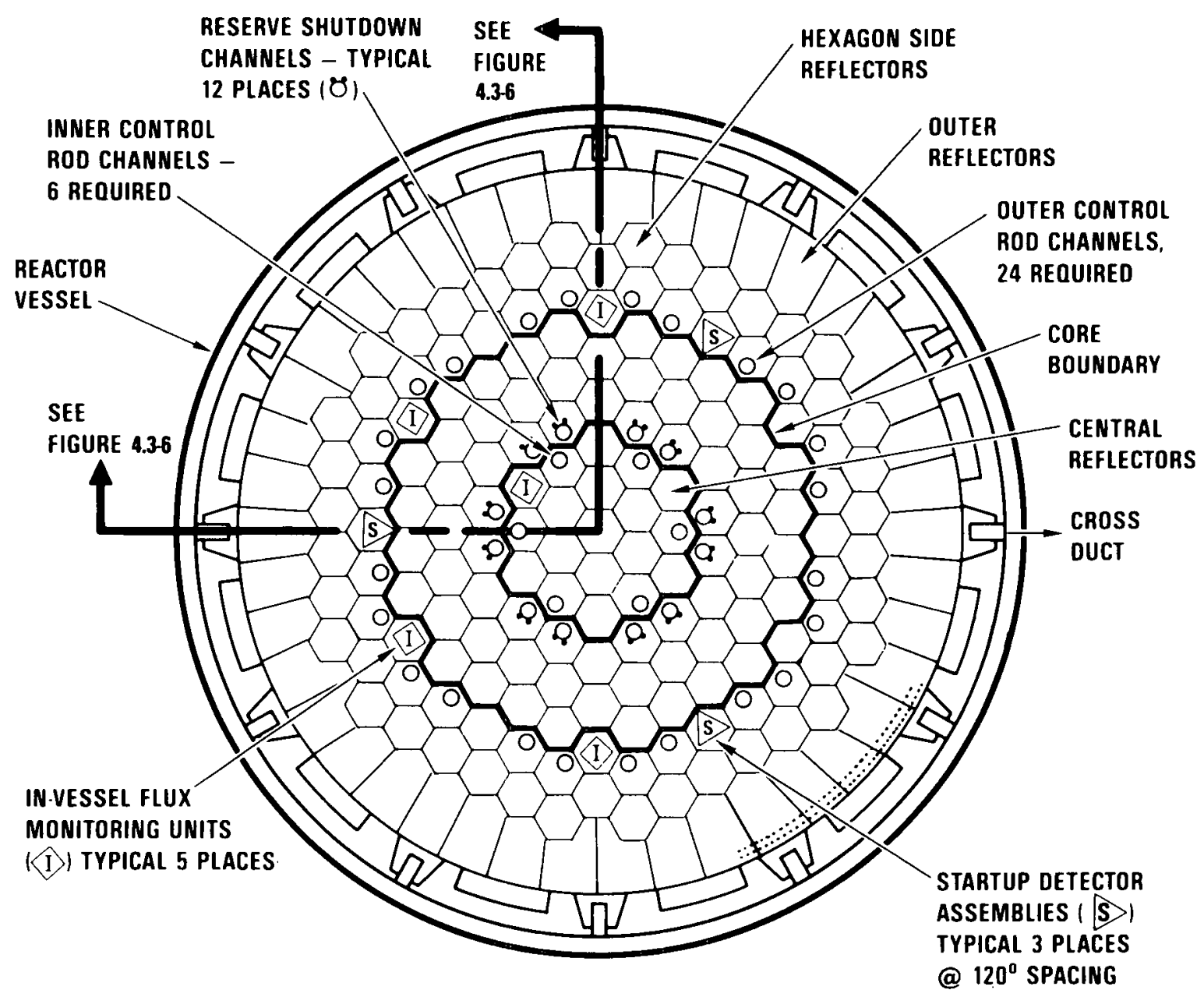

FIGURE 4.3-5

PLAN VIEW OF REACTOR CORE 


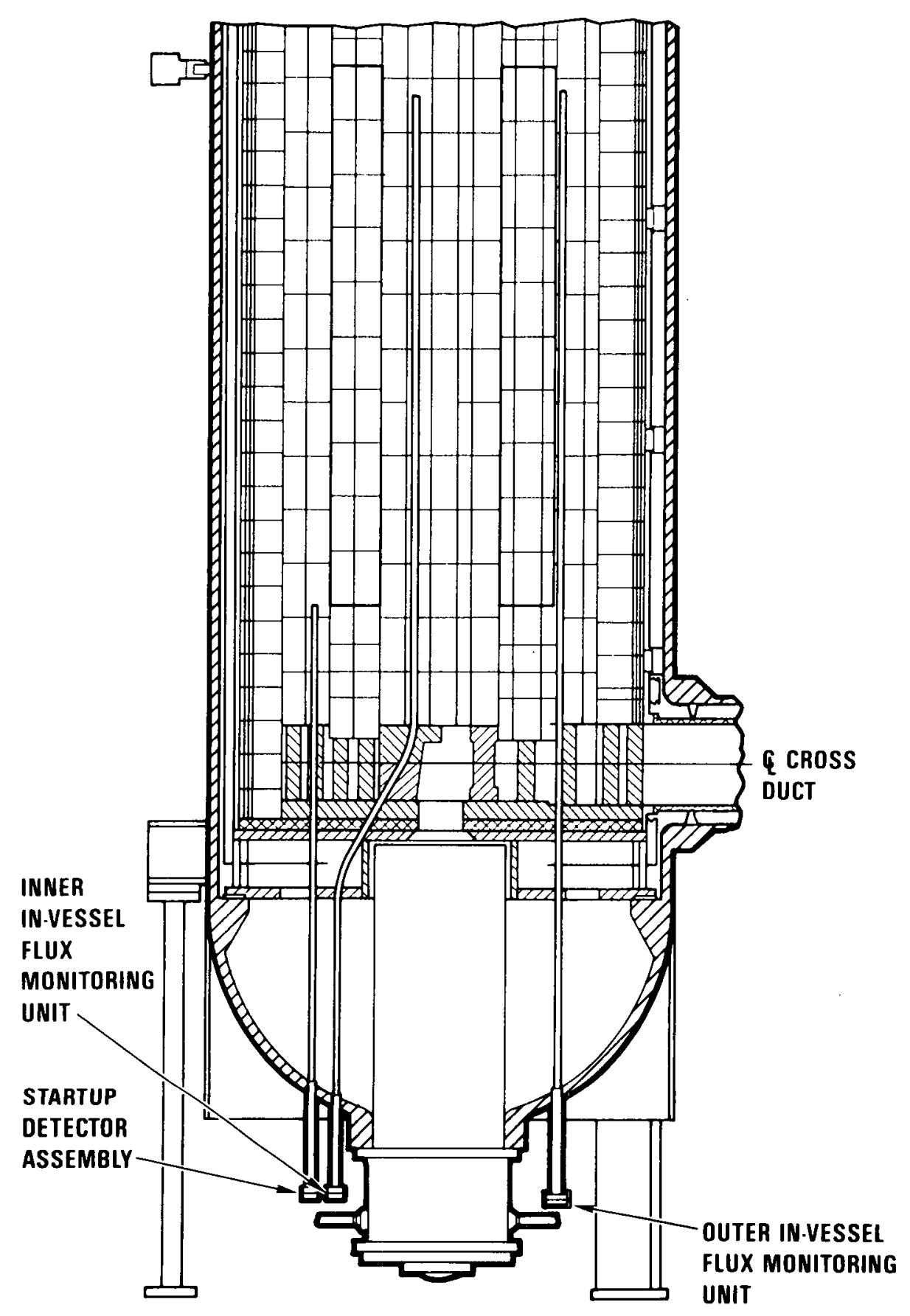

FIGURE 4.3-6

VERTICAL SECTION OF REACTOR CORE

HIGH TEMPERATURE GAS.COOLED REACTOR

PRELIMINAAY SAFETY INFORMATION DOCUMENT

HTGR-86-024 


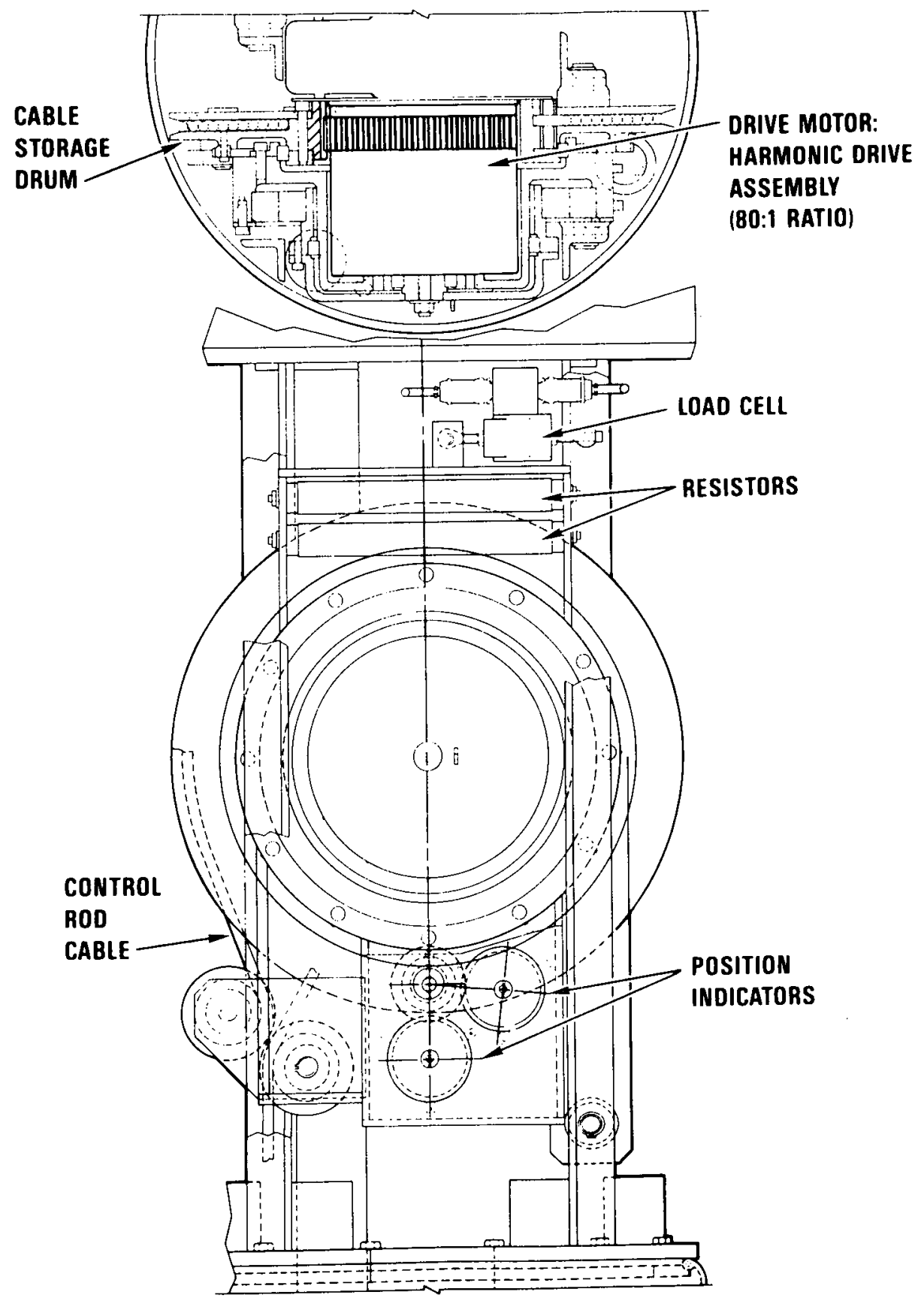

FIGURE 4.3-7

CONTROL ROD DRIVE MECHANISM

HIGH TEMPERATURE GASCOOLED REACTOR

PAELIMINARY SAFETY INFORMATION DOCUMENT

HTGR-86-024 


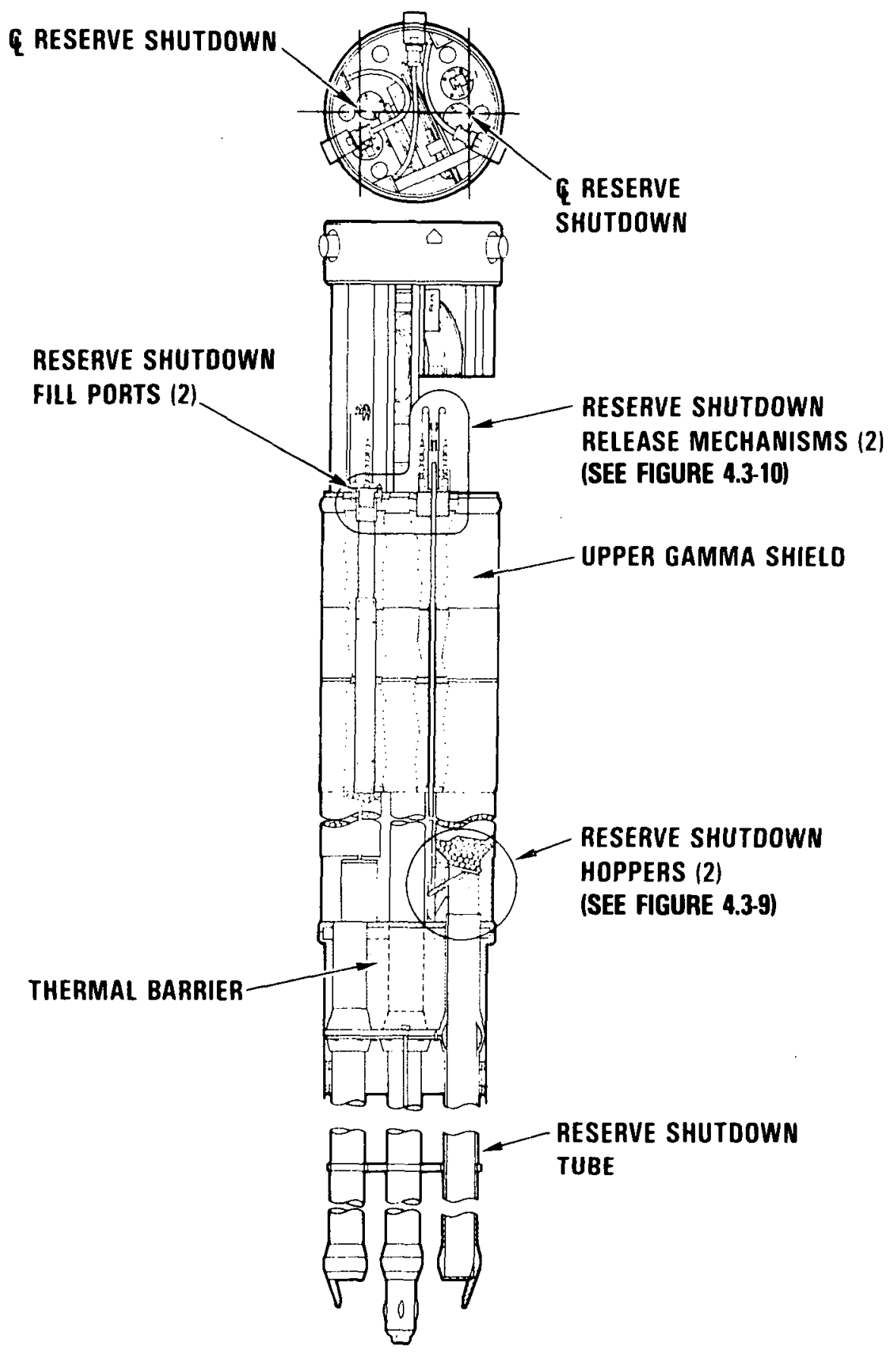

FIGURE $4.3-8$

RESERVE SHUTDOWN CONTROL EQUIPMENT IN AN INNER NEUTRON CONTROL ASSEMBLY

HIGH TEMPERATURE GAS-COOLED REACTOR PRELIMINARY SAFETY INFORMATION DOCUMENT HTGR-86-024 

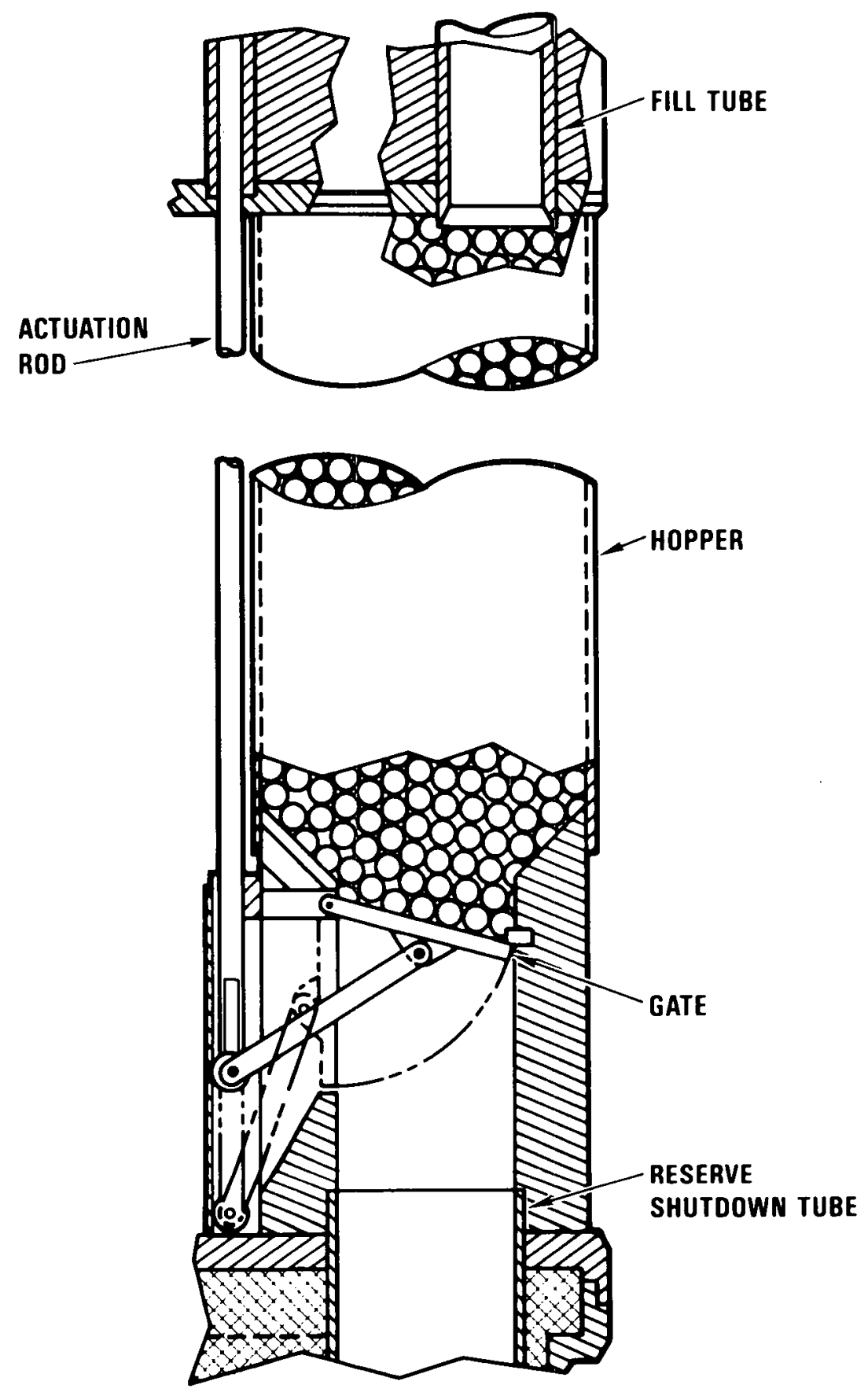

FIGURE 4.3-9

RESERVE SHUTDOWN CONTROL EQUIPMENT HOPPER 


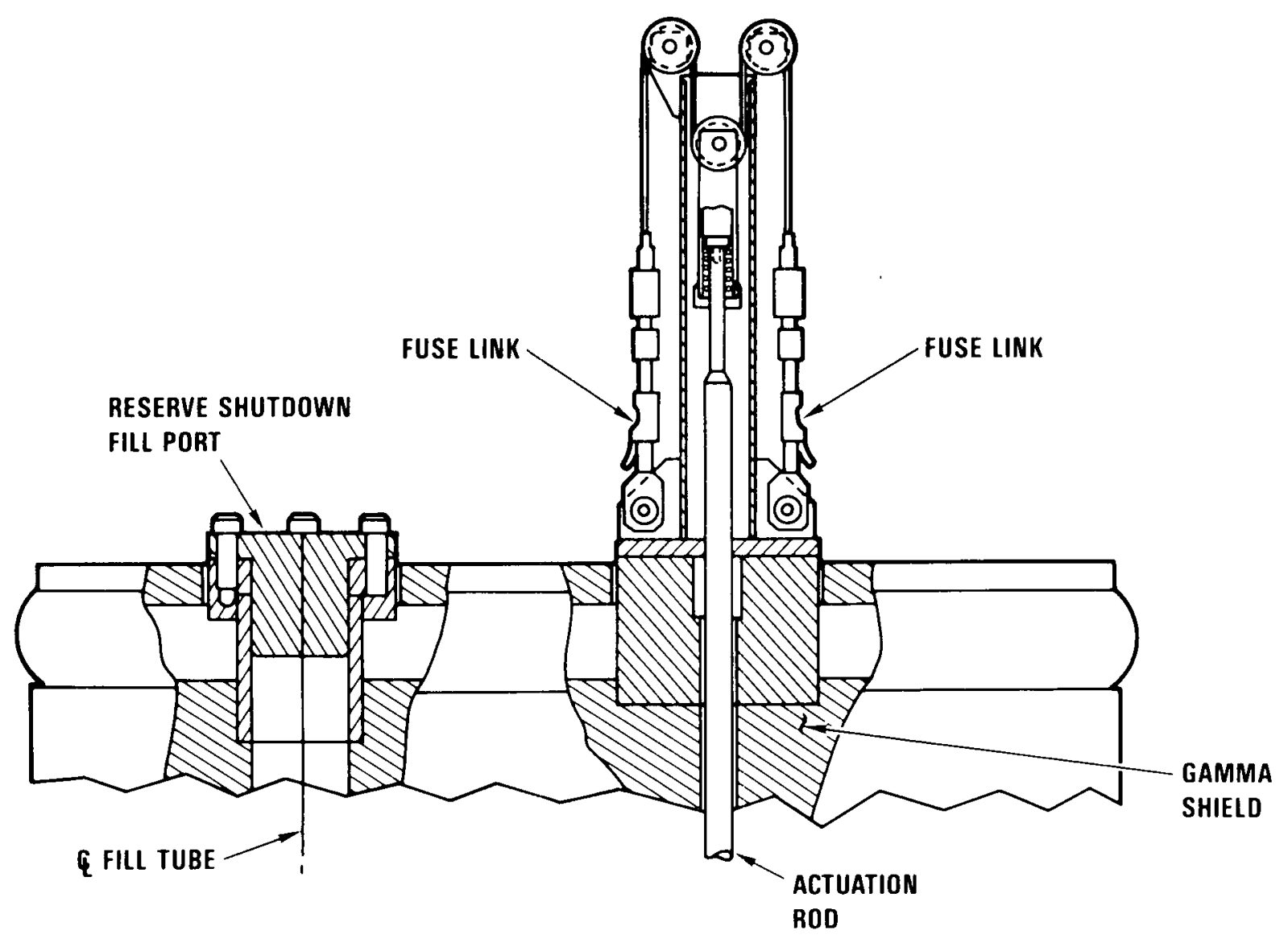

FIGURE 4.3-10

- RESERVE SHUTDOWN CONTROL EQUIPMENT FUSE LINK 


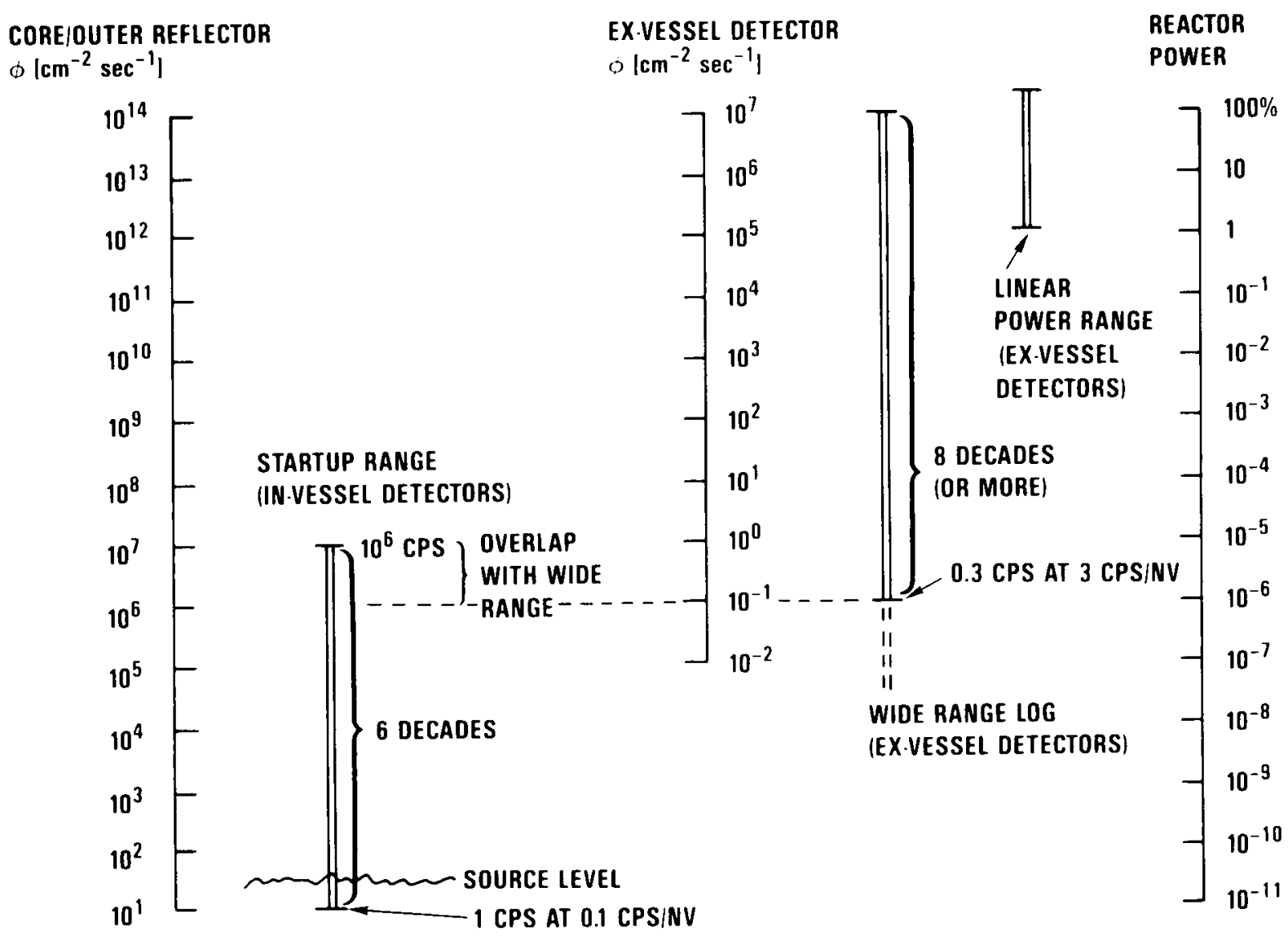

FIGURE 4.3-11

NUCLEAR INSTRUMENTATION RANGES 


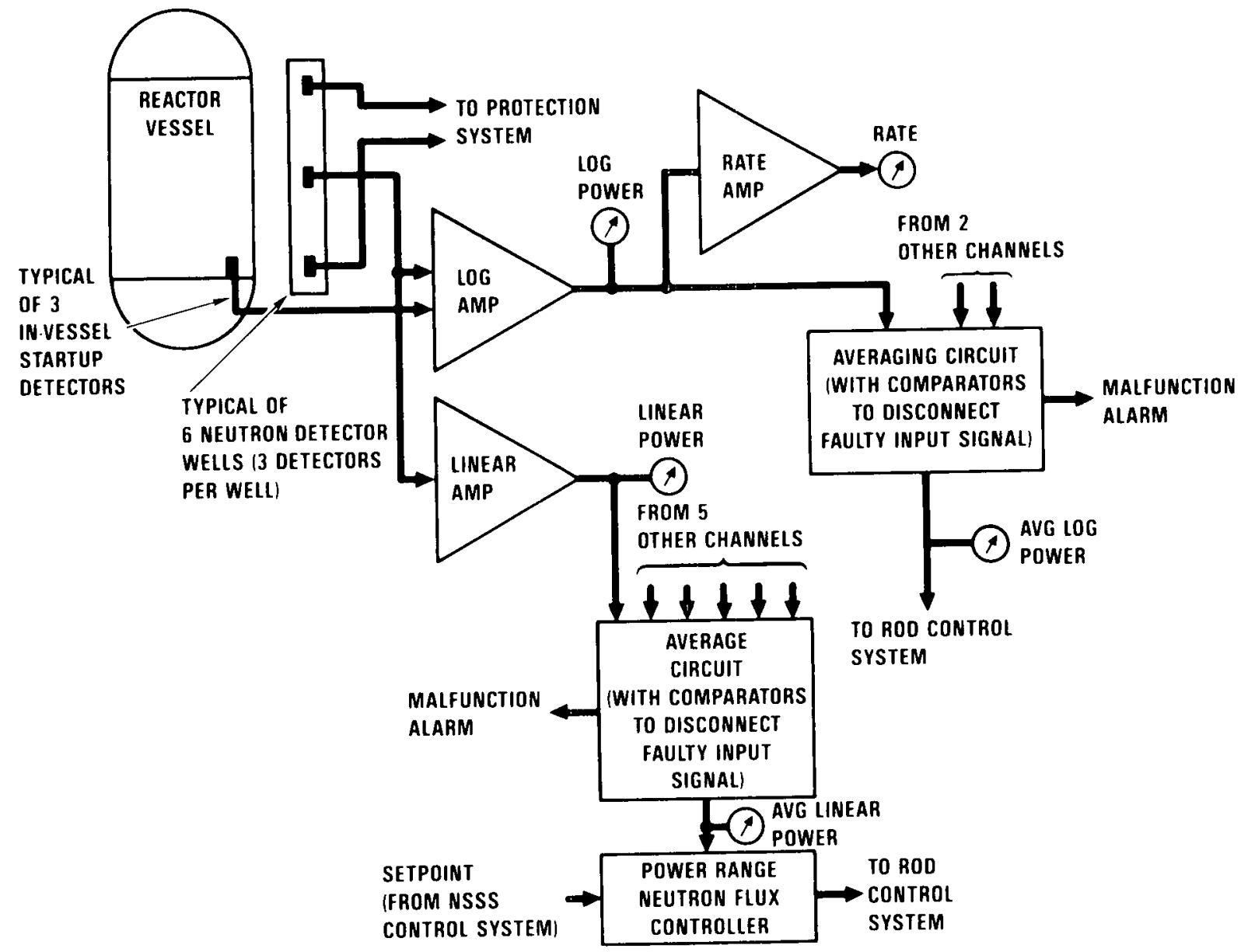

FIGURE 4.3-12

NUCLEAR INSTRUMENTATION

HIGH TEMPERATURE GAS-COOLED REACTOR

PRELIMINARY SAFETY INFORMATION DOCUMENT

HTGR-86-024 
HTGR $-86-024$

\subsection{REACTOR INTERNALS SUBSYSTEM}

\subsubsection{Summary Description}

The Reactor Internals Subsystem (RISS) consists of the core lateral restraint (CIR), permanent side reflector (PSR), graphite core support structure (GCSS), metallic core support structure (MCSS), upper plenum thermal protection structure (UPTPS), and the hot duct. Figure 4.4-1 illustrates the location of the components of the RISS within the Reactor System.

The core lateral restraint and the permanent reflector surround the core; the graphite core support structure and metallic core support structure are located below the core; the upper plenum thermal protection structure is located above the core; and the hot duct is located within the cross duct between the reactor vessel and the steam generator vessel.

\subsubsection{Functions and 10CFR100 Design Criteria}

\subsubsection{Power Generation Functions}

The principal function of the Reactor Internals Subsystem is to provide support and lateral restraint for the reactor core. Other important functions are to channel the primary coolant flow to the core, to control the amount of core coolant bypass flow, and to mix the core exit coolant flow. The reactor internals also augment shielding of the reactor vessel from core radiation.

\subsubsection{Radionuclide Control Functions}

The radionuclide control functions, which are performed by the core lateral restraint, permanent side reflector, graphite core support structure, and metallic core support structure are mainly to remove core heat and to control heat generation as discussed in section 4.1.2.2. These functions are performed by maintaining cooling pathways and the geometry for reactivity control material insertion. 
HTGR $-86-024$

As discussed in Section 4.1.2.2, the radionuclide control function which is performed by the upper plenum thermal protection structure is to limit chemical attack on the fuel by limiting fuel oxidation. This structure functions to provide protection to the upper vessel assuring primary coolant boundary reliability and restricting the possibility of air ingress to the core.

\subsubsection{Classification}

The core lateral restraint, the permanent side reflector, the graphite core support structure, the metallic core support structure, and the upper plenum thermal protection structure are "safety related". The hot duct is not "safety related".

For additional information related to this section, see response to NRC Comment 4-38.

4.4.2.4 10CFR100 Design Criteria for Radionuclide Control

The following 10CFR100 Design Criteria apply:

10CFR100 Design Criterion II: The vessels and other components that limit or prevent the ingress of air or water shall be designed, fabricated, and operated such that the amount of air or water reacting with the core will not exceed acceptable values.

10CFR100 Design Criterion IV: The intrinsic dimensions and power densities of the reactor core, internals, and vessel, and the passive cooling pathways from the core to the environment shall be designed, fabricated, and operated such that the fuel temperatures will not exceed acceptable values.

\subsubsection{Radionuclide Control Design Requirements}

The RISS shall maintain the core geometry for removing core heat by means of conduction and radiation during a module pressurized shutdown. 
The RISS shall maintain a controllable geometry of the core in order to control the heat generation rate, and to assure the capability to insert control into the reactor during both normal and off-normal conditions.

\subsubsection{Design Description}

\subsubsection{Subsystem Configuration}

Stability and alignment of the reactor core components, as well as shielding for the Vessel System (VS), are provided by the permanent side reflector which consists of graphite blocks stacked to form a cylinder around the core, as shown in Figures 4.4-1 and 4.4-2. Radial restraint is provided to the core, through the PSR, by the core lateral restraint located between the outer side reflector and the reactor vessel. The core lateral restraint includes the core barrel with attached coolant inlet channels, and the core barrel seismic keys.

The hexagonal side reflector and the reactor core columns are supported by the graphite core support structure which consists of two layers of graphite blocks supported by graphite posts to form a core outlet plenum. The graphite core support structure (in the lower plenum) under the central reflector columns and above the SCS inlet. port consists of 12 column supports. Half are hexagonal columns and the other half are double columns which form a vaulted support with the centermost column. Figures $4.4-1$ and 4.4-3 show the lower plenum support structures. The entire array of graphite posts and column supports is supported on the lower plenum floor which consists of a layer of graphite on top of a layer of ceramic blocks, the latter acting as an insulator on top of the metallic core support structure.

Vertical support of the reactor core components is provided by the metallic core support structure which is a weldment of two circular plates separated by radially oriented beams that meet at a central hub. The structure is supported by a forged ring that is integral to the reactor vessel.

The upper plenum thermal protection structure consists of metallic plates formed into a shroud within the top head of the reactor vessel to create the core inlet plenum. It includes a thermal barrier attached to the outside of 
the shroud. It is supported by a flange on top of the core barrel.

The hot duct consists of three sections of metallic pipes, two of which are covered with thermal barrier. The assembly is attached to the core barrel and extends through the crossduct to the steam generator vessel. The hot duct includes bellows to accommodate thermal and seismic movements and seals to prevent bypass flow. The hot duct assembly also includes a set of two shrouds, one of which is part of the elbow installation device, and both of which form a channel for the gas being directed to the main circulator.

\subsection{Graphite Structures}

A high-strength, oxidation-resistant rate, grade 2020 graphite from Stackpole Carbon Co. (or equivalent) is used for the lower plenum floor blocks, lower plenum support structure, core support posts, core support blocks, and PSR blocks. Grade 2020 graphite has a mean ultimate axial compressive strength of approximately $71 \mathrm{MPa}(10,300 \mathrm{psi})$ and tensile strength of $20.9 \mathrm{MPa}$ (3000 psi).

\subsection{Permanent Side Reflector}

The PSRs extend over the full height of the core array. The top plane is the top surface of the top reflector. The bottom surface interfaces with the ceramic pads on the metallic core support structure. The PSRs are bounded by the core barrel as shown in Figure 4.4-2. The inner boundary conforms to the faces of the hexagonal side reflector columns. The boundaries form a ring of PSRs which encircle the core. The one location which is an exception to this definition for side reflector is the primary coolant flow channel which connects the lower plenum cavity to the hot duct entrance. The PSR block arrangement in this region is shown in Figure 4.4-8.

Axially, there are a total of 25 layers of PSR, with 42 graphite blocks in each layer. There are seven blocks which repeat in pattern every 60 degrees around the PSR, as shown in Figure 4.4-2. Vertical shear keys, either dowels or flange-socket connections, are provided in all side reflector 
$\therefore$ HTGR $\div 86 \div 024$

columns.li The outermost portion of these reflectors contain several rows of circumferentially staggered boronated pins : Radial thickness of PSR :blocks rranges from 399 to 663 mm $(15$, to 26,1 in: $)$.

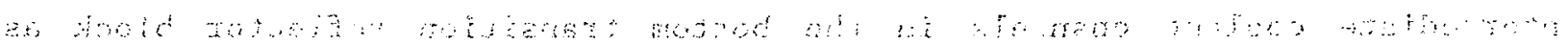

The pattern for PSR blocks is repeated for all layers except for the local area around the hot duct entrance. The PSR blocks in this location must maintain the geometryof the cylindrical flow channel from the lower plenum cavity to the hot duct entrance. The local area; where the block sizes differ from the normal, contains 34 different shäped blocks and two support posts as: shown in Figure $404: 5$ These blocks will provide support for the standard PSR block above and around the channel Two graphite horizontal beams are used to bridge the top of the channel. These beams are stressed well below the design :.limit of the high-strength graphite material by themselves. In addition, two vertical posts (located at the midspan of the beams) are added to provide redundant support. These posts are the same diameter as the core support: posts [228.6 mm (9 in:)] which are near the hot duct entrance.

\subsection{Graphite Core Support Stucture}

The graphite core support:-structure (GCSS) is designed for a 40 year 1 ife and consists : of all. graphite components: below the bottom transition reflector block and above the ceramic alumina pads located on the metallic core support structure: The side boundary is circumscribed by the inner face of the PSR blocks with the exception that GCSS components extend under the PSR at the entrance to the hot duct.

Discussion: of the structural features is divided into four areas, those under of the sactivei core;, under the side reflectors, support posts andrseats;

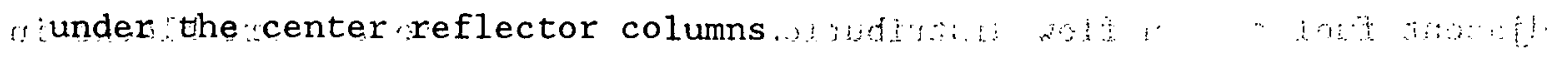

Juritum ob

GCSS Under Active Core: Under each active core column there are two layers of graphite core support blocks and one support post providing a lower plenum

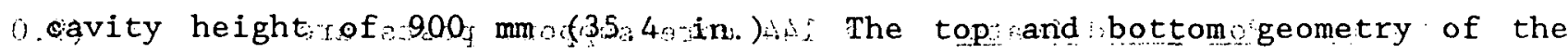
c. support post and seatis shown eingifigure 4.4-5. The first support block 
HTGR - 86- 024

below the bottom reflector blocks is called the flow distribution block. The coolant flow channels leaving the active core pass through two reflectors as shown in Figure 4.4-6. The fuel-element-type channels are converged into six intermediate coolant channels in the bottom transition reflector block as shown in Figure 4.4-7. These six coolant channels are directed to the six vertices of the hexagonal flow distribution block which is shown in Figure 4.4-8. A vertical channel of a cross section of a 120-degree circular sector at every vertex is machined at the lower end of the flow distribution block shown in Section D-D of Figure 4.4-9 as well as the post block beneath it, shown in Figure 4.4-10. The corner 120-degree sector channels form a complete circular channel at the intersection of each three adjacent hexagonal blocks. This intersection and merging of column flow streams provides premixing of the core flows prior to discharging into the lower plenum cavity.

Within the two block layers, three layers of borated pins are provided. Horizontal staggering of the pins from layer to layer provides the maximum shielding effect. The arrangement is conceptually indicated by Figures $4.4-7,4.4-9$, and 4.4-10.

GCSS Under Side Reflector: Under the side reflector columns there are two layers of graphite core support blocks and one support post in each column providing a lower plenum cavity. These blocks and post heights are universal for the side reflector columns except in front of the hot duct entrance. In this region the post block and lower plenum graphite floor blocks are shortened and the post height is increased in order to locally increase the plenum height in front of the channel. The 24 side reflector columns with control rod channels have coolant passages at the bottom of the channels which connect with the lower plenum cavity. These flow channels connect to the adjacent fuel column flow distribution block. The core support blocks in the side' reflector columns have one layer of boron pins to provide thermal neutron shielding.

GCSS Support Posts and Seats: The 144 core support posts are $228.6 \mathrm{~mm}(9.0$ in.) in diameter and are in three lengths, seven posts are $1257.3 \mathrm{~mm}$ (49.5 
HTGR - $86-024$

in.) long, 71 posts are $1161.8 \mathrm{~mm}$ (45.74 in.) 1ong, and 66 posts are $963.7 \mathrm{~mm}$ ( 37.94 in.) long. Each post is cylindrical with spherical ends that mate with a spherical radius post seat, as shown in Figure 4.4-5. The top seat is in the lower core support block (post block) and the bottom seat is in the graphite lower plenum floor. A post diameter larger than structurally required is used to provide more graphite material in the lower plenum cavity to reduce neutron streaming to the hot duct and to provide additional flow mixing.

GCSS Under Center Reflector: Under each of the 19 central (inner) reflector columns there are two core support blocks. These blocks are supported on 12 graphite block column supports shaped as shown in Figure 4.4-3. Six of these are hexagonal columns approximately $305 \mathrm{~mm}$ (12 in.) across flats. Each one supports one reflector column. The remaining six column structures are ten-sided columns in cross section which support two center reflector columns directly above them and which also collectively support the centermost reflector column in a cantilevered arrangement. Configuration and arrangement of these blocks is shown in Figures 4.4-1 and 4.4-3. There is no lower plenum floor footing to support the center column because of the exit port in the center of the lower plenum floor (as shown in Figure 4.4-1) which leads to the shutdown cooling heat exchanger ( $\mathrm{SCHE}$ ). The SCHE is located at the axis of the core but underneath the metallic core support structure.

Primary coolant flow normally passes around the 12 support column structures in the lower plenum cavity on its flow path to the hot duct entrance. During SCHE operation, the primary coolant flow enters the SCHE inlet port (located in the center of the lower plenum floor) by means of 12 gaps between the 12 column supports. The 12 gaps are manifolded into six flow paths to the centermost entrance plenum of the SCHE inlet port as shown in Figure 4.4-3. The width of the gaps is sized to provide the total flow area at any radial location equal to the area of the SCHE inlet port.

The present graphite core support structure (CSS) differs from that of 2240 MW( $t$ ) LHTGR CSS in the following ways. Under the active core, the adjacent side reflector and the columns at the entrance of the hot duct, the single 
HTGR - 86- 024

column per post concept is used in the present design. The remaining graphite blocks, including the permanent and outer hex side reflectors as well as the central reflectors are stacked up from the metallic CSS, while in the LHTGR, the whole core is supported by posts. Seven hex columns (less columns in the periphery) form a region which sits on a star-shaped solid core support block. This CS block, as well as the permanent side reflector (PSR) support block, are supported by three posts.

The graphite core and reflector columns are laterally restrained by the core barrel. In the LHTGR, the PSR blocks are preloaded radially inward by spring pack to form a tight ring. This tight graphite "core barrel" provides restraint to the core columns inside. The $R$ and $D$ requirements related to the CSS are described in the Regulatory Technology Development Plan. (Ref.1)

\subsection{Metallic Structures}

Metallic structures of the Reactor Internals Subsystem consist of the core lateral restraint, metallic core support structure, upper plenum thermal protection structure and hot duct assembly. Materials specifications for these structures are listed in Table 4.4-1.

\subsection{Core Lateral Restraint}

The core lateral restraint structure is composed of metal components consisting of a core barrel, seismic keys, coolant channels, and boss located between the PSR and the reactor vessel as shown in Figures 4.4-11 and 4.4-12. The core barrel is a cylinder composed of approximately $76 \mathrm{~mm}$ ( 3 in.) thick steel to locate, restrain, and limit the motion of the core outer radial boundary. It is attached to the top plate of the core support structure.

The 12 primary coolant inlet channels with internal dimensions of $152 \mathrm{~mm} \mathrm{x}$ $660 \mathrm{~mm}$ (6 in. $\mathrm{x} 26 \mathrm{in.}$ ) are located on the outside surface of the core barrel to direct the primary coolant to the top inlet plenum. During loss of forced circulation, these channels, in conjunction with the core barrel and the 
HTGR - $86-024$

upper plenum thermal protection structure, provide a convection flow path and barrier for the high temperature helium, thereby preventing overheating of the reactor vessel.

There are 48 seismic keys, 12 at each of four elevations. These seismic keys are radially oriented between, and attached to, the core barrel and the reactor vessel to provide lateral restraint for the core barre1. The keys are designed to permit relative expansion between the core barrel and reactor vessel while still maintaining accurate location and lateral restraint of the barrel within the vessel.

A boss located on the external surface of the core barrel provides a flat surface to which the hot duct is attached. A hole through the core barrel and boss permits the primary coolant to flow from the lower plenum to the hot duct.

\subsection{Metallic Core Support Structure}

The metallic core support structure (MCSS) is a component whose basic form is that of a spoked wheel as shown in Figure 4.4-13. The outer perimeter of the structure rests on a ring forging that is integral with the reactor vessel. All major loads are transferred to the vessel through this support. The upper flange of the structure is a solid plate that interfaces with the lower plenum floor. It also supports the side reflector blocks and the core barrel. This plate is solid to limit flow from the bottom plenum to the core outlet plenum. The plate is penetrated by a hole for the ducting to the shutdown cooling heat exchanger. Insulation isolates the shroud of the SCHE from the MCSS. Webs connect the top and bottom plates, effectively forming radial beams from the hub to the perimeter. This hub is insulated from the $687^{\circ} \mathrm{C}\left(1268^{\circ} \mathrm{F}\right)$ gas entering the SCHE during an SCS cooldown. The bottom plate contains holes for passage of the primary coolant. The perimeter is formed by a cylinder connecting the top and bottom plates for added stiffness. The cylinder is penetrated by a series of holes that allow transfer of the primary coolant from the side annulus to the peripheral coolant channels on the core barrel. 


\subsection{Upper Plenum Thermal Protection Structure}

The upper plenum thermal protection structure is composed of two basic elements: 1) a "hot" shroud into which, during normal and SCS operation, gas is exhausted from channels attached to the core barrel and from the core during pressurized conduction cooldown, and 2) a thermal barrier, consisting of insulation and coverplates, that is attached to the outside of the shroud and is designed to protect the reactor vessel from over temperature during the pressurized conduction cooldown. Figure 4.4-14 shows the basic form of the structure.

\subsection{Hot Duct}

The hot duct consists of three primary sections: two cylindrical, horizontal pipe-like sections, and a 90-degree elbow section. The latter includes an integral bellows that attaches to one of the horizontal sections as shown in Figure 4.4-15. Supplemental to these are inner and outer shrouds and an installation/removal mechanism, guide/support rails to assist in the installation and removal of the horizontal sections, and horizontal section attachments .

The attached horizontal sections have a $1.37-\mathrm{m}$ (54-in.) outside diameter with a $13 \mathrm{~mm}$ ( $0.5 \mathrm{in.})$ thick wall. Each section has a length of approximately $2.76 \mathrm{~m}$ (108.5 in.). The pipe thickness is determined by the requirement to sustain the pressure differential as well as to support itself under the imposed environmental conditions. The factors determining the inside diameter of the pipe are: the thermal barrier thickness, the desire to restrict the gas velocity to $61 \mathrm{~m} / \mathrm{s}(200 \mathrm{ft} / \mathrm{s})$ or less, to minimize the pressure drop through the duct, and the desire to use a commercially available bellows stock size (i.e., diameter and thickness).

Each of the horizontal sections is lined with $76 \mathrm{~mm}$ (3 in.) of thermal barrier consisting of $13-\mathrm{mm}$ (0.5-in.) thick coverplates having nominal surface dimensions of 508 by $508 \mathrm{~mm}$ ( 20 by 20 in.), 0.64-mm (0.025-in.) thick seal sheets and high temperature fibrous insulation blankets. With the 
HTGR $-86-024$

thermal barrier, the free-flow diameter of the duct is $1.19 \mathrm{~m}$ ( $47 \mathrm{in}$.). This results in a nominal gas velocity at rated power of approximately $44 \mathrm{~m} / \mathrm{sec}$ $(145 \mathrm{ft} / \mathrm{sec})$. The assigned pressure drop from the inlet at the core outlet plenum to the exhaust at the steam generator vessel flange interface is 4.8 $\mathrm{kPa}(0.7 \mathrm{psi})$.

The elbow section is compressed against the exit flange of the horizontal sections by a levered mechanical device. A bellows accommodates horizontal and vertical movements (thermal and seismic). The bellows is designed as a double-walled type to provide structural redundancy as well as a means for monitoring the pressure differential between the hot and cold gas regions. The vertical element of the elbow interfaces with a component of the upper steam generator shroud. Sealing is achieved with metallic o-rings at all interfacing surfaces.

\subsection{Shielding Features}

The permanent side reflector (PSR), in conjunction with the core barrel, protects the reactor vessel and the core lateral restraint structure from excessive neutron fluence.

The fast ( $\mathrm{E}>0.18 \mathrm{MeV}$ ) neutron flux exiting the active core is attenuated by the graphite reflectors. The attenuation of the total neutron flux exiting the permanent side reflector is enhanced by inclusion of borated steel pins (a neutron absorber material) in the outer portions of the reflector. The shielding poisons are located as far as practical away from the active core boundary to limit their impact on the core reactivity.

The PSR is required to limit the total neutron fluence to the core barrel and seismic keys to $10^{19} \mathrm{n} / \mathrm{sq} \mathrm{cm}$. The predicted total fluence to the core barrel is $3 \times 10^{17} \mathrm{n} / \mathrm{sq} \mathrm{cm}$ across the top section of the core which is the maximum flux location. The predicted value is 3 percent of the allowable limit. The PSR in conjunction with the core barrel is required to limit the total neutron fluence to the reactor vessel to $2 \times 10^{18} \mathrm{n} / \mathrm{sq} \mathrm{cm}$. The predicted fluence is $1.7 \times 10^{17} \mathrm{n} / \mathrm{sq} \mathrm{cm}$ which is 8.5 percent of the 
HTGR $-86-024$

allowable limit (see Section 4.4.5.2.3 for additional shielding performance).

\subsubsection{Subsystem Arrangement}

The general arrangement of the RISS comprising the core lateral restraint, core support structures, PSR, upper plenum thermal protection structure, and hot duct is shown in Figure 4.4-1.

Top access into the reactor vessel for the purpose of repair/replacement is provided via the reactor vessel top head.

Provision for access during any of the periodic in-service inspections of the reactor internals components is made by the top head refueling penetrations and the three startup detector penetrations in the bottom head of the reactor vessel. These inspections would be performed during reactor shutdown conditions.

Access to the hot duct components is provided through the main circulator penetration. In order to inspect the components, the circulator must be removed followed by the assembly containing the bellows and elbow. The bellows, because of shroud and duct geometries, must be inspected and repaired external to the vessel. Both the thermal barrier on the inside of the hot duct as well as the exterior of the pipe and the interior of the outer duct can be inspected after the elbow assembly has been removed.

\subsubsection{Subsystem Operating Modes}

The RISS consists of passive structures that have the primary functions of supporting and restraining the reactor core during all plant conditions, channelling the primary coolant from the reactor vessel to the steam generator vessel during normal operation, and protecting the reactor vessel from overtemperature during pressurized conduction cooldown. 


\subsubsection{Instrumentation and Control}

The only instrumentation required for the Reactor Internals Subsystem is a pressure transducer(s) to monitor the pressure in the space between the double-walled bellows of the hot duct. The transducer indicates a leak in the bellows by indicating a pressure increase or decrease.

\subsubsection{Subsystem Limitations}

To prevent damage to the structures and components, design limits have been imposed on the RISS, by applicable ASME Code, Section III requirements. These are the proposed Subsection CE, Div. 2, for the graphite structures and Subsection NG, Div. 1, for the metallic structures.

\subsubsection{Design Evaluation}

For additional information related to this section, see the responses to NRC Comments 4-27 and 4-37.

\subsubsection{Failure Modes and Effects}

\subsection{Graphite Structures}

Graphite structural components can be subject to thermal, neutron irradiation, and mechanical strains along with vibrational fatigue, chemical attack, and erosion. The potential modes of failure include loss of structural material, cracking, and ultimately, fracture of the component.

In order to provide adequate structural strength and reliability, corrosion allowances are incorporated in component designs on the basis of their sensitivity to oxidation, conditions causing erosion, and surface cracking.

\subsection{Core Support Block Failure Modes and Effects}

The functions of the core support blocks are to support and locate the core components to provide flow passages for the core flow to exit, to partially 
HTGR - $86-024$

mix the core exit flow, and to provide shielding for the core downstream components .

The core support blocks receive little fast neutron irradiation, so that irradiation-induced strains and stresses are very small. Stresses arise from deadweight loads, seismic loads, and from strains due to thermal gradients in the blocks. The stress levels due to these effects are low and failure of a core support block is very unlikely.

The most probable failure of a core support block is a crack into the block propagating from a high stress location. This crack could result in some block fragmentation, with fragment separation up to the cumulative transverse clearances across the core support block array. Total cumulative gap clearance across the array at operating conditions is about $20 \mathrm{~mm}$ ( 0.79 in.). This limits separation of the block pieces such that only small downward displacement around the $229 \mathrm{~mm}$ ( 9 in.) diameter post could occur. The change in cumulative transverse clearance across the array from shutdown to operating conditions is predicted to be small, about $1 \mathrm{~mm}(0.04$ in.). Thus, transverse compression failure of adjacent blocks or further fragmentation of a cracked block due to cyclical wedging during load swings is not expected to occur.

This postulated failure mode would not significantly affect the functions of the core support blocks to support and locate the core components or to mix flows exiting the core. The core flow passages would be maintained, as would the channels for the insertion of reactivity control material. Therefore safe shutdown of the reactor core would not be affected. A localized loss of shielding material could result, but this would not have significant effect of the shielding function of the core support floor blocks. Such a block fracture could reduce coolant flow in one or more of the six flow passages at the corners of the block. Decreased coolant flow would result in some higher fuel temperatures in the core. However, the temperature increases would be slight and localized, so that significant additional fuel failure would not be expected. 
HTGR - $86-024$

4.4.5.1.1.2 Lower Plenum Support Structure Failure Modes and Effects

The lower plenum support structure comprises the core support posts beneath 
HTGR - 86-024

the hexagonal side reflector and fuel columns and the support columns beneath the 19 center reflector columns. The functions of these components are to support and locate the core, to partially mix the core exit flow and to provide shielding for core downstream components.

All hexagonal side reflectors and fuel columns have an individual support post with a post seat at the top and bottom of the lower plenum cavity. The support post diameter is $228.6 \mathrm{~mm}$ ( $9 \mathrm{in.}$ ). This size is selected to provide additional graphite in the lower plenum cavity for neutron shielding as well as mixing the primary coolant. The post size is much larger than structurally required to support the column loads. A fracture of lower plenum support structure is a very unlikely event since the mechanical and thermal stresses are far below design limits.

Should a failure occur in the support structure, it would most probably occur in the post tip or seat. This has been observed in failure tests, where failure has resulted in graphite fragmentation around the post tip/seat, where high local bearing stresses occur.

With this failure, the block elements in the core column above could drop a short distance and became jammed on the damaged post. The functions of the post would continue to be met since the core column flow would be maintained and it would be possible to insert reactivity control material. Safe shutdown of the reactor would not be affected, nor would the flow mixing or shielding functions of the posts.

Failure of the column supports beneath the 19 center reflector columns is even less likely than failure of the surrounding support posts. These graphite column supports are larger in cross section than the cylindrical posts [i.e., $305 \mathrm{~mm}$ (12 in.) across-flats versus $229 \mathrm{~mm}$ (9 in.) diameter]. Flat bearing surfaces on these larger column supports also result in lower interface bearing stresses. However, support deflections from a vertical position can produce locally high bearing stresses at the contact edge which could result in edge cracking failure. But the loss of some edge graphite from the structure would not result in downward axial displacement of the 
HTGR - 86-024

column. Transverse position of the column would continue to be maintained by the surrounding array.

The center column is supported by the arched structure formed by the six ten-sided columns. The bending loads in the structure are small to provide a large margin of safety for the design. In the unlikely event that two or three of the restraining column supports fail, the center column could not drop into the SCS exit port below. The remaining undamaged column supports will provide more than adequate strength to support the center column.

\subsection{Lower Plenum Floor Failure Modes and Effects}

The lower plenum floor graphite layer contains the lower core support post seats. The functions of the core support seats are to support and locate the reactor core.

As discussed in Section 4.4.5.1.1.2, a core support seat could fail as a result of localized high bearing stresses in the post tip/seat. Also, failure of the seat could occur due to bending loads from locally non-uniform contact with the supporting structure beneath.

The most probable failure mode due to high post tip/seat stresses would be a core failure, where the central part of the seat is punched out. The most probable failure mode due to non-uniform contact with the supporting structure beneath would be a vertical crack across the seat. With either failure mode, the core support seat fragments would remain in place, so that only a small downward displacement of the core could occur. The component would continue to perform its functions of supporting and locating the core. Safe shutdown of the reactor core would not be affected.

\subsection{Permanent Side Reflector Failure Modes and Effects}

The PSR blocks provide lateral restraint for the hexagonal core elements and maintain the core radial geometry. The PSR transmits lateral seismic loads from the core barrel to the reactor core and it limits neutron fluences to 


$$
\text { HTGR }-86-024
$$

the core barrel, seismic keys, and the reactor vessel providing graphite material and borated pins for shielding. It also controls the core bypass flow.

If a crack were to occur, the permanent side reflector would continue to perform its functions of restraining and locating the core and of controlling the core bypass flow. The block fragments would be restrained between the core side reflector columns and the core barrel, and by neighboring PSR blocks on each side and above and below. Safe shutdown of the reactor would not be affected. It is possible that a small amount of shielding material could be displaced but this would not be expected to significantly reduce the ability of the permanent side reflector to perform its shielding function.

\subsection{Metallic Structures}

\subsection{Core Lateral Restraint Failure Modes and Effects}

The design of the core lateral restraint (CLR) is intended to make failure of the structure highly unlikely. The CLR is designed to be sufficiently stiff to provide a natural frequency of $20 \mathrm{~Hz}$ or greater during an OBE. The core barrel is designed as a welded structure with all welds being full penetration. All CLR components are designed for the life of the plant. The CLR can be inspected in situ from the top-head penetrations of the reactor vessel. Any crack in the core barrel would result in leakage of cold gas to hot gas which would possibly affect the plant efficiency but would not endanger the primary coolant boundary integrity. The CLR is designed to be accessible for repair/replacement.

Because of the large number of seismic keys (48) restraining the $C L R$ structure and the method of doweling one PSR block on top of another, the consequences of failure of a seismic key or several seismic keys would be insignificant as far as its effects on the PSR structure would be concerned. Therefore, it is very unlikely that a failed seismic key, or the failure of several seismic keys, would prevent a normal, orderly shutdown of the reactor core, nor would core cooling be impaired. 
HTGR - 86- 024

4.4.5.1.2.2 Metallic Core Support Structure Failure Modes and Effects

The failure of the metallic core support structure (MCSS) is a highly unlikely event. The MCSS is designed to be sufficiently stiff to provide a natural frequency of $20 \mathrm{~Hz}$ or greater during an $O B E$. It is also designed for a maximum deflection. To achieve this, the maximum stresses and deflections developed during any of the design conditions are very small and are well below design limits. The MCSS is designed as a welded structure with all welds being full penetration. The entire structure will be fully annealed after fabrication. The interior of each of the 12 "cells" (i.e., the volume contained by portions of the top and bottom plates, segments of the outer and inner cylinder, and the vertical webs) can be inspected in situ. The MCSS is designed to be accessible for repair. Should local failures occur by weld separation, the MCSS is designed so that loads could be spread to adjacent cells to prevent structural collapse. Hence, its ability to perform its functions will be maintained.

\subsection{Upper Plenum Thermal Protection Structures Failure Modes and Effects}

The upper plenum thermal protection structure (UPTPS) is composed of a shroud formed from welded plates and a thermal barrier attached to the outside of the shroud. The main purpose of the UPTPS is to protect the upper portion of the reactor vessel from being overheated during pressurized conduction cooldown. Also, by virtue of its design, it serves to channel the normal operation return gas to the top of the core. The structure, which interfaces with the core barrel, is essentially self-supporting.

The structure is designed for the life of the plant during which time the normal operating temperature is less than $260^{\circ} \mathrm{C}\left(500^{\circ} \mathrm{F}\right)$. Since the structure is fabricated from ASME SB409 (Alloy 800H), no degradation of the material is anticipated, since the normal temperature is well below the creep range and carburization-effects range. During the pressurized conduction cooldown event, the peak temperature of the UPTPS is predicted to be less 
HTGR - $86-024$

than $760^{\circ} \mathrm{C}\left(1400^{\circ} \mathrm{F}\right)$. Although the duration of the event is several hundred hours, only four occurrences are predicted. Hence, any structural failure is extremely unlikely.

Similarly, the thermal barrier metallics are Alloy $800 \mathrm{H}$ while the insulation is high quality, high-temperature fibrous blanket material. The attachments and the coverplates are redundantly designed and oriented such that the failure of any one set will not jeopardize the ability to protect the vessel. However, in the unlikely event the thermal barrier becomes dislodged, the panels cannot move beyond the top row of seismic restraints by virtue of their relative sizes compared to the spaces between the restraints. Even with a panel dislodged, the insulation will remain in place because of component overlap. Hence, the vessel will remain protected, which is the primary function of the UPTPS.

For additional information related to this section, see the response to NRC Comment G-8.A.

\subsection{Hot Duct Failure Modes and Effects}

The hot duct is designed for the life of the plant, and gross structural failure is unlikely. The most likely failure areas are associated with the seals and bellows. Here the most probable modes of failure are relaxation of the seals, distortion of the pipe sections or interfacing flanges, and cracking of the bellows. The result of any of these would be leakage of cold gas to hot gas which would possibly affect the plant efficiency but would not endanger the vessels.

The thermal barrier in the hot duct is designed with considerable redundancy, and failure is highly unlikely. However, the failure of the thermal barrier in the form of loss of insulation would result in an increase in heat load to the cold return gas. The magnitude of this heat load increase depends on the type of failure postulated, e.g., a single coverplate or the loss of the entire thermal barrier. Potential damage to steam generator components from dislodged cover plates is prevented by a flow-moderating screen at the elbow exit. This screen will be sufficiently strong to prevent that passage of a coverplate. 
For additional information related to this section, see the response to NRC Comment G-8.B.

\subsubsection{Steady-State Performance}

\subsection{Thermal Hydraulic Performance}

Helium coolant enters the RS from the cold leg of the cross duct. From there it flows up through the 12 coolant channels outside the core barrel to the top of the core.

Primary coolant enters the upper plenum above the reactor core and flows downward through the coolant channels in the plenum element, then to the top reflector elements above the active core. The metal plenum element on top of each core column contains a small flow plenum. The coolant holes in the plenum elements and the coolant channels in the fuel and top reflector columns below are offset horizontally to minimize the neutron streaming effect.

Approximately 89 percent of the circulator flow passes through the upper plenum and traverses the active core through the coolant channels in the fuel elements. The remaining 11 percent bypasses the active core in the gaps between columns and in the coolant holes in the central reflector and the control rod channels. A small amount of flow is directed to the control rod channels to provide cooling for the control rods. This flow is dictated by the large entrance and exit flow resistances of the control rod channels, so that the flow in these channels is only a weak function of control rod position.

The primary coolant is collected into six larger channels in the lower portion of the bottom reflector blocks, and then splits and merges with the coolant flow from the neighboring fuel elements in the core support block layer prior to exiting to the lower plenum. This coolant flows to the cross duct, located at one side of the lower plenum.

The pressure drop allocated to the RISS is $0.005 \mathrm{MPa}(0.7 \mathrm{psi})$ for the coolant inlet channels, $0.016 \mathrm{MPa}(2.3 \mathrm{psi})$ for the core outlet plenum, and $0.005 \mathrm{MPa}$ ( $0.7 \mathrm{psi})$ for the hot duct. 
When the Shutdown Cooling System (SCS) is in operation, the thermal/hydraulic configuration is different in the lower plenum area. The primary coolant exiting from the core is still collected in the lower plenum. From there it flows radially inward via narrow vertical channels between the central reflector column supports at the lower plenum elevation to a central chamber. The central chamber collects the primary coolant and directs it downward through an opening in the metal core support structure to the shutdown cooling heat exchanger.

The returning primary coolant from the shutdown cooling circulator enters the reactor vessel at its bottom end. The openings in the lower flange of the metal core support structure allow the coolant flowing upward to the space between the flanges of the core support structure, from there to the coolant inlet channels again.

\subsection{Structural/Mechanical Performance}

\subsection{Graphite Structure}

The structures are designed for the deadweight and pressure differential loads. The dimensions of load-bearing components are increased to account for possible material thickness which can be affected by erosion, chemical attack (such as oxidation), or minicracking. The core support structures are all subject to bearing and compression loads which are well below the allowable limits of the high-strength graphite material. Since the strength of the graphite material is approximately 3.4 times greater in compression than tension, the tensile support post/seat Hertzian stresses become the controlling parameter. These stresses are evaluated from previous post/seat test results. For steady state operation of the reactor, the allowable load based on Hertzian stress in both the post tip and seat for a $228.6 \mathrm{~mm}$ (9.0 in.) diameter post is $29,393 \mathrm{~kg}(64,800 \mathrm{lb})$. For comparison, the steady state maximum load applied is $<2,950 \mathrm{~kg}(<6,500 \mathrm{lb})$. The compressive stress in a $228.6 \mathrm{~mm}(9.0 \mathrm{in.})$ diameter post based on $6.35 \mathrm{~mm}(0.25 \mathrm{in.})$ radial reduction for oxidation is $0.73 \mathrm{MPa}$ (106 psi). The allowable compressive strength limit is $11.72 \mathrm{MPa}$ (1700 psi) for the high strength graphite. 
The neutron irradiation dose to the core support structure is very small. The flow distribution block, which is the nearest component to the active core, has a maximum fluence of $2 \times 10^{17} \mathrm{n} / \mathrm{sq} \mathrm{cm}$ ( $E>0.18 \mathrm{MeV}$ ). All other core support components have fluences less than $3 \times 10^{15} \mathrm{n} / \mathrm{sq} \mathrm{cm}$. The core support graphite fluence limit in proposed ASME Code Section III Division 2 Subsection CE, is $4 \times 10^{21} \mathrm{n} / \mathrm{sq} \mathrm{cm}$ (E >0.18 MeV).

The PSR blocks are protected from excessive neutron irradiation by two concentric rings of hexagonal side reflector elements. The inner ring of reflectors may require replacement after three to six fuel replacement cycles with cumulative exposure fluence of $5 \times 10^{21} \mathrm{n} / \mathrm{sq} \mathrm{cm}(\mathrm{E}>0.18 \mathrm{MeV})$.

The PSR blocks are not subjected to severe thermal gradients or high vertical deadweight loads. The PSR design of the $1193.8 \mathrm{~mm}$ (47 in.) diameter primary coolant channel for the lower plenum cavity to the hot duct entrance is shown in Figure 4.4-4. The preliminary estimate of the tensile stress in the support beam above the channel is $0.76 \mathrm{MPa}$ (110 psi) without the use of the support post. The allowable tensile stress for the high strength graphite is $4.69 \mathrm{MPa}$ (680 psi).

For additional information related to this section, see the responses to NRC Comments $4-34$ and 4-35.

\subsection{Metallic Structures}

\subsection{1 Core Lateral Restraint}

The core lateral restraint (CLR) is a passive structure which has the primary function of restraining the core during all plant conditions. During normal full- and partial-power operation, shutdown, and refueling, the stresses in the CLR are extremely low as only deadweight loads are present in the structure. The operating temperature of the core barrel is less than $270^{\circ} \mathrm{C}$ $\left(518^{\circ} \mathrm{F}\right)$ during normal full-power operation due to the continuous flow of core inlet gas through the vertical coolant channels positioned at 12 equally spaced locations on the outer face of the barrel. CLR material design allowables from ASME Section III, Div. 1, Subsection NG for Alloy $800 \mathrm{H}$ are well above the steady-state conditions. 


\subsection{2 Metallic Core Support Structure}

The MCSS is a passive structure which has the primary function of supporting the hexagonal reflectors, permanent side reflector, core barrel, and lower plenum floor. Additionally, it provides passages for the primary coolant to be transferred from the reactor bottom plenum to the inlet channels attached to the core barrel. During normal full- and partial-power operation, shutdown and refueling, the stresses in the MCSS are very low because only deadweight loads are imposed. The maximum steady state operating temperature of the top plate of the MCSS is $343^{\circ} \mathrm{C}\left(650^{\circ} \mathrm{F}\right)$. The source of the heat is the core outlet gas as transferred through the graphite and ceramic blocks atop the MCSS. The underside of the top plate is bathed by the return coolant at approximately $260^{\circ} \mathrm{C}\left(500^{\circ} \mathrm{F}\right)$. The MCSS material design allowables from ASME Section III, Division 1, Section NG for $2-1 / 4 \mathrm{Cr}-1$ Mo steel are well above the steady-state conditions.

\subsection{3 Upper Plenum Thermal Protection Structure}

The UPTPS is a passive structure which has the primary function of limiting the heat flow to the reactor vessel during pressurized conduction cooldown events. During normal steady-state operation it provides a sealed plenum for the return gas from the coolant channels to be directed into the core inlet. During normal and full-power operation, the stresses in the UPTPS are very low because only deadweight loads are imposed. During refueling, very minor side loads are imposed by the penetrations and handling equipment. The maximum steady state operating temperature of the shroud is approximately $260^{\circ} \mathrm{C}\left(500^{\circ} \mathrm{F}\right)$. The UPTPS material design allowables for Alloy $800 \mathrm{H}$ from ASME Section III, Div. 1, Section NG are well above the steady-state conditions.

\subsection{4 Hot Duct}

The hot duct is a passive structure which has the primary function of channeling the primary coolant flow from the core outlet plenum to the steam generator vessel. For normal steady-state operation the hot duct is designed 
for the nominal core outlet temperature $687^{\circ} \mathrm{C}\left(1268^{\circ} \mathrm{F}\right)$ plus streaks up to $760^{\circ} \mathrm{C}\left(1400^{\circ} \mathrm{F}\right)$. The metallic components of the hot duct are made of Alloy $800 \mathrm{H}$ which will adequately accommodate these temperatures. The most significant loads imposed on the duct are expected to be from acoustic vibration and these are well within the capability of the duct (see Section 3.9.3). Also to be considered are the seismically-induced loads, particularly with regard to the bellows. The bellows design can accommodate more than twice the predicted vertical and axial movements. Preliminary calculations show that the stresses are well below those specified in ASME Boiler and Pressure Vessel Code Case N-47.

\subsection{Shielding Performance}

The RISS is designed to reflect neutrons into the core and to thermalize and absorb neutrons leaving the reactor.

\subsection{Permanent Side Reflector}

The PSR has an average radial thickness of $0.548 \mathrm{~m}(21.5 \mathrm{in.})$. This radial thickness combined with the two rings of hexagonal side reflector elements which circumscribe the annular core provides a combined average radial thickness of $1.218 \mathrm{~m}$ ( $47.98 \mathrm{in.})$ of graphite material. The outer portion $152.4 \mathrm{~mm}$ ( 6 in.) of the PSR has four layers of staggered borated steel pins. The borated steel pins are contained vertically in holes in the PSR blocks. They serve as a thermal neutron shield to limit the total neutron fluence to $10^{19} \mathrm{n} / \mathrm{sq} \mathrm{cm}$ to the core barrel and seismic keys and to $2 \times 10^{18} \mathrm{n} / \mathrm{sq} \mathrm{cm}$ to the reactor vessel. The PSR design limits the fluences to below the allowable limits, based on the preliminary shielding analysis of the core and lower portion of the support structure.

The PSR graphite and boron pins also are required to limit neutron streaming down the annular gap between the reactor vessel wall and the core barrel to the hot duct and MCSS. The total fluence is 1 imited to $10^{19} \mathrm{n} / \mathrm{sq} \mathrm{cm}$ to the MCSS and $10^{19} \mathrm{n} / \mathrm{sq} \mathrm{cm}$ to the hot duct. The fluence to the hot duct thermal barrier metallics is limited to $10^{18} \mathrm{n} / \mathrm{sq} \mathrm{cm}$ for both thermal neutrons 
HTGR - 86- 024

$(E \leq 2.4 \mathrm{eV}$ ) and epithermal $(\mathrm{E}>2.4 \mathrm{eV})$. The calculated total fluences to the MCSS and the hot duct are $3 \times 10^{14} \mathrm{n} / \mathrm{sq} \mathrm{cm}$ and $1.7 \times 10^{17} \mathrm{n} / \mathrm{sq} \mathrm{cm}$, respectively.

\subsection{Graphite Core Support Structure}

The GCSS components limit the neutron fluences to the MCSS, the hot duct and the bottom head of the reactor vessel. Two layers of hexagonal core support blocks are directly above the lower plenum cavity. They include graphite and metal clad boronated graphite pins to limit the fluences to metal structures located laterally and directly below the GCSS. The primary coolant passages in the distribution and post blocks are designed to minimize the diameter of the flow channels and to offset the channel paths to limit neutron streaming into the lower plenum cavity. The shielding analysis is an estimate based on results for the $2240-\mathrm{MW}(t)$ HTGR core support blocks having much larger channels of $191.8 \mathrm{~mm}$ (7.55 in.) to $482.6 \mathrm{~mm}$ (19 in.) diameter compared to 67 $\mathrm{mm}$ (2.63 in.) to $116 \mathrm{~mm}$ (4.57 in.). The effect should reduce the neutron streaming factor of 20, appropriate for the 2240-MW(t) HTGR core support block, to a much lower value. The total neutron fluence in the hot duct, however, is approximately $2 \times 10^{17} \mathrm{n} / \mathrm{sq} \mathrm{cm}$ using a factor of 20 for neutron streaming. The conservative preliminary evaluation of the shielding effects of the bottom reflector and core support blocks is that the shielding is adequate.

\subsubsection{Anticipated Operational Occurrence Performance}

The plant anticipated operational occurrences (AOOs) are described in Section 11.6. Those which affect the reactor internals are discussed below.

\subsection{Structural/Mechanical Performance}

The graphite CSS and PSR are required to maintain geometry of the core and reflector array in order to assure capability to shut down the reactor and to provide convection and/or conduction heat paths for the removal of heat. Conditions of potential structural consequence to performance of these 
HTGR - 86- 024

functions are discussed below for identified A00s.

\subsection{Graphite Structures}

AOO-1 includes four accident families which have similar scenarios and radionuclide release paths. The resulting effects of each of these occurrences on the reactor internals graphite structures are:

A00-1(A) and $A 00-1$ (B) both involve the loss of main loop cooling followed by forced convection cooldown using the Shutdown Cooling System. These occurrences do not result in increased deadweight or pressure differential loads on the graphite structure. Some increase in thermal stresses in the core support blocks occur during the cooldown transient. These stress cycles are accounted for in the fatigue life design of these components. The maximum rate of change of core exit helium coolant temperature for these occurrences is about $10^{\circ} \mathrm{C} / \mathrm{minute}\left(17^{\circ} \mathrm{F} / \mathrm{minute}\right)$ over about 50 minutes duration. The resulting transient thermal stresses in the graphite core support components will be significantly lower than those experienced during AOO-1(C). No other adverse consequences to the graphite structure have been identified for these occurrences.

$\mathrm{AOO}-1(\mathrm{C})$ is a reactor trip with main loop cooldown. In this occurrence a higher cooldown rate, and thus higher transient thermal stresses are experienced in the core support components. Core exit helium coolant temperature decreases initially at a maximum rate of about $55^{\circ} \mathrm{C} / \mathrm{minute}$ $\left(100^{\circ} \mathrm{F} / \mathrm{minute}\right)$ for about 3 minutes, then at a lower rate of about $22^{\circ} \mathrm{C} / \mathrm{minute}\left(40^{\circ} \mathrm{F} / \mathrm{minute}\right)$ over 10 minutes. During rapid cooldown transients, coolant channel surfaces of the graphite core support blocks and surfaces of the support posts are cooled relative to the deeper structural mass, creating surface tensile stresses. The magnitude of these stresses has not been established, but based on analytical results for earlier HTGR design configurations, maximum stress levels can be maintained within allowable event and fatigue-life limits by appropriate geometric and/or control response design adjustments if necessary. This occurrence does not result in any other conditions of loading or displacement which might be of structural 
HTGR - 86- 024

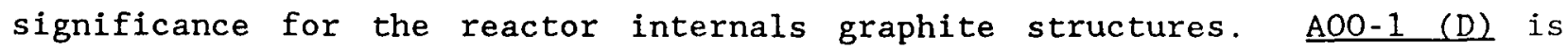
less severe and is bounded by $\mathrm{AOO}-1$ ( $\mathrm{A}, \mathrm{B}$ and $\mathrm{C}$ ).

$\underline{A O O-2}$ is a loss of main and shutdown cooling loops. This results in slow heatup of the midheight PSR graphite to a maximum local temperature at the inner face of about $680^{\circ} \mathrm{C}\left(1256^{\circ} \mathrm{F}\right)$ after about $100 \mathrm{hr}$. The core support graphite structures experience a gradual slight decrease from operating temperatures under RCCS cooling conditions. No structural interferences or degradation of strength of the graphite internals components will occur during this event.

AOO-3 is a control rod withdrawal followed by reactor trip and cooling on the HTS. It results in a slower cooldown rate in the core support graphite structure than A00-1 (C). No structural or heat removal consequences have been identified for this event.

A00-4 is a small steam leak followed by cooldown using the SCS. Thermal and structural load conditions are essentially the same as A00-1(A). Moisture ingress conditions result in $<0.02 \mathrm{~mm}(0.001 \mathrm{in.})$ maximum local surface oxidation of 2020 graphite core support structural components. Based on 0.4 events per reactor year mean frequency, total surface oxidation of $0.3 \mathrm{~mm}$ $(0.01$ in.) thickness is predicted during the reactor lifetime. This cumulative oxidation is within the design corrosion allowance of $2 \mathrm{~mm}$ ( 0.08 in.) thickness on graphite core support structural components.

$\underline{\mathrm{AOO}-5}$ is a small primary coolant leak. Reactor vessel depressurization over a 1-hour period does not result in increased structural loads. Thermal transient conditions are less severe than $\mathrm{AOO}-\mathrm{I}(\mathrm{A})$.

\subsection{Metallic Structures}

\subsection{1 Core Lateral Restraint}

Two AOOs have been analyzed for effects on the core lateral restraint: A00-1, reactor trip from full power, and A0O-3, rod withdrawal with reactor 
HTGR - $86-024$

trip and cooling on HTS. Both events have a negligible effect on core barrel temperature or thermal transients resulting from approximately $2.4^{\circ} \mathrm{C} / \mathrm{min}$ $\left(5^{\circ} \mathrm{F} / \mathrm{min}\right)$ decrease in inlet gas temperature. Changes of this magnitude have little or no effect on interfacing components experiencing differential expansions/ contractions owing to different coefficients of thermal expansion.

The CLR structure was designed to achieve tangential stiffness and a frequency in excess of $20 \mathrm{~Hz}$ during an OBE event to maintain structural integrity. Seismic analysis was performed with two-dimensional special purpose computer codes to develop the loads on the structure. Stress criteria consistent with ASME Boiler and Pressure Vessel Code Section III, Div. 1, Subsection NG is utilized to demonstrate adequately that failure of the structure is not credible.

\subsection{2 Metallic Core Support Structure}

Two AOOS have been examined for their effects on the MCSS: A0O-1, reactor trip from full power, and A0O-3, rod withdrawal with reactor trip and cooling on HTS. The anticipated rate of change in temperature of the structure during these $\mathrm{AOOS}$ is $1^{\circ} \mathrm{F} / \mathrm{min}$; hence, the effect is negligible.

\subsection{3 Upper Plenum Thermal Protection Structure}

AOO-1, reactor trip from full power, and AOO-3, rod withdrawal with reactor trip and cooling on HTS, were examined for their possible effects on the UPTPS. The maximum predicted temperature is $274^{\circ} \mathrm{C}\left(526^{\circ} \mathrm{F}\right)$ which occurs with a temperature rate of rise of less than $2.4^{\circ} \mathrm{C} / \mathrm{min}\left(5^{\circ} \mathrm{F} / \mathrm{min}\right)$. Since Alloy $800 \mathrm{H}$ has been selected for all of the UPTPS metallic components, and it is capable of sustaining long durations at $760^{\circ} \mathrm{C}\left(1400^{\circ} \mathrm{F}\right)$, no detrimental effects are foreseen. Likewise, the selection of high temperature, high purity fibrous insulation greatly minimizes the possibility of its deterioration. 
HTGR - 86-024

4.4.5.3.1.2.4 Hot Duct

Two AOOs have been examined for their effects on the duct components. The anticipated temperature rate of decrease for $A 00-1$ and $A O O-3$ are approximately $8^{\circ} \mathrm{C}\left(14^{\circ} \mathrm{F}\right) / \mathrm{min}$. This temperature change is not expected to have any detrimental effect on the structure.

4.4.5.4 Design Basis Event Performance

Eleven design basis events (DBEs) are described in Chapter 15. Conditions imposed on the reactor internals are described below.

\subsection{Structural/Mechanical Performance}

\subsection{Graphite Structures}

DBE-1 is a loss of HTS and SCS cooling involving a pressurized conduction cooldown. The conduction cooldown thermal transient in this event is similar to AOO-2 in its effects on the reactor internals graphite components. At the time of maximum core temperature, the core support block maximum temperature is $414^{\circ} \mathrm{C}\left(777^{\circ} \mathrm{F}\right)$. This event is less severe than DBE-11 discussed below, and the reactor internals graphite components will safely perform their functions of maintaining controllable geometry and conduction heat paths for decay heat removal.

DBE-2, which is an HTS transient without control rod trip, and DBE-3, which is a control rod withdrawal without HTS cooling, do not result in rapid temperature transients, heatup or structural loading of graphite reactor internals components.

$\underline{\mathrm{DBE}-4}$, which is a control rod withdrawal with Reactor Cavity Cooling System (RCCS) cooling, results in internals graphite temperatures essentially the same as AOO-2. Structural support and heat path functions are not affected.

$\underline{D B E}-5$ is an earthquake which trips the HTS. The seismic design spectrum 
HTGR - 86- 024

loads for the graphite reactor internal components are $1.0 \mathrm{~g}$ horizontal and $0.5 \mathrm{~g}$ vertical, which are the same loads applied to the core. Preliminary analyses show that these loads will not cause component stress allowables to be exceeded. Compared to the fuel elements, the permanent reflector blocks and core support blocks will have larger margins to allowables for combined seismic, thermal and irradiation-induced loads. This is because thermal and irradiation stresses in the permanent reflector blocks are lower as are irradiation stresses in the core support blocks.

Horizontal displacement of the core support blocks (within available transverse clearances) relative to the core support floor causes the core support posts to tilt slightly from vertical. The allowable load decreases with an increasing post angle increment from the true vertical position. The upper post seat is located in the post block layer of the core support blocks. If the layer of blocks are all moved in the same direction, the gaps between the blocks will diminish until the layer goes solid. This produces a maximum offset of $14.22 \mathrm{~mm}$ (0.56 in.). This offset corresponds to an angular post rotation of 0.74 degrees. The load capacity is reduced by 43 percent with a 0.74 degree rotation, and the allowable load becomes $40,279 \mathrm{~kg}$ $(88,600 \mathrm{lb})$ based on a factor of safety of 1.25 required by proposed Subsection CE, Section III, Div. 2 of the ASME Boiler and Pressure Vessel Code for level D. The normal steady-state vertical load is $<2722 \mathrm{~kg} \quad(<6000$ 1b). For a vertical acceleration of $0.5 \mathrm{~g}$ the load increases to approximately $<4100 \mathrm{~kg}(<9000 \mathrm{lb})$ which is well below the allowable limit of $40,279 \mathrm{~kg}$ $(88,6001 \mathrm{~b})$.

$\underline{\mathrm{DBE}-6}$ is an HTS offset steam tube rupture followed by steam generator dump and SCS cooldown. Thermal transient cooldown is essentially the same as A00-1(A). Maximum local surface oxidation of graphite core support components is predicted to be $0.4 \mathrm{~mm}(0.016 \mathrm{in.})$ depth, well within the design corrosion allowance of $2 \mathrm{~mm}$ ( $0.08 \mathrm{in.}$.

$\underline{\mathrm{DBE}-7}$ is a steam in-leak event which starts the same as DBE- 6 but goes to completion with RCCS cooldown. In this case, core graphite temperatures remain high for a long period. However, core support graphite temperatures 
HTGR - 86- 024

decrease throughout the event. Maximum local coolant path surface oxidation of graphite core support components is less than $0.1 \mathrm{~mm}(0.0039$ in.). Structural degradation of graphite internals components is well within design allowance for this event.

$\underline{\mathrm{DBE}-8}$ is a water inleakage with a rate much lower than DBE-6. Initial cooldown rate is high using the HTS, then reduced during completion of cooldown by SCS. Thermal transient conditions are initially the same as AOO-1(C), with consequences to core support components the same. Graphite oxidation is locally higher in graphite core support components than DBE-7 because initially high HTS coolant flow rates result in high oxidant mass transport rates early in the shutdown before significant cooling of core support graphite components has occurred. Maximum local surface oxidation of $0.3 \mathrm{~mm}(0.012 \mathrm{in.})$ is predicted, well within the design allowance of $2 \mathrm{~mm}$ $(0.08 \mathrm{in})$.

$\underline{\text { DBE-9 }}$ is a small initial steam leak followed by slow primary coolant depressurization and SCS cooldown. Thermal transient conditions will be the same as AOO-1(A) with no significant consequences to graphite structures. Oxidation will be less than DBE-8.

$\underline{\mathrm{DBE}-10}$ is a depressurization of the primary circuit and SCS cooldown. This results in a slow cooldown of the graphite internals structures and low thermal stress. For the postulated relief valve leak location, the depressurization flow exits between the circulator discharge and core inlet, thus decreasing core flow and thereby differential pressure. Structural loads on reactor internals graphite components are as a result not increased during the depressurization.

$\underline{\mathrm{DBE}-11}$ is a slow primary circuit depressurization with HTS cooldown for 15 hours followed by the RCCS heat removal. Initial rapid HTS cooldown of graphite internals is the same as $A O O-1(C)$. Subsequent longer term afterheat removal by the RCCS results in a maximum PSR graphite inner face temperature of approximately $870^{\circ} \mathrm{C}\left(1600^{\circ} \mathrm{F}\right)$. Air ingress due to displacement and cooldown is primarily reacted with the higher temperature core and inner 
HTGR - 86- 024

reflector graphite. Core support graphite components are relatively cool and will experience little oxidation. Maximum local PSR graphite block surface oxidation is estimated to be significantly less than the predicted 0.008 percent core-element oxidation.

\subsection{Metallic Structures}

\subsection{1 Core Lateral Restraint}

The most significant DBEs affecting the CLR are DBE-1, DBE-5, and DBE-11. For DBE-1, the pressurized conduction cooldown, the temperature of the core barrel will reach a maximum value of $485^{\circ} \mathrm{C}\left(904^{\circ} \mathrm{F}\right)$ after approximately 100 hours and will then decrease gradually. The structural effects on the core barrel at these temperatures are minimal. This event has a negligible effect on the core barrel as a result of the thermal transient.

For DBE-5, the earthquake design spectrum load for the core lateral restraint structures was estimated as approximately $0.5 \mathrm{~g}$. The value is based on a very stiff core barrel and key support design yielding a natural frequency of about $25 \mathrm{~Hz}$. The lateral restraints must also accomodate the loads caused by lateral impact of the core against the core barrel. Overall, the design shows barrel/key interface stresses well below the material strength. Consequently, the core barrel will prevent excessive core deflections and will ensure that control rod reserve shutdown materials are capable of being inserted into the core when required.

For DBE-11, the depressurized conduction cooldown, the temperature of the core barrel will reach a maximum value of $613^{\circ} \mathrm{C}\left(1135^{\circ} \mathrm{F}\right)$ after approximately 120 hours. The temperature rise is approximately $8^{\circ} \mathrm{C} / \mathrm{hr}$ $\left(15^{\circ} \mathrm{F} / \mathrm{hr}\right)$ which will have negligible effect on interfacing components experiencing differential expansion owing to different coefficients of thermal expansion. The maximum allowable temperature for the core barrel is $760^{\circ} \mathrm{C}\left(1400^{\circ} \mathrm{F}\right)$ for continuous operation. 
HTGR - $86-024$

\subsection{2 Metallic Core Support Structure}

The most significant DBEs have been examined for their effects on the MCSS: DBE-1, pressurized conduction cooldown with core cooling on RCCS; DBE-5, large earthquake with core cooling on SCS, and DBE-6, moisture inleakage.

The maximum predicted temperature of the MCSS (top surface) is $418^{\circ} \mathrm{C}$ $\left(785^{\circ} \mathrm{F}\right)$ during $\mathrm{DBE}-1$ and the resulting stresses are low. Bowing of the structure due to thermal gradients is insignificant. Therefore, the core components can be adequately supported such that the control rods and the reserve shutdown are capable of performing their functions.

The MCSS is designed for high stiffness in order to maintain structural integrity during an SSE event. The seismic analysis indicates that the fundamental frequency is $32 \mathrm{~Hz}$ and a spectrum load of approximately $0.5 \mathrm{~g}$. Comparison with ASME Boiler and Pressure Vessel Code Section III, Div. 1, Subsection NG stress criteria demonstrates that failure of the structure is not credible.

\subsection{3 Upper Plenum Thermal Protection Structure}

The most significant DBEs have been examined for effects on the upper plenum thermal protection structure (UPTPS). DBE-1 indicates a maximum UPTPS temperature of $691^{\circ} \mathrm{C}\left(1275^{\circ} \mathrm{F}\right)$ at approximately $300 \mathrm{hr}$. The resulting loads are substantially below material allowables for Alloy $800 \mathrm{H}$ per ASME Section III, Division 1, Subsection NG. The highest temperature identified for the UPTPS is $760^{\circ} \mathrm{C}\left(1400^{\circ} \mathrm{F}\right)$ during $\mathrm{DBE}-11$. The duration of that temperature is predicted to be less than 20 minutes and is, therefore, inconsequential. The UPTPS has been designed to be sufficiently stiff such that significant distortion of the structure can occur. Therefore, the control rods and reserve shutdown will continue to perform their functions.

\subsection{4 Hot Duct}

Examination has not revealed an applicable DBE. 
HTGR - 86- 024

\subsubsection{5 "Safety-Related" Design Condition Performance}

Eleven "safety-related" design conditions (SRDCs) are described in Section 15. The conditions imposed on the "safety-related" reactor internals are discussed below.

\subsection{Structural/Mechanical Performance}

\subsection{Graphite Structures}

SRDC- 1 and SRDC-4 are the same as their DBE counterparts and produce the same effects on graphite components. See Subsection 4.4.5.4.1.1 for a discussion of DBE- 1 and DBE-4.

$\underline{\text { SRDC-2 }}$ is the same as DBE-2, except cooldown is with the RCCS. In this event, core graphite internals structures will experience peak temperatures essentially the same as AOO-2 with no detrimental effects predicted.

SRDC-3 and SRDC-4 result in the same thermal transient conditions for the internals graphite structures. Maximum temperature conditions are typically the same for all pressurized RCCS cooldown events and are again essentially the same as A00-2. No adverse consequences are expected.

$\underline{\text { SRDC-5 }}$ is an SSE condition. Seismic design basis and evaluation status are discussed under DBE-5.

Structural evaluation of core support and PSR blocks under horizontal dynamic SSE loads and impact conditions will be based on reactor vessel and CLR response. Adjustments to vessel and CLR response characteristics can be made, if required, to limit reactor graphite array loads and deflections to acceptable levels to assure safe control rod insertion and structural integrity of the internals components.

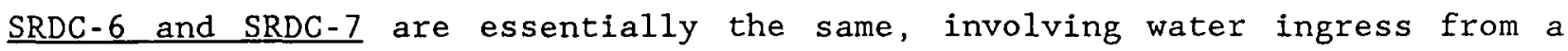
moderate size leak in a steam-generator tube. These events differ from the 
HTGR - $86-024$

corresponding DBEs in that the water inleakage is not terminated until about one-half hour after the initiating event. Reactor cooldown in both cases is by conduction using the RCCS. The temperature of the graphite core support components is expected to stay below about $700^{\circ} \mathrm{C}\left(1300^{\circ} \mathrm{F}\right)$. At this temperature the rate of oxidation is very low such that most of the water (in the form of steam) will react with the much hotter core. There will be a moderate burnoff in the core support components, resulting in some degradation of the structural strength, but the ability of the structure to perform its "safety-related" functions will not be compromised.

SRDC-8 involves water ingress through a small leak, but is otherwise the same as SRDC-6 and SRDC-7. Therefore, the consequences are bounded by SRDCs 6 and 7 .

SRDC-9, which also is a small water leak rate, is the same as SRDC- 8 .

SRDC-10, which is a moderate primary coolant leak with core cooling on RCCS, is the same as DBE-10 with respect to structural loads, i.e., core support structure loads are decreased slightly because of circuit depressurization between the circulator discharge and core inlet. For depressurized RCCS cooldown, reactor internals graphite maximum temperatures are essentially the same as DBE-11.

SRDC-11 involves a slow depressurization with RCCS conduction cooldown after a reactor trip. Graphite internals structures maximum temperatures are essentially the same as DBE-11 and SRDC-10.

\subsection{Metallic Structures}

\subsection{1 Core Lateral Restraint}

SRDC-11, which is a depressurized conduction cooldown, is the most severe condition for the core lateral restraint, as discussed under the DBE events. The thermal condition of the core barrel is well within the $760^{\circ} \mathrm{C}$ $\left(1400^{\circ} \mathrm{F}\right)$ allowable temperature. The CLRs structural design adequacy as a 
HTGR $-86-024$

"safety-related" component was evaluated on the basis of temperature and shown to maintain its integrity and to perform the radionuclide control functions to remove core heat and control heat generation.

For SRDC-6, the depressurized conduction cooldown with moderate moisture ingress, the temperature of the core barrel will reach a maximum value of $607^{\circ} \mathrm{C}\left(1124^{\circ} \mathrm{F}\right)$. The maximum temperature rise is approximately $11^{\circ} \mathrm{C} / \mathrm{hr}$ $\left(20^{\circ} \mathrm{F} / \mathrm{hr}\right)$. Due to the solid contact with the UPTPS, the relative differential expansion will be negligible even though the mean temperature of the UPTPS will be slightly higher. A hold time above $538^{\circ} \mathrm{C}\left(1000^{\circ} \mathrm{F}\right)$ of some 250 hours will have little impact on the core barrel integrity.

\subsection{2 Metallic Core Support Structure}

SRDC-2, which is a pressurized conduction cooldown without control rod trip, is the most severe condition for the MCSS. The local upper surface temperature reaches $418^{\circ} \mathrm{C}\left(785^{\circ} \mathrm{F}\right)$. The maximum temperature differential between the top and bottom surfaces is approximately $140^{\circ} \mathrm{C}\left(250^{\circ} \mathrm{F}\right)$. The structure is sufficiently stiff so that differential bowing is insignificant. Therefore, its ability to support the core components effectively, thereby enabling them to perform their functions of radionuclide control and core heat removal, is sustained.

SRDC-6 results in a peak temperature of $390^{\circ} \mathrm{C}\left(735^{\circ} \mathrm{F}\right)$ at a gradual rate of rise which results in no detrimental effects on the structure.

\subsection{3 Upper Plenum Thermal Protection Structure}

SRDC-10, which is a depressurized conduction cocldown with moderate primary coolant leak, is the condition which imposes the most severe parameters on the UPTPS. The maximum temperature is $711^{\circ} \mathrm{C}\left(1322^{\circ} \mathrm{F}\right)$ which is sustained for but a few hours. Since the loads are very low, the material allowables for Alloy $800 \mathrm{H}$ provide a considerable margin of safety for the components. Hence, the UPTPS 
integrity can be assured to perform its functions of assisting in the control of radionuclides and core heat removal.

SRDC -6 results in a maximum temperature of $440^{\circ} \mathrm{C}\left(825^{\circ} \mathrm{F}\right)$, a maximum rate of rise of $22^{\circ} \mathrm{C} / \mathrm{hr}\left(40^{\circ} \mathrm{F} / \mathrm{hr}\right)$ which will not be detrimental to the UPTPS.

\subsection{4 Hot Duct}

SRDC-4, SRDC-10, and SRDC-11 are the conditions which impose the most severe parameters on the hot duct. The maximum predicted temperature of $688^{\circ} \mathrm{C}$ $\left(1270^{\circ} \mathrm{F}\right)$ is approximately equal to the normal steady-state conditions. Therefore, its ability to perform its functions is not jeopardized.

\subsubsection{Interfaces}

Interfacing requirements imposed on other systems by the Reactor Internals Subsystem are identified in Table 4.1-2, which also includes a description of the interface and a quantitative expression for the interface. 
HTGR $-86-024$

REFERENCES - SECTION 4.4

1. U.S. Department of Energy. Regulatory Technology Development Plan for the Standard MHTGR. DOE-HTGR-86-064. January 1987. 


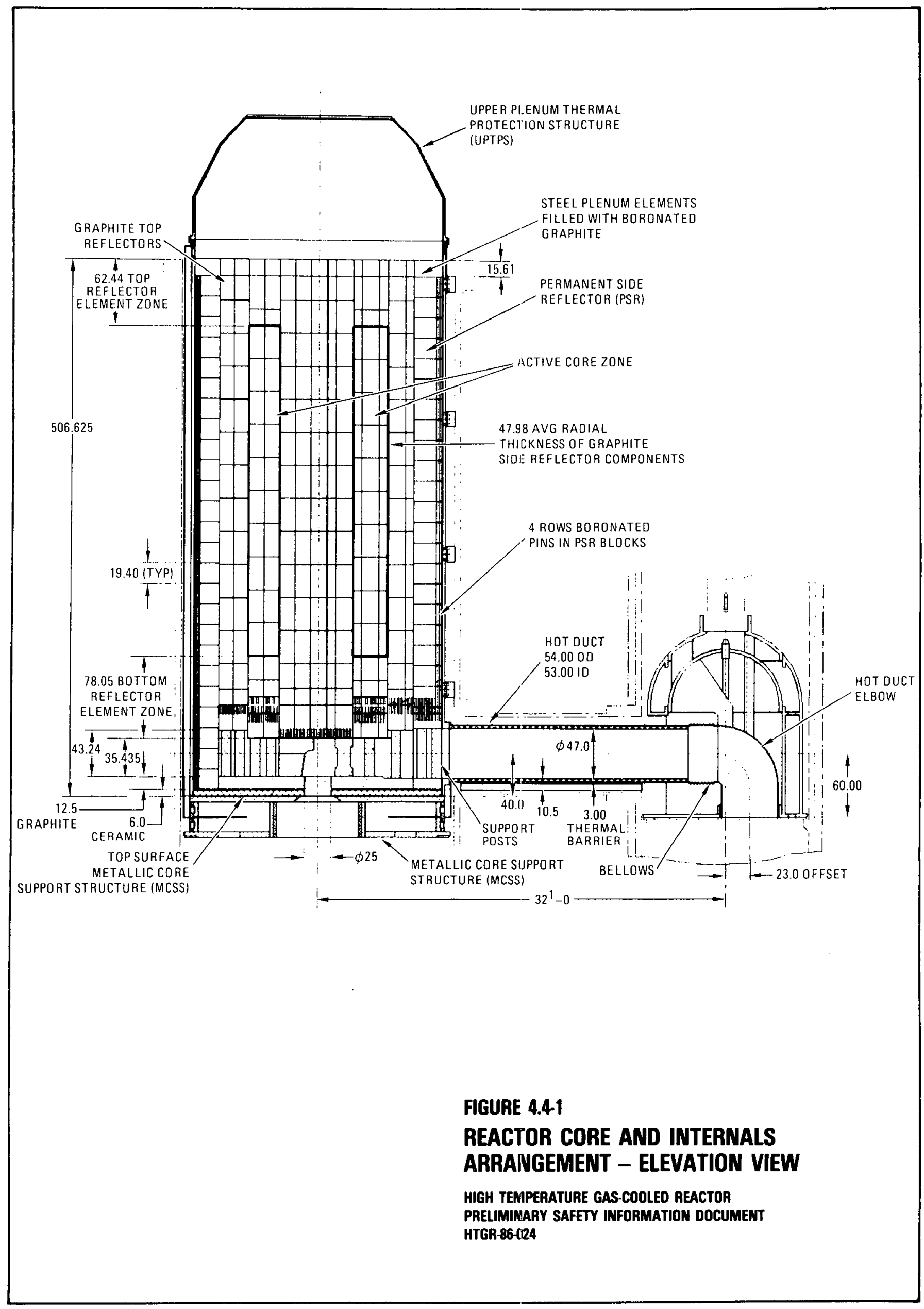




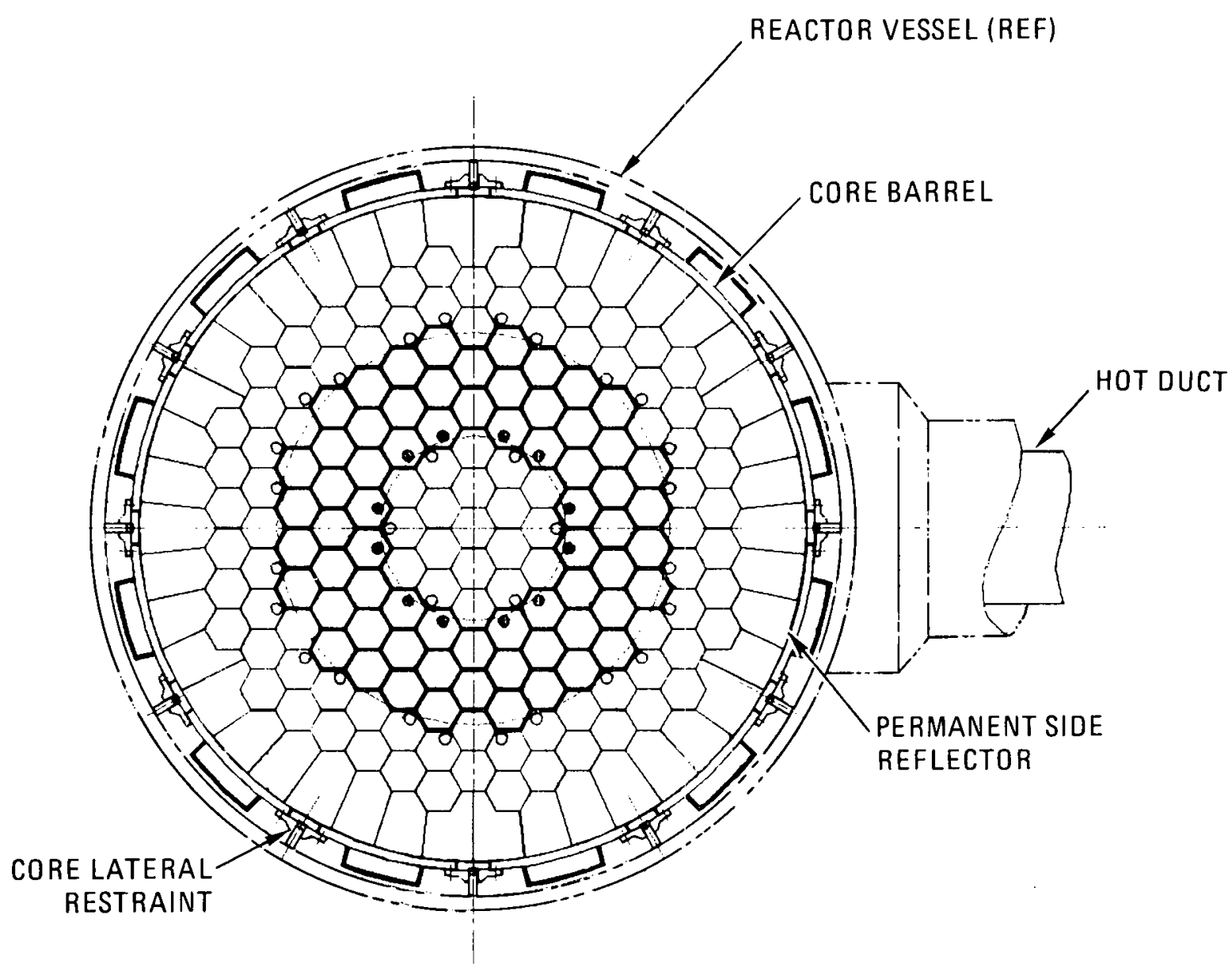

FIGURE 4.42

REACTOR CORE AND INTERNALS ARRANGEMENT - PLAN VIEW 


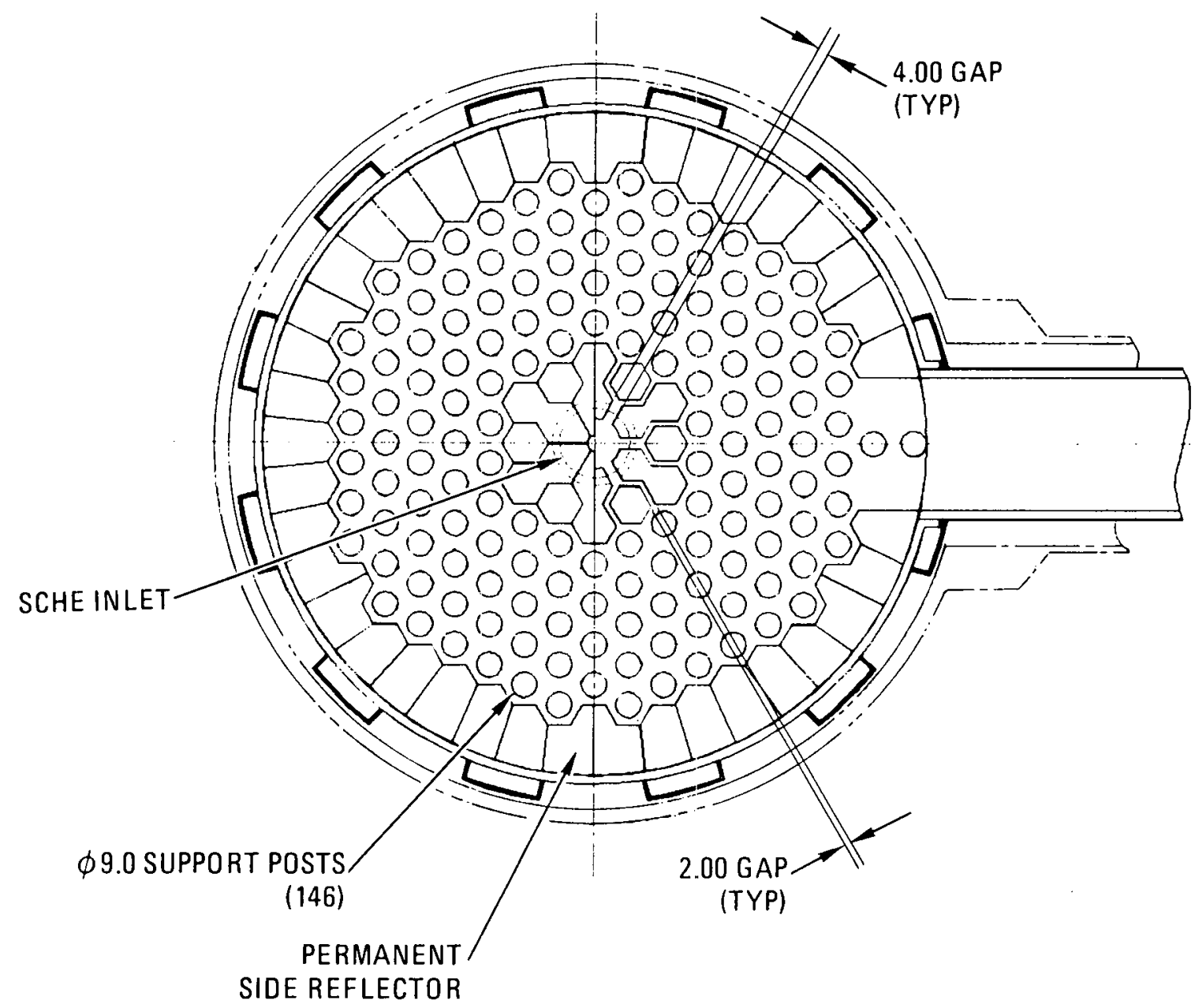

FIGURE 4.43

GRAPHITE CORE SUPPORT STRUCTURE - PLAN VIEW 


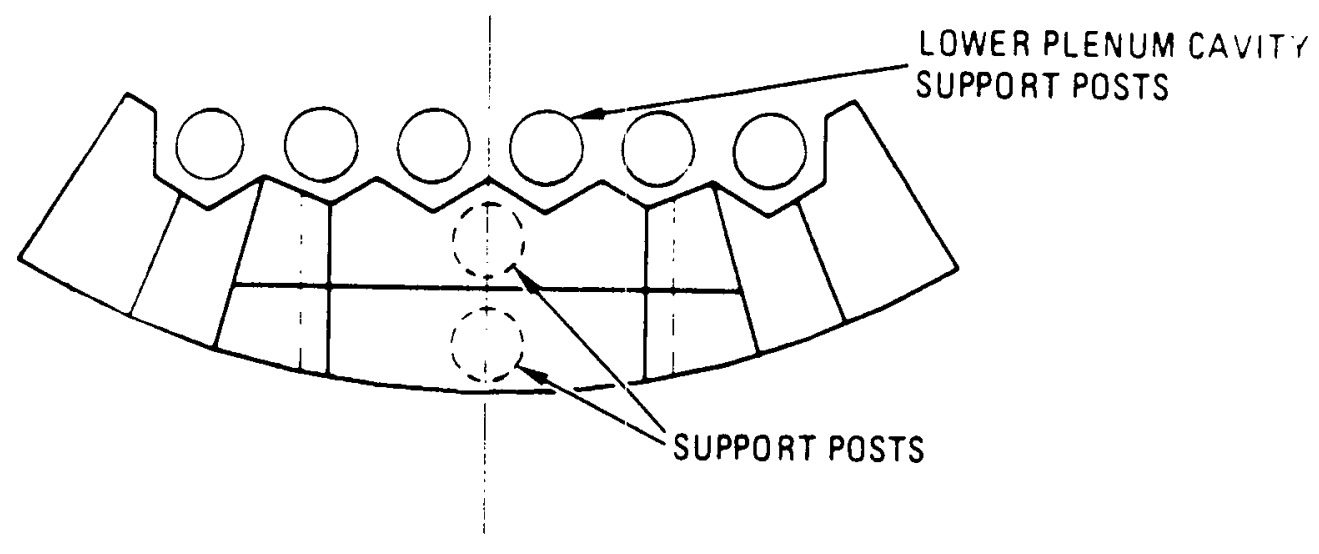

SECTION A-A

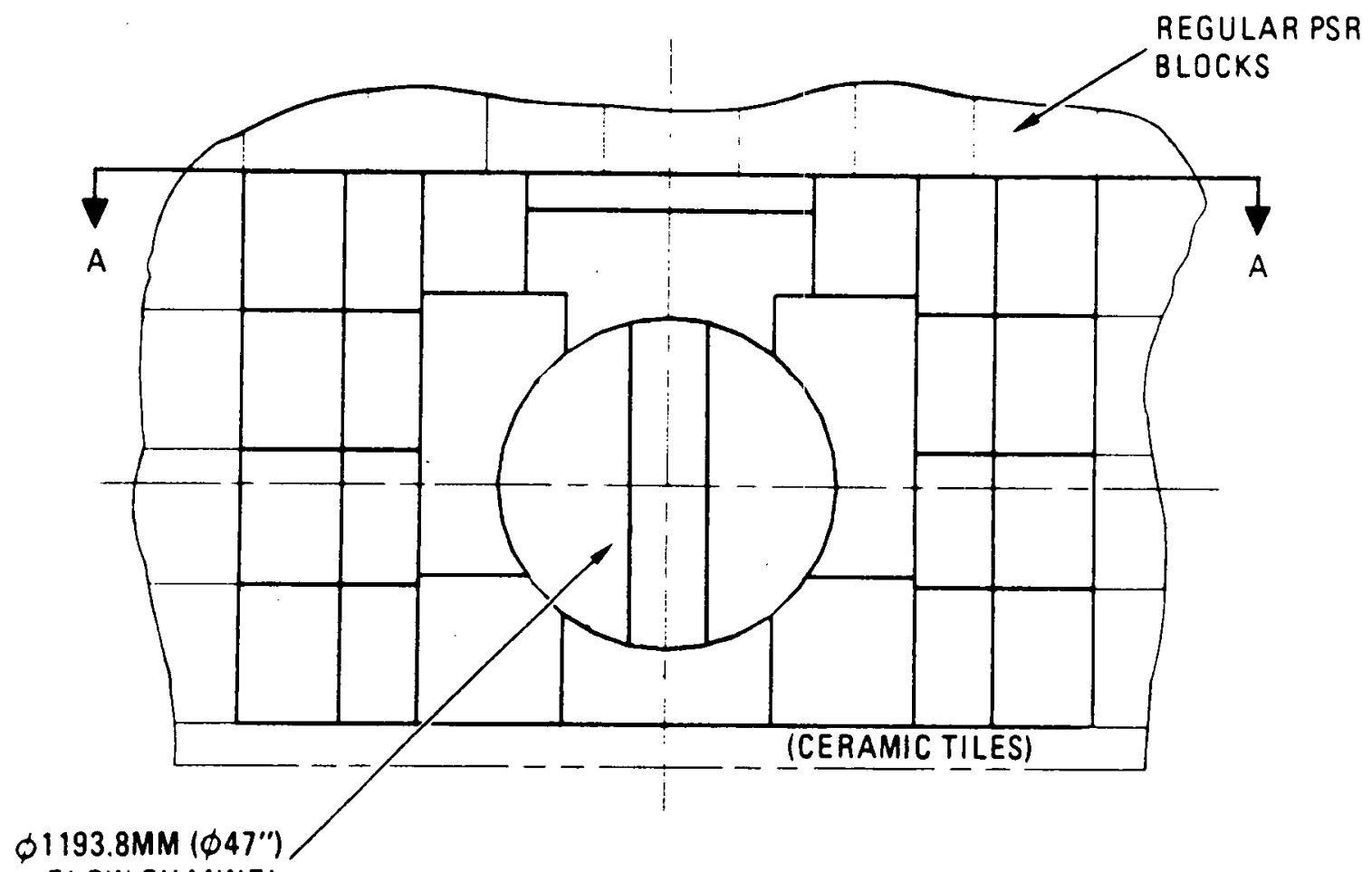

FLOW CHANNEL

\section{ELEVATION VIEW}

FIGURE 4.44

PSR BLOCK STRUCTURE TO THE HOT DUCT ENTRANCE 


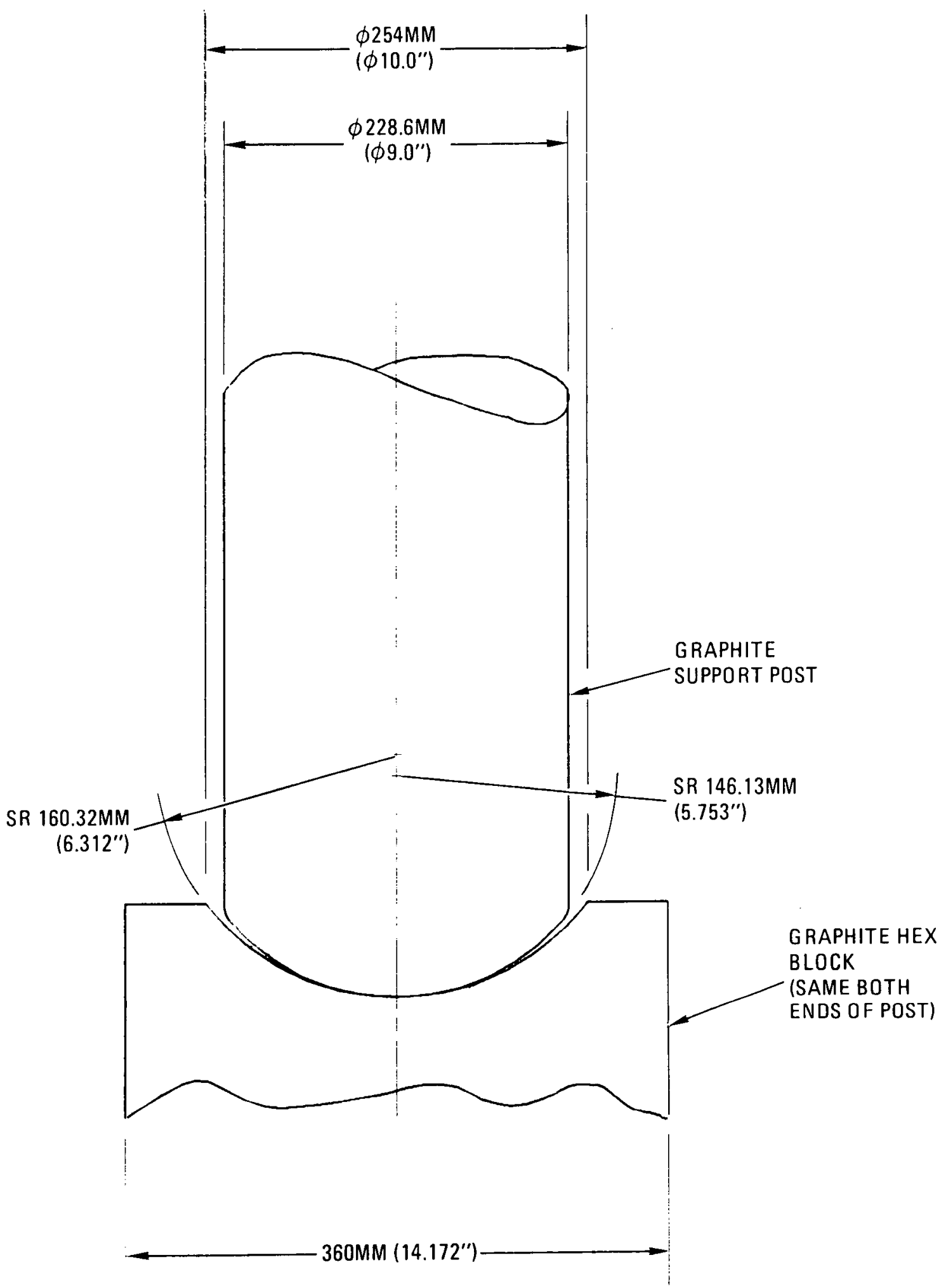

FIGURE 4.45

SUPPORT POST AND SEAT GEOMETRY

HIGH TEMPERATURE GAS-COOLED REACTOR

PRELIMINARY SAFETY INFORMATION DOCUMENT

HTGR-86-024 


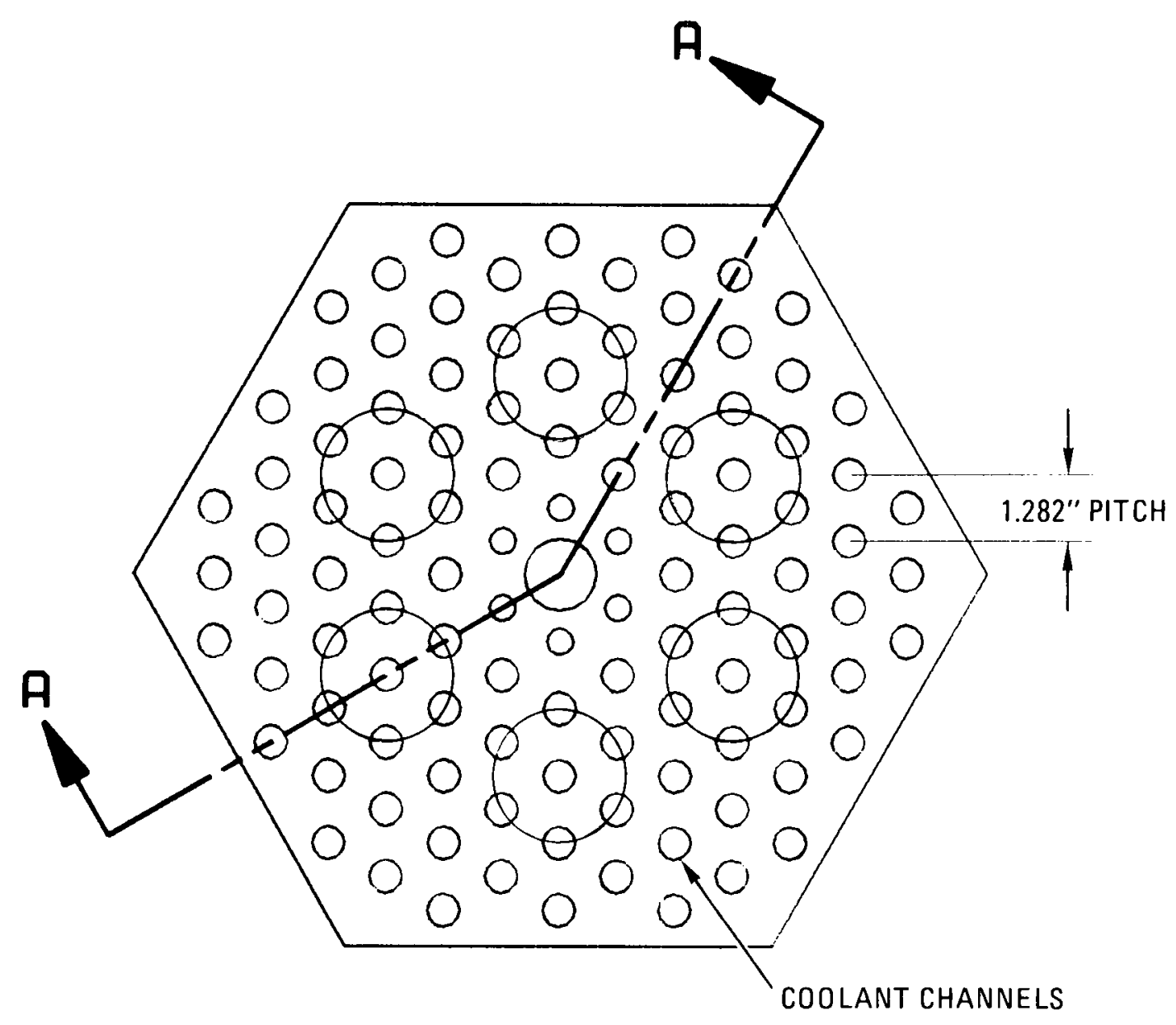

FIGURE 4.46

BOTTOM REFLECTOR 


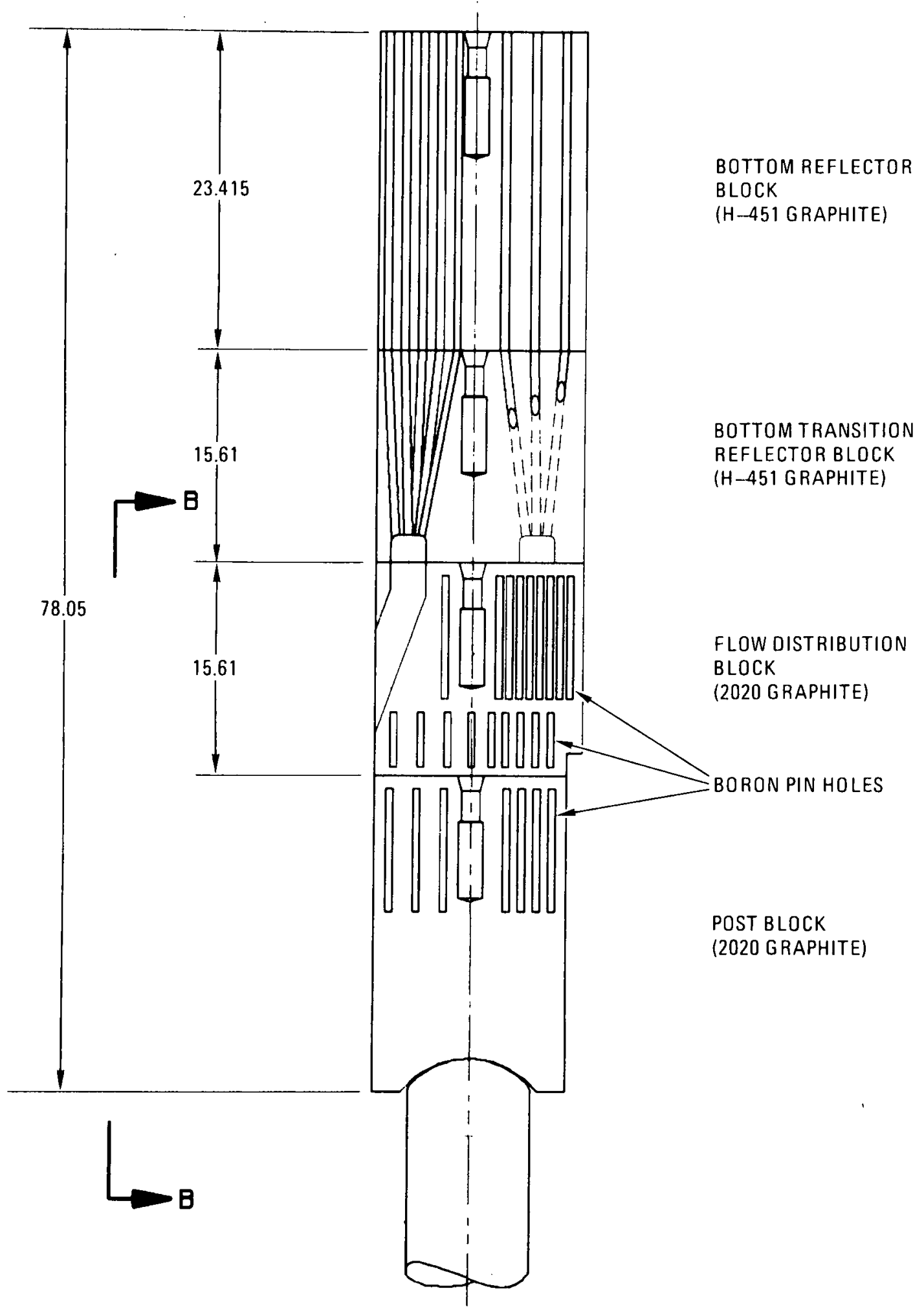

FIGURE 4.47

BOTTOM REFLECTOR AND GRAPHITE CORE SUPPORT

HIGH TEMPERATURE GAS-COOLED REACTOR PRELIMINAARY SAFETY INFORMATION DOCUMENT HTGR-86-024 


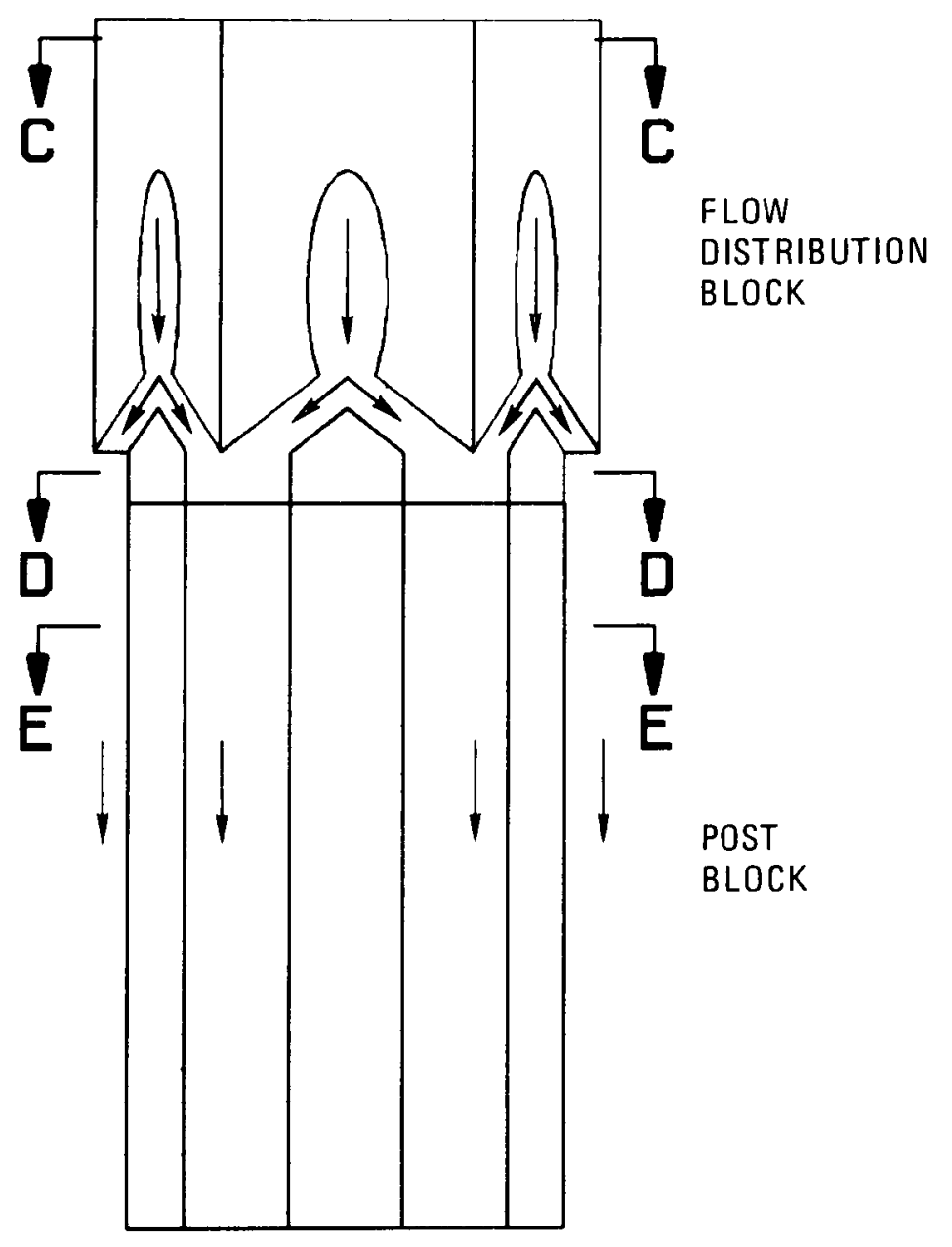

VIEW B-B

FIGURE 4.48

FLOW DISTRIBUTION AND POST BLOCKS 


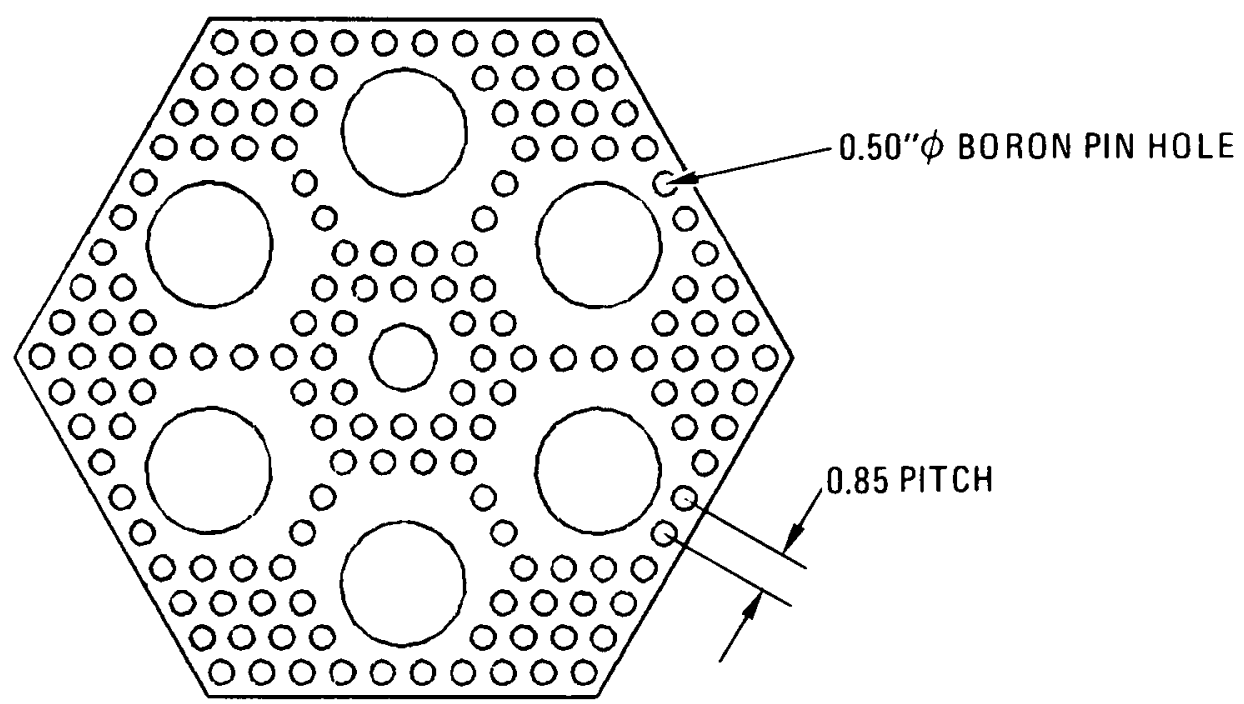

a) SECTION C-C (FIG 4.4-8)

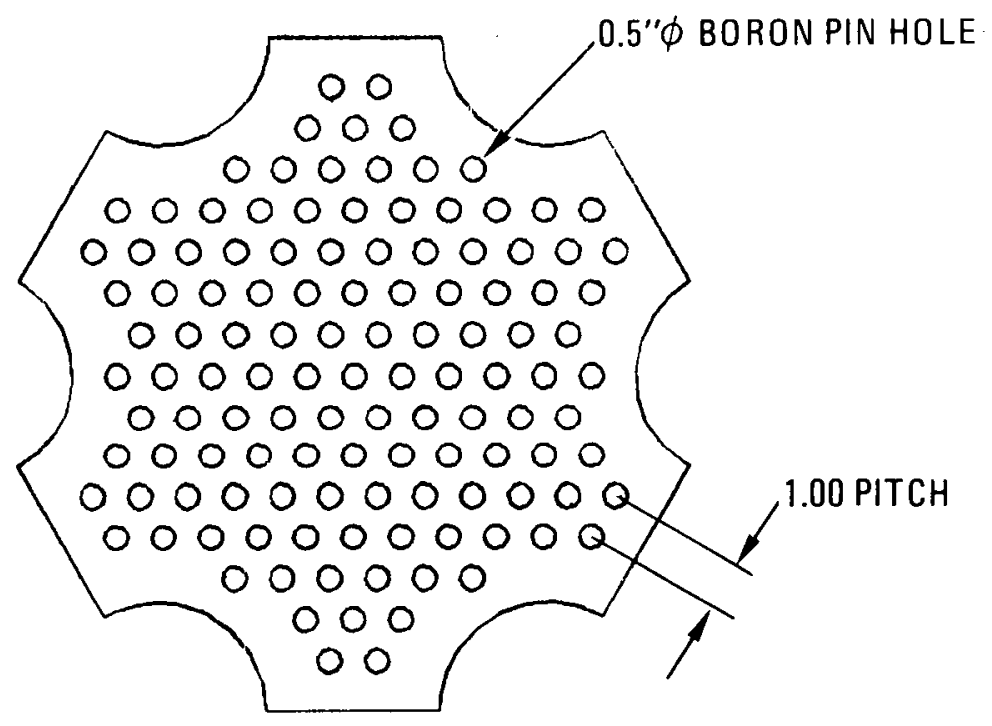

b) SECTION D-D (FIG 4.4-8)

FIGURE 4.49

FLOW DISTRIBUTION BLOCK 


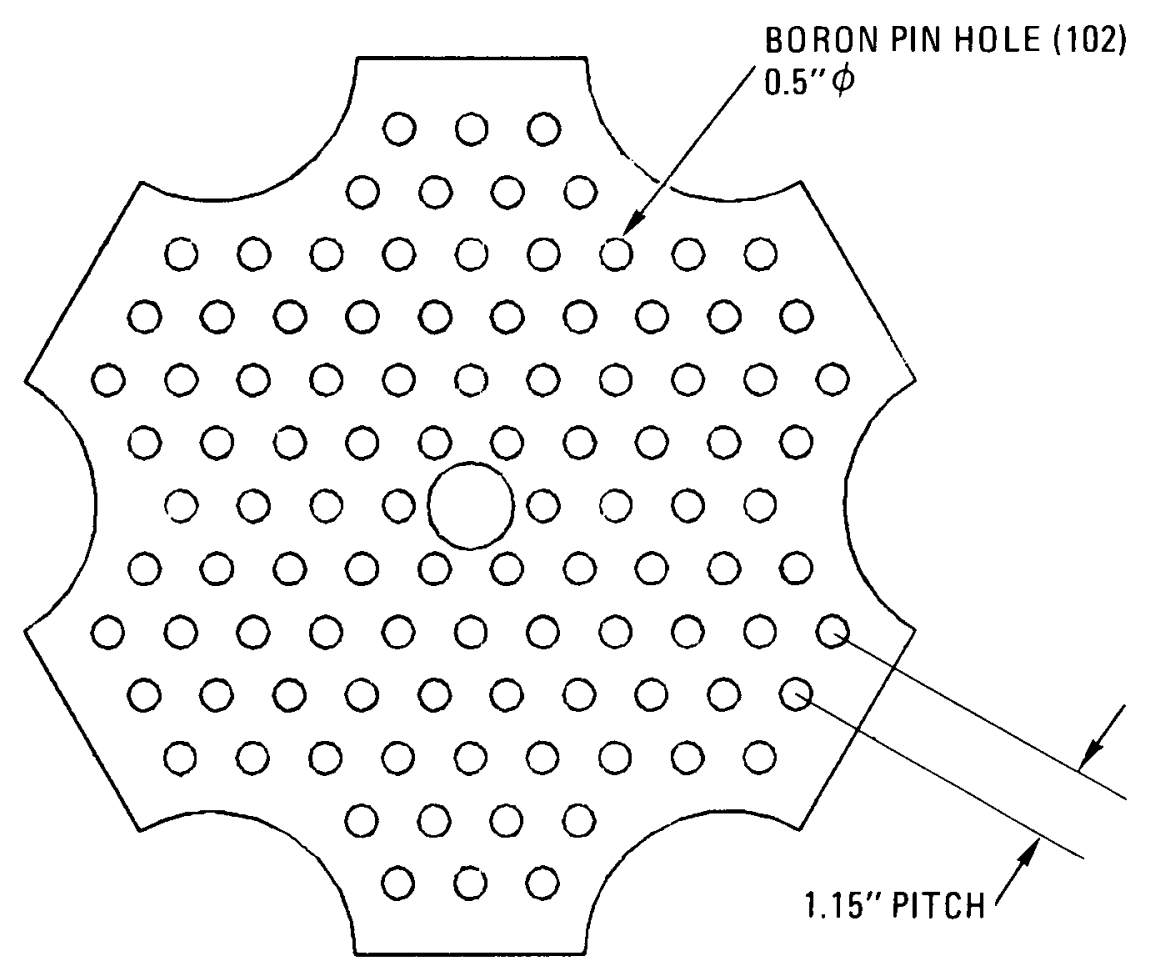

SECTION E-E (FIG 4.4-8)

FIGURE 4.410

POST BLOCK

HIGH TEMPERATURE GAS-COOLED REACTOR

PRELIMINARY SAFETY INFORMATION DOCUMENT

HTGR-86-024 


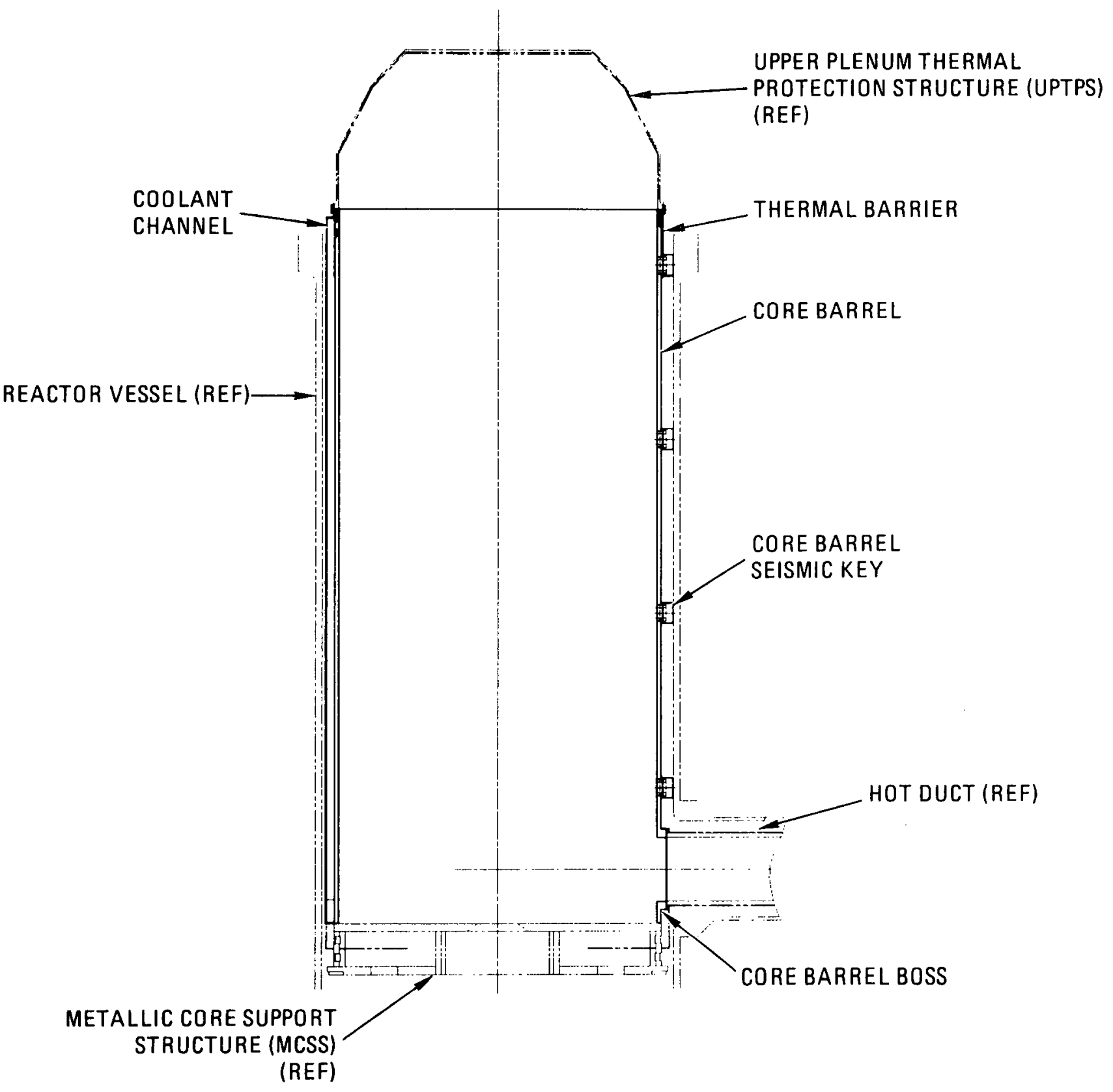

FIGURE 4.411

CORE LATERAL RESTRAINT

STRUCTURE - ELEVATION VIEW

HIGH TEMPERATURE GAS-COOLED REACTOR

PRELIMINARY SAFETY INFORMATION DOCUMENT

HTGR-86-024 


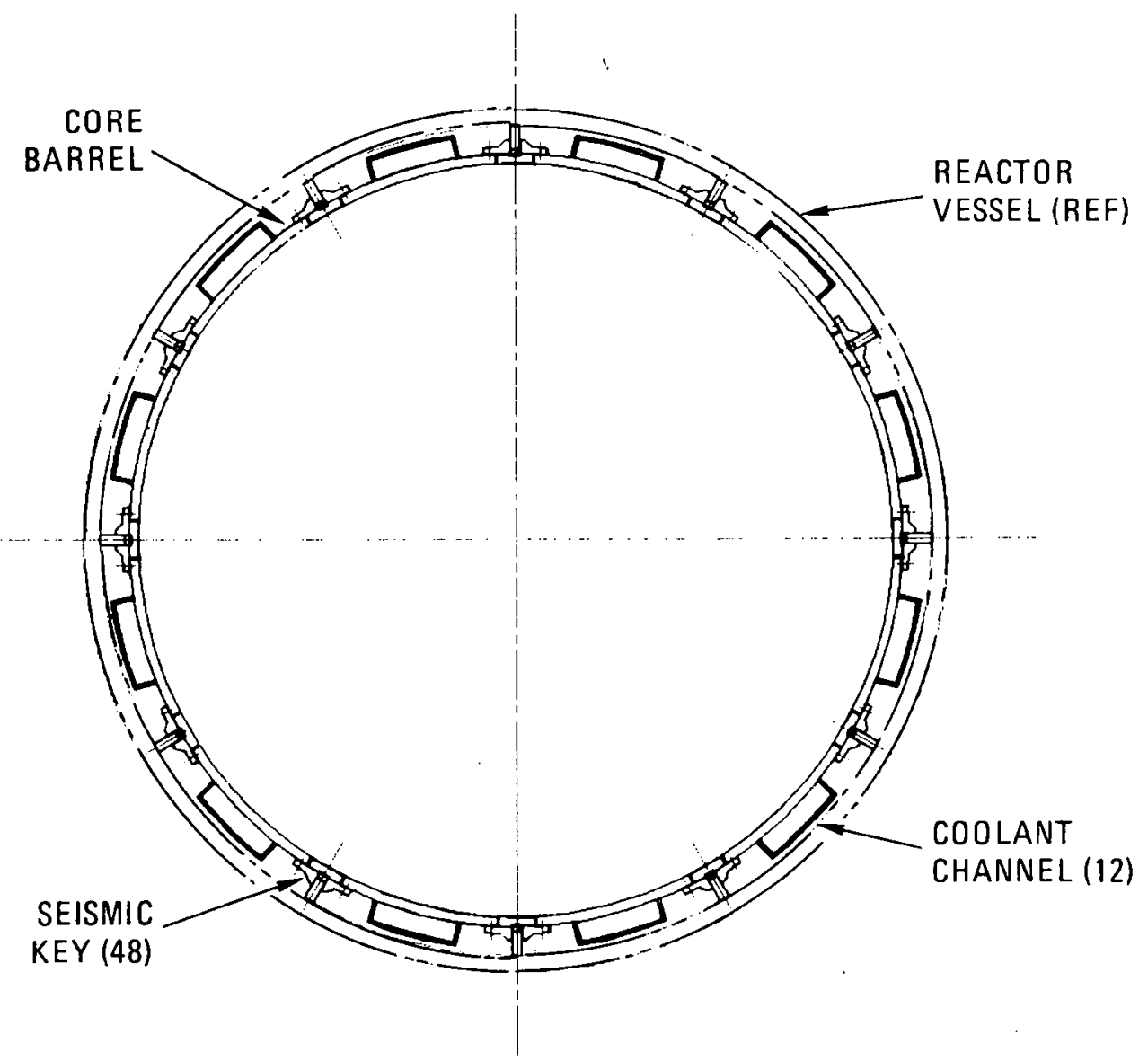

FIGURE 4.412

CORE LATERAL RESTRAINT

STRUCTURE - PLAN VIEW

HIGH TEMPERATURE GAS-COOLED REACTOR

PRELIMIMARY SAFETY INFORMATION DOCUMENT

HTGR-86-024 


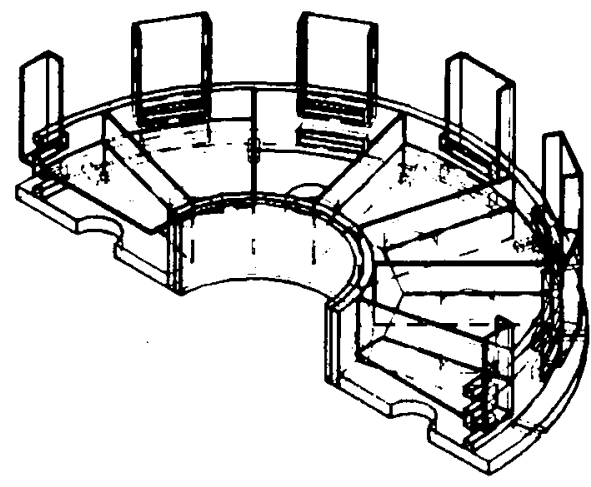

ISOMETRIC VIEW

(THE TOP PLATE HAS BEEN REMOVED

IN THIS VIEW FOR PURPOSE OF CLARITY)

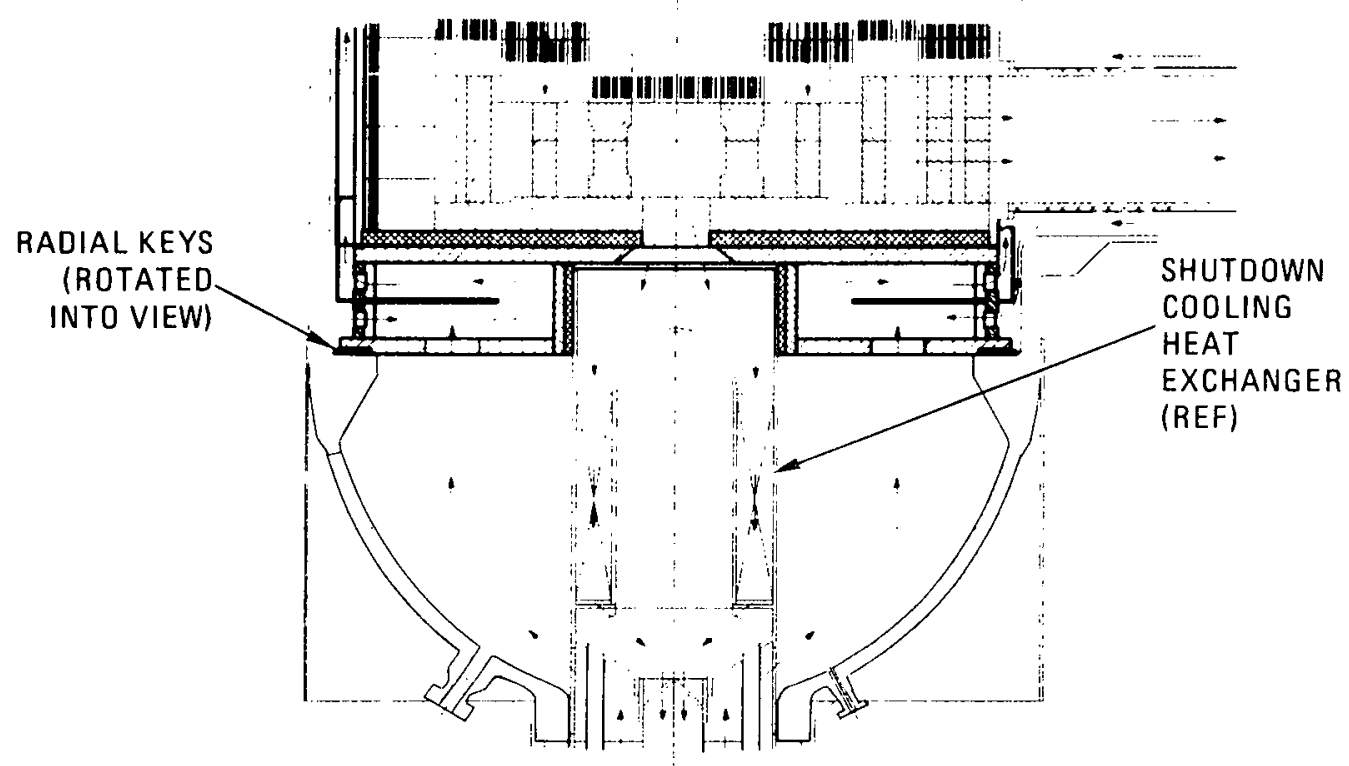

ELEVATION VIEW

SHOWS THE CORE SUPPORT STRUCTURE

INSTALLED IN THE REACTOR.

SHOWS THE GAS FLOW PATTERN

$\longrightarrow$ PRIMARY COOLANT FLOW

$\longrightarrow-$ SHUTDOWN COOLANT FLOW

FIGURE 4.413

METALLIC CORE SUPPORT STRUCTURE

HIGH TEMPERATURE GAS-COOLED REACTOR

PRELIMINARY SAFETY INFORMATION DOCUMENT

HTGR-86-024 


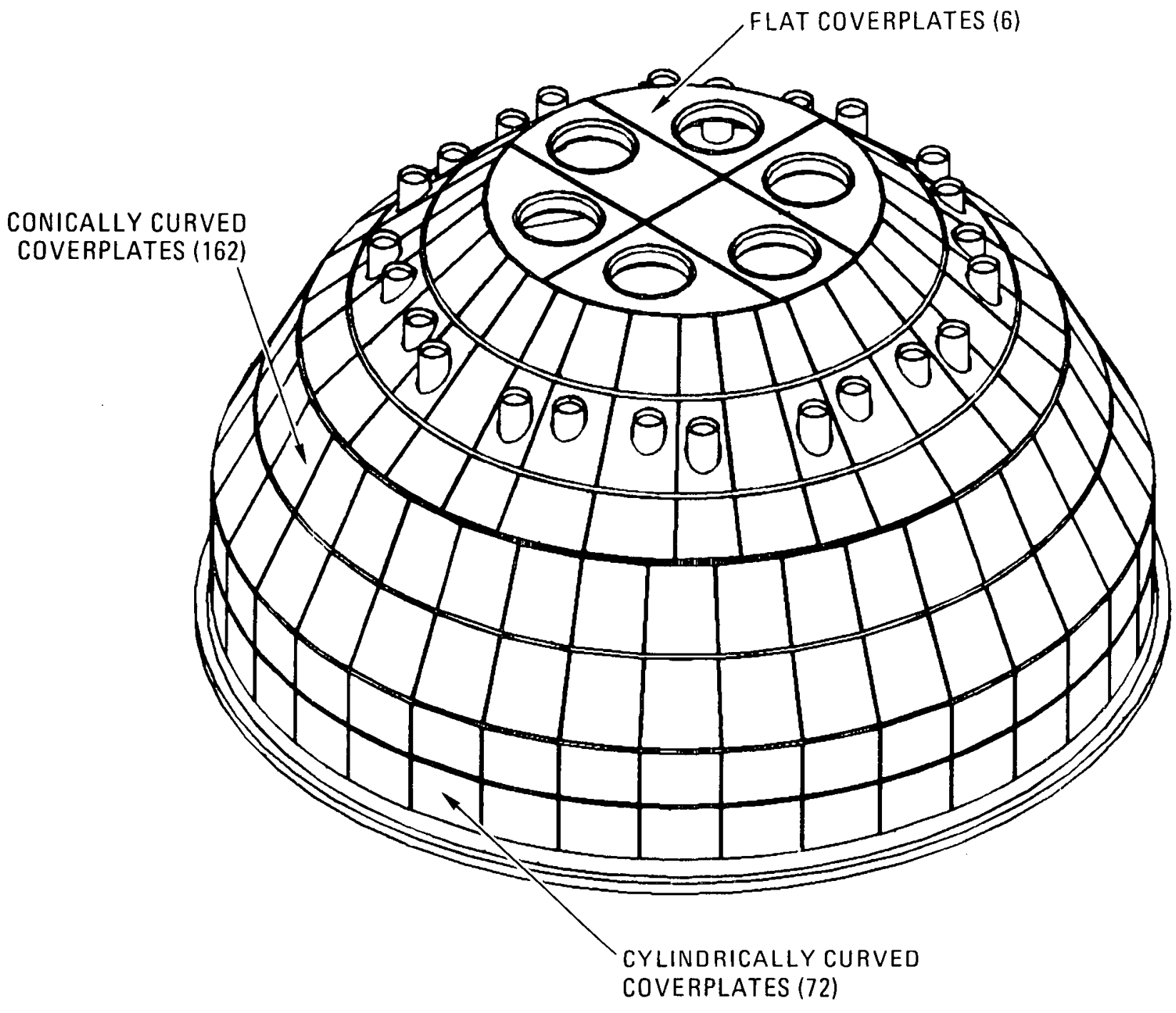

FIGURE 4.414

UPPER PLENUM THERMAL PROTECTION STRUCTURE - ISOMETRIC VIEW 
HTGR - 86-024

TABLE $3.9-5$

ISI TESTING SCHEDULE FOR SAFETY AND RELIEF VALVES

Time Period

Startup through

1st planned outage ${ }^{(2)}$

1st planned outage

through 2 nd planned

outage

2nd planned outage

through $3 r d$ planned

outage
Number of Valves to Be Tested $(1)$

Minimum of $\left(\mathrm{N}_{1} / 60\right) \times$ total valves

in this category

Additional valves to make cumulative

tested at least $\left(\mathrm{N}_{2} / 60\right) \times$ total

valves in this category

Additional valves to make cumulative

tested at least $\left(\mathrm{N}_{3} / 60\right) \times$ total

valves in this category

(1) $\mathrm{N}_{1}, \mathrm{~N}_{2}, \mathrm{~N}_{3}$, etc, is the number of months from startup to first planned outage, second planned outage, third planned outage, etc. When $N$ is a number larger than 60 , all valves which have not been tested during the preceding 5-yr period shall be tested. The following period shall then be considered to be the same as "startup to first planned outage" for purposes of determining test frequency, with the added requirement that at each planned outage all valves which have not been tested during the preceding 5 -yr period shall be tested. The subsequent period will be considered the same as the first planned outage to the second planned outage, etc, with $N$ determined by counting months from the new starting point.

Ref. Table IGV-3510-1.

${ }^{(2)}$ An extended planned outage at intervals $\leq 18$ months. 
HTGR - 86- 024

TABLE $3.9-6$

FLOW VELOCITY DESIGN VALUES FOR THE PRIMARY COOLANT

\begin{tabular}{|c|c|c|c|c|}
\hline \multirow[b]{2}{*}{ Structure } & \multicolumn{2}{|c|}{$\begin{array}{l}\text { Main Loop } \\
\text { Operation }\end{array}$} & \multicolumn{2}{|c|}{$\begin{array}{c}\text { SCS } \\
\text { Operation }\end{array}$} \\
\hline & $(\mathrm{m} / \mathrm{sec})$ & $(\mathrm{ft} / \mathrm{sec})$ & $(\mathrm{m} / \mathrm{sec})$ & $(\mathrm{ft} / \mathrm{sec})$ \\
\hline Main circulator inlet (ISV) & 34.4 & 113 & - & -- \\
\hline Main circulator outlet (diffuser) & 50.0 & 164 & - & - \\
\hline Cold duct & 25.3 & 83 & - & - \\
\hline Core support plate structure & 7.3 & 24 & 6.4 & 21 \\
\hline Core barrel flow channels & 22.6 & 74 & 20.1 & 66 \\
\hline Core exit & 32.3 & 106 & 33.5 & 110 \\
\hline Hot duct & 43.9 & 144 & -- & -- \\
\hline Steam generator bundle & 12.8 & 42 & $\cdots$ & - \\
\hline Steam generator annulus & 15.2 & 50 & -- & - \\
\hline Hot duct support structures & 32.6 & 107 & - & - \\
\hline SCHE bundle & - & -- & 60.9 & 200 \\
\hline SCS circulator inlet (ISV) & -- & -- & 99.1 & 325 \\
\hline SCS circulator outlet (diffuser) & - & - & 38.7 & 127 \\
\hline
\end{tabular}
(1) 1008 flow
(2) Depressurized refueling 
HOT DUCT PIPE

WITH 3"THICK

THERMAL BARRIER
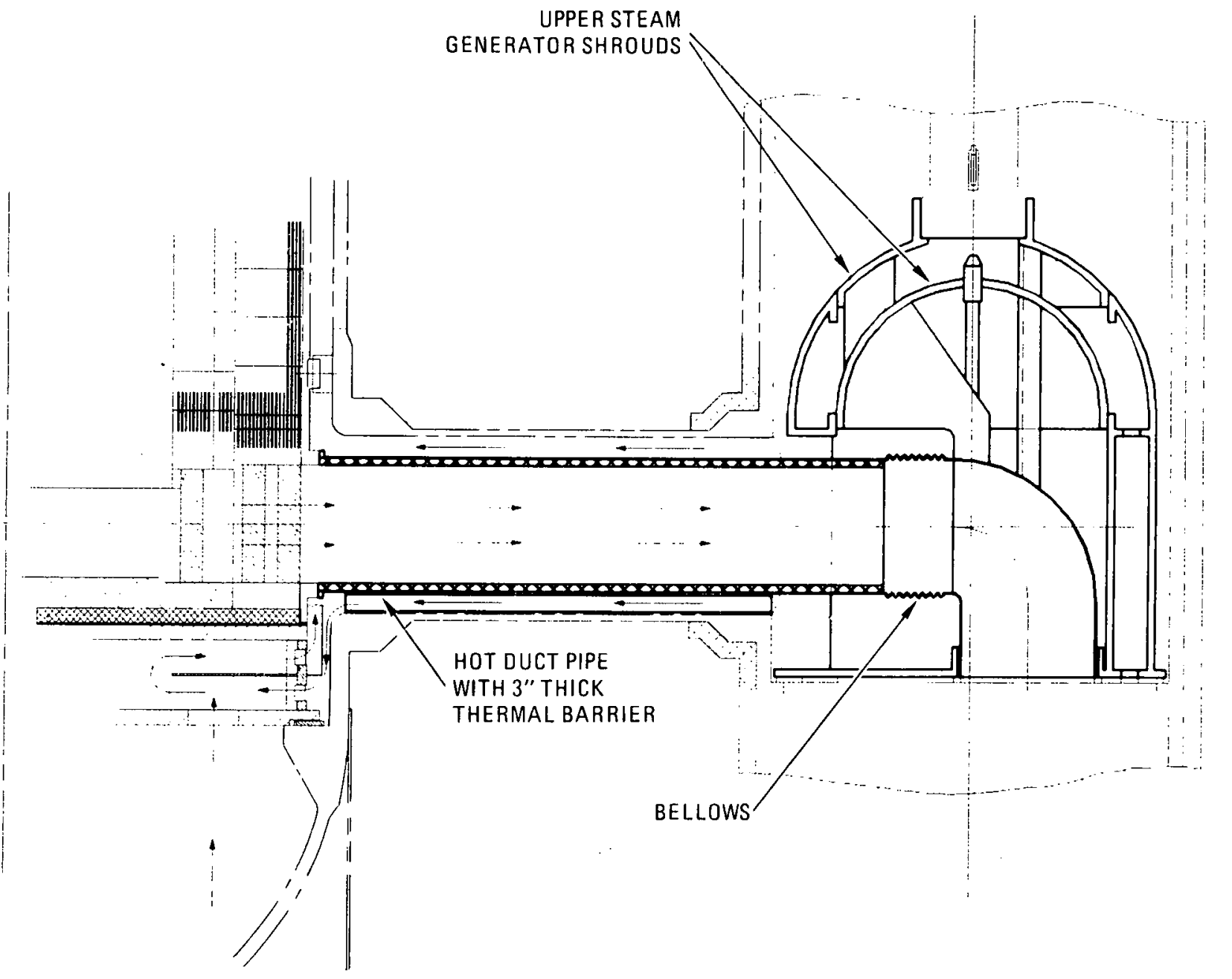

FIGURE 4.415

HOT DUCT - ELEVATION VIEW

HIGH TEMPERATURE GAS-COOLED REACTOR PRELIMINARY SAFETY INFORMATION DOCUMENT HTGR-86-024 


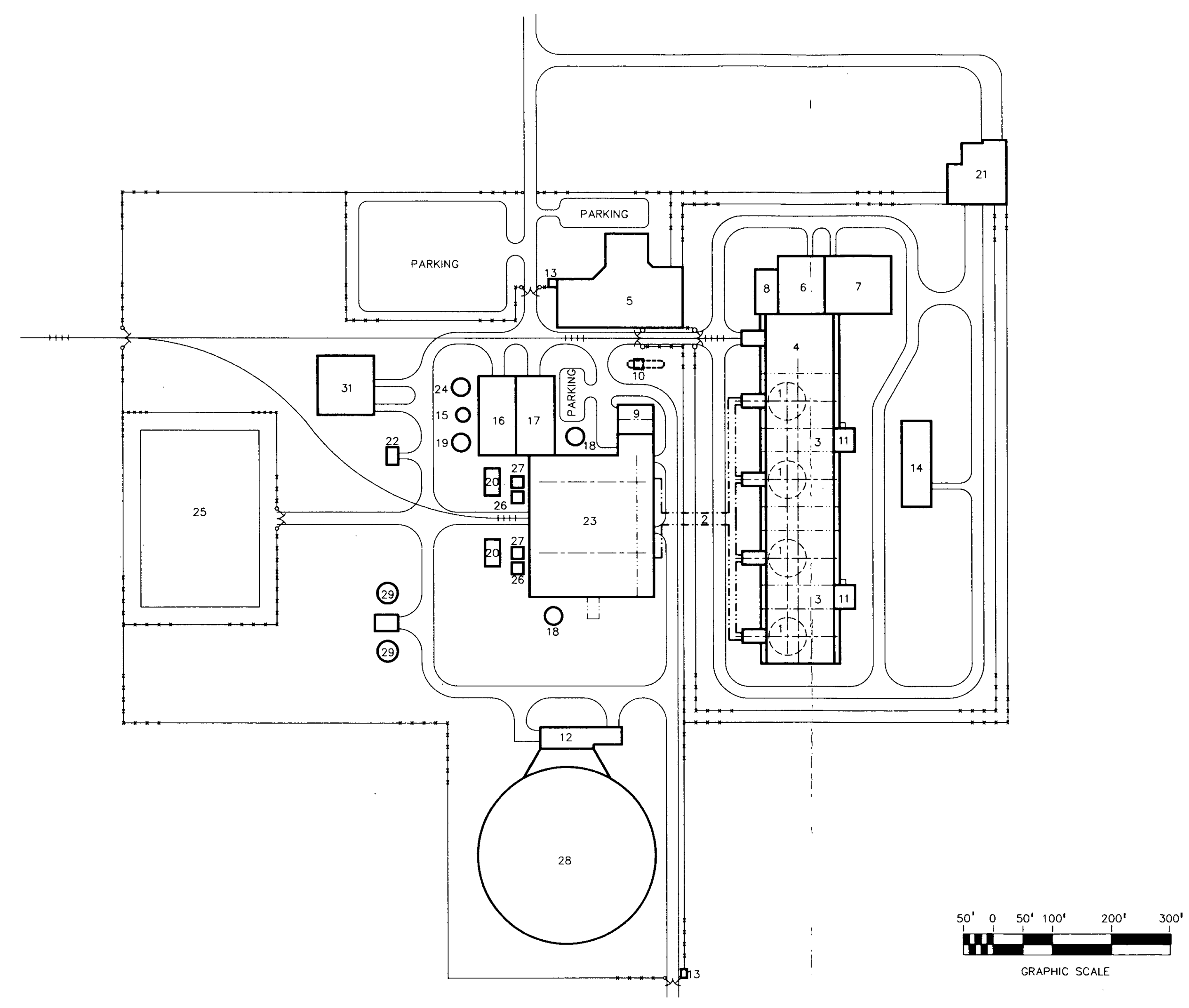

REACTOR BULLING

MAIN STEAM \& FEEDWATER PIIINO

REACTOR AUXILIARY BULLDING
REACTOR SERUCE BUILDING

OPERATIONS CENTER

PERSONNEL SERUCES BUILDING

RADIOACTIVE WASTE MANAGEMENT BULLING

NUCLEAR ISLAND COOLING WATER BUILDING

STANOBY SONER BULONG WA

ULl OL STORAGE TANK \& PUMP HOUSE

$\mathrm{N}_{2}$ ENCLOSURE

HELUM STORAGE BUILDING

CLARIFER

WKEUP WATER TREATMENT \& AUXILARY BOILER BUILOING

MAINENANCE BULLANG

CONOENSATE SURGE TANK

UNIT TRANSFORM

HYDROGEN STORAGE AREA

TURBINE BUILDING

FILLRED WATER STORAGE TANK

PWTCHYARD

AUXILARY TRANSFORMER

UNIT AUXILARY TRANSFORMER
STATION COOLNG TOWER

FIRE WATER STORAGE TANK

FIRE PUMP HOUSE

ECA WAREHOUSE 


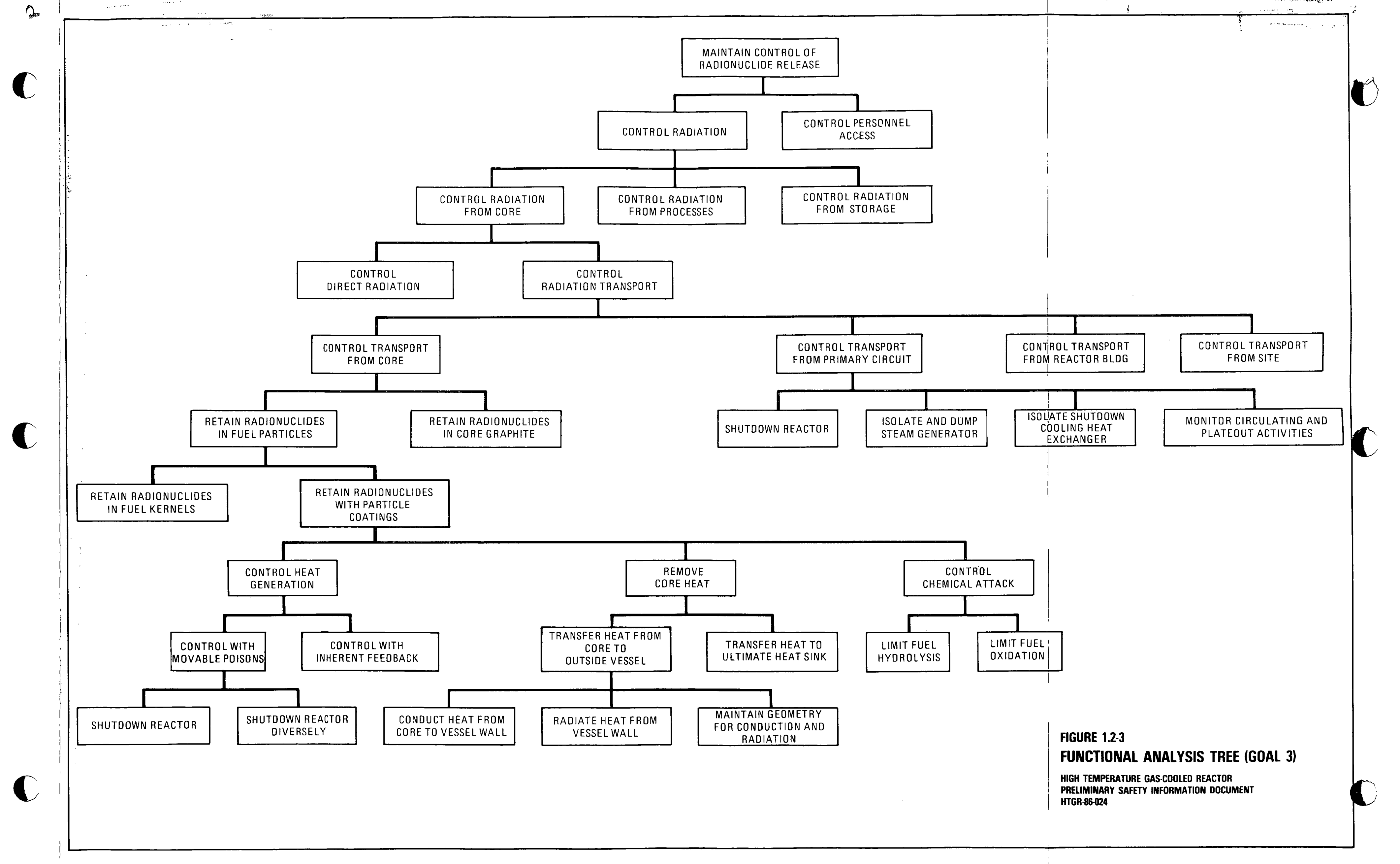

